INEEL/EXT-04-02530

\title{
Feasibility Study of Supercritical Light Water Cooled Reactors for Electric Power Production
}

\author{
Nuclear Energy Research Initiative Project 2001-001 \\ Westinghouse Electric Co. Award Number: DE-FG07-02SF22533 \\ Final Report
12th Quarterly Report
}

Principal Investigators: Philip MacDonald, Dr. Jacopo Buongiorno, Dr. James W. Sterbentz, Cliff Davis, and Prof. Robert Witt

Telephone: 208-526-9634

Fax: 208-526-2930

Email: pem@inel.gov

Collaborating Organizations:

University of Michigan

Principal Investigators: Prof. Gary Was, J. McKinley, and S. Teysseyre

Westinghouse Electric Company

Principal Investigators: Dr. Luca Oriani, Dr. Vefa Kucukboyaci, Lawrence Conway, N. Jonsson, and Dr. Bin Liu 


\section{Executive Summary}

The supercritical water-cooled reactor (SCWR) is one of the six reactor technologies selected for research and development under the Generation-IV program. SCWRs are promising advanced nuclear systems because of their high thermal efficiency (i.e., about $45 \%$ vs. about $33 \%$ efficiency for current Light Water Reactors, LWRs) and considerable plant simplification. SCWRs are basically LWRs operating at higher pressure and temperatures with a direct once-through cycle. Operation above the critical pressure eliminates coolant boiling, so the coolant remains single-phase throughout the system. Thus the need for a pressurizer, steam generators, steam separators and dryers is eliminated. The main mission of the SCWR is generation of low-cost electricity. It is built upon two proven technologies, LWRs, which are the most commonly deployed power generating reactors in the world, and supercritical fossil-fired boilers, a large number of which is also in use around the world.

The reference SCWR design for the U.S. program is a direct cycle system operating at $25.0 \mathrm{MPa}$ with core inlet and outlet temperatures of 280 and $500{ }^{\circ} \mathrm{C}$, respectively. The coolant density decreases from about $760 \mathrm{~kg} / \mathrm{m}^{3}$ at the core inlet to about $90 \mathrm{~kg} / \mathrm{m}^{3}$ at the core outlet. The inlet flow splits with about $10 \%$ of the inlet flow going down the space between the core barrel and the reactor pressure vessel (the downcomer) and about $90 \%$ of the inlet flow going to the plenum at the top of the rector pressure vessel to then flow downward through the core in special water rods to the inlet plenum. Here it mixes with the feedwater from the downcomer and flows upward to remove the heat in the fuel channels. This strategy is employed to provide good moderation at the top of the core. The coolant is heated to about $500{ }^{\circ} \mathrm{C}$ and delivered to the turbine.

The purpose of this NERI project was to assess the reference U.S. Generation IV SCWR design and explore alternatives to determine feasibility. The project was organized into three tasks.

- $\quad$ Task 1. Fuel-cycle Neutronic Analysis and Reactor Core Design.

- Task 2. Fuel Cladding and Structural Material Corrosion and Stress Corrosion Cracking.

- Task 3. Plant Engineering and Reactor Safety Analysis.

\section{Task 1. Fuel-cycle Neutronic Analysis and Reactor Core Design}

Metallic and oxide fertile fuels in a fast-spectrum SCWR were investigated during Year 1 to evaluate the void and Doppler reactivity coefficients, actinide burn rate, and reactivity swing throughout the irradiation cycle. These results were reported in the $1^{\text {st }}$ Quarterly. A variety of other core arrangements and moderator types for a thermal-spectrum SCWR were also assessed during the three years of this project. Detailed results from the solid moderator studies were presented in the $3^{\text {rd }}$ Quarterly and $4^{\text {th }}$ Quarterly Reports and in two papers by Buongiorno and MacDonald (2003a \& 2003b). Results from an analysis of an alternative thermal-spectrum SCWR design based on vertical power channels, hexagonal fuel assemblies, and water moderation between the fuel assemblies were reported in the $2^{\text {nd }}$ Annual Report. Also reported in the $2^{\text {nd }}$ Annual Report were the results of the steady-state thermal-hydraulic analyses -for two other thermal spectrum SCWRs, one design with solid moderator rods, and one design with water filled moderator rods.

This report presents in Chapter 3 the results of a two neutronic evaluations for two different SCWR fuel assembly designs. The first evaluation is for a $25 \times 25$ fuel assembly that used MA956 oxide dispersion steel for the fuel rod cladding, water rod duct, and assembly duct materials. The second is for a $21 \times 21$ fuel assembly that used silicon carbide ( $\mathrm{SiC}$ ) for the fuel rod cladding, water rod duct, and assembly duct materials. 
The $25 \times 25$ fuel assembly with MA956 cladding and duct material contains a 6x6 array of square water rods interspersed uniformly within the $\mathrm{UO}_{2}$ fuel pin array to increase neutron moderation and assembly reactivity. The assembly exhibits many desirable neutronic characteristics that include sufficient reactivity to achieve burnups of at least $31.0 \mathrm{GWD} / \mathrm{MTU}$, a strongly negative Doppler coefficient, and a negative void worth for both the coolant and water rods. The assembly also exhibits some characteristics that may complicate the design, such as a wide spread in the required radial enrichments $(3.2-12.4 \mathrm{wt} \%$ U-235) to flatten the radial power profile, and relatively lower reactivity than in LWRs because of the high parasitic neutron absorption of the MA956 cladding and duct material. In addition, the assembly axial power profile exhibits a strong sensitivity to small changes in axial enrichments that may lead to power oscillations under normal operation, if not properly controlled with burnable poisons and control rods. The sensitivity is believed to be primarily due to the interplay between the non-uniform axial water density profiles that affect neutron moderation and the time-dependent axial burnup of the fissile heavy metal.

The $21 \times 21$ fuel assembly with the duplex $\mathrm{SiC} / \mathrm{SiC}$ for the fuel pin cladding and fuel assembly duct material exhibited better neutronic characteristics than the MA956 assembly with steel structures. This assembly showed a significant increase in core reactivity due to the relatively low parasitic neutron absorption of the silicon carbide. This low parasitic neutron absorption in turn translates into significantly higher burnup (41.0 GWD/MTU) when compared to the burnup of the MA956 steel assembly (31.0 GWD/MTU). In addition, the $\mathrm{SiC}$ assembly exhibits a strong negative Doppler coefficient $\left(-2.5 \mathrm{pcm} /{ }^{\circ} \mathrm{C}\right)$, and negative void worth for both the coolant and water rods. The assembly does however require again a relatively wide spread in the fuel rod radial enrichment $(3.2-12.4 \mathrm{wt} \% \mathrm{U}-$ 235 ) to flatten the radial power profile at beginning-of-life conditions, and in addition would require at least a three-zone axial enrichment to flatten and center the unrodded axial power profile about the core midplane at beginning-of-life. As with the MA956 assembly, the fuel assembly axial power profile appears to exhibit a strong sensitivity to small changes in axial enrichments (and therefore burnup) that could lead to power oscillations under normal operation, if not properly controlled with burnable poisons and control rod movement.

\section{Task 2. Fuel Cladding and Structural Material Corrosion and Stress Corrosion Cracking}

The existing data base on the corrosion and stress-corrosion cracking of austenitic stainless steel and nickel-based alloys in supercritical water is very sparse. Therefore, the focus of this work has been corrosion and stress corrosion cracking testing of candidate fuel cladding and structural materials. During Year 1, a high temperature autoclave with carefully controlled chemistry and containing a constant rate mechanical test device was built and tested at the University of Michigan.

During Years 2 and 3, a variety of austenitic and ferritic-martensitic alloys were tested. The results of that work are presented in Section 4 of this report and briefly summarized below. The austenitic alloys were tested in deaerated water (dissolved oxygen of the order of a few ppb) at temperatures between 400 and $550{ }^{\circ} \mathrm{C}$ and they all showed varying degrees of susceptibility to intergranular stress-corrosion cracking (SCC). Susceptibility was determined by examination of the fracture surface, the gage surface, and by analysis of cross-sections of the tensile bars. All these measurements are required to provide a complete description of the cracking behavior. Alloy 625 is the most susceptible, displaying the highest degree of intergranular fracture and some of the deepest cracks along with a very high crack density. The 304L stainless steel is the next most susceptible material, showing the deepest intergranular cracks. Alloys 690 and 316L are the least susceptible austenitic alloys from all measures considered; crack density, crack depth and crack length. 
The degree of intergranular SCC of the austenitic alloys increases with increasing temperature. As the temperature increases, the crack density decreases but the crack length and depth increase, resulting in a net increase in the intergranular cracking severity as measured by the crack length per unit area.

There is very strong temperature dependence to the oxidation behavior of the austenitic alloys. The oxidation rate, as measured either by the weight gain or oxide thickness, increases faster with increasing temperature. By $550{ }^{\circ} \mathrm{C}$, the austenitic alloy oxide thickness is approaching $10 \mu \mathrm{m}$ within a few hundred hours. The predominant feature among all of the austenitic alloy oxides was the two-layer structure consisting of an iron-rich outer layer and chromium-rich inner layer. X-ray diffraction has shown that the outer layer was magnetite, $\mathrm{Fe}_{3} \mathrm{O}_{4}$. The outer oxide on the Alloy 690 was probably NiO.

The ferritic-martensitic alloys do not display any evidence of intergranular SCC as determined by fracture surface and gage surface analysis. They all display strain softening and ductile rupture. However, the oxidation rates of the ferritic-martensitic alloys are very high compared to the austenitic alloys. At 500 ${ }^{\circ} \mathrm{C}$, the ferritic-martensitic oxidation rates are a factor of 10 greater than those for the austenitic alloys at the same temperature. These alloys also display a two-layer structure, in which the outer layer is identified as magnetite, $\mathrm{Fe}_{3} \mathrm{O}_{4}$. The $\mathrm{O} / \mathrm{M}$ ratio of the inner layer is closer to hematite, but the structure of the inner oxide layer was not verified. The addition of $100 \mathrm{ppb}$ oxygen to the water at $500{ }^{\circ} \mathrm{C}$ resulted in a reduction of the total oxide thickness by about $10 \%$ and a slight increase in the $\mathrm{O} / \mathrm{M}$ ratio. These results are consistent with the objective of combined water chemistry control.

\section{Task 3. Plant Engineering and Reactor Safety Analysis}

SCWR Core Thermal Hydraulic Design Assessment. The Westinghouse Electric Company tasks included an assessment of the reference core thermal hydraulic design. A complete review of the Westinghouse SCWR core assessment activities is provided in Westinghouse Report STD-ES-04-45, while in this report the focus is mostly on the final analyses and the main conclusions of the analyses effort.

The first step in performing the core thermal-hydraulic assessment was identification of the design limits that were then used to evaluate the acceptability of the core design. Section 2 of STD-ES-04-45 and the $2^{\text {nd }}$ and $3^{\text {rd }}$ Quarterly reports for this NERI project (MacDonald et al. 2002a and 2002b) provide the considerations used in defining the design limits for the SCWR. Once the boundaries of the analysis were defined, simplified calculations were performed to provide an initial characterization of the design. These analyses are summarized in Section 3 of STD-ES-04-45. Based on the results of the simplified analysis, it was concluded that the SCWR, due to its very large enthalpy rise along the core, is sensitive to small deviations from nominal conditions, especially variations in the flow to power ratio. Thus, even small effects due to various hot channel factors (coolant flow channel tolerances, operational variations, etc.) might have a large impact on the peak cladding temperature of some fuel rods. This was considered a major feasibility issue for the SCWR, and thus it was decided to perform detailed subchannel analysis of the SCWR core to provide a more in depth assessment of this issue.

The W-VIPRE subchannel analyses code was adapted for the analysis of supercritical water, and new correlations that are considered adequate for SCWR analyses were implemented in the code. A complete characterization, including sensitivity studies, of the SCWR with the modified VIPRE core is documented in Section 5.1.2. Based on these results, sufficient information was available for a preliminary thermalhydraulic optimization of the SCWR core design. Temperature profiles for various core geometries were then analyzed with two different objectives: (1) to identify an optimal geometry that minimizes the temperature differences between core channels, and (2) to confirm and characterize the sensitivity of the 
temperature profile to the local flow to power ratios. The need of maintaining uniform conditions at the exit of the core is dictated by the fact that safety limits need to be verified for the limiting fuel rod, while the overall plant performance depends on the average core exit conditions. Thus, a uniform temperature distribution minimizes the "wasted" design margin. These analyses are documented in Section 5.1.3 (Section 5 of STD-ES-04-45).

Results from the optimization studies suggest that it is possible to obtain a better temperature profile (hence, lower hot channel factors) by employing a more complex assembly configuration. Based on the results of this study, the design should use a geometric configuration with $10 \mathrm{~mm}$ outside diameter fuel rods for the coolant channels facing the water rods and at the assembly periphery, $9.5 \mathrm{~mm}$ outside diameter fuel rods for the assembly corners, and $10.2 \mathrm{~mm}$ outside diameter fuel rods for all other positions. While this study shows a path to obtain an acceptable thermal hydraulic design, it also provides the designer with an important design issue: the flow is clearly extremely sensitive to small variations in the channel flow area. Therefore, rod bowing and even the tolerances in rod dimensions could be crucial in terms of the temperature peaking. This sensitivity, which can be attributed to large channel enthalpy rise coupled with a region of low-density coolant and high exit velocities, renders the design uncertain.

Based on the results of this study, it appears that the reference SCWR design is not feasible. Although additional design and analysis might allow the recovery of some margin, it is unlikely that a SCWR assembly and core design can be developed that provides acceptable performance (i.e. low enough hot channel exit temperature). Therefore, the SCWR core design remains a major feasibility issue for which a solution has yet to be achieved at this stage of the program.

An Evaluation of an Innovative Safety Concept for the SCWR. Preliminary investigations of the safety characteristics of a SCWR performed by INEEL and the Westinghouse have resulted in the development of a novel safety concept for this Generation IV reactor. Previous analyses have shown that the SCWR can meet transient thermal limits for events initiated by loss of main feedwater only if a large capacity auxiliary feedwater system is actuated rapidly. However, the required rapid initiation of auxiliary feedwater was judged to pose significant technical and economic challenges. Consequently, Westinghouse developed an innovative conceptual design that uses a passive circulation system to mitigate the effects of loss of main feedwater. This safety concept utilizes two, relatively small, feedwater tanks that store water for reactor cooling during normal operation and provide sufficient cooling capacity to mitigate the effects of a loss of main feedwater. Main coolant pumps similar to those utilized in advanced light water reactors provide the head required to circulate the flow in the reactor. Although the proposed concept takes advantage of the SCWR once-through, direct cycle concept during normal operation, it allows the establishment of a recirculation path in the system following containment isolation, with an isolation condenser that provides long-term decay heat removal.

The safety characteristics of the design were evaluated for loss-of-flow transients using the RELAP5-3D computer code. The results of these evaluations confirmed the potential of the design. Acceptable shortterm results following loss of flow were obtained by adjusting the coastdown characteristics of the main coolant pumps. Acceptable long-term decay heat removal following loss of flow was obtained with 300 or more tubes in the isolation condenser.

Preliminary evaluations of loss-of-coolant accidents were also performed. The analysis of an accident initiated by a large cold leg break showed that significantly lower cladding temperatures were obtained after the blowdown peak in the proposed design than in a simple, once-through design due to the recirculation loop and the added coolant inventory provided by the feedwater tanks. The milder evolution 
of the accident allows for a significant simplification in the design of an adequate emergency core cooling system.

Structural Response of SCWR Reactor Pressure Vessel to Thermal Transients. A process was developed for examining the SCWR pressure vessel structural consequences of thermal transients. This is important because hydraulic transients are often much shorter than the reactor pressure vessel thermal diffusion time. For the case examined here involving a sudden $30{ }^{\circ} \mathrm{C}\left(54{ }^{\circ} \mathrm{F}\right)$ drop in main feedwater temperature, the peak Von Mises stress is about 30\% higher (65 versus $50 \mathrm{ksi}$ ) than that experienced under static conditions at nominal system pressure. Given the low number of anticipated cycles and the relatively small temperature change, the ASME Code indicates the transient is of no consequence with respect to low-cycle fatigue.

Design of a Thermal Sleeve for the SCWR Hot Leg. The reference SCWR operates at substantially higher reactor coolant outlet temperature and pressure than existing LWRs. Therefore, the $500{ }^{\circ} \mathrm{C}$ reactor coolant outlet water must be isolated from the reactor pressure vessel in order to use conventional vessel materials. We examine hot nozzle isolation and recommend a design for a thermal sleeve. The thermal sleeve consists of a one-inch thick $(\sim 2.5 \mathrm{~cm})$ steel structural insert surrounded by a generous, two-inch $(\sim$ $5 \mathrm{~cm}$ ) radial water gap between thermal sleeve and reactor pressure vessel outlet nozzle. The outlet nozzles should be positioned above the inlet nozzles so that the isolating cold leg flow fills the annular water gap from below. In this way forced convection reinforces natural convection in the gap and peak vessel temperatures are both low and insensitive to water mass flow rate.

Fuel Assembly Conceptual Design. A conceptual design of a fuel assembly for the SCWR was developed to identify any feasibility issues. There are three main difficulties in the SCWR fuel assembly design - the fuel rod spacer, the assembly top structure, and the thermal expansion of the components of the fuel assembly. All of these three aspects were addressed in the preliminary fuel assembly design. 


\section{Table of Contents}

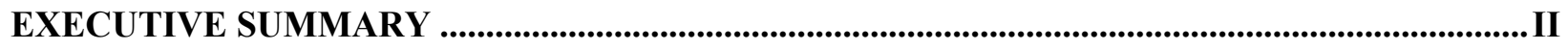

TASK 1. FUEL-CYCLE NEUTRONIC ANALYSIS AND REACTOR CORE DESIGN............................................ II

TASK 2. FUEL ClADDING AND STRUCTURAL MATERIAL CORROSION AND STRESS CORROSION

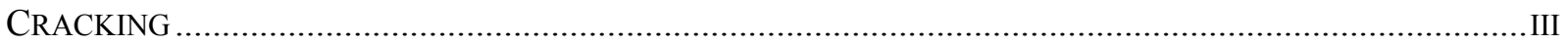

TASK 3. PLANT ENGINEERING AND REACTOR SAFETY ANALYSIS .....................................................IV

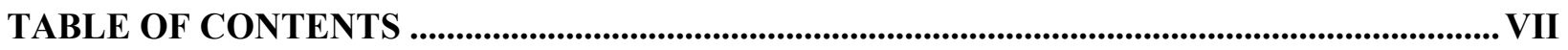

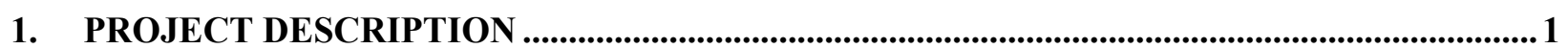

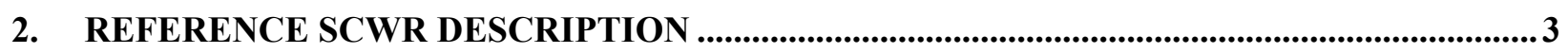

2.1. REFERENCE DESIGN POWER AND COOLANT CONDITIONS ....................................................... 3

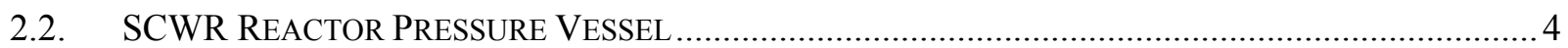

2.3. SCWR CORE AND FUEL ASSEMBLY DESIGN .............................................................. 4

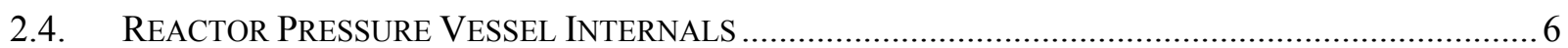

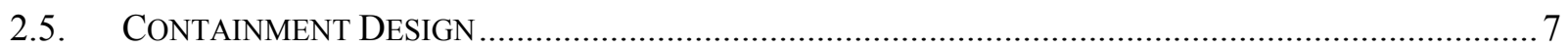

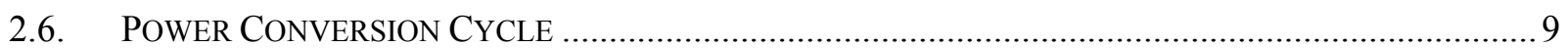

\section{TASK 1 RESULTS: FUEL-CYCLE NEUTRONIC ANALYSIS AND REACTOR CORE}

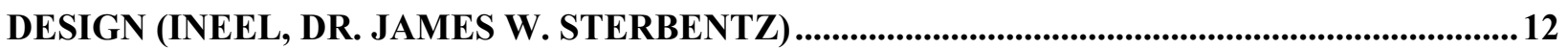

3.1. NEUTRONIC EVALUATION OF A 25X25 SUPERCRITICAL WATER REACTOR FUEL ASSEMBLy

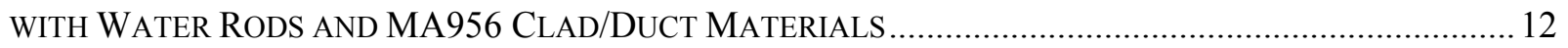

3.1.1. SCWR Fuel Assembly and MCNP Model Description ................................................. 12

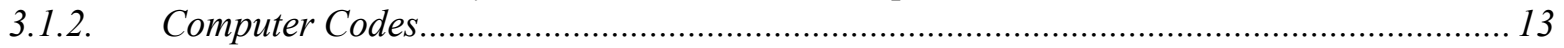

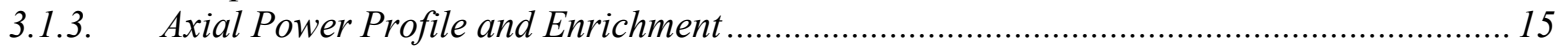

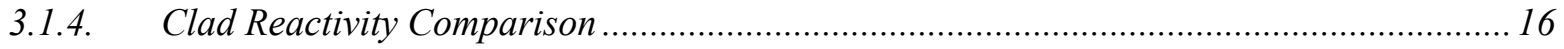

3.1.5. Coolant and Water Rod Void Reactivity ..................................................................... 17

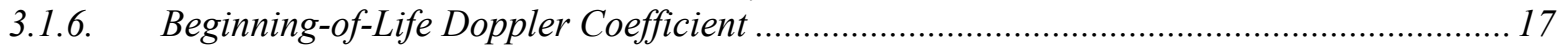

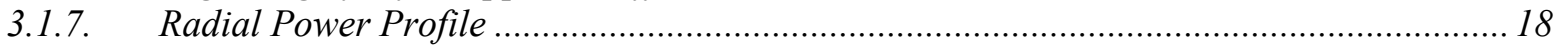

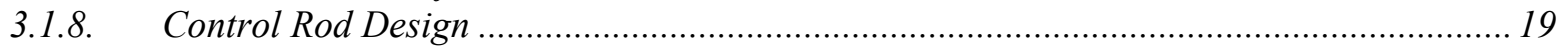

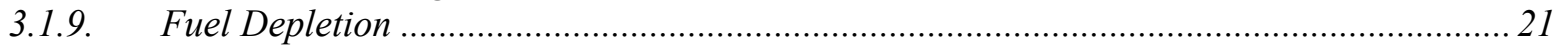

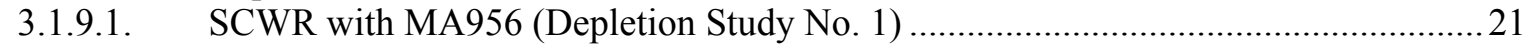

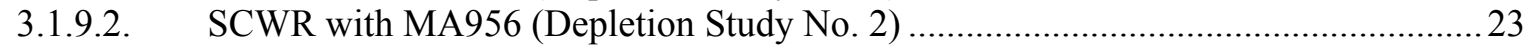

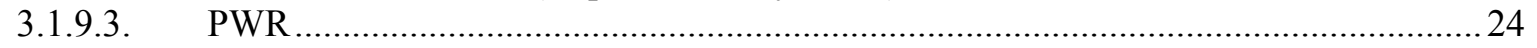

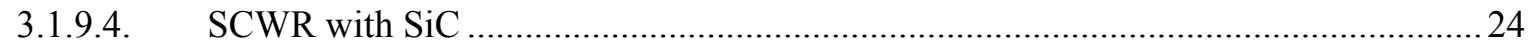

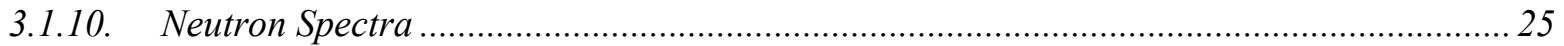

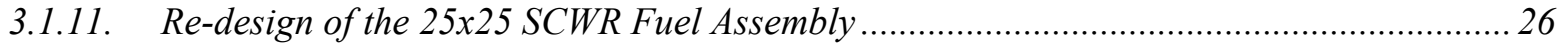

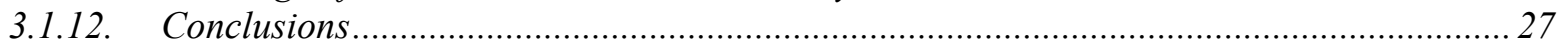

3.2. NEUTRONIC EVALUATION OF A 21X21 SUPERCRITICAL WATER REACTOR FUEL ASSEMBLY

DESIGN WITH WATER RODS AND SIC CLADDING AND DUCT MATERIALS ........................................28

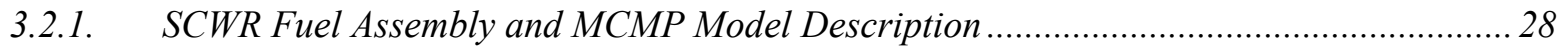

3.2.2. Material Reactivity Comparison (SiC versus MA956) .................................................... 30

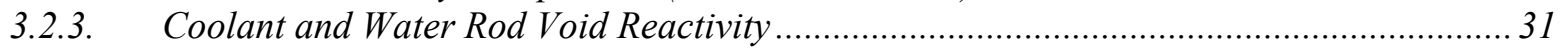

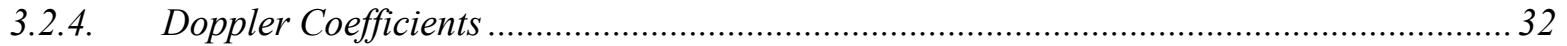

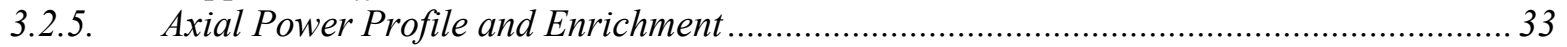

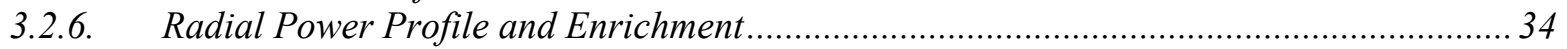

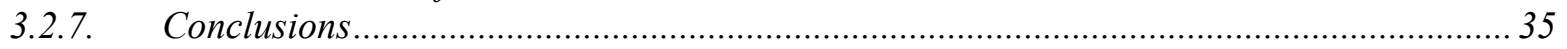




\section{TASK 2 RESULTS: CORROSION AND STRESS CORROSION CRACKING STUDIES (UNIVERSITY OF MICHIGAN, PROF. GARY WAS).}

4.1. CONSTRUCTION AND OPERATION OF THE SCW AUTOCLAVE SySTEM........................................ 37

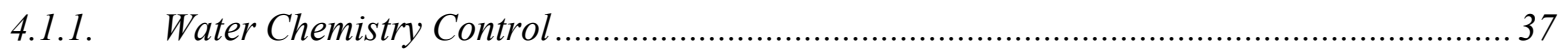

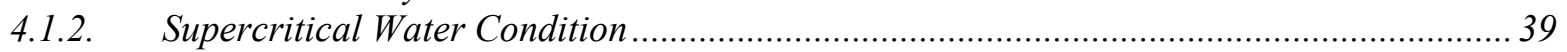

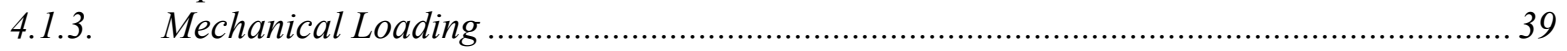

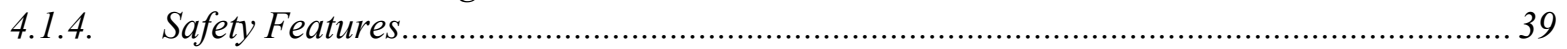

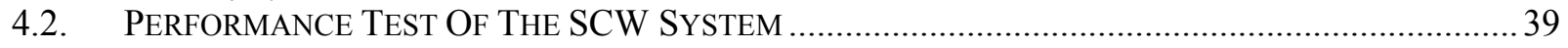

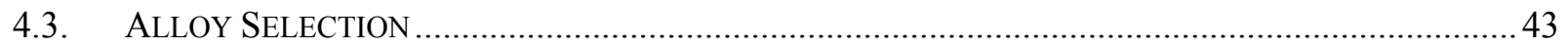

4.4. SCC AND CORROSION IN THE TEMPERATURE RANGE $400-550{ }^{\circ} \mathrm{C}$ IN DEAERATED SCW ...... 44

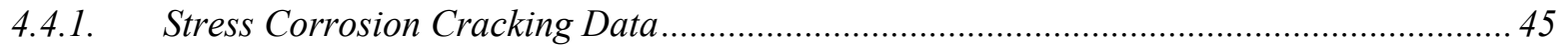

4.4.2. Discussion of Stress Corrosion Cracking Results............................................................ 53

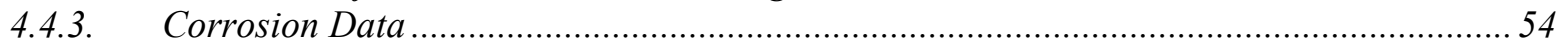

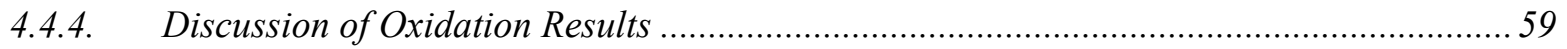

4.5. EFFECT OF OXYGEN CONTENT ON SCC AND CORROSION OF 304L STAINLESS STEEL............. 60

4.6. EFFECT OF OXYGEN CONTENT ON SCC AND CORROSION OF FERRITIC-MARTENSITIC ALLOYS

AT $500^{\circ} \mathrm{C}$

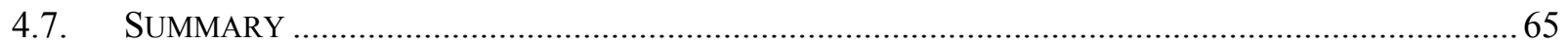

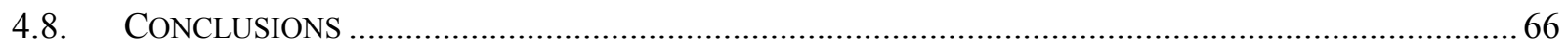

5. TASK 3 RESULTS: PLANT ENGINEERING AND REACTOR SAFETY ANALYSIS .........67

5.1. THERMAL-HYdRAUliC ASSESSMENT OF A SUPERCRITICAL WATER REACTOR (SCWR) CORE (Westinghouse Electric Co., DR. LuCA ORIANI AND DR. Vefa N. KuCUKBOYACI)......................67

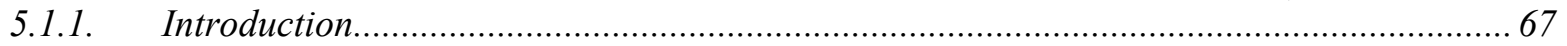

5.1.2. Initial Supercritical Water Reactor Sub-Channel Analysis ............................................ 68

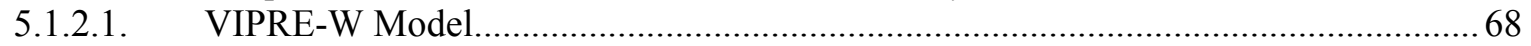

5.1.2.2. Heat Transfer and Friction Loss Correlations ......................................................... 74

5.1.2.3. Thermal-Hydraulic Profiles in the Hot and Cold Channels for Different Radial Power

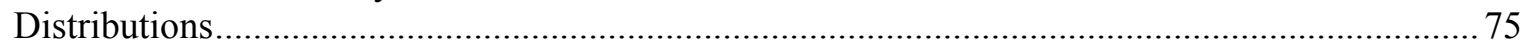

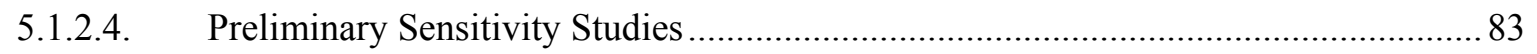

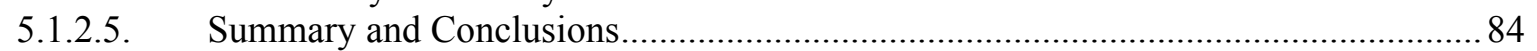

5.1.3. Thermal-Hydraulic Optimization Studies of the Supercritical Water Reactor Fuel

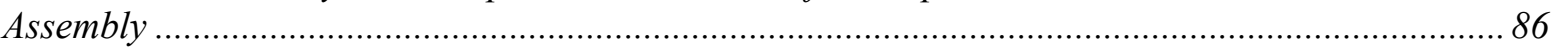

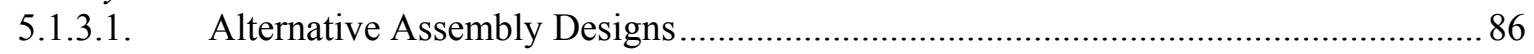

5.1.3.2. Thermal-Hydraulic Profiles in the Hot and Cold Channels for Different Assembly

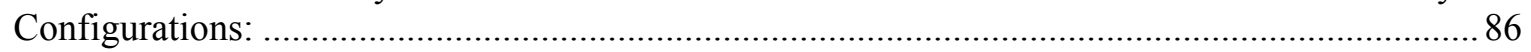

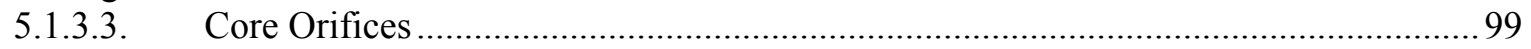

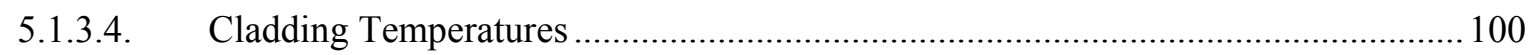

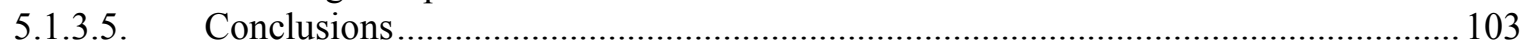

5.2. AN EVALUATION OF AN INNOVATIVE SAFETY CONCEPT FOR THE SCWR (INEEL: C. B. DAVIS,

WEStinghOUSE ElECTRIC CO.: DR. L. ORIANI, L. E. CONWAY, AND N. JONSSON) ......................... 104

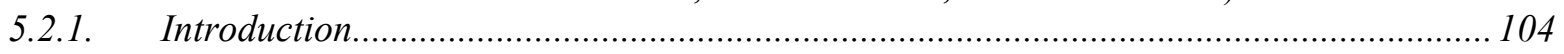

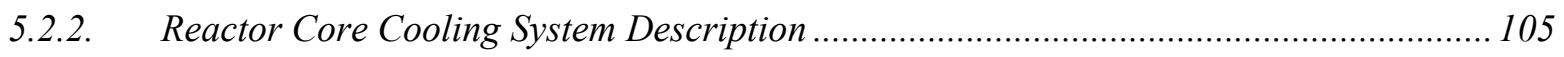

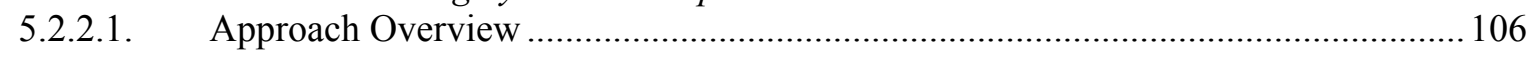

5.2.2.2. Anticipated Response Following Loss-of-Flow Events....................................... 108

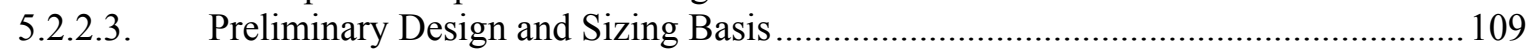

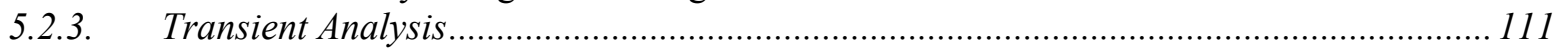

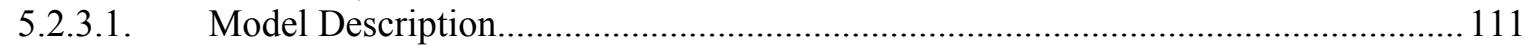

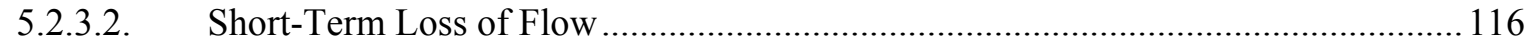

5.2.3.3. Long-Term Loss of Main Feedwater ............................................................... 119 


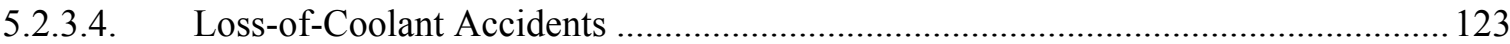

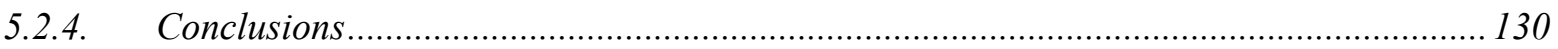

5.3. STRUCTURAL RESPONSE OF SCWR REACTOR PRESSURE VESSEL TO THERMAL TRANSIENTS

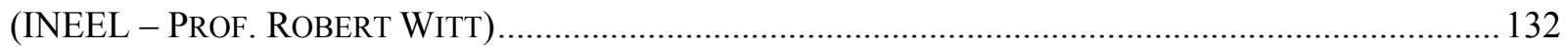

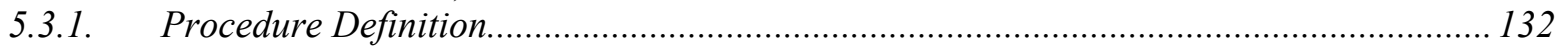

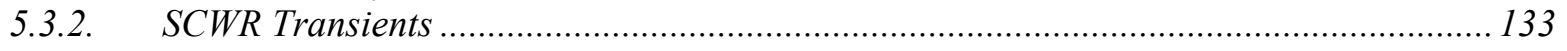

5.3.3. Limitations Of Finite Element Analysis In Step Change Problems …........................... 135

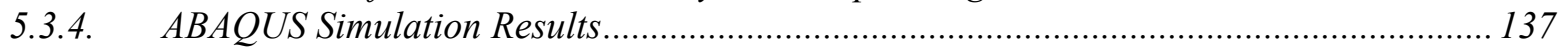

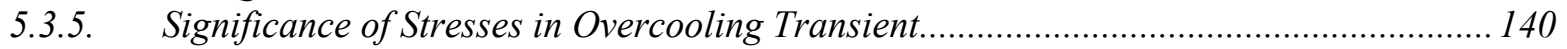

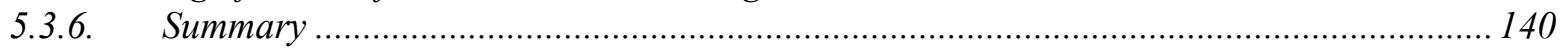

5.4. DESIGN OF THERMAL SLEEVE FOR SCWR (INEEL - PROF. ROBERT WITT).......................... 142

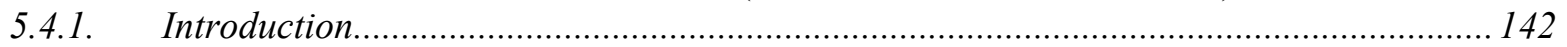

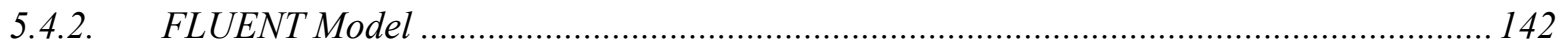

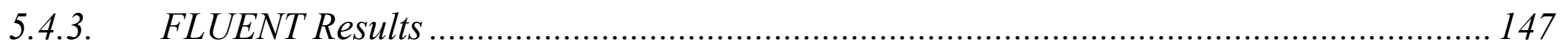

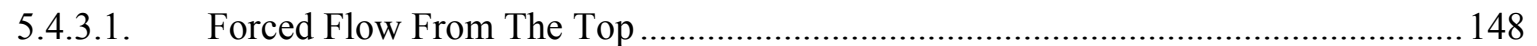

5.4.3.2. Forced Flow From The Bottom ....................................................................... 152

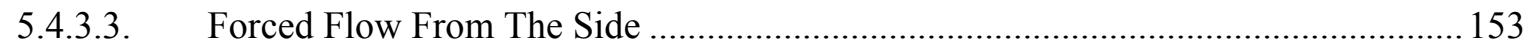

5.4.3.4. Forced Flow From Top Or Bottom With Smaller Annular Gap .............................. 157

5.4.4. Sensitivity of Results to Modeling Choices ...................................................................... 158

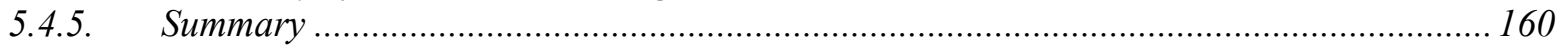

5.5. Fuel ASSEMBly CONCEPTUAL DeSign (WESTINGHOUSE - DR. BIN LIU, LAWRENCE CONWAY

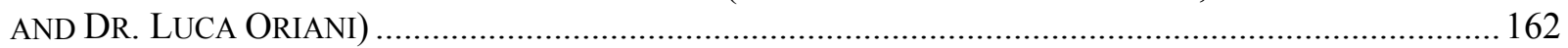

5.5.1. Description of the SCWR Preliminary Fuel Assembly Design ...................................... 162

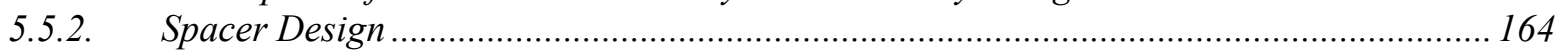

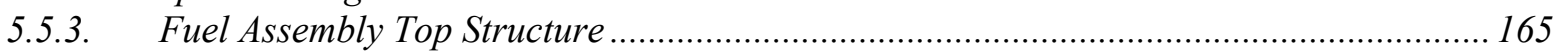

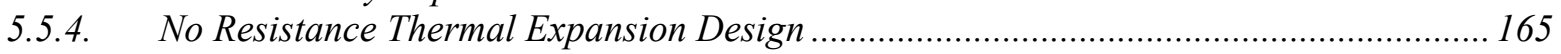

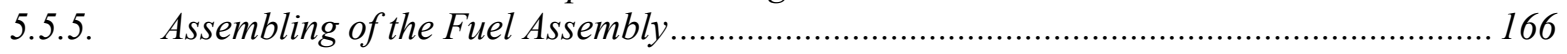

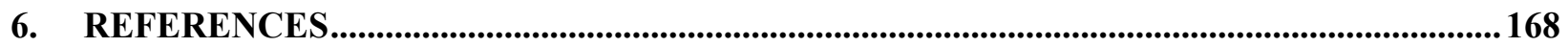

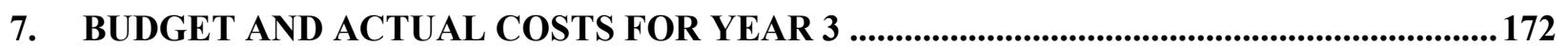

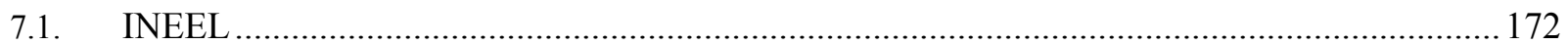

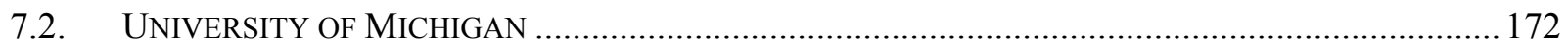

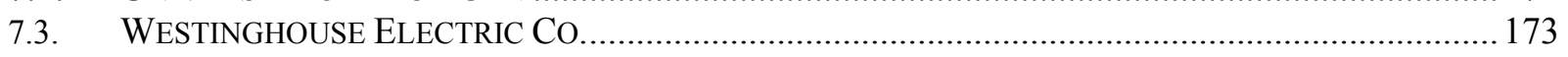

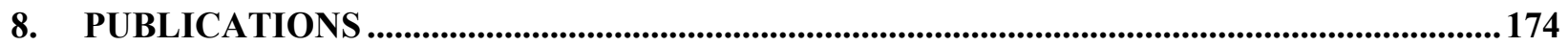




\section{Project Description}

The supercritical water-cooled reactor (SCWR) is one of the six reactor technologies selected for research and development under the Generation-IV program. SCWRs are promising advanced nuclear systems because of their high thermal efficiency (i.e., about $45 \%$ vs. about 33\% efficiency for current Light Water Reactors, LWRs) and considerable plant simplification. SCWRs are basically LWRs operating at higher pressure and temperatures with a direct once-through cycle. Operation above the critical pressure eliminates coolant boiling, so the coolant remains single-phase throughout the system. Thus the need for a pressurizer, steam generators, steam separators and dryers is eliminated. The main mission of the SCWR is generation of low-cost electricity. It is built upon two proven technologies, LWRs, which are the most commonly deployed power generating reactors in the world, and supercritical fossil-fired boilers, a large number of which is also in use around the world.

The work on this NERI project has been closely coordinated with the work on the Generation IV SCWR project. The results from both projects have resulted in the identification of a reference U.S. SCWR design, which is described in Section 2 of this report. The candidate materials to be used in the SCWR are described in a document by Buongiorno et al. [2003].

The reference SCWR design for the U.S. program is a direct cycle system operating at $25.0 \mathrm{MPa}$ with core inlet and outlet temperatures of 280 and $500{ }^{\circ} \mathrm{C}$, respectively. The coolant density decreases from about $760 \mathrm{~kg} / \mathrm{m}^{3}$ at the core inlet to about $90 \mathrm{~kg} / \mathrm{m}^{3}$ at the core outlet. The inlet flow splits with about $10 \%$ of the inlet flow going down the space between the core barrel and the reactor pressure vessel (the downcomer) and about $90 \%$ of the inlet flow going to the plenum at the top of the rector pressure vessel to then flow downward through the core in special water rods to the inlet plenum. Here it mixes with the feedwater from the downcomer and flows upward to remove the heat in the fuel channels. This strategy is employed to provide good moderation at the top of the core. The coolant is heated to about $500{ }^{\circ} \mathrm{C}$ and delivered to the turbine.

The purpose of this NERI project was to assess the reference U.S. Generation IV SCWR design and explore alternatives to determine feasibility. The project was organized into three tasks.

Task 1. Fuel-cycle Neutronic Analysis and Reactor Core Design (INEEL). Metallic and oxide fertile fuels in a fast-spectrum SCWR were investigated during Year 1 to evaluate the void and Doppler reactivity coefficients, actinide burn rate, and reactivity swing throughout the irradiation cycle. These results were reported in the $1^{\text {st }}$ Quarterly (MacDonald et al. 2001). A variety of other core arrangements and moderator types for a thermal-spectrum SCWR were also assessed during the three years of this project. The detailed results from the solid moderator studies are presented in the $3^{\text {rd }}$ Quarterly (MacDonald et al. 2002a) and $4^{\text {th }}$ Quarterly Reports (MacDonald et al. 2002b) and in two papers by Buongiorno and MacDonald (2003a \& 2003b). Results from an analysis of an alternative thermalspectrum SCWR design based on vertical power channels, hexagonal fuel assemblies, and water moderation between the fuel assemblies were reported in the $2^{\text {nd }}$ Annual Report (MacDonald et al. 2003). Also reported in the $2^{\text {nd }}$ Annual Report were the results of the steady-state thermal-hydraulic analyses of two other thermal spectrum SCWRs (both with square fuel assemblies containing a $25 \times 25$ fuel rod array and a $6 \times 6$ moderator rod array), one design with solid moderator rods, and one design with water filled moderator rods.

This report presents in Chapter 3 the results of a neutronic evaluation of a $25 \times 25$ fuel assembly that uses MA956 for the fuel rod cladding, water rod duct, and assembly duct materials and the results of a 
neutronic evaluation of a $21 \times 21$ SCWR assembly that uses silicon carbide ( $\mathrm{SiC}$ ) for the fuel rod cladding, water rod duct, and assembly duct materials.

Task 2. Fuel Cladding and Structural Material Corrosion and Stress Corrosion Cracking (University of Michigan). The existing data base on the corrosion and stress-corrosion cracking of austenitic stainless steel and nickel-based alloys in supercritical water is very sparse. Therefore, the focus of this work has been corrosion and stress corrosion cracking testing of candidate fuel cladding and structural materials. During Year 1, a high temperature autoclave with carefully controlled chemistry and containing a constant rate mechanical test device was built and tested at the University of Michigan. During Years 2 and 3, a variety of austenitic and ferritic-martensitic alloys were tested. The results of that work are presented in Section 4 of this report.

Task 3. Plant Engineering and Reactor Safety Analysis (Westinghouse and INEEL). The optimal configuration of the power conversion cycle was identified in Year 1. Particular emphasis was given to the applicability of current supercritical fossil-fired plant technology and experience to a direct-cycle nuclear system. Also during Year 1 preliminary core design criteria were developed, a critical review of the supercritical water heat transfer correlations was completed, preliminary hot channel factors were identified, approximate temperature and density profiles in the average and hot channels were calculated, and improvements were made in the RELAP5 and VIPRE computer codes.

During Year 2, an assessment of the water rod density and moderation effectiveness and a more detailed steady-state sub-channel analysis of the reactor core were undertaken with the goal of establishing power limits and safety margins under normal operating conditions. Also, the response of the plant to accident situations and anticipated transients without scram was assessed for the solid moderator, water rod, and power channel-hexagonal fuel assembly core designs.

During Year 3, the Westinghouse tasks included further assessment of the reference core thermal hydraulic design (see Section 5.1). Results from optimization studies suggested that it was possible to obtain a better temperature profile and lower hot channel factors by employing a more complex assembly configuration. Based on the results of this study, the design should use a geometric configuration with smaller fuel rods for the coolant channels facing the water rods, at the assembly periphery, and for the assembly corners. In addition, the Westinghouse researchers developed the innovative safety design for the SCWR presented in Section 5.2. This safety concept utilizes two, relatively small, feedwater tanks that store water for reactor cooling during normal operation and provide sufficient cooling capacity to mitigate the effects of a loss of main feedwater. Main coolant pumps similar to those utilized in advanced LWRs provide the head required to circulate the flow in the reactor. The safety characteristics of the design were evaluated at the INEEL using the RELAP5-3D computer code and we confirmed the potential of the design.

Also during year 3, the structural consequences of various SCWR pressure vessel thermal transients were assessed, the problem of the hot nozzle isolation was examined and a design for a thermal sleeve was developed, and a conceptual design of a fuel assembly for the SCWR was developed. This work is discussed in Sections 5.3, 5.4, and 5.5 of this report. 


\section{Reference SCWR Description}

\subsection{Reference Design Power and Coolant Conditions}

As mentioned in the project description, we have chosen to focus on a direct cycle plant design. Highpressure $(25.0 \mathrm{MPa})$ coolant enters the vessel at $280{ }^{\circ} \mathrm{C}$. The inlet flow splits with about $10 \%$ of the inlet flow going down the space between the core barrel and the reactor pressure vessel (the down-comer) and about $90 \%$ of the inlet flow going to the plenum at the top of the rector pressure vessel to then flow downward through the core in special water rods to the inlet plenum. This strategy is employed to provide good moderation at the top of the core. The coolant is heated to about $500{ }^{\circ} \mathrm{C}$ and delivered to a power conversion cycle similar to that used in supercritical fossil-fired plants: high- intermediate- and low-pressure turbines are employed with two re-heaters. The single most significant factor in going from the current pressurized water reactor (PWR) and BWR designs to the SCWR is the associated increase in outlet coolant temperature from 300 to $500{ }^{\circ} \mathrm{C}$.

The reference power, efficiency, pressure, and coolant flow rate and temperatures are listed in Table 1. Figure 1 is a sketch of the reactor pressure vessel and internals showing the coolant flow paths.

Table 1. U.S. GenerationIV SCWR reference design power and coolant conditions.

\begin{tabular}{|l|l|}
\hline Parameter & Value \\
\hline $\begin{array}{l}\text { Thermal } \\
\text { power }\end{array}$ & $3575 \mathrm{MWt}$ \\
\hline $\begin{array}{l}\text { Net electric } \\
\text { power }\end{array}$ & $\begin{array}{l}1600 \\
\mathrm{MWe}\end{array}$ \\
\hline $\begin{array}{l}\text { Net thermal } \\
\text { efficiency }\end{array}$ & $44.8 \%$ \\
\hline $\begin{array}{l}\text { Operating } \\
\text { pressure }\end{array}$ & $25 \mathrm{MPa}$ \\
\hline $\begin{array}{l}\text { Reactor inlet } \\
\text { temperature }\end{array}$ & $280^{\circ} \mathrm{C}$ \\
\hline $\begin{array}{l}\text { Reactor } \\
\text { outlet } \\
\text { temperature }\end{array}$ & $500^{\circ} \mathrm{C}$ \\
\hline $\begin{array}{l}\text { Reactor flow } \\
\text { rate }\end{array}$ & $1843 \mathrm{~kg} / \mathrm{s}$ \\
\hline Plant lifetime & 60 years \\
\hline
\end{tabular}

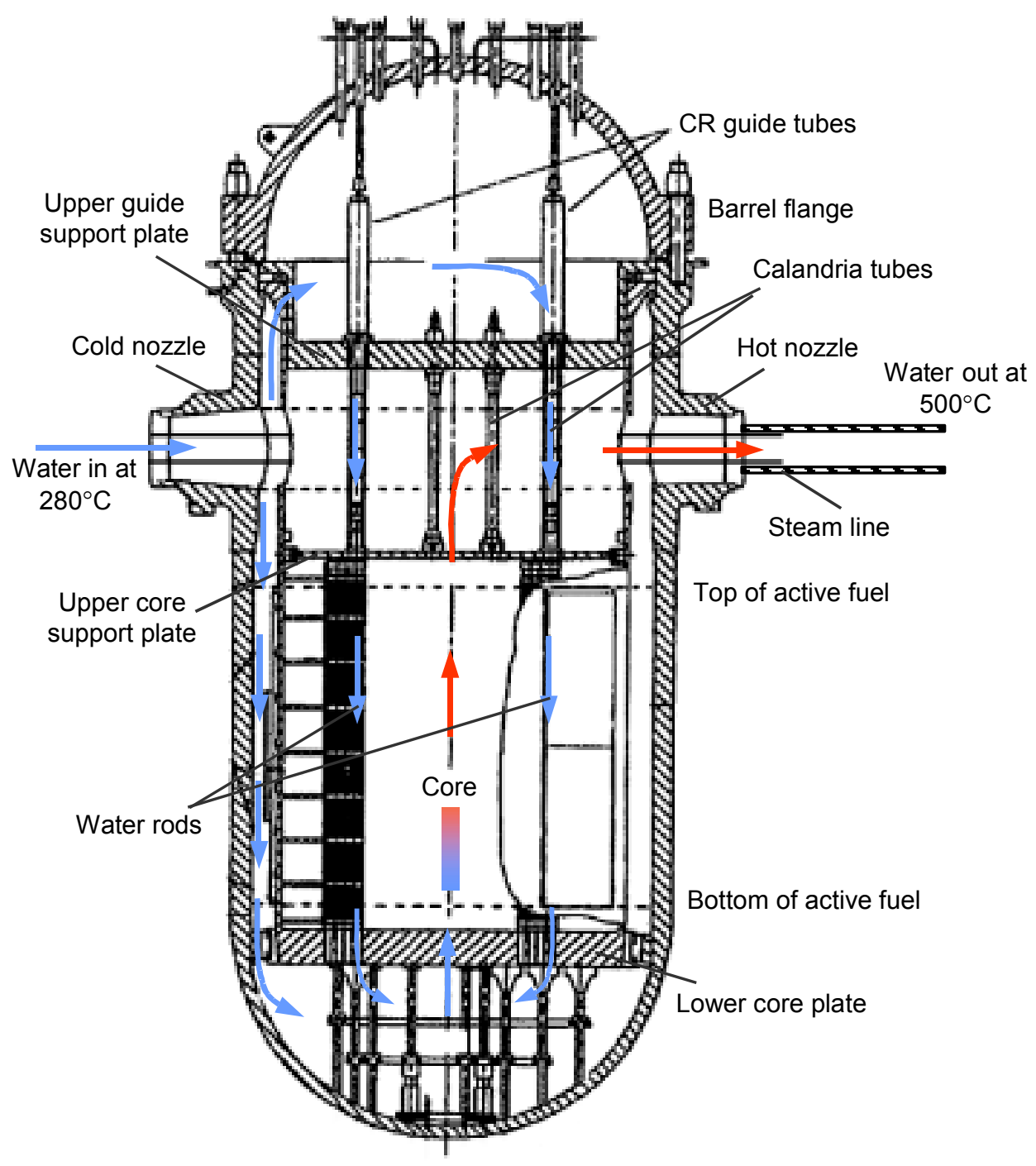

Figure 1. The SCWR reactor pressure vessel and internals. 


\subsection{SCWR Reactor Pressure Vessel}

A three-dimensional cad-cam representation of the current vessel design is shown in Figure 2. The key vessel dimensions are listed in Table 2. This vessel design is similar to a typical large-size PWR vessel design with no major penetrations through the lower head. However the thickness is significantly larger due to the higher operating pressure. The vessel appears to be within the current manufacturing capability in Japan and possibly elsewhere. The hot nozzles will be protected with a thermal sleeve against the full outlet temperature. They will operate at temperatures only slightly above $280^{\circ} \mathrm{C}$. The rest of the vessel will be exposed to $280{ }^{\circ} \mathrm{C}$ inlet coolant on the inside surfaces. Also, the inside surfaces will be clad with stainless steel, probably Type 308 stainless steel.

Table 2. Reference reactor pressure vessel design for the U.S. Generation-IV SCWR.

\begin{tabular}{|l|l|}
\hline Parameter & Value \\
\hline Height & $12.4 \mathrm{~m}$ \\
\hline Material & $\begin{array}{l}\text { SA-533 or SA-508 } \\
\text { Grade 3, Class 1 }\end{array}$ \\
\hline Design pressure & $\begin{array}{l}27.5 \mathrm{MPa}(110 \% \text { of } \\
\text { nominal pressure })\end{array}$ \\
\hline Operating temperature & $280^{\circ} \mathrm{C}$ \\
\hline $\begin{array}{l}\text { Number of cold/hot } \\
\text { nozzles }\end{array}$ & $2 / 2$ \\
\hline Inside diameter of shell & $5.322 \mathrm{~m}(209.5 \mathrm{in})$. \\
\hline Thickness of shell & $0.457 \mathrm{~m}(18$ in) \\
\hline $\begin{array}{l}\text { Thickness of the shell in } \\
\text { the nozzle region }\end{array}$ & $0.629 \mathrm{~m}(24.75 \mathrm{in})$. \\
\hline Inside diameter of head & $5.352 \mathrm{~m}(210 \mathrm{in})$ \\
\hline Thickness of head & $0.305 \mathrm{~m}(12 \mathrm{in})$ \\
\hline Vessel weight & $\begin{array}{l}780 \mathrm{mt}(1.7 \mathrm{million} \\
\text { lbs })\end{array}$ \\
\hline Peak fast fluence, $>1 \mathrm{MeV}$ & $<5 \times 10^{19} \mathrm{n} / \mathrm{cm}^{2}$ \\
\hline
\end{tabular}

\subsection{SCWR Core And Fuel Assembly Design}

The reference SCWR core design is shown in Figure 3. The relevant dimensions are listed in Table 3. The core will have 145 assemblies with an equivalent diameter of about 3.9 meters. The core barrel will have inside and outside diameters of about 4.3 and 4.4 meters, respectively. The average power density will be about $70 \mathrm{~kW} / \mathrm{L}$ with a total target power peaking factor of about 2.0. The core pressure drop will be around 0.15 $\mathrm{MPa}$ (comparable with typical LWR pressure drops) and inlet orifices will be used to adjust the flow to each

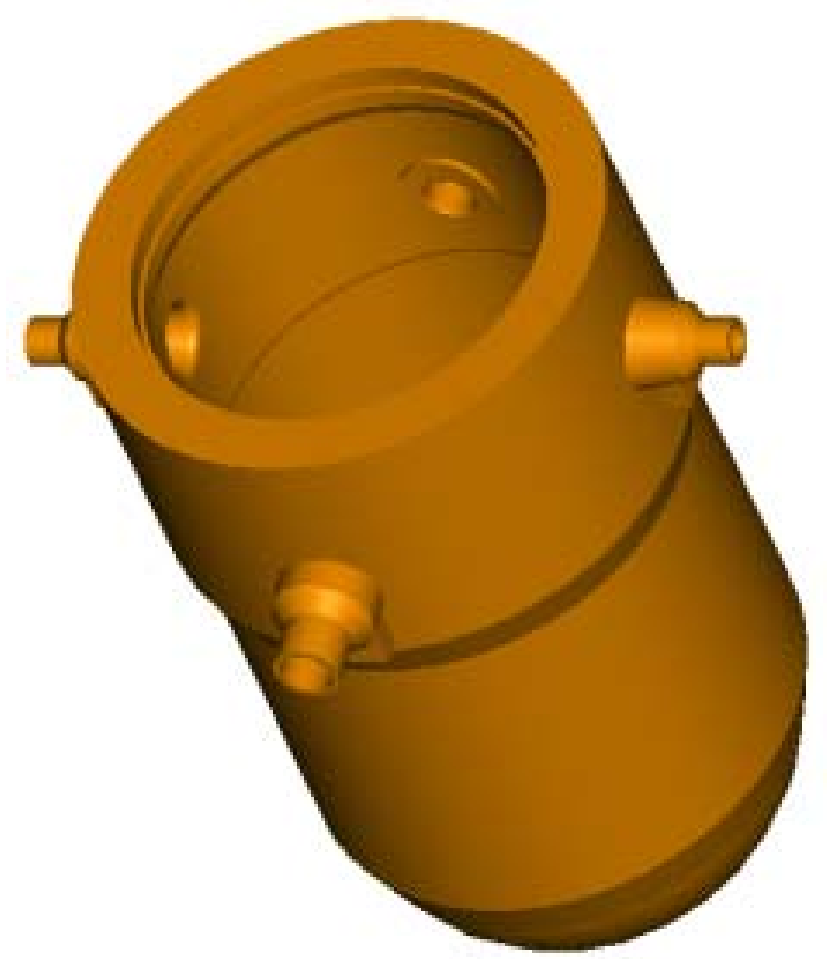

Figure 2. Three-dimensional cad-com representation of the current SCWR pressure vessel design.

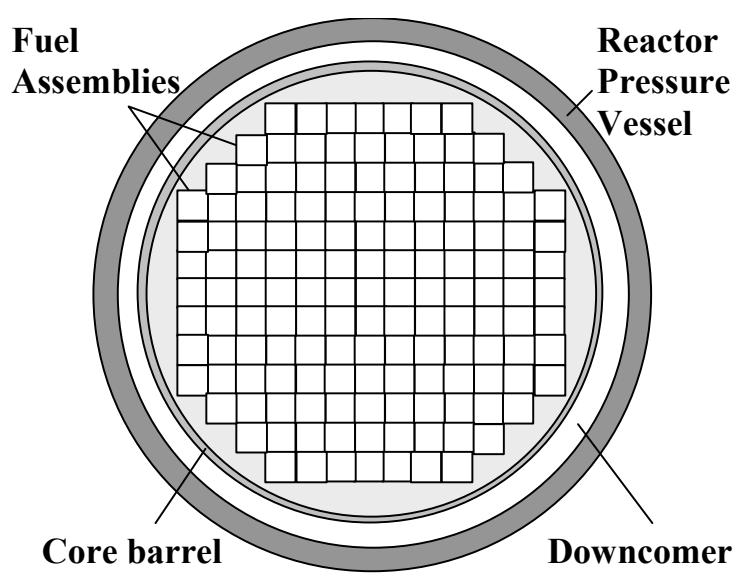

Figure 3. Sketch of the reference SCWR core. 
assembly based on its expected power. As mentioned above, about $90 \%$ of the inlet flow will be passed through the water rods with a flow rate in the water rods of about $1660 \mathrm{~kg} / \mathrm{s}$.

Table 3. Reference reactor core design for the U.S. Generation-IV SCWR.

\begin{tabular}{|l|l|}
\hline Parameter & Value \\
\hline Number of fuel assemblies & 145 \\
\hline Equivalent diameter & $3.93 \mathrm{~m}$ \\
\hline Core barrel inside and outside diameter & $4.3 / 4.5 \mathrm{~m}$ \\
\hline Axial/Radial/Local/Total Peaking Factor & $1.4 / 1.3 / 1.1 / 2.0$ (best estimate) \\
& $1.4 / 1.4 / 1.2 / 2.35$ (safety analysis) \\
\hline Average power density & $69.4 \mathrm{~kW} / \mathrm{L}$ \\
\hline Average linear power & $19.2 \mathrm{~kW} / \mathrm{m}$ \\
\hline Peak linear power at steady-state conditions & $39 \mathrm{~kW} / \mathrm{m}$ \\
\hline Core pressure drop & $0.15 \mathrm{MPa}$ \\
\hline Water rod flow & $1660 \mathrm{~kg} / \mathrm{s}(90 \%$ of nominal flow rate) \\
\hline
\end{tabular}

The reference SCWR fuel assembly design is shown in Figure 4 and the relevant dimensions are listed in Table 4. It is assumed that there will only be one instrumentation tube in each assembly at the center fuel rod location. Also, a number of the dimensions are tentative including the fuel bundle wall thickness and the inter-assembly gap size and the fuel pin spacer have yet to be designed.

Table 4. Reference fuel assembly design for the U.S.

\section{Generation-IV SCWR.}

\begin{tabular}{|l|l|}
\hline Parameter & Value \\
\hline Fuel pin lattice & $\begin{array}{l}\text { Square } \\
25 \times 25 \text { array }\end{array}$ \\
\hline Number of fuel pins per assembly & 300 \\
\hline Pitch to diameter ratio & 1.09804 \\
\hline Number of water rods per assembly & 36 \\
\hline Water rod side & $33.6 \mathrm{~mm}$ \\
\hline Water rod wall thickness & $0.4 \mathrm{~mm}$ \\
\hline Water rod wall materials & TBD \\
\hline $\begin{array}{l}\text { Number of instrumentation rods per } \\
\text { assembly }\end{array}$ & 1 \\
\hline $\begin{array}{l}\text { Number of control rod fingers per } \\
\text { assembly }\end{array}$ & 12 \\
\hline Control rod material & $\mathrm{B}_{4} \mathrm{C}$ \\
\hline Number of spacer grids & 14 \\
\hline Assembly wall thickness & $3 \mathrm{~mm}$ \\
\hline Assembly wall material & $\mathrm{TBD}$ \\
\hline Assembly side & $286 \mathrm{~mm}$ \\
\hline Inter-assembly gap & $2 \mathrm{~mm}$ \\
\hline Assembly pitch & $288 \mathrm{~mm}$ \\
\hline
\end{tabular}

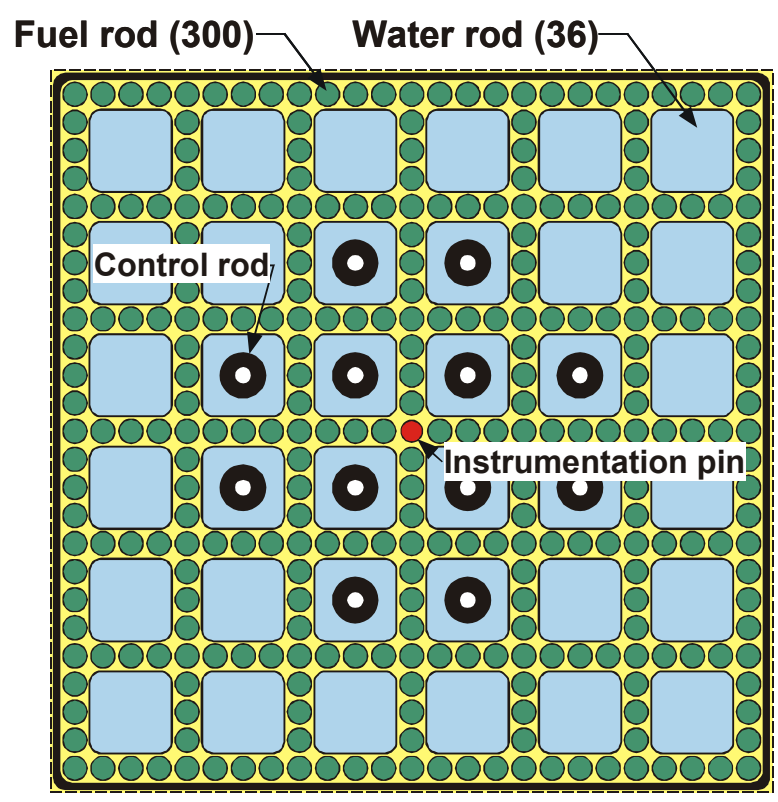

Figure 4. The SCWR fuel assembly with metal water rod boxes.

The reference fuel pin dimensions are listed in Table 5. With the exception of the plenum length and fill pressure, the fuel pin dimensions are typical of 17 by 17 PWR fuel assembly pins. However, the fuel pin pitch is considerably smaller than the pitch used in LWRs. The U-235 enrichment, the $\mathrm{Gd}_{2} \mathrm{O}_{3}$ loading and fuel burnup are typical of the values used in high burnup LWR fuel. 
Table 5. Reference fuel pin design for the U.S. Generation-IV SCWR.

\begin{tabular}{|l|l|}
\hline Parameter & Value \\
\hline Fuel pin outside diameter & $10.2 \mathrm{~mm}$ \\
\hline Fuel pin pitch & $11.2 \mathrm{~mm}$ \\
\hline Cladding thickness & $0.63 \mathrm{~mm}$ \\
\hline Cladding materials & TBD \\
\hline Fuel pellet outside diameter & $8.78 \mathrm{~mm}$ \\
\hline Pellet to cladding gap (cold) & $80 \mathrm{microns}$ \\
\hline Fuel composition & $\mathrm{UO}_{2}, 95 \% \mathrm{TD}$ \\
\hline Fuel density & $10.4215 \mathrm{~g} / \mathrm{cc}$ \\
\hline Heated fuel length & $4.27 \mathrm{~m}$ \\
\hline Fission gas plenum length & $0.6 \mathrm{~m}$ \\
\hline Total fuel pin height & $4.87 \mathrm{~m}$ \\
\hline Fill gas pressure at room temperature & $6.0 \mathrm{MPa}$ \\
\hline
\end{tabular}

\subsection{Reactor Pressure Vessel Internals}

The important reactor pressure vessel internals include the lower core support plate, the core former, the core barrel, the upper core support plate, the calandria tubes located immediately above the upper core support plate, the upper guide support plate, the hot nozzle thermal sleeve or insulation, and the control rod guide tubes. The location and approximate shape of most of these components is shown in Figure 1. All the reactor pressure vessel internals components will be designed for periodic replacement so that high fluence (>20 dpa) loadings will not need to be considered.

Some of these components, including the lower core support plate and the control rod guide tubes in the upper head, will be subjected to normal PWR coolant temperature conditions and will be similar to the components typically used in PWRs. However, a number of the reactor pressure vessel internals, including the core barrel (or possibly the core former, depending on the design details), the upper guide support plate, the calandria tubes, and the reactor pressure vessel hot nozzle sleeve, will be in contact with the inlet temperature at $280{ }^{\circ} \mathrm{C}$ on one side and the hot outlet coolant at a temperature of $500{ }^{\circ} \mathrm{C}$ on the other side. Our preliminary stress analyses indicate that we will not be able to use metal wall designs that are similar to those currently used in LWRs for those components. Such a high temperature drop across those walls will cause the thermal stresses and deformations to be too large and/or cause too much heat to be transferred across the walls. For example, a simplified thermal stress analysis of the upper guide support plate was performed using a temperature difference of $220{ }^{\circ} \mathrm{C}\left(396{ }^{\circ} \mathrm{F}\right)$ and the Pro/Mechanica software. The result was that much of the structure will exceed the 3 Sm Primary + Secondary stress limit of Subsection NG of the ASME code as shown in Figure 5. Resolution of these issues may require new design features including special materials, insulation layers, and/or use of an insulating layer between double walls.

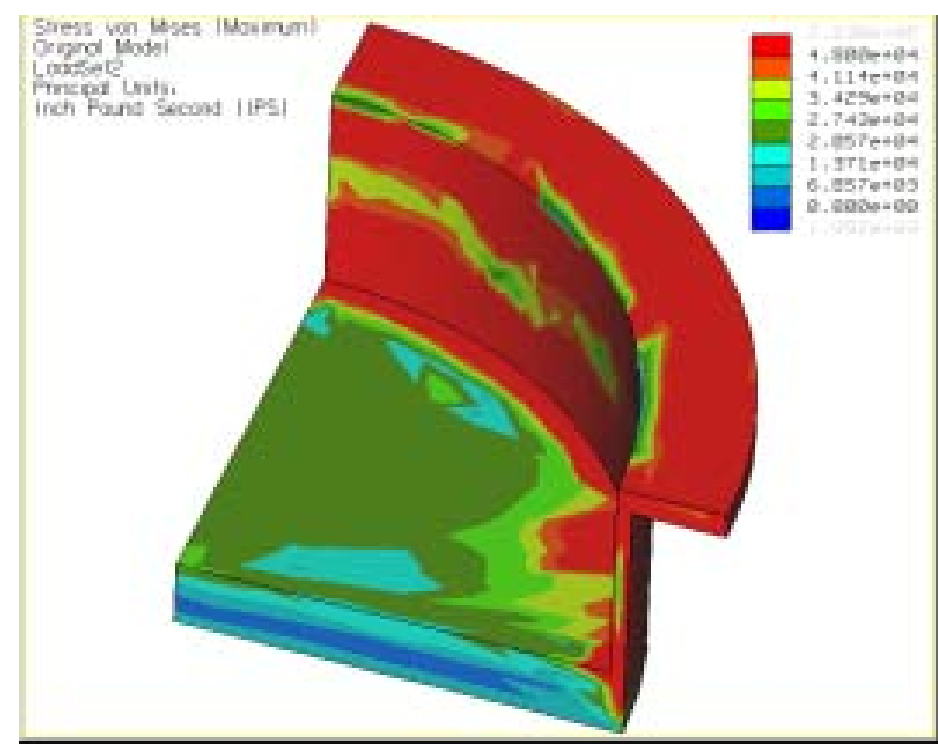

Figure 5. Results of the preliminary thermal stress analysis of the upper guide support plate. 
Some other reactor pressure vessel internals components, such as the upper core support plate, will be exposed to the outlet coolant at a temperature of about $500{ }^{\circ} \mathrm{C}$ on all sides.

The size and shape of most of the reactor pressure vessel internals discussed above should be similar to comparable components in a large Westinghouse designed PWR. However, it should be noted that the design of the calandria tubes that guide the flow of the moderator water through the hot region above the core and guide the control rods is not complete. We need to minimize the heat transfer surface area; one way to do that is to combine the outside water moderator boxes into one channel in the region above the core.

\subsection{Containment Design}

The SCWR containment will be a pressuresuppression type containment with a condensation pool, essentially the same design as modern BWRs [Jonsson 2003]. The key containment parameters are listed in Table 6. A 3-dimensional isometric sketch of the SCWR containment is shown in Figure 6 and an axial view with dimensions is shown in Figure 7. The dry and wet well volumes were calculated to limit the pressure build-up to typical BWR levels following a LOCA or a severe accident with core melting (hydrogen generation from cladding oxidation is considered). Also, the concrete floors were designed to withstand such loads. The condensation pool water inventory provides ample margin for residual heat removal and meets the requirement that active safety systems are not needed during the first 12 hours following an initiating event resulting in a severe accident. The blow-down pipes or vents are placed in the outer cylindrical walls due to lack of space in the inner cylindrical walls.

Compared to the advanced BWR containment designs, the SCWR containment drywell can be reduced because:

- The SCWR has only 2 steam and feedwater lines.

- The SCWR has a smaller diameter pressure vessel.

- The control rods enter the reactor pressure vessel from the top. Also, there are fewer control rod drive installations and fewer
Table 6. SCWR containment parameters.

\begin{tabular}{|l|l|}
\hline Parameter & Value \\
\hline Dry well volume & $5000 \mathrm{~m}^{3}$ \\
\hline Wet well gas volume & $3300 \mathrm{~m}^{3}$ \\
\hline Wet well condensation pool volume & $5640 \mathrm{~m}^{3}$ \\
\hline Blow-down area & $\begin{array}{l}18 \mathrm{~m}^{2} \\
(\sim 60 \\
\text { vents) }\end{array}$ \\
\hline Dry well maximum pressure & $510 \mathrm{kPa}$ \\
\hline Wet well maximum pressure & $470 \mathrm{kPa}$ \\
\hline $\begin{array}{l}\text { Dry to wet well maximum pressure } \\
\text { difference }\end{array}$ & $300 \mathrm{kPa}$ \\
\hline Dry well temperature local (short time) & $500^{\circ} \mathrm{C}$ \\
\hline Dry well temperature global (short time) & $350^{\circ} \mathrm{C}$ \\
\hline Dry well temperature global (long time) & $150^{\circ} \mathrm{C}$ \\
\hline Wet well gas temperature & $100^{\circ} \mathrm{C}$ \\
\hline Condensation pool temperature & $<100^{\circ} \mathrm{C}$ \\
\hline
\end{tabular}

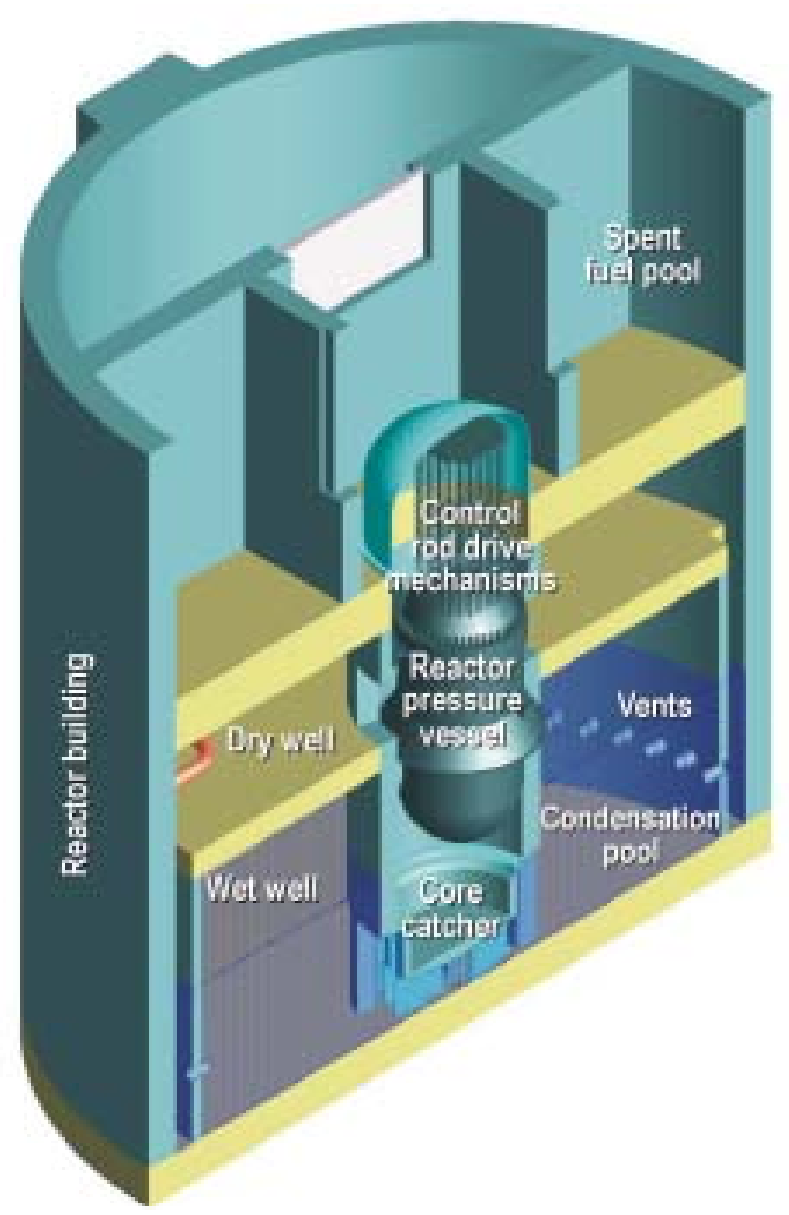

Figure 6. SCWR pressure suppression pool type containment. 
areas for transportation of equipment. Also, installations for control rod drive maintenance are not needed below the pressure vessel.

- There are no internal recirculation pumps.

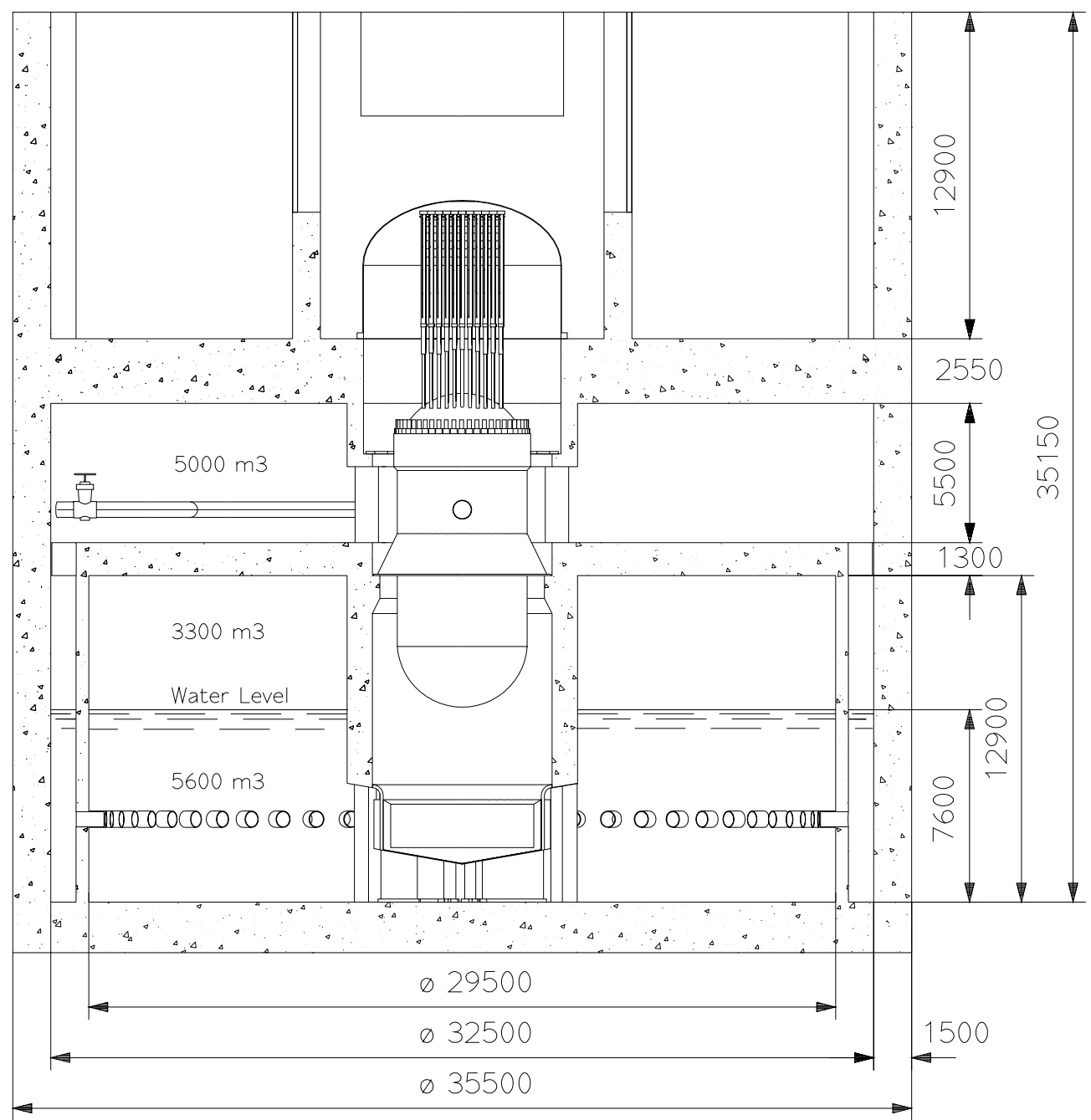

Figure 7. SCWR pressure suppression containment building.

On the other hand, the SCWR containment drywell volume is increased because of the high temperature fluid to the turbine, since additional cooling and thermal expansion space are needed. Also, the concrete must accommodate higher temperatures during an accident. Furthermore the SCWR containment is lower because the pressure vessel is lower. However, this will tend to increase the diameter of the containment and will also lead to less space for connections and floorings. When all these effects are included, the SCWR containment is somewhat smaller than that of an advanced BWR of similar thermal power, and thus significantly smaller on a per unit electric power basis.

Because the potential for core damage in a SCWR is similar to traditional LWRs, enhanced safety is only possible if the offsite consequences of a core damage accident are negligible. The European Utility Requirements statements regarding severe accidents and mitigation of their effects were adopted: "Core debris cooling. This can be achieved via a solidly founded technical demonstration for either in-vessel 
debris cooling or ex-vessel debris cooling" [European Utility Requirements 2001]. Therefore, the current SCWR design includes a core catcher under the reactor pressure vessel, thus achieving ex-vessel retention. However, based on the power rating and the size of the SCWR vessel, an alternative solution featuring in-vessel core debris cooling should also be possible.

\subsection{Power Conversion Cycle}

The reference SCWR system will have a power conversion cycle that is very similar to a supercritical coal-fired plant, with the boiler replaced by the nuclear reactor. As part of the U.S. Gen-IV SCWR R\&D program, Burns \& Roe Enterprises Inc. has performed a conceptual study of the power conversion cycle for the SCWR to identify an optimal configuration that will maximize the thermal efficiency and minimize the capital cost [Burns \& Roe 2003]. Particular attention was given to ensure that all components are either commercially available or within current design capabilities. A schematic of the SCWR power conversion cycle is shown in Figure 8; the operating conditions are reported in Table VII and the turbine expansion is shown in Figure 9.

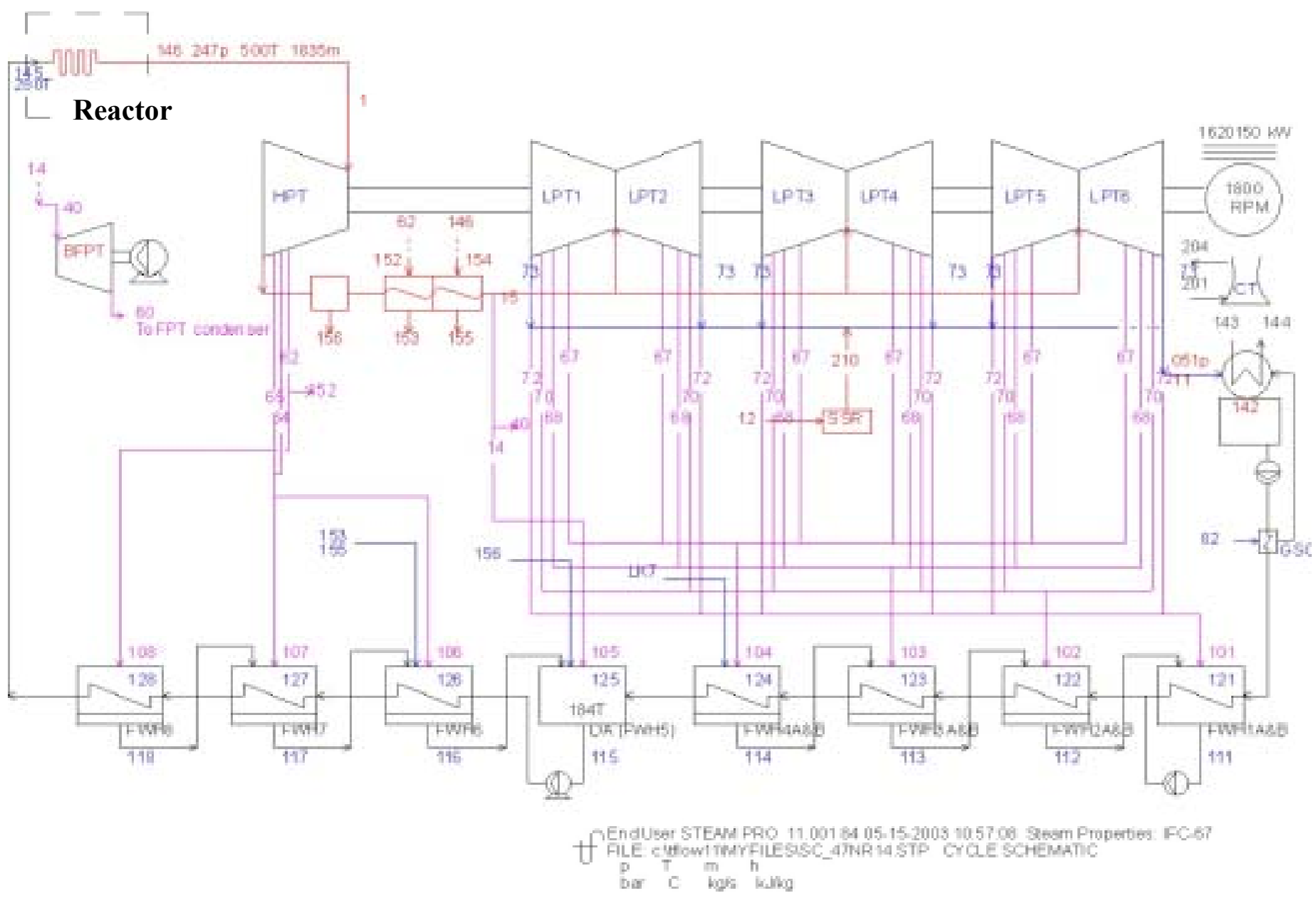

Figure 8. Schematic of the SCWR power conversion cycle (HPT $=$ high pressure turbine, LPT $=$ low pressure turbine, FWH = feedwater heater).

The cycle is based on a large single-shaft turbine with one high-pressure/intermediate-pressure unit and three low-pressure units operating at reduced speed $(1800 \mathrm{rpm})$. The reduced speed is needed to prevent 
excessive steam speeds and high stresses in the 52" blade stages of the low-pressure units. The steam parameters at the high-pressure/intermediate-pressure unit inlet are $494{ }^{\circ} \mathrm{C}$ and $23.4 \mathrm{MPa}$, well within current capabilities of fossil plants. Similarly to traditional LWR cycles, a moisture separator-reheater (MSR) module is located between the high-pressure/intermediate-pressure and the low-pressure turbines, and reheating is achieved with the steam. Heat rejection occurs in traditional natural-draft cooling towers. Eight feedwater heaters raise the condensate temperature to the reactor inlet level of $280{ }^{\circ} \mathrm{C}$. The main feedwater pumps are turbine-driven and operate at about $190^{\circ} \mathrm{C}$. There are two steam lines with outside diameters of $0.470 \mathrm{~m}$ (18.5 in.) and inside diameters of 0.368 (14.5 in.). The material identified by Burns and Roe for these lines is Alloy P92 (9Cr-2W).

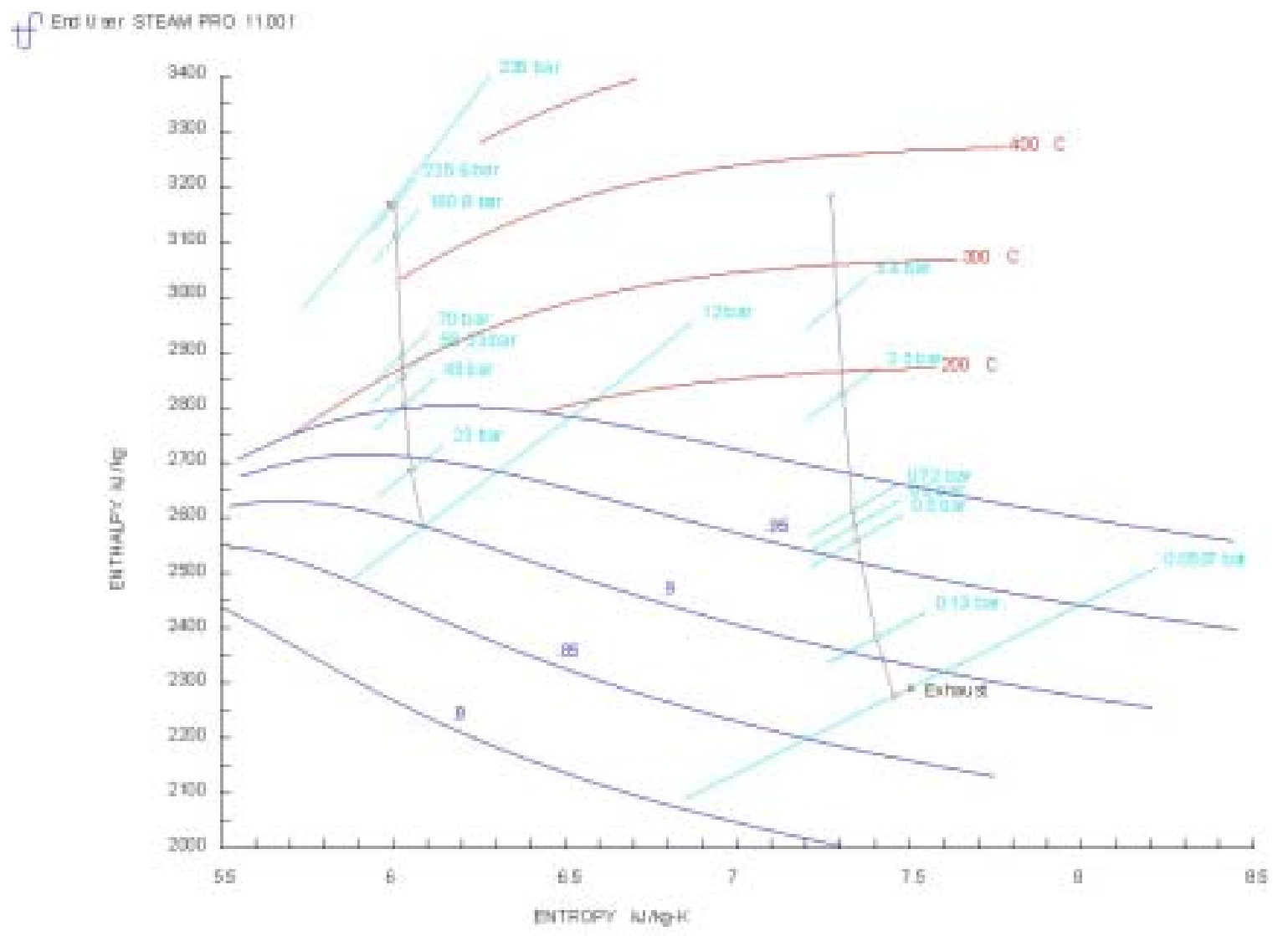

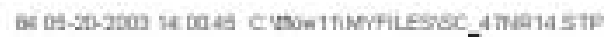

Figure 9. Enthalpy versus entropy at various steam/water fractions and pressures for the SCWR turbine expansion and reheating.

The cycle shown in Figure 9 and Table 7 achieves a net thermal efficiency (net power to grid / fission power) of $44.8 \%$, which accounts for all losses and the plant self-consumption (excluding the nuclear island). 
Table 7. List of pressures, temperatures, mass flow, and enthalpy at the numbered locations of Figure 8.

\begin{tabular}{|c|c|c|c|c|}
\hline Stream & p [bar] & $\mathbf{T}[\mathrm{C}]$ & $\mathrm{T}[\mathrm{kg} / \mathrm{s}]$ & $\mathrm{h}[\mathrm{kJ} / \mathrm{kg}]$ \\
\hline 1 Throttle or initial condition outside ST & 235 & $\overline{494}$ & 1722.47 & 3167.3 \\
\hline 6 PIPT ahead of intercept valve & 12 & 188 & 1130.63 & 2773.7 \\
\hline 11 Condenser (LPT exhaust & 0.05 & 33.1 & 782.36 & 2290.3 \\
\hline 12 SSR Inlet & 1.24 & 105.8 & 0.94 & 2616.5 \\
\hline 14 After 2nd RH & 12 & 363 & 149.69 & 3182.2 \\
\hline 15 LPT Crossover & 12 & 363 & 982.07 & 3182.2 \\
\hline 40 Inlet stream of FPT & 11.43 & 361.4 & 96.15 & 3179.9 \\
\hline 60 Extr1 (or exh if only 1 group) of FPT & 0.07 & 38.7 & 96.15 & 2410.4 \\
\hline 62 Add / extr of ST group 2 & 70 & 313.3 & 265.4 & 2893 \\
\hline 64 Add / extr of ST group 4 & 45 & 259.4 & 127.38 & 2805.3 \\
\hline 65 Add / extr of ST group 5 & 23 & 219.6 & 75.74 & 2684.8 \\
\hline 67 Add / extr of ST group 7 & 5.4 & 264.2 & 13.39 & 2989.3 \\
\hline 68 Add / extr of ST group 8 & 2.5 & 179.2 & 6.82 & 2825.1 \\
\hline 70 Add / extr of ST group 10 & 0.6 & 86 & 9.84 & 2585.1 \\
\hline 72 Add / extr of ST group 12 & 0.13 & 51.1 & 3.33 & 2382.1 \\
\hline 73 Add / extr of ST group 13 & 0.05 & 33.1 & 130.3 & 2290.3 \\
\hline 82 Stream to GSC 0.83 & 0.83 & N/A & 0.38 & 2616.5 \\
\hline 101 Heating steam at FWH1 & 0.12 & 49.5 & 19.96 & 2379.8 \\
\hline 102 Heating steam at FWH2 & 0.58 & 85 & 59.06 & 2582.7 \\
\hline 103 Heating steam at FWH3 & 2.4 & 177.8 & 40.94 & 2822.8 \\
\hline 104 Heating steam at FWH4 & 5.18 & 262.8 & 80.32 & 2987 \\
\hline 105 Heating steam at FWH5 & 11.08 & 361.1 & 53.54 & 3179.9 \\
\hline 106 Heating steam at FWH6 & 22.05 & 217.4 & 75.74 & 2682.4 \\
\hline 107 Heating steam at FWH7 & 42.17 & 254.5 & 127.38 & 2803 \\
\hline 108 Heating steam at FWH8 & 67.11 & 309.6 & 157.45 & 2890.7 \\
\hline 111 Drain liquid at FWH1 & 0.12 & 49.5 & 200.94 & 207.3 \\
\hline 112 Drain liquid at FWH2 & 0.58 & 52.9 & 180.99 & 221.5 \\
\hline 113 Drain liquid at $\mathrm{FWH} 3$ & 2.4 & 87.8 & 121.93 & 367.7 \\
\hline 114 Drain liquid at FWH4 & 5.18 & 112 & 80.99 & 470.2 \\
\hline 115 Drain liquid at FWH5 & 11.08 & 184.4 & 1842.92 & 782.5 \\
\hline 116 Drain liquid at FWH6 & 22.05 & 195.6 & 588.98 & 832.7 \\
\hline 117 Drain liquid at FWH7 & 42.17 & 220 & 513.24 & 944 \\
\hline 118 Drain liquid at FWH8 & 67.11 & 256.3 & 385.86 & 1116.4 \\
\hline 121 Feedwater into FWH1 & 19.42 & 34.2 & 878.88 & 145 \\
\hline 122 Feedwater into FWH2 & 17.81 & 47.3 & 1079.83 & 199.6 \\
\hline 123 Feedwater into FWH3 & 15.55 & 82.2 & 1079.83 & 345.2 \\
\hline 124 Feedwater into FWH4 & 14.69 & 106.1 & 1079.83 & 446 \\
\hline 125 Feedwater into FWH5 & 11.08 & 150.5 & 1079.83 & 634.5 \\
\hline 126 Feedwater into FWH6 & 253.69 & 190 & 1842.92 & 819.2 \\
\hline 127 Feedwater into FWH7 & 253.13 & 214.4 & 1842.92 & 926.2 \\
\hline 128 Feedwater into FWH8 & 252.53 & 250.7 & 1842.92 & 1090.8 \\
\hline 142 Feed water leaving condenser & 0.35 & 33.1 & 782.74 & 138.8 \\
\hline 143 Cooling water into condenser & 3.74 & 17.7 & 30275.3 & 74.5 \\
\hline 144 Cooling water leaving condenser & 2.51 & 31 & 30275.3 & 130.1 \\
\hline 145 Feed water into reactor & 252.01 & 280 & 1842.92 & 1230 \\
\hline 146 Steam leaving reactor & 246.75 & 499.7 & 1842.92 & 3169.6 \\
\hline 152 Heating steam of $1 \mathrm{st} \mathrm{RH}$ & 70 & 313.3 & 107.95 & 2893 \\
\hline 153 Drain of 1 st $\mathrm{RH}$ & $\mathrm{N} / \mathrm{A}$ & N/A & 107.95 & 825.7 \\
\hline 154 Heating steam of $2 n d \mathrm{RH}$ & 246.75 & 499.7 & 120.46 & 3169.6 \\
\hline 155 Drain of $2 \mathrm{nd} \mathrm{RH}$ & N/A & N/A & 120.46 & 1188.2 \\
\hline 156 Moisture separator drain & $\mathrm{N} / \mathrm{A}$ & $\mathrm{N} / \mathrm{A}$ & 120.57 & 798.4 \\
\hline 201 Cooling tower inlet air & N/A & 20 & 32549.72 & $N / A$ \\
\hline 204 Cooling tower exit air & $\mathrm{N} / \mathrm{A}$ & 27.2 & 33201.16 & $N / A$ \\
\hline 210 SSR to condenser & 1.24 & 105.8 & 0.94 & 2616.5 \\
\hline Valve Stem leak 1 => LPcrs & $\mathrm{N} / \mathrm{A}$ & $\mathrm{N} / \mathrm{A}$ & 1.13 & 3167.3 \\
\hline Valve Stem leak 2 => SSR & N/A & $\mathrm{N} / \mathrm{A}$ & 0.05 & 3167.3 \\
\hline HPT LP leak 1 => FWH4 & $\mathrm{N} / \mathrm{A}$ & N/A & 0.67 & 2583.4 \\
\hline HPT LP leak 2 => SSR & $\mathrm{N} / \mathrm{A}$ & N/A & 0.89 & 2583.4 \\
\hline
\end{tabular}




\section{Task 1 Results: Fuel-Cycle Neutronic Analysis and Reactor Core Design (INEEL, Dr. James W. Sterbentz)}

\subsection{Neutronic Evaluation of a 25x25 Supercritical Water Reactor Fuel Assembly with Water Rods and MA956 Clad/Duct Materials}

The core physics characteristics of the reference design described in Section 2 above was calculated. The fuel rod cladding, water rod duct, and assembly duct material was assumed to be an oxide dispersion steel (ODS steel) known as MA956. The coolant channels (formed by the square water rod ducts and the assembly duct) contain the uranium oxide fuel rods and light water coolant. Both the coolant water and water in the water moderator rods varied in density as a function of axial position along the assembly length.

\subsubsection{SCWR Fuel Assembly and MCNP Model Description}

The 25x25 SCWR fuel assembly geometry is shown in Figure 4 in Section 2 above. The outer fuel assembly dimensions are square with $28.6-\mathrm{cm}$ long sides with a total axial length of approximately 4.87$\mathrm{m}$. The assembly is essentially a $25 \times 25$ pin array of cylindrical fuel pins with a $6 \times 6$ array of water rods inserted within the pin array. The 36 square water rods displace 324 fuel pins leaving 300 fuel pins to generate thermal power and a single instrumentation rod at the very center of the assembly. An assembly duct surrounds the fuel rod and water rod arrays.

The length of the active core or the length of each uranium oxide fuel pellet stack is $427.0-\mathrm{cm}$. The $\mathrm{UO}_{2}$ fuel pellet diameter is $0.878-\mathrm{cm}$, the clad thickness is $0.63-\mathrm{mm}$, and the overall pin diameter is $1.02-\mathrm{cm}$. Fuel enrichment is assumed to be approximately $5.0 \mathrm{wt} \% \mathrm{U}-235$. Below the active fuel pellet stack, each fuel rod contains a $60-\mathrm{cm}$ length fission gas plenum. The water rods are $3.36-\mathrm{cm}$ square with a wall thickness of $0.4-\mathrm{mm}$. The gap between the assembly edge and the assembly duct or inter-assembly gap is 3.0-mm in width and is filled with fuel rod coolant. Additional assembly geometric dimensions and materials are listed in Tables I, IV, and V in Section 2 above.

The fuel rod coolant is light water with the axial density profile plotted in Figure 10 at the axial midpoint elevation. The water rod also contains light water, but has a different axial density profile. The water rod water is segregated from the fuel rod coolant by the water rod duct. The coolant and water rod water axial flows are diametrically opposed, the coolant water flowing from the bottom of the core to the top and vice versa for the water rod water.

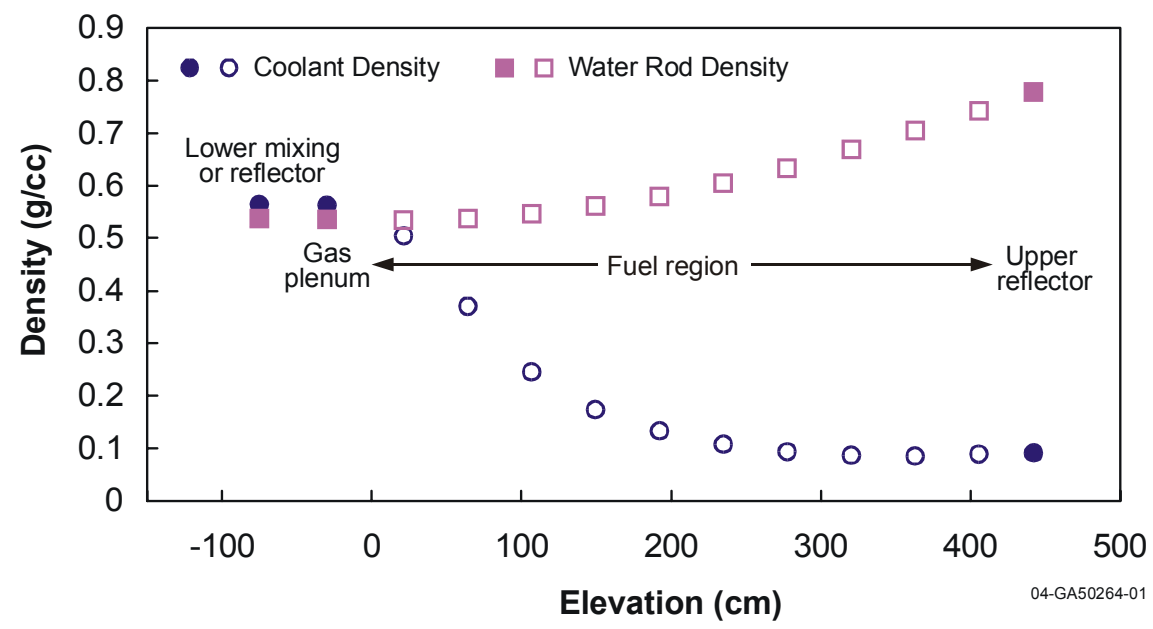

Figure 10. SCWR water rod and coolant water density profiles. 
Based on the reference $25 \times 25$ fuel assembly shown in Figure 4 and the data in Tables IV and V, a symmetric, 1/8-assembly, MCNP computer model was developed with fully explicit fuel rods, water rods, and assembly duct. Figure 11 shows a cross sectional view of the 1/8-assembly MCNP model.

The fuel rods and water rods are modeled full length in the axial direction with a water reflector above the top of the active fuel region, a $60-\mathrm{cm}$ long gas plenum on the bottom of each fuel rod, and below the gas plenum at the bottom of each fuel rod, a mixing region that doubles as a lower water reflector. Figure 11 shows the $1 / 8$-assembly geometry model and each component along with the fuel rod row and column coordinate label in order to identify specific fuel rods. A reflective boundary condition is applied to the three exterior planes encompassing the triangular partial assembly in order to convert the 1/8-partial assembly model into an infinite lattice of $25 \times 25$ SCWR water rod fuel assemblies.

The 427-cm active pellet stack length in each fuel pin is subdivided into 10

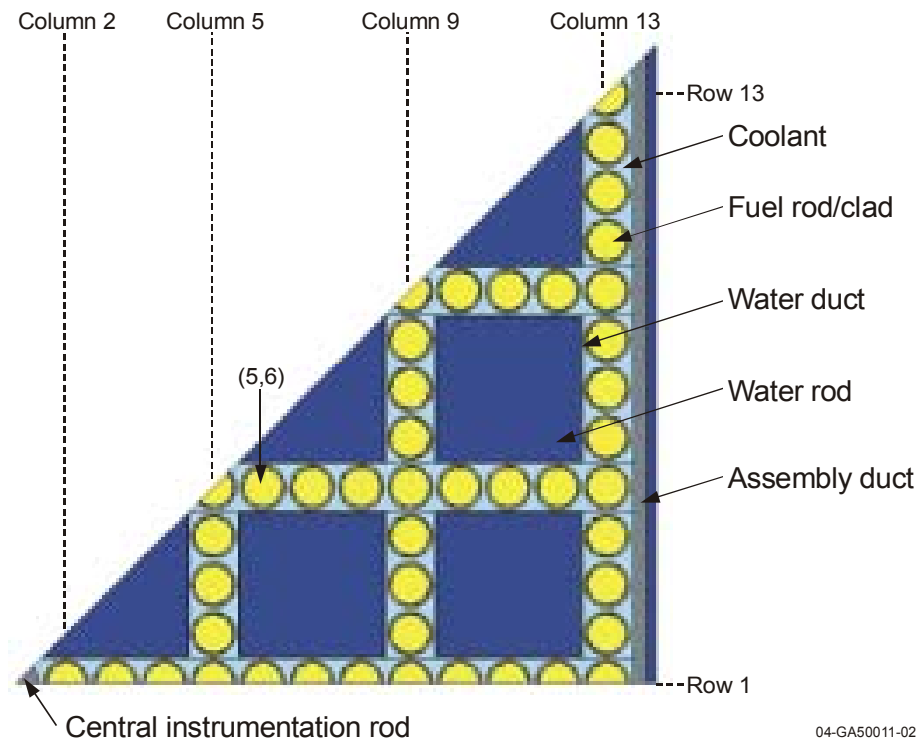

Figure 11. MCNP 1/8-assembly model of the $25 \times 25$ SCWR fuel assembly lattice showing the fuel rods, water rods, coolant channels, and individual fuel rod coordinate row-andcolumn identification numbers.

increments; each increment has a length of $42.7-\mathrm{cm}$. The $60-\mathrm{cm}$ length fission gas plenum beneath the bottom of the active fuel is also modeled along with a top and bottom coolant reflector with appropriate inlet and outlet water densities. The coolant channel axial lengths are also subdivided into to 10 axial volumes with appropriately assigned water densities based on the data in Figure 10. In a similar fashion, the water rod water is also modeled explicitly and subdivided into 10 axial lengths with water densities based on Figure 10 data. The 10 axial cells for the fuel, coolant, and water rod all coincide at the same core elevations.

As mentioned, the coolant and water rod axial water densities were modeled with ten equal-length axial volume cells to approximate the predicted continuous water densities for the two different distributions. The neutron transport $S(\alpha, \beta)$ data libraries for the coolant and water rod water are both assumed to be 527 ${ }^{\circ} \mathrm{C}$, and the average fuel temperature is assumed to be $608{ }^{\circ} \mathrm{C}$. These temperatures correspond to the available MCNP temperature-dependent cross section libraries that most closely match the assembly temperature conditions.

\subsubsection{Computer Codes}

The reactor physics computer codes MCNP, ORIGEN2, and MOCUP have been used exclusively to perform all neutronic analyses presented in this report. Each is discussed briefly below.

The MCNP (Monte Carlo N-Particle) codes Version 4B and 4C (MCNP4B 1997, MCNP4C 2000) are general purpose, continuous energy, generalized geometry, coupled neutron-photon-electron Monte Carlo 
transport codes. The geometry capability allows the construction of very explicit, three-dimensional representations of unit cells, assemblies, or core models. With reflective boundary conditions applied to appropriate radial surfaces, infinite lattice k-infinity values can be calculated for infinite radial-extent unit cell and assembly models, and full core models.

In addition, MCNP also has a powerful tally capability to calculate neutron fluxes, nuclear reaction rates, and radiation energy deposition averaged over any cell volume in the model. This allows the user to estimate spectral and spatial flux characteristics, fuel rod fission power, neutron fluence, radionuclide production rates, and neutron cross sections [fission, radiative capture, $(n, 2 n)$, and $(n, 3 n)$ ]. The neutron cross-sections can then be used directly in a depletion calculation.

The continuous-energy neutron cross sections typically range from $10^{-5} \mathrm{eV}$ to $20 \mathrm{MeV}$. The photon energy range is from $1 \mathrm{keV}$ to $100 \mathrm{MeV}$, and the electron energy is from $1 \mathrm{keV}$ to $1,000 \mathrm{MeV}$. A wide variety of nuclide cross-section and reaction data are available from the Evaluated Nuclear Data Files Version 5 and 6, or ENDF/B-V and ENDF/B-VI. In addition, some MCNP cross sections at high temperatures are also available, but primarily just for the uranium isotopes.

Because the MCNP computer code is a Monte Carlo code, the calculated results are reported by the code with an associated statistical uncertainty or relative error. The relative errors translate into one-sigma statistical uncertainty values by multiplication of the relative error and the calculated result. Two-sigma and three-sigma confidence intervals are obtained by further multiplying the one-sigma values by a factor of two and three, respectively. The confidence levels associated with one-, two-, and three-sigma values are $68.3 \%, 95.4 \%$, and $99.7 \%$, respectively. All statistical error values reported in this study are either the relative error or the one-sigma values, unless otherwise stated. Error bars on calculated data are often smaller than the plotted symbol and therefore not visible.

The ORIGEN2 (ㅁak Ridge Isotope Generation) Version 2 and 2.1 code (Croff 1980) is used to calculate the complex time-dependent and coupled behavior of both radioactive and stable isotopes under flux irradiation or power production time profiles. This includes the isotopic buildup due to production and destruction mechanisms, which include transmutation (radiative capture), fission, threshold particle reactions, and radioactive decay processes. The code mathematical basis uses the matrix exponential method to solve large numbers of coupled ordinary differential equations relating isotopic concentrations with a high degree of accuracy. This code can be used to perform depletion or burnup calculations.

ORIGEN2 input data includes rod or assembly power (MWt) or irradiation flux $\left(\mathrm{n} / \mathrm{cm}^{2} / \mathrm{sec}\right)$, calculated one-group neutron reaction cross sections, and heavy metal loading. ORIGEN2 will output isotopic concentrations (moles, curies, grams), activities, and decay heats for over 1700 activation products, actinide and daughter products, and fission product isotopes. Decay and cross section libraries come with the standard code issue. One of these libraries is the pressurized water reactor (PWR) cross-section library or the "pwrxsliba" library; this library is used as our base library, which is updated to reflect SCWR-specific cross section changes during the course of a burnup calculation.

A special feature in the ORIGEN2 code allows the analyst to update or modify the standard cross section library with user-calculated cross sections, thereby allowing a depletion calculation to be reactor specific. ORIGEN2 performs a depletion calculation using effective one-group cross sections calculated, in our case, with MCNP calculated tally data.

The MOCUP (MCNP-ORIGEN2 Coupled Utility Program) code (Babcock et al. 1994) is a system of external processors that links input and output files from the MCNP and ORIGEN2 codes in order to perform a time-dependent burnup or depletion calculation. MOCUP is composed of three processing modules, namely menpPRO, origenPRO, and compPRO. Each module performs a specific, sequential 
task during each burnup iteration. No modifications are required to the MCNP or ORIGEN2 codes in order to run the MOCUP code system.

The MOCUP code system performs a multitude of data manipulations, but just three main functions. These three functions include: (1) read MCNP flux and reaction rate output data and convert these data to one-group cross sections, (2) load these cross sections into the ORIGEN2 input file so they can update cross sections in the base library, and (3) read the ORIGEN2 isotopic concentration output punch file and create a new MCNP fuel composition. The new MCNP composition reflects the changes in heavy metal and fission product isotopic depletion or buildup as the result of burnup during the time step.

\subsubsection{Axial Power Profile and Enrichment}

Axial power profiles were calculated for each of the fuel rods in the reference $1 / 8$-assembly model at beginning-of-life conditions. The $\mathrm{UO}_{2}$ fuel was initially assumed to have a uniform $5.0-\mathrm{wt} \% \mathrm{U}-235$ axial enrichment in each fuel rod throughout the assembly. A collective rod power profile for the $5.0-\mathrm{wt} \%$ case is shown in Figure 12 and exhibits a power skewing toward the top of the core with a peak-to-average value of 1.6. In the model, each fuel rod is divided into ten equal-length axial cell volumes and the power in each cell is averaged over the cell's volume, hence the ten axial dots per curve delineation.

Although not shown in Figure 12, each of the fuel rods in the assembly exhibited basically the same axial power profile shape, but were shifted up or down in magnitude indicative of a variation in the rod powers across the assembly. Fuel rods along the outer edge of the assembly, and particularly those nearest the corners of the assembly, exhibited a significant decrease in the relative rod power.

In order to improve the axial power profile shape and thereby decrease the peak-toaverage value as well, an axial enrichment study was conducted. After testing several

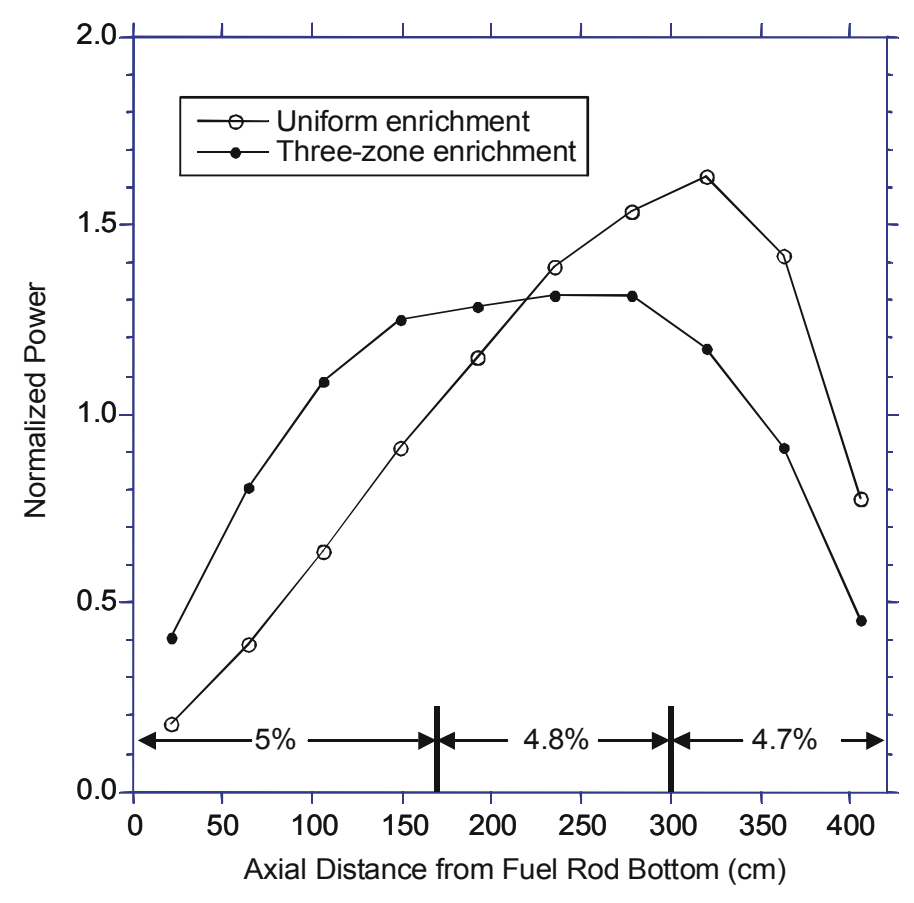

Figure 12. Axial fuel rod power profiles. axial enrichment profiles, the best axial power profile (Figure 12) converged using a three-zone enrichment. Further refinements could of course be made, but the three-zone enrichment produced a reasonable beginning-of-life axial power shape, and the fewer the enrichment zones, the less the fuel cost. The three-zone enrichments were (1) $5.0 \%$ at the bottom of the active fuel region (axial elevation $0-170.8-\mathrm{cm}$, or $0.0-0.4 \mathrm{z} / \mathrm{L}$ ), (2) $4.8 \%$ enrichment in the middle (170.8-298.9-cm, or 0.4-0.7 z/L), and (3) 4.7\% enrichment at the top (298.9-427.0-cm, or 0.7-1.0 $\mathrm{z} / \mathrm{L}$ ). Figure 12 shows the normalized three-zone enrichment axial power profile relative to the uniform $5.0 \mathrm{wt} \%$ profile. The three-zone enrichment produces a power profile that is centered about the core midplane and has a reduced peak-to-average of approximately 1.3. The three-zone enrichment resulted in a 1.00:0.96:0.94 relative zone enrichment ratios, and an overall effective rod enrichment of $4.85 \mathrm{wt} \% \mathrm{U}$ 235. 


\subsubsection{Clad Reactivity Comparison}

Four materials, (1) our SCWR reference clad material the ferritic oxide dispersion (ODS) steel MA956, (2) Alloy 718, (3) silicon carbide (SiC), and (4) the standard Zircaloy-4 (Zr-4) used in current commercial thermal water reactors today for cladding, were considered in a study to compare reactivity worth. Table 8 lists the major elemental constituents of these four materials. It is expected that MA956 and Alloy 718 will reduce the assembly reactivity because of parasitic neutron absorption primarily from the nickel, iron, and chromium.

Table 8. Major elemental constituents for MA956, Alloy 718, Zircaloy-4, and SiC.

\begin{tabular}{|c|c|c|c|c|}
\hline Element & $\begin{array}{c}\text { MA956 } \\
\text { (Wt \%) }\end{array}$ & $\begin{array}{c}\text { Alloy 718 } \\
\text { (Wt \%) }\end{array}$ & $\begin{array}{c}\text { Zr-4 } \\
\text { (Wt \%) }\end{array}$ & $\begin{array}{c}\mathbf{S i C} \\
\text { (Wt \%) }\end{array}$ \\
\hline $\mathrm{C}$ & & 0.038 & 0.027 & 30.0 \\
\hline $\mathrm{O}$ & 0.1488 & & 0.120 & \\
\hline $\mathrm{Al}$ & 5.75 & 0.49 & & \\
\hline $\mathrm{Si}$ & & 0.19 & & 70.0 \\
\hline $\mathrm{Ti}$ & 0.60 & 0.91 & & \\
\hline $\mathrm{V}$ & & 0.01 & & \\
\hline $\mathrm{Cr}$ & 21.5 & 19.08 & 0.10 & \\
\hline $\mathrm{Mn}$ & & 0.20 & & \\
\hline $\mathrm{Fe}$ & 71.45 & 18.122 & 0.21 & \\
\hline $\mathrm{Ni}$ & & 52.90 & 0.007 & \\
\hline $\mathrm{Y}$ & 0.5512 & & & \\
\hline $\mathrm{Zr}$ & & & 98.057 & \\
\hline $\mathrm{Nb}$ & & 5.05 & 0.012 & \\
\hline $\mathrm{Mo}$ & & 3.01 & & \\
\hline $\mathrm{Sn}$ & & & 1.45 & \\
\hline Density (g/cc) & $\mathbf{7 . 2 5}$ & $\mathbf{8 . 1 9}$ & $\mathbf{6 . 5 7}$ & $\mathbf{2 . 9 7 4 9}$ \\
\hline
\end{tabular}

In order to assess the relative reactivity gain or penalty associated with the three candidate SCWR fuel cladding materials (MA956, Alloy 718, SiC), Zircaloy-4 was chosen as the comparison basis. Zircaloy-4 was first substituted into the $1 / 8$-assembly model for the fuel clad, water rod duct, and assembly duct material and a k-infinity value calculated. In a similar manner, MA956, Alloy 718, and SiC were also substituted into the model for k-infinity and worth comparisons to $\mathrm{Zr}-4$. Table 9 gives the calculated kinfinity values for the four different clad/duct materials. Note, in addition to the fuel cladding material substitution, the water rod duct and assembly duct material were also substituted and assumed to be the same material as the fuel cladding in each case. The axial three-zone enrichment derived previously in the axial enrichment study was assumed for all fuel rods in the calculations.

Table 9. Assembly lattice k-infinity for four different clad materials.

\begin{tabular}{|c|c|c|}
\hline Clad Material & K-infinity & $\begin{array}{c}\text { Reactivity } \\
\mathbf{( \$ )}\end{array}$ \\
\hline Zircaloy-4 & $1.425477(0.0002)$ & -- \\
\hline MA956 (ODS) & $1.266155(0.0002)$ & -13.58 \\
\hline Alloy 718 & $1.153701(0.0002)$ & -25.42 \\
\hline SiC & $1.436039(0.0002)$ & +0.79 \\
\hline
\end{tabular}

Numbers in parentheses are the one-sigma statistical relative error. 
It is apparent that both MA956 and Alloy 718 result in a significant reactivity penalty relative to Zircolay4. Relative to Alloy 718, MA956 looks considerably better with only half the reactivity penalty. The MA956 parasitic neutron absorption of the major constituents Fe-Cr-Al appears to be considerably less than the parasitic absorption of the Ni-Cr-Fe-Nb-Mo in the Alloy 718. The SiC on the other hand, is slightly better than $\mathrm{Zr}-4$ from a reactivity standpoint. [All the reactivity values are calculated based on the formula $\left(\mathrm{k}_{2}-\mathrm{k}_{1}\right) /\left(\mathrm{k}_{1} \mathrm{k}_{2}\right)$, where $\mathrm{k}_{1}=1.425477(\mathrm{Zr}-4)$ and an effective delayed beta fraction of 0.0065$]$.

\subsubsection{Coolant and Water Rod Void Reactivity}

The water in the coolant channels and water rods was systematically voided in order to estimate the effect on the infinite assembly lattice k-infinity. The $\mathrm{UO}_{2}$ fuel is again assumed to have the three-zone axial enrichment throughout the assembly. The fuel rod clad, water rod duct, and assembly duct material was assumed to be MA956. Table 10 gives the k-infinity results for (1) the normal condition or no voiding, (2) voiding only the coolant water, (3) voiding only the water rod water, and (4) voiding both the coolant and the water rods.

Table 10. Assembly k-infinity comparison for various assembly material replacements.

\begin{tabular}{|l|l|l|l|l|l|l|}
\hline $\begin{array}{c}\text { Input } \\
\text { file }\end{array}$ & $\begin{array}{c}\text { Coolant } \\
\text { Water }\end{array}$ & $\begin{array}{c}\text { Water } \\
\text { Rod } \\
\text { Water }\end{array}$ & K-infinity & $\begin{array}{c}\text { Relative } \\
\text { Error }\end{array}$ & $\Delta \mathbf{k}$ & $\begin{array}{c}\text { Reactivity } \\
\text { Worth } \\
\text { (\$) }\end{array}$ \\
\hline w.2f & Present & Present & 1.255373 & 0.0002 & -- & -- \\
\hline w.5f & Void & Present & 1.250137 & 0.0002 & -0.00524 & -0.51 \\
\hline w.7f & Present & Void & 0.877521 & 0.0003 & -0.37785 & -52.77 \\
\hline w.6f & Void & Void & 0.641961 & 0.0002 & -0.61341 & -117.10 \\
\hline
\end{tabular}

From Table 10, voiding just the coolant (loss of the coolant in the channels around the fuel rods) has only a small, but negative effect on the lattice k-infinity (approximately -51 cents). Voiding just the water rods alone produces a much stronger or more negative decrease in k-infinity and the reactivity (approximately -\$52.8). Voiding both the coolant and water rods drops the lattice k-infinity even more, as expected, down to a very subcritical level, where the core now becomes basically an under-fueled fast reactor.

\subsubsection{Beginning-of-Life Doppler Coefficient}

The beginning-of-life fuel Doppler coefficient of reactivity is estimated for an infinite assembly lattice with the three-zone axial enrichment and with the fuel cladding, water rod duct, and assembly duct all made out of MA956. Both the coolant and water rod $\mathrm{S}(\alpha, \beta)$ temperatures are again assumed to be fixed at a temperature of $527^{\circ} \mathrm{C}$, while the fuel temperature is varied from $127{ }^{\circ} \mathrm{C}$ up to $2200{ }^{\circ} \mathrm{C}$ in non-uniform increments. Figure 13 shows the calculated kinfinity values as a function of fuel temperature.

The discontinuity in the curve in Figure 13 was traced to differences in the MCNP uranium (both U235 and U-238) neutron cross-section libraries. The cross section libraries at temperatures less than 927

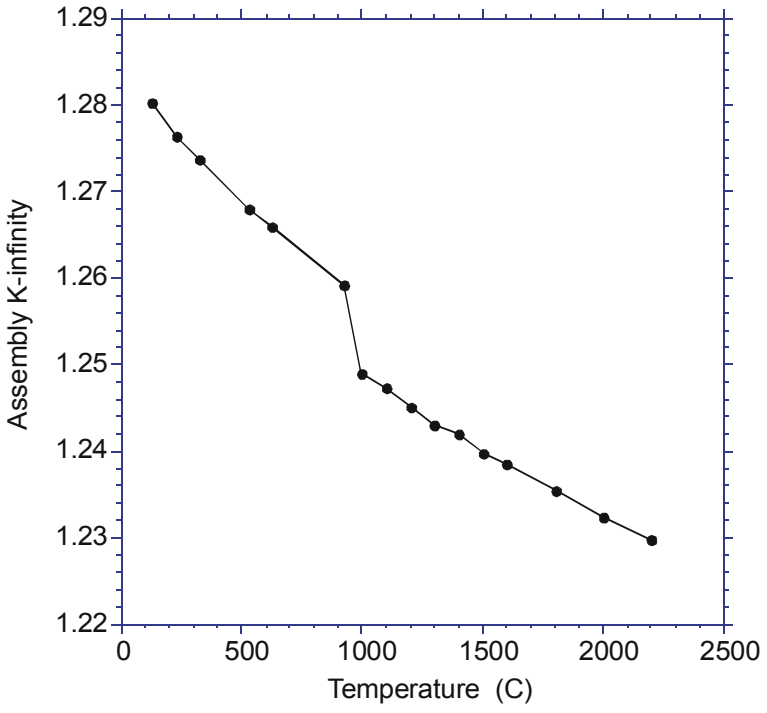

Figure 13. Assembly k-infinity as a function of fuel temperature. 
${ }^{\circ} \mathrm{C}$ were generated using ENDF/B-VI Revision 2 data. The newer, more recently generated cross section libraries at $1000{ }^{\circ} \mathrm{C}$ and above were generated with ENDF/B-VI Revision 5 data. Changes in the ENDF/B-VI U-235 data include modifications to the resonance parameters and fission neutron yields (nubar). The resonance data were re-evaluated over the entire resolved resonance energy range. The capture resonance integral over the energy range $0.5 \mathrm{eV}$ to $20 \mathrm{MeV}$ increased about $6 \%$, while the fission resonance integral decreased about $1 \%$. The changes in nubar were less significant, with the yield increased from 2.4320 to 2.4367 over the energy range or $1.0 \mathrm{E}-5 \mathrm{eV}$ to $1.0 \mathrm{eV}$, and increased from 2.4320 to 2.4338 over the energy range $2.0 \mathrm{eV}$ to $10,000 \mathrm{eV}$. The yield was unchanged above $15,000 \mathrm{eV}$. The relatively large increase in the capture integral was probably the most significant change, and most likely is the reason for the $\sim 0.5 \%$ drop in the eigenvalues shown in the figure. The only change made to the U238 cross section data was a reduction in the capture cross section at $0.0253 \mathrm{eV}$ from 0.3326 to 0.3320 barns, with appropriate adjustments at lower energies to maintain the $1 / \mathrm{v}$-behavior. It is interesting to note that these seemingly small cross section changes have such a large impact on the k-infinity.

The calculated Doppler coefficients $(\Delta \mathrm{k} / \Delta \mathrm{T})$ are shown in Figure 14 . Note the $900-1000{ }^{\circ} \mathrm{C}$ cross-section set dependent discontinuity in Figure 13 has been omitted. The Doppler coefficients are all strongly negative across the fuel temperature range. In addition, the coefficient curve exhibits an upward or less negative trend with increasing fuel temperature, but still nicely negative even above $2000^{\circ} \mathrm{C}$.

The Doppler temperature coefficient data plotted in Figure 14 are still somewhat erratic due to the inherent statistical uncertainty associated with the Monte Carlo method. The one-sigma error bars range from approximately $10-20 \%$ of the Figure 14 values. Despite this slight non-physical behavior, the data clearly demonstrates that the Doppler coefficients are strongly negative over the temperature range of interest. Deterministic codes and models will be required in the future to recalculate smoother and perhaps more accurate Doppler coefficient curves.

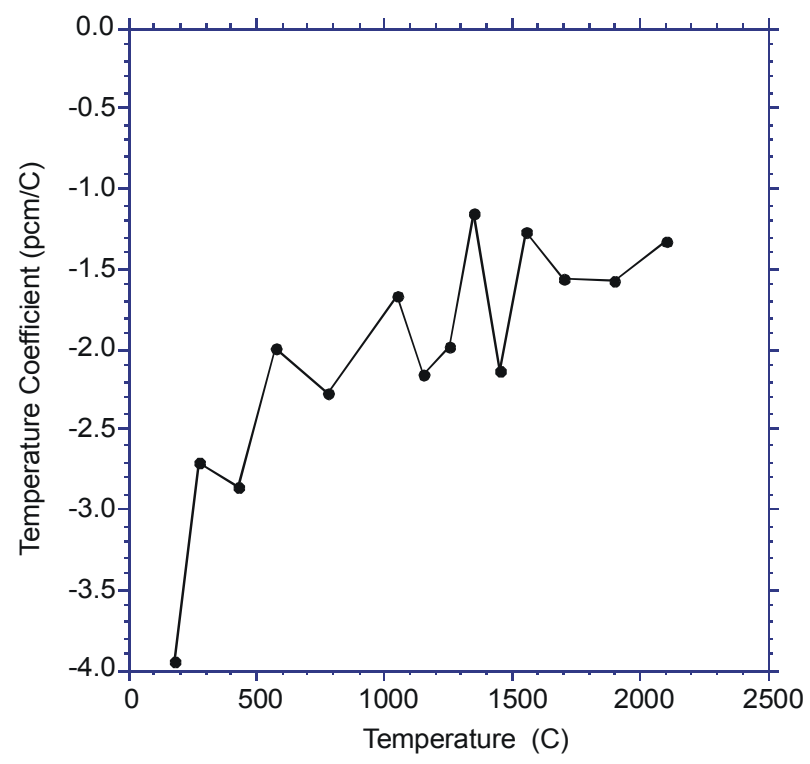

Figure 14. Fuel Doppler coefficient at beginning-oflife.

\subsubsection{Radial Power Profile}

The goal of the radial fuel rod enrichment study was to try to make the individual fuel rod total thermal powers essentially the same across the fuel assembly. With a uniform fuel rod enrichment, fuel rods near the center of the assembly tend to have higher relative powers than those near the assembly periphery and corners. The assembly fuel rod radial power profile was flattened by iteratively scaling the individual fuel rod enrichments up or down. In this manner, radial power peaking of the assembly fuel rods was reduced through selective rod enrichments. As a starting point, an initial $5.0 \mathrm{wt} \% \mathrm{U}-235$ uniform rod enrichment was assumed throughout the SCWR assembly with no axial variation. Based on the calculated rod powers, the U-235 number density in each fuel rod was adjusted in order to flatten the radial power profile. Eight iterations were required to produce a relatively flat radial power profile with the minimum-to-average and peak-to-average confined to 0.95 and 1.04 for all the fuel rods in the assembly with the majority between 0.98 and 1.02 . 
Figures 15 shows the final converged rod enrichments and Figure 16 shows their associated peak-toaverage power peaking values. The enrichments span from 3.2 to $12.4-\mathrm{wt} \% \mathrm{U}$ 235 resulting in an overall effective rod enrichment for the SCWR assembly of approximately $5.43-\mathrm{wt} \%$ U-235. Note the relatively large increase in enrichment for those rods on the fuel assembly periphery and those near the assembly corners (in particular, the rods in Column 13 and Rows 10-13). .

\subsubsection{Control Rod Design}

In support of the fuel assembly and core internals mechanical design effort, an analysis of control rod worth was initiated in order to determine how many and what type of neutron control rod absorber would be required to achieve beginning-of-life cold shutdown $\left(\mathrm{k}_{\mathrm{inf}}<0.95\right)$. For the neutronic calculations, cold shutdown assumes that the reactor fuel, coolant, and water rod light water temperatures are all at $20.85^{\circ} \mathrm{C}$ (room temperature) and the water densities to be identically $1.0 \mathrm{~g} / \mathrm{cc}$. Figure 4 in Section 2 shows the SCWR reference design with 12 control rods located in the center of the $6 \times 6$ water rod channel array in a $25 \times 25$ pin assembly were obtained.

Because of complications with the mechanical design of the fuel assembly, particular interest in the control rod worth study was focused on minimizing the number of control rods per assembly, and in particular whether or not the reference design could achieve cold shutdown with 12 centrally located rods as shown in Figure 4, or whether 16 control rods per assembly would be required (an additional 4 rods located at the corners to complete a $4 \times 4$ array).

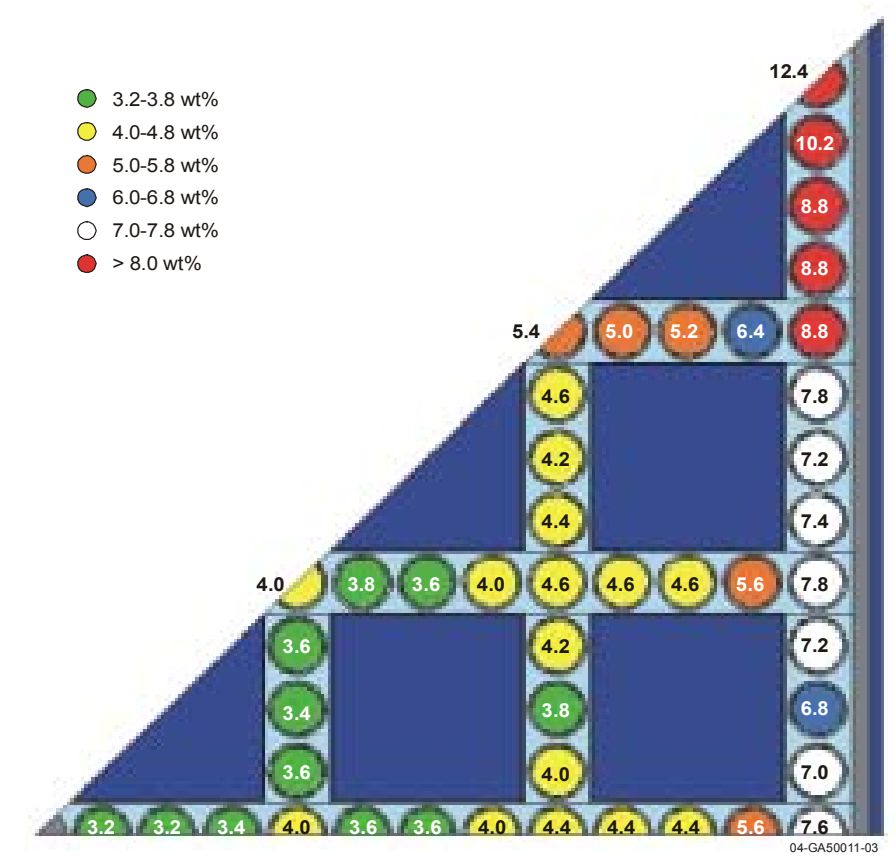

Figure 15. Fuel pin enrichments

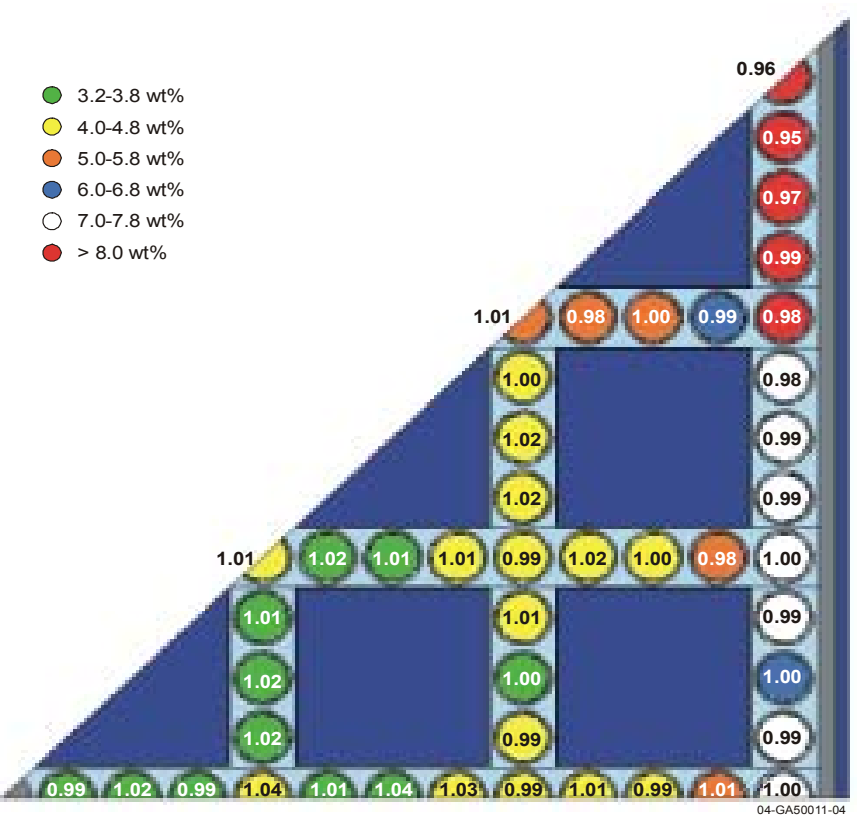

Figure 16. Peak-to-average pin powers.

The first type of control rod considered was a silver-indium-cadmium (Ag-In-Cd) metallic cylindrical bar with a central hole. The reference control rods were assumed to be annular with an outer radius of $0.93218 \mathrm{~cm}$ and an inner radius of $0.3175 \mathrm{~cm}$. The Ag-In-Cd metal is assumed to have a density of 0.367 $\mathrm{lbm} / \mathrm{in}^{3}(10.159 \mathrm{~g} / \mathrm{cc})$ with weight fractions of $80 \% \mathrm{Ag}, 15 \% \mathrm{In}$, and $5 \% \mathrm{Cd}$. Table 11 below lists the calculated k-infinity for 12 and 16 controls while varying the inner and outer control radius. 
Table 11. Infinite assembly lattice k-infinity results for Ag-In-Cd control rod insertion.

\begin{tabular}{|c|c|c|c|c|}
\hline $\begin{array}{c}\text { No. of Inserted } \\
\text { Control Rods }\end{array}$ & $\begin{array}{c}\text { CR Inner Radius } \\
\text { (cm) }\end{array}$ & $\begin{array}{c}\text { CR Outer Radius } \\
\text { (cm) }\end{array}$ & K-infinity & $\begin{array}{c}\text { Relative } \\
\text { Error }\end{array}$ \\
\hline 0 & 0.3175 & 0.93218 & 1.281278 & 0.0002 \\
\hline 12 & 0.3175 & 0.93218 & 1.085154 & 0.0003 \\
\hline 12 & 0.0 & 0.93218 & 1.081858 & 0.0002 \\
\hline 12 & 0.0 & 1.00 & 1.073052 & 0.0002 \\
\hline 12 & 0.0 & 1.20 & 1.047593 & 0.0003 \\
\hline 12 & 0.0 & 1.40 & 1.027744 & 0.0003 \\
\hline 12 & 0.0 & 1.60 & 1.011620 & 0.0003 \\
\hline 16 & 0.3175 & 0.93218 & 1.017334 & 0.0003 \\
\hline 16 & 0.0 & 0.93218 & 1.013481 & 0.0003 \\
\hline 16 & 0.0 & 1.00 & 1.000473 & 0.0003 \\
\hline 16 & 0.0 & 1.20 & 0.968144 & 0.0003 \\
\hline 16 & 0.0 & 1.40 & $\mathbf{0 . 9 4 0 5 0 7}$ & 0.0003 \\
\hline 16 & 0.0 & 1.60 & $\mathbf{0 . 9 1 9 1 8 5}$ & 0.0003 \\
\hline
\end{tabular}

Based on the calculated results in Table 11, it was determined that we cannot achieve cold shutdown $\left(\mathrm{k}_{\text {inf }}\right.$ $=0.95$ ) with only 12 rods using the Ag-In-Cd composition assumed. However, it appears we should be able to achieve cold shutdown with $16 \mathrm{Ag}-\mathrm{In}-\mathrm{Cd}$ control rods with an increased outer radius of greater than approximately $1.3 \mathrm{~cm}$. Note: the largest control rod radius that could be accommodated into the water rod square channel is $1.64 \mathrm{~cm}$. Unfortunately, the use of 16 large control rods is undesirable, because it increases the complexity of the upper calandria/piping design. Therefore, additional analyses using $\mathrm{B}_{4} \mathrm{C}$ control rods with potentially higher worth were evaluated next.

The second type of control rod considered was a boron carbide $\left(\mathrm{B}_{4} \mathrm{C}\right)$ solid cylindrical bar with no central hole. The reference control rod was assumed to have an outer radius of $0.93599 \mathrm{~cm}$. The $\mathrm{B}_{4} \mathrm{C}$ is assumed to have a density of $0.066 \mathrm{lbm} / \mathrm{in}^{3}(1.827 \mathrm{~g} / \mathrm{cc})$ with a weight fraction of boron $>77 \%$. In addition to increasing the size of the control rod diameter to increase the neutron absorption, we also have the ability to increase the B-10 enrichment to achieve our goal cold shutdown of $\mathrm{k}_{\mathrm{inf}}=0.95$. Table 12 below lists the calculated k-infinity for 12 control rods while varying the inner and outer control radius.

Table 12. Infinite assembly lattice $k$-infinity results for $\mathrm{B}_{4} \mathrm{C}$ control rod insertion.

\begin{tabular}{|c|c|c|c|c|c|c|}
\hline $\begin{array}{c}\text { No. of } \\
\text { Inserted } \\
\text { Control } \\
\text { Rods }\end{array}$ & $\begin{array}{c}\text { CR Inner } \\
\text { Radius } \\
\text { (cm) }\end{array}$ & $\begin{array}{c}\text { CR Outer } \\
\text { Radius } \\
\\
\text { (cm) }\end{array}$ & $\begin{array}{c}\text { B-10 } \\
\text { Enrich } \\
(\mathrm{a} / \mathrm{o}) \\
\end{array}$ & $\begin{array}{c}\text { Boron } \\
\text { Weight } \\
\text { Fraction } \\
\text { (wt\%) }\end{array}$ & K-infinity & $\begin{array}{c}\text { Relative } \\
\text { Error }\end{array}$ \\
\hline 0 & 0.0 & 0.93599 & 19.9 & 78.26 & 1.281278 & 0.0002 \\
\hline 12 & 0.0 & 0.93599 & 19.9 & 78.26 & 1.055204 & 0.0003 \\
\hline 12 & 0.0 & 0.93599 & 30.0 & 78.10 & 1.044863 & 0.0003 \\
\hline 12 & 0.0 & 0.93599 & 50.0 & 77.78 & 1.031868 & 0.0003 \\
\hline 12 & 0.0 & 0.93599 & 70.0 & 77.45 & 1.022159 & 0.0003 \\
\hline 12 & 0.0 & 1.20 & 19.9 & 78.26 & 1.021556 & 0.0003 \\
\hline 12 & 0.0 & 1.40 & 19.9 & 78.26 & 1.002311 & 0.0003 \\
\hline 12 & 0.0 & 1.60 & 19.9 & 78.26 & 0.987776 & 0.0003 \\
\hline 12 & 0.0 & 1.60 & 70.0 & 77.45 & 0.944996 & 0.0003 \\
\hline 12 & 0.0 & 1.60 & 80.0 & 77.28 & 0.940062 & 0.0003 \\
\hline 12 & 0.0 & 1.60 & 90.0 & 77.10 & 0.935185 & 0.0003 \\
\hline
\end{tabular}

Based on the calculated results in Table 12, it was determined that we can achieve cold shutdown $\left(\mathrm{k}_{\text {inf }}=0.95\right)$ with only 12 rods, as desired, using the $\mathrm{B}_{4} \mathrm{C}$ composition assumed. It will require however, a large diameter control rod of approximately $1.60 \mathrm{~cm}$ radius (no central hole) and the use of enriched B-10 greater than 70 atom percent. Note again the largest control rod radius that could be accommodated into the water rod square channel is $1.64 \mathrm{~cm}$. An 
alternative approach is to use "burnable poisons", which will significantly reduce the control size and number requirements. This approach will be investigated in the future.

\subsubsection{Fuel Depletion}

Two fuel depletion studies were performed for the SCWR with MA956. The first fuel depletion study produced un-damped axial power oscillations as a function of burnup despite the use of a coolant density feedback mechanism based on the axial fuel rod power profile. The feedback mechanism was employed in attempt to control axial power oscillations. A description of this calculation will be provided and is designated as "Depletion Study No. 1" below. The second SCWR depletion calculation was specifically designed to achieve two goals: (1) a more stable depletion calculation under the assumption of a constant axial fuel rod burnup, and (2) to provide a reasonable one-to-one comparison with the depletion of a standard PWR assembly and the 21x21 SCWR fuel assembly using SiC fuel cladding/duct materials (discussed in more detail in Section 3.2 below). Reactivity letdown curves will be presented for these three reactor fuel assembly designs.

\subsubsection{SCWR with MA956 (Depletion Study No. 1)}

The MCNP model used in this depletion calculation was an SCWR unit cell consisting of a water rod surrounded by 16 half and quarter fuel rods. The 4 quarter-volume fuel rods were located in the corners of the unit cell. The fuel rods were divided into 10 equal volume axial cells. As in the assembly model, the fuel cladding and water rod duct material was MA956. However, to limit the scope of the depletion study, it was decided to deplete just a single fuel rod segmented into ten axial zones. The basic unit cell was able to accurately capture the energy flux and reaction rate information in order to calculate appropriate one-group neutron cross sections for the depletion calculation. In the unit cell model, the following conditions were assumed: (1) unrodded, (2) no burnable poisons in the lattice, and (3) a constant, rod-average linear heat generation rate. The following brief discussion describes the unique characteristics of the unit cell model in more detail.

The unit cell dimensions and material characteristics are based on the $1 / 8$-assembly model. In order to add the coolant feedback to the depletion calculation, a special FORTRAN computer program was developed to calculate the coolant water density profile as a function of the axial power profile, enthalpy, and a fixed coolant inlet and outlet water temperatures. Therefore, instead of using the Figure 10 axial coolant water density profiles in the unit cell model, it was decided to first converge the axial enrichment, axial coolant water density, and axial fuel rod power profile. In order to converge these three profiles, the following constraints were imposed:

(1) Inlet coolant temperature $=365.78^{\circ} \mathrm{C}$

(2) Outlet coolant temperature $=500^{\circ} \mathrm{C}$

(3) Constant enthalpy rise over the length of the heated fuel rod

The inlet coolant temperature $\left(365.78{ }^{\circ} \mathrm{C}\right)$ at the bottom of the fuel is based on thermo-hydraulic calculations in which there is mixing of core-heated water rod water and inlet coolant water $\left(\sim 280{ }^{\circ} \mathrm{C}\right)$. The axial power profile is calculated using MCNP where the fuel rod is segmented into 10-equal volume cells. The uranium enrichments were varied in these 10 cells in order to obtain a reasonable axial power profile as discussed in Section 3.1.4 above (i.e. a power profile symmetrical about the core midplane with the peak at or near the midplane). In this case, it is typically a chopped-cosine shaped curve with a peakto-average of approximately 1.5. Once the enrichment and power profiles were converged, the power profile was then used as input to determine how the fuel rod heat energy was to be added as a rise in coolant enthalpy axially up the coolant channel. Finally, the coolant axial enthalpy can be directly 
correlated to the coolant water density. The new coolant water density profile is then fed back into the MCNP model to calculate a new power profile and the search then continues for a new enrichment.

This iterative process was repeated until a reasonably converged solution was obtained. As a note, the most iteration intensive part of the process was the axial enrichment adjustments required to obtain a reasonable power profile with the peak at the midplane. It should be noted that relatively small adjustments in the enrichment profile were able to significantly shift the peak above or below the midplane.

Table 13 provides the converged beginning-of-life coolant density $(\mathrm{g} / \mathrm{cc})$ water profile along with the axial enrichment (three-zone). Note that the axial enrichment profile is slightly different than the one obtained in the axial enrichment study presented in Section 3.1.4 above using a different coolant profile. Figure 17 shows the converged beginning-of-life axial power profile (dashed line is a curve fit to the data). Note: the water rod axial water density profile was assumed to remain constant throughout the depletion calculation per the Figure 10 data, again listed in Table 13.

Table 13. Converged beginning-of-life SCWR water densities for the coolant.

\begin{tabular}{|c|c|c|c|c|c|}
\hline Region & $\begin{array}{l}\text { Lower } \\
\text { Elevation } \\
(\mathrm{cm})\end{array}$ & $\begin{array}{l}\text { Upper } \\
\text { Elevation } \\
\text { (cm) }\end{array}$ & $\begin{array}{c}\text { Coolant } \\
\text { Density } \\
\text { (g/cc) }\end{array}$ & $\begin{array}{l}\text { Water Rod } \\
\text { Density } \\
\text { (g/cc) }\end{array}$ & $\begin{array}{l}\mathrm{UO}_{2} \text { Enrich } \\
\text { (wt\% U235) }\end{array}$ \\
\hline $\begin{array}{l}\text { Lower mixing or } \\
\text { reflector }\end{array}$ & -90.48 & -60.00 & 0.5649 & 0.5379 & \\
\hline Gas plenum & -60.00 & 0.00 & 0.5629 & 0.5363 & \\
\hline Fuel (bottom) & 0.00 & 42.7 & 0.54732 & 0.5345 & 5.0 \\
\hline Fuel & 42.7 & 85.4 & 0.49647 & 0.5375 & 5.0 \\
\hline Fuel & 85.4 & 128.1 & 0.40936 & 0.5468 & 5.0 \\
\hline Fuel & 128.1 & 170.8 & 0.30866 & 0.5608 & 5.0 \\
\hline Fuel & 170.8 & 213.5 & 0.22573 & 0.5796 & 5.0 \\
\hline Fuel & 213.5 & 256.2 & 0.17009 & 0.6044 & 5.0 \\
\hline Fuel & 256.2 & 298.9 & 0.13481 & 0.6336 & 4.9 \\
\hline Fuel & 298.9 & 341.6 & 0.11265 & 0.6683 & 4.8 \\
\hline Fuel & 341.6 & 384.3 & 0.09918 & 0.7056 & 4.8 \\
\hline Fuel (top) & 384.3 & 427.0 & 0.09200 & 0.7427 & 4.8 \\
\hline Upper reflector & 427.0 & 457.48 & 0.09171 & 0.7779 & \\
\hline
\end{tabular}

The converged axial enrichment was assumed to be the same for all 16 fuel rods in the unit cell. The bottom 6 fuel zones are assumed to have a beginning-of-life enrichment of $5.0 \mathrm{wt} \%$, the middle 1 zone $4.9 \mathrm{wt} \%$, and the top 3 zones $4.8 \mathrm{wt} \%$. The overall effective rod enrichment is $4.93 \mathrm{wt} \% \mathrm{U}-235$ and this is the same enrichment assumed later in the PWR unit cell fuel rod and the SCWR with SiC for comparison purposes.

The SCWR unit cell depletion model, although a subset of the assembly geometry, can accurately capture the important neutron spectra information for the calculation of the neutron cross sections at each time step in the burnup calculation. Neutron cross sections are calculated in each of the 10 axial cells of segments of the fuel rods. Fission, radiative capture,

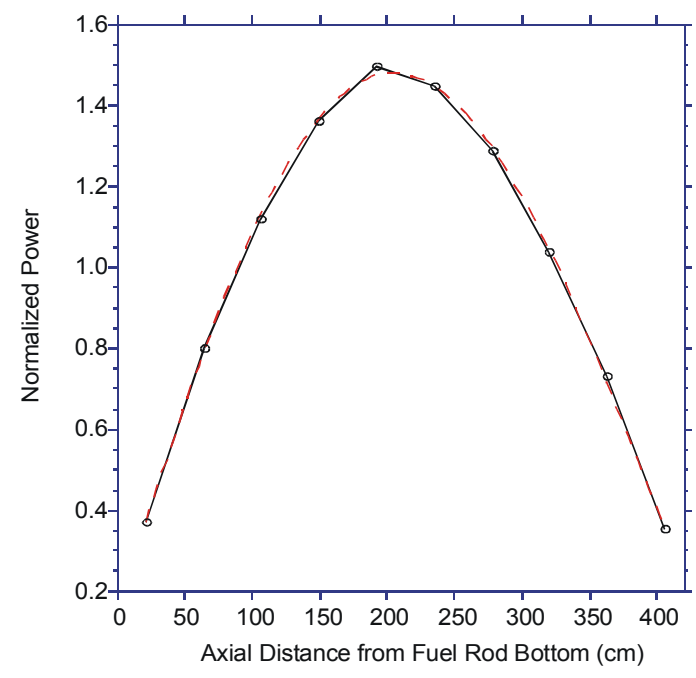

Figure 17. Converged beginning-of-life axial fuel rod power profile. 
(n, 2n), and (n, 3n) cross sections are calculated for 37 different actinides and 77 fission products at each burnup time step. In addition, the unit cell model is used to calculate the axial power distribution in the fuel rods. The SCWR fuel rods are assumed to have a constant power output or constant linear heat generation rate over the burnup calculation. For the SCWR with MA956, the linear heat generation rate was assumed to be $19.2 \mathrm{~kW} / \mathrm{m}$.

The goal of this first depletion calculation was to axially deplete a single fuel rod with coolant water density feedback based on the changing axial power profile. If power increased in a particular axial region, it was initially assumed that the coolant water density would decrease in that region, reduce the neutron moderation, and then suppress the rod power in that axial region in the next depletion time step. However, because the coolant has at best a very small reactivity effect on the unit cell and assembly (Table 5) and the fact that coolant axial density profile did not change substantially with variations in the power profile, the feedback mechanism did little to dampen the wild and previously seen axial power profile oscillations that developed around 180 EFPD into the depletion. The depletion calculation was halted after 420 EFPD (or 15 intensive depletion steps using 30-day burnup increments). Note: In reality, the axial power profile will be controlled with gray control rods, burnable poisons, etc.

\subsubsection{SCWR with MA956 (Depletion Study No. 2)}

In order to circumvent the wild and undamped power profile oscillations as a function of increasing burnup, it was decided to perform a more stable depletion calculation without the axial segmentation of the fuel rod and instead deplete the single fuel rod as a whole, uniformly and at a constant linear heat generation rate of $19.2 \mathrm{~kW} / \mathrm{m}$. The same unit cell model was used but without the fuel rod axial segmentation. This not only accelerated the depletion calculation, it allowed for a more equal basis to compare reactivity letdown curves to the PWR and the SCWR with SiC. In addition, from the first depletion study above for the SCWR with MA956, the converged beginning-of-life axial enrichment profile was converted into a uniform 4.93-wt\% U235 single rod enrichment and the converged beginningof-life coolant water density was used in the unit cell. The coolant water density was then held constant throughout the depletion calculation, as was the water rod water density (both profiles per Table 9 data).

Figure 18 shows the reactivity letdown curve for the SCWR with MA956. A burnup of approximately 31.0 GWD/MTU can be achieved in a once-through cycle before the unit cell would drop below the critical point.

In order to compare reactivity letdown curves for the 1) SCWR with MA956, 2) PWR, and 3) SCWR with SiC, several parameters were fixed in each depletion calculation. First, an effective enrichment of $4.93 \mathrm{wt} \% \mathrm{U}-235$ was used in the three different unit cells, and in the cases of the SCWR with MA956 and the SCWR with SiC, the coolant and water rod water axial density profiles were the same and fixed throughout the depletion calculation with the profiles as shown in Figure 10. The following two subsections describe the PWR and SCWR with SiC depletion calculations in more detail.

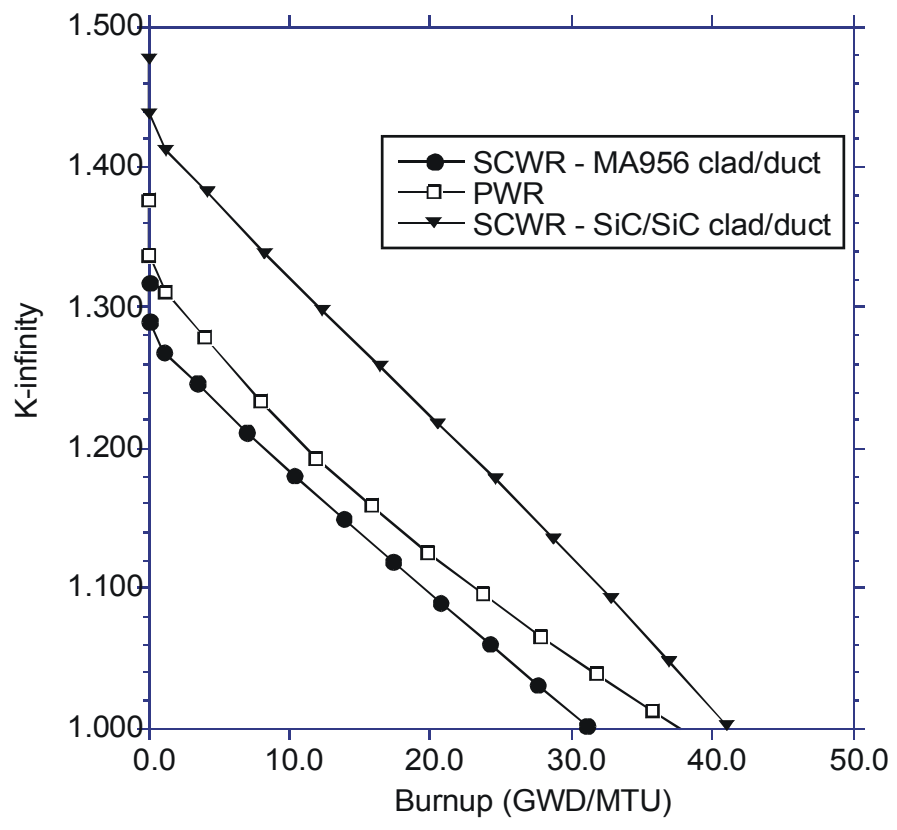

Figure 18. Comparison of reactivity letdown curves for the SCWR with MA956, PWR, and SCWR with SiC. 


\subsubsection{3. $P W R$}

The PWR unit cell was based on a 17x17 Westinghouse fuel assembly. The fuel rod radius was 0.4749 $\mathrm{cm}$, the Zircaloy-4 clad was $0.572 \mathrm{~mm}$ thick, the rod pitch was $1.25 \mathrm{~cm}$, and the coolant water density was assumed to be $0.6963 \mathrm{~g} / \mathrm{cc}$ over the entire 12-ft fuel rod length. As stated above, the $\mathrm{UO}_{2}$ enrichment was assumed to be $4.93 \mathrm{wt} \%$ U-235 and uniform over the fuel rod length. The PWR fuel rod was also assumed to have a constant power output or linear heat generation rate of $19.0 \mathrm{~kW} / \mathrm{m}$ over the burnup calculation. Under the above assumptions, the resulting beginning-of-life single fuel rod uranium mass was approximately $87.32 \mathrm{~g} \mathrm{U} 235$ and $1,683.87 \mathrm{~g} \mathrm{U} 238$.

The PWR reactivity letdown curve is shown in Figure 18. It is apparent from the figure that the initial kinfinity or reactivity at $0.0 \mathrm{GWD} / \mathrm{MTU}$ for the PWR $\left(\mathrm{k}_{\mathrm{inf}}=1.377009\right)$ is somewhat higher than the SCWR with MA956 $\left(\mathrm{k}_{\text {inf }}=1.317900\right)$ and one might expect the PWR to be able to sustain a longer critical burnup and indeed this the case. The PWR unit cell can achieve a burnup of approximately 38.0 GWD/MTU, while the SCWR with MA956 can sustain only $31.0 \mathrm{GWD} / \mathrm{MTU}$.

\subsubsection{SCWR with $\mathrm{SiC}$}

For comparison purposes, a depletion calculation was also performed for a single fuel rod in a unit cell based on the $21 \times 21$ SCWR assembly with $\mathrm{SiC} / \mathrm{SiC}$ cladding on the fuel rods, and water rod and assembly duct material made out of $\mathrm{SiC}$ as well. The effective enrichment was assumed to be $4.93 \mathrm{wt} \% \mathrm{U} 235$ and the water rod and coolant water densities are those shown in Figure 10. Figure 18 also shows the SCWR with $\mathrm{SiC}$ reactivity letdown curve. The relatively high beginning-of-life k-infinity (1.4777861) is indicative of the potential for a relatively higher achievable burnup and this is the case. The SCWR with $\mathrm{SiC}(\mathrm{SiC} / \mathrm{SiC}$ clad, $\mathrm{SiC}$ water rod duct, $\mathrm{SiC}$ assembly duct) can achieve a burnup of approximately 41.0 GWD/MTU, which is higher than the PWR case of $38.0 \mathrm{GWD} / \mathrm{MTU}$ and substantially higher than the SCWR with MA956 at 31.0 GWD/MTU.

The burnup comparison of the two SCWR and the one PWR fuel assemblies must be put in perspective. First, the comparison of the two SCWR assemblies is reasonable, since both operate at similar power densities. The $25 \times 25$ SCWR fuel assembly (MA956) with a $19.2 \mathrm{~kW} / \mathrm{m}$ LHGR and 300 fuel rods per assembly has a power density of the $70.4 \mathrm{~W} / \mathrm{cc}$, whereas the $21 \mathrm{x} 21 \mathrm{SCWR}$ fuel assembly (SiC) with a $25.0 \mathrm{~kW} / \mathrm{m}$ LHGR and 216 fuel rods per assembly has a power density of the $67.4 \mathrm{~W} / \mathrm{cc}$. In addition to the greater burnup, the $21 \times 21$ assembly requires less uranium than the $25 \times 25$ fuel assembly, for example, a beginning-of-life uranium loading of only $561.6 \mathrm{~kg}$ is required for the $21 \times 21$ versus the substantially more $712.4 \mathrm{~kg}$ for the $25 \times 25 \mathrm{SCWR}$ fuel assembly. The superiority of the SiC versus the MA956 material from a neutronics standpoint is evident.

The PWR fuel assembly, with a $19.0 \mathrm{~kW} / \mathrm{m}$ LHGR, 264 fuel rods per assembly, and a beginning-of-life $467.6 \mathrm{~kg}$ U/assembly uranium loading, operates at a considerably higher power density, namely 109.5 W/cc, than either of the two SCWR fuel assemblies. This higher power density gives the PWR fuel assembly a substantial burnup and economic advantage. The specific powers for the three assemblies studied are similar at 39.3, 34.5, and $41.1 \mathrm{~kW} / \mathrm{kgU}$ for the PWR, SCWR with MA956, and the SCWR with $\mathrm{SiC}$, respectively. Table 14 provides a summary of additional data for comparing the three fuel assemblies. 
Table 14. Additional data for comparing the three fuel assemblies.

\begin{tabular}{|l|c|c|c|}
\hline \multicolumn{1}{|c|}{ Parameter } & PWR & $\begin{array}{c}\text { SCWR with } \\
\text { MA956 }\end{array}$ & $\begin{array}{c}\text { SCWR with } \\
\text { SiC }\end{array}$ \\
\hline No. of fuel rods & 264 & 300 & 216 \\
\hline LHGR (kW/m) & 19.0 & 19.2 & 25.0 \\
\hline Power per Rod (kW/rod) & 69.54 & 81.98 & 106.75 \\
\hline Total Assembly Power (MW/assembly) & 18.358 & 24.595 & 23.058 \\
\hline Assembly Volume (cc/assembly) & $167,613.36$ & $349,268.92$ & $341,980.00$ \\
\hline Power Density (W/cc) & 109.52 & 70.42 & 67.43 \\
\hline $\begin{array}{l}\text { Beginning-of-Life Uranium Mass } \\
\text { (kg/assembly) }\end{array}$ & 467.6 & 712.4 & 561.6 \\
\hline Specific Power (kW/kgU) & 39.26 & 34.52 & 41.05 \\
\hline Burnup U-235 (\%) & 62.6 & 58.9 & 75.6 \\
\hline
\end{tabular}

\subsubsection{Neutron Spectra}

Neutron spectra in the fuel rods were calculated using the 25x25 SCWR fuel assembly with MA956, the 21x21 SCWR fuel assembly with SiC, and the PWR unit cell geometry models described above in the depletion section. The three unit cell models are assumed to have the same $4.93 \mathrm{wt} \%$ U235 uranium enrichment at beginning-of-life. In addition, the two SCWR models used the same coolant and water rod axial water density profiles. The goal was to make the best comparison possible between the different fuel assembly designs. Figure 18 shows the beginning-of-life neutron spectra for the (1) SCWR with MA956, (2), PWR, and (3) the SCWR with SiC, each normalized to the linear heat generation rates of 19.2, 19.0, and $25.0 \mathrm{~kW} / \mathrm{m}$, respectively. A couple features are notable in Figure 18. First, the PWR exhibits a harder fast and epithermal spectra than the two SCWR unit cells, and second the SCWR with $\mathrm{SiC}$ exhibits a larger thermal pulse than either the SCWR with MA956 or the PWR. The larger thermal pulses in both the SCWR unit cells are more readily apparent in Figure 19. Figure 19 shows the same three spectra, but normalized and clearly shows the SCWR with SiC with a larger fraction of its total neutrons in the thermal region relative to both the SCWR with MA956 and the PWR.

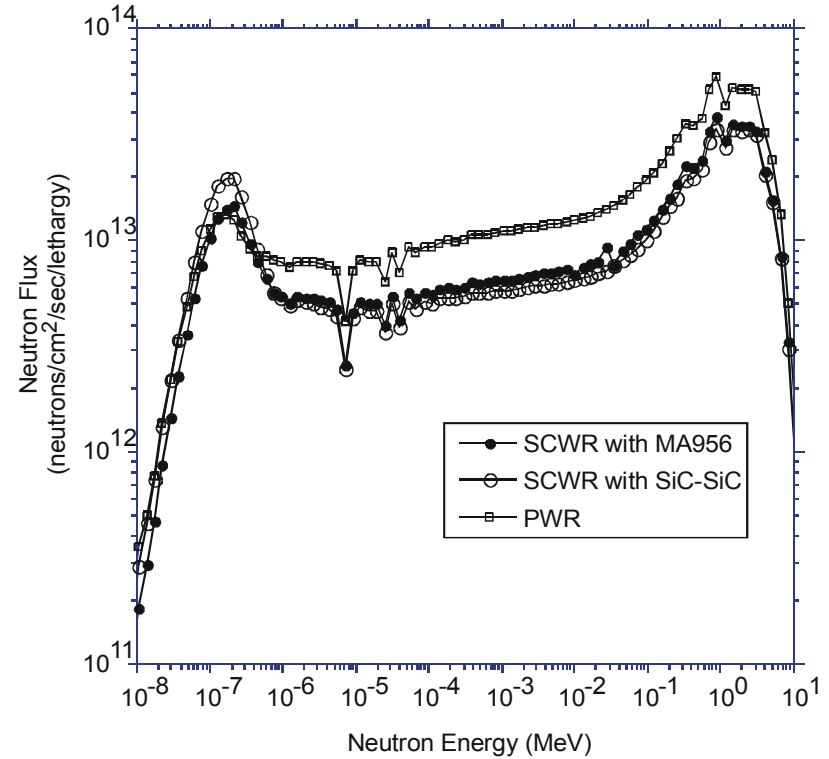

Figure 18. SCWR and PWR neutron spectra.

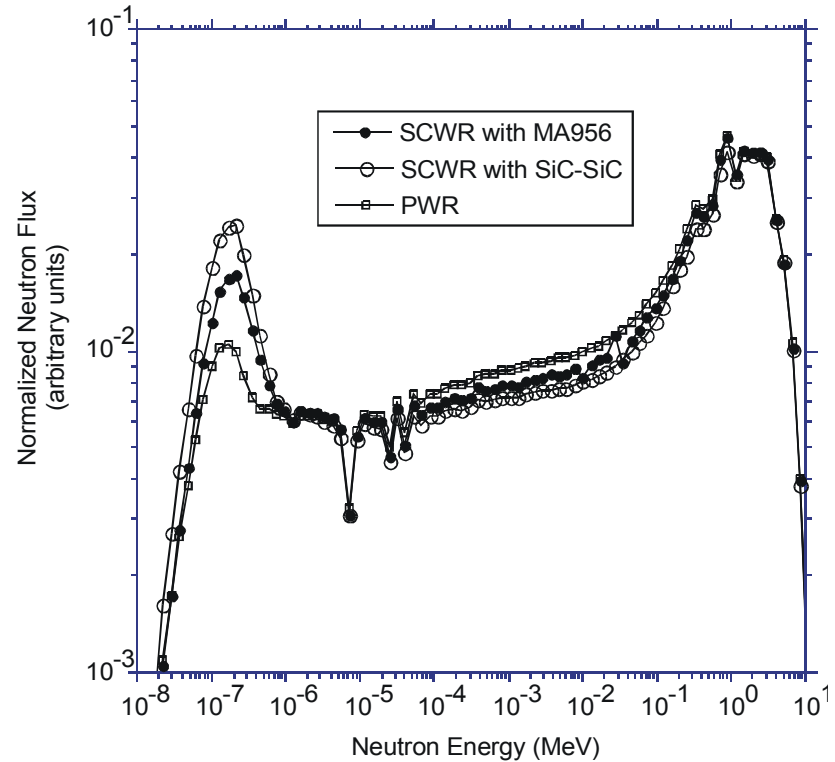

Figure 19. Normalized SCWR and PWR neutron spectra. 
The higher fraction of thermal neutrons in the SCWR with SiC is due to its relatively higher hydrogen to uranium atomic ratio $(\mathrm{H} / \mathrm{U})$. For the three unit cells, the $(\mathrm{H}: \mathrm{U})$ ratios are estimated to be 4.97, 6.30, and 3.22 for the SCWR with MA956, SCWR with SiC, and the PWR, respectively. The H/U ratio is highest for the SCWR with $\mathrm{SiC}$, which corresponds to the higher thermal neutron pulse or more thermalized spectra. Conversely, the PWR with the lowest ratio shows the characteristics of a relatively harder spectrum.

\subsubsection{Re-design of the $25 \times 25$ SCWR Fuel Assembly}

As discussed in Section 5.1 of this report, the $25 \times 25$ SCWR fuel assembly underwent a slight design change based on thermo-hydraulic considerations. In this re-design, some of the fuel rod outer diameters (OD) were reduced from the reference case of $10.2 \mathrm{~mm}$ to 9.5 and $10.0 \mathrm{~mm}$, otherwise the assembly remained the same. Table 15 shows the fuel rod ODs for the two cases along with the row and column numbers defined per Figure 11.

The reference fuel rod had a $0.439-\mathrm{cm}$ fuel pellet radius, $0.447-\mathrm{cm}$ clad inner radius, and $0.51-\mathrm{cm}$ pin radius or a 10.2-mm OD. The re-design fuel rod with the new $10.0-\mathrm{mm}$ OD has a $0.429-\mathrm{cm}$ fuel pellet radius, $0.437-\mathrm{cm}$ clad inner radius, and $0.50-\mathrm{cm}$ pin radius. Note some of the fuel rods in the re-design fuel assembly still have a $10.2-\mathrm{mm}$ OD as in the reference case and that the pin at coordinate at $(1,1)$ is the instrumentation pin with the 9.5-mm OD.

The overall neutronic effect for the re-design assembly relative to the reference design is an increase in the coolant volume and a decrease in the uranium mass for the assembly as a whole. This translates into a higher $\mathrm{H} / \mathrm{U}$ atomic ratio and, therefore, the k-infinity for the assembly increases. The reference k-infinity is $1.268262(0.0002)$ and the re-design assembly has a value of $1.269054(0.0002)$. The reactivity increase is small $(+0.08 \$)$ and perhaps negligible. Basically, the re-design moves the physics parameters in the direction of the $21 \times 21$ SCWR fuel assembly with SiC (relatively higher H/U ratio), but only slightly.

Table 15. Re-design fuel rod OD for the $25 \times 25$ SCWR fuel assembly.

\begin{tabular}{|c|c|c|c|}
\hline Fuel Rod Row & Fuel Rod Column & Reference OD (mm) & Re-design OD (mm) \\
\hline 1 (Instrumentation pin) & 1 & 10.2 & 10.2 \\
\hline 1 & 2,4 & 10.2 & 10.2 \\
\hline 1 & 3 & 10.2 & 10.0 \\
\hline $1,2,4,5$ & 5 & 10.2 & 10.2 \\
\hline 3 & 5 & 10.2 & 10.0 \\
\hline 1,5 & 6 & 10.2 & 10.2 \\
\hline 1,5 & 7 & 10.2 & 10.0 \\
\hline 1,5 & 8 & 10.2 & 10.2 \\
\hline $1,2,4,5,6,8,9$ & 9 & 10.2 & 10.2 \\
\hline 3,7 & 9 & 10.2 & 10.0 \\
\hline $1,5,9$ & 10 & 10.2 & 10.2 \\
\hline $1,5,9$ & 11 & 10.2 & 10.0 \\
\hline $1,5,9$ & 12 & 10.2 & 10.2 \\
\hline 12 & 13 & 10.2 & 10.0 \\
\hline 13 & 13 & 10.2 & 9.5 \\
\hline
\end{tabular}

The radial power profile was calculated for the re-design assembly and compared to the reference assembly. The radial power profile changed only slightly $(<0.1 \mathrm{wt} \% \mathrm{U} 235)$. The maximum adjustment would occur for the highest enrichment corner pin with the adjustment estimated to be only a 0.2 -wt $\%$ U- 
235 reduction in the enrichment. The re-design of the $25 \times 25$ SCWR fuel assembly is expected to have only a minor impact on the other physics parameters calculated herein.

\subsubsection{Conclusions}

It can be concluded that $25 \times 25$ SCWR fuel assembly with ODS steel MA956 structural material exhibits some desirable neutronic characteristics. For example, the worth of the coolant and the water rod water are both negative. The individual worth of the water rod alone or the combined coolant and water rod worth would both shutdown the nuclear chain reaction in the event of loss-of-coolant accidents. The beginning-of-life Doppler coefficients of reactivity are estimated to be strongly negative and it is projected that the Doppler coefficients would remain negative over the course of the assembly burnup. Based on reactivity calculations, the ODS steel MA956 does achieve better neutron economy than the Alloy 718 which would translate into a longer burnup potential for the MA956 fuel assembly versus an Alloy 718 assembly. However, a significant reactivity advantage can be gained by using $\mathrm{SiC} / \mathrm{SiC}$ fuel cladding and water rod duct material versus MA956, in fact the use of $\mathrm{SiC} / \mathrm{SiC}$ provides slightly more reactivity than the use of Zircaloy-4. Both $\mathrm{SiC}$ and Zircaloy-4 have very low parasitic neutron absorption properties relative to MA956.

In addition, a centrally located 12-control rod array in the fuel assembly with $\mathrm{B}_{4} \mathrm{C}$ can meet the beginning-of-life cold reactivity core shutdown condition of $\mathrm{k}_{\text {inf }}=0.95$. These calculations were done without burnable poisons for reactivity hold down and one should also keep in mind that the utilization of burnable poisons in future fuel assembly designs will most likely allow use of both $\mathrm{B}_{4} \mathrm{C}$ and $\mathrm{In}-\mathrm{Cd}-\mathrm{Ag}$ control rods, and reduce the control rod size and number requirements.

In the case of the SCWR with MA956, the unrodded radial and axial power profiles can be flattened through enrichment variation. For radial power flattening, a much broader enrichment range may be required, for example, 3.2 to $12.4-\mathrm{wt} \% \mathrm{U}-235$. For axial power flattening, a three-zone axial enrichment scheme using a relatively tight enrichment range of 4.8-5.0-wt $\%$ U-235 would suffice. However, it should be strongly noted that the enrichment range is very tight and very small changes in this axial enrichment profile resulted in significant movement of the axial power peak. This does not bode well for a reactor design in which small changes in the U-235 concentration axially (due to burnup for example) may substantially shift the axial power distribution. The axial power enrichment profile was also very sensitive to changes in the water rod water density, and to a lesser extent coolant water density. Because of the axial asymmetries inherent in the SCWR 25x25 fuel assembly (e.g. enrichment, coolant water density, and water rod water density) and expected perturbations during normal operation, control rod insertion and burnable poisons will be required to hold down excess reactivity and control burnup, but perhaps more importantly to mitigate any axial power oscillations in the core. The three-zone axial enrichment scheme was shown to produce a symmetrical axial power profile with a peak-to-average value of approximately 1.3-1.5 for the unrodded condition.

For an effective assembly enrichment of $4.93 \mathrm{wt} \% \mathrm{U}-235$ in the $25 \times 25 \mathrm{SCWR}$ assembly with MA956 as the structural material, a once-through burnup of approximately $31.0 \mathrm{GWD} / \mathrm{MTU}$ could be achieved for an infinite unit cell lattice before subcriticality resulted. Relative to the 21x21 SCWR assembly with SiC as the structural material (fuel cladding, water rod duct, and assembly duct material), a substantial increase in burnup of up to $41.0 \mathrm{GWD} / \mathrm{MTU}$ is possible. Based on the assumed linier heat generation rates, the $25 \times 25$ and the $21 \times 21$ fuel assemblies have comparable power densities, namely, $70.4 \mathrm{~W} / \mathrm{cc}$ and $67.4 \mathrm{~W} / \mathrm{cc}$, respectively.

In addition, for comparison purposes, a standard $17 \times 17$ commercial PWR fuel assembly was also depleted. For an assumed uniform 4.93-wt\% U235 enrichment, the PWR fuel assembly can achieve a 
burnup of approximately $38.0 \mathrm{GWD} / \mathrm{MTU}$. Although the SCWR with SiC slightly exceeds the PWR burnup or energy expenditure per unit mass of initial uranium, the PWR fuel assembly operates at a much higher power density, $109.5 \mathrm{~W} / \mathrm{cc}$ versus $67.4 \mathrm{~W} / \mathrm{cc}$, and therefore has a significant advantage over the SCWR fuel assemblies.

\subsection{Neutronic Evaluation of a $21 \times 21$ Supercritical Water Reactor Fuel Assembly Design with Water Rods and SiC Cladding and Duct Materials}

The core physics performance characteristics of a 21x21 SCWR assembly that uses SiC for the fuel rod cladding, water rod duct, and assembly duct material is discussed in this section. Relative to an ODS, such as MA956, the SiC material should exhibit lower neutron absorption and hence provide considerably more assembly reactivity. This is indeed the case. SiC also exhibits a few other positive neutronic characteristics that should help promote its use as a SCWR fuel assembly material. Throughout the evaluation here, comparison results will be presented that attempt to compare the $21 \times 21 \mathrm{SCWR}$ fuel assembly with $\mathrm{SiC}$ clad/duct materials with a $25 \times 25 \mathrm{SCWR}$ fuel assembly with MA956 clad/duct materials, and in some sections an additional comparison will be made with calculated results for a standard pressurized water reactor (PWR) fuel assembly based on a Westinghouse 17x17 fuel assembly.

\subsubsection{SCWR Fuel Assembly and MCMP Model Description}

The 21x21 SCWR fuel assembly geometry is shown in Figure 20. The outer fuel assembly dimensions are square with $28.3-\mathrm{cm}$ long sides with a total axial length of approximately $4.87-\mathrm{m}$. The assembly is essentially a $21 \times 21$ pin array of cylindrical fuel pins with a $5 \times 5$ array of water rods inserted within the pin array. The 25 square water rods displace 225 fuel pins leaving 216 fuel pins to generate thermal power and a single instrumentation rod at the very center of the assembly. An assembly duct contains the fuel rod and water rod arrays.

The length of the active core or the length of each uranium oxide fuel pellet stack is $427.0-\mathrm{cm}$. The $\mathrm{UO}_{2}$ fuel pellet diameter is $0.91872-\mathrm{cm}$, the combined thickness of the double layer clad is assumed to $1.4224-\mathrm{mm}$, and the overall pin diameter is $1.2192-\mathrm{cm}$. Fuel enrichment is assumed to be approximately 5.0 $\mathrm{wt} \% \mathrm{U}-235$. Below the fuel pellet stack, each fuel rod contains a $60-\mathrm{cm}$ long fission gas plenum. The clad, water rod duct, and assembly duct material is assumed to be silicon carbide; the clad more specifically a duplex monolithic $\mathrm{SiC}$ layer surrounded by a porous $\mathrm{SiC}$ layer. The mean density of the $\mathrm{SiC}$ clad is 2.9749 $\mathrm{g} / \mathrm{cc}$. The water rods are $3.96-\mathrm{cm}$ square with a wall

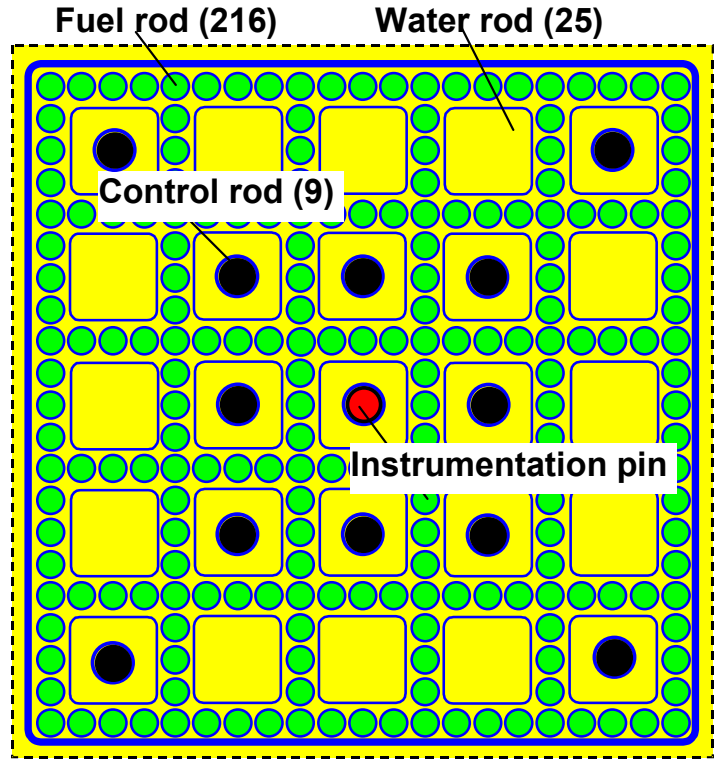

Figure 20. The $21 \times 21 \mathrm{SCWR}$ fuel assembly showing fuel rods, water rods, control rods, instrumentation pin, water rod ducts, and assembly duct.

thickness of $0.4-\mathrm{mm}$. The water gap between the assemblies or inter-assembly gap is $2.0-\mathrm{mm}$ in width and is filled with fuel rod coolant. Additional assembly geometric dimensions and materials are listed in Table 16. 
Table 16. Characteristics of the $21 \times 21$ SCWR fuel assembly with SiC/SiC-clad fuel pins.

\begin{tabular}{|l|l|}
\hline \multicolumn{1}{|c|}{ Parameter } & \multicolumn{1}{c|}{ Value } \\
\hline Fuel pin lattice & Square $21 \times 21$ array \\
\hline Number of fuel pins per assembly & 216 \\
\hline Pitch-to-diameter ratio & 1.082 \\
\hline Number of water rods per assembly & 25 \\
\hline Water rod side & $39.6 \mathrm{~mm}$ (square) \\
\hline Water rod wall thickness & $0.4 \mathrm{~mm}$ \\
\hline Number of instrumentation rods per assembly & 1 \\
\hline Assembly duct thickness & $3 \mathrm{~mm}$ \\
\hline Assembly side & $283 \mathrm{~mm}$ \\
\hline Inter-assembly gap & $2 \mathrm{~mm}$ \\
\hline Assembly pitch & $285 \mathrm{~mm}$ \\
\hline Fuel Pin OD & $12.192 \mathrm{~mm}(0.48$ in.) \\
\hline Cladding type & SiC duplex \\
\hline Monolithic SiC layer thickness & $1.0160 \mathrm{~mm}(0.04$ in.) \\
\hline Monolithic SiC layer density & $3.1 \mathrm{~g} / \mathrm{cc}$ \\
\hline Porous SiC layer thickness & $0.4064 \mathrm{~mm}(0.016$ in.) \\
\hline Porous SiC layer density & $2.7 \mathrm{~g} / \mathrm{cc}$ \\
\hline Total cladding thickness & $1.4224 \mathrm{~mm}(0.056$ in.) \\
\hline Composite or Mean clad density & $2.9749 \mathrm{~g} / \mathrm{cc}$ \\
\hline Fuel Pellet OD & $9.1872 \mathrm{~mm}(0.3617$ in.) \\
\hline Cold gap width & $80 \mathrm{microns}(0.003$ in.) \\
\hline Fuel composition & $\mathrm{UO}, \quad(95 \%$ theoretical density) \\
\hline Active fuel length & $4.27 \mathrm{~m}$ \\
\hline Fuel density & $10.4215 \mathrm{~g} / \mathrm{cc}$ \\
\hline FG plenum length (at the fuel pin bottom) & $60 \mathrm{~cm}(23.6$ in.) \\
\hline Fill pressure & $6.0 \mathrm{MPa}($ at room temperature $)$ \\
\hline Average linear generation rate & $25.0 \mathrm{~kW} / \mathrm{m}$ \\
\hline Average specific power & $36.2 \mathrm{~kW} / \mathrm{kg} \mathrm{UO} 2$ \\
\hline
\end{tabular}

The fuel rod coolant is light water with the axial density profile shown Figure 10. The water rod also contains light water, but has a different axial density profile (Figure 10). The water rod water is segregated from the fuel rod coolant by the water rod duct. The coolant and water rod water axial flows are diametrically opposed, the coolant water flowing from the bottom of the core to the top and vice versa for the water rod water.

Based on the design discussed above, a symmetric, 1/8-assembly, MCNP computer model was developed with fully explicit fuel rods, water rods, and assembly duct. Figure 21 shows a cross sectional view of the 1/8assembly MCNP model. The $\mathrm{SiC} / \mathrm{SiC}$ duplex fuel cladding material was modeled as a single composite material with a mean density of $2.9749 \mathrm{~g} / \mathrm{cc}$, which is based on the monolithic

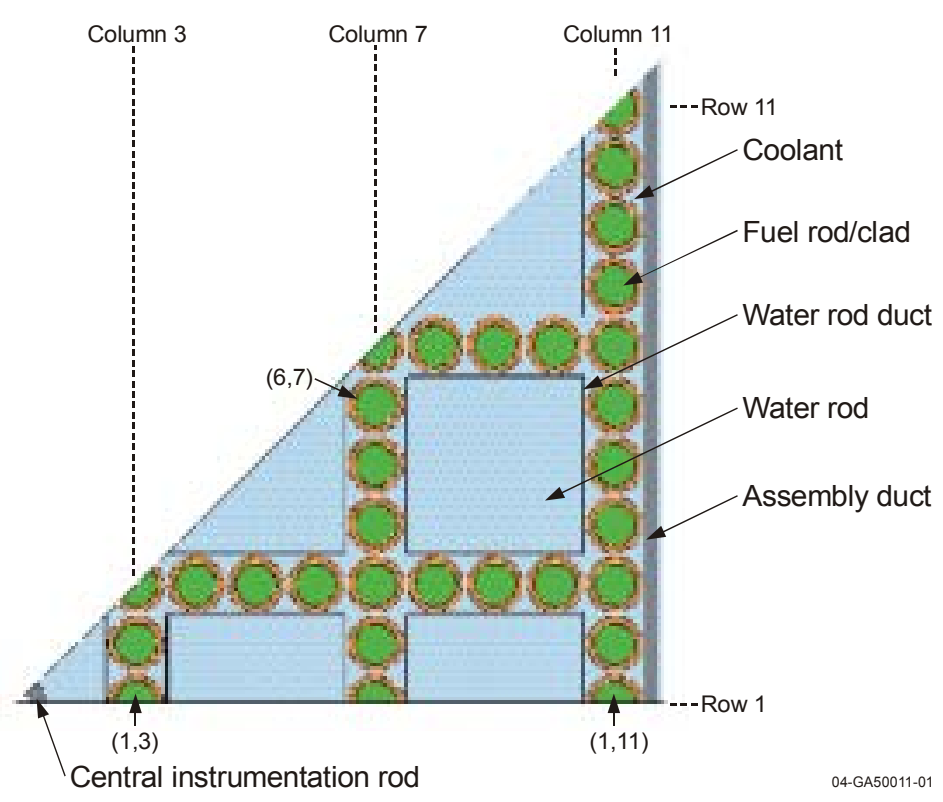

Figure 21. MCNP 1/8-assembly model of the 21x21 SCWR fuel assembly with $\mathrm{SiC} / \mathrm{SiC}$ cladding/duct materials. 
and porous fuel cladding material thicknesses and densities listed in Table 16. This same SiC composite material was used for the water rod duct and assembly duct materials as well.

The fuel rods and water rods were modeled full length in the axial direction with a water reflector above the top of the active fuel region, a $60-\mathrm{cm}$ long gas plenum on the bottom of each fuel rod, and below the gas plenum at the bottom of each fuel rod, a mixing region that doubles as a lower water reflector. A reflective boundary condition was applied to the three exterior planes encompassing the triangular partial assembly in order to convert the 1/8-partial assembly model into an infinite lattice of $21 \times 21$ SCWR water rod fuel assemblies.

The 427-cm active pellet stack length in each fuel pin was subdivided into 10 increments; each increment had a length of $42.7-\mathrm{cm}$. The $60-\mathrm{cm}$ length fission gas plenum beneath the bottom of the active fuel was also modeled along with a top and bottom coolant reflector with appropriate inlet and outlet water densities. The coolant channel axial lengths were also subdivided into to 10 axial volumes with appropriately assigned water densities as shown in Figure 10. In a similar fashion, the water rod water was also modeled explicitly and subdivided into 10 axial lengths with the water densities shown in Figure 10. The 10 axial cells for the fuel, coolant, and water rod all coincide at the same core elevations. The neutron transport $S(\alpha, \beta)$ data libraries for the coolant and water rod water were both are assumed to be $527{ }^{\circ} \mathrm{C}$, and the average fuel temperature was assumed to be $608{ }^{\circ} \mathrm{C}$. These temperatures correspond to available MCNP temperature-dependent cross section libraries.

The reactor physics computer codes MCNP, ORIGEN2, and MOCUP discussed above in Section 3.1.2 were used exclusively to perform all neutronic analyses.

\subsubsection{Material Reactivity Comparison ( $\mathrm{SiC}$ versus MA956)}

In order to compare the neutronic reactivity difference between MA956 and the SiC material, the MCNP 1/8-assembly model with MA956 clad, MA956 water rod duct, and MA956 assembly duct was used to calculate k-infinity and reactivity worths in which the MA956 material is successively replaced with SiC. A positive reactivity gain is expected due to the lower radiative capture cross sections of silicon and carbon relative to the transition metals composing MA956. Table 17 presents the calculated k-infinity results for the successive material replacements of MA956 with SiC.

Table 17. Assembly lattice k-infinity and reactivity worth comparison for various assembly material replacements.

\begin{tabular}{|c|c|c|c|c|c|c|c|}
\hline $\begin{array}{l}\text { Enrichment } \\
\text { (Wt\%U-235) }\end{array}$ & $\begin{array}{c}\text { Clad } \\
\text { Thickness } \\
(\mathrm{mm})\end{array}$ & $\begin{array}{l}\text { Cladding } \\
\text { Material }\end{array}$ & $\begin{array}{c}\text { Water Rod } \\
\text { Duct } \\
\text { Material }\end{array}$ & $\begin{array}{l}\text { Assembly } \\
\text { Duct } \\
\text { Material }\end{array}$ & $\begin{array}{c}\mathrm{K}- \\
\text { infinity }\end{array}$ & $\begin{array}{c}\text { Relative } \\
\text { Error }\end{array}$ & $\begin{array}{c}\text { Worth } \\
\text { (\$) }\end{array}$ \\
\hline 5.0 & 1.4224 & MA956 & MA956 & MA956 & $\begin{array}{c}1.1648 \\
70\end{array}$ & 0.0002 & ---- \\
\hline 5.0 & 1.4224 & $\mathrm{SiC}$ & MA956 & MA956 & $\begin{array}{c}1.3543 \\
73\end{array}$ & 0.0002 & +18.5 \\
\hline 5.0 & 1.4224 & $\mathrm{SiC}$ & $\mathrm{SiC}$ & MA956 & $\begin{array}{c}1.3948 \\
81\end{array}$ & 0.0002 & +21.8 \\
\hline 5.0 & 1.4224 & $\mathrm{SiC}$ & $\mathrm{SiC}$ & $\mathrm{SiC}$ & $\begin{array}{c}1.4533 \\
04\end{array}$ & 0.0002 & +26.2 \\
\hline $4.85^{\circ}$ & 1.4224 & $\mathrm{SiC}$ & $\mathrm{SiC}$ & $\mathrm{SiC}$ & $\begin{array}{c}1.4505 \\
50\end{array}$ & 0.0002 & \\
\hline 5.0 & 0.630 & MA956 & MA956 & MA956 & $\begin{array}{c}1.2779 \\
97\end{array}$ & 0.0002 & +11.7 \\
\hline
\end{tabular}

* Effective enrichment for a fuel rod with a 5.0, 4.8, and $4.7 \mathrm{wt} \% \mathrm{U}-235$ axial distribution. 
From Table 17, it is clear that the use of $\mathrm{SiC}$, instead of MA956, provides a significant positive reactivity advantage. This is most apparent in the material substitution of the fuel cladding, which gives a positive reactivity increase of approximately $+18.5 \$$. Additionally, the replacement of both the MA956 water rod and assembly ducts with $\mathrm{SiC}$ can add an additional $7.7 \$$ of positive reactivity. So there is a very large positive reactivity advantage in using $\mathrm{SiC}$ over MA956. [All reactivity values are calculated based on the formula $\left(\mathrm{k}_{2}-\mathrm{k}_{1}\right) /\left(\mathrm{k}_{1} \mathrm{k}_{2}\right)$ and an effective delayed fraction of 0.0065$]$.

The data in Table 17 was evaluated based on the current proposed SiC/SiC clad thickness of $1.4224 \mathrm{~mm}$. This is approximately $125 \%$ thicker than that currently proposed MA956 fuel rod cladding thickness of $0.630 \mathrm{~mm}$. The thinner clad wall thickness for MA956 should potentially offset the reactivity gain by the use of $\mathrm{SiC} / \mathrm{SiC}$ clad material. In an attempt to assess the relative reactivity gain of the $\mathrm{SiC} / \mathrm{SiC}$ substitution and taking into consideration the difference in cladding thickness, the bottom row in Table 17 presents the re-calculated k-infinity for the all MA956 case with the thinner clad. Now the reactivity advantage of the $\mathrm{SiC} / \mathrm{SiC}$ is reduced to $+11.7 \$$, instead of $+18.5 \$$. This is still a substantial reactivity gain for the SiC material.

As a side note, the $\mathrm{UO}_{2}$ fuel was assumed to have a uniform 5.0-wt $\%$ U-235 enrichment throughout the assembly. From the axial power profile flattening study (discussed below), it was found that a $5.0 \%$ enrichment in the bottom of the active fuel region $(0-170.8-\mathrm{cm})$, a $4.8 \%$ enrichment in the middle $(170.8$ $298.9-\mathrm{cm})$, and a $4.7 \%$ enrichment at the top $(298.9-427.0-\mathrm{cm})$ produced a relatively flatter axial power profile. This new enrichment profile produces an effective rod enrichment of $4.85 \mathrm{wt} \%$. Listed in Row 5 of Table 17 is the k-infinity value associated with the $4.85-\mathrm{wt} \%$ enrichment that results in only a small reactivity loss, or approximately -20 cents.

\subsubsection{Coolant and Water Rod Void Reactivity}

The water in the MCNP 1/8-assembly model coolant channels and water rods was systematically voided in order to estimate the effect on the infinite assembly lattice k-infinity. The $\mathrm{UO}_{2}$ fuel is assumed to have a uniform $5.0 \mathrm{wt} \% \mathrm{U}-235$ enrichment throughout the assembly and the fuel cladding, water rod duct, and assembly duct material was assumed to be SiC. Table 18 gives the k-infinity results for first voiding the coolant water, then the coolant and the water rods individually, and then voiding both.

Table 18. Assembly k-infinity comparison for coolant and water rod voiding.

\begin{tabular}{|l|l|l|l|l|l|l|}
\hline Input file & $\begin{array}{c}\text { Coolant } \\
\text { Water }\end{array}$ & $\begin{array}{c}\text { Water Rod } \\
\text { Water }\end{array}$ & K-infinity & $\begin{array}{c}\text { Relative } \\
\text { Error }\end{array}$ & $\begin{array}{c}\text { Change } \\
\text { in k }\end{array}$ & $\begin{array}{l}\text { Reactivity } \\
\text { Worth } \\
\mathbf{( \$ )}\end{array}$ \\
\hline SiC.1b & Present & Present & 1.453304 & 0.0002 & -- & -- \\
\hline SiCw1 & Void & Present & 1.450126 & 0.0002 & -0.00318 & -0.23 \\
\hline SiCw3 & Present & Void & 1.022154 & 0.0002 & -0.43115 & -44.65 \\
\hline SiCw2 & Void & Void & 0.688784 & 0.0002 & -0.76452 & -117.50 \\
\hline
\end{tabular}

From Table 18, voiding just the coolant (loss of the coolant in the channels around the fuel rods) has only a small, but negative effect on the lattice k-infinity (approximately -23 cents). Voiding just the water rods alone produced a very strong negative decrease in the k-infinity (approximately $-\$ 44.7$ ). Voiding both the coolant and water rods drops the lattice k-infinity significantly, down to a very subcritical level, where the core now becomes basically an under-fueled fast reactor.

If one compares the two k-infinity values in Table 18 between the SiC.1b and SiCw3 cases, it is not readily apparent whether or not the $21 \times 21$ assembly is over-moderated or under-moderated. In order to 
determine whether the assembly is over-moderated or under-moderated, the water rod water density was systematically reduced in density. The resulting k-infinities monotonically decreased with decreasing water rod density and did not go through an optimal or maximum value, hence we can conclude that the assembly is under-moderated, as desired.

\subsubsection{Doppler Coefficients}

The beginning-of-life fuel Doppler coefficient of reactivity is estimated for an infinite assembly lattice with a uniform $5.0-\mathrm{wt} \%$ U-235 enrichment and where the fuel cladding, water rod duct, and assembly duct are all made out of SiC. Both the coolant and water $\operatorname{rod} S(\alpha, \beta)$ temperatures are again assumed to be fixed at a temperature of $527^{\circ} \mathrm{C}$, while the fuel temperature is varied from $21^{\circ} \mathrm{C}$ up to 2200 ${ }^{\circ} \mathrm{C}$ in non-uniform increments. Figure 22 shows the calculated k-infinity values as a function of fuel temperature.

The two discontinuities in the curve in Figure 22 are the result of using three different sets of cross section data generated with ENDF/B-VI data, but different revisions of the data. The first discontinuity occurs at the 20 and $126{ }^{\circ} \mathrm{C}$ temperature points. The second discontinuity occurs at the 900 and $1000{ }^{\circ} \mathrm{C}$ temperature points. This second discontinuity was traced to differences in the MCNP uranium (both U-235 and U-238) cross-section libraries as discussed in Section 3.1.6 above.

The calculated Doppler coefficients $(\Delta \mathrm{k} / \Delta \mathrm{T})$ are shown in Figure 23. The two discontinuities in Figure 22 have been omitted so as not to introduce the large and unphysical temperature coefficient spikes in the Figure 23 curve. The Doppler coefficients are all strongly negative across the fuel temperature range and the average Doppler coefficient is approximately $-2.32 \mathrm{pcm} /{ }^{\circ} \mathrm{C}$ over the entire temperature range. Note the coefficient curve exhibits an upward or less negative trend with increasing fuel temperature, but still nicely negative even above $2000^{\circ} \mathrm{C}$.

The Doppler temperature coefficient data plotted in Figure 23 are still somewhat erratic even with the discontinuities omitted, this being due to the inherent statistical uncertainty associated with the Monte Carlo method. This is to be expected. Despite this slight non-physical behavior, the data clearly demonstrates that the Doppler coefficient is strongly negative over the temperature range of

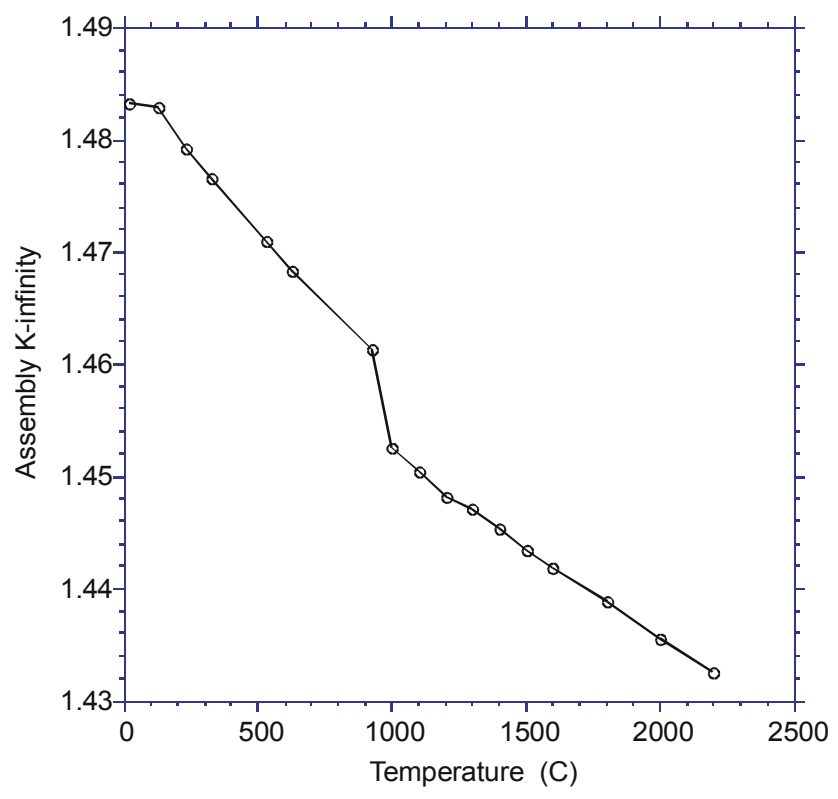

Figure 22. Assembly k-infinity as a function of fuel temperature.

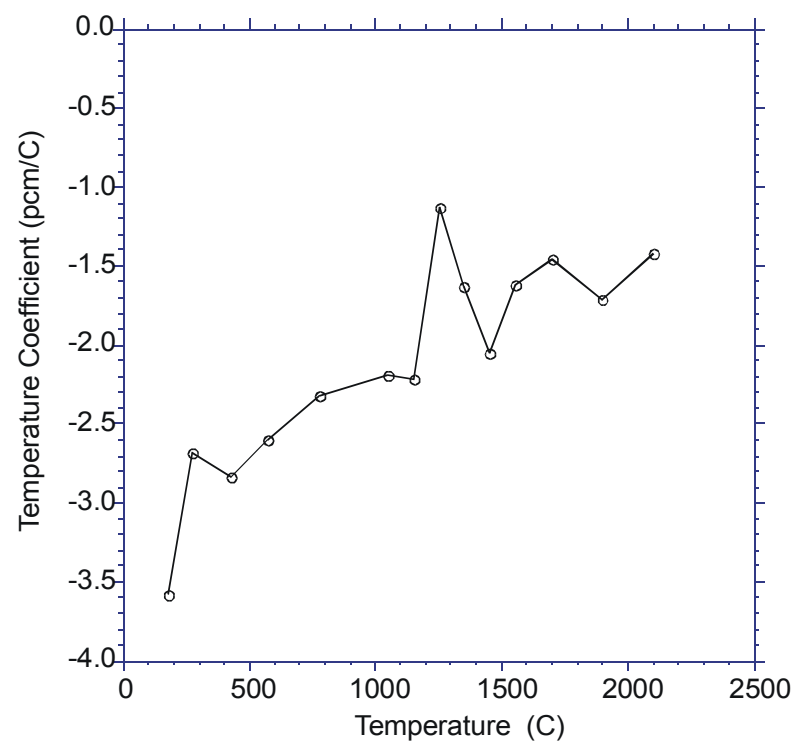

Figure 23. Fuel Doppler coefficient at beginning-oflifo 
interest. One-sigma error bars of $10-20 \%$ of the plotted values can be expected. Deterministic codes and models will be required in the future to recalculate smoother and perhaps more accurate Doppler coefficient curves.

The Doppler coefficient has also been estimated at a burnup of $16.8 \mathrm{GWd} / \mathrm{MTU}$ (410 EFPD) using the same SCWR unit cell model used in the depletion calculation. Although the fuel composition contains 37 actinides and 77 fission products, only the uranium (U-235 and U-238) isotopes are increased in temperature due to the lack of MCNP fission product nuclide cross section data at high temperatures. Table 19 lists the k-infinity values as a function of temperature.

Table 19. Doppler coefficients at 410 EFPD burnup.

\begin{tabular}{|c|c|c|c|}
\hline $\begin{array}{c}\text { Fuel Temp } \\
\left({ }^{\circ} \mathbf{C}\right)\end{array}$ & $\begin{array}{c}\text { Water Temp } \\
\left({ }^{\circ} \mathbf{C}\right)\end{array}$ & k-infinity & $\begin{array}{c}\text { Relative } \\
\text { Error }\end{array}$ \\
\hline 21 & 527 & 1.236051 & 0.0004 \\
\hline 127 & 527 & 1.235870 & 0.0003 \\
\hline 227 & 527 & 1.233613 & 0.0003 \\
\hline 327 & 527 & 1.232787 & 0.0004 \\
\hline 527 & 527 & 1.228325 & 0.0004 \\
\hline 627 & 527 & 1.225594 & 0.0003 \\
\hline 927 & 527 & 1.222404 & 0.0004 \\
\hline 1000 & 527 & 1.216069 & 0.0004 \\
\hline 1100 & 527 & 1.214546 & 0.0004 \\
\hline 1200 & 527 & 1.212847 & 0.0004 \\
\hline 1300 & 527 & 1.213055 & 0.0004 \\
\hline 1400 & 527 & 1.209570 & 0.0004 \\
\hline 1500 & 527 & 1.209105 & 0.0004 \\
\hline 1600 & 527 & 1.209685 & 0.0004 \\
\hline 1800 & 527 & 1.205843 & 0.0004 \\
\hline 2000 & 527 & 1.204144 & 0.0004 \\
\hline 2200 & 527 & 1.201434 & 0.0004 \\
\hline
\end{tabular}

The general trend for k-infinity is downward as the fuel temperature increases. This is of course the desired trend that will produce negative Doppler temperature coefficients of reactivity, the average Doppler coefficient over the entire temperature range being approximately $-1.59 \mathrm{pcm} /{ }^{\circ} \mathrm{C}$. Note: the Doppler coefficients would be even more negative if cross section libraries at high temperature had been available for the other actinides (e.g. plutonium isotopes) and fission product resonance absorbers, besides just the two uranium isotopes.

\subsubsection{Axial Power Profile and Enrichment}

Axial power profiles were calculated for each of the fuel rods in the 1/8-assembly model with SiC fuel cladding, water rod duct, and assembly duct material at beginning-of-life conditions. The $\mathrm{UO}_{2}$ fuel was initially assumed to have a uniform 5.0-wt $\%$ U-235 axial enrichment in each fuel rod throughout the assembly. Several individual rod power profiles for the $5.0-\mathrm{wt} \%$ case are shown in Figure 24 . All the curves seem to exhibit a very reasonable beginning-of-life power profile shape, although the curves are not exactly centered about the midplane $(\mathrm{z} / \mathrm{L}=0.5)$. In the model, each fuel rod is divided into ten equallength axial cell volumes and the power in each cell is averaged over the cell's volume, hence the ten axial dots per curve delineation.

The axial peak-to-average is approximately 1.45. Of particular note is the fact that all the fuel rods throughout the assembly exhibit the same axial power profile shape, i.e. rod profiles virtually overlay one 
another. This is indicative of a relatively long thermal neutron mean free path and low neutron absorption within the SiC SCWR fuel assembly lattice.

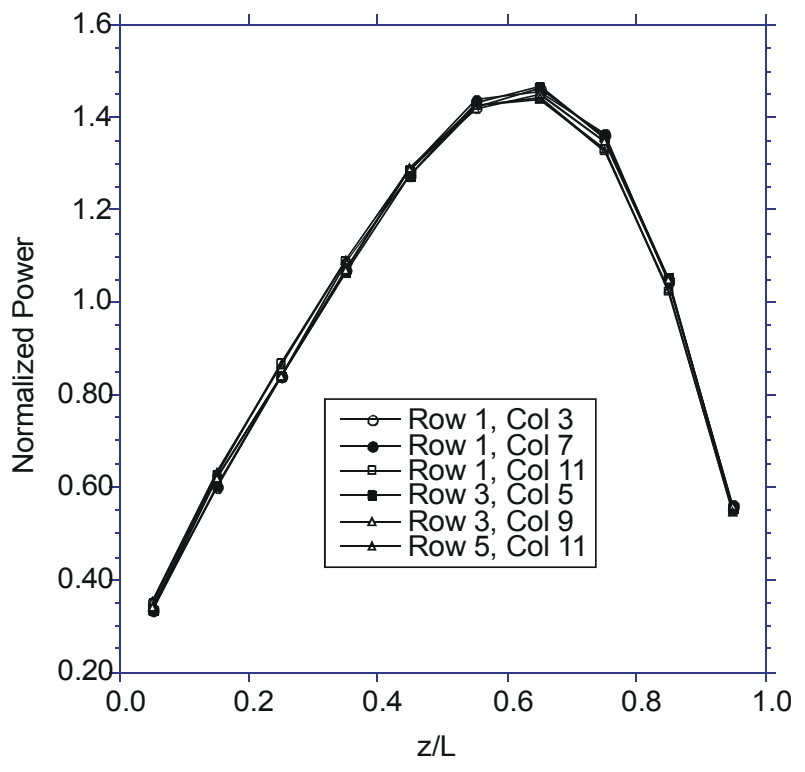

Figure 24. Axial power profile for a uniform 5.0 wt\% axial enrichment.

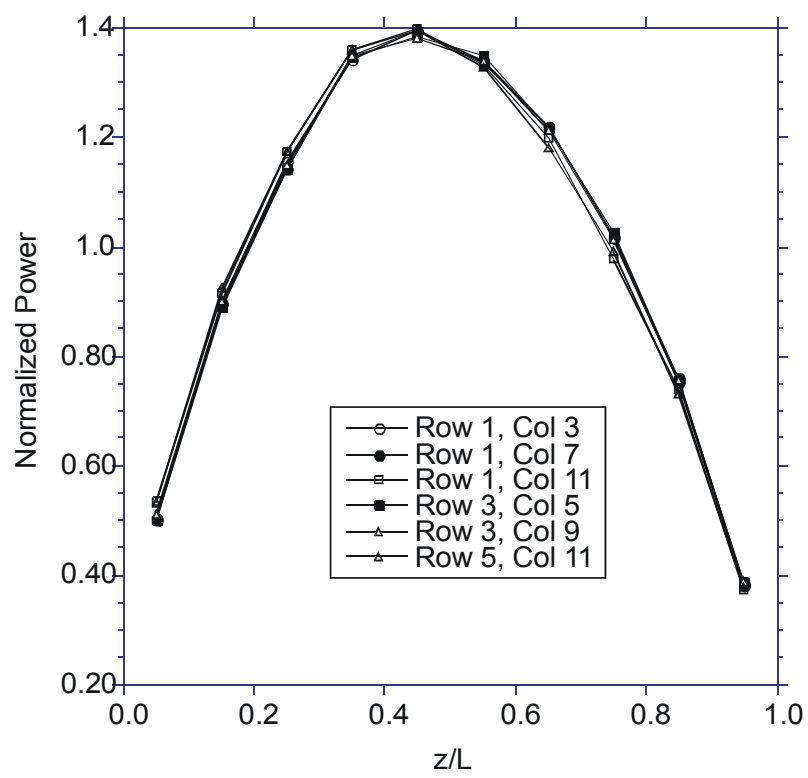

Figure 25. Fuel rod axial power profile for threezone enrichment.

Despite the already reasonable axial power profile with the uniform $5.0 \mathrm{wt} \% \mathrm{U}-235$ enrichment, an attempt was made to center the power peak at the midplane by axial enrichment variation using the relatively coarse 10 axial segments per fuel rod. Results of this study indicate that an enrichment of 5.0\% at the bottom of the active fuel region $(0-170.8-\mathrm{cm}$, or $0.0-0.4 \mathrm{z} / \mathrm{L}), 4.8 \%$ enrichment in the middle $(170.8-298.9-\mathrm{cm}$, or $0.4-0.7 \mathrm{z} / \mathrm{L})$, and $4.7 \%$ enrichment at the top $(298.9-427.0-\mathrm{cm}$, or $0.7-1.0 \mathrm{z} / \mathrm{L})$ produced a slightly flatter axial power profile with a peak-to-average value of 1.4. Figure 25 shows the normalized axial power profile for several fuel rods. This axial enrichment resulted in a 1.00:0.96:0.94 relative zone enrichment ratio and an overall effective rod enrichment of $4.85 \mathrm{wt} \% \mathrm{U}-235$.

Again note that the fuel rods throughout the assembly exhibit the same axial power profile shape, and that the midplane peak is not exactly centered. Movement of the midplane peak was very sensitive to small axial enrichment changes - more on this issue in the depletion section.

\subsubsection{Radial Power Profile and Enrichment}

As in the MA946 study, the goal of the radial fuel rod enrichment study was to try to make the individual fuel rod total thermal powers essentially the same across the fuel assembly. With a uniform fuel rod enrichment, fuel rods near the center of the assembly tend to have higher total powers than those near the assembly periphery and corners. The assembly fuel rod radial power profile was flattened by iteratively scaling the individual fuel rod enrichments up or down. In this manner, radial power peaking of the assembly fuel rods was reduced through selective rod enrichments. As a starting point, an initial $5.0 \mathrm{wt} \%$ U-235 uniform rod enrichment was assumed throughout the SCWR assembly with no axial variation. Based on the calculated rod powers, the U-235 number density in each fuel rod was adjusted in order to flatten the radial power profile. Eight iterations were required to produce a relatively flat radial power profile with the minimum-to-average and peak-to-average confined to 0.96 and 1.03 , with the exception 
of rod 30 at 0.94 . Figures 26 and 27 show the individual assembly fuel rods, the final converged rod enrichments, and their associated peak-to-average relative power values.

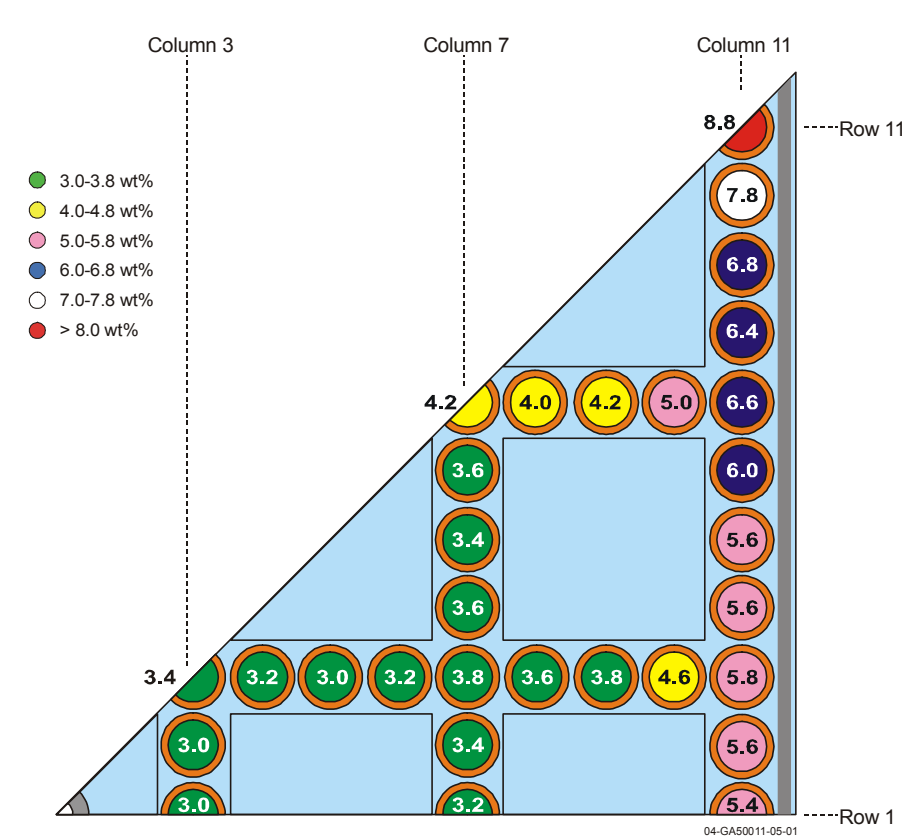

Figure 26. Final converged rod enrichments for the $21 \times 21$ SCWR fuel assembly design with water rods and $\mathrm{SiC}$ cladding and duct materials.

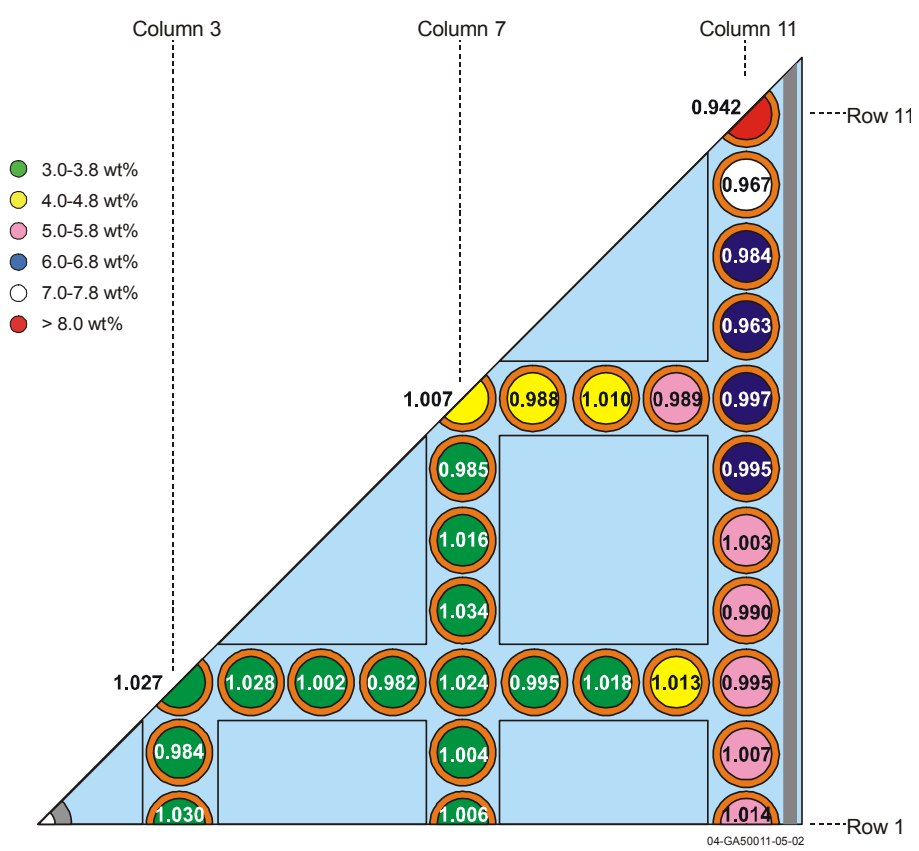

Figure 27. Peak-to-average relative power values for the 21x21 SCWR fuel assembly design with water rods and $\mathrm{SiC}$ cladding and duct materials.

The enrichments span from 3.0 to 8.8 -wt $\%$ U-235 resulting in an overall effective rod enrichment for the SCWR assembly of approximately $4.65 \mathrm{wt} \% \mathrm{U}-235$. Note the relatively large increase in enrichment for those rods on the fuel assembly periphery and those near the assembly corners (in particular, rods in Column 11 and Rows 7-11).

\subsubsection{Conclusions}

We conclude that the $21 \times 21$ SCWR fuel assembly with SiC exhibits many desirable neutronic characteristics; some very similar to the $25 \times 25$ SCWR fuel assembly with MA956, but others, such as burnup, better than the $25 \times 25 \mathrm{SCWR}$ fuel assembly. Use of $\mathrm{SiC} / \mathrm{SiC}$ fuel cladding and $\mathrm{SiC}$ as the water moderator rod and assembly duct material will produce a substantial positive reactivity gain that in turns translates into a potentially higher assembly burnup. Compared to a PWR fuel assembly of comparable uranium enrichment, the SCWR with $\mathrm{SiC}$ appears to be able to also achieve a slightly higher burnup, 41.0 GWD/MTU versus 38.0 GWD/MTU.

In addition, the $\mathrm{SiC}$ fuel assembly lattice exhibits other desirable characteristics which include: (1) negative void reactivity upon loss of coolant and/or water rod water, (2) strong negative Doppler coefficients at beginning-of-life and solid indications that this persists as a function of burnup as well, (3) an under-moderated fuel assembly, and (4) a neutron spectra (discussed in Section 3.1.10) similar to, but slightly softer than both the SCWR with MA956 and a commercial PWR water reactor (due to the higher $\mathrm{H} / \mathrm{U}$ ratio in the case of the SCWR with $\mathrm{SiC}$ ). 
In the case of the SCWR with $\mathrm{SiC}$, the unrodded axial and radial power profiles can be flattened through enrichment variation. For axial power flattening, a three-zone axial enrichment scheme using a relatively tight enrichment range of 4.7-5.0-wt\% U235 would suffice. A three-zone axial enrichment scheme was shown to produce a symmetrical axial power profile with a peak-to-average value of approximately 1.4 for the unrodded condition. It should be noted that the axial enrichment profile was very sensitive to the coolant and water rod water axial density profiles used in the calculations. For radial power flattening, a much broader enrichment range may be required, for example, 3.0 to 8.8 -wt $\%$ U-235. The higher enrichments are required for fuel rods on the periphery and corners of the assembly in order to achieve relatively constant fuel rod powers across the assembly at beginning-of-life. Because of the axial asymmetries inherent in the $21 \times 21$ SCWR fuel assembly (e.g. enrichment, coolant water density, water rod water density), control rod insertion and possibly burnable poisons will most likely be required to hold down excess reactivity in order to control burnup and eliminate any axial power oscillations in the core.

As discussed in Section 3.1.9, an effective assembly enrichment of $4.93 \mathrm{wt} \% \mathrm{U}-235$ in the $21 \times 21$ SCWR assembly with $\mathrm{SiC}$ as the fuel cladding and moderator rod and assembly structural material resulted in a once-through burnup of approximately $41.0 \mathrm{GWD} / \mathrm{MTU}$. A relative burnup of only $31.0 \mathrm{GWD} / \mathrm{MTU}$ is possible in the $25 \times 25$ SCWR assembly with MA956 as the fuel cladding and structural material. Based on the assumed linear heat generation rates, the $25 \times 25$ and the $21 \times 21$ fuel assemblies have comparable power densities, namely, $70.4 \mathrm{~W} / \mathrm{cc}$ and $67.4 \mathrm{~W} / \mathrm{cc}$, respectively.

In addition, for comparison purposes, a standard $17 \times 17$ commercial PWR fuel assembly was also depleted. For an assumed uniform 4.93-wt $\%$ U-235 enrichment, the PWR fuel assembly can achieve a burnup of approximately $38.0 \mathrm{GWD} / \mathrm{MTU}$. Although the SCWR with SiC slightly exceeds the PWR burnup or energy expenditure per unit mass of initial uranium, the PWR fuel assembly operates at a much higher power density, $109.5 \mathrm{~W} / \mathrm{cc}$ versus $67.4 \mathrm{~W} / \mathrm{cc}$, and therefore has a significant advantage over the SCWR fuel assemblies. 


\section{Task 2 Results: Corrosion and Stress Corrosion Cracking Studies (University of Michigan, Prof. Gary Was)}

\subsection{Construction And Operation Of The SCW Autoclave System}

The supercritical water loop was fabricated in the High Temperature Corrosion Laboratory of the University of Michigan. The loop was constructed and performance tested in the first year of the program according to the design points described in Table 20. A schematic of the loop is shown in Figure 28 and a photograph of the completed system is shown in Figure 29. Water is stored in a column with the amount of water controlled by addition of gas to the column. An ion exchanger is used to control the conductivity. The oxygen content is read at the exit of the column and on the inlet line. The conductivity is read at room temperature both in the inlet and the outlet line. The water flows to an autoclave in which constant extension rate tensile (CERT) tests and U-bend or exposure tests can be performed at temperatures up to $550^{\circ} \mathrm{C}$ and under a pressure of up to $34.5 \mathrm{MPa}$. The temperature is read in the vessel and the pressure is read at room temperature in the inlet and outlet lines.

Table 20. Design and operating limits for the SCW loop in the High Temperature Corrosion Laboratory of the University of Michigan.

\begin{tabular}{|l|l|l|l|}
\hline Parameter & Design limit or range & Typical operating range & Variability \\
\hline Temperature & $550^{\circ} \mathrm{C}$ & $400-500{ }^{\circ} \mathrm{C}$ & $\pm 2{ }^{\circ} \mathrm{C}$ \\
\hline Pressure & $34.5 \mathrm{MPa}$ & $25.5 \mathrm{MPa}$ & $\pm 0.2 \mathrm{MPa}$ \\
\hline Strain rate & $1 \times 10^{-8}$ to $1 \times 10^{-5} \mathrm{~s}^{-1}$ & $1-5 \times 10^{-1} \mathrm{~s}^{-1}$ & $\mathrm{NA}$ \\
\hline Load & $5000 \mathrm{lb}$ & $1000 \mathrm{lb}$ & $1 \%$ \\
\hline Flow rate & $<100 \mathrm{ml} / \mathrm{min}$ & $10-30 \mathrm{ml} / \mathrm{min}$ & $\mathrm{NA}$ \\
\hline Oxygen content & $<10 \mathrm{ppb}$ to $20 \mathrm{ppm}$ & $10-100 \mathrm{ppb}$ & $1 \mathrm{ppb}$ \\
\hline Conductivity & $0.07 \mu \mathrm{S} / \mathrm{cm}$ & $0.1-0.2 \mu \mathrm{S} / \mathrm{cm}$ & $.01 \mu \mathrm{S}$ \\
\hline \# SCC samples & 1 & 1 & $\mathrm{NA}$ \\
\hline \# Corrosion samples & 8 & 8 & $\mathrm{NA}$ \\
\hline
\end{tabular}

\subsubsection{Water Chemistry Control}

Water chemistry control includes the control of conductivity, $\mathrm{pH}$, dissolved oxygen content, and the concentration of specific chemicals. The chemistry is controlled in the glass columns. First, the auxiliary column is filled with distilled water from a pure water reservoir. Chemicals required for a test are added to the water in the auxiliary column. After the desired water chemistry is achieved, the feedwater is supplied to the main column. Gas cylinders containing argon, nitrogen, or hydrogen, are connected to both the auxiliary and main columns. Purging with a gas controls the amount of dissolved oxygen in the water. Water travels from the main column to the main pump and into the test vessel and then back to the main column, establishing a water loop. The main pump controls the flow rate of circulating water. Water from the test vessel passes the filter and ion exchanger where corrosion products or any undesired contaminant are removed. The conductivity and dissolved oxygen content are monitored during tests at the inlet and outlet of the test vessel. The $\mathrm{pH}$ of the water is periodically sampled from the drain line of the main column. 


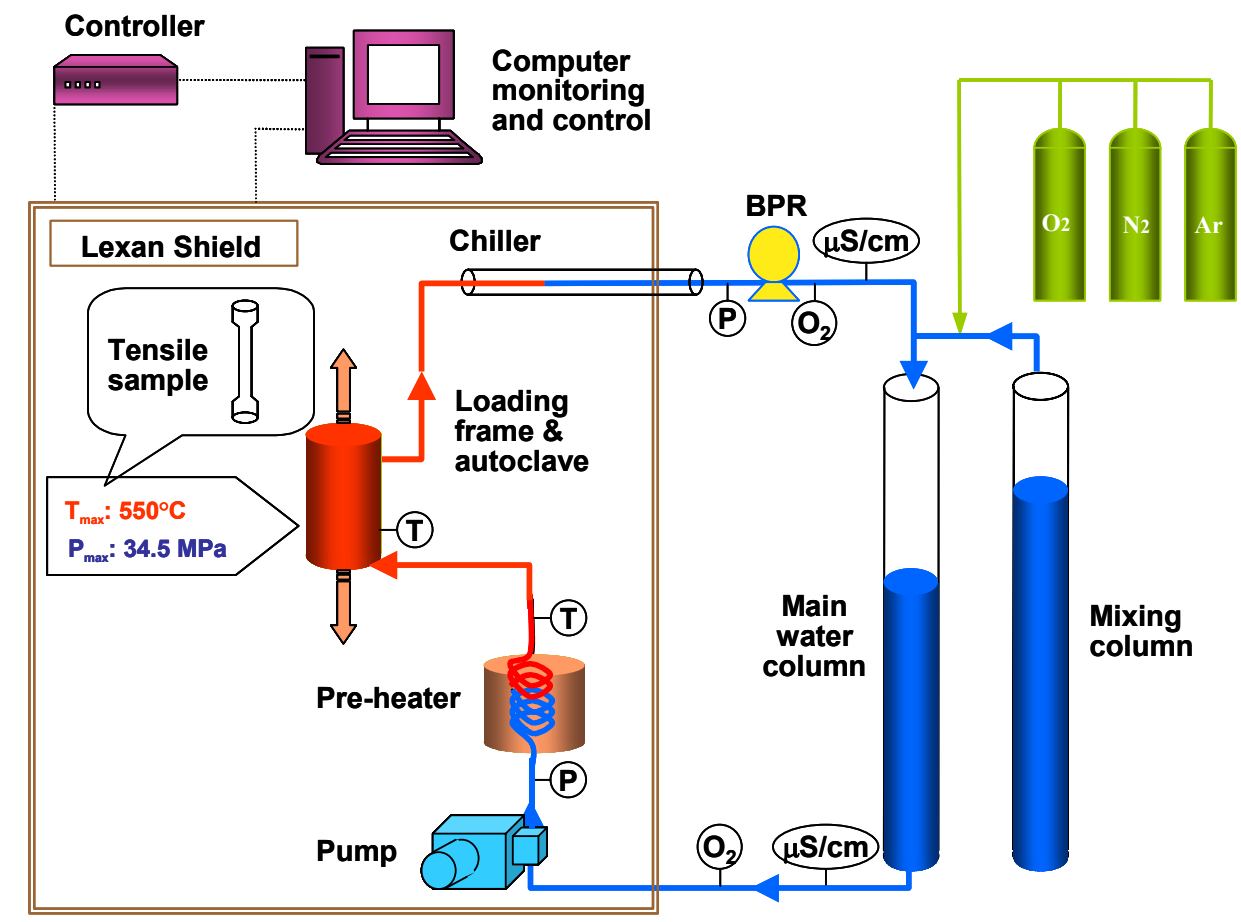

Figure 28. Schematic diagram of the SCW loop in the High Temperature Corrosion Laboratory at the University of Michigan.

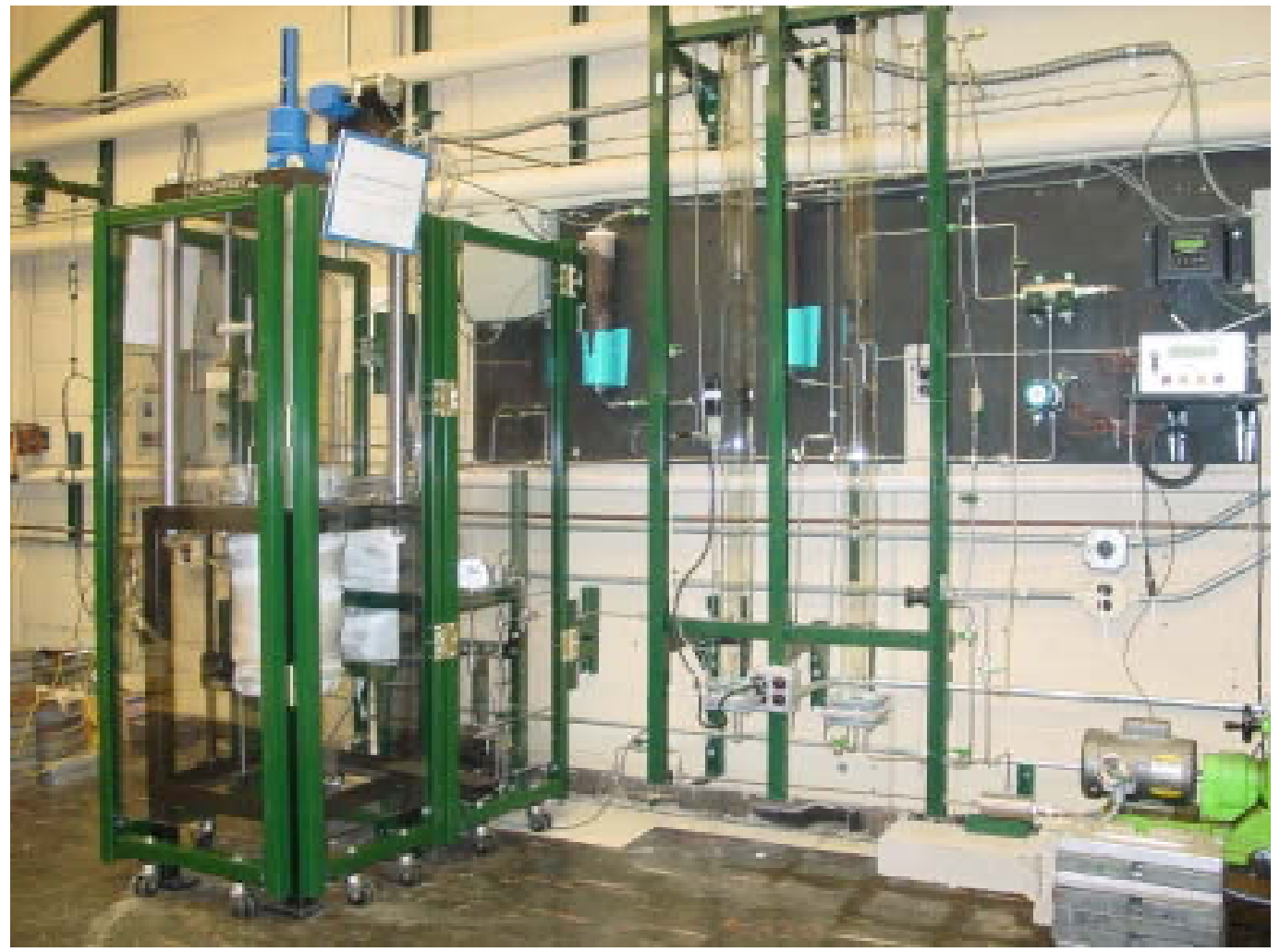

Figure 29. Photograph of the SCW loop. 


\subsubsection{Supercritical Water Condition}

The state of water is determined by the temperature and pressure. Water circulated by the main pump is pressurized via a "back-pressure regulator". A small pin in the backpressure regulator controls the amount of water flowing out of the regulator, thereby maintaining a constant pressure. The control of pressure is achieved by rotating the handle on the regulator and checking the pressure indicated by the pressure gauge. The water is heated to a certain temperature by the radiant pre-heater before it flows into the vessel and where it is heated up to the desired temperature by the main ceramic heater. The water flowing out of the vessel is cooled in the double tube chiller. The pressure and temperature in the vessel are monitored during tests and recorded by the pressure transducer connected to the tubing of the pump outlet and thermo-couple secured inside of the vessel.

\subsubsection{Mechanical Loading}

Once the environmental conditions, water chemistry, pressure, and temperature are achieved, a load can be placed on the tensile sample. Mechanical loading is achieved using a stepper motor attached to a load frame. A tensile sample is connected to the motor through a pull rod, on which a linear voltage displacement transducer (LVDT) and a load cell are installed to monitor the amount of strain and load on a sample. The loading mode can be programmed using LabView software connected to a motion controller. The motion controller controls the motor function using the input values of strain and load and the programmed loading mode. The rotation of the motor determines the displacement of the pull rod that determines the mechanical condition of a sample.

One unique feature of this system is that a pressure balance system is attached to the top of the test vessel. When water in the vessel is pressurized, the pressure pushes the pull rod outward, which results in undesired pre-straining of a sample. The high pressure of a supercritical water system will impose a load on the sample high enough to cause plastic deformation. The pressure balance system maintains the strain (displacement) of a sample constant without regard to water pressure before loading.

\subsubsection{Safety Features}

Since the loop system is operated at high temperature and pressure, safety features are required. There are two safety features on the high-pressure section of the apparatus between the pump and backpressure regulator, a safety valve and rupture disc. The safety valve is located just after the pump and is designed to open automatically when the water pressure increases beyond a set value. At this set value, the pump also turns off, preventing further pressurization. The disc is designed to endure the design pressure and rupture at higher pressures.

\subsection{Performance Test Of The SCW System}

Because this is the first such system built, the performance of the SCW system will be described in some detail. Test conditions $\left(25.5 \mathrm{MPa}(3700 \mathrm{psig}), 550{ }^{\circ} \mathrm{C}\right)$ were reached and maintain for a period of 20 hours for the first time on June 14, 2002. Figure 30 shows the temperature and pressure history for the performance test. The first graph shows that the temperature was quite stable with a variation of around $\pm 2{ }^{\circ} \mathrm{C}$. The second graph shows the pressure variation during the increase in temperature to the set point of $550^{\circ} \mathrm{C}$. The pressure varied by around $0.7 \mathrm{MPa}(100 \mathrm{psig})$ during the temperature rise. Once the temperature had stabilized, the variation of pressure was reduced to only about $\pm 0.14 \mathrm{MPa}(20 \mathrm{psig})$. 


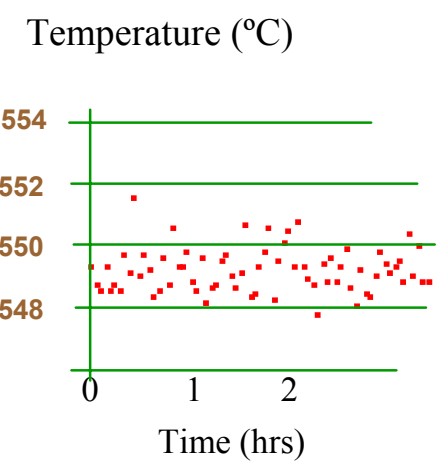

Temperature variation at constant pressure.

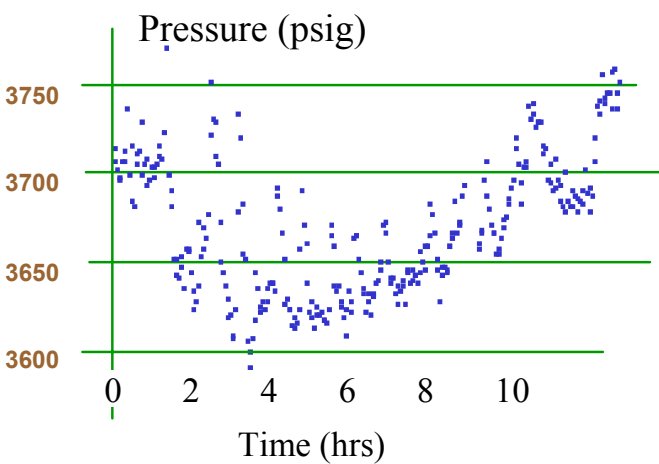

Evolution of the pressure during the temperature increase (before test conditions were achieved).

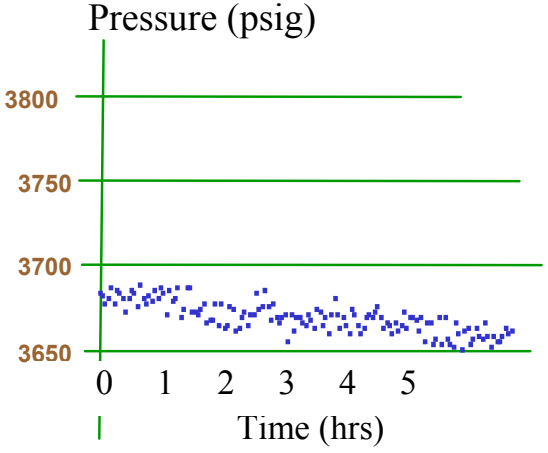

Evolution of the pressure when the temperature is stable.

\section{Figure 30. Performance test at $550^{\circ} \mathrm{C}$ and $25.5 \mathrm{MPa}(3700 \mathrm{psi})$.}

A dummy sample was strained in supercritical water $\left(25.5 \mathrm{MPa}, 550{ }^{\circ} \mathrm{C}\right)$ to about $6 \%$ strain in our test apparatus. On the load versus time curve shown in Figure 31, the load cell records an increase of load whereas the pull rod doesn't move until a load of 80 $\mathrm{lbs}$ is reached. Then the load drops before increasing again. This behavior during the period of elastic deformation is probably due to friction between the bal seals and the pull rod. When the sample is strained in the SCW test apparatus, the load recorded by the load cell is less stable ( \pm 15 lbs of variation) than it was during a test performed in air at $20^{\circ} \mathrm{C}$ and $0 \mathrm{MPa}(0 \mathrm{psig})$. In order to capture the actual stress-strain behavior, a series of tests were performed to determine the relationship

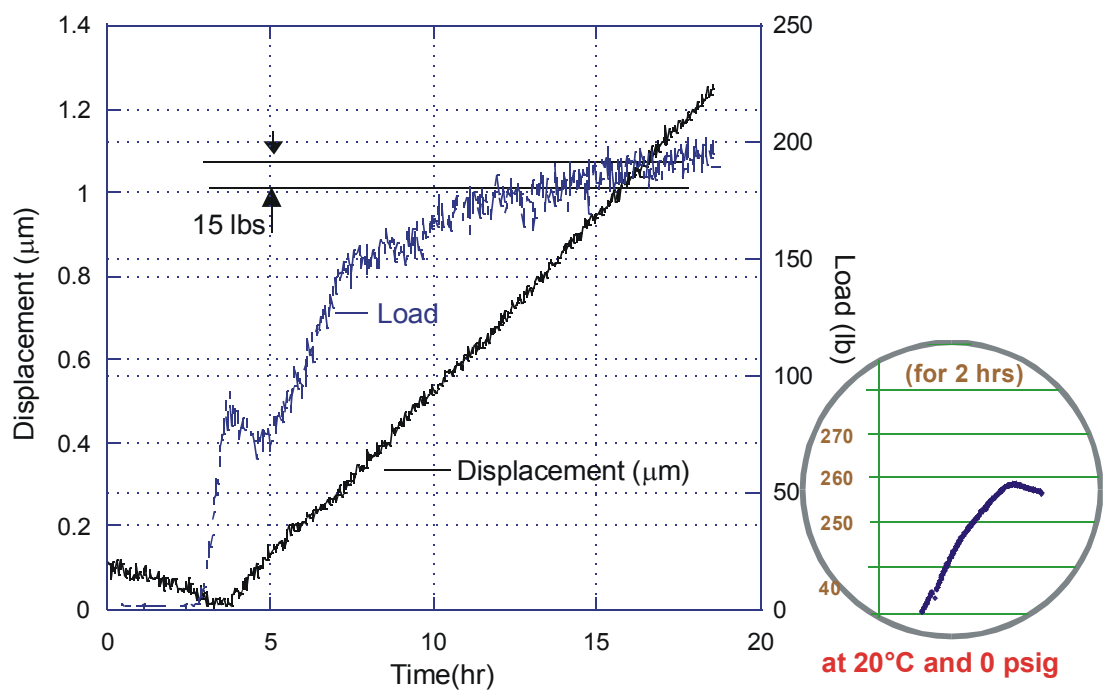

Figure 31. Load and displacement versus time obtained with a dummy sample at test conditions of $25.5 \mathrm{Mpa}$ and $550{ }^{\circ} \mathrm{C}$. The inset shows the load versus time taken from a sample strained in air at $20^{\circ} \mathrm{C}$. between the pressure and recorded load.

To determine if either the variation of pressure during a test (in supercritical water) or the increase of pressure at the beginning of the test can have any effect on the load and extension of the sample, several tests were performed. As shown in Figure 32, there is no correlation between a pressure change of around 1.4 $\mathrm{MPa}(200 \mathrm{psig})$ and the specimen load (within about plus or minus15 lbs). 
At room temperature, pressure changes were observed to affect load and displacement. Figure 33 plots the response of the specimen load and displacement to a pressure change at room temperature. To be able to read the response of the load during the test, the initial load was set as $240 \mathrm{lb}$. First the pressure was increased from 0 to 2000 psig in 2 steps of 1000 psig each. Then the pressure was dropped to zero in the same step-wise manner. Each pressure change resulted in a change in the sample load and displacement. An increase of pressure causes a decrease in load, and vice-versa. This behavior is somewhat puzzling since with a pressure balance system, the load should be insensitive to changes in pressure as in the supercritical condition shown in Figure 32.

The response of the sample displacement is also not well understood. Some unanticipated behavior, such as a drop in displacement related to a drop of load (A), or an increase in displacement related to an increase of load (B) was recorded. The effects of these results on the actual behavior on the sample is still not clear, but as the peculiar behavior takes place while the sample was being strained elastically, they are not expected to adversely affect a constant extension rate experiment that is typically taken to several tens of percent plastic strain.

Figure 34 shows the effect of pressure changes on the measured load at room temperature, when pressure was increased from $0 \mathrm{MPa}$ to $25.5 \mathrm{MPa}$

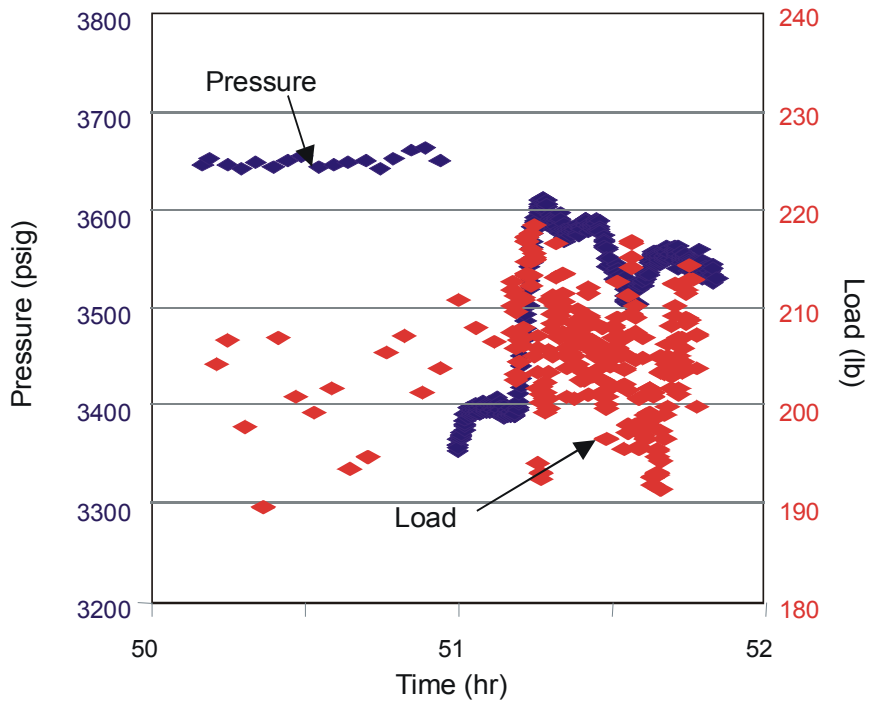

Figure 32. Response of load to a change in pressure at supercritical water condition $\left(25.5 \mathrm{MPa}, 5^{\circ}{ }^{\circ} \mathrm{C}\right)$.

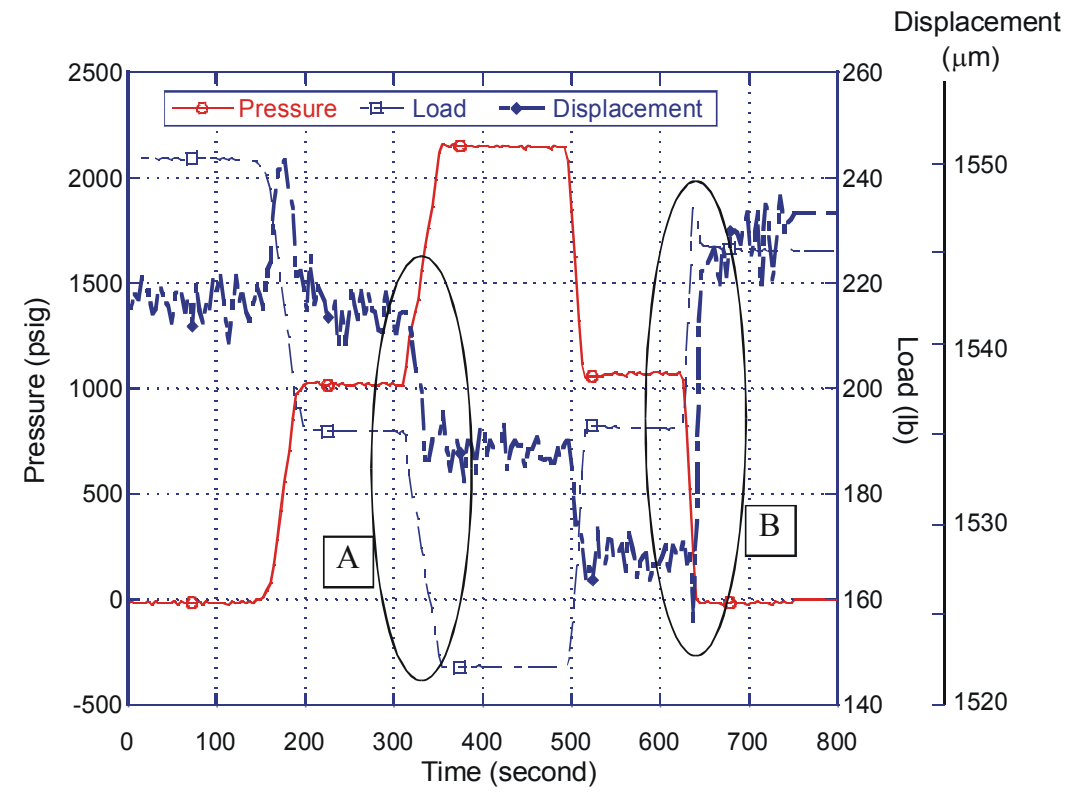

Figure 33. Response of load and displacement to a change in pressure at room temperature. Each change of pressure causes an opposite reaction to the load. Some responses of the displacement (A, B) are still unclear.

(3700 psig). The graph shows that the displacement changed by about $30 \mu \mathrm{m}$. Such a small displacement should not impact the sample strain, particularly if there is play in the load-train.

The general shape of the load versus time plot recorded during a straining test performed in our facility is plotted in Figure 35. This shape can be divided into 3 regimes. In the first, the load reaches the maximum static friction due to the bal seals on the pull rod. When the load exceeds the static friction force, the rod starts to move (Regime 2). As there is some play in the load-train, the load doesn't increase immediately because the only force on the load cell is due to the dynamic friction of the bal seals on the 
rod. In the $3^{\text {rd }}$ regime, the entire pull rod line is tight and the sample is strained. So, when a sample is strained, the recorded load includes the contribution of dynamic friction.

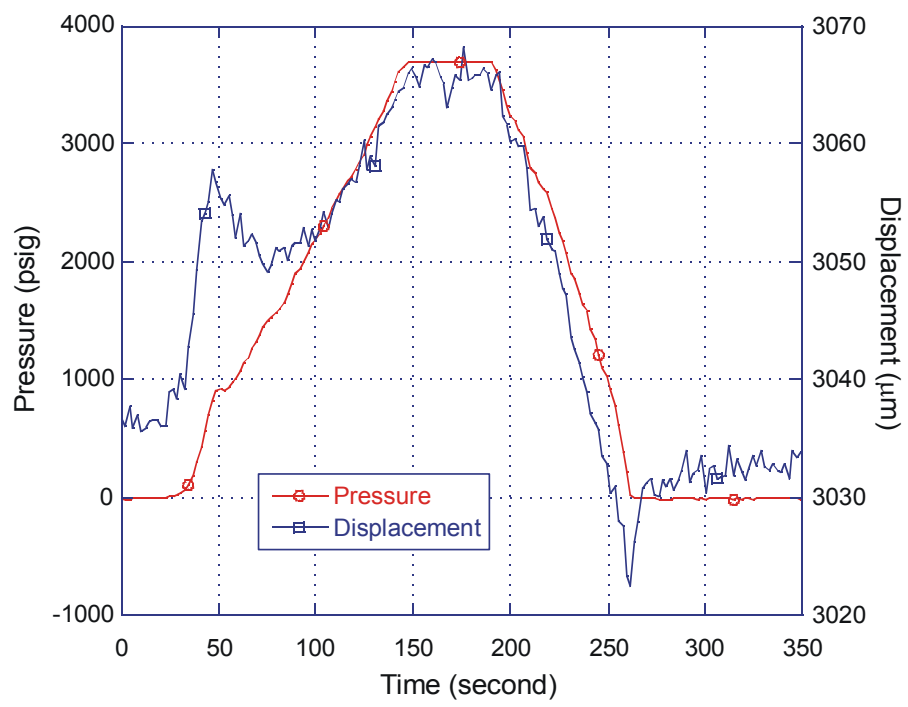

Figure 34. Change in displacement during an increase in pressure at room temperature.

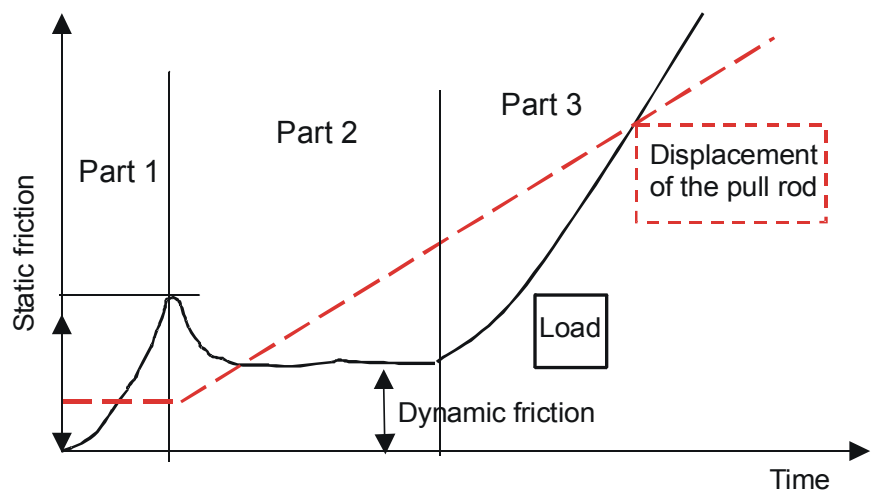

Figure 35. General shape of load versus time and displacement versus time curves obtained in our facility.
To determine the friction force, a sample of 316-steel was strained to just above the yield stress at room temperature in air and in highpressure (25.5 MPa) water, Figure 36. Curve A, taken from the test performed in air, shows that the load reaches $12 \mathrm{lbs}$ before it decreases somewhat and then maintains a steady value for 2000 seconds until the sample begins to strain. This test allowed us to determine that the friction on the pull rod is around $12 \mathrm{lbs}$ at $0 \mathrm{MPa}$. If this factor is taken into account, the yield stress of the sample becomes $225 \mathrm{MPa}$, which is in agreement with the value given by the supplier (220 MPa).

Curve B, taken from the test performed at 25.5 $\mathrm{MPa}$, shows that the static friction in the system is $77 \mathrm{lbs}$ and the dynamic friction is 33 lbs. This data allows us to determine the true load and lengthening of the sample from the recorded data.

After the test, the sample was removed and the plastic deformation was determined by measuring the length change of the sample. The measured elongation was $90 \pm 25 \mu \mathrm{m}$. The displacement recorded by the LVDT during the test was $110 \mu \mathrm{m}$. This value is within the error range of

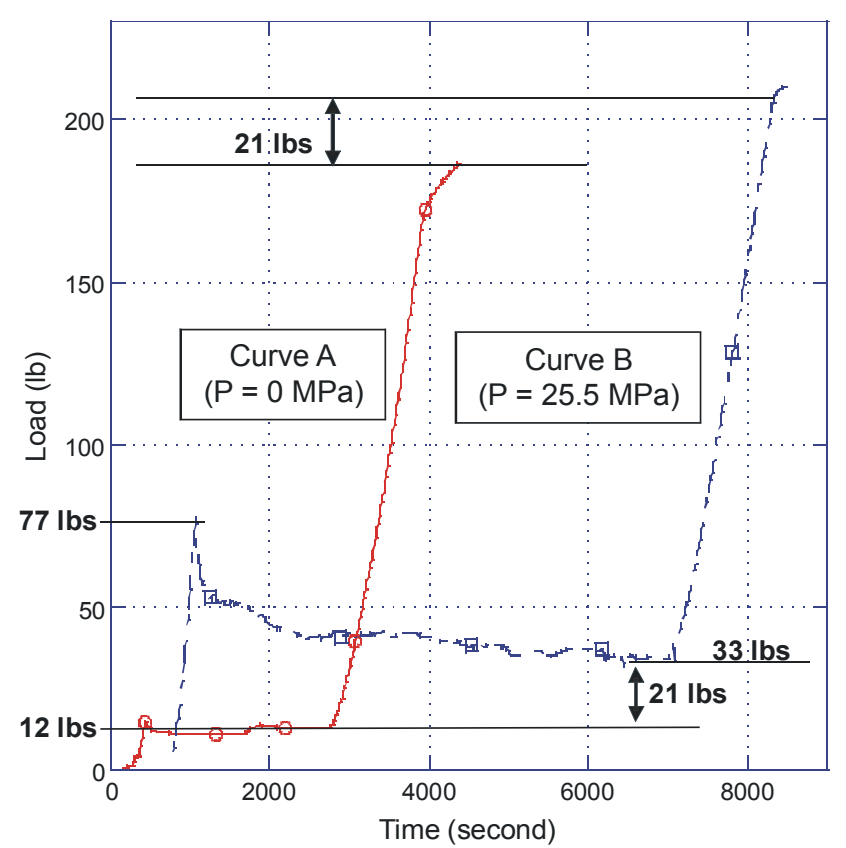

Figure 36. Load versus time curves of a sample strained in air (0 MPa) and then in high-pressure (25.5 MPa) water. The increase in pressure directly affects the load recorded by the load cell through its effect on the dynamic friction. 
the sample elongation measured directly on the sample after the test and as such, the two readings are reasonably consistent.

\subsection{Alloy Selection}

Based on literature and previous experience, various alloys for SCWRs were considered and candidate alloys for testing were determined. In making our selection, application history to fossil plants, alloy limitations, properties of alloys, and considerations for potential application to nuclear plants were considered. The alloys reviewed are listed in Table 21 and the chemical compositions of the alloys are shown in Table 22. In Table 21, the alloys shown in bold letters were selected as the highest priority candidate alloys.

Table 21. Candidate alloys for supercritical water reactor core materials application

\begin{tabular}{|c|c|c|c|}
\hline Class & Alloy & $\begin{array}{l}\text { Application } \\
\text { History }\end{array}$ & Remarks \\
\hline \multirow[t]{2}{*}{$\begin{array}{l}\text { Austenitic stainless } \\
\text { steel }\end{array}$} & 304L SS & $\begin{array}{l}\text { - Reactor internals in } \\
\text { LWRs }\end{array}$ & \multirow{2}{*}{$\begin{array}{l}\text { - Good general corrosion } \\
\text { resistance and moderated strength } \\
\text { through the } 400-500^{\circ} \mathrm{C} \text { range. } \\
\text { - Loss of strength at the upper end } \\
\text { of the range, localized corrosion } \\
\text { (intergranular SCC) in oxidizing } \\
\text { conditions and susceptibility to } \\
\text { radiation-induced swelling in the } \\
400-600^{\circ} \mathrm{C} \text { range. }\end{array}$} \\
\hline & 316L SS & $\begin{array}{l}\text { - Reactor internals in } \\
\text { LWRs } \\
\text { - Cladding in liquid } \\
\text { metal fast breeder } \\
\text { reactors }\end{array}$ & \\
\hline \multirow[t]{2}{*}{$\begin{array}{l}\text { Solid solution Ni-base } \\
\text { austenitic alloy }\end{array}$} & Alloy 600 & \multirow[t]{2}{*}{$\begin{array}{l}\text { - Steam generator } \\
\text { tubing in PWRs }\end{array}$} & $\begin{array}{l}\text { - Susceptible to intergranular SCC } \\
\text { in PWR conditions. }\end{array}$ \\
\hline & Alloy 690 & & $\begin{array}{l}\text { - Less susceptible to IGSCC than } \\
\text { alloy } 600 .\end{array}$ \\
\hline \multirow[t]{2}{*}{$\begin{array}{l}\text { Precipitation hardened } \\
\text { Ni-base alloy }\end{array}$} & Alloy 625 & $\begin{array}{l}\text { - Reactor-core and } \\
\text { control rod } \\
\text { components in LWRs }\end{array}$ & $\begin{array}{l}\text { - Can be hardened by } \gamma^{\prime \prime} \text { phase }\left[\mathrm{Ni}_{3}\right. \\
(\mathrm{Nb}, \mathrm{Al}, \mathrm{Ti})] \text { precipitated by aging. } \\
\text { - Higher strength up to about } 700 \\
{ }^{\circ} \mathrm{C} \text { than solid solution Ni-base } \\
\text { alloys. }\end{array}$ \\
\hline & Alloy 718 & $\begin{array}{l}\text { - Reactor core } \\
\text { internals in LWRs }\end{array}$ & $\begin{array}{l}\text { - Hardened by } \gamma^{\prime}\left[\mathrm{Ni}_{3}(\mathrm{Nb})\right] \text { and } \gamma^{\prime \prime} \\
{\left[\mathrm{Ni}_{3}(\mathrm{Nb}, \mathrm{Al}, \mathrm{Ti})\right] \text { precipitates. }} \\
- \text { Higher strength up to about } 700 \\
{ }^{\circ} \mathrm{C} \text { than solid solution Ni-base } \\
\text { alloys. }\end{array}$ \\
\hline \multirow{3}{*}{$\begin{array}{l}\text { Ferritic/martensitic } \\
\text { steels }\end{array}$} & HT-9 & \multirow{3}{*}{$\begin{array}{l}\text { - Structural } \\
\text { applications in } \\
\text { supercritical power } \\
\text { plants }\end{array}$} & \multirow{3}{*}{$\begin{array}{l}\text { - Lower coefficient of thermal } \\
\text { expansion and higher thermal } \\
\text { conductivity than austenitic steels. } \\
\text { - High swelling resistance in fast } \\
\text { neutron, ion, and electron } \\
\text { irradiation conditions. }\end{array}$} \\
\hline & T-91 & & \\
\hline & HCM12A & & \\
\hline
\end{tabular}


Table 22. Nominal composition of candidate alloys

\begin{tabular}{|c|c|c|c|c|c|c|c|c|c|c|c|c|c|c|}
\hline Alloy & $\mathrm{Cr}$ & $\mathrm{Ni}$ & $\mathrm{Fe}$ & C & Mo & $\mathrm{Cu}$ & $\mathbf{W}$ & $\mathbf{N b}$ & Al & $\mathrm{Ti}$ & Mn & $\mathbf{S i}$ & $\mathbf{V}$ & N/B \\
\hline \multicolumn{15}{|c|}{ Austenitic stainless steels } \\
\hline 304 SS & $\begin{array}{c}18- \\
20\end{array}$ & $8-11$ & Bal. & 0.08 & & & & & & & & & & \\
\hline 316 SS & $\begin{array}{c}16- \\
18\end{array}$ & $\begin{array}{c}11- \\
14\end{array}$ & Bal. & $\begin{array}{l}0.08 \\
\max \end{array}$ & $\begin{array}{c}2.0 \\
- \\
3.0\end{array}$ & & & & & & & & & \\
\hline \multicolumn{15}{|c|}{ Solid solution nickel-base alloys } \\
\hline Alloy 600 & 15.5 & 76 & 8.0 & 0.08 & & & & & & & 0.5 & 0.2 & & \\
\hline Alloy 690 & 30 & 60 & 9.5 & 0.03 & & & & & & & & & & \\
\hline \multicolumn{15}{|c|}{ Precipitation hardened nickel-base alloys } \\
\hline Alloy 625 & 21.5 & 61 & 2.5 & 0.05 & 9.0 & & & 3.6 & 0.2 & 0.2 & 0.2 & 0.2 & & \\
\hline Alloy 718 & 19.0 & 52.5 & 18.5 & 0.04 & 3.0 & & & 5.1 & 0.5 & 0.9 & 0.2 & 0.2 & & \\
\hline \multicolumn{15}{|c|}{ Ferritic-martensitic alloys } \\
\hline HT-9 & 12 & 0.5 & Bal. & 0.20 & 1.0 & & 0.5 & & & & 0.6 & 0.4 & 0.25 & \\
\hline T-91 & 9 & & Bal. & 0.10 & 1.0 & & & 0.08 & & & $\begin{array}{c}0.4 \\
5\end{array}$ & 0.4 & 0.20 & $0.05 \mathrm{~N}$ \\
\hline HCM12A & 12 & & Bal. & 0.11 & 0.4 & 1.0 & 2.0 & 0.05 & & & 0.6 & 0.1 & & $\begin{array}{l}0.06 \mathrm{~N} / \\
0.003 \mathrm{~B}\end{array}$ \\
\hline
\end{tabular}

\subsection{SCC And Corrosion In The Temperature Range $400-550^{\circ} \mathrm{C}$ in Deaerated SCW}

The austenitic alloys are expected to operate in a SCWR in relatively deaerated coolant, as this is likely to be the least aggressive environment for SCWR materials. Therefore, the alloys were first tested in deaerated coolant over a range of temperatures from $400^{\circ} \mathrm{C}$ to $550^{\circ} \mathrm{C}$, spanning the applicable range of SCWR operation up to the temperature limit of our system. The experiments were generally stopped when the sample failed. However, the coolant conditions in a SCWR may not be fully deaerated water due to radiolysis. So, following testing in deaerated SCW, tests in aerated SCW were conducted at the maximum temperature of $550^{\circ} \mathrm{C}$ to get a first look at the magnitude of the effect of oxygen on the corrosion and SCC of our specimens.

The ferritic-martensitic alloys will also likely perform best in a low oxygen environment. However, there is data from fossil plant operation to suggest that there is an optimum concentration of oxygen between 50 and $150 \mathrm{ppb}$ that results in a more stable oxide film and slower oxidation rates than the deaerated condition. Very high oxygen levels are known to produce high oxidation rates. Therefore, a comparative set of experiments were conducted on the ferritic-martensitic alloys in deaerated SCW vs. SCW containing $100 \mathrm{ppb}$ oxygen to assess the effect of small amounts of oxygen on oxidation. For the ferriticmartensitic alloys, oxidation rather than SCC is expected to be the critical performance variable.

Following this logic, Section 4.4.1 presents the results on austenitic alloys in deaerated SCW, followed by the effect of oxygen on austenitic alloy performance in $550^{\circ} \mathrm{C} \mathrm{SCW}$ (Section 4.4.2), and lastly, the role of low oxygen concentration in ferritic-martensitic is evaluated in Section 4.4.3.

Finally, during the project, a second SCW test facility was constructed and completed primarily for an INERI program. This system was similar to the system described earlier with the following exceptions: It had a larger vessel (by factor of 4), it did not use the pressure balance concept for the pull rods, it has a temperature limit of $600^{\circ} \mathrm{C}$, and most importantly, it was built to strain 4 samples simultaneously. Some of the data presented below was collected in the new multi-sample system in addition to the single-sample system. 


\subsubsection{Stress Corrosion Cracking Data}

Stress corrosion cracking susceptibility was determined by measuring the extent of cracking on the fracture surface, the gage surface, and on cross-sections of the tensile bars following constant extension rate tests at a nominal strain rate of $3 \times 10^{-7} \mathrm{~s}^{-1}$. Cracking propensity was determined for all four alloys at 400,500 , and $550{ }^{\circ} \mathrm{C}$. Only alloy 690 was strained in $450{ }^{\circ} \mathrm{C} \mathrm{SCW}$ water because this experiment was done in parallel with the $400{ }^{\circ} \mathrm{C}$ test but in the single-sample system. Since only one alloy could be tested, Alloy 690 was selected because it is the one that has shown the least SCC susceptibility in the three other conditions. In this way, both the effect of alloy and temperature on SCC propensity could be determined. Each of the stainless steel and nickel base alloys had corrosion coupons exposed at all temperatures. Stress-strain curves obtained at each temperature are presented in Figures 37 through 40.

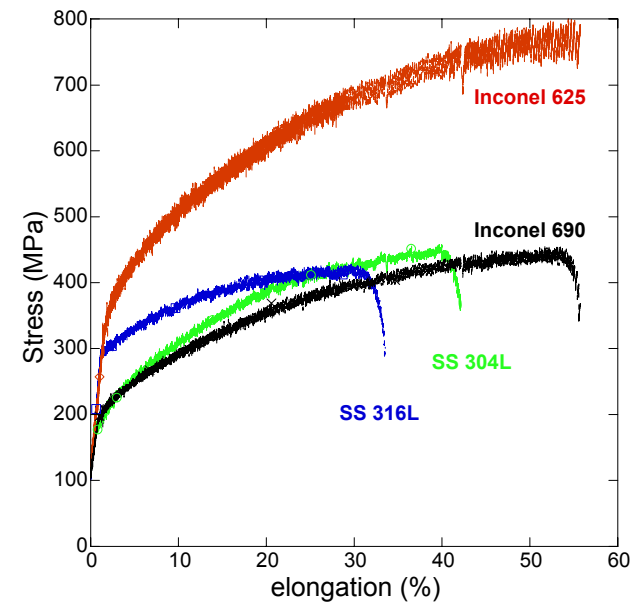

Figure 37. Stress-strain curves obtained for the austenitic alloys in deaerated $\mathrm{SCW}$ at $400^{\circ} \mathrm{C}$.

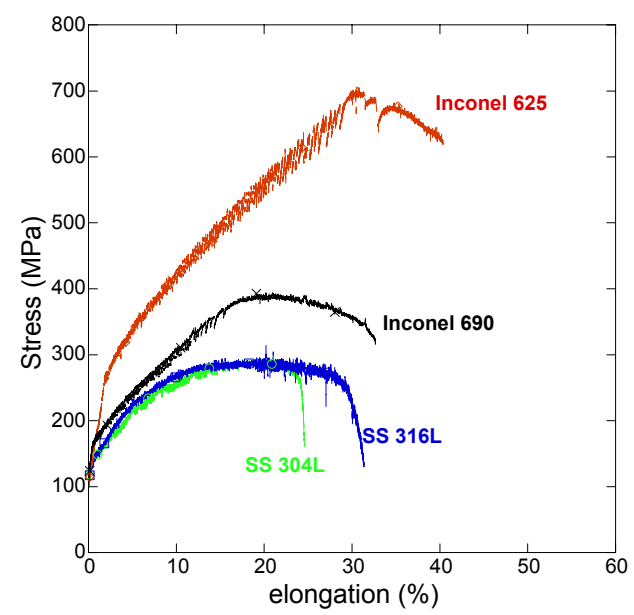

Figure 39. Stress-strain curves obtained for the austenitic alloys in deaerated $\mathrm{SCW} 550{ }^{\circ} \mathrm{C}$.

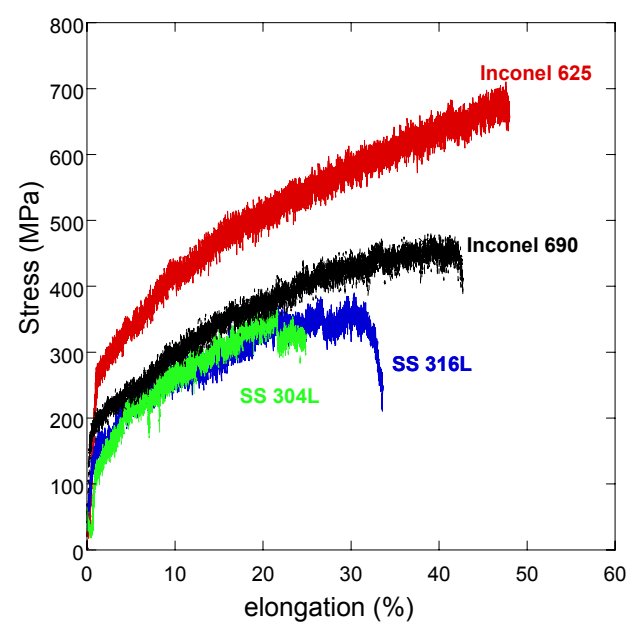

Figure 38. Stress-strain curves obtained for the austenitic alloys in deaerated $\mathrm{SCW}$ at $500^{\circ} \mathrm{C}$.

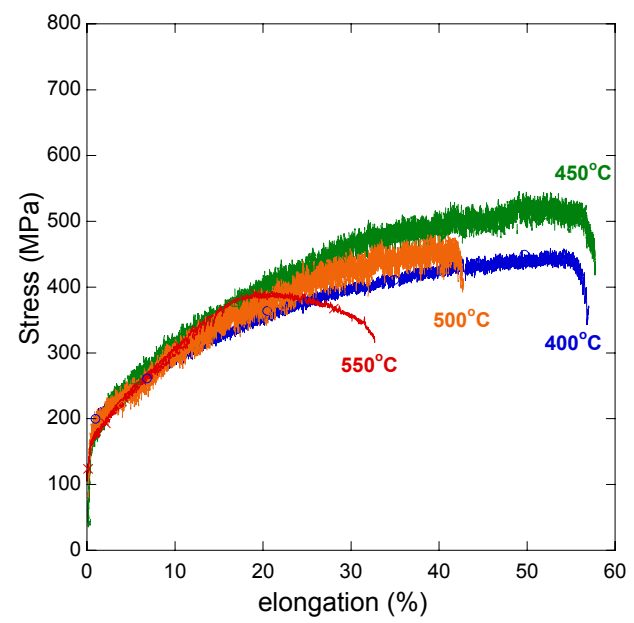

Figure 40. Stress-strain curves obtained for alloy 690 at all four temperatures.

The relative behaviors are similar at all temperatures with the elongation and maximum stress decreasing with increasing temperature. Alloy 625 is the strongest at all temperatures and Alloy 690 is slightly stronger than the stainless alloys, which show very similar behavior. The yield stress for Alloy 316L at 
$400{ }^{\circ} \mathrm{C}$ is higher than expected because this sample was accidentally plastically strained during loading. So this result is considered an anomaly.

The fracture mode of all the fracture surfaces at 400 and $450{ }^{\circ} \mathrm{C}$ is ductile. The fracture surface does not show any intergranular cracking. At $500{ }^{\circ} \mathrm{C}$, intergranular fracture of the failure surface is observed in Alloy 625 . At $550^{\circ} \mathrm{C}$, the fracture surfaces were badly oxidized, obscuring the mode of failure. Figure 41 shows the fracture surfaces for the $500^{\circ} \mathrm{C}$ tests. Intergranular cracking is evident in the $304 \mathrm{~L}$ and 625 fracture surfaces and there is an indication of intergranular cracking on the Alloy 690 fracture surface as well. There was no evidence of intergranular cracking on the fracture surface of the $316 \mathrm{~L}$ sample. Figure 42 shows the cracking on the gage surface of one of the alloys, 625, as a function of temperature between $400^{\circ} \mathrm{C}$ and $550^{\circ} \mathrm{C}$. Note that cracking is noticeably intergranular and the crack density is very high.
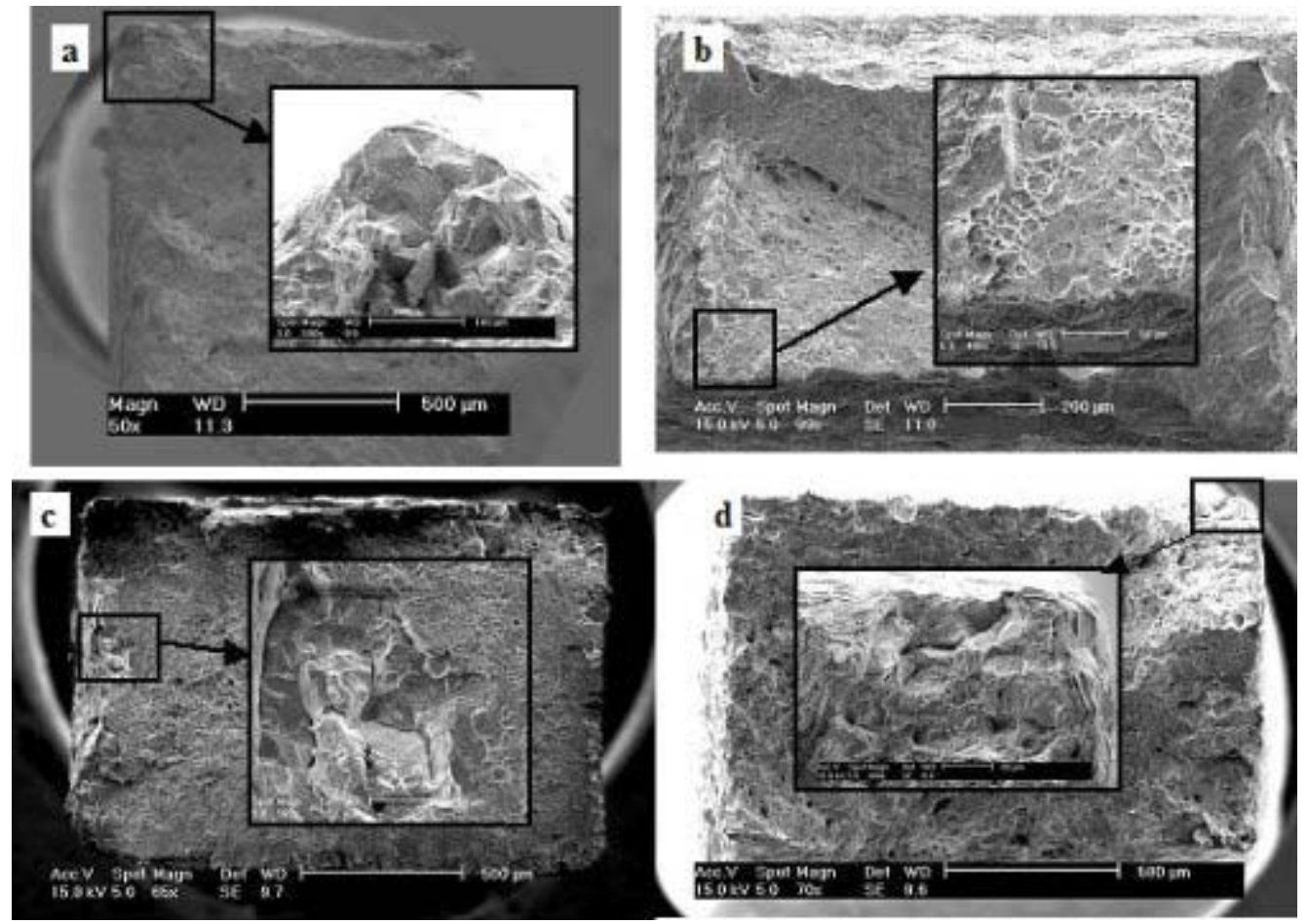

Figure 41. Fracture surfaces of samples; a) $304 \mathrm{~L}$ in $550{ }^{\circ} \mathrm{C}$, non-deaerated $\mathrm{SCW}$, and b) $316 \mathrm{~L}$, c) 625 and d) 690 in $500{ }^{\circ} \mathrm{C}$ deaerated SCW.

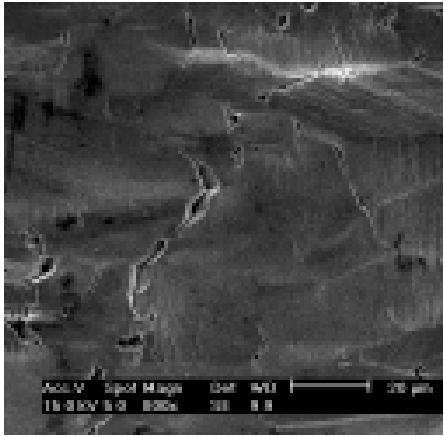

(a)

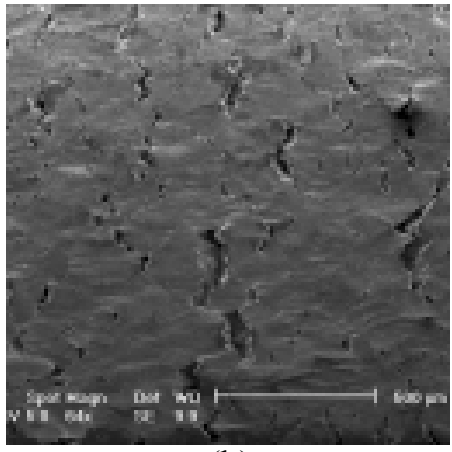

(b)

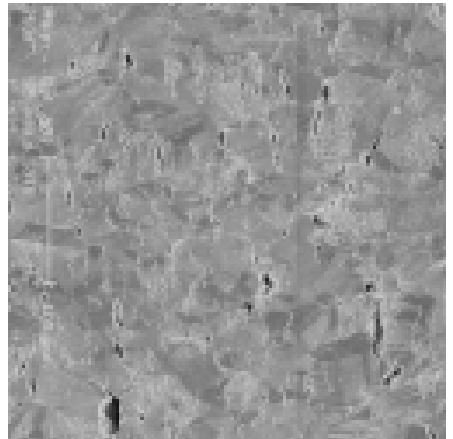

(c)

Figure 42. Cracks on the gage surfaces of alloy 625 tested in deaerated $\mathrm{SCW}$ at (a) $400{ }^{\circ} \mathrm{C}$, (b) $500{ }^{\circ} \mathrm{C}$ and (c) $550{ }^{\circ} \mathrm{C}$. 
However, the gage surfaces exhibited a significant amount of cracking at all temperatures. Crack densities on the gage surfaces measured at the different temperatures are presented Figure 43a. As shown in the figure, the crack density is higher at the lower temperatures. Yet, crack density does not present a complete picture of the cracking propensity. While the densities are lower at higher temperature, the cracks are longer. Figure $43 \mathrm{~b}$ displays the crack length per unit area, which is a product of the crack length and crack density and is a more complete measure of the extent of cracking. The crack length as measured on the surface, and the maximum crack depth as measured from cross-sections, are shown in Figures $43 \mathrm{c}$ and $\mathrm{d}$, respectively. Note that they are in good agreement and show that with increasing temperature, crack length increases while the crack density decreases and the severity of cracking, as measured by the crack length per unit area, increases with temperature. Also of note is the relative susceptibility to intergranular cracking, as measured by the crack length per unit area, Figure 43b. Clearly, the nickel-base Alloy 625 exhibits the worse intergranular cracking of all the alloys. The 304L stainless steel is the next worse alloy overall, followed by Alloys 316L and 690.

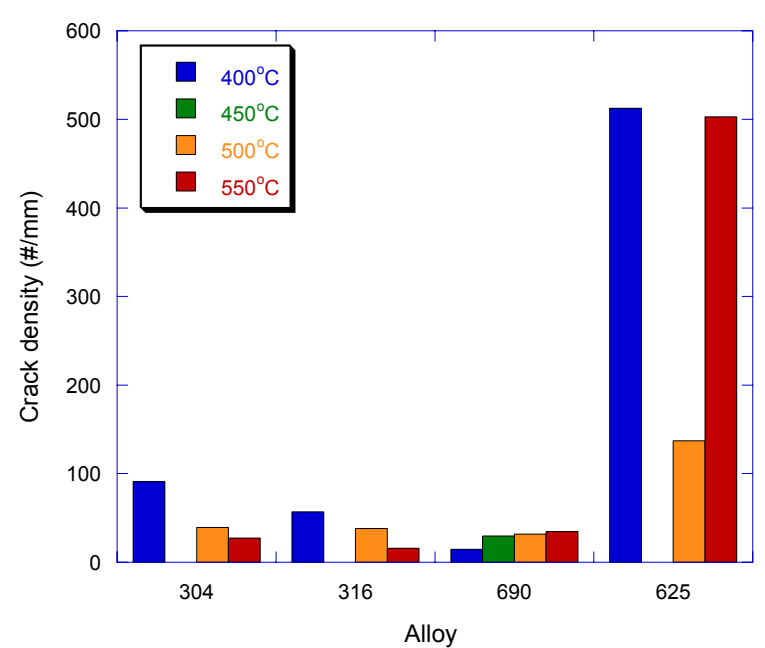

(a)

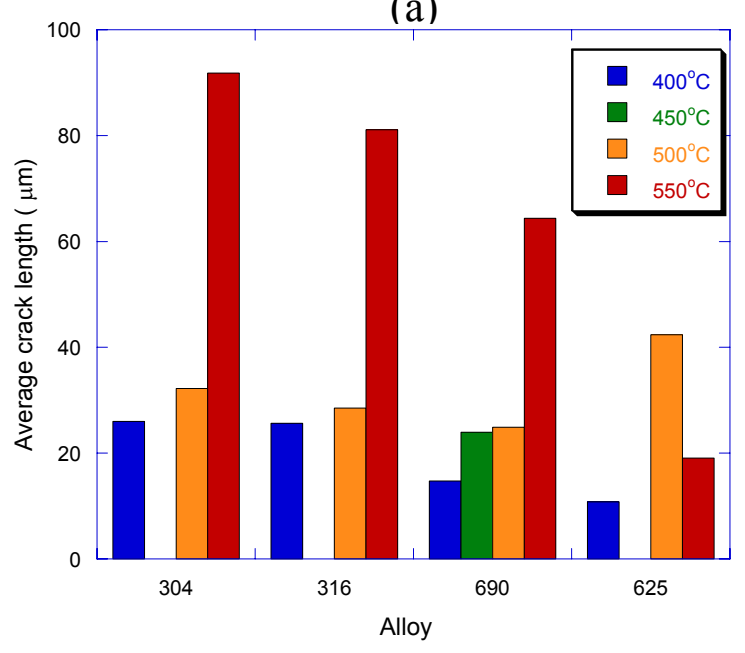

(c)

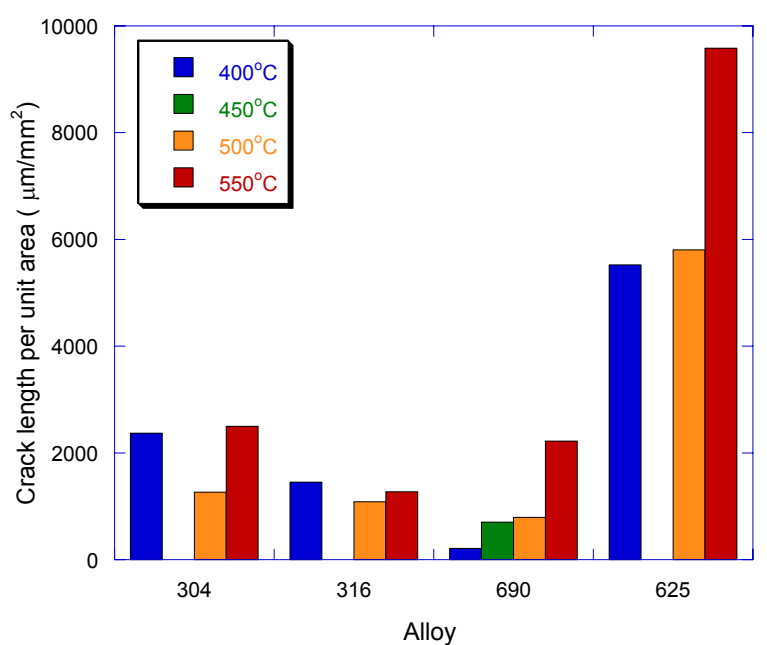

(b)

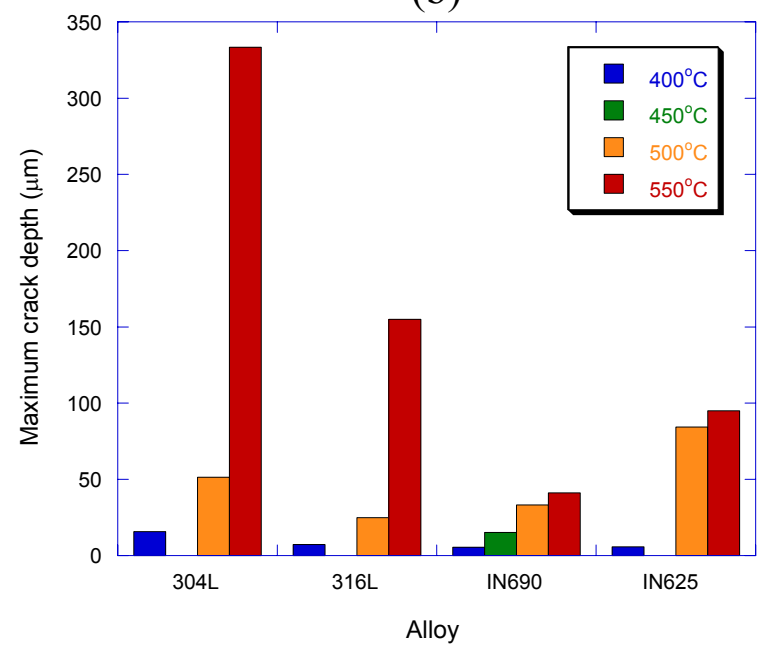

(d)

Figure 43. Gage surface crack density (a), crack length per unit area (b), crack length (c), and maximum crack depth (d) obtained after straining in 400, 450, 500 and $550{ }^{\circ} \mathrm{C}$ in deaerated $\mathrm{SCW}$ at $3 \times 10^{-7} \mathrm{~s}^{-1}$. 
The cracking mode was determined by cross-section analysis of the failed tensile samples. All of the tensile samples have been cross-sectioned and analyzed in the SEM in order to identify the nature of the cracking; transgranular (TG) or intergranular (IG). The cross sections were then etched to allow the identification of the grain boundaries, Figures 44 - 47. Cross-section analysis shows two types of cracking behavior. In the first, cracks appear to propagate through the oxide film and then continue into the underlying metal. This is the case for some of the cracks in Alloys 316L (Figure 45) and 690 (Figure 47). While at first glance, these cracks would appear to be transgranular by virtue of their straightness and their orientation at $90^{\circ}$ to the tensile stress, subsequent etching of the 316 stainless steel sample has revealed grain boundaries extending from the blunted tips of all cracks observed so far. The second type of cracking is exemplified in Alloys 625 and 304 where the crack depth is much greater and the cracks display the characteristic intergranular path. In these cases, the role of the oxide film is much less prominent. A summary of the data collected after completion of CERT experiments performed in 400, 450 and $500{ }^{\circ} \mathrm{C} \mathrm{SCW}$ at $3 \times 10^{-7} \mathrm{~s}^{-1}$ is presented in Table 23 .

Table 23. Results of constant extension rate experiments performed in deaerated SCW (25.5 MPa, $\mathrm{O}_{2}<10 \mathrm{ppb}$, conductivity $<0.1 \mu \mathrm{S} / \mathrm{cm}$.

\begin{tabular}{|c|c|c|c|c|c|c|c|c|c|c|}
\hline $\begin{array}{c}\text { Temp } \\
\left({ }^{\circ} \mathrm{C}\right)\end{array}$ & Alloy & $\begin{array}{c}\text { YS } \\
(\mathrm{MPa})\end{array}$ & $\begin{array}{c}\text { Max } \\
\text { stress } \\
\text { (MPa) }\end{array}$ & $\begin{array}{c}\text { Strain } \\
(\%)\end{array}$ & $\begin{array}{l}\text { Time } \\
\text { at } \\
\text { Temp } \\
\text { (hr) }\end{array}$ & $\begin{array}{l}\text { Fracture } \\
\text { surface }\end{array}$ & $\begin{array}{c}\text { Crack } \\
\text { density } \\
\left(\# / \mathrm{mm}^{2}\right)\end{array}$ & $\begin{array}{c}\text { Crack } \\
\text { depth } \\
(\mu \mathrm{m})\end{array}$ & $\begin{array}{c}\text { Crack } \\
\text { length } \\
(\mu \mathrm{m})\end{array}$ & $\begin{array}{c}\text { Crack } \\
\text { length / } \\
\text { unit area } \\
\left(\mu \mathrm{m} / \mathrm{mm}^{2}\right)\end{array}$ \\
\hline \multirow{4}{*}{400} & $304 \mathrm{~L}$ & 195 & 460 & 42 & 431 & Ductile & 91 & 15.7 & 26.0 & 2370.8 \\
\hline & $316 L^{1}$ & $\mathrm{~N} / \mathrm{A}$ & 440 & 33 & 339 & Ductile & 57 & 7.3 & 25.6 & 2456.1 \\
\hline & 625 & 370 & 790 & 56 & 575 & Ductile & 513 & 5.8 & 10.8 & 5523.4 \\
\hline & 690 & 215 & 460 & 56 & 575 & Ductile & 15 & 5.5 & 14.7 & 213.3 \\
\hline 450 & 690 & 180 & 510 & 58 & 578 & Ductile & 30 & 15.1 & 24.0 & 709.4 \\
\hline \multirow{4}{*}{500} & $304 L^{2}$ & 120 & 340 & $25^{2}$ & 290 & Did not fail & 39 & 514 & 322 & 1267.9 \\
\hline & 316L & 140 & 350 & 33 & 330 & Ductile & 38 & 24.9 & 28.5 & 1086.9 \\
\hline & 625 & 270 & 675 & 47 & 454 & $\begin{array}{l}\text { Intergranular } \\
+ \text { ductile }\end{array}$ & 137 & 84.2 & 42.4 & 5805.4 \\
\hline & 690 & 174 & 455 & 42 & 419 & $\begin{array}{c}\text { Granular + } \\
\text { ductile }\end{array}$ & 32 & 33.1 & 24.9 & 795.9 \\
\hline \multirow{5}{*}{550} & & & & & & & & & & \\
\hline & $304 \mathrm{~L}$ & 136 & 290 & 24 & 485 & $\begin{array}{l}\text { Intergranular } \\
\text { + ductile }\end{array}$ & 27 & 333.5 & 91.8 & 2501.4 \\
\hline & $316 \mathrm{~L}$ & 136 & 290 & 31 & 485 & Ductile & 16 & 155.0 & 81.1 & 1276.7 \\
\hline & 625 & 270 & 700 & 40 & 485 & Ductile & 503 & 95.0 & 19.1 & 9582.8 \\
\hline & 690 & 168 & 388 & 32 & 485 & Ductile & 35 & 41.1 & 64.4 & 2221.0 \\
\hline
\end{tabular}

${ }^{1}$ The 316L sample was pre-stressed to approximately $300 \mathrm{MPa}$.

${ }^{2}$ Experiment stopped at $25 \%$ elongation. 

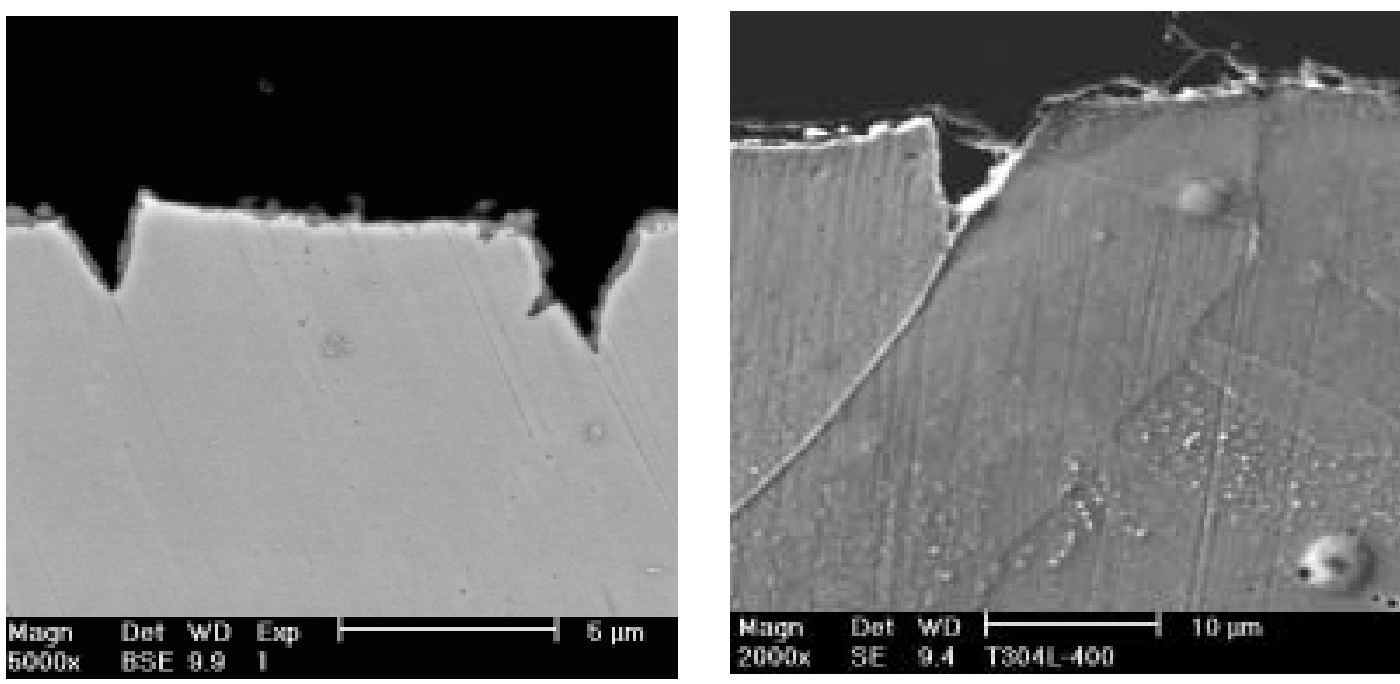

(a)
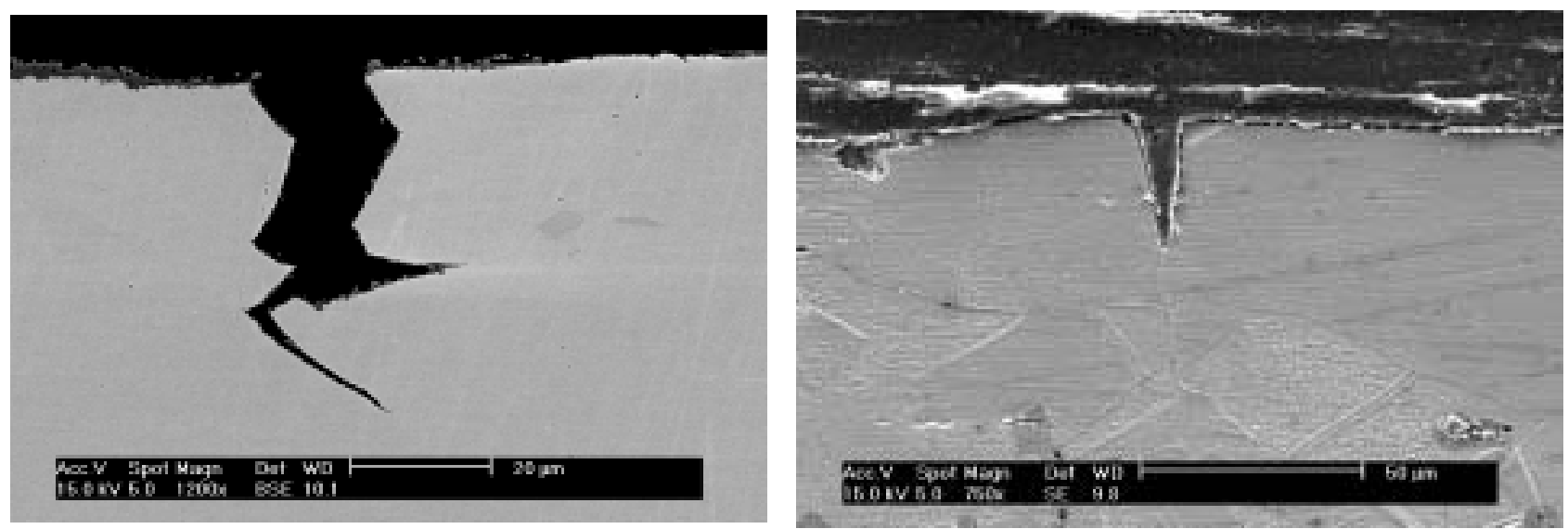

(b)
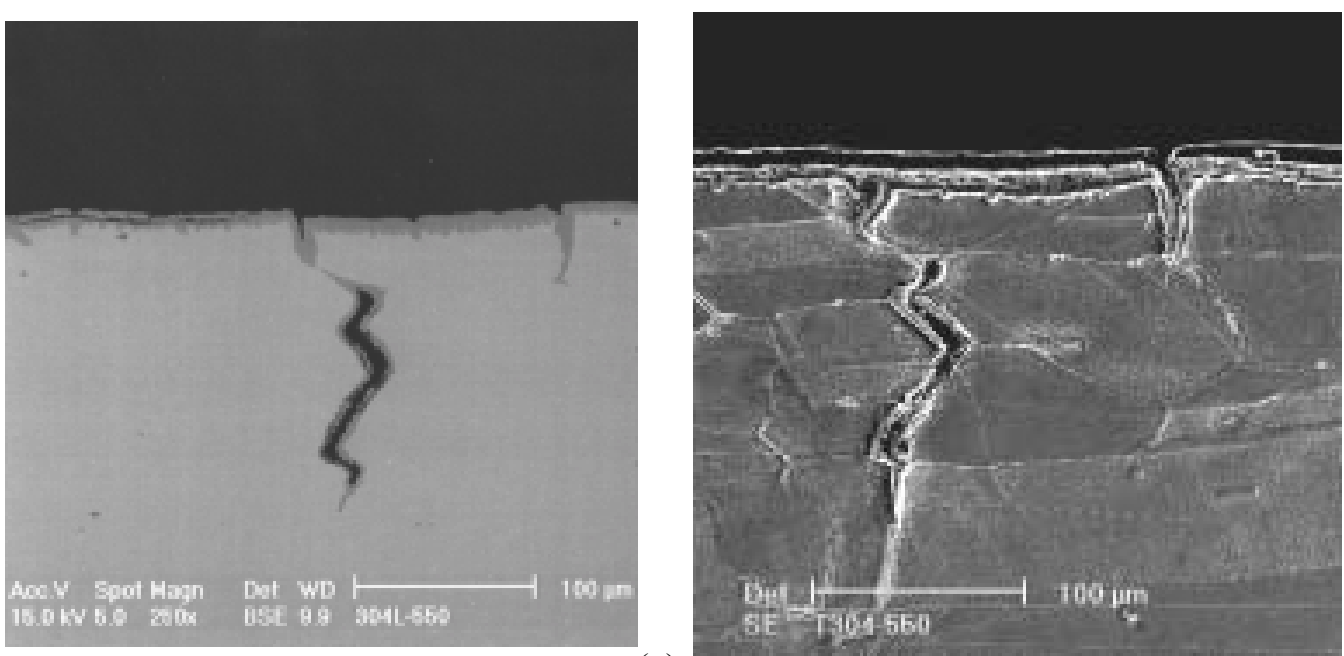

(c)

Figure 44. Cross sections of the 304L stainless steel SCC sample tested in deaerated SCW at a) 400 ${ }^{\circ} \mathrm{C}$, b) $500{ }^{\circ} \mathrm{C}$ and c) $550{ }^{\circ} \mathrm{C}$. 

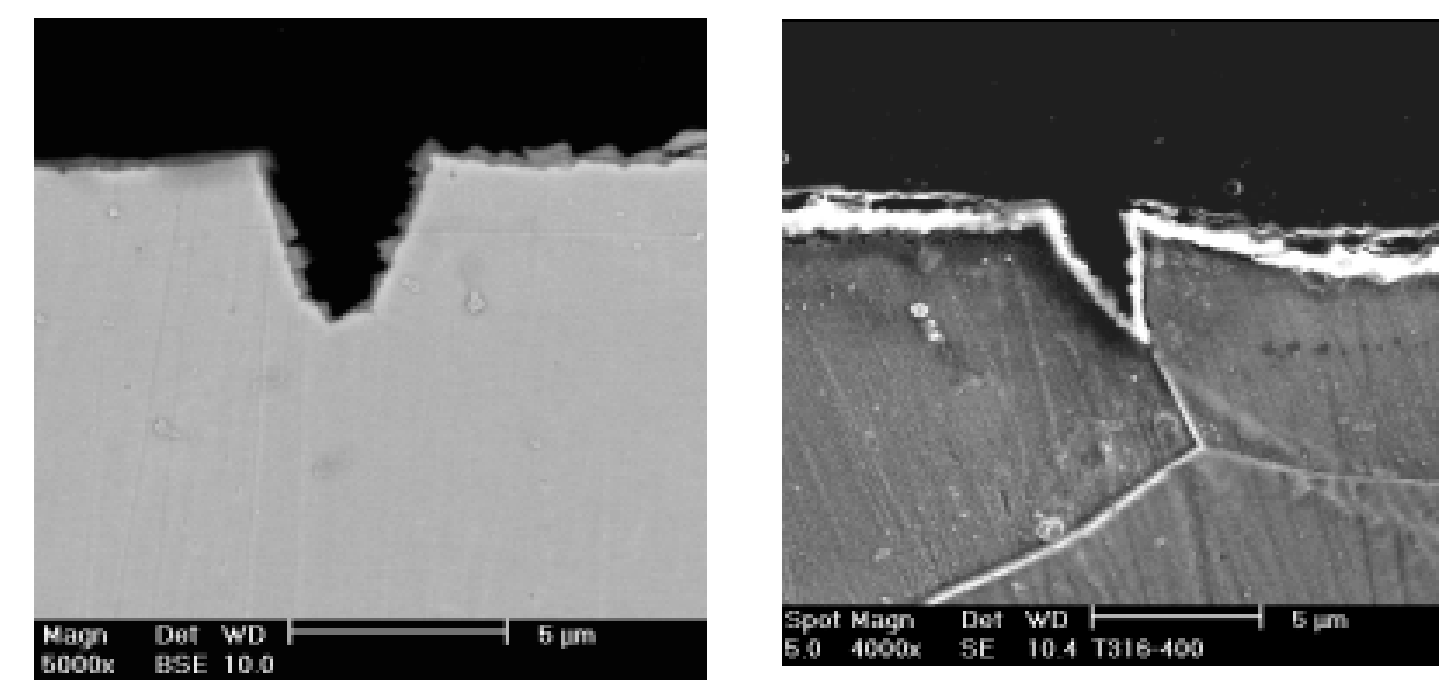

(a)
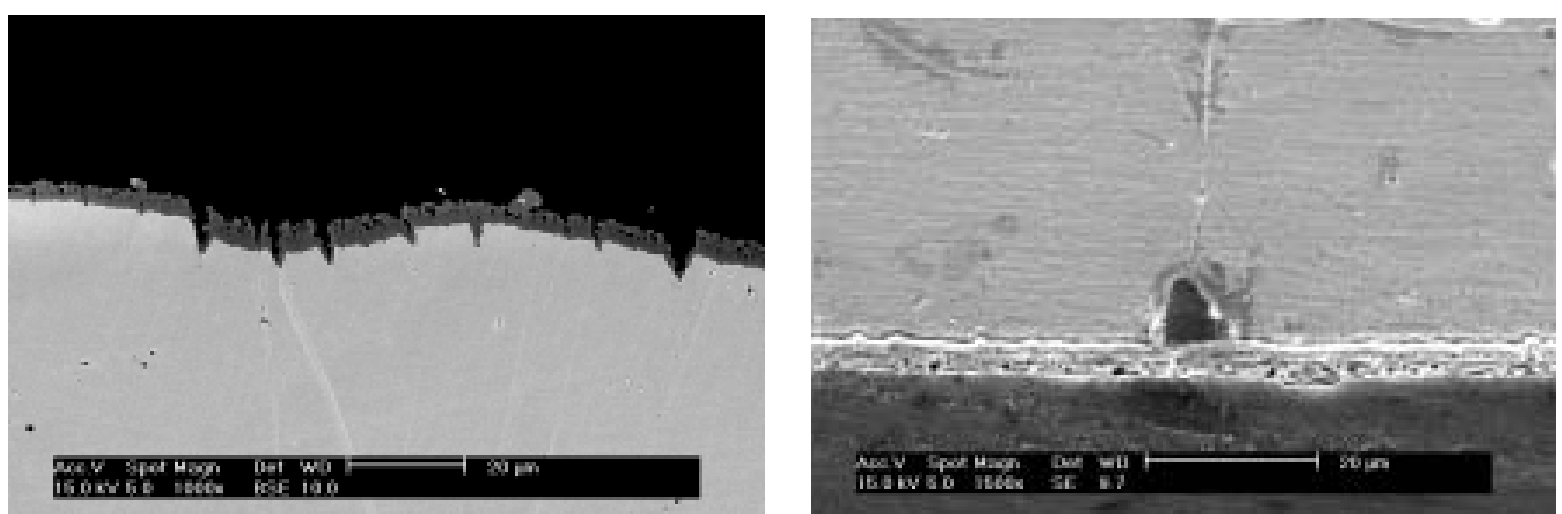

(b)
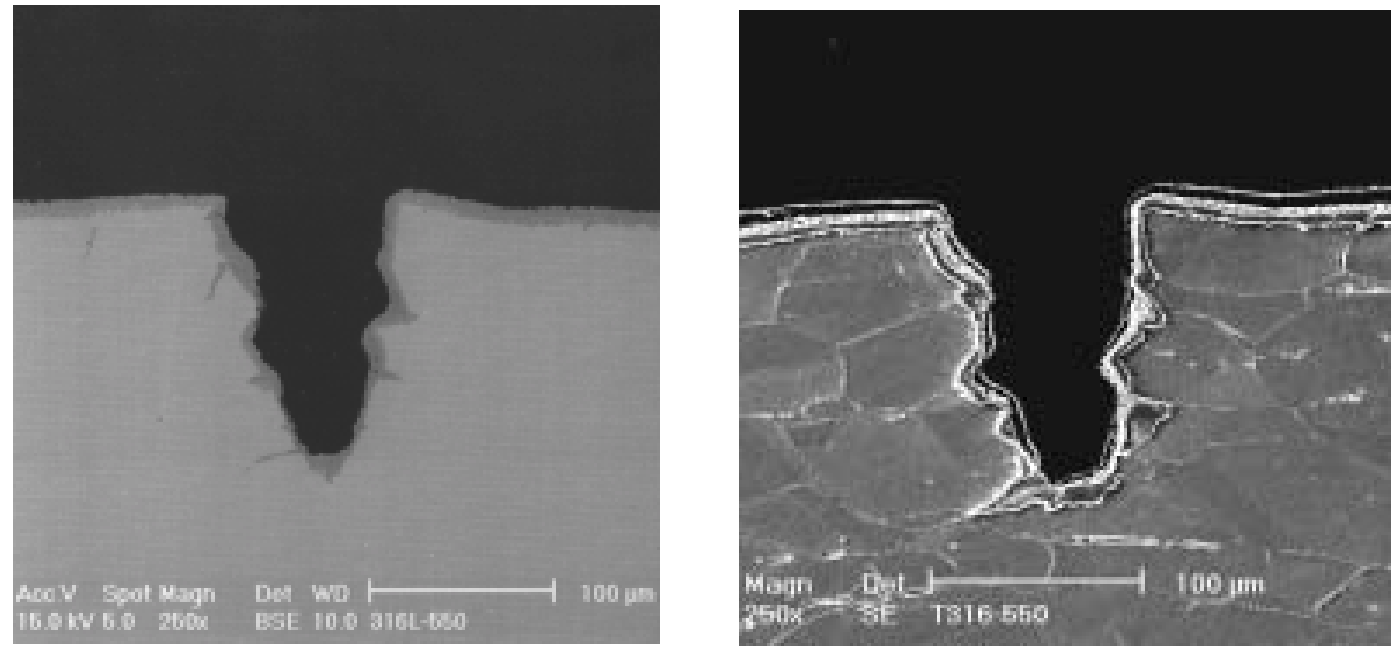

(c)

Figure 45. Cross sections of the 316L stainless steel SCC sample tested in deaerated SCW at a) 400 ${ }^{\circ} \mathrm{C}$, b) $500{ }^{\circ} \mathrm{C}$ and c) $550{ }^{\circ} \mathrm{C}$. 

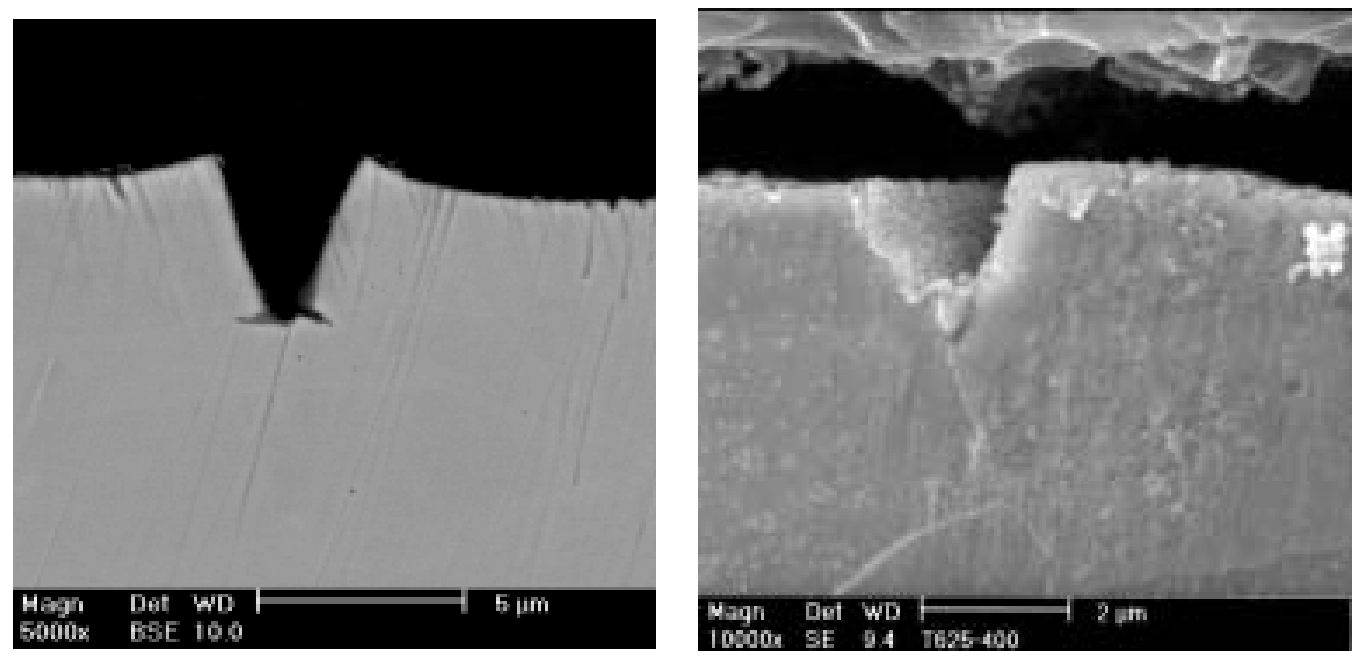

(a)
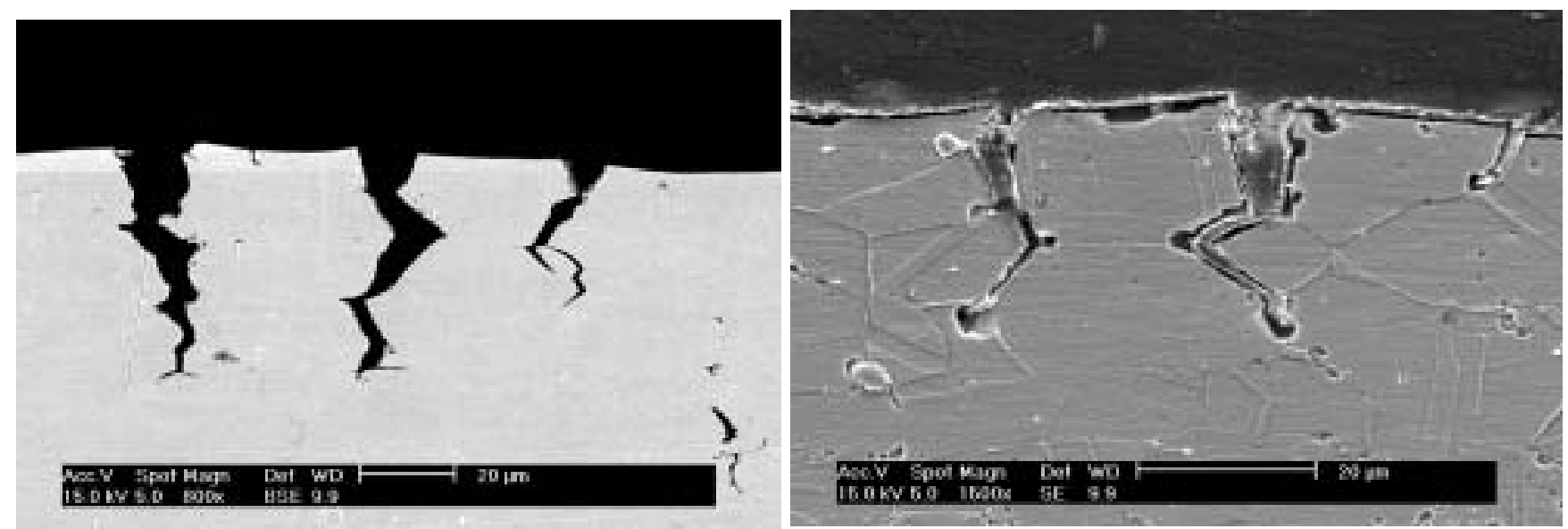

(b)
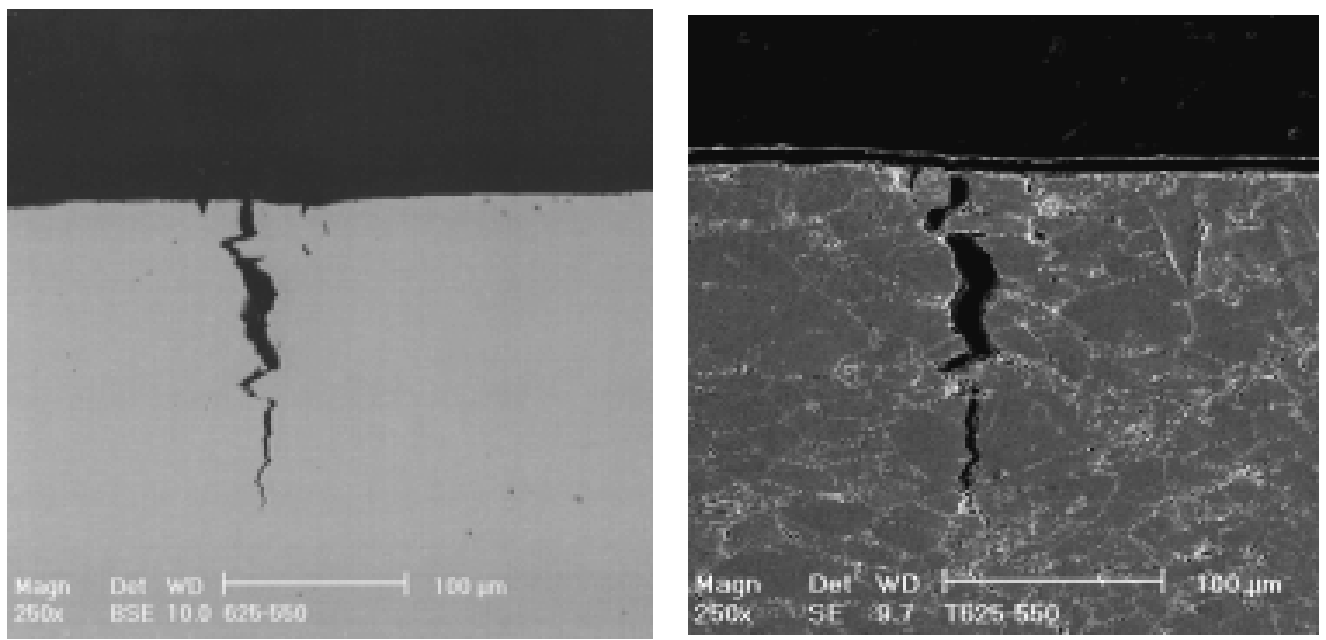

(c))

Figure 46. Cross sections of the Alloy $625 \mathrm{SCC}$ sample tested in deaerated SCW at a) $400{ }^{\circ} \mathrm{C}$, b) $500{ }^{\circ} \mathrm{C}$ and c) $550{ }^{\circ} \mathrm{C}$. 


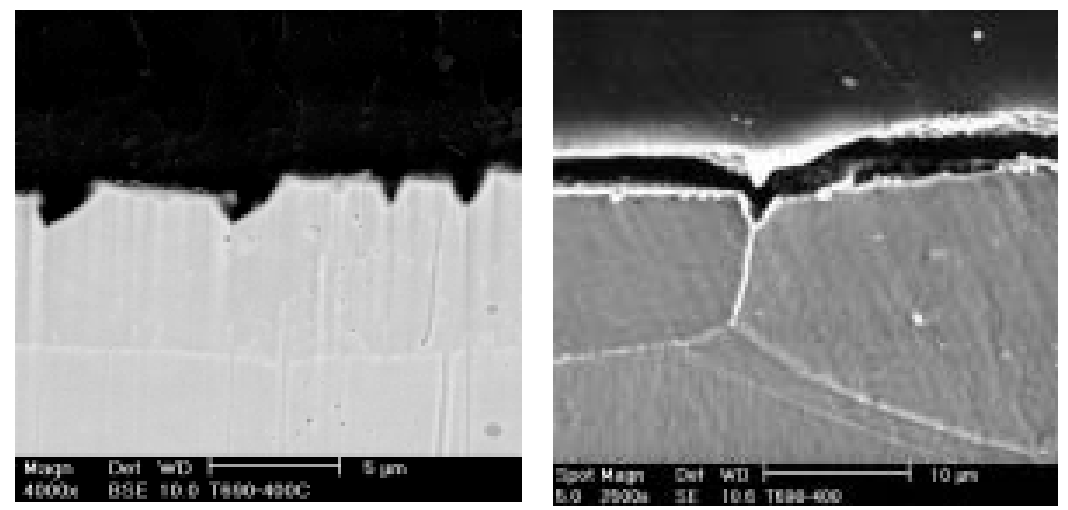

(a)

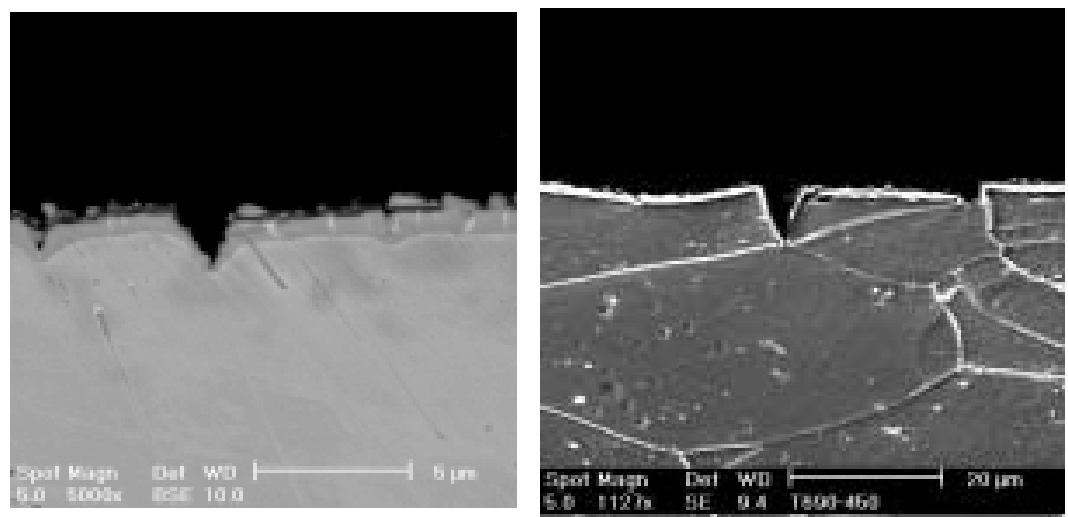

(b)

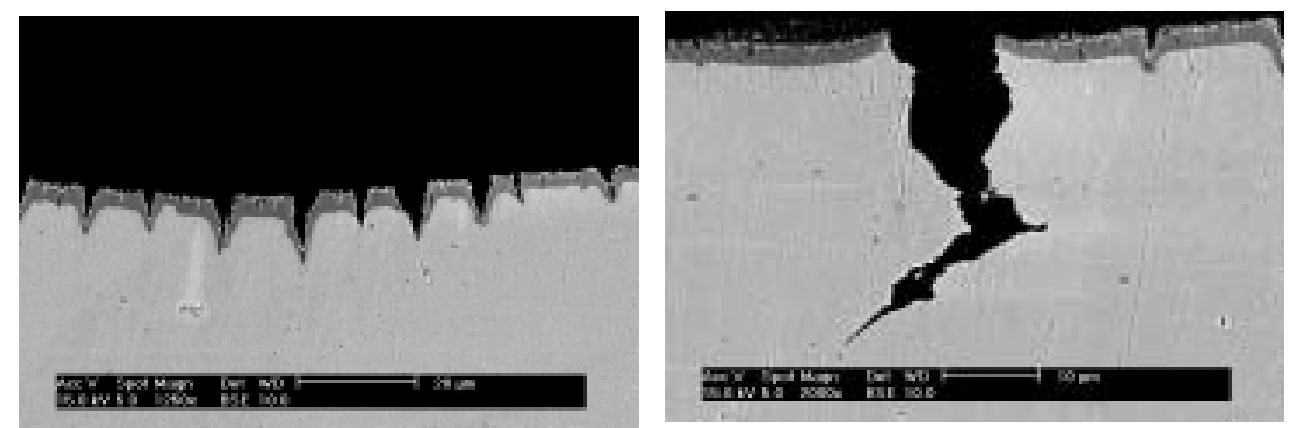

(c)

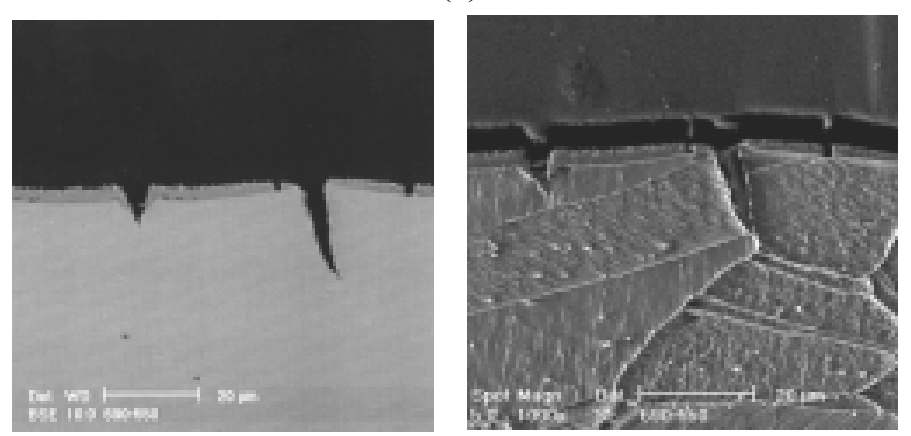

(d)

Figure 47. Cross sections of the Alloy 690 SCC sample tested in deaerated SCW at a) $400{ }^{\circ} \mathrm{C}$, b) $450{ }^{\circ} \mathrm{C}$. c) $500{ }^{\circ} \mathrm{C}$ and d) $550{ }^{\circ} \mathrm{C}$. 


\subsubsection{Discussion of Stress Corrosion Cracking Results}

These results show a number of interesting dependencies of cracking of austenitic alloys in SCW. First, all of the alloys studied exhibit some degree of intergranular cracking over the temperature range 400 to $550{ }^{\circ} \mathrm{C}$. Second, Alloy 625 exhibits the most severe cracking, followed by the $304 \mathrm{~L}$ stainless steel and then Alloys 316L and 690. The fracture surfaces are not a good indication of the intergranular cracking due to the fracture mode being obscured during oxidation following fracture, and also due to the poor statistical results from the fracture surfaces. A better measure is obtained through analysis of the gage sections and the cross-sections of the tensile bars. Cracking severity, as measured by the crack length per unit area (crack density $\mathrm{x}$ crack length on the gage surface) shows that there is a trend toward increasing crack length and decreasing crack density with temperature. Further, the crack lengths measured on the gage surfaces correlate well with the crack depths measured on the cross sections.

Unfortunately, there is little data on intergranular cracking susceptibility of austenitic alloys in pure supercritical water. An early result for SCC of 316 SS in degassed SCW was reported by Boyd and Pray [1957]. Their samples were exposed to $732{ }^{\circ} \mathrm{C}, 34.5 \mathrm{MPa} \mathrm{SCW}$ and stressed to $90 \%$ of the stress required to cause rupture in 1000 hours $(103 \mathrm{MPa})$. It was found that the 316 stainless steel failed after one week of exposure. The fracture surface and side surfaces revealed the presence of transgranular cracking. This result is similar, but not exactly the same as that for 316L stainless steel in this study. Yet in both cases, environmentally-assisted cracking occurred in 316 under degassed SCW conditions. The differences may be due to the significantly different temperature and pressure or the difference in the type of test (constant stress vs. constant extension rate).

Fournier et al. [2001] used CERT experiments at a strain rate of $1 \times 10^{-6} \mathrm{~s}^{-1}$ to test Alloys 690 and 718 in $400{ }^{\circ} \mathrm{C}, 25 \mathrm{MPa} \mathrm{SCW}$ under aerated conditions. Alloy 718 failed by IGSCC where the entire fracture surface was intergranular in nature and exhibited no necking. It was determined that the cracking was initiated by the oxidation of niobium precipitates in the alloy. Alloy 690 failed by completely ductile rupture and showed a significant amount of necking. Both of these alloys were also tested in air environments at $600{ }^{\circ} \mathrm{C}$ using the same type of CERT experiments. The tests in air revealed behavior for each alloy similar to that seen in SCW at $400{ }^{\circ} \mathrm{C}$. The ductile fracture mode observed by Fournier is similar to that found in the 690 experiment in this study, with the exception of the region of "granular" fracture and the lack of necking in the sample.

Tsuchiya et al. [2003] investigated the behavior of sensitized 304 and 316 stainless steels using CERT experiments at $4 \times 10^{-7} \mathrm{~s}^{-1}$. The test temperature ranged from $290-550{ }^{\circ} \mathrm{C}$, with a pressure of $25 \mathrm{MPa}$, a dissolved oxygen content of $8 \mathrm{ppm}$, and high purity water. For both alloys, the fracture surface did not show any sign of IGSCC at temperatures above $400{ }^{\circ} \mathrm{C}$. The 304 did show intergranular SCC on the fracture surface at temperatures below $400{ }^{\circ} \mathrm{C}$. Both alloys had small cracks on the side surface when exposed to SCW. Since the presence of cracking on the side surfaces is a better indicator of intergranular susceptibility than the fracture surface alone, these results actually agree well with those of the current study for $304 \mathrm{SS}$. The results for $316 \mathrm{~L}$ correspond directly with the results for $316 \mathrm{~L}$ found in this study.

Watanabe et al. [2003] examined the SCC behavior of sensitized 316 stainless steel as a function of pressure using CERT experiments at $2.78 \times 10^{-6} \mathrm{~s}^{-1}$. They found that the fracture surface of the alloy was almost completely intergranular in nature under subcritical conditions of $360{ }^{\circ} \mathrm{C}$ and $25 \mathrm{MPa}$. The fracture was transgranular under $400{ }^{\circ} \mathrm{C}, 30 \mathrm{MPa}$ supercritical conditions. However, as the pressure was increased at $400{ }^{\circ} \mathrm{C}$, the fracture mode gradually changed to increasingly intergranular SCC. The presence of their environmental effects on the cracking of 316 correlates well with the results of this study. 
In summary, all of the austenitic alloys studied, 304L, 316L, 625 and 690 appear to have some level of susceptibility to stress corrosion cracking in SCW with the degree of susceptibility varying with alloy and the specific environmental conditions. Overall, the 304L stainless steel and the Alloy 625 display the greatest degree of susceptibility.

\subsubsection{Corrosion Data}

The corrosion was measured from $1 \mathrm{~cm} \times 2 \mathrm{~cm} \times 0.1 \mathrm{~cm}$ corrosion coupons exposed in the same autoclave during the CERT tests. The corrosion is characterized by the weight gain of the coupons, and by cross-section analysis of the coupons to determine the oxide thickness, layer structure, and composition profile.

The weight gain change results are summarized in Figure 48. Every alloy had an increased weight gain with temperature with the exception of Alloy 625. A notable point is that the weight gain increase accelerates with increasing temperatures for all alloys. Weight gain increase is greatest for the highest 50 ${ }^{\circ} \mathrm{C}$ temperature increment, next highest for the middle $50{ }^{\circ} \mathrm{C}$ increment and lowest for the bottom $50{ }^{\circ} \mathrm{C}$ increment in temperature. For alloy 625, the weight gain increases slowly between 400 and $500{ }^{\circ} \mathrm{C}$ but it is still very low. The weight gains are summarized in Table 24 along with the oxide thickness as measured from cross-section samples. The two measures of oxidation are in very good agreement overall, the greatest weight gain (or oxide thickness) occurring for the Alloys 316L and 690, less for the 304 stainless steel and extremely little for the Alloy 625.

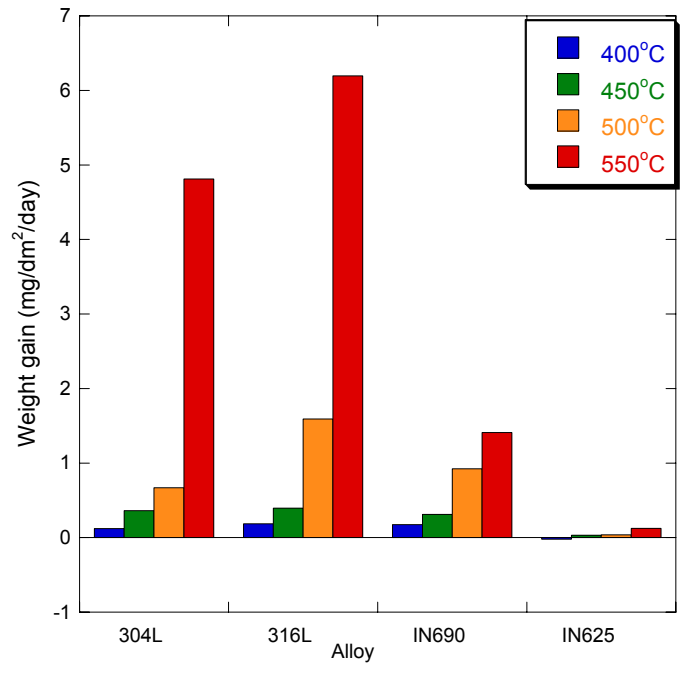

(a)

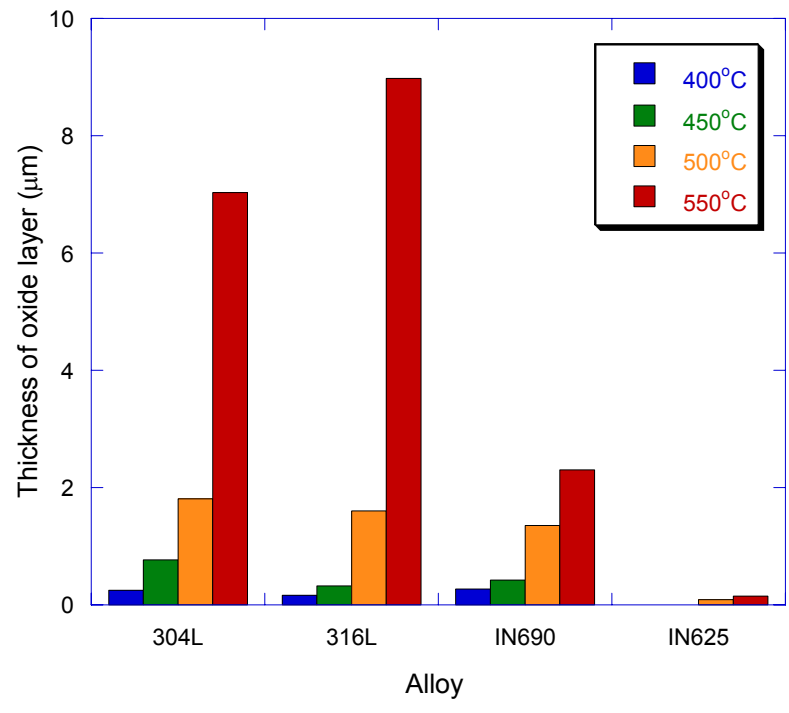

(b)

Figure 48. Weight change (a), and oxide thickness (b) obtained for the studied alloys in 400,450 , and $500{ }^{\circ} \mathrm{C}$ in deaerated $\mathrm{SCW}$.

Composition vs. depth profiles taken on the corrosion coupon cross-sections using energy dispersive spectrometry in scanning electron microscopy revealed several interesting features. First, most of the samples displayed two clear oxide layers, an outer oxide rich in iron and a chromium rich inner oxide layer. A transition zone between the inner oxide layer and the substrate was characterized by a high nickel content and rapidly decreasing oxygen content in the austenitic stainless steels. While nickel is probably in the metallic state, the oxygen content is much higher than the solubility level and may represent a supersaturated state. Figures 49-51 show the composition vs. depth profiles for the 304L, 
316L and 690 alloys at each of the temperatures. The oxide layer on the Alloy 625 was too thin to profile at any temperature. At $450{ }^{\circ} \mathrm{C}$, Figure 49 , all but the $316 \mathrm{~L}$ stainless steel show the two layer structure. Oxides at this temperature are all less than about $1.5 \mu \mathrm{m}$. At $500{ }^{\circ} \mathrm{C}$, Figure 50 , the oxides are thicker and all show the two layer structure of an iron-rich outer layer and a chromium rich inner layer. The peaking of $\mathrm{Ni}$ at the metal-inner layer oxide is very evident in both of the stainless alloys. At $550{ }^{\circ} \mathrm{C}$, the oxides are considerably thicker (up to almost $10 \mu \mathrm{m}$ ) and show very clear and distinct 2-layer structures.

Table 24. Summary of oxidation data for each alloy in the temperature range 400 to $550{ }^{\circ} \mathrm{C}$.

\begin{tabular}{|c|c|c|c|c|c|c|c|}
\hline $\begin{array}{c}\text { Temp } \\
\left({ }^{\circ} \mathrm{C}\right)\end{array}$ & Alloy & $\begin{array}{l}\text { Exposur } \\
\text { e time } \\
\text { (hr) }\end{array}$ & $\begin{array}{c}\text { Weight } \\
\text { gain } \\
\left(\mathrm{mg} / \mathrm{dm}^{2}\right)\end{array}$ & $\begin{array}{c}\text { Weight } \\
\text { gain rate } \\
\text { (mg/dm } \\
\text { /day) }\end{array}$ & $\begin{array}{c}\text { Oxide } \\
\text { thickness } \\
(\mu \mathrm{m})\end{array}$ & $\begin{array}{l}\text { Layer } \\
\text { structure }\end{array}$ & $\begin{array}{c}\text { Oxide } \\
\text { structure }\end{array}$ \\
\hline \multirow{4}{*}{400} & $304 \mathrm{~L}$ & 575 & 2.88 & 0.120 & 0.25 & NM & $\begin{array}{l}\text { Predominantly } \\
\mathrm{Fe}_{3} \mathrm{O}_{4}\end{array}$ \\
\hline & $316 \mathrm{~L}$ & 575 & 4.5 & 0.188 & 0.17 & NM & $\begin{array}{l}\text { Predominantly } \\
\mathrm{Fe}_{3} \mathrm{O}_{4}\end{array}$ \\
\hline & 625 & 575 & -0.5 & -0.021 & $<0.1$ & NM & NM \\
\hline & 690 & 575 & 4.25 & 0.177 & 0.27 & NM & $\mathrm{NiO}$ \\
\hline \multirow{4}{*}{450} & $304 \mathrm{~L}$ & 578 & 8.75 & 0.363 & 0.77 & $\begin{array}{l}\text { Fe-rich outer } \\
\text { Cr-rich inner }\end{array}$ & NM \\
\hline & $316 \mathrm{~L}$ & 578 & 9.5 & 0.394 & 0.32 & Fe-rich layer & NM \\
\hline & 625 & 578 & 0.75 & 0.031 & $<0.1$ & NM & NM \\
\hline & 690 & 578 & 7.5 & 0.311 & 0.42 & Fe-rich layer & NM \\
\hline \multirow{4}{*}{500} & $304 \mathrm{~L}$ & 419 & 11.4 & 0.670 & 0.80 & $\begin{array}{l}\text { Fe-rich outer } \\
\text { Cr-rich inner }\end{array}$ & $\begin{array}{l}\text { Predominantly } \\
\mathrm{Fe}_{3} \mathrm{O}_{4}\end{array}$ \\
\hline & $316 \mathrm{~L}$ & 419 & 27.75 & 1.592 & 1.53 & $\begin{array}{l}\text { Fe-rich outer } \\
\text { Cr-rich inner }\end{array}$ & $\begin{array}{l}\text { Predominantly } \\
\mathrm{Fe}_{3} \mathrm{O}_{4}\end{array}$ \\
\hline & 625 & 419 & 0.63 & 0.036 & 0.13 & NM & NM \\
\hline & 690 & 419 & 16.1 & 0.922 & 1.28 & $\begin{array}{l}\text { Fe-rich outer } \\
\text { Cr-rich inner }\end{array}$ & $\mathrm{NiO}, \mathrm{NiCrO}_{4}$ \\
\hline \multirow[t]{4}{*}{550} & $304 \mathrm{~L}$ & 485 & 97.25 & 4.812 & 7.03 & $\begin{array}{l}\text { Fe-rich outer } \\
\text { Cr-rich inner }\end{array}$ & NM \\
\hline & $316 \mathrm{~L}$ & 485 & 125.25 & 6.198 & 8.97 & $\begin{array}{l}\text { Fe-rich outer } \\
\text { Cr-rich inner }\end{array}$ & NM \\
\hline & 625 & 485 & 2.5 & 0.123 & 0.15 & NM & NM \\
\hline & 690 & 485 & 28.5 & 1.410 & 2.30 & $\begin{array}{l}\text { Fe-rich outer } \\
\text { Ni-rich mid. } \\
\text { Cr-rich inner }\end{array}$ & NM \\
\hline
\end{tabular}

$\mathrm{NM}=$ not measured

Glancing angle $\left(3^{\circ}\right) \mathrm{X}$-ray diffraction of the layers was conducted to determine the type of oxide present. Results are summarized in Table 24 and show that for the stainless steel alloys at $500{ }^{\circ} \mathrm{C}$, the predominant oxide is magnetite $\left(\mathrm{Fe}_{3} \mathrm{O}_{4}\right)$. The Alloy 690 oxide formed at $500{ }^{\circ} \mathrm{C}$ was composed of a mixture of NiO and a nickel-chrome spinel of probably composition $\mathrm{NiCrO}_{4}$. The $\mathrm{NiO}$ layer is likely the top layer with the spinel as the inner layer, though this could not be verified by $\mathrm{x}$-ray analysis. 

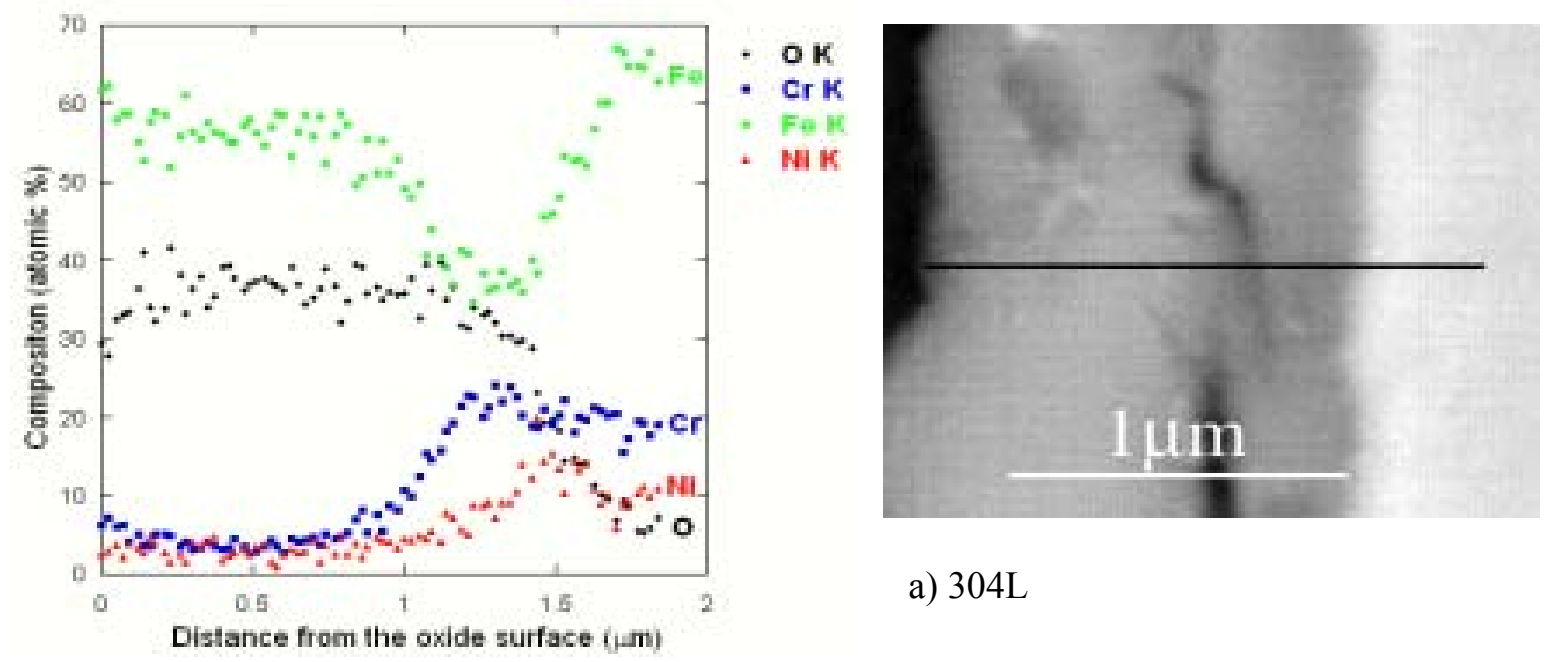

a) $304 \mathrm{~L}$

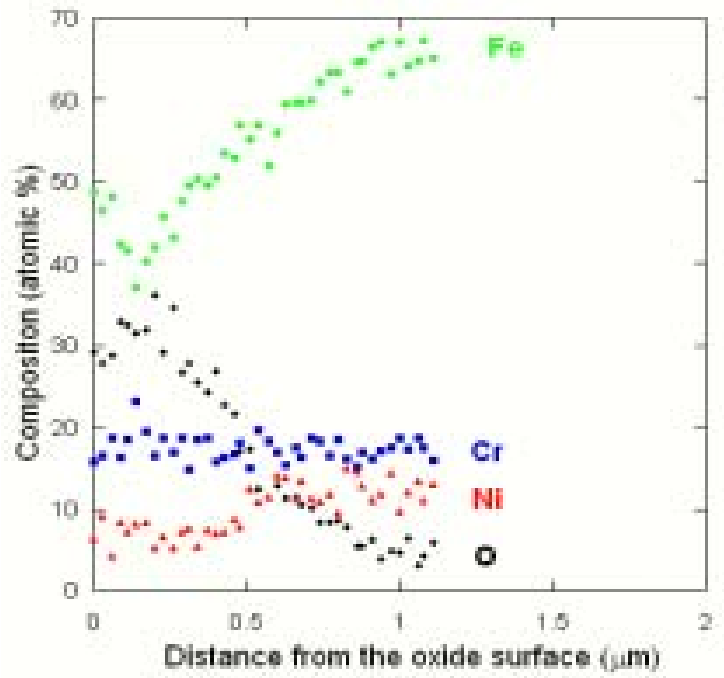

+ O K
- Cr K
Fe K
MIK

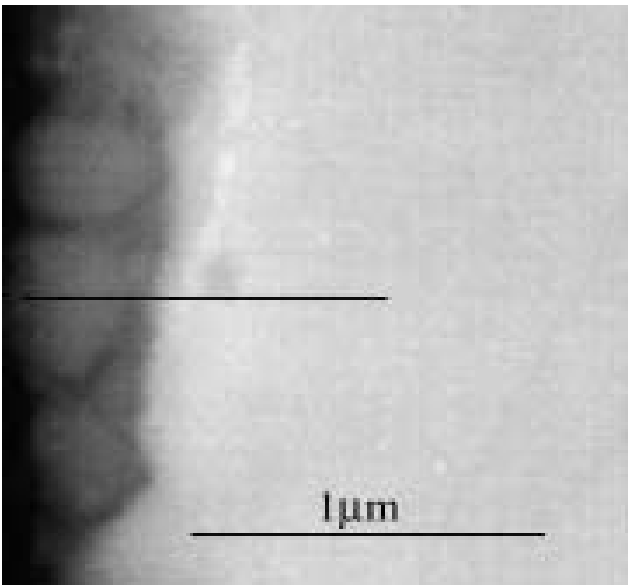

b) $316 \mathrm{~L}$
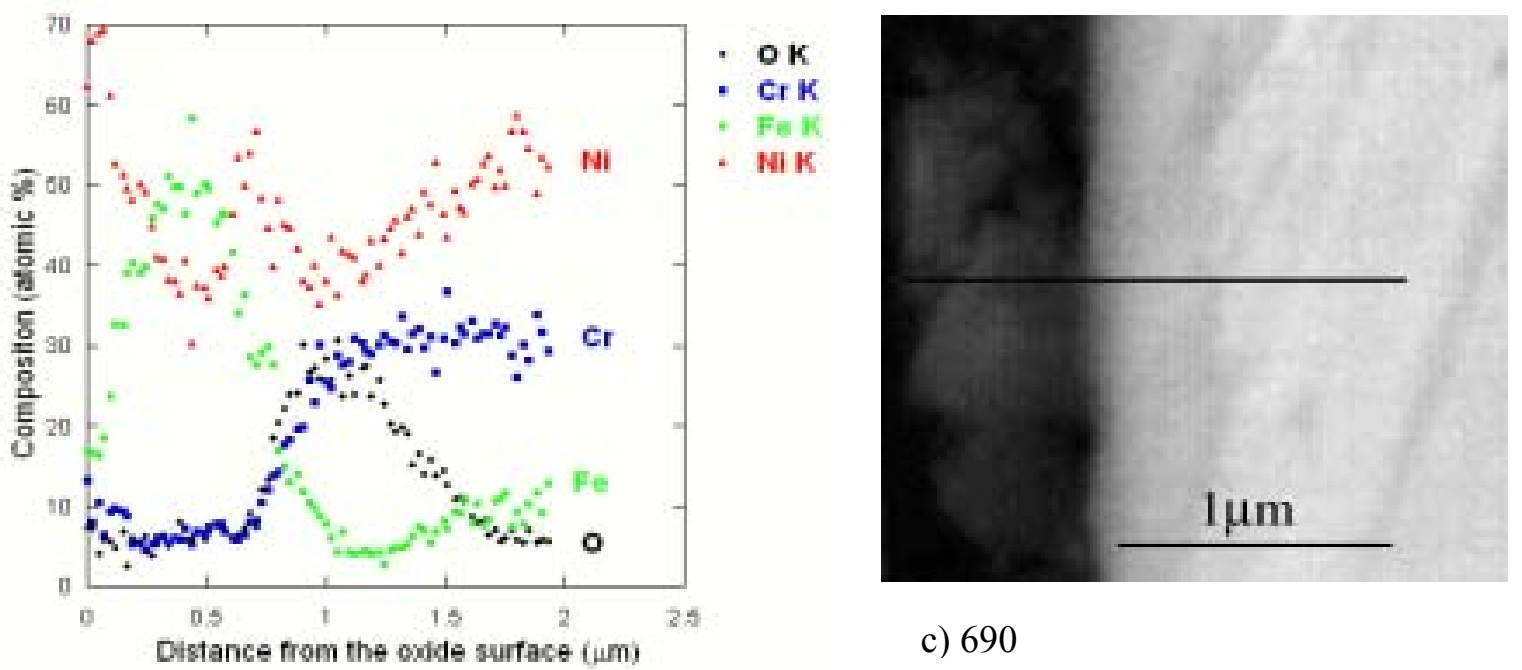

c) 690

Figure 49. Oxide composition profiles and accompanying micrographs for a) 304L, b) 316L and c) 690 in deaerated $\mathrm{SCW}$ at $450{ }^{\circ} \mathrm{C}$. 

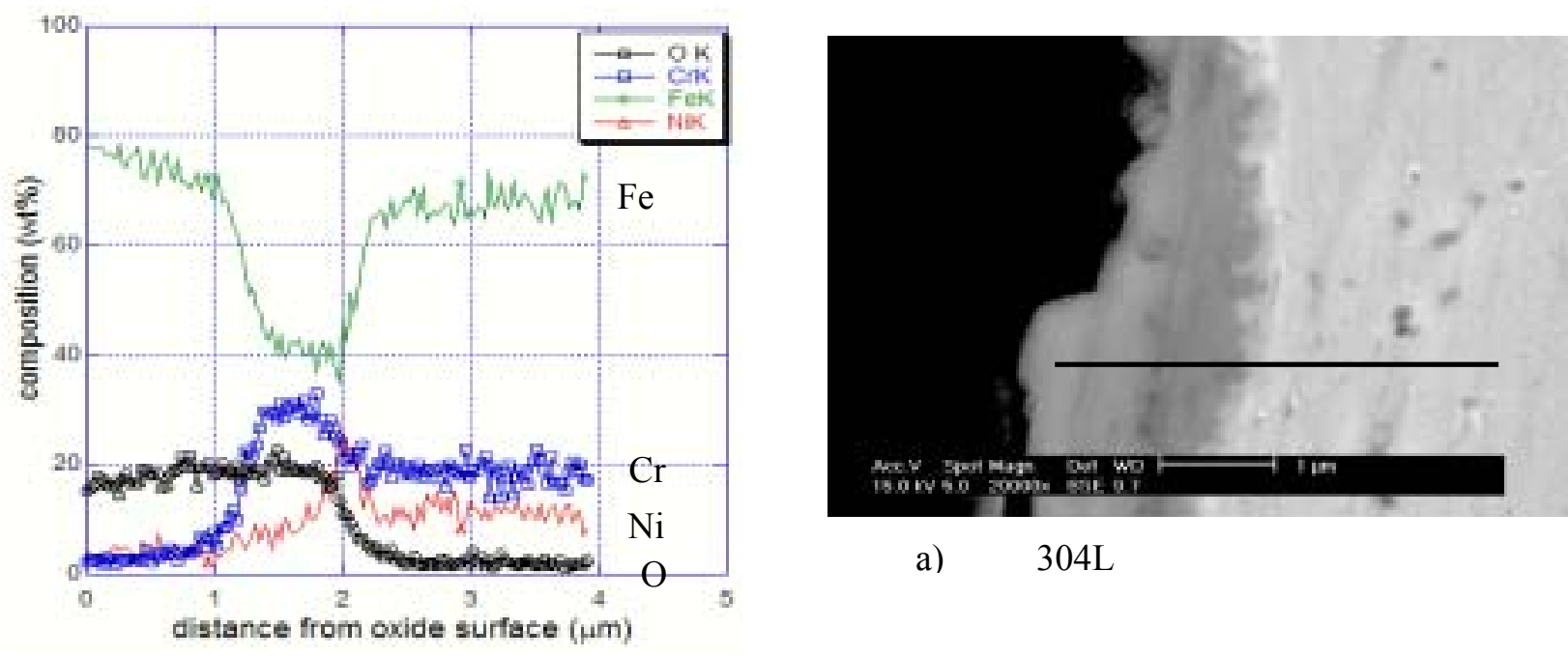

a) $\quad 304 \mathrm{~L}$
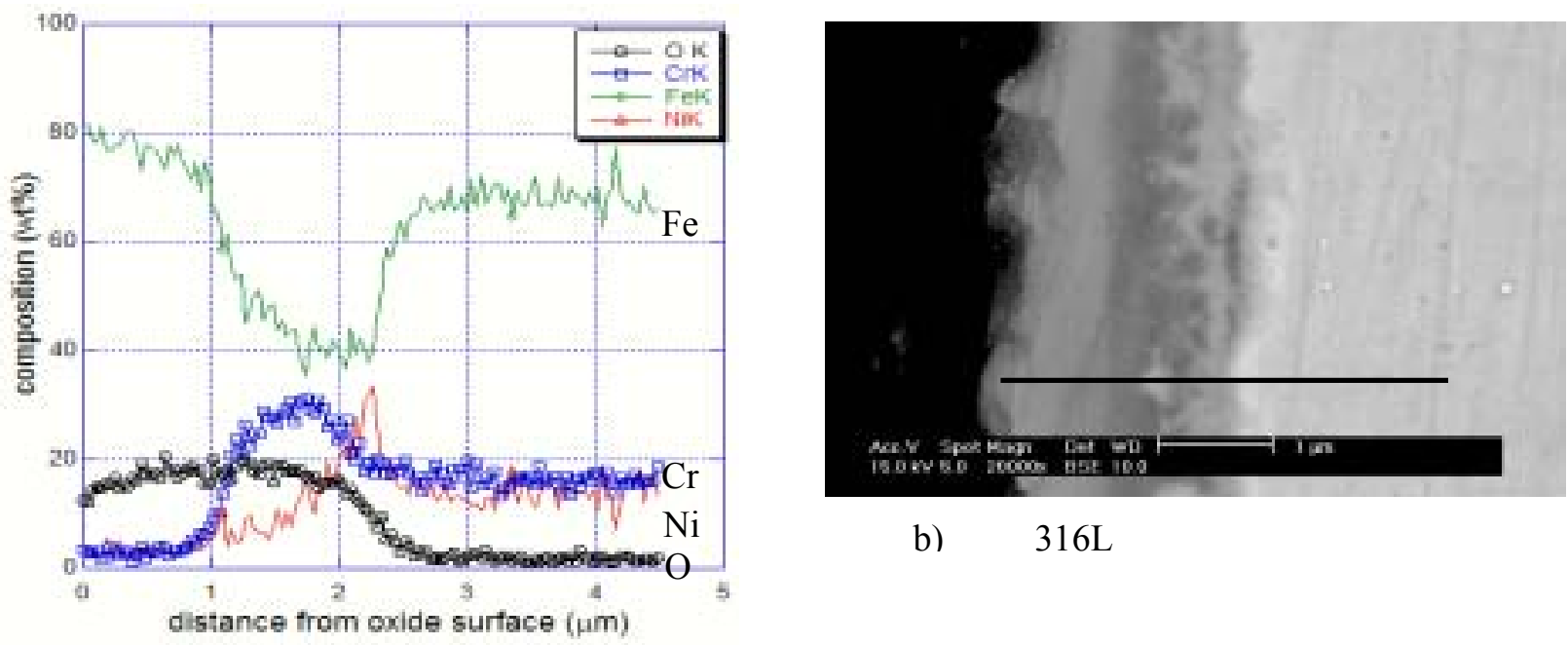

b) $\quad 316 \mathrm{~L}$
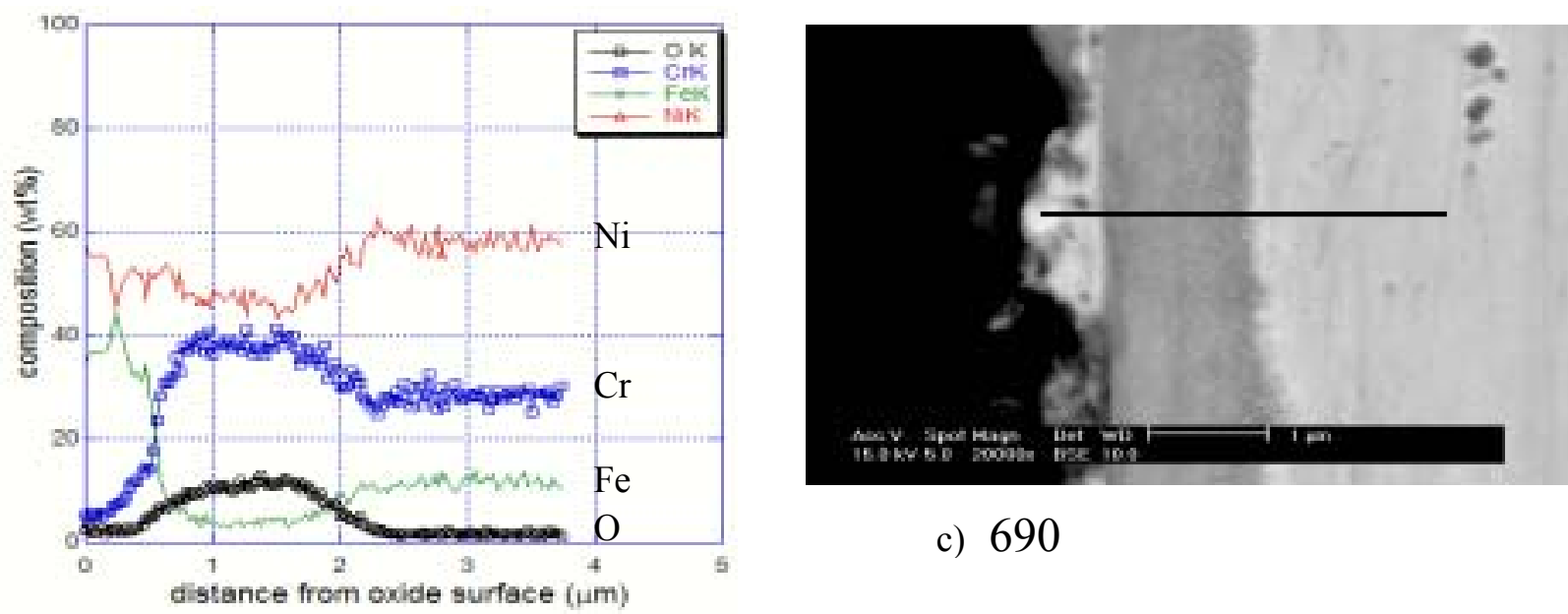

c) 690

Figure 50. Oxide composition profiles and accompanying mierographs for a) $304 \mathrm{~L}, \mathrm{~b}) 316 \mathrm{~L}$ and c) 690 in deaerated $\mathrm{SCW}$ at $500{ }^{\circ} \mathrm{C}$. 

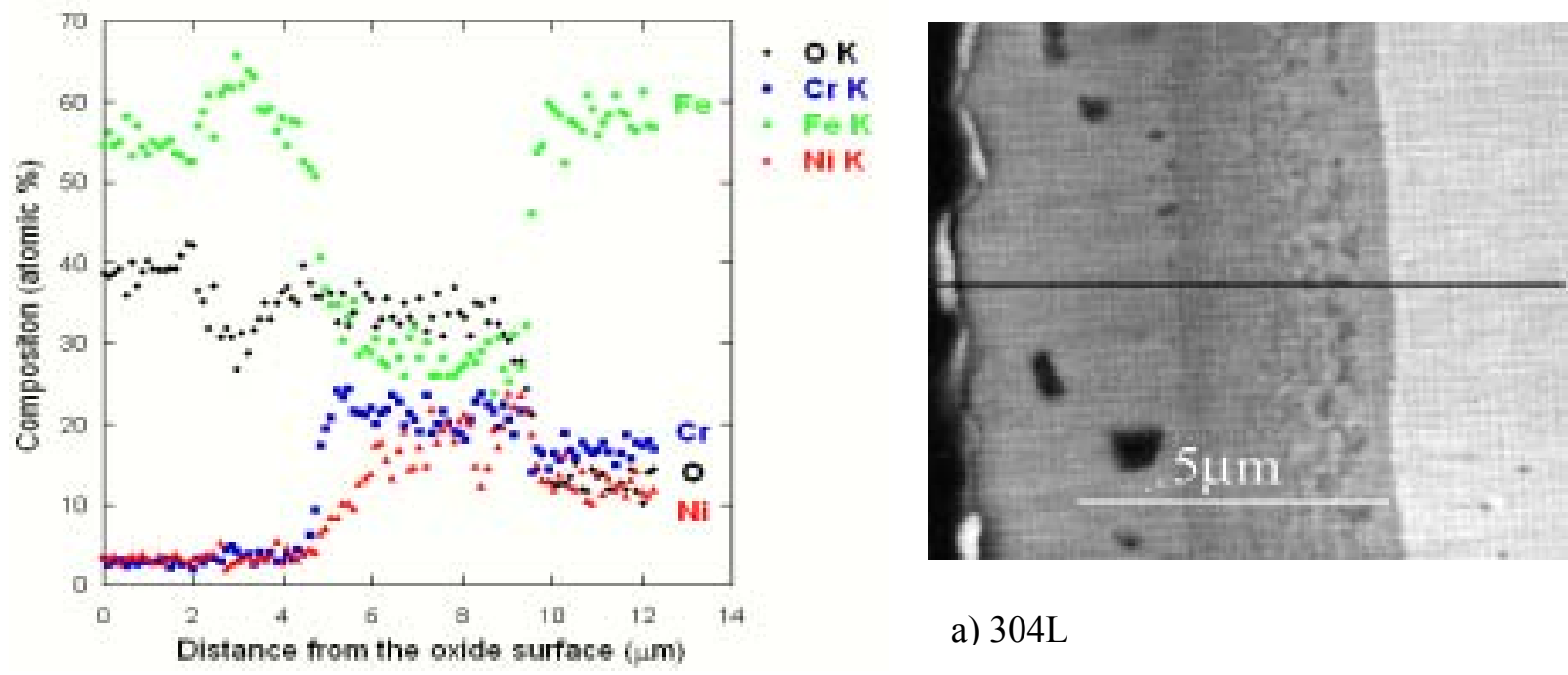

a) $304 \mathrm{~L}$
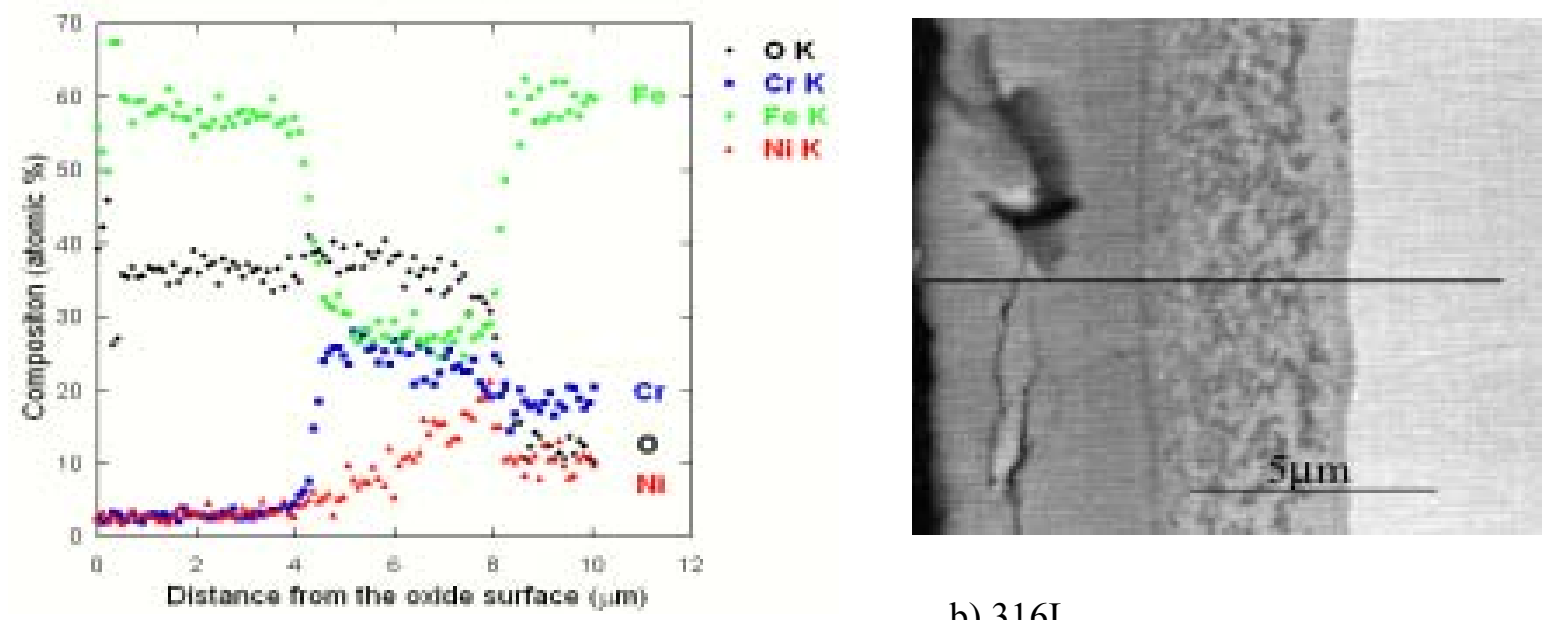

b) $316 \mathrm{~L}$
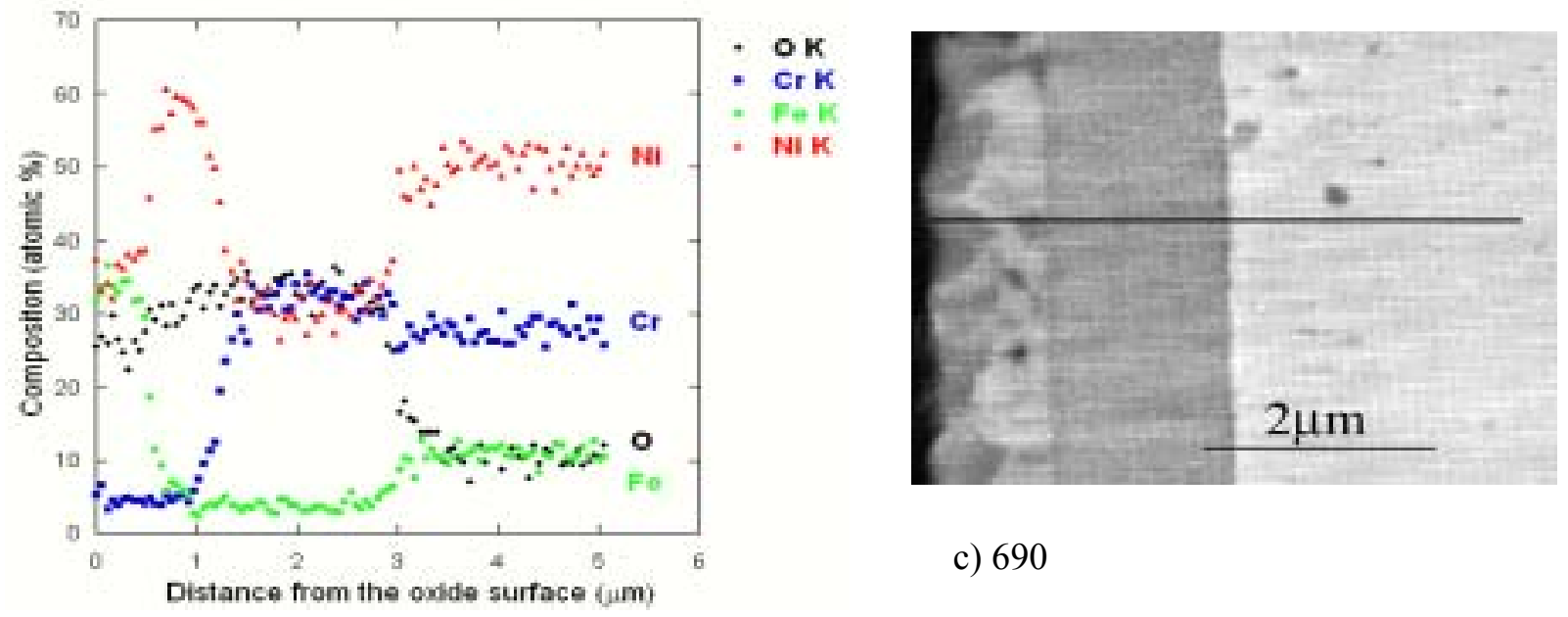

c) 690

Figure 51. Oxide composition profiles and accompanying micrographs for a) 304L, b) 316L and c) 690 in deaerated $\mathrm{SCW}$ at $500{ }^{\circ} \mathrm{C}$. 


\subsubsection{Discussion of Oxidation Results}

The oxidation behavior can be summarized as follows. Oxidation is a strong function of temperature for all alloys, with oxidation increasing non-linearly with temperature. The extent of oxidation as measured by weight gain and oxide thickness are in excellent agreement. The oxide consists of a two-layer structure in all cases studied, in which the outer layer is iron-rich and the inner layer is chromium-rich in the stainless steels. The outer layer is determined to be magnetite and the inner layer is likely an ironchromium spinel. For the nickel-base Alloy 690, the outer layer is nickel-rich and the inner layer is chromium-rich. The outer layer is likely $\mathrm{NiO}$ and the inner layer is most probably a nickel-chromium spinel, $\mathrm{NiCrO}_{4}$.

Because studies of oxides formed in pure SCW are lacking, it is interesting to compare the oxide composition and layer structure formed in pure supercritical water to that formed in vacuum, air and subcritical water. At $600{ }^{\circ} \mathrm{C}$ in vacuum, Zielinksy and Kurzylowski [2000] found that the oxide film on 316 stainless steel is composed of 2 layers: an outer layer consisting mainly of iron oxide, $\mathrm{Fe}_{2} \mathrm{O}_{3}$ (identified by diffraction in TEM), and an inner layer consisting of chromium oxide. Nickel oxide is not present and there is a near surface zone that contains a reduced concentration of $\mathrm{Cr}$ and a high concentration of Ni. These observations are close to what we observed in $500{ }^{\circ} \mathrm{C} \mathrm{SCW}$. They also observed as many as 7 layers to the oxide after exposure of stainless steel in air with iron oxide dominating the outer layers and chromium oxide more prevalent in the inner layers. But they observed a much higher content of $\mathrm{Ni}$ and $\mathrm{Mo}$ in the outer layer.

Briggs [1990] found that oxidation in air at most temperatures showed that a duplex oxide is formed: the outer-most layer consisting of alpha- $\mathrm{Fe}_{2} \mathrm{O}_{3}$, forming before the inner oxide, an iron- chromium oxide. At reduced oxygen partial pressures, a thin, chromium-rich oxide forms first through which grows an iron oxide over layer. At very low oxygen pressure (below $10^{-3} \mathrm{~Pa}$ ) and temperatures above $350{ }^{\circ} \mathrm{C}$, chromium predominates throughout the oxide layer.

Da Cunha Belo et al. [1998] studied the oxide film formed in primary water after $2000 \mathrm{hr}$ of exposure. The outermost part of the film consisted of $\mathrm{Ni}_{0}{ }_{73} \mathrm{Fe}_{2,25} \mathrm{O}_{4}$ inverse spinel. In the intermediate part, both $\mathrm{Ni}_{0}$ ${ }_{73} \mathrm{Fe}_{2,25} \mathrm{O}_{4}$ and $\mathrm{Fe}_{3} \mathrm{O}_{4}$ inverse spinels were detected. Finally, the inner part of the film consisted of mixed chromium oxides $\left(\mathrm{Cr}_{2} \mathrm{O}_{3}+\mathrm{FeCr}_{2} \mathrm{O}_{4}\right)$ and $\mathrm{Fe}_{3} \mathrm{O}_{4}$. This analysis also shows the high concentration of $\mathrm{Ni}$ and $\mathrm{Fe}$ in the outer layer and $\mathrm{Cr}$ in the inner one.

Montenor et al. [2000] studied the effect of $\mathrm{pH}$. They found that when the $\mathrm{pH}$ is just above 5, only chromium oxide is present. When the $\mathrm{pH}$ increases, the chromium concentration of the film decreases in favor of $\mathrm{Fe}$ and $\mathrm{Ni}$. The concentration profile of the oxide formed on their $316 \mathrm{~L}$ sample at $\mathrm{pH} 8$ for 720 $\mathrm{h}$ is similar to what we obtained for $316 \mathrm{~L}$ in $500{ }^{\circ} \mathrm{C}$ deaerated water except that the Ni content is higher. However, after $2200 \mathrm{hr}$ in the same environment, the outer layer is mainly chromium oxide [Dupin et al. 2002].

Haymard et al. [2003] exposed Alloy 316 to degassed, oxygenated water and water containing $3 \% \mathrm{H}_{2} \mathrm{O}_{2}$ at $40 \mathrm{MPa}$ and $420{ }^{\circ} \mathrm{C}$. They found that the introduction of $\mathrm{H}_{2} \mathrm{O}_{2}$ increased the oxidation rate by a factor of 10 over that in pure water. The difference between degassed water and oxygenated water is not significant.

Recently, Kasahara et al. [2003] began a study of potential materials for SCWR's. They looked at the corrosion behavior of Alloys 304, 316, 690, and 625 in subcritical and supercritical water at 290, 380, and $550{ }^{\circ} \mathrm{C}$. All of these experiments lasted for 500 hours and were run at $25 \mathrm{MPa}$ with $8 \mathrm{ppm}$ dissolved oxygen and a conductivity of less than $0.1 \mu \mathrm{S} / \mathrm{cm}$. They revealed that the 316 and 304 stainless steels 
experience weight gains that decreased slightly from 290 to $380{ }^{\circ} \mathrm{C}$ and increased dramatically from approximately $5 \mathrm{mg} / \mathrm{dm}^{2}$ for both alloys at $380{ }^{\circ} \mathrm{C}$ to approximately $90 \mathrm{mg} / \mathrm{dm}^{2}$ for Alloy 304 and approximately $70 \mathrm{mg} / \mathrm{dm}^{2}$ for Alloy 316 after 500 hours of exposure. This compares to weight gains of $11 \mathrm{mg} / \mathrm{dm}^{2}$ and $27 \mathrm{mg} / \mathrm{dm}^{2}$ for the $304 \mathrm{~L}$ and $316 \mathrm{~L}$ stainless steels, respectively, in this study. The difference is likely due to the high oxygen condition used by Kasahara et al. In their work, both the Alloys 625 and 690 showed less weight gain than that of the austenitic stainless steels. However, the results for the nickel-based alloys showed that at some points they gained weight and at other points they lost weight. For example, at $380{ }^{\circ} \mathrm{C}$ Alloy 625 gained approximately $4 \mathrm{mg} / \mathrm{dm}^{2}$ and Alloy 690 had almost no weight change at all after 500 hours. However, at $550{ }^{\circ} \mathrm{C}$, Alloy 625 showed no change in weight and Alloy 690 lost approximately $10 \mathrm{mg} / \mathrm{dm}^{2}$. Both Kasahara's results and the results of this study indicate that more analysis of the oxide than just weight gain will be required to characterize and understand the oxidation of these alloys in supercritical water.

\subsection{Effect Of Oxygen Content On SCC And Corrosion Of 304L Stainless Steel}

Selected experiments were conducted to evaluate the effect of oxygen content on the oxidation and SCC behavior of 304L stainless steel, as high oxygen content is a possible condition in the core of an SCWR. Three SCW conditions were examined; $500{ }^{\circ} \mathrm{C}$ deaerated SCW, $550{ }^{\circ} \mathrm{C}$ deaerated SCW and $550{ }^{\circ} \mathrm{C}$ nondeaerated SCW. Between these three conditions, the effects of temperature and oxygen on both oxidation and SCC can be deduced. The results are plotted in Figure 52. Note that the effect of aeration is to greatly accelerate the oxidation behavior of $304 \mathrm{~L}$ compared to the deaerated case. In fact, the increase in oxidation rate in going from deaerated SCW to nondeaerated $\mathrm{SCW}$ is comparable to that in going from 500 to $550{ }^{\circ} \mathrm{C}$ in deaerated SCW. Also, although not shown, the morphology of the oxide changes as well. The non-deaerated sample at $550{ }^{\circ} \mathrm{C}$ was the only sample to show three distinct layers, in which the two inner layers were similar in composition to those in deaerated SCW, but a third, outer layer was also present that contained a high chromium content and low $\mathrm{Fe}$ content. These results are also summarized in Table 25.

SCC is also strongly affected by aeration. Figure 53 shows the intergranular cracking on the gage section for the three conditions examined. Consistent with what was shown

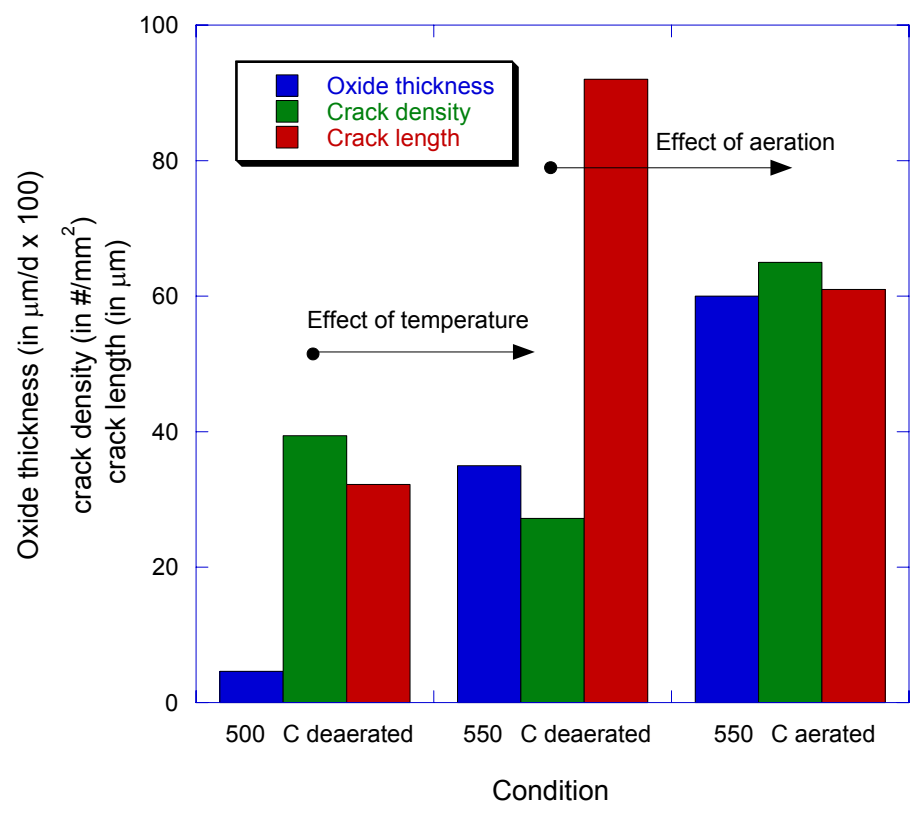

Figure 52. Oxide thickness, gage surface crack density and crack length for $304 \mathrm{~L}$ in $500 \mathrm{C}$ deaerated $\mathrm{SCW}, 550$ ${ }^{\circ} \mathrm{C}$ deaerated SCW and $550{ }^{\circ} \mathrm{C}$ non-deaerated SCW. in the last section, increasing temperature decreases the crack density and increases the crack length. The effect of oxygen is to increase the crack density over the deaerated case, while decreasing the crack length. As measured by crack length per unit of area (crack length $\mathrm{x}$ crack density), cracking in the nondeaerated $550{ }^{\circ} \mathrm{C}$ case is about $60 \%$ more severe than that in the deaerated case. 
Table 25. Oxidation and SCC behavior of 304L in deaerated and aerated SCW.

\begin{tabular}{|l|c|c|c|}
\hline Feature/condition & $\mathbf{5 0 0}^{\mathbf{}} \mathbf{C}$ deaerated & $\mathbf{5 5 0}^{\circ} \mathbf{C}$ deaerated & $\mathbf{5 5 0}^{\circ} \mathbf{C}$ non-deaerated \\
\hline Oxide thickness $(\mu \mathrm{m} / \mathrm{d})$ & 0.046 & 0.35 & 0.60 \\
\hline Crack density $\left(\# / \mathrm{mm}^{2}\right)$ & 39.4 & 27.2 & 64.8 \\
\hline Crack length $(\mu \mathrm{m})$ & 32.2 & 91.8 & 60.6 \\
\hline
\end{tabular}

$304 \mathrm{~L} 500^{\circ} \mathrm{C}$ deaerated
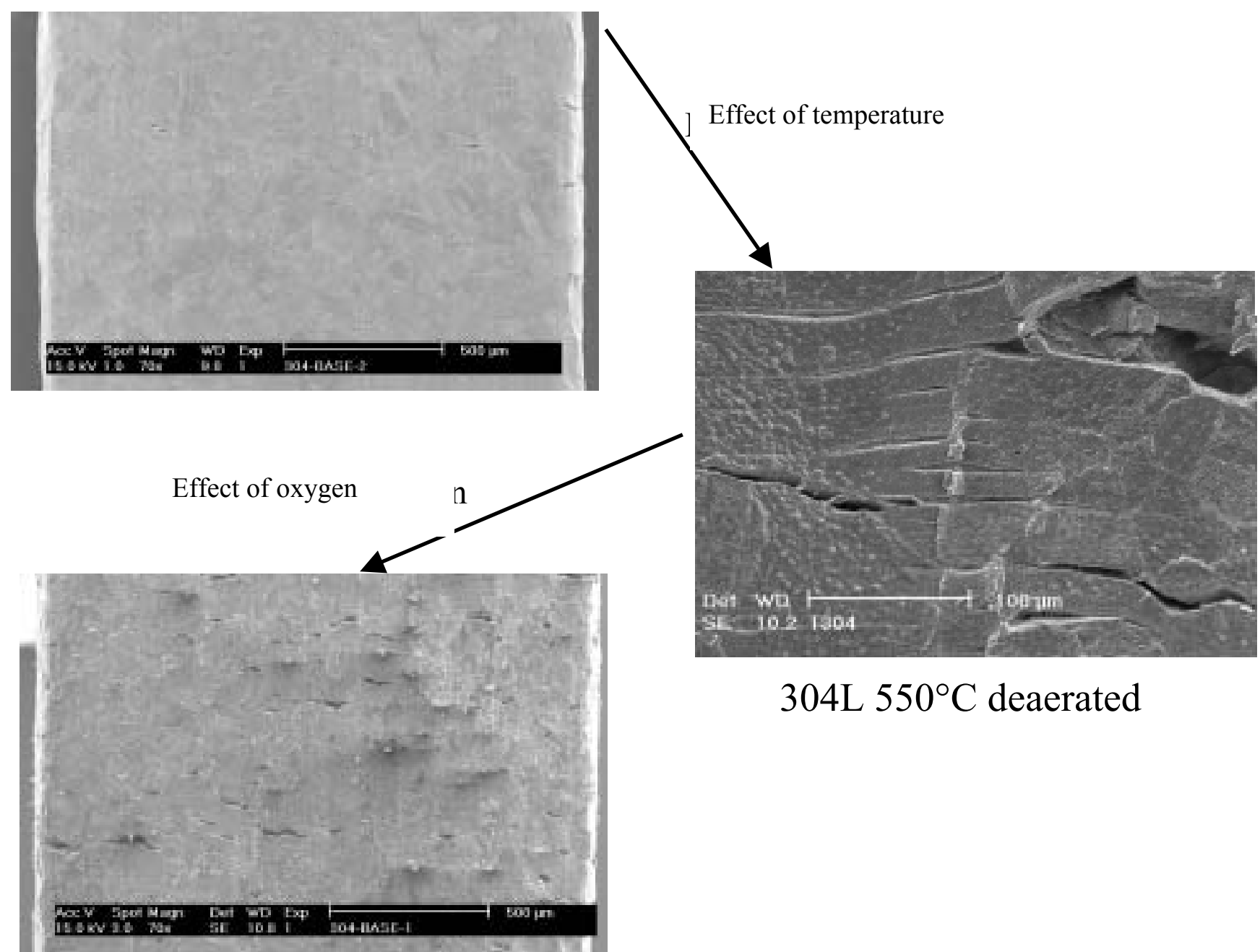

$304 \mathrm{~L} 550^{\circ} \mathrm{C}$ deaerated

\section{$304 \mathrm{~L} 550^{\circ} \mathrm{C}$ non-deaerated}

Figure 53. Surface crack morphology in $304 \mathrm{~L}$ tested in $500{ }^{\circ} \mathrm{C}$ deaerated $\mathrm{SCW}, 550{ }^{\circ} \mathrm{C}$ nondeaerated SCW and $550{ }^{\circ} \mathrm{C}$ deaerated SCW.

\subsection{Effect Of Oxygen Content On SCC And Corrosion Of Ferritic- Martensitic Alloys At $500{ }^{\circ} \mathrm{C}$}

Limited experiments were performed with the ferritic-martensitic candidate alloys and these were aimed at investigating the effect of small levels of oxygen on corrosion and SCC. CERT tests with a strain rate 
of $3 \times 10^{-7} \mathrm{~s}^{-1}$ were performed in the multi test SCC loop with samples of HT-9, HCM12A, and two T91, along with exposure coupons. All the stress-strain plots showed similar work softening behaviors as illustrated in Figure 54(a). Also, the two T91 samples exhibited different stress-strain behavior. The literature data for the mechanical properties of T91 show a large amount of scatter such that the different stress-strain plots for the two T-91 samples fall within this scatter. The behavior of T-91 in deaerated $\mathrm{SCW}, 100 \mathrm{ppb} \mathrm{O}_{2}$ in SCW and Ar gas, all at $500{ }^{\circ} \mathrm{C}$ are shown in Figure 54(b). Only the sample in $\mathrm{Ar}$ has an atypical yield point. Otherwise, the stress-strain behaviors are similar, as are the strains at failure. The argon tests were conducted to serve as reference data for the SCW tests.

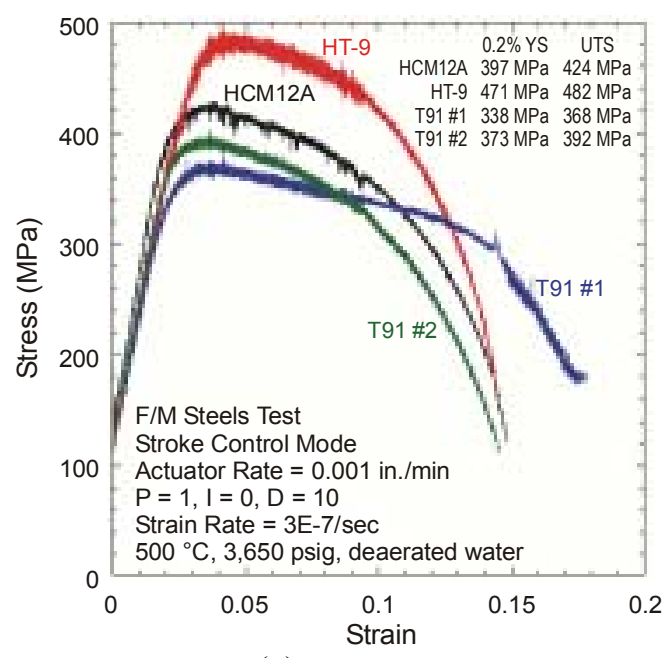

(a)

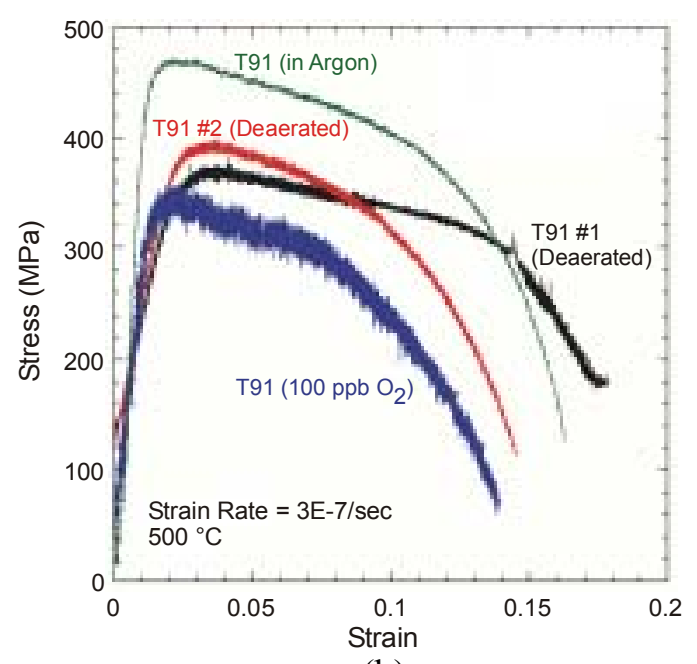

(b)

Figure 54. Engineering stress-strain curves for (a) ferritic-martensitic steels tested in deaerated SCW and (b) T91 compared with the results tested in 100 ppb DO SCW and pure Ar gas.

Typical ductile fracture surfaces were observed, as shown in Figure 55. The fracture surfaces of all the samples except T91 \#1 were exposed to SCW for about a day while waiting for the T91 sample to fail. Therefore, they contained more oxide and were not as clear as that of the T91 \#1 sample. The HT-9 sample showed less necking than other samples. The gage section surface cracks on the HT-9 sample were deeper and wider than the others, as shown in Figure 56. Some surface cracks on the HT-9 sample have an appearance similar to intergranular SCC cracks. The facture and side surfaces of the T91 sample exposed to $100 \mathrm{ppb}$ DO were similar to those of the sample in the deaerated SCW except for the presence of continuous side cracks. The reduction of area for the T91 sample exposed to SCW was lower than that exposed to argon gas.

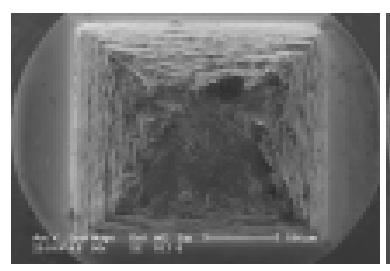

(a) HT-9

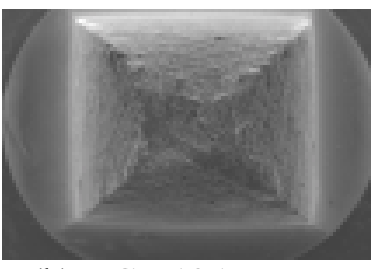

(b) HCM12A

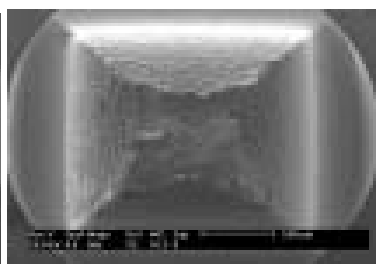

(c) T91 \#1

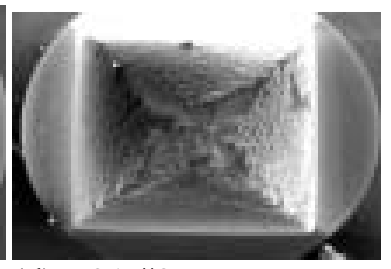

(d) T91 \#2

Figure 55. SEM images of the fracture surfaces. 


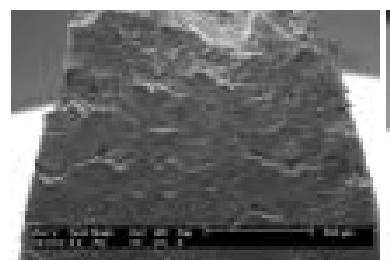

(a) HT-9

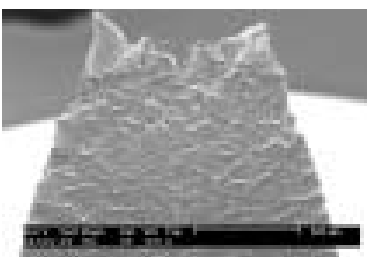

(b) HCM12A

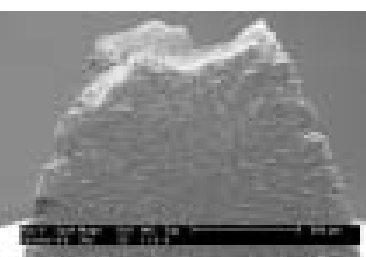

(c) T91 \#1

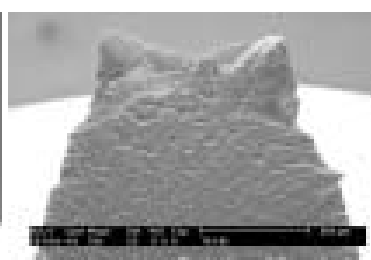

(d) T91 \#2

Figure 56. SEM images of the gage section surfaces.

SEM, EDS, XRD, and XPS were used to analyze the T91 and HCM12A samples exposed to the deaerated SCW. The images from the SEM show two distinct oxide layers from the metal substrate, Figure 57. The results of the composition profile using EDS line scan show two distinct oxide/metal ratios. The atomic percent ratio of the $\mathrm{O} / \mathrm{Fe}$ in the outer oxide layer is 1.27 for the $\mathrm{T} 91$ and 1.30 for the $\mathrm{HCM} 12 \mathrm{~A}$. These values are close to the ratio of the $\mathrm{O} / \mathrm{Fe}$ in $\mathrm{Fe}_{3} \mathrm{O}_{4}(1.33)$. For the inner layer, the $\mathrm{O} / \mathrm{M}$ ratios $(\mathrm{M}=(\mathrm{Fe}, \mathrm{Cr}))$ are 1.46 for the $\mathrm{T} 91$ and 1.37 for the HCM12A. These values are between the $\mathrm{O} / \mathrm{M}$ ratio of $\mathrm{M}_{2} \mathrm{O}_{3}(1.5)$ and $\mathrm{M}_{3} \mathrm{O}_{4}$ (1.33).

The addition of $100 \mathrm{ppb}$ oxygen to the water resulted in two changes to the oxide films on both the T91 and HCM12A. First, the films were about 10\% thinner than in the deaerated case. Second, the stoichiometry of the oxide was slightly more oxygen rich. Both of these observations are consistent with the objectives of combined water chemistry control [Dooley et al. 1992 and 1995] in which the addition of small amounts of oxygen enhance the formation of hematite crystals between the magnetite grains and reduce the oxidation rate. However, the XRD measurements were made only of the outer oxide and this was only magnetite.

Result from the XRD agrees with the chemical composition profiles of the outer oxide layer by the EDS technique. The diffraction patterns show that the outer layer is magnetite $\left(\mathrm{Fe}_{3} \mathrm{O}_{4}\right)$. Because the penetration of X-rays from the surface ranges from $1-5 \mu \mathrm{m}$ and the outer layer is $\sim 5 \mu \mathrm{m}$, only the characteristics of the outer layer are measured. Therefore, it can be concluded that the outer oxide structure is magnetite $\left(\mathrm{Fe}_{3} \mathrm{O}_{4}\right)$.

The XPS analysis suggests that $\mathrm{Fe}_{2} \mathrm{O}_{3}, \mathrm{Fe}_{3} \mathrm{O}_{4}$ and $\mathrm{FeOOH}$ are present in a very thin surface layer. The analysis depth of the XPS is only a few to a hundred nanometers. So it may be possible that a thin layer composed of hematite and $\mathrm{FeOOH}$ sits on top of the magnetite layer. The estimated thickness of this film should be the same as the penetration length for the X-rays.

In conclusion, these results suggest the following oxide structure starting at the metal-oxide interface: metal $-\mathrm{M}_{2} \mathrm{O}_{3}$ or $\mathrm{M}_{3} \mathrm{O}_{4}$ - magnetite - hematite and $\mathrm{FeOOH}$ film. The inner layer likely forms by a solid state oxidation process. The middle layer probably forms by the re-precipitation of magnetite by reprecipitation of the dissolve iron ions. This picture is similar to the oxidation of T91 under steam at 575$650{ }^{\circ} \mathrm{C}$ [Briggs 1990].

For comparison, the weight gain measured after exposure in $500{ }^{\circ} \mathrm{C}$ deaerated SCW for the austenitic alloys is compared to that from the ferritic-martensitic alloys in Figure 58. As shown here, the weight gain is more that 10 times higher for the ferritic-martensitic alloys than for the austenitic alloys. 

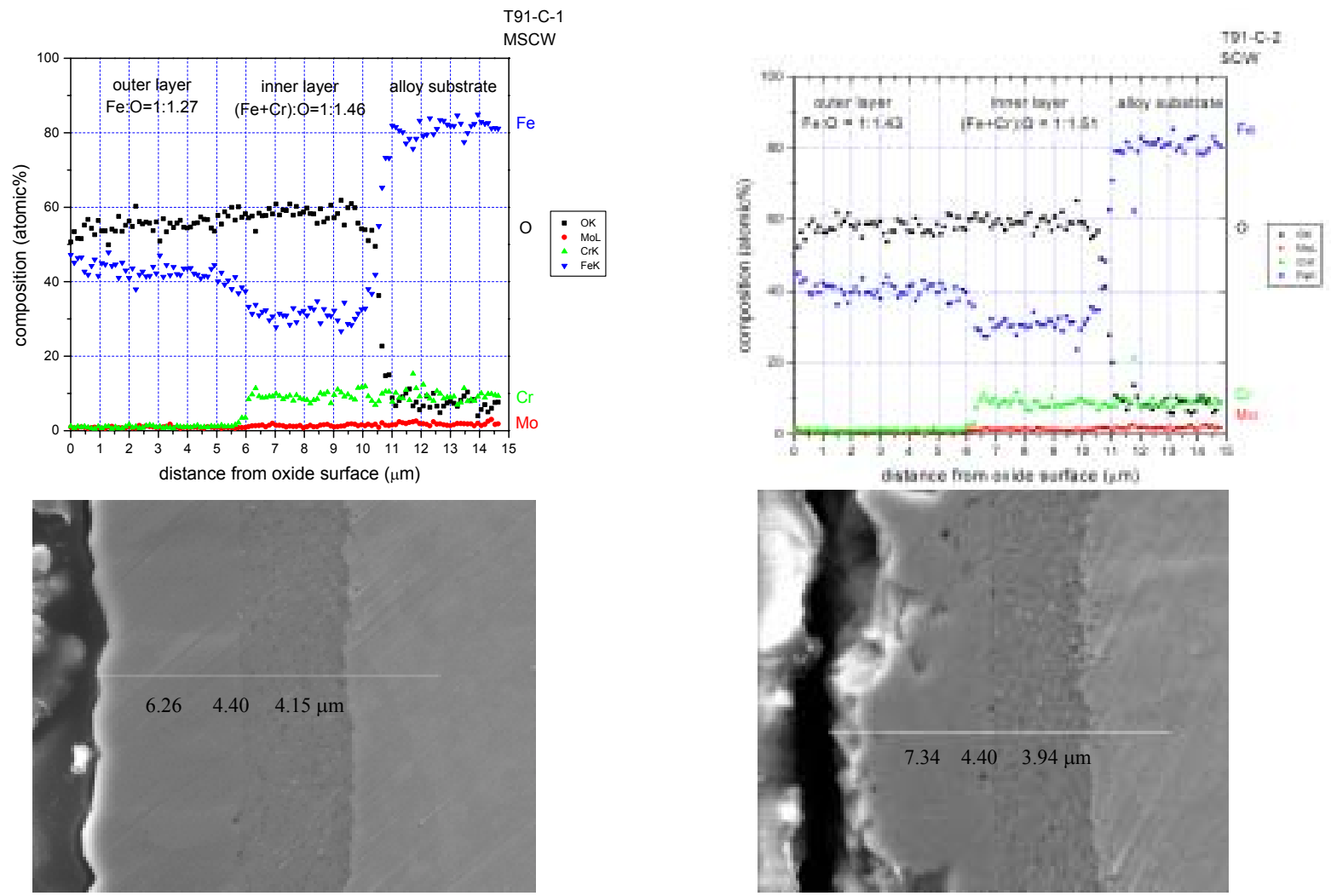

(a) T91 in deaerated SCW

\section{(b) T91 in $100 \mathrm{ppb}$ DO SCW}
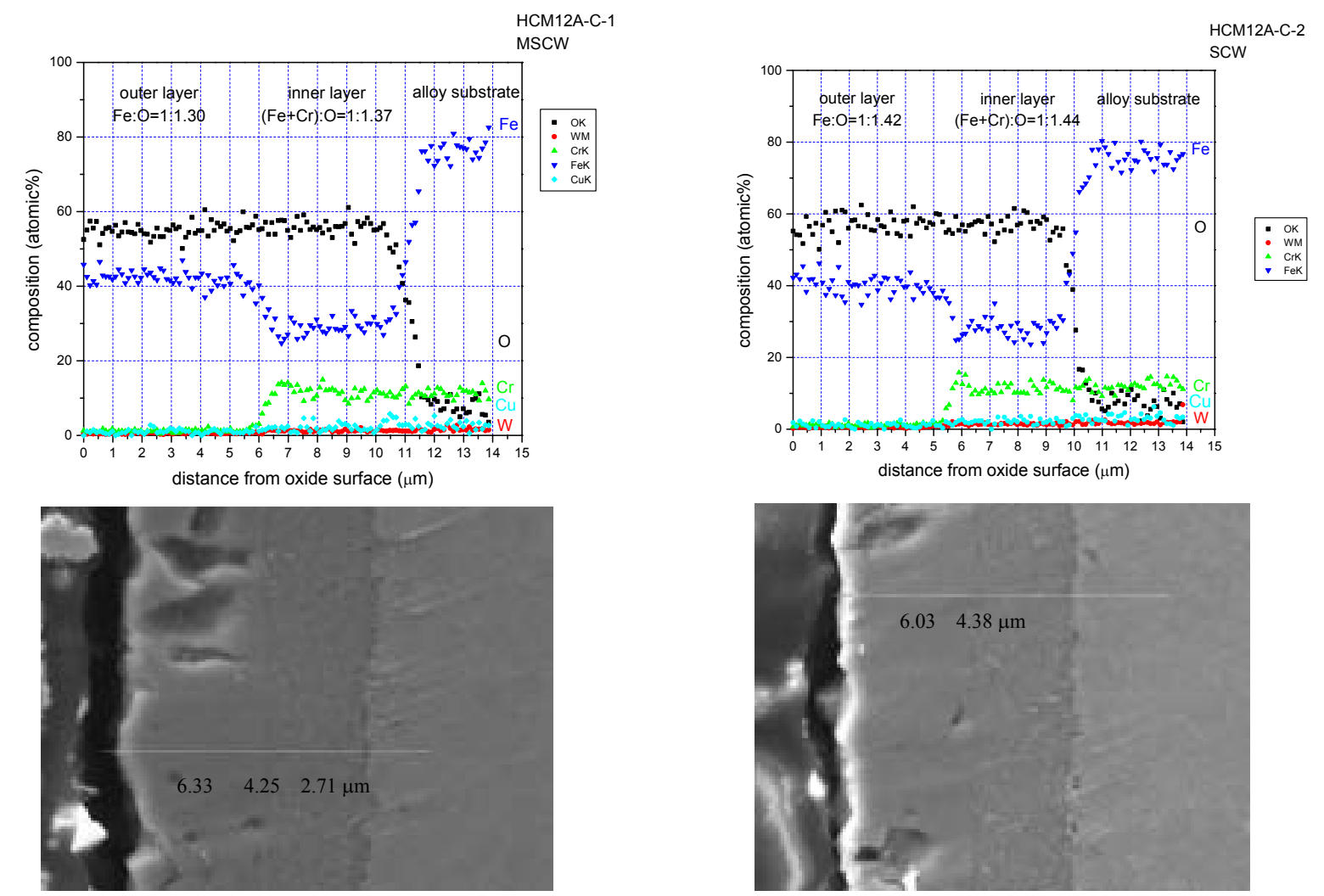

(a) HCM12A in deaerated SCW

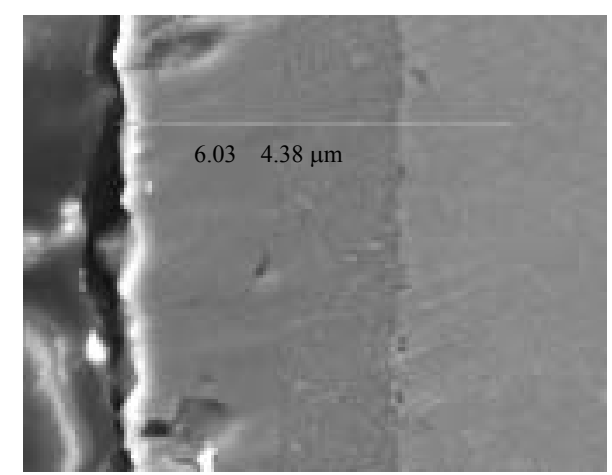

(b) HCM12A in 100 ppb DO SCW

Figure 57. Chemical composition profiles on oxide layer cross-section by using EDS analysis. 


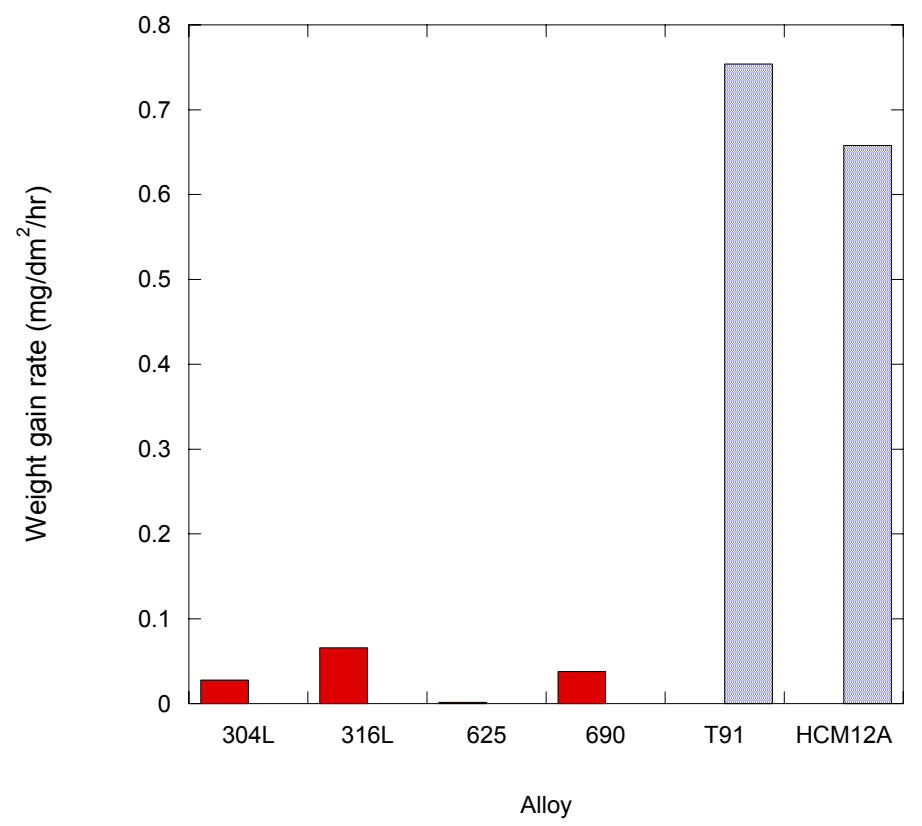

Figure 58. Weight gain rate for austenitic alloys compared to ferritic-martensitic alloys in $500{ }^{\circ} \mathrm{C}$ deaerated SCW.

\subsection{Summary}

All the austenitic alloys tested in deaerated water at temperatures between 400 and $550{ }^{\circ} \mathrm{C}$ show varying degrees of susceptibility to intergranular SCC. Susceptibility is determined by examination of the fracture surface, the gage surface, and by analysis of cross-sections of the tensile bars. All these measures are required to provide the complete description of the cracking behavior. Alloy 625 is the most susceptible, displaying the highest degree of intergranular fracture and some of the deepest cracks along with a very high crack density. The $304 \mathrm{~L}$ stainless steel is the next most susceptible material, showing the deepest intergranular cracks. Alloys 690 and 316L are the least susceptible from all measures considered; crack density, crack depth and crack length.

The degree of austenitic alloy intergranular SCC increases with increasing temperature. As the temperature increases, the crack density decreases but the crack length and depth increase, resulting in a net increase in the intergranular cracking severity as measured by the crack length per unit area.

There is a very strong temperature dependence to the oxidation behavior of the austenitic alloys. The oxidation rate, as measured either by the weight gain or oxide thickness, increases faster with increasing temperature. By $550{ }^{\circ} \mathrm{C}$, the oxide thickness is approaching $10 \mu \mathrm{m}$ within a few houndards of hours. The predominant feature among all of the austenitic alloy oxides is the two-layer structure in which the outer layer is predominantly iron-rich and the inner layer is chromium-rich. X-ray diffraction has shown that the outer layer is magnetite, $\mathrm{Fe}_{3} \mathrm{O}_{4}$. The outer oxide on the 690 alloy is likely NiO.

The ferritic-martensitic alloys do not display any evidence of intergranular SCC as determined by the fracture surface and gage surface analyses. They all display strain softening and ductile rupture. However, the oxidation rates of the ferritic-martensitic alloys are very high compared to the austenitic alloys. At $500{ }^{\circ} \mathrm{C}$, the ferritic-martensitic oxidation rates are a factor of 10 greater than those for the austenitic at the same temperature. These alloys also display a two-layer structure, in which the outer layer is identified as magnetite, $\mathrm{Fe}_{3} \mathrm{O}_{4}$. The $\mathrm{O} / \mathrm{M}$ ratio of the inner layer is closer to hematite, but the 
structure of the inner oxide layer was not verified. The addition of $100 \mathrm{ppb}$ oxygen to the water at $500{ }^{\circ} \mathrm{C}$ resulted in a reduction of the total oxide thickness by about $10 \%$ and a slight increase in the $\mathrm{O} / \mathrm{M}$ ratio. These results are consistent with the objective of combined water chemistry control.

\subsection{Conclusions}

From the standpoint of stress corrosion cracking, Alloy 304L stainless steel and Alloy 625 display significant intergranular SCC over the entire temperature range studied in pure, deaerated supercritical water. Alloy 304L stainless steel has also shown susceptibility to cracking in light water reactor core environments, principally in BWR core shrouds. As such, the region of susceptibility of this alloy to intergranular SCC spans the subcritical and supercritical temperature range $\left(288\right.$ to $550{ }^{\circ} \mathrm{C}$ ), which includes the vast majority of the operational temperature range for the current SCWR design. Alloy 625 also displays significant intergranular SCC susceptibility over the same temperature range. There is much less LWR experience with this alloy, so the susceptibility in LWR environments under subcritical conditions is uncertain. Alloys 316L stainless steel and Alloy 690 both exhibit significantly less intergranular SCC over the temperature range from 400 to $550{ }^{\circ} \mathrm{C}$. Alloy 690 also shows excellent intergranular SCC resistance in the primary water in pressurized water reactors at subcooled temperatures $\left(<320^{\circ} \mathrm{C}\right)$. Alloy $316 \mathrm{~L}$ stainless steel has exhibited intergranular SCC in core shrouds in BWRs at 288 ${ }^{\circ} \mathrm{C}$, but the problems have been mainly observed in Japanese plants where surface preparation methods are suspected as the cause for the high incidence of cracking. All of the austenitic alloys performed well in oxidation tests with oxidation rates on the order of one tenth that of the ferritic-martensitic alloys. However, Alloy 625 exhibited pitting which could become a significant problem in extended exposures.

On the basis of these results, Alloy 316L stainless steel and Alloy 690 are recommended for further study for SCWR core materials application. Next steps with these alloys should be SCC testing under more oxidizing conditions to determine the intergranular SCC resistance in more prototypical environments. Also, these alloys should be investigated for their susceptibility to irradiation assisted SCC by conducting irradiations at relevant temperatures and then subjecting the alloys to SCC testing in the same environments as tested here. Proton irradiations should be conducted first to provide a direct comparison with the results in this report. If the tests prove promising, then further testing should be done on neutron irradiated samples in both constant extension rate mode and also in crack growth rate mode.

The ferritic-martensitic alloys performed well in the limited SCC tests conducted at $500^{\circ} \mathrm{C}$. The only evidence of cracking was in the HT-9 alloy in $500{ }^{\circ} \mathrm{C}$, deaerated, supercritical water, and these observations need to be confirmed by a more comprehensive analysis, and by extension of the experiments to lower temperatures. Ferritic-martensitic alloys have been considered for other reactor designs, but they have not been used as core components in current LWRs. The challenge for use of the ferritic-martensitic alloys in SCWRs is their oxidation rate which is typically 10x that of the austenitic alloys. Preliminary results show that water chemistry has the potential to somewhat reduce the oxidation rates of the ferritic-martensitic alloys in supercritical water.

On the basis of these results, the ferritic-martensitic alloys should be explored further using two approaches. First, more tests need to be conducted in supercritical water with varying oxygen level to determine the extent to which the oxidation rate can be controlled by the water chemistry. Second, it is unlikely that these alloys can be used for some of the very thin section components in the current SCWR design unless the oxidation rates are substantially reduced. It is recommended that both bulk alloying (either by experiment or by considering some of the more advanced $9 \mathrm{Cr}$ and $12 \mathrm{Cr}$ steels) and surface modification should be explored as strategies for reducing the oxidation rate by up to an order of magnitude. 


\title{
5. Task 3 Results: Plant Engineering and Reactor Safety Analysis
}

\subsection{Thermal-Hydraulic Assessment of a Supercritical Water Reactor (SCWR) Core (Westinghouse Electric Co., Dr. Luca Oriani and Dr. Vefa N. Kucukboyaci)}

\begin{abstract}
5.1.1. Introduction
The Westinghouse tasks included an assessment of the SCWR reference core thermal hydraulic design. A complete review of the Westinghouse SCWR core assessment activities is provided in Westinghouse Report STD-ES-04-45, while in this report the focus is mostly on the final analyses and the main conclusions of the analyses effort.

The first step in performing the core thermal-hydraulic assessment was identification of the design limits that were then used to evaluate the acceptability of the core design. Section 2 of STD-ES-04-45 and the $2^{\text {nd }}$ and $3^{\text {rd }}$ Quarterly reports for this NERI project (MacDonald et al. 2002a and 2002b) provide the considerations used in defining the design limits for the SCWR. Once the boundaries of the analysis were defined, simplified calculations were performed to provide an initial characterization of the design. These analyses are summarized in Section 3 of STD-ES-04-45 and the Year 2 Annual Report (MacDonald et al. 2003). Based on the results of the simplified analysis, it was concluded that the SCWR, due to its very large enthalpy rise along the core, is sensitive to small deviations from normal conditions, especially variations in the flow to power ratio. Thus, even small effects due to various hot channel factors (coolant flow channel tolerances, operational variations, etc.) might have a large impact on the peak cladding temperature of some fuel rods. This is a major feasibility issue for the SCWR, and thus it was decided to perform detailed subchannel analysis of the SCWR core to provide a more in depth assessment of this issue.
\end{abstract}

The W-VIPRE code was adapted for the analysis of reactor cores with supercritical water, and new correlations that are considered adequate for SCWR analysis were implemented in the code. The modified W-VIPRE code and the input assumptions for the analysis of the SCWR core are summarized in Subsection 5.1.2.1. A complete characterization, including sensitivity studies, of the SCWR with the modified VIPRE core is documented in Sections 5.1.2.2 and 5.1.2.3, while Section 5.1.2.4 summarizes the results of this initial subchannel analyses study.

Based on these results, sufficient information was available for a preliminary thermal-hydraulic optimization of the SCWR core design. Temperature profiles for various core geometries were then analyzed with two different objectives: (1) to identify an optimal geometry that minimizes the temperature differences between core channels, and (2) to confirm and characterize the sensitivity of the temperature profile to the local flow to power ratios. The need of maintaining uniform conditions at the exit of the core is dictated by the fact that safety limits need to be verified for the limiting fuel rod, while the plant performance depends on the average core exit conditions. Thus, a uniform temperature distribution minimizes the "wasted" design margin. These analyses are documented in Section 5.1.3 (Section 5 of STD-ES-04-45).

Based on the results of this study, the SCWR with the reference core design does not appear to be feasible. Although additional design and analysis might allow the recovery of some margin, it is unlikely that a SCWR assembly and core design can be developed that provides acceptable performance (i.e. low 
enough hot channel exit temperature). Therefore, the SCWR core design remains a major feasibility issue for which a solution has yet to be achieved.

\subsubsection{Initial Supercritical Water Reactor Sub-Channel Analysis}

Following the preliminary thermal-hydraulic analyses of the SCWR system, which were qualitative in nature, more detailed sub-channel analyses of the SCWR core were performed. The VIPRE-W code, used by Westinghouse for detailed LWR core thermal-hydraulic design analyses and for LWR licensing purposes, was adapted for use in these analyses. VIPRE-W was already capable of handling supercritical water conditions; therefore most of the required modifications had to do with implementation of constitutive models (heat transfer correlations and friction loss correlations). Also, while the EPRI water/steam properties implemented in the code are capable of handling supercritical water up to a temperature of about $800{ }^{\circ} \mathrm{C}$ and a pressure of up to $100 \mathrm{MPa}$, the ASME steam tables typically used by Westinghouse were also added to the code to provide for comparison between the EPRI and ASME tables, and to verify the accuracy of the tables in the supercritical region.

Section 5.1.2.1 presents the VIPRE-W model. For this analysis, a quarter core with a detailed assembly in the center, and simplified lumped assemblies elsewhere, were considered. The constitutive equations used for heat transfer and friction loss are presented in Section 5.1.2.2. The thermal-hydraulic profiles including the pressure-drop, flow velocity, temperature, and enthalpy rise in the hot and average channels are presented in Section 5.1.2.3 for both the nominal and above-nominal power conditions. Finally, a preliminary sensitivity study is presented in Section 5.1.2.4 that evaluates the effects of changes in selected parameters including fuel pitch, loss coefficients, and inlet temperature.

\subsubsection{VIPRE-W Model}

A VIPRE-W model was developed for sub-channel analysis of the Supercritical Water Reactor (SCWR). A quarter-core is considered in this model, with explicit channel/gap and fuel rod representation in the central fuel assembly. The channels and rods are lumped in all the other assemblies; hence each fuel assembly is represented by a single channel and fuel rod. The water channels are not modeled (assumed adiabatic boundaries), since their presence will not have a significant impact on the coolant channel thermal-hydraulics (they are isolated from the channels), and modeling the water rods would complicate the VIPRE-W code.

On the basis of our preliminary SCWR analyses, it was decided to develop and use two separate core models. One model was used for the core-wide analyses (for example to evaluate flow splits between assemblies, size the inlet orifices for an optimal flow distribution, evaluate parallel channel stability, etc.) and one model included a detailed model of the center assembly. The core-wide model is identical to the model described in the following paragraphs, except for the central assembly, which was also lumped into a single channel.

Table 26 shows the summary of the current SCWR reference design. All sub-channel data in this model are based on the information provided in this table. Note that this model is not identical to the one used for the previous simplified analyses. This is consistent with the evolving nature of this program, since different analysis and optimization tasks were ongoing in parallel. 
Table 26: Summary table for the SCWR reference design.

\begin{tabular}{|c|c|c|c|}
\hline Parameter & Value & Parameter & Value \\
\hline Thermal power & $3022 \mathrm{MW}$ & FUEL ASSEMBLY & \\
\hline Electric power & $1315 \mathrm{MW}$ & Fuel pin lattice & Square \\
\hline Thermal efficiency & $43.5 \%$ & Fuel pins per assembly & 301 \\
\hline Operating pressure & $25 \mathrm{MPa}$ & Water rods per assembly & 36 \\
\hline Reactor inlet/outlet temp & $280 / 500^{\circ} \mathrm{C}$ & Water rod side & $32.6 \mathrm{~mm}$ \\
\hline Reactor flow rate & $1561 \mathrm{~kg} / \mathrm{s}$ & Water rod wall thickness & $0.4 \mathrm{~mm}$ \\
\hline FUEL PIN & & Water rod wall materials & TBD \\
\hline Fuel pin OD & $10.2 \mathrm{~mm}$ & $\begin{array}{l}\text { Number of instrumentation } \\
\text { rods per assembly }\end{array}$ & 1 \\
\hline Fuel pin pitch & $11.2 \mathrm{~mm}$ & $\begin{array}{l}\text { Number of CR fingers per } \\
\text { assembly }\end{array}$ & 36 \\
\hline Cladding thickness & $0.63 \mathrm{~mm}$ & CR material & $\begin{array}{l}\mathrm{B}_{4} \mathrm{C} \text { for scram, } \\
\mathrm{Ag}-\mathrm{In}-\mathrm{Cd} \text { for control }\end{array}$ \\
\hline Cladding materials & ODS steel & Number of spacer grids & 14 \\
\hline Fuel pellet OD & $8.94 \mathrm{~mm}$ & Assembly wall thickness & $3 \mathrm{~mm}$ \\
\hline Fuel composition & $\mathrm{UO}_{2}, 95 \% \mathrm{TD}$ & Assembly wall material & ODS steel \\
\hline Fuel enrichment & $5 \%$ wt. average & Assembly side & $292.2 \mathrm{~mm}$ \\
\hline Average burnup at discharge & $45,000 \mathrm{MWD} / \mathrm{t}$ & Inter-assembly gap & $4 \mathrm{~mm}$ \\
\hline Burnable poisons & $\mathrm{Gd}_{2} \mathrm{O}_{3}$ & Assembly pitch & $296.2 \mathrm{~mm}$ \\
\hline Heated length & $4.27 \mathrm{~m}$ & CORE & \\
\hline Fission gas plenum length & $0.39 \mathrm{~m}$ & Number of fuel assemblies & 121 \\
\hline Total fuel pin height & $4.66 \mathrm{~m}$ & Equivalent diameter & $3.68 \mathrm{~m}$ \\
\hline Fill gas pressure at room temp & 3.0 MPa & Core barrel ID/OD & $4.1 / 4.2 \mathrm{~m}$ \\
\hline $\begin{array}{l}\text { REACTOR PRESSURE } \\
\text { VESSEL }\end{array}$ & & $\begin{array}{l}\text { Axial/Radial/Local/Total } \\
\text { Peaking Factor }\end{array}$ & $\begin{array}{l}1.4 / 1.3 / 1.1 / 2.0 \text { (best estimate) } \\
1.4 / 1.4 / 1.2 / 2.35 \text { (safety } \\
\text { analysis) }\end{array}$ \\
\hline ID/OD/Height & $4.6 / 5.34 / 12.40 \mathrm{~m}$ & Average power density & $66.7 \mathrm{~kW} / \mathrm{L}$ \\
\hline Material & $\begin{array}{l}\text { Carbon steel clad } \\
\text { with stainless steel }\end{array}$ & Average linear power & $19.5 \mathrm{~kW} / \mathrm{m}$ \\
\hline Cold/hot nozzles & $2 / 2$ & $\begin{array}{l}\text { Peak linear power at steady- } \\
\text { state conditions }\end{array}$ & $39 \mathrm{~kW} / \mathrm{m}$ \\
\hline Operating temperature & $280^{\circ} \mathrm{C}$ & Core pressure drop & $0.15 \mathrm{MPa}$ \\
\hline Design pressure & $27.5 \mathrm{MPa}$ & Water rod flow & $468 \mathrm{~kg} / \mathrm{s}$ \\
\hline
\end{tabular}

Figure 59 shows the quarter-core VIPRE-W model of the SCWR. A total of 169 channels, of which 133 are in the central assembly, are present in this model. The channels are divided into 129 axial nodes with $\sim 1.5$ inch axial length. 204 gaps connect the channels in the central assembly. Each fuel assembly has a $25 \times 25$ rod arrangement with 36 water channels. There are 300 fuel rods and a single instrumentation rod per assembly. Note that since the SCWR design employs canned fuel assemblies, no cross-flows, hence no gaps exist between assemblies. In VIPRE-W modeling, a sub-channel is defined by the flow area, wetted perimeter, and heated perimeter; gaps are defined by the channel indices that they connect, gap widths, and centre-to-centre distance between the channels. Tables $27-29$ show how the flow areas, and wetted and heated perimeters are calculated for different types of channels. Figure 60 shows the detailed channel, gap, and fuel rod configurations in the central assembly. 


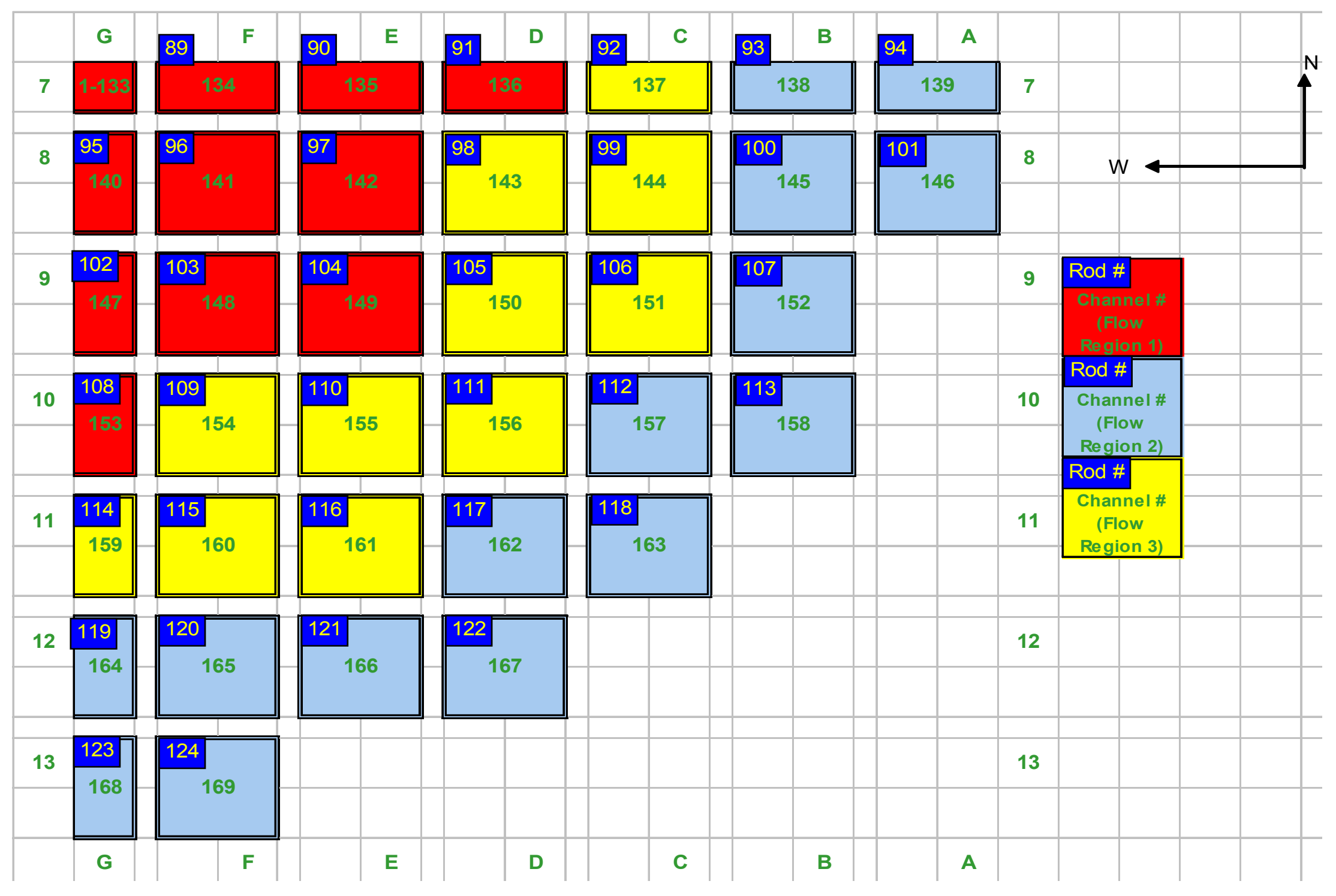

Figure 59. VIPRE-W core model for the SCWR. 

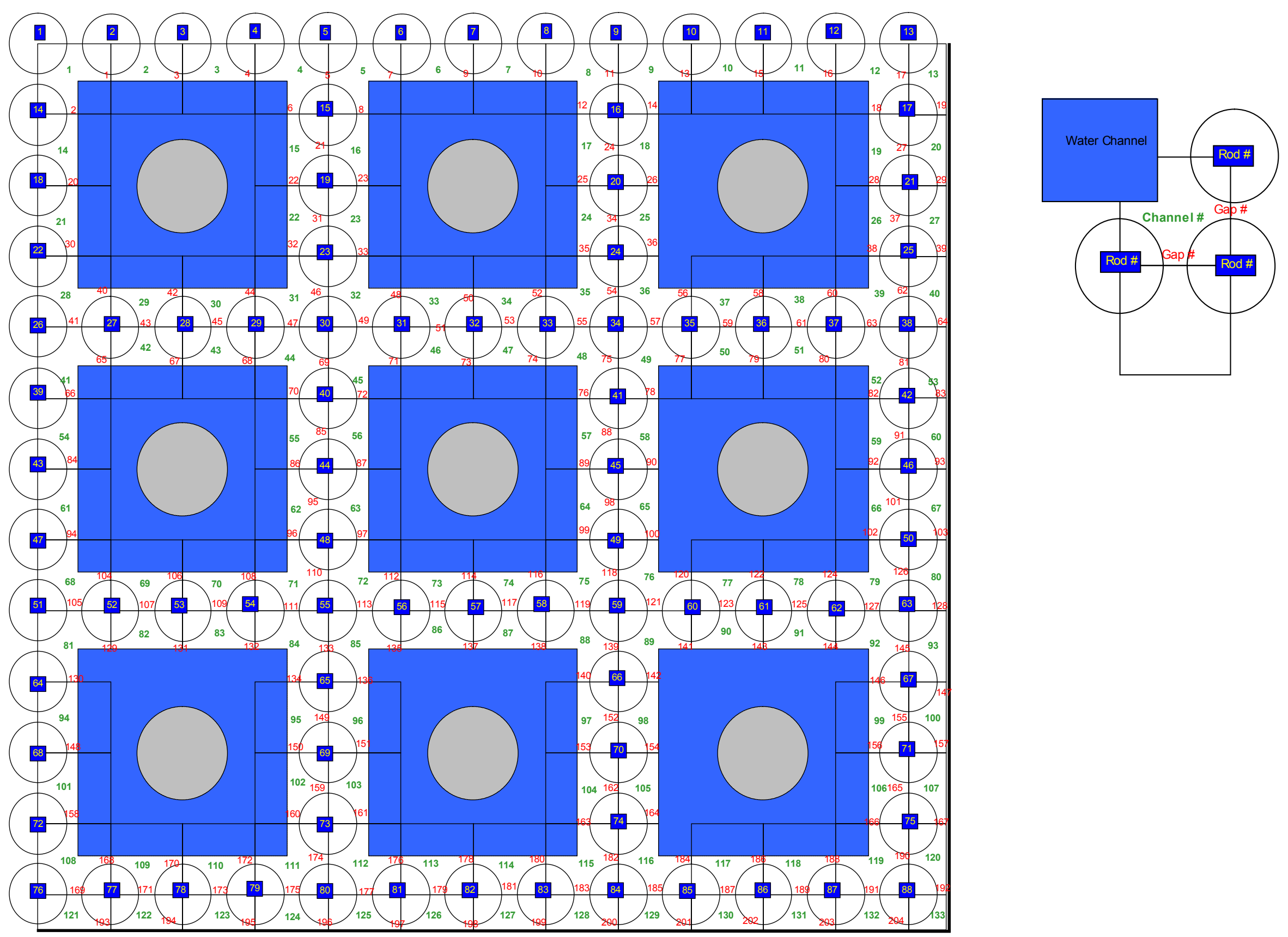

Figure 60. Channels, gaps, antd rods in the central fuel assembly. 
Table 27. Calculation of the flow areas used in the SCWR Model

Flow Area Type

1

2

3

4

5
Flow Area Equation

$$
\frac{3}{4} P_{r o d}^{2}-\frac{3}{4} * \pi * \frac{D_{r o d}^{2}}{4}
$$

$$
\frac{1}{2} P_{r o d}^{2}-\frac{1}{2} * \pi * \frac{D_{r o d}^{2}}{4}
$$$$
\frac{1}{4} P_{r o d}^{2}-\frac{1}{4} * \pi * \frac{D_{r o d}^{2}}{4}
$$

$$
\frac{1}{2}\left(P_{\text {assy }}^{2}-301 * \pi * \frac{D^{2}}{4}-36 *\left(9 * P_{\text {rod }}^{2}\right)\right)
$$

$$
P_{a s s y}^{2}-301 * \pi * \frac{D^{2}}{4}-36 *\left(9 * P_{r o d}^{2}\right)
$$

Flow Area $\left(i^{2}\right)$

0.0508329

0.0338886

0.0169443

10.2004771

20.4009541

Table 28. Calculation of the wetted perimeters used in the SCWR Model

Wetted Perimeter Type

1

2

3

4

5
Wetted Perimeter Equation

$$
\frac{3}{4} * \pi * D_{r o d}+P_{r o d}
$$$$
\frac{1}{2} * \pi * D_{\text {rod }}+P_{\text {rod }}
$$$$
\frac{1}{4} * \pi * D_{\text {rod }}
$$

$\frac{1}{2}\left(4 * P_{\text {assy }}+301 * \pi * D+36 * 4 *\left(3 * P_{\text {rod }}\right)\right)$

$4 * P_{a s s y}+301 * \pi * D+36 * 4 *\left(3 * P_{r o d}\right)$
Wetted Perimeter (in)

0.3153961

307.1597982

614.3195964

Table 29. Calculation of the heated perimeters used in the SCWR Model

Heated Perimeter Type$$
1
$$

2

3

4

5

\section{Heated Perimeter Equation} $\frac{3}{4} * \pi * D_{\text {rod }}$

$\frac{1}{2} * \pi * D_{\text {rod }}$

$\frac{1}{4} * \pi * D_{\text {rod }}$

$\frac{1}{2}(300 * \pi * D)$

$300 * \pi * D$
Heated Perimeter (in) 0.946188338

0.630792225

0.315396113

189.2377000

378.4753000

Three different radial power distributions were used to analyze the central assembly. One was based on use of a single fuel rod enrichment, one was based on use of five enrichments, as depicted in Figure 61, and one was based on the assumption of an ideal enrichment distribution that would make the power in all 
the fuel rods the same. Table 30 shows the three radial power distributions in the central assembly. A symmetric chopped cosine axial power profile with a peaking factor of 1.55 was used for all the fuel rods in the assembly. The total heated length was 168.11 inches and the axial power profile started at $\sim 10$ inches relative to the channel inlet, considering the inlet nozzle and other non-power structures in the assembly.

Table 30. Radial power distributions used in the VIPRE-W calculations

\begin{tabular}{|c|c|c|c|}
\hline \multirow[b]{2}{*}{$\begin{array}{c}\text { Pin } \\
\text { Number }\end{array}$} & \multicolumn{3}{|c|}{ Normalized Power } \\
\hline & $\begin{array}{c}\text { Uniform } \\
\text { enrichment }\end{array}$ & $\begin{array}{l}5 \text { enrichments } \\
\text { (not optimized) }\end{array}$ & $\begin{array}{l}\text { Ideal enrichment } \\
\text { distribution }\end{array}$ \\
\hline$(1,1)$ & 0 (inst.pin) & 0 (inst. pin) & 0 (inst.pin) \\
\hline$(1,2)$ & 1.2129 & 1.0362 & 1.000 \\
\hline$(1,3)$ & 1.2710 (hot pin) & 1.0959 & 1.000 \\
\hline$(1,4)$ & 1.1643 & 1.1470 & 1.000 \\
\hline$(1,5)$ & 1.0542 & 1.1486 (hot pin) & 1.000 \\
\hline$(1,6)$ & 1.1388 & 1.0857 & 1.000 \\
\hline$(1,7)$ & 1.2191 & 1.0482 & 1.000 \\
\hline$(1,8)$ & 1.1294 & 1.0794 & 1.000 \\
\hline$(1,9)$ & 1.0132 & 1.0345 & 1.000 \\
\hline$(1,10)$ & 1.0798 & 0.9907 & 1.000 \\
\hline$(1,11)$ & 1.1201 & 1.0033 & 1.000 \\
\hline$(1,12)$ & 0.9808 & 0.9571 & 1.000 \\
\hline$(1,13)$ & 0.7741 & 0.8864 & 1.000 \\
\hline$(2,5)$ & 1.1588 & 1.0976 & 1.000 \\
\hline$(2,9)$ & 1.1062 & 1.0314 & 1.000 \\
\hline$(2,13)$ & 0.8164 & 0.9593 & 1.000 \\
\hline$(3,5)$ & 1.2316 & 1.0725 & 1.000 \\
\hline$(3,9)$ & 1.1863 & 0.9823 & 1.000 \\
\hline$(3,13)$ & 0.8599 & 1.0111 & 1.000 \\
\hline$(4,5)$ & 1.1523 & 1.0716 & 1.000 \\
\hline$(4,9)$ & 1.1014 & 1.0354 & 1.000 \\
\hline$(4,13)$ & 0.8214 & 0.9680 & 1.000 \\
\hline$(5,5)$ & 1.0396 & 1.0514 & 1.000 \\
\hline$(5,6)$ & 1.1345 & 1.0632 & 1.000 \\
\hline$(5,7)$ & 1.2119 & 1.0386 & 1.000 \\
\hline$(5,8)$ & 1.1243 & 1.0657 & 1.000 \\
\hline$(5,9)$ & 0.9963 & 1.0622 & 1.000 \\
\hline$(5,10)$ & 1.0659 & 0.9815 & 1.000 \\
\hline$(5,11)$ & 1.1031 & 1.0076 & 1.000 \\
\hline$(5,12)$ & 0.9703 & 0.9502 & 1.000 \\
\hline$(5,13)$ & 0.7713 & 0.8859 & 1.000 \\
\hline$(6,9)$ & 1.0969 & 1.0292 & 1.000 \\
\hline$(6,13)$ & 0.8111 & 0.9322 & 1.000 \\
\hline$(7,9)$ & 1.1651 & 1.0849 & 1.000 \\
\hline$(7,13)$ & 0.8437 & 0.9977 & 1.000 \\
\hline$(8,9)$ & 1.0812 & 1.0766 & 1.000 \\
\hline$(8,13)$ & 0.7960 & 0.9298 & 1.000 \\
\hline$(9,9)$ & 0.9601 & 0.9528 & 1.000 \\
\hline$(9,10)$ & 1.0290 & 1.0118 & 1.000 \\
\hline$(9,11)$ & 1.0579 & 1.0462 & 1.000 \\
\hline$(9,12)$ & 0.9359 & 0.8842 & 1.000 \\
\hline$(9,13)$ & 0.7412 & 0.9318 & 1.000 \\
\hline$(10,13)$ & 0.7658 & 0.8654 & 1.000 \\
\hline$(11,13)$ & 0.7773 & 0.8953 & 1.000 \\
\hline$(12,13)$ & 0.7027 & 0.8934 & 1.000 \\
\hline$(13,13)$ & 0.6112 & 0.7574 & 1.000 \\
\hline
\end{tabular}

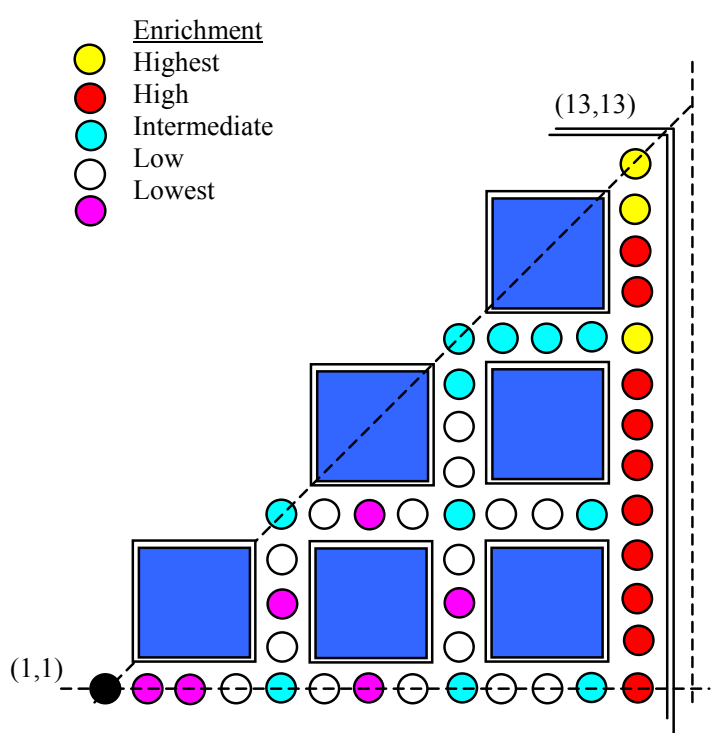

Figure 61. Enrichment configuration used to calculate the local power distribution

The total inlet flow was specified as $859.5815 \mathrm{lbm} / \mathrm{s}$ and uniformly split among the channels as equal mass flux per channel. 


\subsubsection{Heat Transfer and Friction Loss Correlations}

The three heat transfer correlations implemented in the VIPRE-W code were:

\section{Correlation of Bishop et al. (1964):}

$$
\begin{aligned}
& N u_{B}=0.0069 \operatorname{Re}_{B}^{0.90} \operatorname{Pr}_{B}^{0.06}\left(\frac{\rho_{w}}{\rho_{b}}\right)^{0.43}\left(1+\frac{2.4 D}{L}\right) \\
& \operatorname{Pr}_{B}=\left(\frac{C_{P} \mu_{B}}{\lambda_{b}}\right) \\
& C_{P}=\left(\frac{h_{w}-h_{b}}{T_{w}-T_{b}}\right)
\end{aligned}
$$

Parameter Ranges:
P: $22.6-27.5 \mathrm{MPa}$
G: $\quad 0.68-3.6 \mathrm{Mg} / \mathrm{m}^{\wedge} 2 \mathrm{~s}$
Q: $0.31-3.5 \mathrm{MW} / \mathrm{m}^{\wedge} 2$
D: $2.5-5.1 \mathrm{~m}$
L/D: $30-365$
$\mathrm{T}_{\mathrm{B}}: 294-525^{\circ} \mathrm{C}$
$\Delta: 16-216{ }^{\circ} \mathrm{C}$

Correlation of Oka-Koshizuka et al. (2000):

$$
\begin{aligned}
& N u=0.015 \mathrm{Re}^{0.85} \operatorname{Pr}^{C} \\
& C=0.69-\frac{81000}{D H F}+f_{c} q^{\prime \prime} \\
& f_{c}= \begin{cases}2.9 E-08+\frac{0.11}{D H F} & 0 \leq h \leq 1500 \mathrm{KJ} / \mathrm{kg} \\
-8.7 E-08-\frac{0.65}{D H F} & 1500 \leq h \leq 3300 \mathrm{KJ} / \mathrm{kg} \\
-9.7 E-07+\frac{1.30}{D H F} & 3300 \leq h \leq 4000 \mathrm{KJ} / \mathrm{kg}\end{cases} \\
& \text { and } D H F=200 . G^{1.2}
\end{aligned}
$$

\section{Correlation of Jackson (1979):}

$$
N u_{b}=0.0183 \cdot \operatorname{Re}_{b}{ }^{0.82} \cdot \operatorname{Pr}_{b}^{0.5} \cdot\left(\frac{\rho_{w}}{\rho_{b}}\right)^{0.3}\left(\frac{\overline{c p}}{c p_{b}}\right)^{n}
$$

where: $b$ indicates bulk fluid properties, $w$ indicate wall properties, $\overline{c p}$ indicates an integrated value $\left(\overline{C p}=\frac{h_{w}-h_{b}}{T_{w}-T_{b}}\right)$ and $n$ is defined as:

$$
\begin{aligned}
& n=0.4 \text { for } T_{b}<T_{w}<T_{p c} \text { and for } T_{p c}<T_{b}<1.2 T_{p c} \\
& \left.n=0.4+0.2\left(\left(T_{w} / T_{p c}\right)-1\right)\right) \text { for } T_{b}<T_{p c}<T_{w} \\
& n=0.4+0.2\left(\left(T_{w} / T_{p c}\right)-1\right)\left(1-5\left(\left(T_{w} / T_{p c}\right)-1\right)\right) \text { for } T_{p c}<T_{b}<1.2 T_{p c} \text { and } T_{b}<T_{w}
\end{aligned}
$$

Axial friction pressure drop is calculated for turbulent flow at supercritical pressures using the following correlation (Petrov and Popov 1988): 
$f=\left(1.82 \log \left(\frac{\operatorname{Re}}{8}\right)\right)^{-2.0}\left(\frac{\rho_{W}}{\rho_{B}}\right)^{0.4}$

Typical PWR axial friction coefficients are used at the inlet, outlet and mid-grids $(2.37,0.97$, and 0.725 , respectively). As for the lateral resistance, the Idel'chik correlation (Idel'chik 1966) for cross-flow over banks of tubes is used, in which the lateral drag coefficient is calculated as:

Lateral drag coeff $=1.52 *\left\{\left(\frac{\text { Pitch }}{\text { Diameter }}\right)-1.0\right\}^{-0.5}$

\subsubsection{Thermal-Hydraulic Profiles in the Hot and Cold Channels for Different Radial Power Distributions}

Using the model described above, VIPRE-W simulations were performed to obtain thermal-hydraulic profiles of interest, including pressure drop, flow velocity, density, temperature, and enthalpy rise. The results are presented for both nominal and above-nominal power and flow conditions and for both the hot and cold channels, where hot channel is defined as the channel where the maximum coolant temperature occurs and the cold channel as the one with the lowest coolant exit temperature in the bundle.

Nominal Power and Flow Conditions. A first analysis was performed to evaluate the thermal-hydraulic characteristics of the SCWR core at nominal reactor conditions. The SCWR core model was analyzed assuming boundary conditions directly derived from the reference configuration presented in Table 26 .

Figure 62 shows the pressure drop in the hot and cold channels of the hot assembly for the case with a power distribution from a single enrichment. For both hot and cold channels, the total pressure drop calculated is $\sim 15.6 \mathrm{psi}$, which is comparable to LWR cores. The figure also shows the axial pressure losses associated with the grid spacers, which were placed uniformly along the channel. Note that both the SCWR grid design and location are still open design issues, so generic assumptions were made based on PWR and BWR related experience. Similar values were obtained for the cases of an assembly with 5 different fuel rod enrichments and a uniform power distribution.

Figure 63 shows the flow velocity profile along

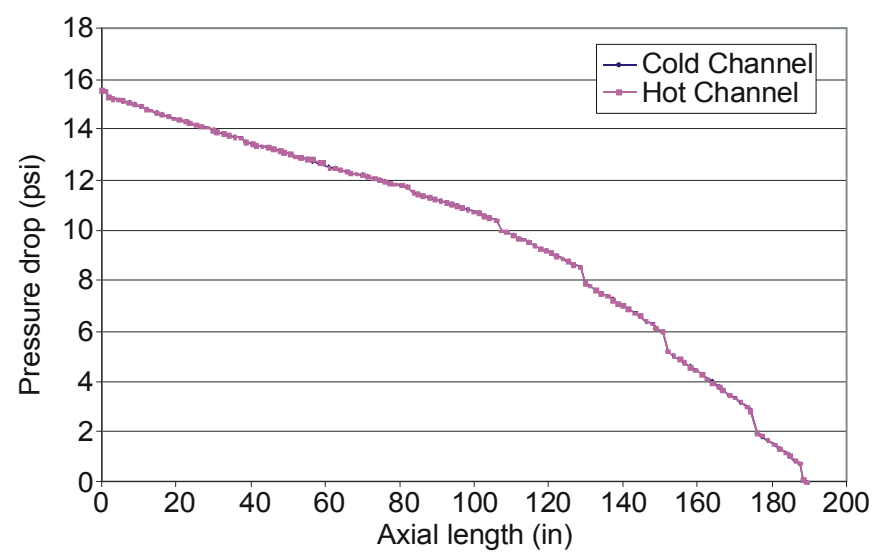

Figure 62. Pressure drop in hot and cold channels for an assembly with single fuel enrichment.

hot and cold channels for the case with the five different fuel rod enrichments. In the lower core part (up to 60 inches), hot and cold velocities are almost identical; from that point on, they start to differ due to density differences as seen in Figure 64 . The exit velocity in the hot channel is $\sim 1.35$ times larger as compared to the cold channel. This difference is even larger (factor of $\sim 1.9$ ) for single enrichment case, and very small $(\sim 1$.) for the uniform power distribution case. Figure 64 also shows a drastic density change along the channel; in the hot channel the difference between the inlet and outlet densities is greater than an order of magnitude. This effect clearly confirms the high sensitivity of the SCWR core to hot channel factors, as identified during the first year simplified analyses. Reducing the power peaking factors is clearly essential for the SCWR core (see the difference between the three power distribution cases): this will require an optimized assembly design to reduce nuclear peaking factors. Also, this 
analysis does not have any allowance for uncertainties: as demonstrated in previous analysis and as is common knowledge for PWR and BWR core designers, hot channel factors due to uncertainties are responsible for significant penalties in core analysis. These effects will only be amplified by the SCWR design.

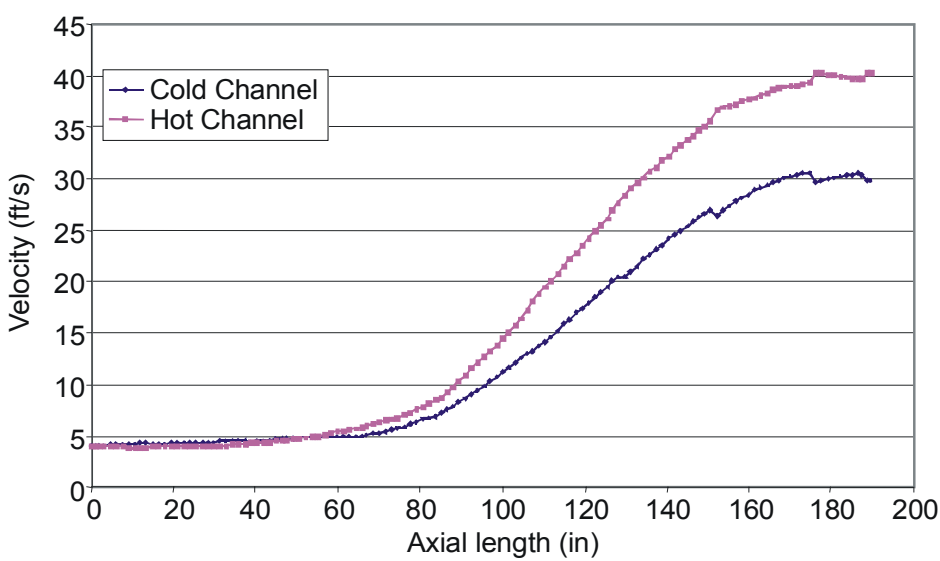

Figure 63. Flow velocity in hot and cold channels for an assembly with 5 different enrichments.

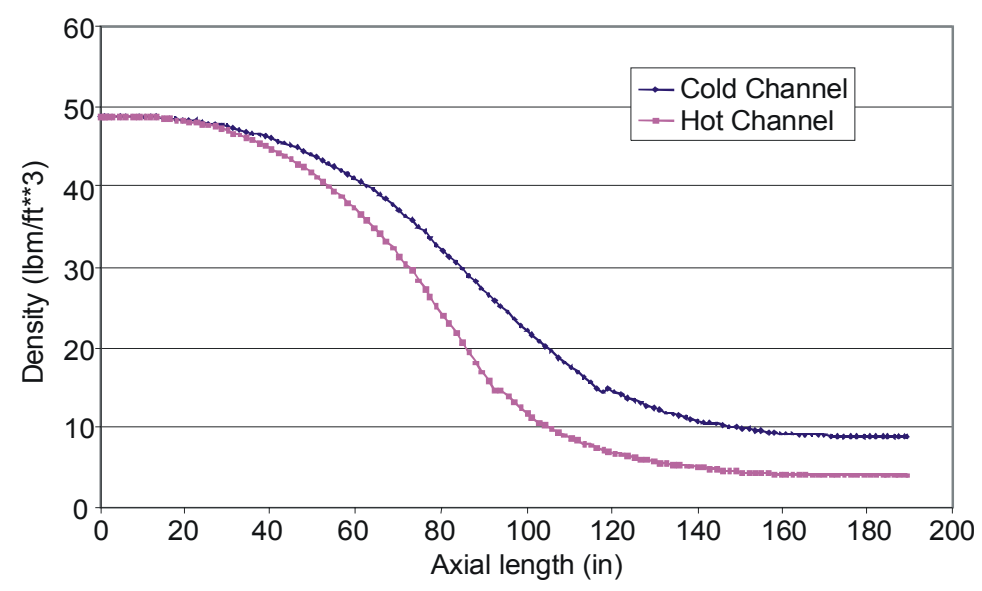

Figure 64. Coolant density profiles in hot and cold channels for an assembly with 5 different enrichments.

Figures 65 and 66 show the hot and cold channel temperature and enthalpy profiles for different assembly power distributions. In the assembly with single enrichment, the temperature rise in the cold channel is calculated as $108{ }^{\circ} \mathrm{C}\left(195^{\circ} \mathrm{F}\right)$, where as it is $488^{\circ} \mathrm{C}\left(878^{\circ} \mathrm{F}\right)$ in the hot channel. For the 5 enrichments case, the temperature rises in the cold and hot channels are $131{ }^{\circ} \mathrm{C}\left(235^{\circ} \mathrm{F}\right)$ and $368^{\circ} \mathrm{C}\left(663{ }^{\circ} \mathrm{F}\right)$, and for the uniform power case, $194{ }^{\circ} \mathrm{C}\left(350{ }^{\circ} \mathrm{F}\right)$ and $365^{\circ} \mathrm{C}\left(657^{\circ} \mathrm{F}\right)$, respectively. These results indicate that multiple enrichments in the fuel assembly are essential for a lower peaking factor and acceptable temperature differences between hot and average channels. However, the current design does not achieve acceptable performance, since the differences in temperature rises between hot and cold channels is too large in each of the cases considered. It should be noted that the results of the uniform enrichment case might mislead the analyst to a pessimistic interpretation: if the temperature difference for this ideal case is still so high, no acceptable design would be possible. However, this conclusion is incorrect: the reason for the high temperature differences in this case is the assembly geometry. The reference $25 \times 25$ canned assembly design with water boxes has channels with a very high wetted perimeter compared to their flow area (mainly the subchannels near the boundary of the assembly). In the upper core region, where a lowdensity fluid with high velocities is present, the effect of these high wetted perimeters on the pressure losses is significant, thus depleting flow in the side channels and directing more flow to the central channels. This naturally gives rise to an unbalanced design with high coolant temperature differences between different subchannels. This issue can be solved by a better assembly design (a design that provides a larger flow area to the lateral channels) or by optimizing the radial power distribution, (a peaked-to-the-center rather than a flat distribution). Both solutions are feasible and can improve the performance. The approach we discuss below in Section 5.2 is to modify the coolant geometry to obtain more uniform flow through the channels and then assume that the power distribution can be made perfectly flat. However, as discussed in Section 3 of this report, it is not possible to obtain a perfectly flat power distribution even with a large number of fuel rod enrichments.

These analyses stresses once again the importance of any effect that affects the hot channel factors on the SCWR core response. 

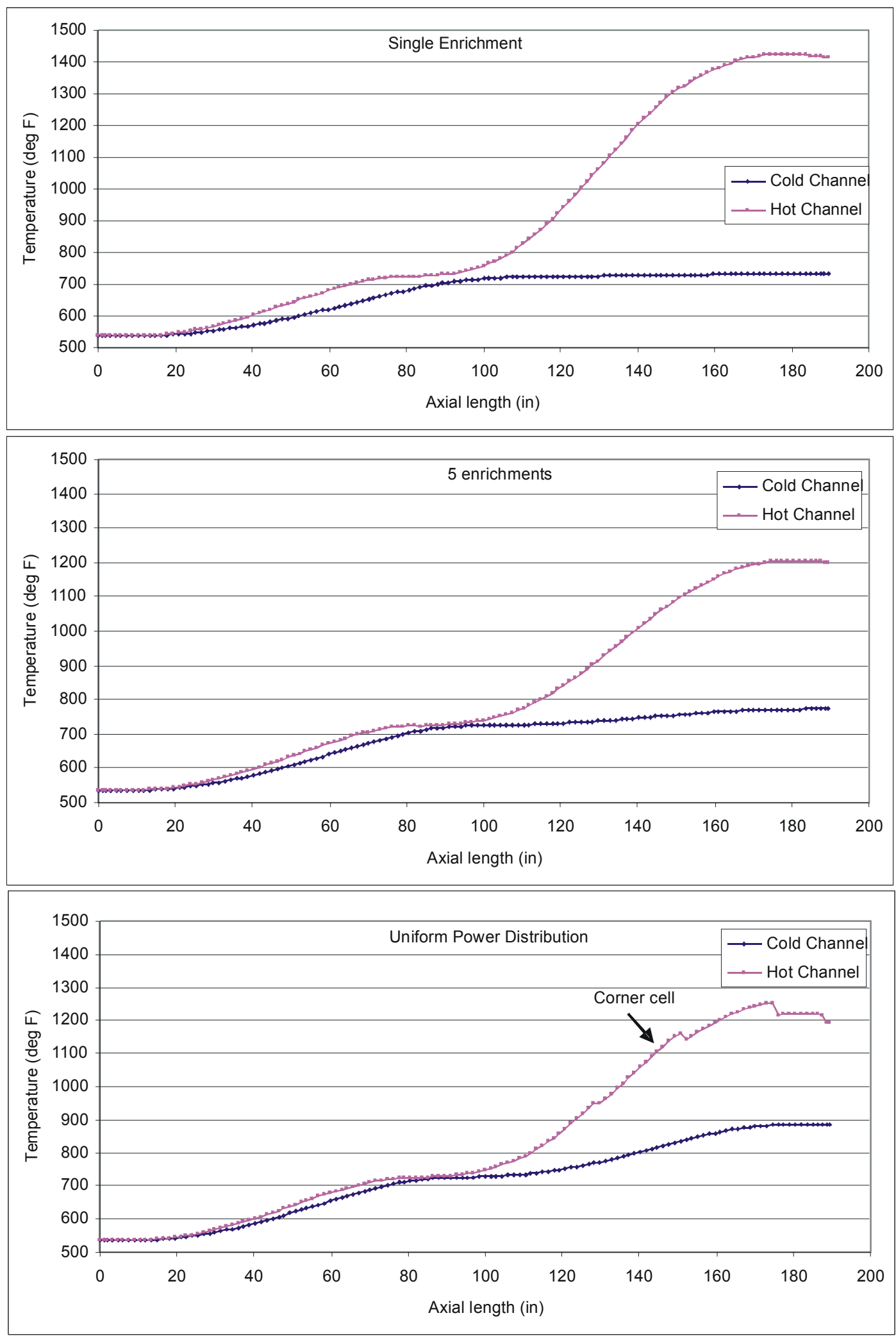

Figure 65. Hot and cold channel temperature profiles for different assembly power distributions. 


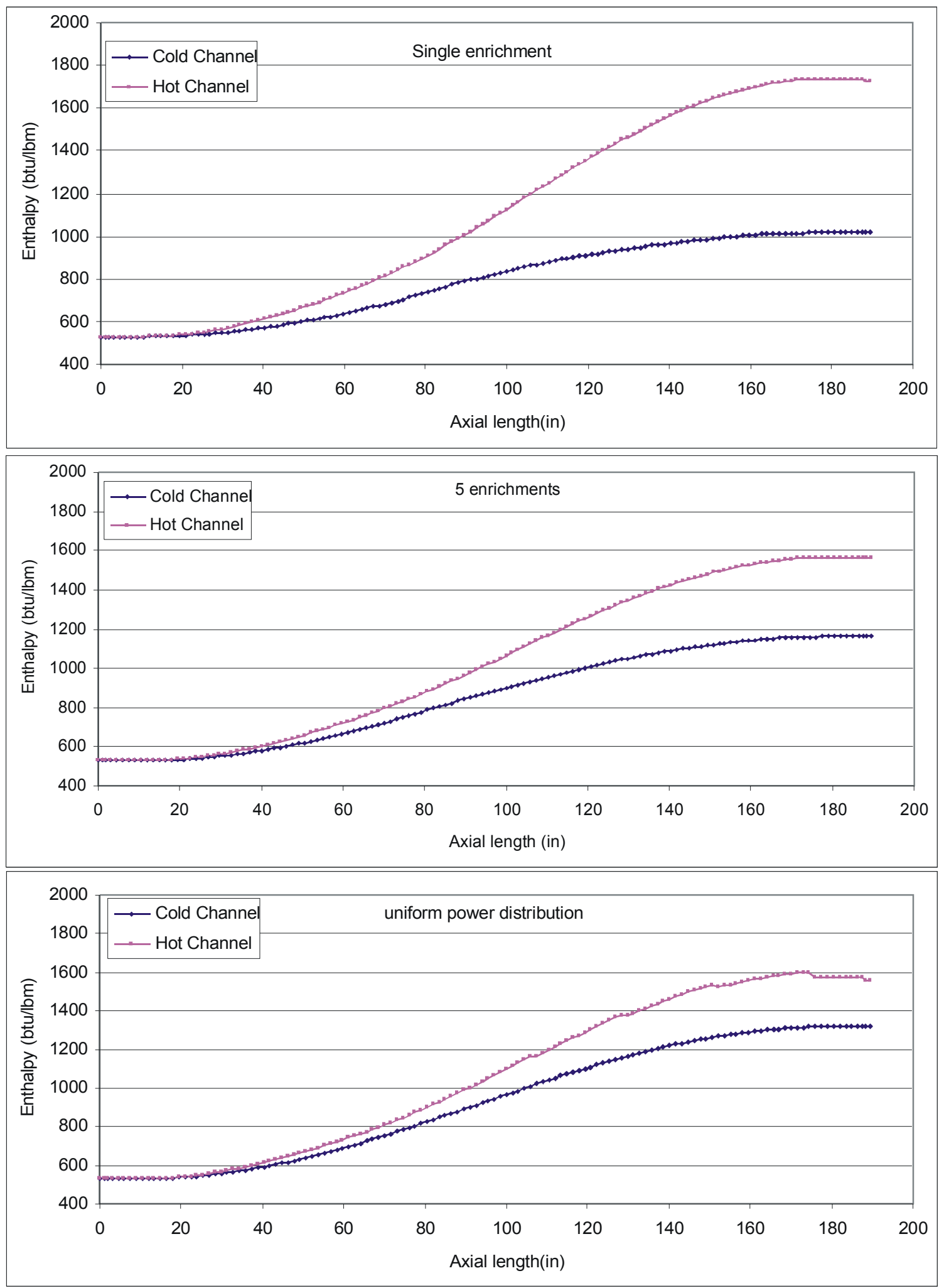

Figure 66. Coolant enthalpy in the hot and cold channels for different assembly power distributions. 
Figure 67 shows three-dimensional coolant temperature profiles in the central assembly at nominal conditions. Note that quarter symmetry is used in the calculations and that the southwest corner channel is the instrumentation channel. The temperature profile closely follows the assembly power distribution. Channels right around the water boxes (e.g., Channels 2, 3, 6, 7, etc. in Figure 60) generally have higher temperatures compared to channels in between water box corners (e.g., Channels 31, 32, 44, 48, etc.), due to differences in hydraulic diameters (as discussed above they have a larger wetted perimeter compared to their flow area). As evident from the figure, the temperature distribution becomes more uniform and the hot channel temperature is reduced in the multiple enrichment case. In the ideal case of uniform power distribution, the temperature variation between channels is minimal with the exception of the northeast corner channel (as discussed above). A design optimization of the assembly can eliminate or significantly reduce this penalty.

Above Nominal Power and Flow Conditions. Following characterization of the SCWR hot assembly at nominal power and flow conditions discussed in the previous section, a series of calculations were performed to evaluate the thermal-hydraulic behavior of the SCWR hot assembly at different overall power levels and flow rates. In this test matrix, the power and flow rate were varied from $100 \%$ to $130 \%$ to provide a parametric evaluation of the core-wide hot channel factors. It was assumed that an appropriate core design would try to offset an increase in power in selected assemblies by properly designing the assembly orifices to deliver more flow to the assemblies with the higher power. Thus, cases with increased power, and increased power and flow were run. Cases with increased flow only were not run. Delivering more flow to channels with lower relative power would simply mean that some other core areas would be depleted of flow.

Tables 31 and 32 present a summary of the results in terms of hot- and cold-channel maximum temperatures. Here again, the tables show that the most promising cases are the ones using 5 -enrichments in the assembly. Note that the uniform power distribution case does not reflect ideal results due to the very high wetted perimeter of the corner channel mentioned above.

Figure 68 shows the temperature profiles in the assembly with 5 enrichments for power levels from $100 \%$ to $130 \%$ while keeping the flow rates constant at the nominal value (110\%). At nominal power level, the maximum temperature in the assembly is calculated as $651{ }^{\circ} \mathrm{C}\left(1203{ }^{\circ} \mathrm{F}\right)$. A $10 \%$ power increase raises the maximum temperature by a factor of $\sim 1.1255$; a $20 \%$ increase by $\sim 1.217$, and a $30 \%$ increase by $\sim 1.236$. This trend can be attributed to the decreasing heat capacity of water with increasing temperature at these pressures and temperatures. The ratios are more interesting than the absolute values, since the reference assembly design needs to be optimized on the basis of the considerations provided above. The case with nominal flow and $130 \%$ power can be used again to verify the need for a flow distribution that matches as closely as possible the radial power distribution. If this is not the case, the hot channel temperature will rapidly get to unacceptable results.

Note that the peak cladding temperature limit for the anticipated operational occurrences was tentatively defined as $620^{\circ} \mathrm{C}\left(1148{ }^{\circ} \mathrm{F}\right)$. Since these analyses are performed at steady state conditions, naturally some margin to the safety analysis limit will have to be demonstrated. Also, note that cladding temperatures are not calculated, only coolant temperatures. The approach used is to optimize the assembly design on the basis of fluid temperatures (the cladding temperature will obviously be higher) and then perform detailed peak cladding temperature calculations only for the cases that provide acceptable results from a fluid temperature point of view of. 

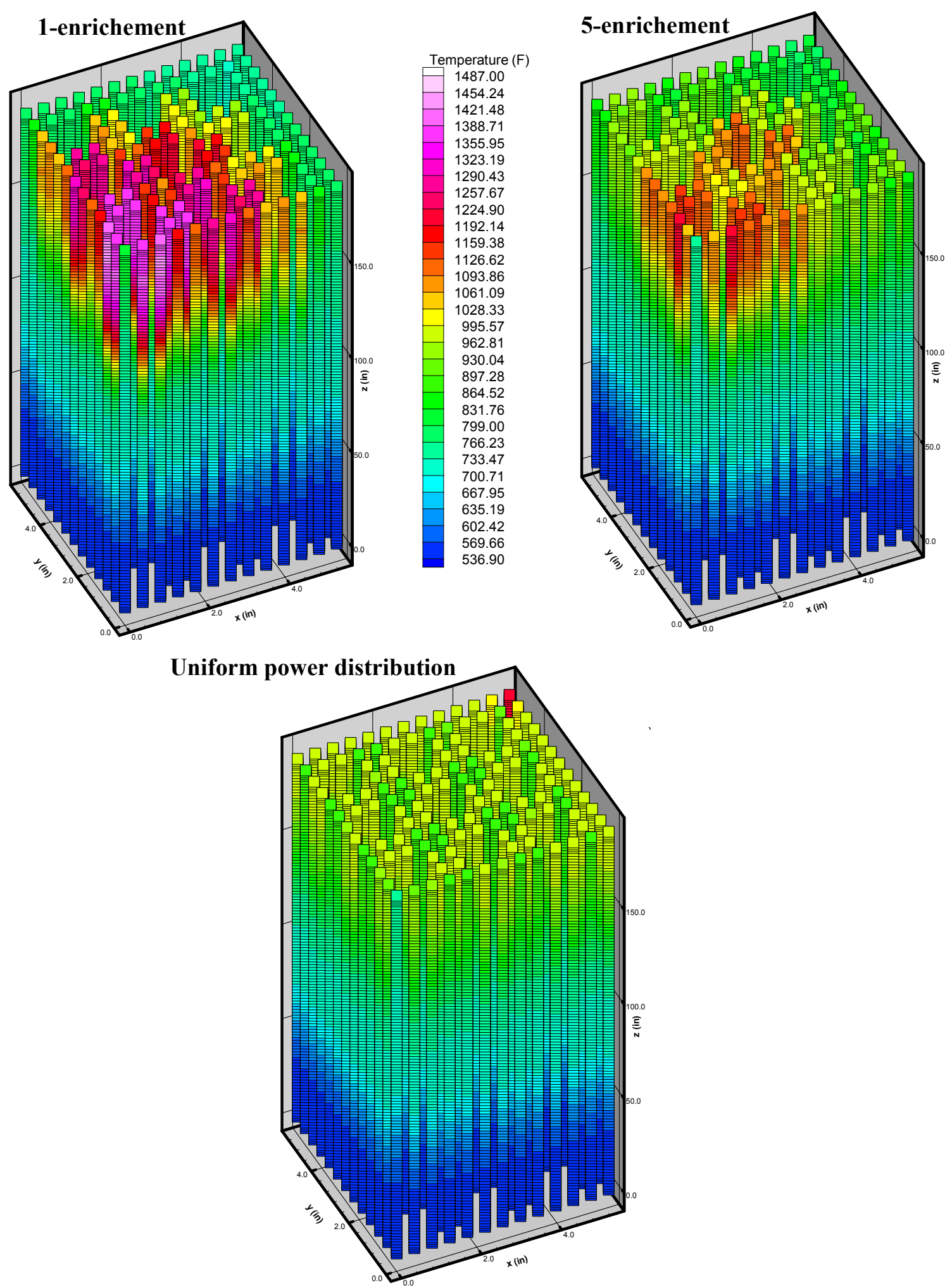

Figure 67. Channel temperature profiles for three local radial power distributions at nominal power. 
Table 31: Maximum temperatures in the hot-channel for different power and flow levels.

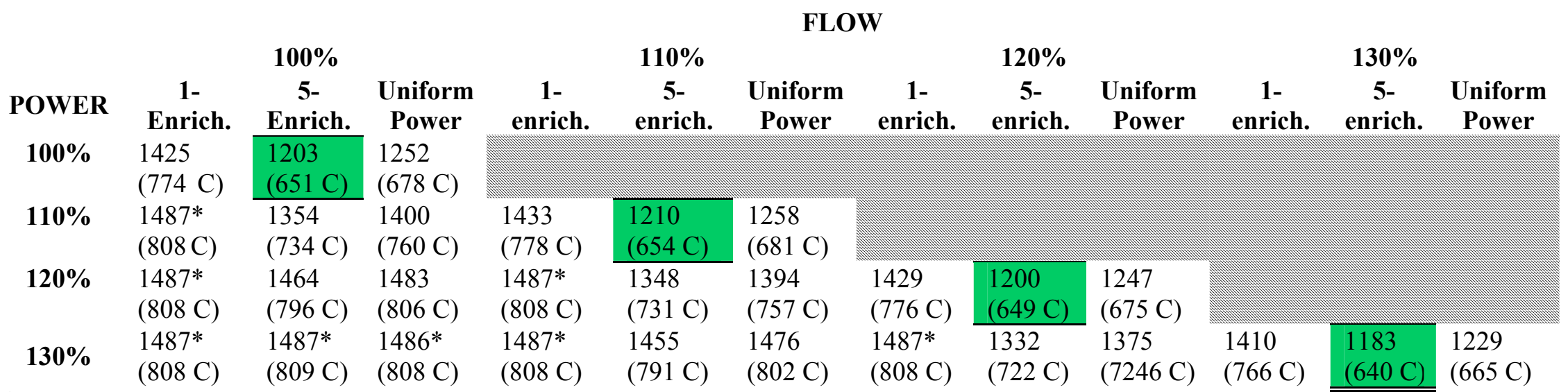

*This temperature value is not valid due to the limitations of the steam tables in VIPRE-W (see section 2.4, paragraph 2)

Table 32: Maximum temperatures in the cold-channel for different power and flow levels.

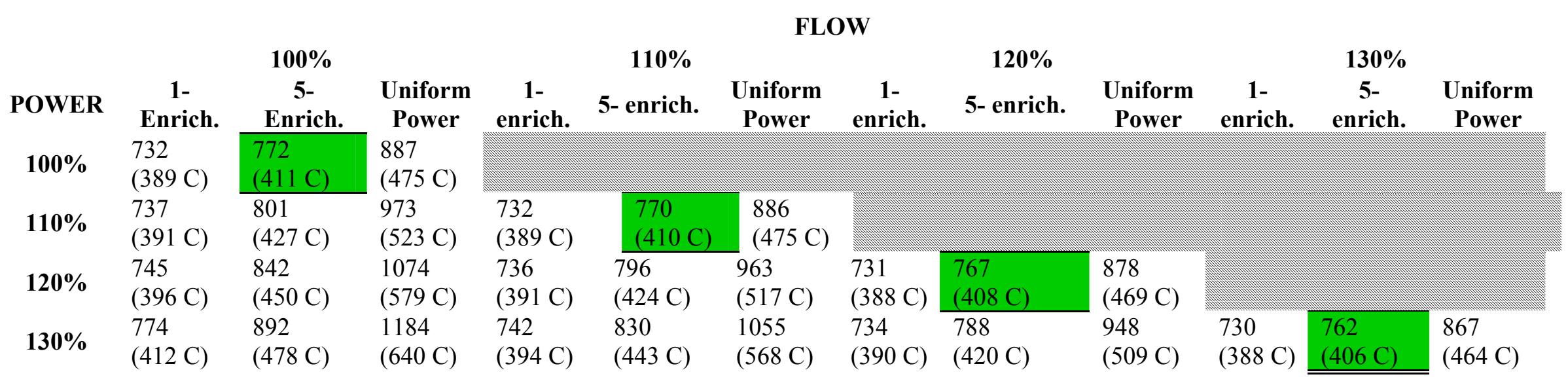



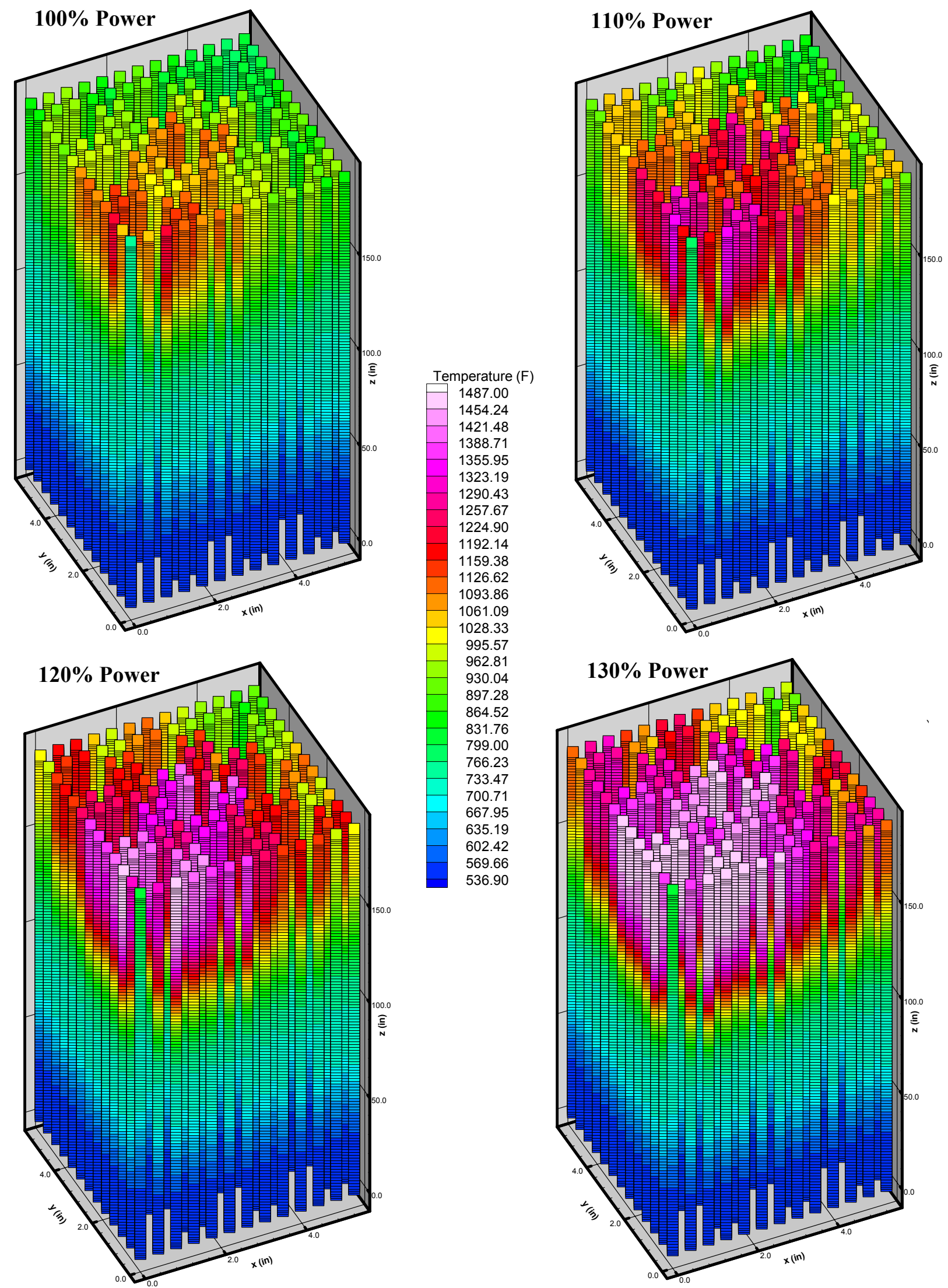

Figure 68. Temperature profiles for power levels from $100 \%$ to $130 \%$ in the assembly with 5 different enrichments. 


\subsubsection{Preliminary Sensitivity Studies}

As identified in the previous section and as natural for a novel design, the assembly design used for the first analyses can only be considered a starting point, a reference to improve the understanding of the SCWR core relevant characteristics and then identify improvements. Based on the previous analysis, it appears that there is a clear need to optimize the assembly flow characteristics and core power profiles to a level beyond that of current LWRs. A complex and detailed assembly design will be needed to achieve acceptable performance (in terms of temperature distributions and peak cladding temperatures), with multiple levels of enrichments and a geometry optimized for improved thermal-hydraulic performance. "Simplicity" cannot, and should not, be a feature of the SCWR core.

Sensitivities to different design parameters are discussed in this section. Four parameters were selected for this purpose: fuel rod pitch, lateral loss coefficient, axial friction factor correlation, and coolant inlet temperature.

Fuel Pitch. The fuel pitch was increased from 0.44094 in. $(11.2 \mathrm{~mm})$ to 0.4448 in $(11.3 \mathrm{~mm})$. This increase in the fuel pitch resulted in a slightly larger flow area, but maintained the heated and wetted perimeters the same as in the reference case. As seen in Figure 69, the change in the hot-channel temperature profiles is minimal. The maximum temperatures in the hot channels were reduced by about 6 , 4.6, and $7{ }^{\circ} \mathrm{C}$ in the 1 -enrichment, 5enrichment, and uniform power cases, respectively. The cold channel temperatures were increased by about $0.5,0.8$, and $0.8{ }^{\circ} \mathrm{C}$, in the same order.

Lateral Loss Coefficient. The lateral loss coefficient was artificially reduced from its calculated value of

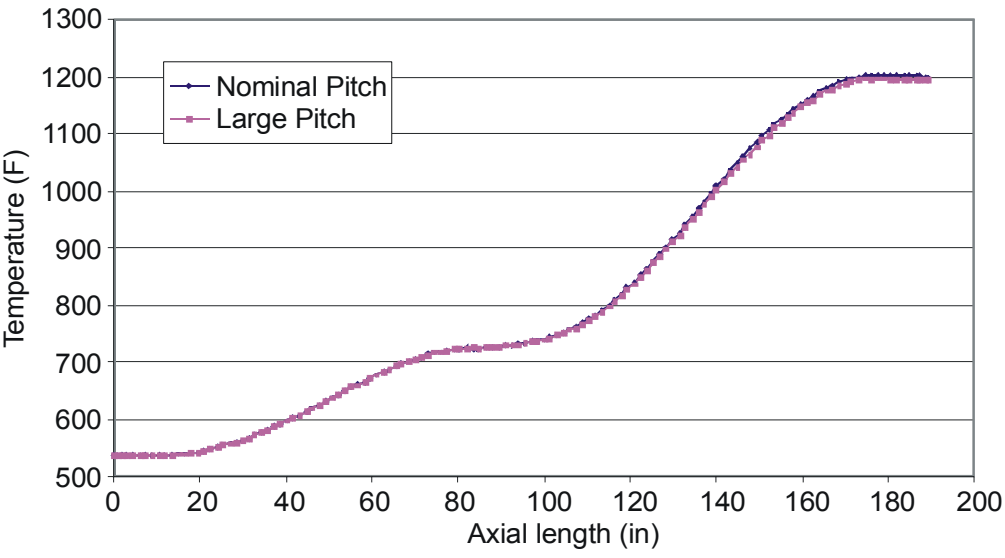

Figure 69. Hot-channel temperature profile using nominal and large fuel pitch for the assembly with 5 enrichments.

4.85 to 0.485 , providing less

resistance for cross-flow among channels inside the assembly. The results are similar to the previous case, yet less pronounced. The maximum temperatures in the hot channels were reduced by about $4,0.2$, and $0.06{ }^{\circ} \mathrm{C}$ in the 1 -enrichment, 5-enrichment, and uniform power cases, respectively. The cold channel temperatures were increased by about $0.2,0.2$, and $1.6{ }^{\circ} \mathrm{C}$, in the same order. The results from the fuel pitch and lateral loss coefficient sensitivity analyses are an indication that assumptions related to the cross-flow calculations (gap width, centroid distance and lateral loss coefficient) do not have a critical impact on the temperature distributions. This is a typical result for LWRs cores and is a required justification of the use of a sub-channel analysis code, which has the fundamental assumption of a dominant flow direction (axial).

Axial Friction Factor Correlation. Analyses were performed using the axial friction factor given in Equation 4. Here, we replace that equation with the conventional Blasius formula, in which the coefficients are calculated as:

$$
f=0.18 * \operatorname{Re}^{-0.2}+64
$$


Blasius formulation calculates $\sim 0.97$ psia larger total pressure drop as compared to Equation 4 . These differences are shown in Figure 70.

Using the Blasius formulation raises the maximum temperatures in the hotchannel by about 10,7 , and $15{ }^{\circ} \mathrm{C}$ in the 1-enrichment, 5-enrichment, and uniform power assemblies, respectively. The cold channel temperatures are reduced by about 1 , 3 , and $2{ }^{\circ} \mathrm{C}$, in the same order. The effect is due to the fact that if a higher friction loss coefficient is calculated, then the effects discussed in the previous sections regarding flow depletion in the lateral channels become more important.

Coolant Inlet Temperature. The coolant inlet temperatures were increased by 2 and $6{ }^{\circ} \mathrm{C}$ and the resulting effects are shown in Figure 71. A $2{ }^{\circ} \mathrm{c}$ increase in the inlet temperature raises the maximum hot channel temperatures by about 3,5 , and $4{ }^{\circ} \mathrm{C}$ in the 1-enrichment, 5enrichment, and uniform power assemblies, respectively. Similarly, a $6{ }^{\circ} \mathrm{C}$ increase in the inlet temperature leads to an increase of about 7,11 , and $11{ }^{\circ} \mathrm{C}$ in the temperatures in the hot channels for the 1-enrichment, 5-

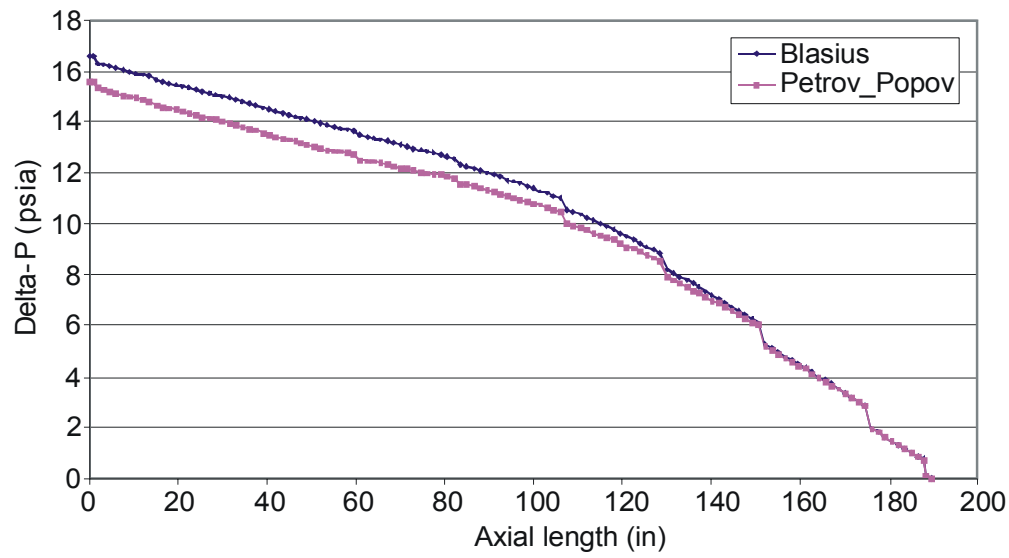

Figure 70. Pressure losses from different correlations in the hot channel of the 5-enrichment case.

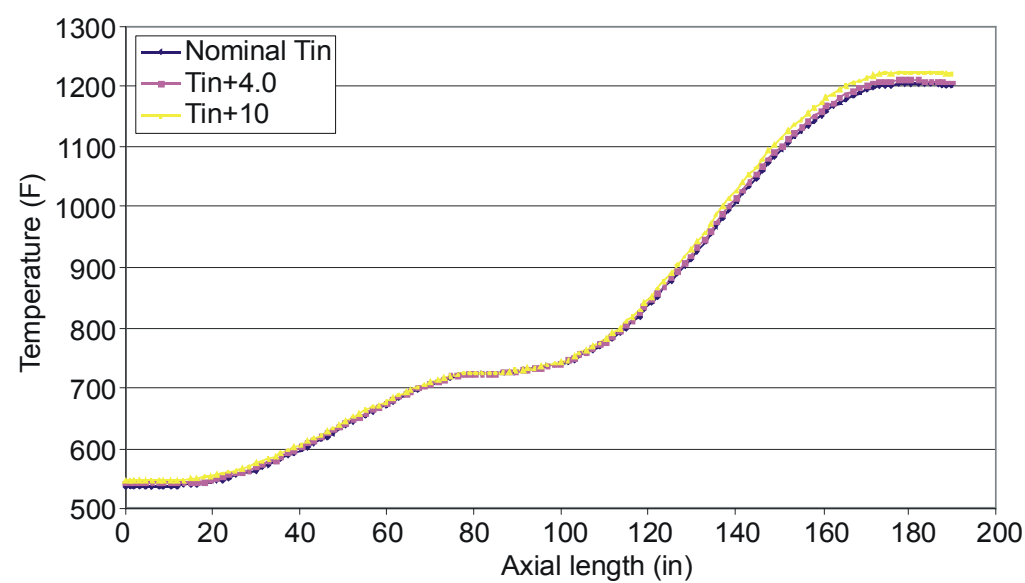

Figure 71. Hot channel temperature profiles for different inlet temperatures in the 5-enrichments case.

enrichment, and uniform power assemblies, respectively. The effects are relatively small for the cold channels: about $0.2,0.9$, and $2.5^{\circ} \mathrm{C}$ for $2{ }^{\circ} \mathrm{C}$ increase and about $0.6,2.8$, and $7{ }^{\circ} \mathrm{C}$ for $6^{\circ} \mathrm{C}$ increase.

\subsubsection{Summary and Conclusions}

During a first set of subchannel investigations, the VIPRE_W code was modified for supercritical water applications, a VIPRE-W model of the SCWR core was completed and preliminary ${ }^{1}$ sub-channel analyses to investigate the thermal-hydraulic behavior of the SCWR core were performed.

These preliminary analyses were used in first place to assess the code's capability and the appropriateness of the SCWR core model used in the analyses. The following concerns have been identified:

\footnotetext{
${ }^{1}$ The authors would like to stress the preliminary nature of these calculations. Model qualification and code verification not being complete, the results in this report should be considered only indicative and verified against engineering judgment.
} 
- A revised SCWR core model for thermal-hydraulic analysis that relies on a two-pass rather than onepass approach needs to be utilized. In the first pass, a complete core model may be used for coupled neutronic-thermal hydraulic calculations to evaluate flow distributions in the assembly and to compute the input power in each assembly. Using results from the core-wise model as boundary conditions, a detailed subchannel model of the hot assembly can be used for detailed peak cladding temperature calculations and verification of design limits.

- While the modified VIPRE-W code performed relatively well in the analyses, an important limit was identified. Use of the default water properties for the SCWR analyses significantly limits the code capabilities. In particular, at temperatures above $\sim 1400{ }^{\circ} \mathrm{F}$, the EPRI functions lose validity. This would have little impact on the final analyses $\left(1400^{\circ} \mathrm{F}\right.$ is well above the maximum allowable peak cladding temperature for normal operation), but is considered an excessive limitation for these preliminary analyses and for transient and accident analyses. Therefore, the need to implement a more appropriate set of properties was considered urgent.

Using the code and the core model discussed in this report, and considering their limitations, a set of preliminary analyses were performed to characterize the SCWR core. Using three different local power distributions in the central assembly, temperature distributions in the hot assembly were evaluated for different conditions, which ultimately demonstrate the limitations of the current design and the challenges in the design of a SCWR core. The model did not calculate the fuel or cladding temperature, nevertheless coolant temperature is still a valid indicator of design feasibility. In this respect, it is concluded that multiple enrichments in the assembly for a flatter power distribution and an optimized assembly geometry for better flow distribution are essential to lower the hot channel temperatures. The effort to minimize local peaking factors in the hot assembly leads to a complex assembly design that needs to rely on the BWR assembly design experience.

Analyses were also performed to evaluate the thermal-hydraulic performance of the SCWR core at different power and flow levels. Furthermore, sensitivity studies were performed in which some of the design parameters are slightly perturbed (e.g., lateral loss coefficient factors and inlet temperatures) or different correlations (axial friction factor) were used.

To be able to critically judge these results two fundamental limits have to be considered, and will be stressed again in following sections:

- The subchannel analyses presented herein assume that the water rods are perfectly insulated, so that no heat transfer between coolant and moderator is possible. This is a necessary assumption given the limitation of the VIPRE code, which does not model the down flow in the water rods. However, this introduces a potentially significant impact on the analyses, since the effect of the heat transfer between the water rods and the coolant will tend to provide a source of balancing between the various channels, since higher temperature channels will tend to exchange more heat then colder channels, and this will tend to make the core exit conditions more homogeneous. While this effect should not significantly change the nature of the results, it is still necessary to correctly account for this phenomenon. This requires the development of more advanced subchannel analysis codes, but is beyond the scope of this study.

- The analysis presented do not account directly for hot channel factors. 


\subsubsection{Thermal-Hydraulic Optimization Studies of the Supercritical Water Reactor Fuel Assembly}

The analysis effort discussed above in Section 5.1.2 focused on improving the understanding of the assembly and core performance and identifying important performance parameters. Based on this improved understanding, an optimization effort was pursued. The first step in this effort was the optimization of the assembly coolant flow areas to reduce the hot spots in the assembly. A uniform (flat) radial power distribution was assumed in this study. As discussed in Section 3 of this report, it will be difficult to obtain a perfectly uniform power distribution in a SCWR and further work, which is beyond the scope of this project, will be required to optimize both the coolant geometry and the power distribution together. The second step was the core wide optimization: based on the optimized assembly design, the focus shifted to designing a core with a flat and stable in time radial power profile, and on designing an appropriate orifice scheme to provide increased flow to the assemblies that are characterized by higher peaking factors.

\subsubsection{Alternative Assembly Designs}

For this first optimization, the coolant channels with high wetted perimeters, hence high flow resistance, were modified by reducing the diameter of the corresponding rods, mainly the ones on the assembly periphery and directly facing the water channels, and in some cases, partial length rods $(2 / 3$ of the nominal heated length) replaced the full-length rods at assembly corners. Figure 72 shows the rods and the surrounding channels that have been modified for the optimization studies. Tables 33, 34, and 35 show the flow areas and wetted and heated perimeters used in the assembly models. Note that the fuel rod pitch is $11.2 \mathrm{~mm}$ and the nominal and modified diameters are $10.2 \mathrm{~mm}$ and $9.5 \mathrm{~mm}(9.8 \mathrm{~mm}$. and $10.0 \mathrm{~mm}$ also considered as discussed in the following sections), respectively. Note that tables show values only for a modified diameter of $9.5 \mathrm{~mm}$.

\subsubsection{Thermal-Hydraulic Profiles in the Hot and Cold Channels for Different Assembly Configurations:}

Four assembly configurations were considered for this optimization: 1.) thin rods (either $9.5 \mathrm{~mm}, 9.8 \mathrm{~mm}$ or $10.0 \mathrm{~mm}$ diameter) directly facing the water channels and around the assembly periphery, 2.) partial length rods on the assembly corners, 3.) full-length, but thinner rods $(9.5 \mathrm{~mm})$ on the assembly corners, and 4.) a combination of 1 and 2. For each of these cases, temperature profiles are presented for both hot and cold channels, where the hot channel is defined as the channel where the maximum temperature occurs and the cold channel is the channel with the lowest exit temperature in the bundle. The exit temperature from the hot channel is one of the critical design parameters: for an optimal design, this temperature should be close to the average channel exit temperature.

Figure 73 shows the three-dimensional coolant temperature profiles in the assembly at $100 \%$ power. Note that quarter symmetry is used in the calculations and that the southwest corner channel is the instrumentation channel. In the nominal geometry case, the channels right around the water boxes (e.g., Channels 2, 3, 6, 7, etc. in Figure 72) generally have higher temperatures compared to the channels in between the water box corners (e.g., Channels 31, 32, 44, 48, etc.), due to their larger wetted perimeters compared to the flow areas. The northeast corner channel yields the highest temperature in the nominal geometry case. As further seen in the figure, reducing the axial length of the rod in this corner shifts the hot channel to a different location and reduces the maximum temperature. 


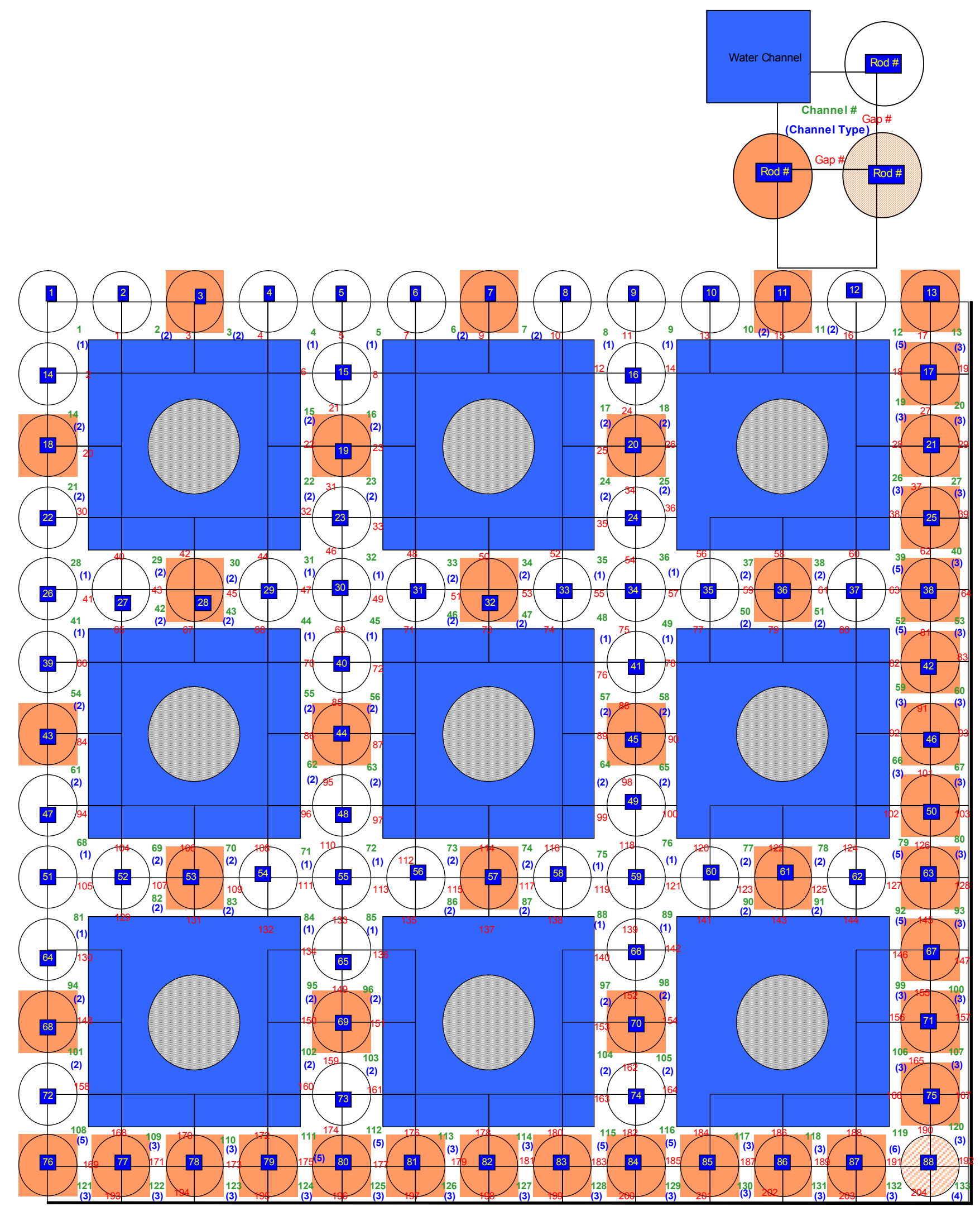

Figure 72. Modified SCWR assembly model. 
Table 33 Calculation of the flow areas used in the SCWR Models

Channel

Type

Nominal Assembly

1

$\frac{3}{4} P_{r o d}^{2}-\frac{3}{4} * \pi * \frac{D_{n o m}^{2}}{4}$

$\frac{1}{2} P_{\text {rod }}^{2}-\frac{1}{2} * \pi * \frac{D_{\text {nom }}^{2}}{4}$

$\frac{1}{2} P_{\text {rod }}^{2}-\frac{1}{2} * \pi * \frac{D_{\text {nom }}^{2}}{4}$

$\frac{1}{4} P_{r o d}^{2}-\frac{1}{4} * \pi * \frac{D_{\text {nom }}^{2}}{4}$

$\frac{3}{4} P_{\text {rod }}^{2}-\frac{3}{4} * \pi * \frac{D_{\text {nom }}^{2}}{4}$

$\frac{3}{4} P_{\text {rod }}^{2}-\frac{3}{4} * \pi * \frac{D_{\text {nom }}^{2}}{4}$
Flow Area Equation

Modified Assembly

$\frac{3}{4} P_{r o d}^{2}-\frac{3}{4} * \pi * \frac{D_{\text {nom }}^{2}}{4}$

$\frac{1}{2} P_{\text {rod }}^{2}-\frac{1}{4} * \pi *\left(\frac{D_{\text {nom }}^{2}}{4}+\frac{D_{\mathrm{mod}}^{2}}{4}\right)$

$\frac{1}{2} P_{\text {rod }}^{2}-\frac{1}{2} * \pi * \frac{D_{\mathrm{mod}}^{2}}{4}$

$\frac{1}{4} P_{\text {rod }}^{2}-\frac{1}{4} * \pi * \frac{D_{\mathrm{mod}}^{2}}{4}$

$\frac{3}{4} P_{r o d}^{2}-\pi *\left(\frac{1}{4} * \frac{D_{n o m}^{2}}{4}+\frac{1}{2} * \frac{D_{\mathrm{mod}}^{2}}{4}\right)$

$$
\frac{3}{4} P_{\text {rod }}^{2}-\frac{3}{4} * \pi * \frac{D_{\mathrm{mod}}^{2}}{4}
$$

0.0338886

0.0338886

0.0508329

0.0592267

0.0508329

Flow Area $\left(\mathrm{in}^{2}\right)$

Nominal Modified

Assembly Assembly

$0.0508329 \quad 0.0508329$

$0.0169443 \quad 0.0211412$

0.0634236

Nominal Diameter $=D_{\text {nom }}=10.2 \mathrm{~mm} ;$ Modified diameter $=D_{\bmod }=9.5 \mathrm{~mm}$

Table 34 Calculation of the wetted perimeters used in the SCWR Models

\section{Channel}

Type

Nominal Assembly

$\frac{3}{4} * \pi * D_{\text {nom }}+P_{\text {rod }}$

$\frac{1}{2} * \pi * D_{\text {nom }}+P_{\text {rod }}$

2

3

4

$5 \quad \frac{3}{4} * \pi * D_{\text {nom }}+P_{\text {rod }}$

$\frac{1}{2} * \pi * D_{\text {nom }}+P_{\text {rod }}$

$\frac{1}{4} * \pi * D_{\text {nom }}+P_{\text {rod }}$

Wetted Perimeter Equation

Modified Assembly

$\frac{3}{4} * \pi * D_{\text {mod }}+P_{\text {rod }}$

$\frac{1}{4} * \pi *\left(D_{\text {nom }}+D_{\text {mod }}\right)+P_{\text {rod }}$

$\frac{1}{2} * \pi * D_{\text {mod }}+P_{\text {rod }}$

$\frac{1}{4} * \pi * D_{\text {mod }}+P_{\text {rod }}$

$\pi *\left(\frac{1}{4} * D_{\text {nom }}+\frac{1}{2} * D_{\text {mod }}\right)+P_{\text {rod }}$

$\frac{3}{4} * \pi * D_{\text {mod }}+P_{\text {rod }}$
Wetted Perimeter (in)

Nominal Assembly

Modified

Assembly

1.38713321 .3871332

1.07173711 .0500923

$1.0717371 \quad 1.0284474$

$0.7563410 \quad 0.7346962$

1.38713321 .3438436

1.38713321 .3221987

Nominal Diameter $=D_{\text {nom }}=10.2 \mathrm{~mm} ;$ Modified diameter $=D_{\bmod }=9.5 \mathrm{~mm}$ 
Table 35. Calculation of the heated perimeters used in the SCWR Model

\begin{tabular}{|c|c|c|c|c|}
\hline \multirow{2}{*}{$\begin{array}{c}\text { Channel } \\
\text { Type }\end{array}$} & \multicolumn{2}{|c|}{ Heated Perimeter Equation } & \multicolumn{2}{|c|}{ Wetted Perimeter (in) } \\
\hline & Nominal Assembly & Modified Assembly & $\begin{array}{c}\text { Nominal } \\
\text { Assembly }\end{array}$ & $\begin{array}{l}\text { Modified } \\
\text { Assembly }\end{array}$ \\
\hline 1 & $\frac{3}{4} * \pi * D_{\text {пот }}$ & $\frac{3}{4} * \pi * D_{\bmod }$ & 0.9461883 & 0.9461883 \\
\hline 2 & $\frac{1}{2} * \pi * D_{n o m}$ & $\frac{1}{4} * \pi *\left(D_{\text {nom }}+D_{\mathrm{mod}}\right)$ & 0.6307922 & 0.609147 \\
\hline 3 & $\frac{1}{2} * \pi * D_{n o m}$ & $\frac{1}{2} * \pi * D_{\bmod }$ & 0.6307922 & 0.5875026 \\
\hline 4 & $\frac{1}{4} * \pi * D_{n o m}$ & $\frac{1}{4} * \pi * D_{\mathrm{mod}}$ & 0.3153961 & 0.2937513 \\
\hline 5 & $\frac{3}{4} * \pi * D_{n o m}$ & $\pi *\left(\frac{1}{4} * D_{n o m}+\frac{1}{2} * D_{\mathrm{mod}}\right)$ & 0.9461883 & 0.9028987 \\
\hline 6 & $\frac{3}{4} * \pi * D_{n o m}$ & $\frac{3}{4} * \pi * D_{\bmod }$ & 0.9461883 & 0.8812538 \\
\hline
\end{tabular}

Three-dimensional plots, such as the one provided in Figure 73, were fundamental in the optimization process since they allowed the analyst to visualize the temperature profiles in the core and thus identify the channels that should be modified to receive more flow. The nominal case showed how all the channels directly facing the water rods or the assembly wall tended to receive lower flow than the other channels. The reason for this behavior is the larger wetted perimeter in these channels, which increases their flow resistance. Any increase in the pressure loss and flow resistance of a subchannel tends to direct flow away from that channel and towards channels with lower flow resistance. Unfortunately, in the SCWR this effect is self enhancing: as less flow is available in these channels, the temperatures will increase, thus densities will decrease, the flow velocities will increase, and even more flow will be directed away from these channels.

Therefore, the assembly must be designed to minimize these unbalanced flow effects. As a first try, the corner rod was replaced with a part length rod. This eliminates, as shown in Figure 73, the temperature peak at that location, but still does little from the point of view of the overall assembly profile. However, a better design can improve the performance even more, for example replacing the rods in the high resistance channels with thinner $9.5 \mathrm{~mm}$ diameter rods. As shown in Figure 73, this has, however, a negative effect since now the remaining, unmodified channels tend to have a too large a flow resistance, and thus high temperature regions are created in the center of the assembly. This however indicates that while the reduction in diameter is excessive (it essentially drives the peak temperature to different areas of the assembly but does little to reduce the peak temperature) this approach can be used to optimize the assembly flow distribution.

Figure 74 shows the hot and cold channel temperature profiles for $100 \%$ power and the different assembly configurations discussed above. In the nominal assembly configuration, the temperature rise in the hot channel is $366{ }^{\circ} \mathrm{C}$, whereas it is $194{ }^{\circ} \mathrm{C}$ in the cold channel. For the case of partial length rods, temperature rises in the hot and cold channels are $250^{\circ} \mathrm{C}$ and $159{ }^{\circ} \mathrm{C}$. For the case of thin rods $(9.5 \mathrm{~mm})$ temperature rises in the hot and cold channels are $393{ }^{\circ} \mathrm{C}$ and $116^{\circ} \mathrm{C}$, and for the combined partial length and thin rod case, $397^{\circ} \mathrm{C}$ and $117^{\circ} \mathrm{C}$, respectively. 
NOMINAL

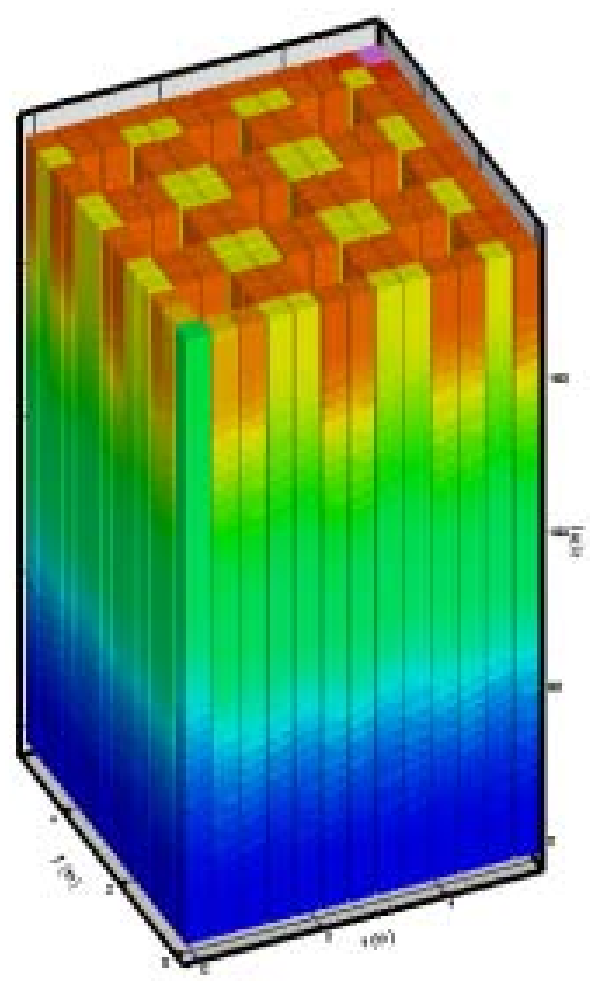

THIN RODS (9.5 mm)

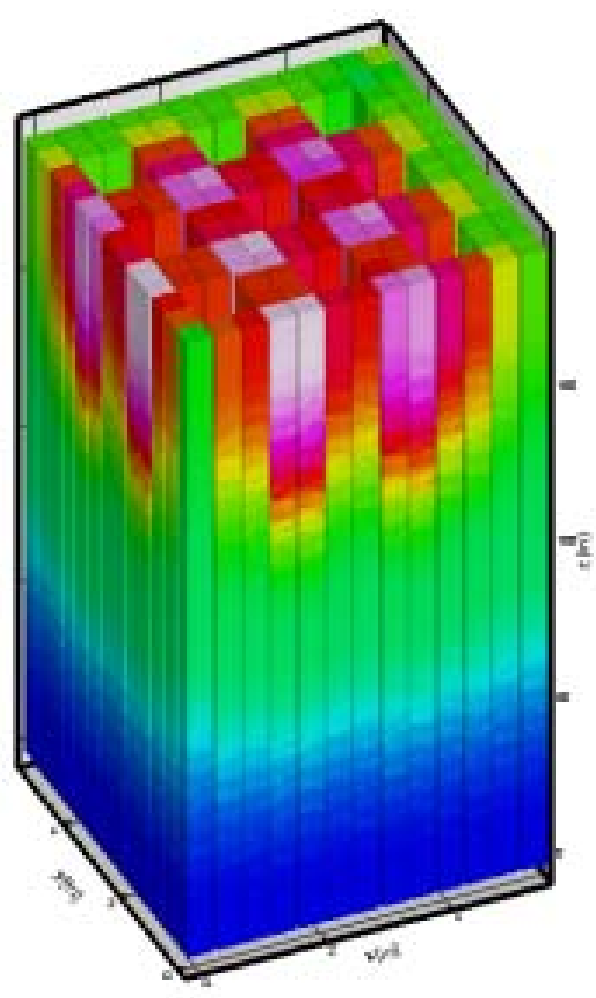

PARTIAL LENGTH

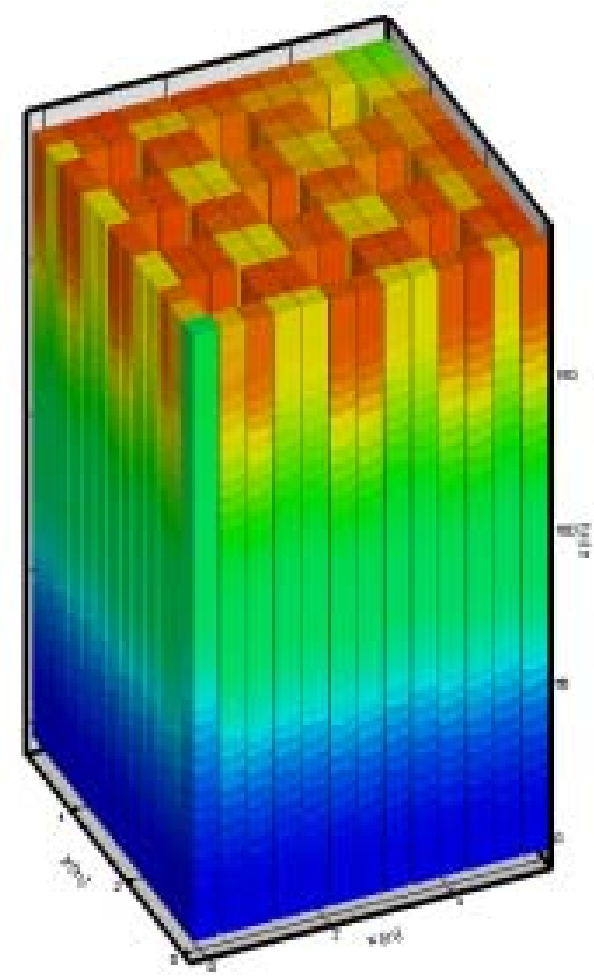

PARTIAL LENGTH + THIN RODS $(9.5 \mathrm{~mm})$

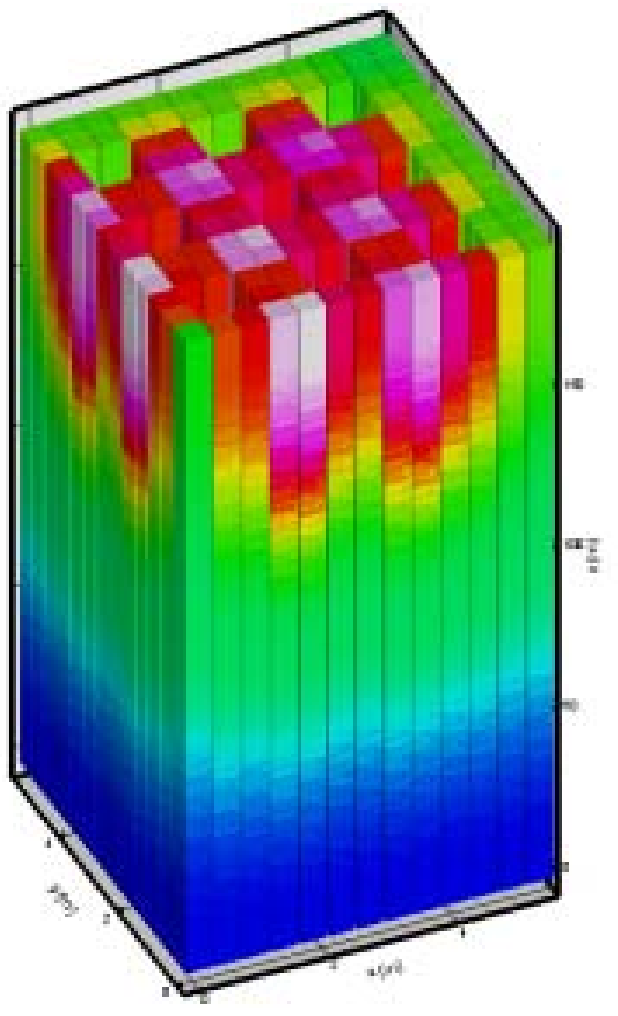

Figure 73. Temperature distributions for $100 \%$ power. 

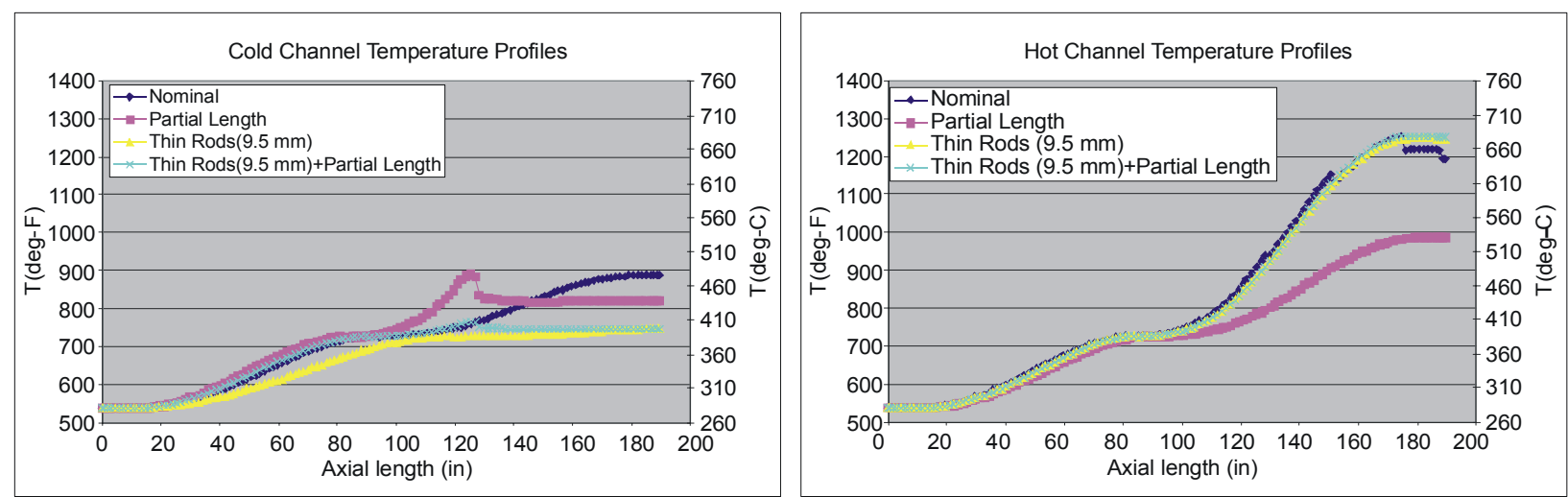

Figure 74. Temperature profiles in the hot and cold channels for $100 \%$ power and $9.5 \mathrm{~mm}$ thin rods.

Figure 75 shows the three-dimensional coolant temperature profiles in the assembly at $110 \%$ power. This and similar cases with increased assembly power input were used to simulate the effect of enthalpy rise on the hot channel factors. While the $110 \%$ case is a very "optimistic" case, it is considered representative of the SCWR for two main reasons:

1. Any larger increase would have an effect on the channel outlet temperature that would make satisfying the design parameters impossible.

2. Even if the radial peaking factors are higher than the $10 \%$ used in this analysis, it will therefore be necessary to direct more flow to the hot assemblies through an adequate orifice scheme.

Similar temperature profiles are obtained as the $100 \%$ power case, except for higher temperature rises, as seen in Figure 76 . For $110 \%$ power level, temperature rise in the hot channel for nominal geometry is $448{ }^{\circ} \mathrm{C}$, whereas it is $243{ }^{\circ} \mathrm{C}$ in the cold channel. For the case of partial length rods, temperature rises in the hot and cold channels are $316^{\circ} \mathrm{C}$ and $195^{\circ} \mathrm{C}$. For the case of thin rods $(9.5 \mathrm{~mm})$ temperature rises in the hot and cold channels are $479{ }^{\circ} \mathrm{C}$ and $126^{\circ} \mathrm{C}$, and for the combined partial length and thin rod case, $485{ }^{\circ} \mathrm{C}$ and $126^{\circ} \mathrm{C}$, respectively. 
NOMINAL

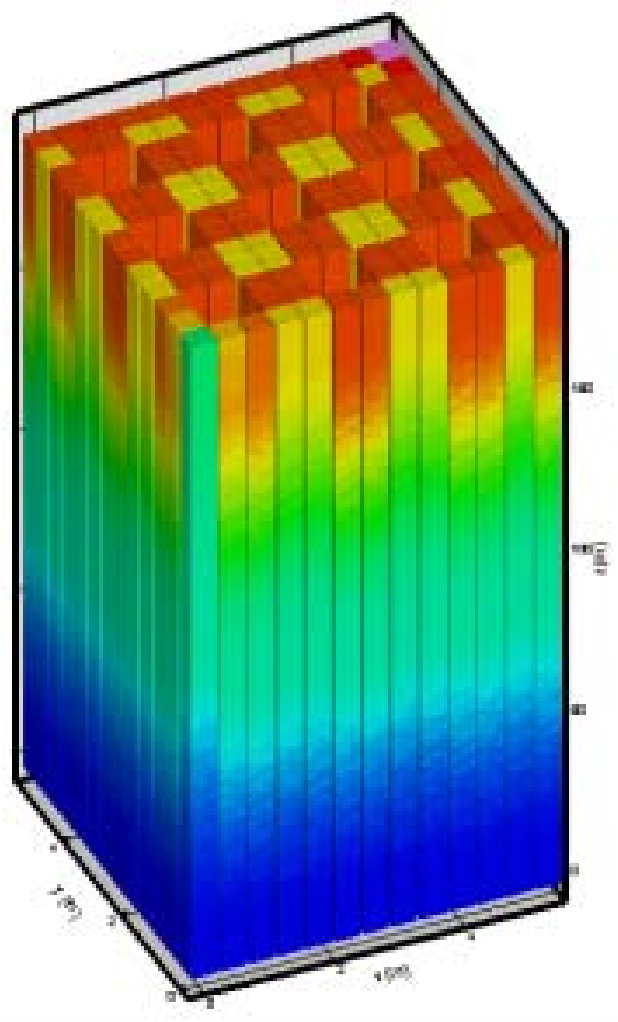

THIN RODS (9.5 mm)

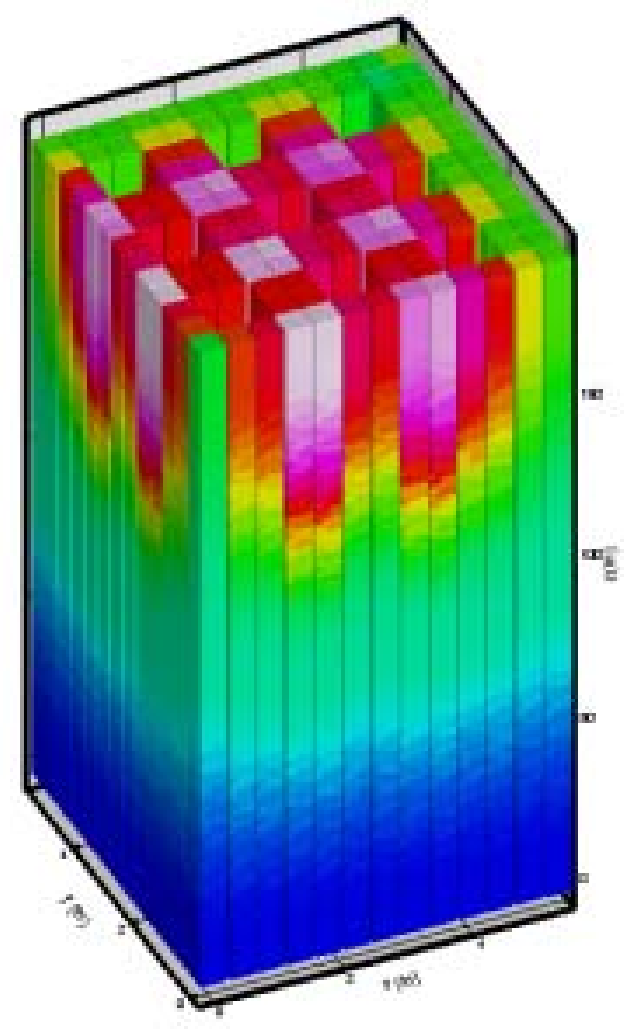

PARTIAI I FNGTH

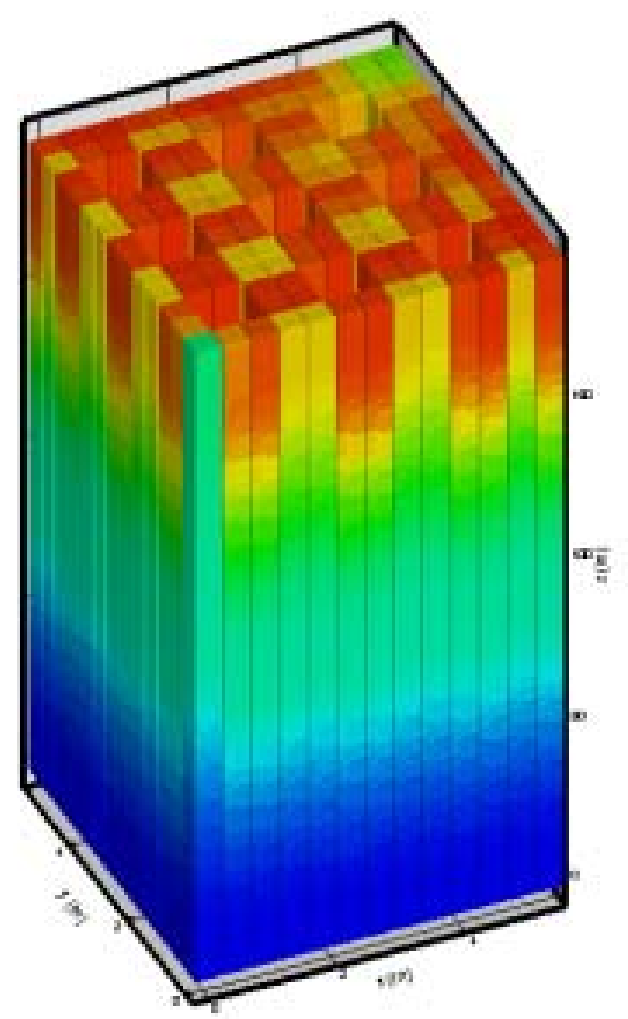

PARTIAL LENGTH+ THIN RODS (9.5 mm)

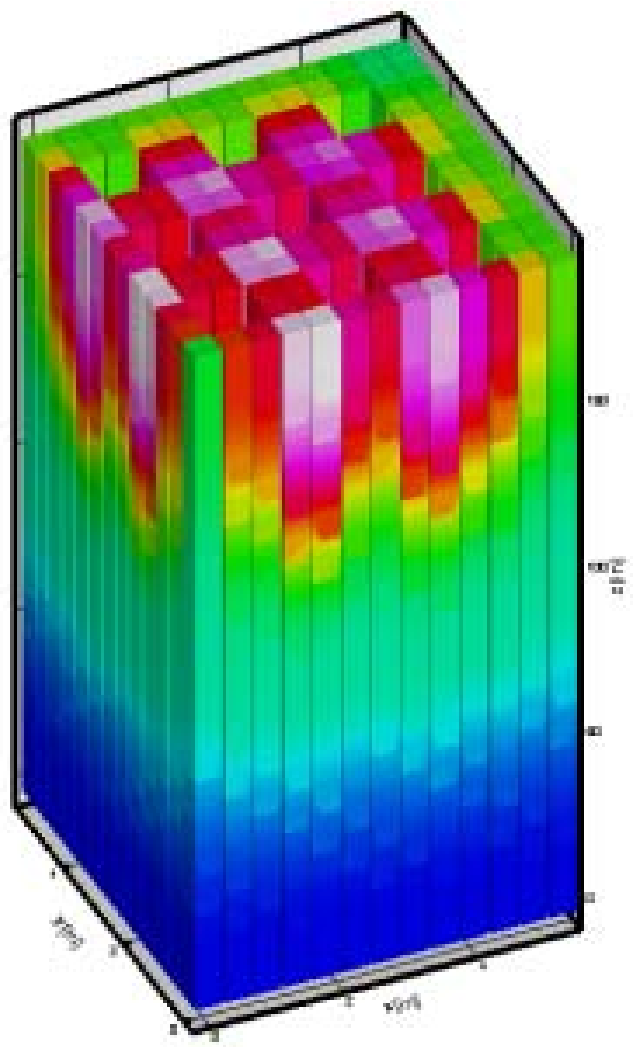

Figure 75. Temperature distributions for $110 \%$ power. 

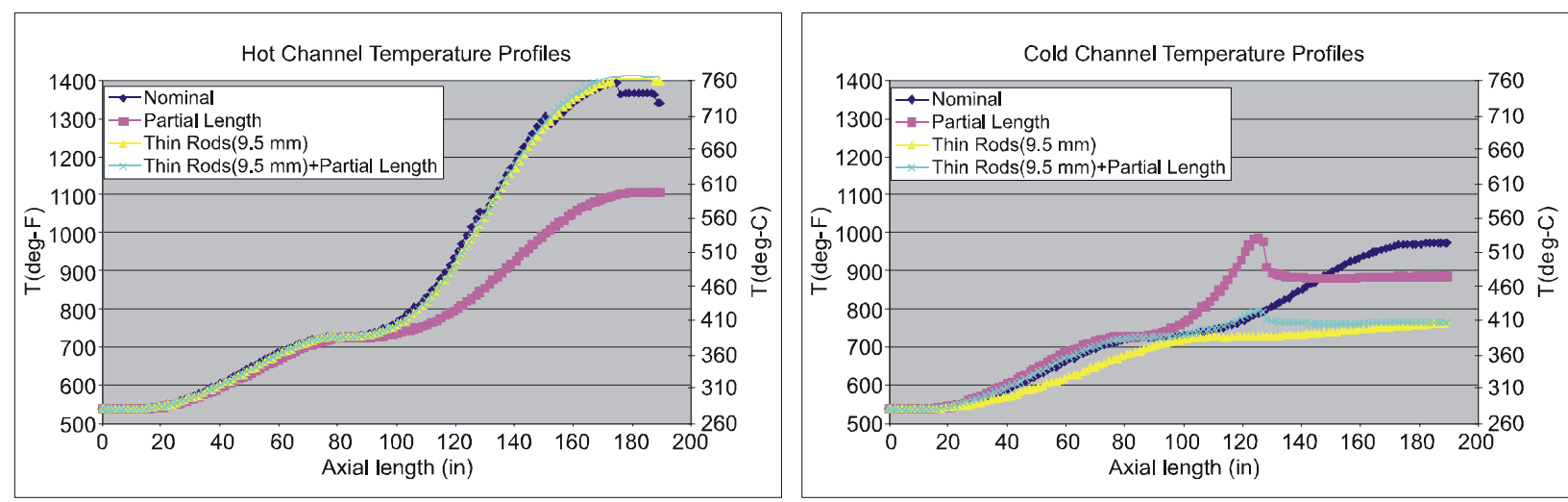

Figure 76. Hot and cold temperature profiles for $110 \%$ power and $9.5 \mathrm{~mm}$ thin rods

To further optimize the assembly geometry, a case with $9.8 \mathrm{~mm}$ rods was also considered, as the previous results show that the peak temperature is pushed to the channels that use regular size rods, thus indicating that the reduction in outside diameter is too large when $9.5 \mathrm{~mm}$ rods are used.

The temperature profiles for the assembly with $9.8 \mathrm{~mm}$ thin rods are shown in Figures 77, 78, and 79. The temperature rise in the hot channel for the thin rods case is $292{ }^{\circ} \mathrm{C}$. When partial length rods are used in combination with $9.8 \mathrm{~mm}$ thin rods, a similar temperature rise is seen in the hot channel: $301{ }^{\circ} \mathrm{C}$. In the cold channels, the temperature rise is $153{ }^{\circ} \mathrm{C}$ for the thin-rods case, and $129{ }^{\circ} \mathrm{C}$ for the combination case. These cases were repeated for $110 \%$ power: hot channel temperature rises are $371{ }^{\circ} \mathrm{C}$ and $382{ }^{\circ} \mathrm{C}$ for the thin-rod and combination cases, respectively. The temperature rises for the cold channels are 181 ${ }^{\circ} \mathrm{C}$ and $147^{\circ} \mathrm{C}$.

Even the $9.8 \mathrm{~mm}$ rods still tend to push the peak coolant temperature to the channels with the larger, regular size rods and thus one additional case was considered and geometries with up to three different rod sizes were also included in the study. Temperature profiles with $10.0 \mathrm{~mm}$ thin rods facing the water channels and around the periphery are shown in Figures 80, 81, and 82. The temperature rise in the hot channel for the thin rods case is $291{ }^{\circ} \mathrm{C}$. When full length, but thinner rods $(9.5 \mathrm{~mm})$ are placed at assembly corners in combination with $10.0 \mathrm{~mm}$ rod, temperature rise in the hot channel becomes $245^{\circ} \mathrm{C}$, which is the lowest value of all cases in this study. In the cold channels, the temperature rise is $170{ }^{\circ} \mathrm{C}$ for the thin-rods case, and $146{ }^{\circ} \mathrm{C}$ for the combination case. These cases were repeated for $110 \%$ power: the hot channel temperature rises are $365{ }^{\circ} \mathrm{C}$ and $314{ }^{\circ} \mathrm{C}$ for the thin-rod and thinner rod on the corners cases, respectively. The temperature rises for the cold channels are $208{ }^{\circ} \mathrm{C}$ and $168^{\circ} \mathrm{C}$.

Finally, a summary of maximum hot and cold channel temperatures are provided in Tables 36 and 37 . In Table 38, bundle average exit and maximum temperatures are presented for comparison. As evident from the discussions above and from this table, the case with thin rods $(10 \mathrm{~mm})$ facing the water boxes and around the assembly periphery and a thinner $(9.5 \mathrm{~mm})$ rod at the north-west corner yields the minimum temperature difference between the average bundle exit and maximum hot channel temperatures. 


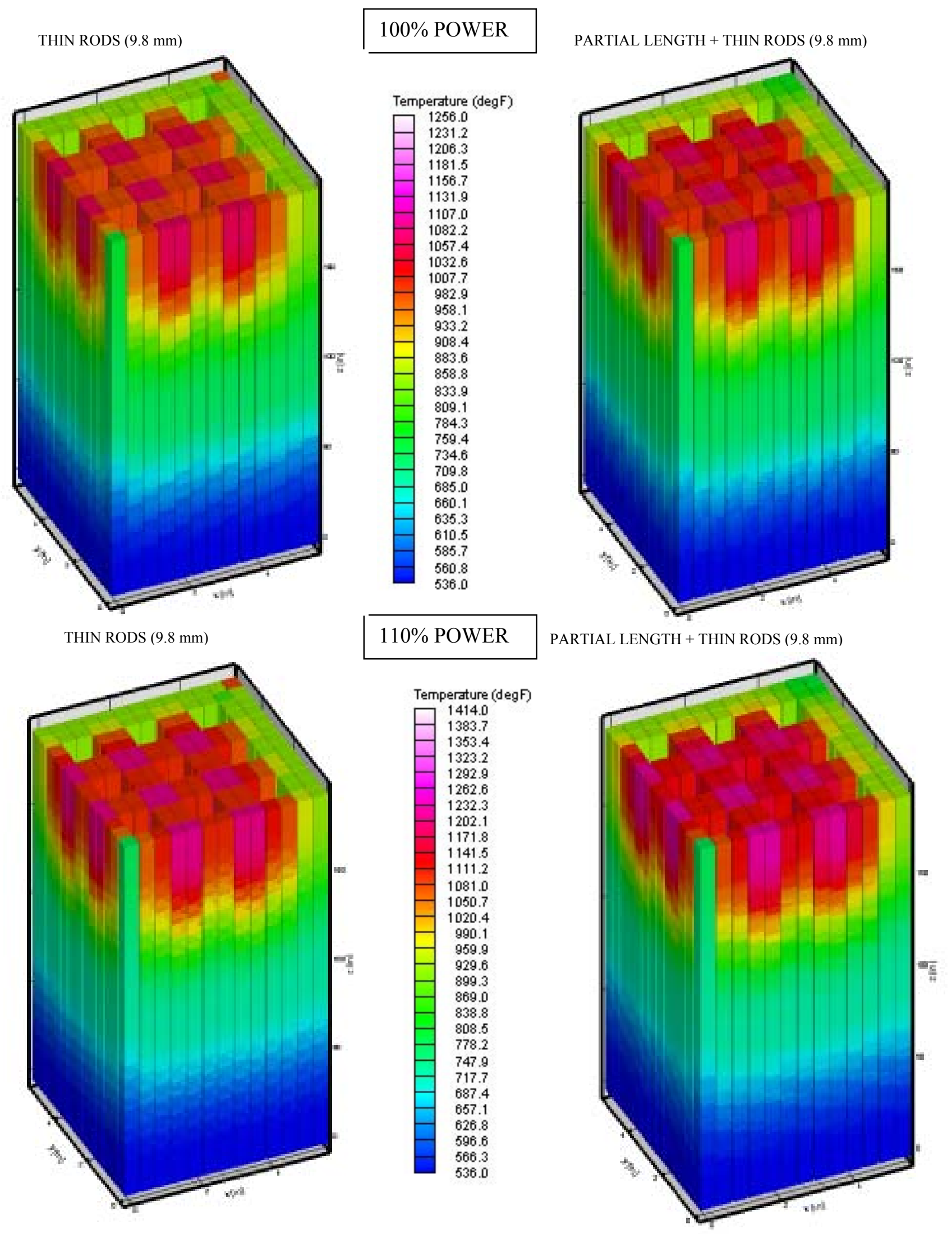

Figure 77. Temperature distributions for $100 \%$ and $110 \%$ power with $9.8 \mathrm{~mm}$ thin rods. 

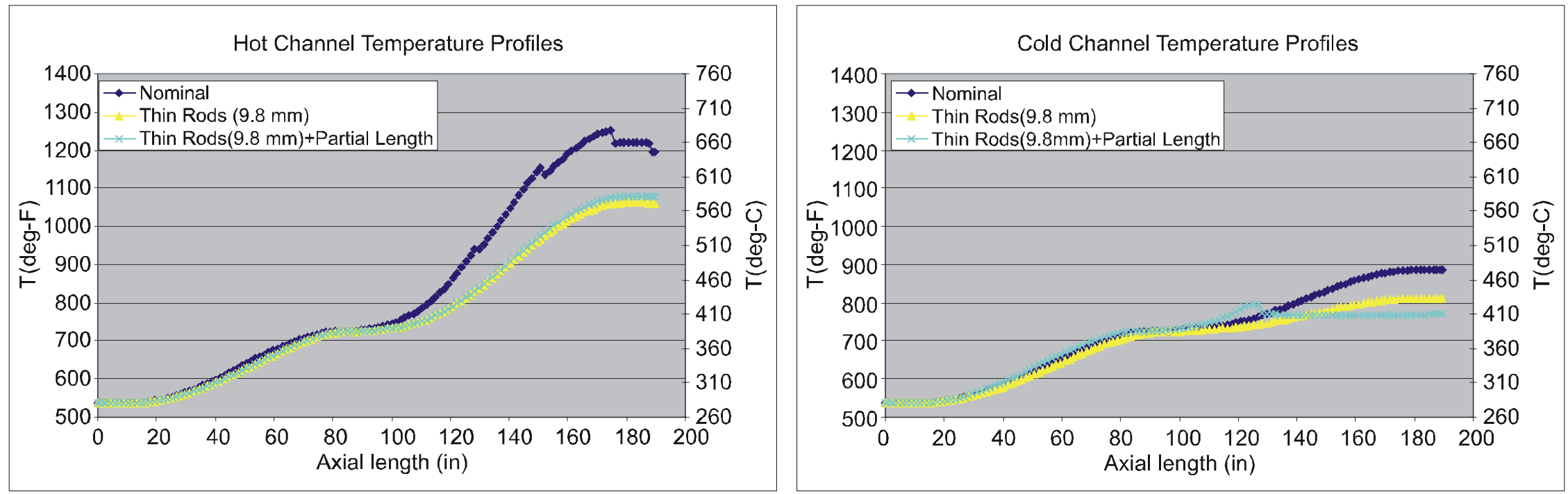

Figure 78. Hot and cold channel temperature profiles for nominal power and $9.8 \mathrm{~mm}$ thin rods.
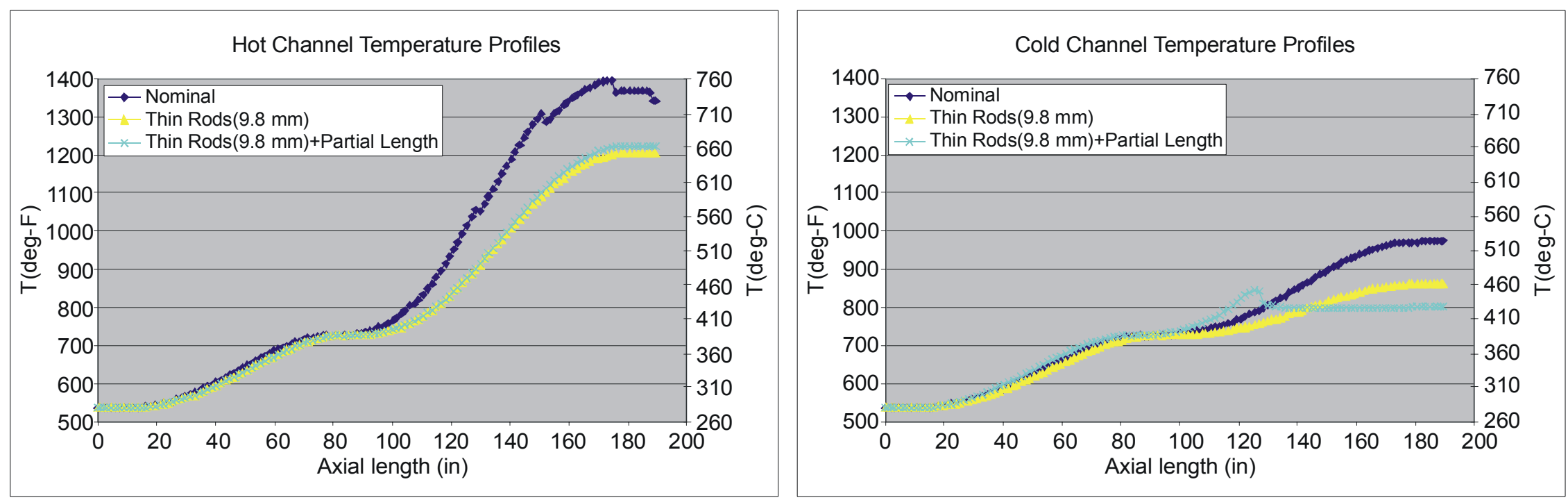

Figure 79. Hot and cold temperature profiles for $110 \%$ power and $9.8 \mathrm{~mm}$ thin rods 
THIN RODS (10.0 mm)

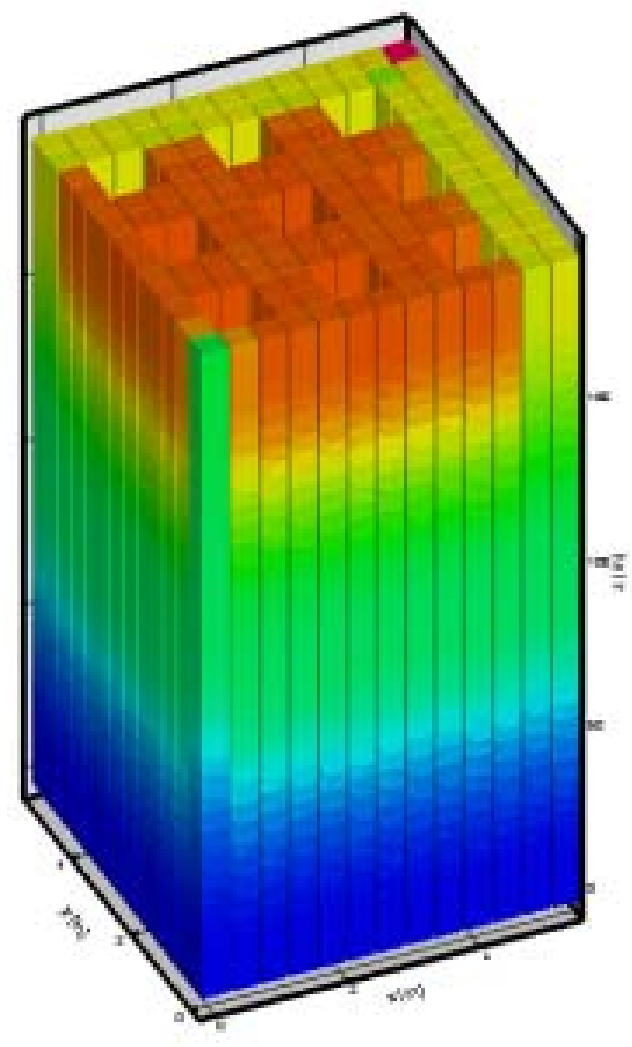

THIN RODS (10.0 mm)

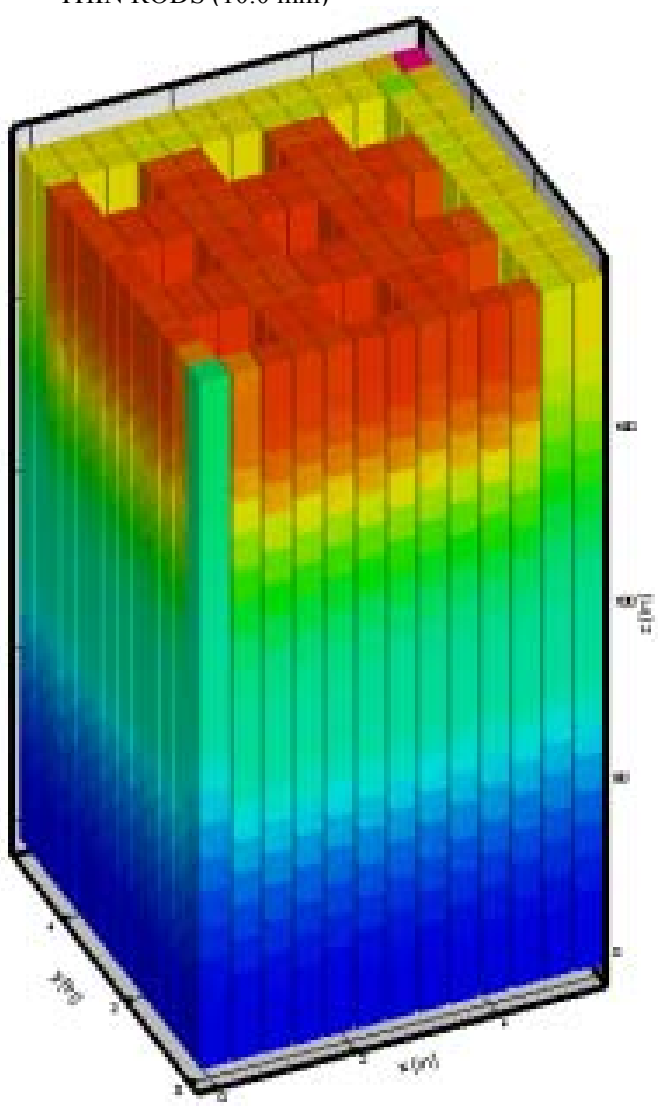

Temperature (degF)

$\square \quad 1256.0$

1231.2

1206.3

1181.5

1156.7

1131.9

1107.0

1082.2

1057.4

1032.6

1007.7

982.9

958.1

933.2

908.4

883.6

858.8

833.9

809.1

784.3

759.4

734.6

709.8

685.0

660.1

635.3

610.5

585.7

560.8

536.0

\section{$110 \%$ POWER}

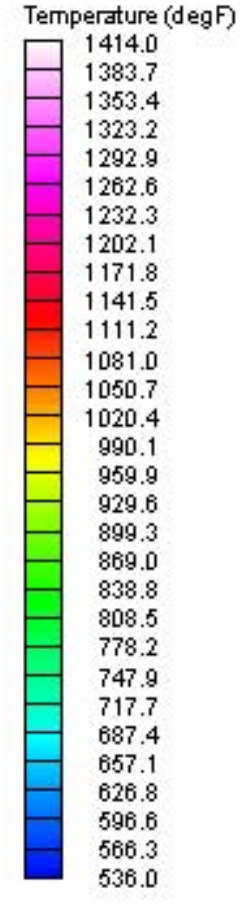

THIN RODS $(10.0 \mathrm{~mm})+9.5 \mathrm{~mm}$ corner $\operatorname{rod}$

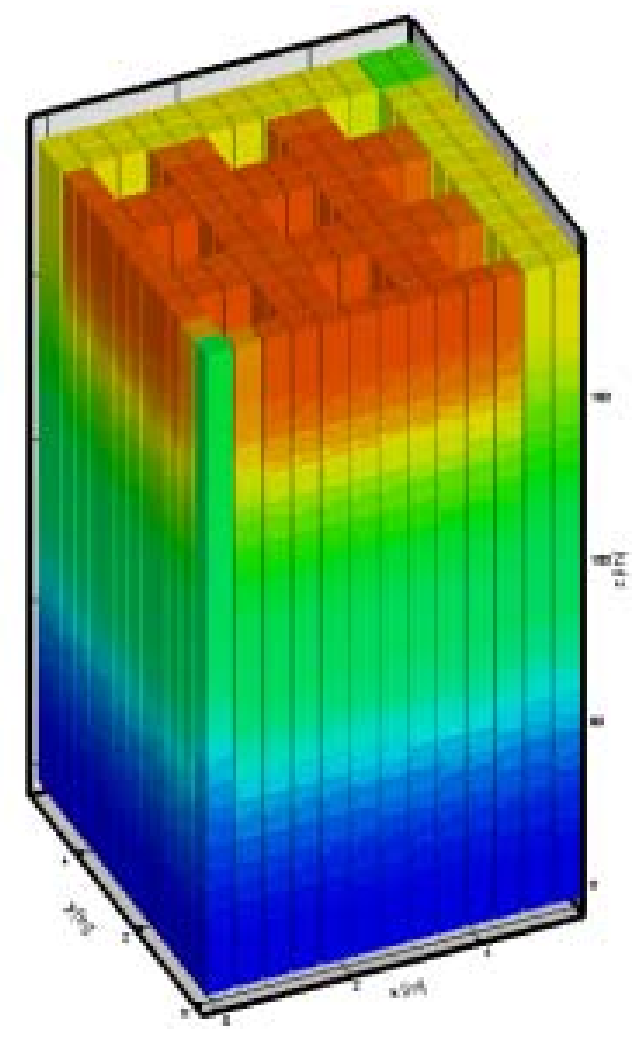

THIN RODS $(10.0 \mathrm{~mm})+9.5 \mathrm{~mm}$ corner rod

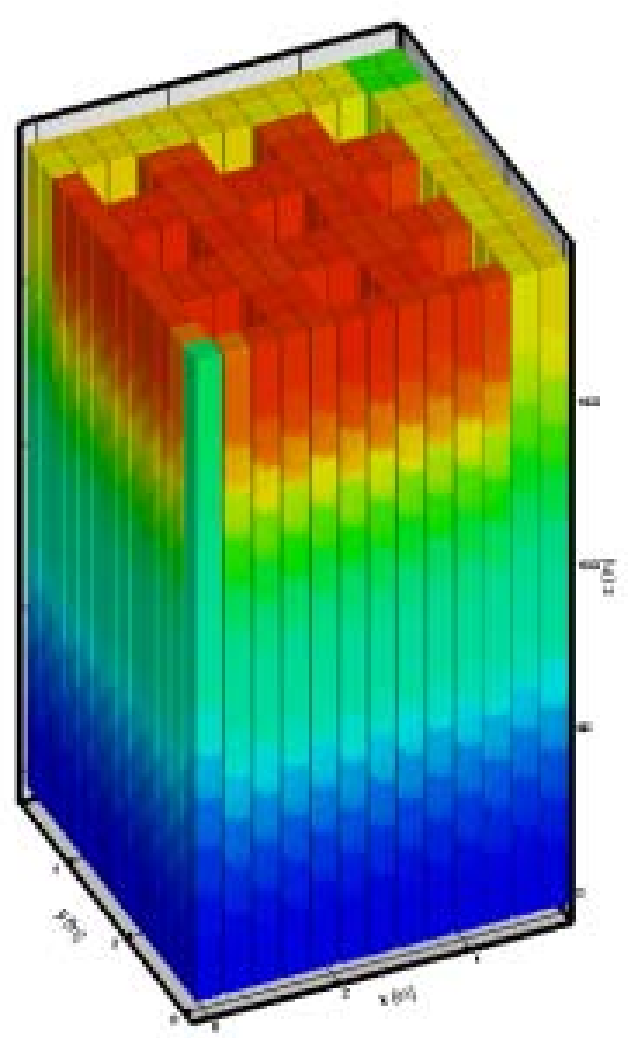

Figure 80. Temperature distributions for $100 \%$ and $110 \%$ power with $10 . \mathrm{mm}$ thin rods and 9.5 mm corner rod. 

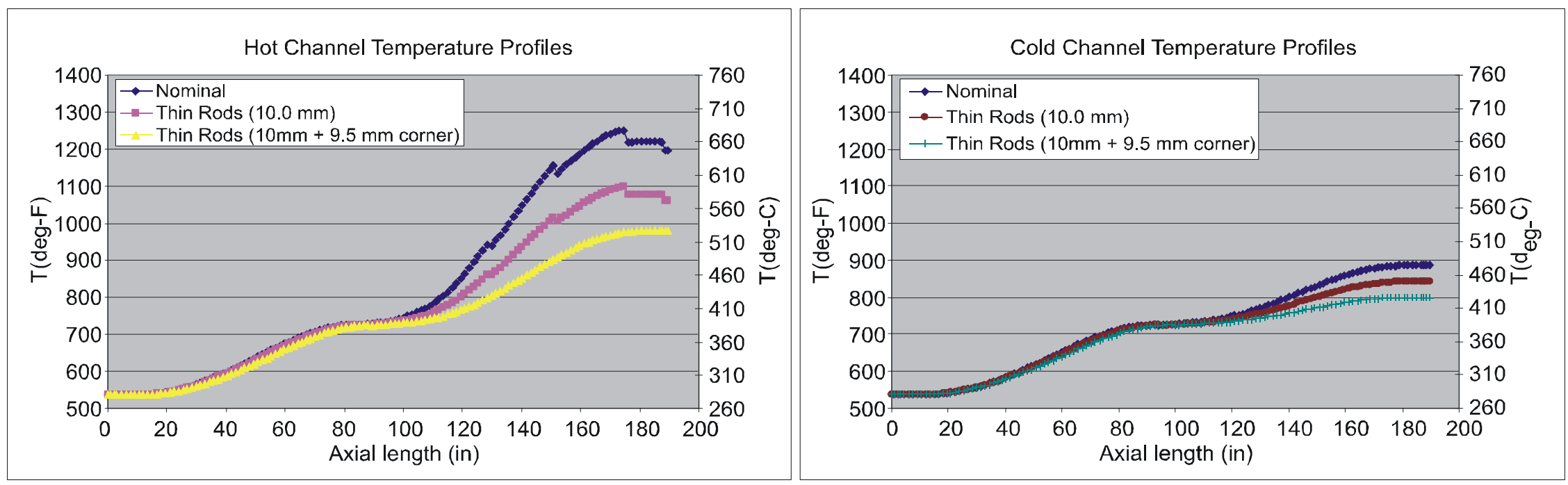

Figure 81. Hot and cold temperature profiles for $100 \%$ power and $10.0 \mathrm{~mm}$ thin rods (and $9.5 \mathrm{~mm}$ corner rods).
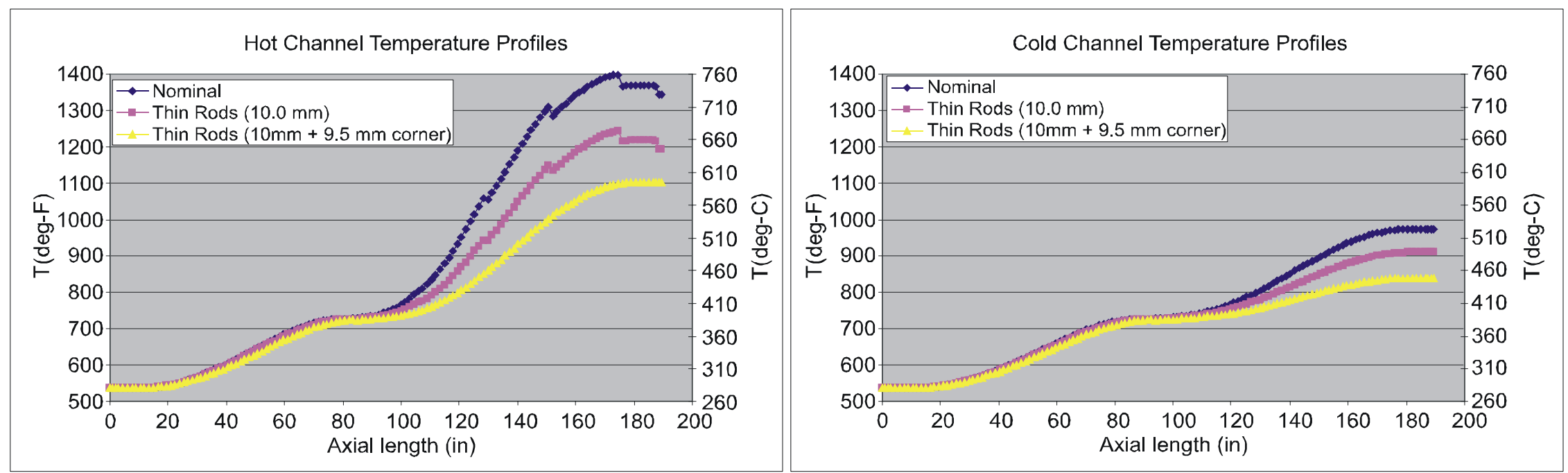

Figure 82. Hot and cold temperature profiles for $110 \%$ power and $10.0 \mathrm{~mm}$ thin rods (and $9.5 \mathrm{~mm}$ corner rods). 
Table 36. Maximum temperatures in the hot-channel for different assembly configurations and power levels in ${ }^{\circ} \mathrm{F}$.

\section{Configuration}

\begin{tabular}{|c|c|c|c|c|c|c|c|c|}
\hline POWER & Nominal & $\begin{array}{l}\text { Partial } \\
\text { Length }\end{array}$ & $\begin{array}{c}\text { Thin Rods } \\
(9.5 \mathrm{~mm})\end{array}$ & $\begin{array}{l}\text { Thin Rods } \\
\text { (9.5 mm)+ } \\
\text { Partial Length }\end{array}$ & $\begin{array}{l}\text { Thin } \\
\text { Rods } \\
(9.8 \mathrm{~mm})\end{array}$ & $\begin{array}{c}\text { Thin Rods } \\
\text { (9.8 mm)+ } \\
\text { Partial Length }\end{array}$ & $\begin{array}{l}\text { Thin Rods } \\
(10.0 \mathrm{~mm})\end{array}$ & $\begin{array}{c}\text { Thin Rods } \\
(10.0 \mathrm{~mm}- \\
9.5 \mathrm{~mm} \\
\text { corner })\end{array}$ \\
\hline $100 \%$ & $\begin{array}{c}1251 \\
\left(677^{\circ} \mathrm{C}\right)\end{array}$ & $\begin{array}{c}987 \\
\left(530^{\circ} \mathrm{C}\right) \\
\end{array}$ & $\begin{array}{c}1248 \\
\left(676^{\circ} \mathrm{C}\right)\end{array}$ & $\begin{array}{c}1256 \\
\left(680^{\circ} \mathrm{C}\right)\end{array}$ & $\begin{array}{c}1062 \\
\left(572^{\circ} \mathrm{C}\right) \\
\end{array}$ & $\begin{array}{c}1079 \\
\left(582^{\circ} \mathrm{C}\right)\end{array}$ & $\begin{array}{c}1098 \\
\left(592^{\circ} \mathrm{C}\right)\end{array}$ & $\begin{array}{c}979 \\
\left(526^{\circ} \mathrm{C}\right) \\
\end{array}$ \\
\hline $110 \%$ & $\begin{array}{c}1398 \\
\left(759^{\circ} \mathrm{C}\right)\end{array}$ & $\begin{array}{c}1107 \\
\left(597^{\circ} \mathrm{C}\right) \\
\end{array}$ & $\begin{array}{c}1403 \\
\left(762^{\circ} \mathrm{C}\right)\end{array}$ & $\begin{array}{c}1415 \\
\left(768^{\circ} \mathrm{C}\right)\end{array}$ & $\begin{array}{c}1206 \\
\left(652^{\circ} \mathrm{C}\right) \\
\end{array}$ & $\begin{array}{c}1225 \\
\left(663^{\circ} \mathrm{C}\right)\end{array}$ & $\begin{array}{c}1243 \\
\left(673^{\circ} \mathrm{C}\right)\end{array}$ & $\begin{array}{c}1102 \\
\left(595^{\circ} \mathrm{C}\right) \\
\end{array}$ \\
\hline
\end{tabular}

Table 37. Maximum temperatures in the cold-channel for different assembly configurations and power levels in ${ }^{\circ} \mathrm{F}$.

\section{Configuration}

\begin{tabular}{|c|c|c|c|c|c|c|c|c|}
\hline POWER & Nominal & $\begin{array}{l}\text { Partial } \\
\text { Length }\end{array}$ & $\begin{array}{c}\text { Thin Rods } \\
(9.5 \mathrm{~mm})\end{array}$ & $\begin{array}{c}\text { Thin Rods } \\
\text { (9.5 mm)+ } \\
\text { Partial Length }\end{array}$ & $\begin{array}{c}\text { Thin } \\
\text { Rods } \\
(9.8 \mathrm{~mm})\end{array}$ & $\begin{array}{c}\text { Thin Rods } \\
\text { (9.8 mm)+ } \\
\text { Partial Length }\end{array}$ & $\begin{array}{l}\text { Thin Rods } \\
(10.0 \mathrm{~mm})\end{array}$ & $\begin{array}{c}\text { Thin Rods } \\
\text { (10.0 mm- } \\
9.5 \mathrm{~mm} \\
\text { corner) }\end{array}$ \\
\hline $100 \%$ & $\begin{array}{l}887 \\
\left(475^{\circ} \mathrm{C}\right)\end{array}$ & $\begin{array}{l}890 \\
\left(477^{\circ} \mathrm{C}\right)\end{array}$ & $\begin{array}{l}745 \\
\left(396^{\circ} \mathrm{C}\right)\end{array}$ & $\begin{array}{l}766 \\
\left(408^{\circ} \mathrm{C}\right)\end{array}$ & $\begin{array}{l}812 \\
\left(433^{\circ} \mathrm{C}\right)\end{array}$ & $\begin{array}{l}797 \\
\left(425^{\circ} \mathrm{C}\right)\end{array}$ & $\begin{array}{l}843 \\
\left(475^{\circ} \mathrm{C}\right)\end{array}$ & $\begin{array}{l}800 \\
\left(427^{\circ} \mathrm{C}\right)\end{array}$ \\
\hline $110 \%$ & $\begin{array}{l}976 \\
\left(524^{\circ} \mathrm{C}\right)\end{array}$ & $\begin{array}{l}989 \\
\left(532^{\circ} \mathrm{C}\right)\end{array}$ & $\begin{array}{l}763 \\
\left(406^{\circ} \mathrm{C}\right)\end{array}$ & $\begin{array}{l}796 \\
\left(424^{\circ} \mathrm{C}\right)\end{array}$ & $\begin{array}{l}863 \\
\left(462^{\circ} \mathrm{C}\right)\end{array}$ & $\begin{array}{l}846 \\
\left(452^{\circ} \mathrm{C}\right)\end{array}$ & $\begin{array}{l}910 \\
\left(489^{\circ} \mathrm{C}\right)\end{array}$ & $\begin{array}{l}840 \\
\left(449^{\circ} \mathrm{C}\right)\end{array}$ \\
\hline
\end{tabular}

Table 38. Maximum and bundle average temperatures for different assembly configurations in ${ }^{\circ} \mathbf{F}$.

\begin{tabular}{|c|c|c|c|c|c|c|c|c|c|}
\hline \multirow[b]{2}{*}{ POWER } & \multirow[b]{2}{*}{$\begin{array}{c}\text { Temperatur } \\
\text { e }\end{array}$} & \multirow[b]{2}{*}{ Nominal } & \multirow[b]{2}{*}{$\begin{array}{l}\text { Partial } \\
\text { Length }\end{array}$} & \multicolumn{4}{|c|}{ Configuration } & \multirow[b]{2}{*}{$\begin{array}{l}\text { Thin } \\
\text { Rods } \\
(\mathbf{1 0 . 0} \\
\text { mm) }\end{array}$} & \multirow[b]{2}{*}{$\begin{array}{c}\text { Thin Rods } \\
\text { (10.0 mm- } \\
9.5 \mathrm{~mm} \\
\text { corner) } \\
\end{array}$} \\
\hline & & & & $\begin{array}{l}\text { Thin } \\
\text { Rods } \\
(9.5 \\
\text { mm) }\end{array}$ & $\begin{array}{c}\text { Thin Rods } \\
\text { (9.5 mm)+ } \\
\text { Partial } \\
\text { Length }\end{array}$ & $\begin{array}{c}\text { Thin } \\
\text { Rods } \\
(9.8 \\
\text { mm) } \\
\end{array}$ & $\begin{array}{c}\text { Thin Rods } \\
\text { (9.8 mm)+ } \\
\text { Partial } \\
\text { Length }\end{array}$ & & \\
\hline \multirow{3}{*}{$100 \%$} & Average & $\begin{array}{c}933 \\
\left(501^{\circ} \mathrm{C}\right)\end{array}$ & $\begin{array}{c}931 \\
\left(450^{\circ} \mathrm{C}\right)\end{array}$ & $\begin{array}{c}934 \\
\left(501^{\circ} \mathrm{C}\right)\end{array}$ & $\begin{array}{c}931 \\
\left(499^{\circ} \mathrm{C}\right)\end{array}$ & $\begin{array}{c}934 \\
\left(501^{\circ} \mathrm{C}\right)\end{array}$ & $\begin{array}{c}931 \\
\left(499^{\circ} \mathrm{C}\right)\end{array}$ & $\begin{array}{c}934 \\
\left(501^{\circ} \mathrm{C}\right)\end{array}$ & $\begin{array}{c}899 \\
\left(501^{\circ} \mathrm{C}\right)\end{array}$ \\
\hline & Maximum & $\begin{array}{c}1252 \\
\left(677^{\circ} \mathrm{C}\right)\end{array}$ & $\begin{array}{c}987 \\
\left(530^{\circ} \mathrm{C}\right)\end{array}$ & $\begin{array}{c}1248 \\
\left(676^{\circ} \mathrm{C}\right)\end{array}$ & $\begin{array}{c}1256 \\
\left(680^{\circ} \mathrm{C}\right)\end{array}$ & $\begin{array}{c}1062 \\
\left(572^{\circ} \mathrm{C}\right)\end{array}$ & $\begin{array}{c}1079 \\
\left(582^{\circ} \mathrm{C}\right)\end{array}$ & $\begin{array}{c}1098 \\
\left(592^{\circ} \mathrm{C}\right)\end{array}$ & $\begin{array}{c}979 \\
\left(526^{\circ} \mathrm{C}\right)\end{array}$ \\
\hline & $\begin{array}{c}\Delta-T \\
\text { (Max-Ave) }\end{array}$ & $\begin{array}{c}317 \\
\left(176^{\circ} \mathrm{C}\right)\end{array}$ & $\begin{array}{c}56 \\
\left(31^{\circ} \mathrm{C}\right)\end{array}$ & $\begin{array}{c}315 \\
\left(175^{\circ} \mathrm{C}\right)\end{array}$ & $\begin{array}{c}325 \\
\left(181^{\circ} \mathrm{C}\right)\end{array}$ & $\begin{array}{c}129 \\
\left(72^{\circ} \mathrm{C}\right)\end{array}$ & $\begin{array}{c}148 \\
\left(82^{\circ} \mathrm{C}\right)\end{array}$ & $\begin{array}{c}165 \\
\left(91^{\circ} \mathrm{C}\right)\end{array}$ & $\begin{array}{c}45 \\
\left(25^{\circ} \mathrm{C}\right)\end{array}$ \\
\hline $110 \%$ & $\begin{array}{c}\Delta-T \\
(M a x-A v e)\end{array}$ & $\begin{array}{c}361 \\
\left(201^{\circ} \mathrm{C}\right)\end{array}$ & $\begin{array}{c}73 \\
\left(41^{\circ} \mathrm{C}\right)\end{array}$ & $\begin{array}{c}366 \\
\left(203^{\circ} \mathrm{C}\right)\end{array}$ & $\begin{array}{c}381 \\
\left(212^{\circ} \mathrm{C}\right)\end{array}$ & $\begin{array}{c}169 \\
\left(94^{\circ} \mathrm{C}\right)\end{array}$ & $\begin{array}{c}191 \\
\left(106^{\circ} \mathrm{C}\right)\end{array}$ & $\begin{array}{c}206 \\
\left(115^{\circ} \mathrm{C}\right)\end{array}$ & $\begin{array}{c}65 \\
\left(36^{\circ} \mathrm{C}\right)\end{array}$ \\
\hline
\end{tabular}




\subsubsection{Core Orifices}

In order to achieve uniform channel exit temperatures throughout the core, an orifice scheme is necessary. To demonstrate and verify the feasibility of this process using the VIPRE-W code, a quarter core was modeled with each assembly considered as a single lumped channel. Three different radial rings with different relative powers were considered. By assigning different loss coefficients at the inlets and forcing a uniform pressure drop across the first node of each channel, different mass flow rates were achieved through each channel leading to a uniform exit temperature distribution. Figure 83 shows the power, mass flux and channel exit temperatures for the no-orifice case. Since flow is equally distributed among the channels, the exit temperatures from the central channels are $\sim 440{ }^{\circ} \mathrm{F}$ higher than the outside channels. When we apply the orifice scheme, VIPRE-W redistributes the flow and creates a uniform pressure drop. As seen in Figure 84, the channel exit temperatures throughout the core are virtually identical, and mass flux in the channels are distributed in a manner corresponding to the radial power distribution, leading to a relatively uniform temperature distribution.

A "perfect" orifice scheme is naturally impossible since the core power distributions are not constant during the fuel cycle. It appears, however, possible that by an adequate neutronic design and an orifice scheme, the power to flow ratio might be maintained throughout the core between 1.1 and 0.9. While this represents an aggressive objective, the results provided in Section 4.2 show that any larger value would lead to excessive temperatures in the hot channel, making a successful core design all but impossible.

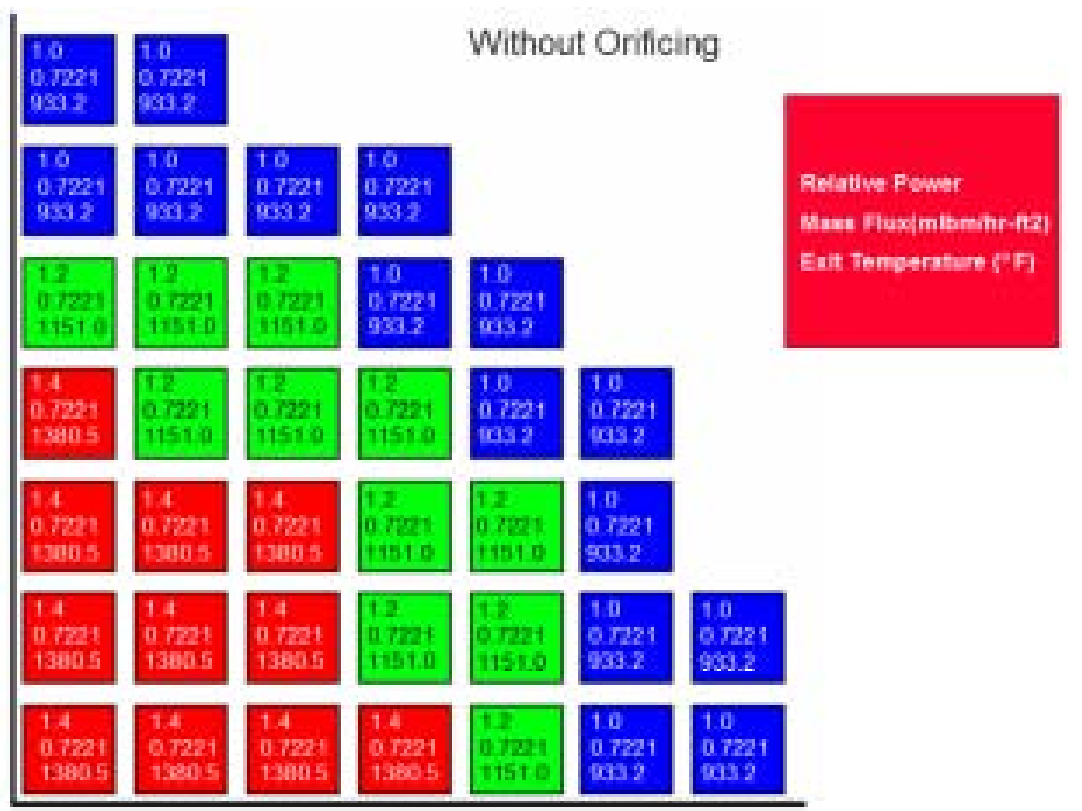

Figure 83. Power, mass flux, and core exit temperatures without orifices.

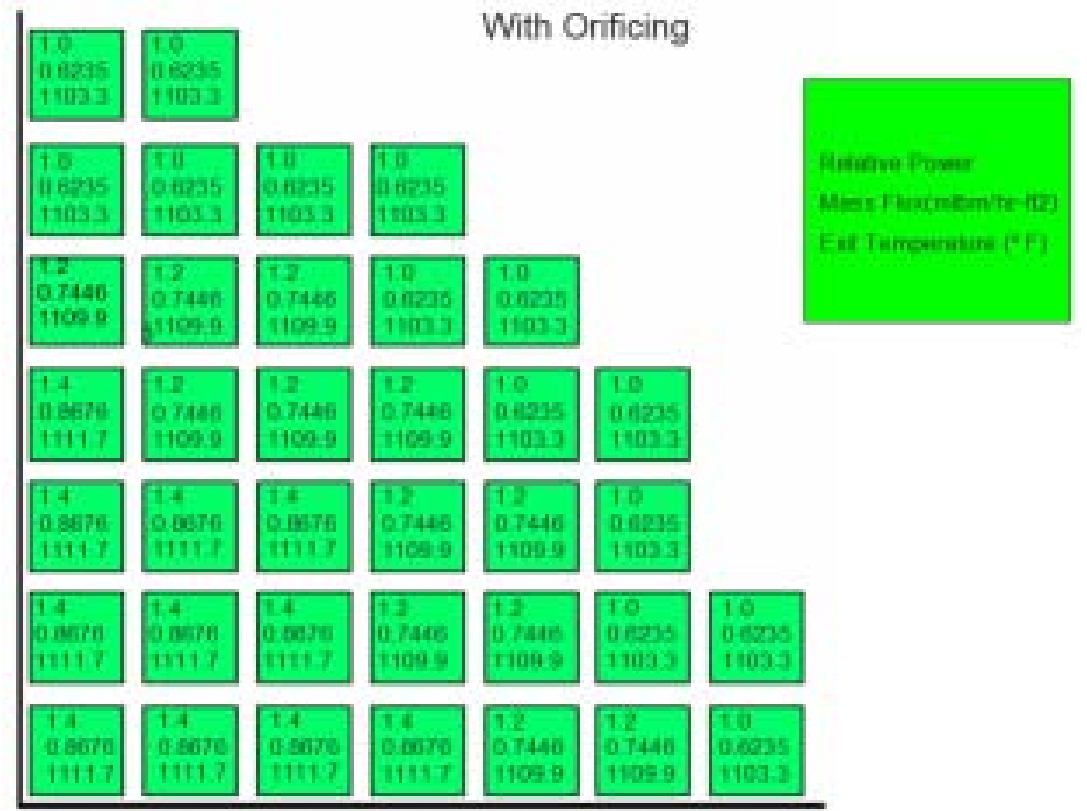

Figure 84. Power, mass flux, and core exit temperatures with orifices. 


\subsubsection{Cladding Temperatures}

As discussed above, we made slight modifications to the SCWR assembly design by either replacing the full-length rods at the assembly corners with partial length rods $(2 / 3$ of the nominal heated length) or by placing thinner rods on the assembly periphery, and directly facing the water boxes, to reduce the high flow resistance in those channels. The VIPRE-W models did not utilize a conduction model in these studies, hence we only focused on channel coolant temperatures and did not address cladding temperature profiles in the SCWR fuel assembly. This section documents the analyses of the cladding temperatures.

Based on the results documented in Section 5.3, three assembly configurations were considered for this study: 1.) a nominal configuration, in which all rods have uniform dimensions, 2.) an assembly geometry with partial length rods on the assembly corners, and 3.) an assembly geometry with partial length rods on the assembly corners plus thin rods directly facing the water channels and around the assembly periphery. For each of these cases, the average clad temperature profiles are presented for the hot channel, where the hot channel is defined as the channel where the peak clad temperature occurs. The average cladding temperature is calculated by simple averaging of the clad inside and outside surface temperatures.

Figure 85 shows the heat transfer coefficient as a function of temperature calculated using various correlations described in Section 5.1.2 above. All the correlations tend to yield similar results in regions far away from the pseudo-critical temperatures. In the low temperature region, the Bishop correlation tends to predict much lower heat transfer coefficients than the Dittus-Boelter correlation, while the other correlations are in good agreement. Around the pseudo critical temperature the Jackson correlation tends to over predict heat transfer compared to the Bishop and OkaKoshizuka correlations. From a qualitative point of view, the closest behavior to the Dittus-Boelter correlation appears to be resulting from the Jackson correlation.

Figure 86 shows the hot channel average cladding temperature profiles calculated using different correlations

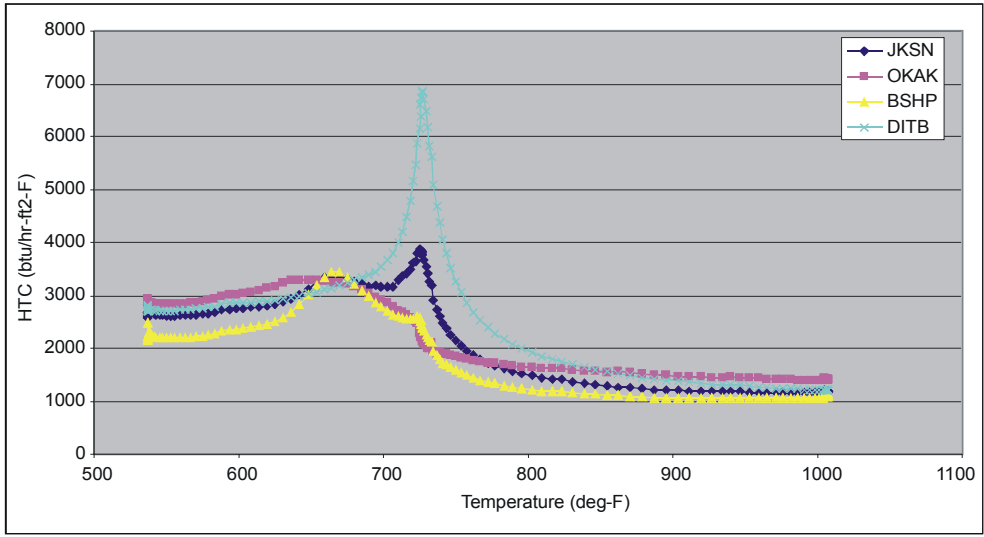

Figure 85. Heat transfer coefficient as a function of temperature for different correlations.

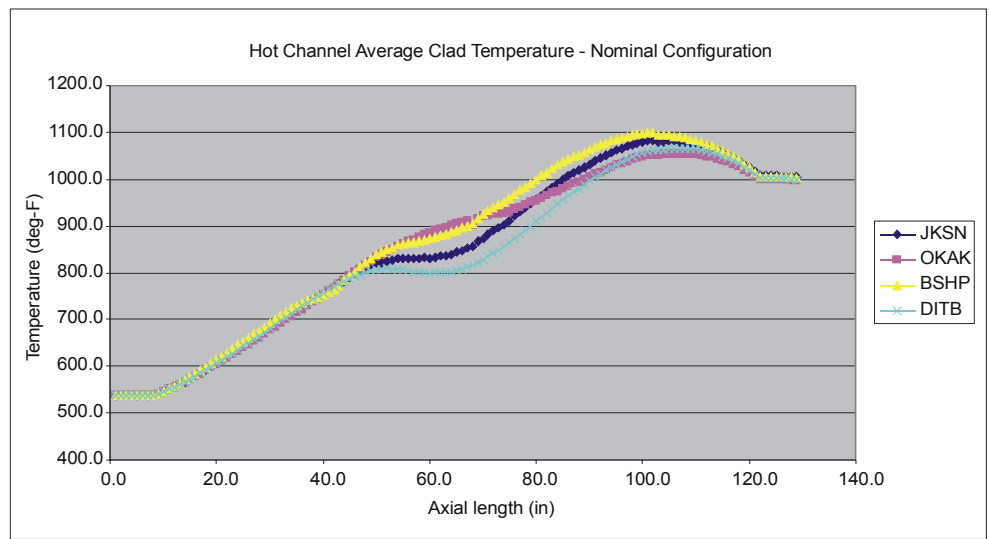

Figure 86. Axial clad temperature profile in the hot channel for different heat transfer correlations. for $100 \%$ power and nominal assembly configuration. Bishop calculates the highest peak cladding temperature, $1099{ }^{\circ} \mathrm{F}\left(593{ }^{\circ} \mathrm{C}\right)$ and OkaKoshizuka calculates the lowest, $1055^{\circ} \mathrm{F}\left(568{ }^{\circ} \mathrm{C}\right)$, where as Jackson is in between Dittus-Boelter and Bishop at $1083^{\circ} \mathrm{F}\left(584{ }^{\circ} \mathrm{C}\right)$. 
Figure 87 shows the three-dimensional average clad temperature profiles calculated using the Jackson correlation for the different assembly configurations at $100 \%$ power. Note that quarter symmetry is used in the calculations and that the southwest corner channel is the instrumentation channel. Similar to channel coolant temperature profiles presented in the last section, the fuel rods right around the water boxes generally have higher temperatures compared to rods in between water box corners, due to the larger wetted perimeters compared to the flow areas in the channels where these rods reside. The northeast corner rod has the highest temperature in the nominal geometry case. As further seen in the figure, reducing the axial length of the rod in this corner shifts the peak clad temperature to a different location and reduces the maximum temperature. Temperatures in the rods directly facing the water boxes and around the assembly periphery are significantly reduced when the diameter of these rods are reduced. However as evident from Figure 87, the higher temperatures are now pushed to rods around the water box corners, contrary to the nominal geometry case. This however indicates that while the reduction in diameter is excessive (it essentially drives the peak temperature to different areas of the assembly but does little to reduce the peak temperature) this approach can be used to optimize the assembly flow distribution.

A summary of maximum average clad temperatures calculated using different assembly configurations, heat transfer correlations, and power levels is provided in Table 39. As evident from this table and the discussions regarding the channel temperatures presented above, the case with thin rods $(10 \mathrm{~mm})$ facing the water boxes and around the assembly periphery and a thinner $(9.5 \mathrm{~mm})$ rod at the north-west corner yields the minimum peak clad temperature in the hot channel.

Table 39. Peak Clad Temperatures in the HOT-channel calculated using different heat transfer correlations for different assembly configurations and power levels.

\section{Configuration}

\begin{tabular}{|c|c|c|c|c|c|c|c|}
\hline power & Correlation & Nominal & $\begin{array}{l}\text { Partial } \\
\text { Length }\end{array}$ & $\begin{array}{c}\text { Thin } \\
\text { Rods } \\
(9.5 \mathrm{~mm})\end{array}$ & $\begin{array}{c}\text { Thin } \\
\text { Rods } \\
(9.5 \\
\text { mm)+ } \\
\text { Partial } \\
\text { Length }\end{array}$ & $\begin{array}{c}\text { Thin } \\
\text { Rods } \\
(9.8 \mathrm{~mm})\end{array}$ & $\begin{array}{c}\text { Thin Rods } \\
\text { (10.0 mm- } \\
9.5 \mathrm{~mm} \\
\text { corner) }\end{array}$ \\
\hline \multirow{6}{*}{$100 \%$} & Jackson & 1069 & $\begin{array}{c}1041 \\
\left.561^{\circ} \mathrm{C}\right)\end{array}$ & $\begin{array}{c}1332 \\
\left(722^{\circ} \mathrm{C}\right)\end{array}$ & 1333 & $\begin{array}{c}1136 \\
\left(613^{\circ} \mathrm{C}\right)\end{array}$ & $\begin{array}{c}1049 \\
\left(565^{\circ} \mathrm{C}\right)\end{array}$ \\
\hline & Oka- & 1044 & 1024 & 1307 & $\begin{array}{l}1308 \\
1308\end{array}$ & $\begin{array}{c}(013 \mathrm{C}) \\
1112\end{array}$ & 1030 \\
\hline & Koshizuka & $\left(562^{\circ} \mathrm{C}\right)$ & $\left(551^{\circ} \mathrm{C}\right)$ & $\left(708^{\circ} \mathrm{C}\right)$ & $\left(709^{\circ} \mathrm{C}\right)$ & $\left(600^{\circ} \mathrm{C}\right)$ & $\left(554^{\circ} \mathrm{C}\right)$ \\
\hline & Bishop & $\begin{array}{c}1084 \\
\left(585^{\circ} \mathrm{C}\right)\end{array}$ & $\begin{array}{c}1070 \\
\left(577^{\circ} \mathrm{C}\right)\end{array}$ & $\begin{array}{c}1353 \\
\left(734^{\circ} \mathrm{C}\right)\end{array}$ & $\begin{array}{c}1355 \\
\left(735^{\circ} \mathrm{C}\right)\end{array}$ & $\begin{array}{c}1150 \\
\left(621^{\circ} \mathrm{C}\right)\end{array}$ & $\begin{array}{c}1063 \\
\left(573^{\circ} \mathrm{C}\right)\end{array}$ \\
\hline & Dittus-Boelter & 1056 & 1034 & 1322 & 1323 & 1128 & 1041 \\
\hline & & $\left(569^{\circ} \mathrm{C}\right)$ & $\left(557^{\circ} \mathrm{C}\right)$ & $\left(717^{\circ} \mathrm{C}\right)$ & $\left(717^{\circ} \mathrm{C}\right)$ & $\left(609^{\circ} \mathrm{C}\right)$ & $\left(560^{\circ} \mathrm{C}\right)$ \\
\hline \multirow{7}{*}{$110 \%$} & Jackson & 1216 & 1169 & 1510 & 1522 & 1286 & 1176 \\
\hline & & $\left(658^{\circ} \mathrm{C}\right)$ & $\left(631^{\circ} \mathrm{C}\right)$ & $\left(821^{\circ} \mathrm{C}\right)$ & $\left(828^{\circ} \mathrm{C}\right)$ & $\left(697^{\circ} \mathrm{C}\right)$ & $\left(636^{\circ} \mathrm{C}\right)$ \\
\hline & Oka- & 1191 & 1147 & 1458 & 1464 & 1262 & 1152 \\
\hline & Koshizuka & $\left(644^{\circ} \mathrm{C}\right)$ & $\left(620^{\circ} \mathrm{C}\right)$ & $\left(792^{\circ} \mathrm{C}\right)$ & $\left(796^{\circ} \mathrm{C}\right)$ & $\left(683^{\circ} \mathrm{C}\right)$ & $\left(622^{\circ} \mathrm{C}\right)$ \\
\hline & Bishop & 1237 & 1199 & 1544 & 1557 & 1303 & 1193 \\
\hline & & $\left(669^{\circ} \mathrm{C}\right)$ & $\left(648^{\circ} \mathrm{C}\right)$ & $\left(840^{\circ} \mathrm{C}\right)$ & $\left(847^{\circ} \mathrm{C}\right)$ & $\left(706^{\circ} \mathrm{C}\right)$ & $\left(645^{\circ} \mathrm{C}\right)$ \\
\hline & Dittus-Boelter & $\begin{array}{c}1201 \\
\left(649^{\circ} \mathrm{C}\right)\end{array}$ & $\begin{array}{c}1162 \\
\left(628^{\circ} \mathrm{C}\right)\end{array}$ & $\begin{array}{c}1487 \\
\left(808^{\circ} \mathrm{C}\right)\end{array}$ & $\begin{array}{c}1497 \\
\left(814^{\circ} \mathrm{C}\right)\end{array}$ & $\begin{array}{c}1277 \\
\left(692^{\circ} \mathrm{C}\right)\end{array}$ & $\begin{array}{c}1168 \\
\left(631^{\circ} \mathrm{C}\right)\end{array}$ \\
\hline
\end{tabular}


Nominal Configuration

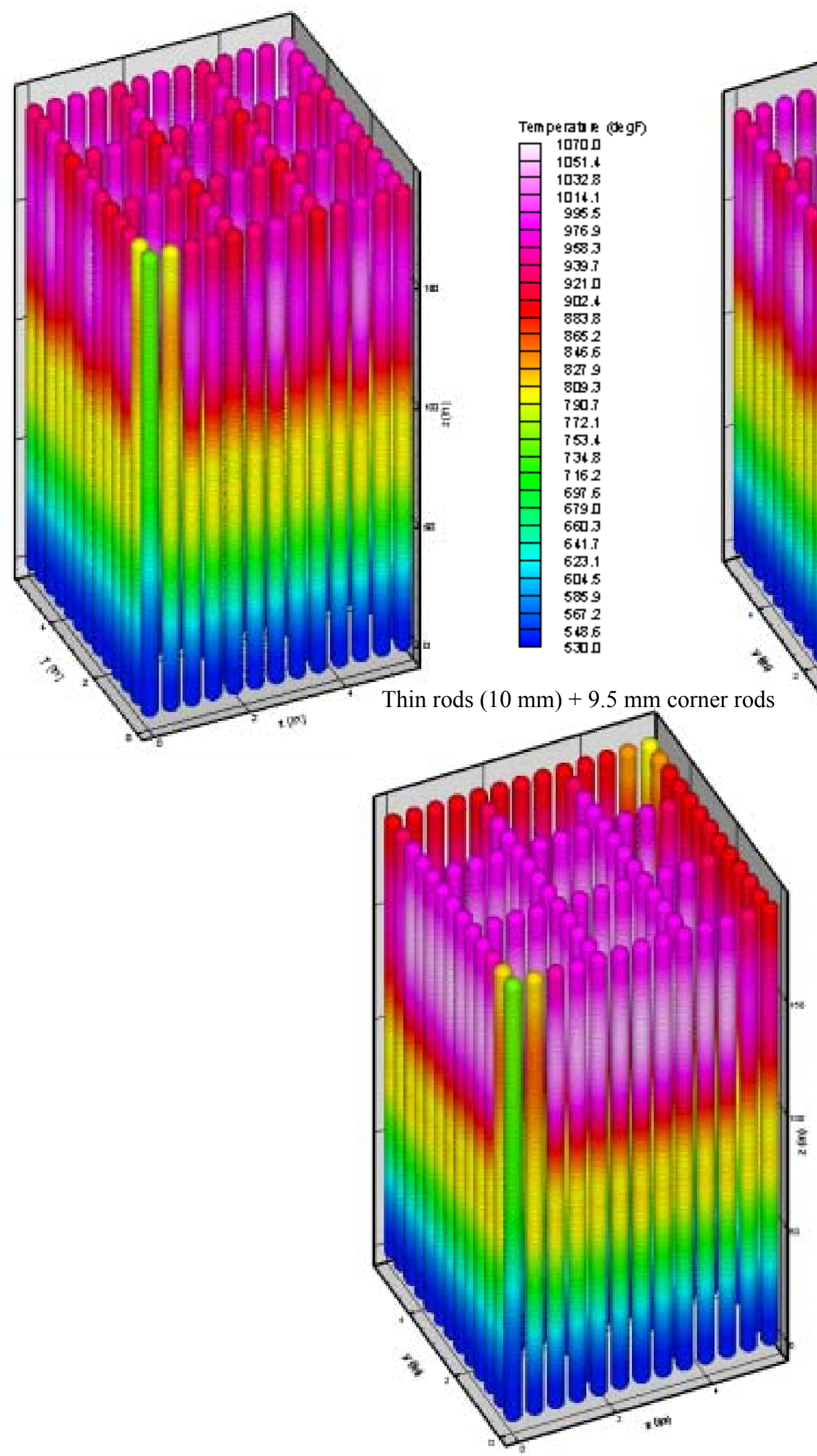

Partial length corner rods
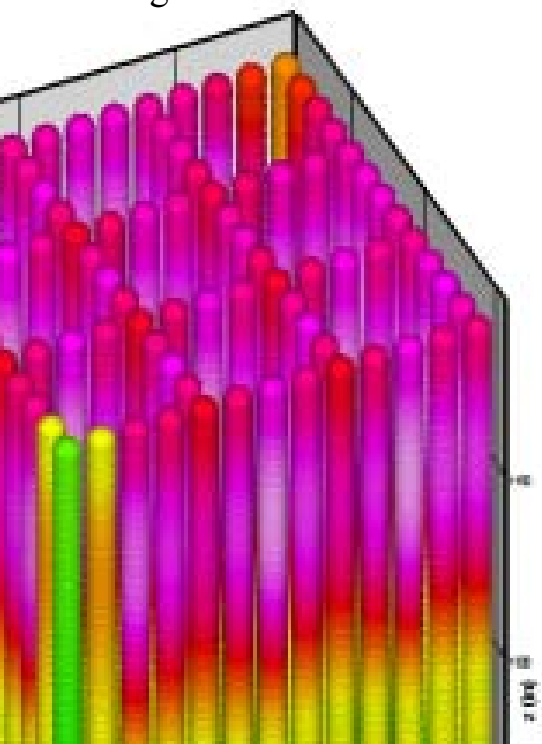

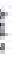

Figure 87. Three-dimensional average clad temperature profiles for different assembly configurations using Jackson Correlation. 


\subsubsection{Conclusions}

Results from the optimization studies, even though any neutronic coupling is ignored, suggest that it is possible to obtain a better temperature profile (hence, lower hot channel factors) by employing a slightly more complex fuel assembly configuration. The fact that $10.0 \mathrm{~mm}$ rods yielded better results as compared to $9.5 \mathrm{~mm}$ rods further imply that sharp flow area differences between neighboring channels would have a detrimental effect, as to hinder uniform flow distribution.

Based on the results of this study the following should be considered:

1. The design should use the geometric configuration with three different rod diameters $(10.2 \mathrm{~mm}$, $10 \mathrm{~mm}$, and $9.5 \mathrm{~mm}$, according to the pattern discussed in the previous sections: the $10 \mathrm{~mm}$ outside diameter rods for the channels facing the water rods and at the assembly periphery, the $9.5 \mathrm{~mm}$ rods for the assembly corners, and the $10.2 \mathrm{~mm}$ rods for all other positions). No part length rods should be used. Note that a different value of the nominal rod outside diameter could be used in place of the $10.2 \mathrm{~mm}$ used in this analysis, however, the same ratio between the rods outside diameters should be maintained.

2. As discussed in Section 3.1.11, these small coolant flow geometry changes do not change the power distribution to any significant extent. Also, Section indicates that it is impossible to get the power distribution flatter than about plus or minus $5 \%$.

While this study shows a path to obtain a better thermal hydraulic design, it also provides the designer with an important design issue: the flow is clearly very sensitive to small variations in the channel flow area. Therefore, rod bowing and ballooning effects, and even the tolerances in the fuel rod, water box, and assembly shroud dimensions will significantly effect peaking factors. T his sensitivity, which can be attributed to the large channel enthalpy rise coupled with a region of low-density phase and high exit velocities, renders the design process extremely difficult.

These results therefore confirm the concerns identified in Section 5.1.1. As discussed in all previous Sections and in the various reports provided during the SCWR program, designing an assembly and core that provides acceptable performance (i.e. low enough exit coolant temperatures in the hot channels) remains a major feasibility issue for which a solution has yet to be achieved. Based on these results, the risk connected with further research activities on the SCWR concept is judged extremely high. 


\subsection{An Evaluation of an Innovative Safety Concept for the SCWR (INEEL: C. B. Davis, Westinghouse Electric Co.: Dr. L. Oriani, L. E. Conway, and N. Jonsson)}

\subsubsection{Introduction}

This section describes work related to plant engineering and reactor safety analysis. Previous proposed designs of a SCWR have utilized once-through direct-cycle concepts such as described in Section 2 of this report. In the once-through design, "feedwater" flows through the vessel where it is turned into "steam", but there is no potential circulation between the feedwater and steam lines. Analyses have shown that a transient initiated by a loss of main feedwater (LOMF) can be a challenging event for a SCWR with a once-through design. As shown in Figure 88, MacDonald et al. [2003] evaluated the effects of LOMF events in a SCWR with a once-through design. The results indicated that acceptable cladding temperatures could be obtained if significant auxiliary feedwater flow is initiated rapidly. Specifically, if the auxiliary feedwater is initiated within $4.25 \mathrm{~s}$ of the LOMF and the auxiliary feedwater flow is at least $15 \%$ of the initial main feedwater flow rate, then the peak cladding temperature would remain less than the transient limit of $840{ }^{\circ} \mathrm{C}$. By meeting this limit, fuel rods would not be damaged during the event and the reactor could be restarted relatively rapidly.

Although the analysis of MacDonald et al.

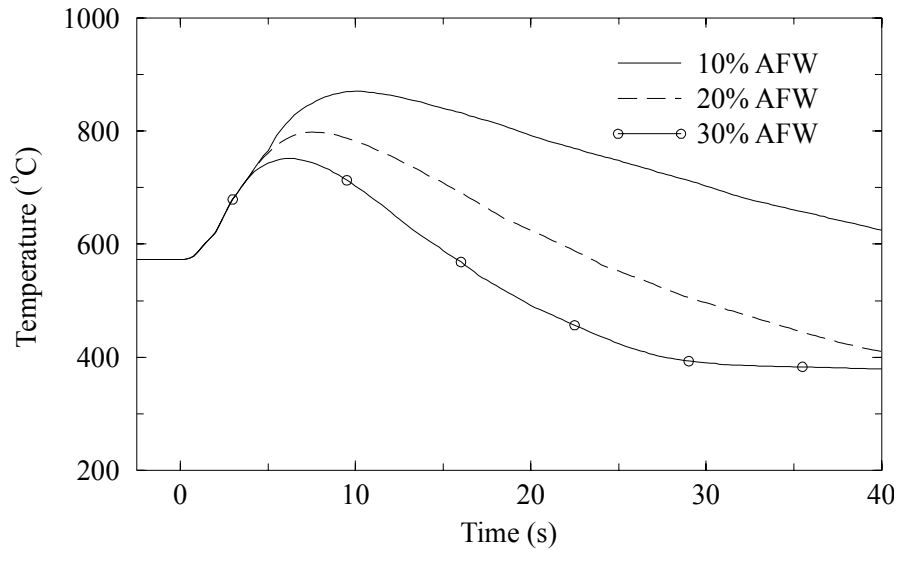

Figure 88. The effect of auxiliary feedwater on peak cladding temperature following a LOMF. [2003] showed that it is possible to meet transient cladding temperature limits following a LOMF, the auxiliary feedwater requirements will present significant design challenges, and are actually considered impossible within a reasonable extrapolation of current technology. For example, auxiliary feedwater initiation within $4.25 \mathrm{~s}$ of a LOMF is much faster than assumed for currently operating pressurized PWRs, in which auxiliary feedwater is typically not assumed to start until one minute after an actuation signal. The one-minute delay is used to detect the occurrence of the event, start and load diesel generators, start the motor-driven or steam-driven auxiliary feedwater pumps, and to open the required valves. Furthermore, the required amount of auxiliary feedwater flow for the SCWR is significantly larger than for currently operating PWRs, where auxiliary feedwater removes decay heat and thus is generally sized to provide less than $5 \%$ of the rated main feedwater flow. In addition, the head required of the pumps to begin delivering water to the system is almost four times higher than for current auxiliary feedwater systems.

\footnotetext{
${ }^{2}$ In this work, the word "steam" is used in reference to the relatively low-density fluid that exists at temperatures above the pseudo-critical value, while "water" refers to the relatively high-density fluid that exists at temperatures below the pseudo-critical value. Naturally, it is understood that "water" and "steam" are not formally correct terms when supercritical conditions are considered.
} 
In order to avoid the design challenges and cost associated with developing an active auxiliary feedwater system that meets the requirements for the SCWR, Westinghouse [Oriani et al. 2004] developed an innovative conceptual design that uses a passive circulation system to mitigate the effects of a LOMF transient. The proposed design features feedwater tanks that supply water to the reactor core and main coolant pumps that provide forced circulation during LOMF events. The feedwater tanks are connected to both the cold and hot legs. The proposed design remains essentially once through during normal, steady operation, but the connections between the tanks and the hot and cold legs allow recirculation during LOMF events. The combination of the liquid inventory in the feedwater tanks, the flow provided by the main coolant pumps during coastdown, and the circulation between the hot and cold legs allows the proposed design to passively meet cladding thermal limits following a LOMF transient. An isolation condenser provides long-term decay heat removal.

The safety characteristics of the proposed design during short-term and long-term loss-of-flow events and loss-of-coolant accidents (LOCAs) have been evaluated using the RELAP5-3D [INEEL 2003] computer code. The RELAP5-3D computer code has been recently improved for the analysis of reactors cooled by supercritical water [MacDonald et al. 2003 and Riemke et al. 2003].

Section 5.2.2 of this report describes the conceptual design of the SCWR with the proposed circulation system. Section 5.2.3 describes the RELAP5 model of the design and presents transient results. Conclusions are provided in Section 5.2.4 and the references are at the end of this report.

\subsubsection{Reactor Core Cooling System Description}

An overview of the safety characteristics of a once-through direct cycle SCWR is described in Westinghouse [2003], which identifies the LOMF as a critical transient for the SCWR. The report also discusses four potential approaches to solve this problem:

1. Increase the reliability of the main feedwater system to make the LOMF a Condition III accident,

2. Design for a continuously operating auxiliary feedwater,

3. Design the safety systems so that an acceptable performance in the response of a LOMF event can be obtained, and finally

4. Design the reactor core cooling system for the SCWR in such a way that an improved response to the LOMF event is passively built into the design.

Approaches 1, 2, and 3 are extensively discussed in Westinghouse [2003]. Our opinion is that Approaches 1 and 2 would not be acceptable. The main issue with Approach 1 is that the LOMF can be caused by loss of offsite power, which occurs relatively frequently at U. S. plants. Although the loss of offsite power also causes early control rod insertion, sequences initiated by combined failures in the power supply and main feedwater systems have the potential to result in a LOMF and a delayed reactor trip, and are thus of concern. The main issue with Approach 2 is that a continuously operating auxiliary feedwater system is also vulnerable to loss of offsite power. Powering the auxiliary feedwater pumps by a continuously operating diesel generator raises issues concerning long-term operation of the diesels, maintenance, and cost. As discussed in Section 5.2.1, the main issue with Approach 3 is that it appears difficult to achieve a design that provides the extremely fast response required to mitigate the consequences of a LOMF event. If such a design were achieved, it would likely be vulnerable to spurious actuations that would degrade the operational characteristics of the plant. Therefore, a revised design of the SCWR reactor core cooling system is proposed.

Another basis for the design presented here is the studies of hot channel factors described in Section 5.1 above. In both studies, a critical feasibility issue for the SCWR is the large increase in fluid enthalpy in 
the core, which results in the SCWR being very sensitive to hot channel factors and to operational transients that affect the enthalpy rise along the hot channel. Due to these features, any rapid reduction in core flow for the SCWR, such as occurs during the LOMF, leads to an increase in peak cladding temperatures that challenges the safety analysis limit. In view of the fact that the LOMF is considered to be a transient that is expected to occur with relatively high frequency, the plant response should not result in such a challenge.

An overview of the proposed design is presented in Section 5.2.2.1. A qualitative evaluation of the anticipated response following loss-of-flow events is presented in Section 5.2.2.2. Section 5.2.2.3 describes the basis for the proposed design.

\subsubsection{Approach Overview}

A LOMF event is a critical transient for the SCWR because it results not only in a loss of core flow but also causes a rapid loss in coolant inventory in the core region. The coupling of these two effects is equivalent to a concurrent complete loss of circulation flow in the core coupled with a loss of main feedwater in a BWR. Moreover, the large enthalpy rise in the core and the lack of a circulation loop in the SCWR once-through design makes this event more challenging than a BWR event. In the SCWR, the loss of flow is extremely rapid and since the SCWR initially contains very little coolant mass, this leads to a rapid and large increase in peak cladding temperature in the first few seconds following the event initiation.

The concept that is proposed is to decouple the "inventory" (feedwater) and "core flow" functions in the design so that a more inherently safe response can be obtained for the SCWR. Therefore, a circulation loop is added to the reactor core cooling system, where feedwater is used to control inventory in the reactor cooling system and circulation pumps are used to provide/maintain core flow. The proposed concept is illustrated in Figure 89.

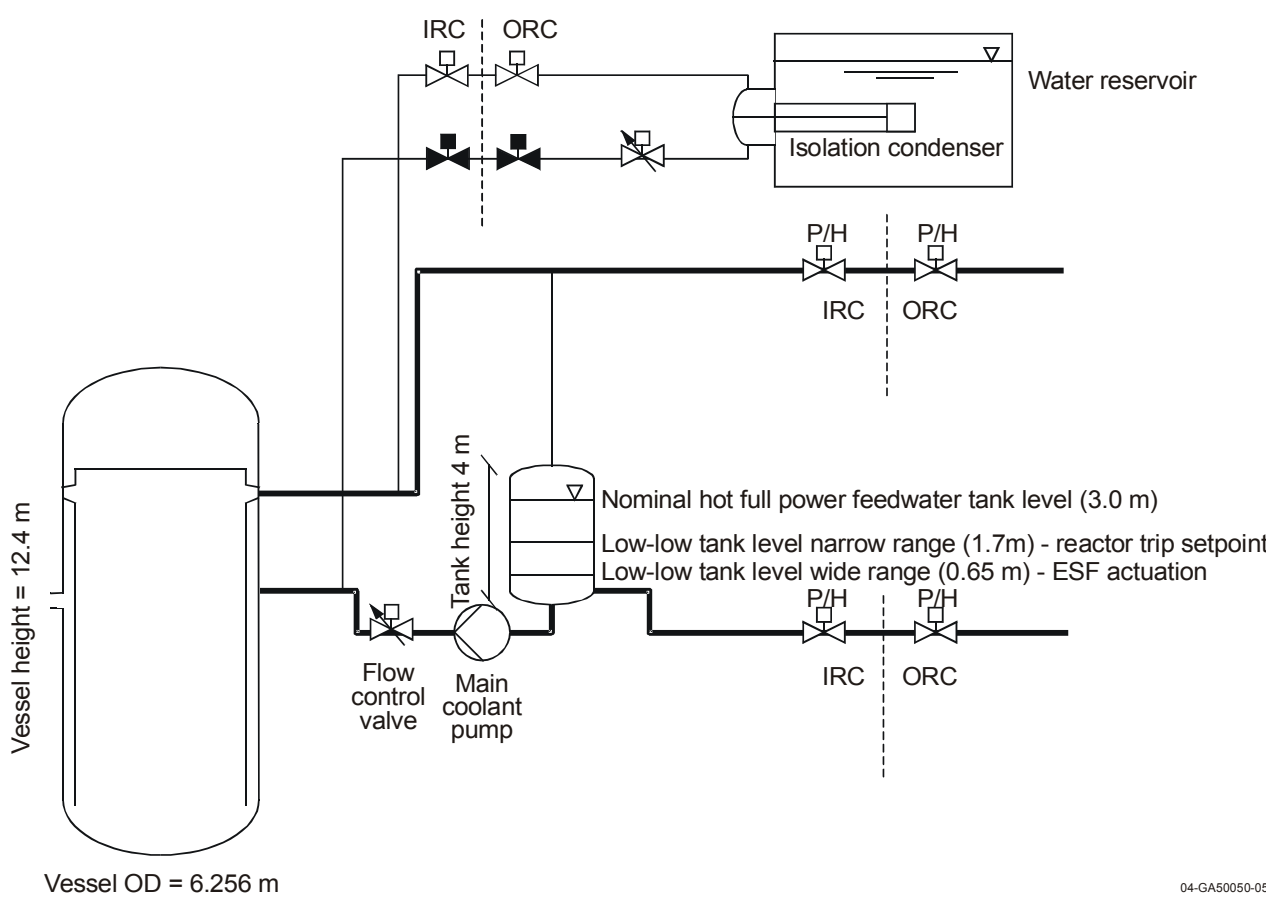

Figure 89. Conceptual flow diagram for the SCWR reactor core cooling system. 
It should be noted that the above statements on the SCWR response to a LOMF event do not apply to the long-term consequences of this event. From the point of view of long-term decay heat removal, the SCWR system does not present significant differences from other LWRs, and several approaches are available to add sufficient water to the reactor vessel to cool the core and remove decay heat either by passive (e.g. isolation condenser) or active (e.g. auxiliary feedwater) means.

This concept shown in Figure 89 is based on the addition of a tank connected to each feedwater line. These tanks, subsequently referred to as feedwater tanks, are located downstream of the feedwater isolation valves. The main feedwater flow maintains inventory in the tank during normal operation. The feedwater tanks are also connected to the steam line upstream of the main steam isolation valves via a pressure balance line so that the pressure in each tank is maintained equal to the pressure in the main steam line. Note that heat transfer at the interface between the steam and water regions of the tank is not expected to be a critical issue, since the tank will be designed to minimize mixing at the water surface so that a heated layer of water is established and maintained. Also, any energy lost by the steam to the liquid region will simply act to preheat the water before delivery to the reactor vessel. The relative elevations of the various components are sketched in Figure 90.

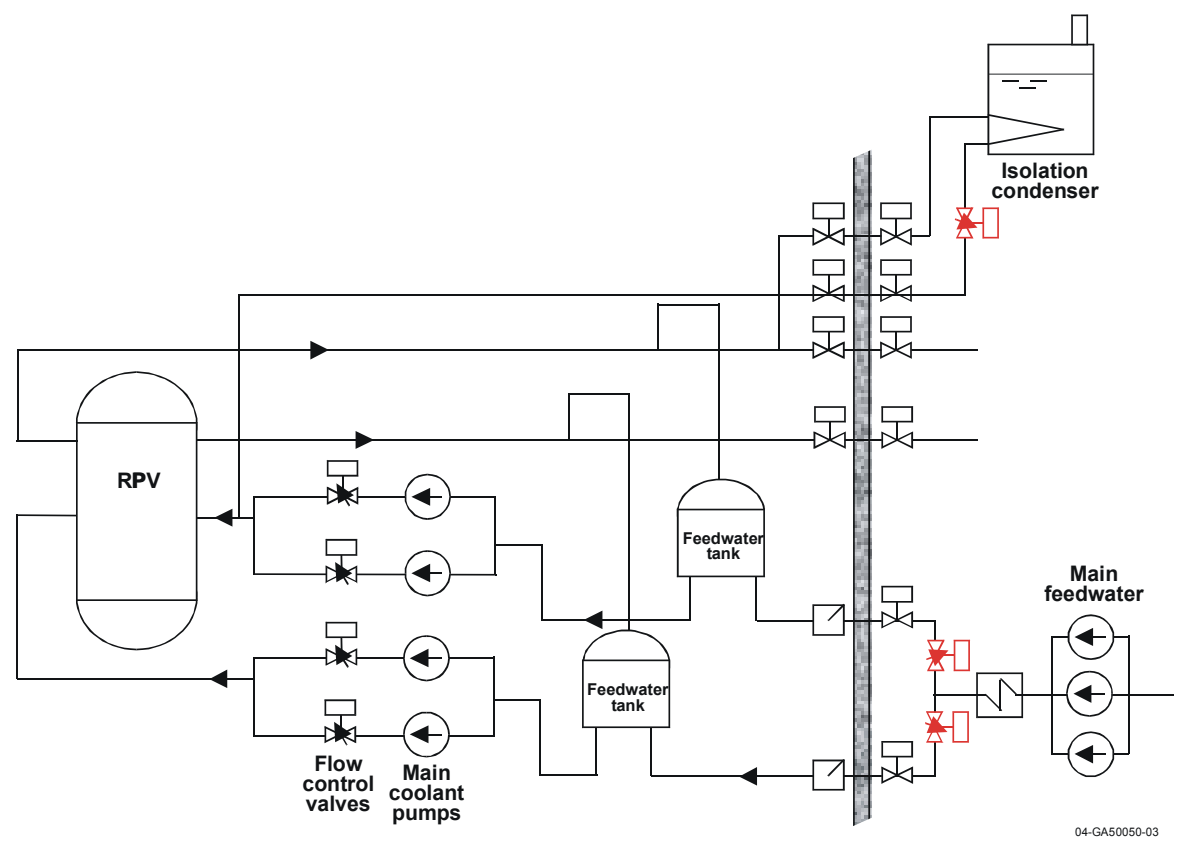

Figure 90. Conceptual elevation view for Loop 1 of the SCWR reactor core cooling system.

The flow to the core is provided from the feedwater tanks using four main coolant pumps. Compared to PWRs, these main coolant pumps will be required to provide a lower flow rate (less than $500 \mathrm{~kg} / \mathrm{s} \mathrm{per}$ pump) and a comparable developed head. Although the design has not been finalized, the results described in Section 5.2.3.1 indicate that the required head is about 1.0 MPa (150 psia). Note that a variation with two coolant supply lines from each of the two tanks to the reactor vessel is also possible to reduce the size of the largest possible cold leg break. This would increase the number of cold leg nozzles in the vessel from two to four, but can be considered an option to reduce the severity of a cold leg guillotine rupture, and thus simplify and reduce the cost of the emergency core cooling system. Another option that is still being considered is the sizing basis for the pumps: each pump provides $25 \%$ of the rated core flow in the current configuration. Should such a pump not be available, the plant power would have to be significantly reduced. This is a common approach for PWRs, but to increase plant reliability 
an option that features four pumps rated at $33 \%$ or $50 \%$ of the total feedwater flow can be also considered.

The discharge line from each main coolant pump includes a flow control valve that is essential for SCWR operation. Since the reactor system essentially remains a once-through design, the amount of flow provided to the core must be proportional to the core power. The flow control valves will operate at their full open position during operation at the rated thermal power, but will progressively close during load following maneuver or partial power operation. While beyond the scope of this application, the control of these valves can be assumed to be of a feed-forward nature, similar to control systems for Babcock \& Wilcox PWRs. Based on core thermal power, the valves will move to an anticipated position. A feedback term will then be used to correct this position based on the desired flow and on various plant heat balance variables, such as steam temperature.

A disadvantage of this design concept is that additional hot water from the feedwater tanks will be expelled into the containment during a LOCA. For this reason, the tank size should be minimized to provide only the amount of water required to prevent an excessive fuel cladding temperature excursion following a LOMF event, considered here to be the limiting event for the tank sizing. Naturally, the added water inventory is also one of the most important advantages of this concept, since it creates sufficient inertia to simplify operation of the plant and to mitigate most design basis events.

\subsubsection{Anticipated Response Following Loss-of-Flow Events}

Following a LOMF event, the level in the feedwater tanks will start to drop. When a low-level set point (the reactor trip set-point) is reached, a reactor trip will be generated and the motor-driven startup feedwater pumps will be actuated to restore/maintain the tank inventory. If the startup feedwater system, which is not a safety grade system, is not available, the water level will continue to drop until a second low-level set point (the safety actuation set-point) is reached. Upon reaching this safety limit, the safetygrade means of decay heat removal will be actuated (in Figures 89 and 90, an isolation condenser is assumed). A discussion of the basis for these two set points is included in the next section. Steam produced by the decay heat will be relieved through the steam dump system if the main condenser is available or through the safety relief valves to the suppression pool if the condenser is not available.

As long as the water level is maintained in the feedwater tanks, the main coolant pumps will be capable of maintaining core flow. If feedwater flow is lost, the only function lost is the inventory control in the tanks, but core flow is not affected in the short term. The tanks will be sized so to provide sufficient time for reactor shutdown before the level drops to the point where a trip of the main coolant pumps is required.

It should be noted that this feature makes the proposed response of the SCWR to a LOMF similar to that of current LWRs, thus providing the same level of safety as these designs. This design also has significant advantages for normal plant operation (for example a simplified feedwater flow control via programmed level in the feedwater tanks), and allows a simplification of the safety systems.

For an event that causes a loss of power to the main coolant pumps, core flow will start to decrease rapidly. As in other LWRs, the design basis for the response to these events is to provide a reactor trip before the flow decreases to a point where fuel damage would occur. Given the low developed head required of these main coolant pumps compared to the feedwater pumps, this can be achieved by designing the main coolant pumps with a sufficient inertia to coast down slowly following a loss of power. Conventional PWR coolant pumps already provide a large inertia that can be increased by increasing the flywheel size (moment of inertia). The required inertia is defined on the basis of the 
transient analyses described in Section 5.2.3.2. Protection against this event will be provided by the following plant features:

1. Reactor trip on under-voltage, under-frequency or under-speed of the main coolant pumps. Typically two of these three signals are part of the protection system. The purpose of these signals is to monitor the pump status and provide a reactor trip signal upon indication of a loss of power to the pumps. Typically, a reactor trip signal will be generated and the reactor trip breakers will be opened about $1.5 \mathrm{~s}$ after the loss of power to the pumps.

2. A low loop flow signal is provided as a diverse signal to mitigate a complete loss-of-flow event, and is the main protection for partial loss-of-flow events and locked rotor accidents. In the SCWR, the set point for this signal will be defined as a function of the core thermal power (in a conventional PWR the set point is constant since the flow is constant at all power levels).

In the previous discussion, LOMF and loss-of-flow events have been considered separately. However, a complete loss of non-emergency AC power would lead to a simultaneous LOMF and loss of flow. The event would evolve as described above for the loss-of-flow event. The initial part of the transient would be dominated by the consequences of the loss of flow. The main coolant pumps would coast down providing sufficient flow in the short term to the reactor, until the reactor trip has occurred and sufficient water has been added to the reactor vessel. The long-term consequences of this event would be mitigated by the start-up feedwater system, which would maintain coolant inventory, and the steam dump valves or the isolation condenser, which would provide decay heat removal. It should be noted that from the point of view of consequences, such an event would be less limiting than the LOMF event discussed above because the reactor trip would occur earlier, and thus there would be a larger inventory in the feedwater tanks at the time of the trip.

\subsubsection{Preliminary Design and Sizing Basis}

The preliminary sizing of the feedwater tanks is based on the following considerations:

1. During normal operation, the main feedwater pumps/flow control valves maintain the tank inventory at a constant level. In case of a LOMF, the level in the tanks will begin to drop. To allow sufficient time before the reactor trip is necessary and to prevent spurious trips, a water volume above the reactor trip set point corresponding to a total of $10 \mathrm{~s}$ of full water flow to the core is provided. This means that following a LOMF the level will start to drop, but the protection system set point for reactor trip will not be reached for a significant time, here assumed to be $10 \mathrm{~s}$. For this purpose, a total of $20,000 \mathrm{~kg}$ of water above the set point is required (assuming a nominal flow rate of $2000 \mathrm{~kg} / \mathrm{s}$ ). With a water density (at $280{ }^{\circ} \mathrm{C}$ and $25 \mathrm{MPa}$ ) of $777 \mathrm{~kg} / \mathrm{m}^{3}$, this corresponds to a total water volume of about $26 \mathrm{~m}^{3}$.

2. If feedwater is unavailable for a period longer than this $10 \mathrm{~s}$ grace period, the level in the tanks will drop to the reactor trip set point (similar to a low-low narrow-range steam generator level in current PWRs). A reactor trip signal will be generated and the control rods will be released. Assuming a typical insertion time of $3.5 \mathrm{~s}$, and a delay on this signal of $2.0 \mathrm{~s}$, the rods can be conservatively assumed to be inserted and the core shut down within $6 \mathrm{~s}$ (conservative maximum insertion time). The main coolant flow control valves (see below) will move to their "decay heat removal" position if the reactor coolant circulation pumps are operating. With the reactor trip set point, an actuation signal for the startup feedwater system (note that this system is not safety grade, but is the normally used system for startup and maintaining hot standby conditions) will be generated. If offsite power is not available, the diesel generators will be started, and then various plant loads will be loaded on the diesels. A total of $45 \mathrm{~s}$ including signal delay, diesel startup and 
startup feedwater load on the diesels is conservatively assumed. The design should be such that the safety grade decay heat removal system (in this case the isolation condenser) is actuated only if the normally available systems are unavailable. Therefore, the isolation condenser actuation set point should allow a sufficient time to start and align the startup feedwater system to terminate the loss of inventory. Thus, enough water must be available in the tank for decay heat removal for the first $45 \mathrm{~s}$ following reactor trip signal. The amount of water required is calculated conservatively as $6 \mathrm{~s}$ of full power and $39 \mathrm{~s}$ of $5 \%$ power as $(6 \mathrm{~s}+39 \mathrm{~s} \times 0.05) \times 2000 \mathrm{~kg} / \mathrm{s}=$ $15,900 \mathrm{~kg} \approx 16,000 \mathrm{~kg}$. With a water density of $777 \mathrm{~kg} / \mathrm{m}^{3}$, this corresponds to a total water volume of about $21 \mathrm{~m}^{3}$.

3. If the startup feedwater is not made available in $45 \mathrm{~s}$ after reactor trip, the tank level will drop until the reactor protection system actuation set point for the engineered safeguards feature is reached (similar to a low-low wide range steam generator level, in advanced passive PWRs). Upon reaching this set point, a main coolant pump trip will be generated to prevent the risk of pump damage due to cavitation, and the safety grade decay heat removal system will be initiated. As an example, if an isolation condenser is used, the actuation signal of the engineered safeguards feature will trip the main coolant pumps, isolate the main steam and feed lines to prevent any further loss of reactor coolant, and open the isolation valves in the discharge line of the isolation condenser so that decay heat will be removed via natural circulation. To guarantee that enough water is available at this stage to maintain the core covered with water, an additional $10,000 \mathrm{~kg}$ of water is assumed above the main coolant pump suction. With a water density of $777 \mathrm{~kg} / \mathrm{m}^{3}$, this corresponds to a water volume of about $13 \mathrm{~m}^{3}$.

Thus, the total volume required for the feedwater tanks is $26+21+13=60 \mathrm{~m}^{3}$ of water. Two tanks will be included in the design, so each tank requires a liquid inventory of $30 \mathrm{~m}^{3}$. For simplicity, assuming a cylindrical tank and a normal liquid level of 3 meters requires that the cross-sectional area of each tank be $10 \mathrm{~m}^{2}$, corresponding to an inner diameter of $3.6 \mathrm{~m}$. The reactor trip set point (low-low narrow range level $)$ is $3.0 \mathrm{~m}-26 \mathrm{~m}^{3} /\left(2 \times 10 \mathrm{~m}^{2}\right)=1.7 \mathrm{~m}$ from the bottom of the tank. The set point for isolating the feed and steam lines and actuating the isolation condenser for decay heat removal (low-low wide range level $)$ is $3.0 \mathrm{~m}-(26+21) \mathrm{m}^{3} /\left(2 \times 10 \mathrm{~m}^{2}\right)=0.65 \mathrm{~m}$. To provide flexibility during normal operation, the overall height of the tanks is assumed to be $4.0 \mathrm{~m}$. The heights derived here are summarized in Figure 90.

Note that the use of the feedwater tanks has some important consequences on the design for other events:

1. The total water inventory in the feedwater tanks is significant and should provide initial mitigation of most LOCAs. The limiting break would probably be a break in the cold leg, since this would also lead to a loss of inventory from one of the two feedwater tanks. The main issue in LOCA mitigation that needs to be addressed in the design of the emergency core coolant system is how core flooding will be accomplished. A significant volume of injection water is required to fill the reactor vessel, which initially is almost empty. Some preliminary analyses will be required to define an optimal LOCA mitigation strategy, but obviously if the cold leg pipes are reduced in size (for example using two cold legs for each feedwater tank as discussed above), it may be possible to design a strategy that relies on reactor system depressurization and then gravity injection from the feedwater tanks in the short term and from the containment in the long term.

2. An important consequence of this design is that the feedwater tank level, not the feedwater flow, will control the flow supplied to the reactor vessel. Thus, the feedwater flow will not directly control or be controlled by the reactor power. However, with the direct, once-through cycle used for the SCWR, it is important that core flow is defined as a controlled function of reactor power. 
If core flow is too high for the power level of the plant, temperature in the steam line will drop significantly. Likewise, core flow that is too low for the plant power will lead to higher than nominal steam temperatures. Therefore, flow control valves are placed downstream of the main coolant pumps. The core flow control will probably use a mixed feed-forward/feedback signal, where the valves are moved to the position anticipated for the core power demand, and then feedback terms are used to fine-tune the valve position so that plant heat balance parameters are satisfied.

3. Signals will be provided to protect against overfilling the feedwater tanks. First, the feedwater flow control valve, which is located upstream of the feedwater tanks, will be closed on a highlevel signal (control system). On a high-high-level signal (protection system), feedwater isolation valves will be closed, and the main feedwater pumps and the turbine will be tripped.

4. Following a reactor trip, with the main coolant pumps tripped and the system removing heat via natural circulation, the reactor vessel and feedwater tanks will tend towards an equilibrium condition. In principle, the water levels in the feedwater tanks and in the reactor vessel should equalize. However, since the core will still be producing heat, the gravitational head in the reactor vessel and in the tanks will actually equalize. Since the core fluid density will be lower (either as a hotter supercritical fluid or water with actual steam voids if boiling in the subcritical region) than in the feedwater tanks, the mixture level in the reactor vessel can be expected to be higher then the level in the feedwater tanks. Note that the tank level will be defined as a function of power level, so that a programmed low level will be present at zero power conditions. This will prevent the risk of having a mixture level in the vessel above the reactor vessel hot leg (steam discharge line) piping elevation.

The proposed configuration, with the isolation condenser used for safety-grade decay heat removal and the startup feedwater system used for non-safety-grade decay heat removal, provides one possible design, but other options are available depending on the results of the transient analysis.

\subsubsection{Transient Analysis}

The response of the SCWR with the proposed reactor core cooling system during loss-of-flow transients and LOCAs has been evaluated using the RELAP5-3D computer program [INEEL 2003]. A RELAP5 model of the proposed SCWR design was developed and is described in Section 5.2.3.1. The model represents the core and reactor vessel described in Section 2 of this document and the proposed reactor core cooling system described in Section 5.2.2 above. The RELAP5 model was then used to simulate short-term and long-term loss-of-flow transients as described in Sections 5.2.3.2 and 5.2.3.3, respectively. The model was also used to simulate LOCAs initiated by $200 \%$ double-ended guillotine ruptures in the cold leg, hot leg and steam line as described in Section 5.2.3.4. Given the complexity of LOCA evaluation models, the analysis presented herein is only intended to provide design support and a basis for a better understanding of the response of the proposed concept and is not a rigorous safety evaluation.

\subsubsection{Model Description}

The RELAP5 reactor model of the SCWR design is illustrated in Figure 91. The model represents the reactor vessel including the downcomer (Component 300), lower plenum (Components 310 and 315), core (Components 325, 330, and 335), upper plenum (Component 360), upper head (Component 370) and water rods (Components 375, 380, and 385). Feedwater enters the downcomer, where most of it is directed upwards into the upper head. The liquid then flows downwards through the water rods where it acts as moderator. The moderator mixes with the flow from the downcomer in the lower plenum and then 
enters the fuel assemblies and acts as coolant. The core is modeled with three parallel channels, one (Component 325) representing a high-powered fuel bundle, one (Component 330) representing 155 average-powered fuel bundles, and one (Component 335) representing a low-powered fuel bundle. The water rods are represented with three parallel channels corresponding to the highpowered, average-powered, and low-powered assemblies. The heated length is divided equally into ten axial control volumes. Heat structures are used to represent fuel rods, water rods, and assembly walls in each core channel, as well as the reactor vessel and core barrel. A separate heat structure is used to model four hot rods in the highpowered fuel bundle. The fuel rod gas plenum is located below the bottom of the heated length to minimize the heat transfer from the fuel assemblies to the water rods. The uppermost two levels of the water rod walls, which are above the top of the active fuel, are heavily insulated to minimize the heat transfer.

The radial peaking factors of the high-powered, average-powered, and low-powered fuel bundles are assumed to be $1.40,1.0$, and 0.60 , respectively. The local peaking factor of the hot rods is 1.2 . The axial power profile is based on the two-zone enrichment curve shown in Figure 3 of MacDonald et al. [2002b] and has a peak value of 1.41 . The models assume that $2.6 \%$ of the power appears as direct moderator heating, with $80 \%$ deposited in the water rods and the remainder deposited in the coolant channel. The fuel rods contain uranium dioxide clad with ODS ferritic steel MA956 and a 0.8-mm gas gap.

Orifices are simulated at the bottom of each core channel to achieve a uniform power-to-flow ratio across the core. Although the flow through each coolant channel is consistent with the radial peaking factor, heat transfer to the water rod results in fluid temperature variations between the high-powered, averagepowered, and low-powered assemblies. The resulting variations in heat transfer to the water rods are sufficient to cause large variations in water rod flow per assembly. For example, in preliminary calculations the flow through the water rods in the hot assembly was up rather than down. Orifices are placed at the top of the water rods to help balance the flow between water rods. The equivalent orifice area is about $7 \%$ of that of the flow area of the water rods. The resulting variation in water rod flow per assembly is $+/-4 \%$, with the water rods in the high-powered assembly receiving less than the average flow and water rods in the low-powered assembly receiving more than the average flow.

The RELAP5 model of the SCWR core cooling system is shown in Figure 92. The reactor core cooling system is modeled as two loops that are identical except for component numbers and the isolation condenser (Component 465), which is attached to Loop 1. The loops contain a common feedwater supply (Components 100 and 105) and separate feedwater tanks (Components 125 and 225), main coolant pumps 
(Components 135, 155, 235, and 255), safety relief valves (Components 416 and 516), main steam isolation valves (Components 420 and 520), steam headers (Components 427 and 527), and connecting piping. The functions of the turbine stop valves and turbine control valves are combined and represented by Components 430 and 530. Components 126 and 226 represent the pressure balance lines that connect the top of the feedwater tanks and the steam lines. The isolation condenser is normally isolated from the system by a closed valve (Component 470). For convenience, the piping upstream of the feedwater tanks (Components $110-120$ and $210-220$ ) will hereafter be referred to as feedwater lines. The piping downstream of the feedwater tanks (Components $130-180$ and $230-280$ ) will be referred to as cold legs. Similarly, the piping between the reactor vessel and the pressure balance line connection (Components 405 and 505) will be referred to as hot legs, while the piping downstream of the pressure balance line connections (Components $415-427$ and 515-527) will be referred to as steam lines.

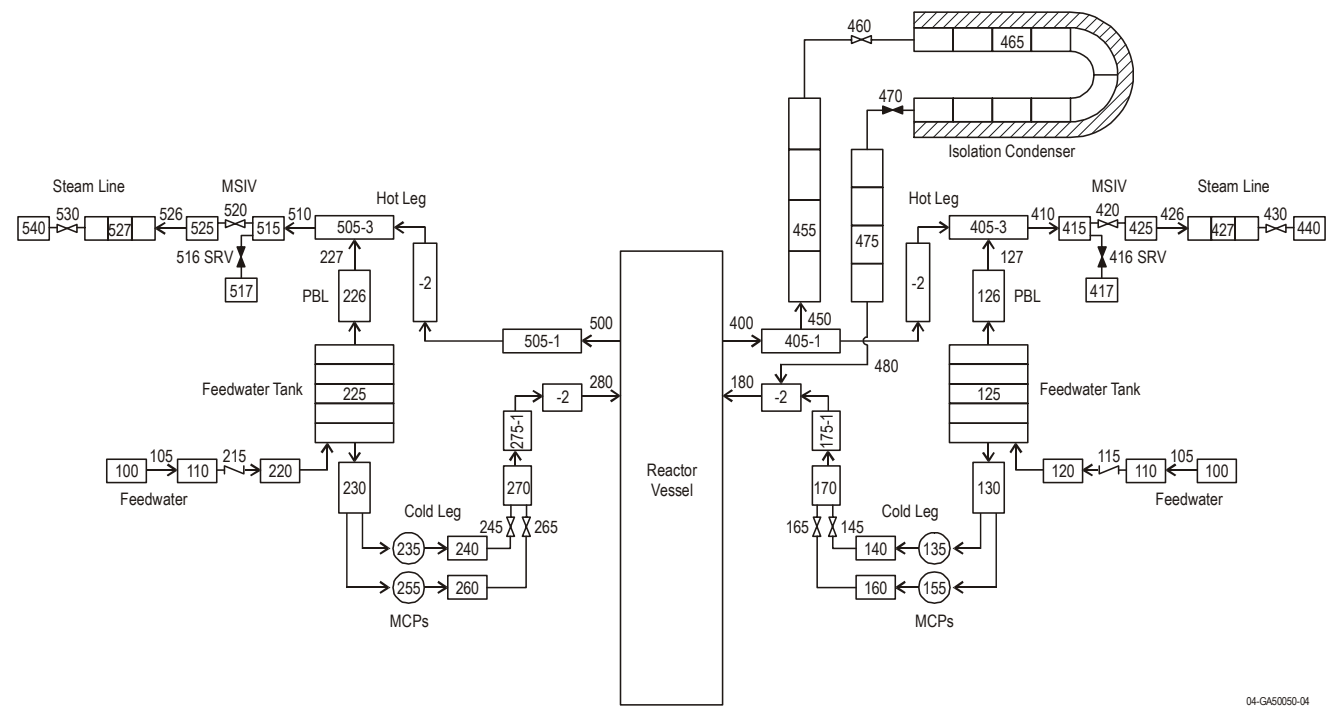

Figure 92. RELAP5 model of the reactor core cooling system.

The feedwater line flow and temperature are controlled by a time-dependent junction (Component 105) and a time-dependent volume (Component 100), respectively.

The main coolant pumps are sized to provide the desired flow at rated operating conditions. The rated head compensates for the pressure drop across the vessel, cold legs, and hot legs at rated flow. The head produced by the pumps is assumed to be a linear function of flow and produces a maximum head (at no flow) that is $10 \%$ greater than the rated head.

The steam line pressures are controlled by a combination of time-dependent volumes (Components 440 and 540 in Figure 92) and the form loss coefficients at the turbine control/stop valves (Components 420 and 430). The pressure in each time-dependent volume is set at a low value (1.0 MPa) and the form loss coefficients adjusted to obtain the desired steam line pressure. This method allows the model to approximately simulate the flow demanded by the turbine during a transient.

The safety relief valves, Components 416 and 516 of Figure 92, provide overpressure protection. The safety relief valves are modeled as four banks of valves, with a total relief capacity corresponding to $100 \%$ of the steam flow at rated conditions. The first bank of valves is sized to relieve $10 \%$ of the steam flow at rated conditions. The other three banks are sized to relieve $30 \%$ of the steam flow at rated 
conditions. The opening set points of the four banks are staggered, with the first bank opening at the lowest pressure and each subsequent bank opening at a higher pressure. Specifically, the first bank of valves opens when the pressure exceeds $26 \mathrm{MPa}$ and closes when the pressure drops below 25.25 MPa. The second bank of valves opens when the pressure exceeds $26.5 \mathrm{MPa}$ and closes when the pressure drops below $25.75 \mathrm{MPa}$. The third bank opens and closes at pressures of 27.0 and $26.25 \mathrm{MPa}$, while the fourth bank opens and closes at pressures of 27.5 and $26.75 \mathrm{MPa}$.

The model uses the Jackson [2002] forced convection heat transfer correlation for the fuel rods and both walls of the water rods. Buoyancy effects are calculated using the semi-empirical correlation of Jackson [1979] as described by Wu el al. [2002] for a tube. Heat transfer coefficients for the other surfaces in the reactor vessel, such as the core barrel and reactor vessel, are calculated using the correlation of Bishop et al. [1964]. The Bishop correlation is also applied on the inside (high-pressure side) of the tubes in the isolation condenser. These correlations are described in detail in Appendix A of MacDonald et al. [2003].

Transient reactor power is calculated using a bestestimate point kinetics model. The model uses representative PWR values for the kinetics, decay heat, and scram parameters. The reactivity feedback model is used to simulate the effects of changes in the fuel temperature and fluid density. The Doppler and density feedback coefficients are $-2.3 \mathrm{pcm} / \mathrm{K}\left(-3.54 \times 10^{-3} \$ / \mathrm{K}\right)$ and $+13.3 \mathrm{pcm} / \mathrm{kg} / \mathrm{m}^{3}$ $\left(+2.046 \times 10^{-2} \$ /\left(\mathrm{kg} / \mathrm{m}^{3}\right)\right)$, respectively. Powersquared averaging is used to determine the weighting factors for the Doppler feedback. The weighting factors for the density feedback are based on linear weighting of the power deposited in the fluid due to direct heating. The control rods begin moving $0.8 \mathrm{~s}$ after the scram signal is generated, and are fully inserted $2.5 \mathrm{~s}$ later. The total control rod worth is about $11 \$$.

The geometry simulated by the model is summarized in Table 40.

Two steady states were obtained with the model as shown in Table 41. The first steady state represents rated operating conditions. The second
Table 40. Summary of the RELAP5 SCWR model.

\begin{tabular}{|c|c|}
\hline Parameter & Value \\
\hline \multicolumn{2}{|l|}{ Fuel Assembly: } \\
\hline Number of fuel assemblies & 145 \\
\hline Assembly outer width, $\mathrm{mm}$ & 286 \\
\hline Assembly wall thickness, $\mathrm{mm}$ & 3.0 \\
\hline Number of fuel pins per assembly & 300 \\
\hline Fuel outer diameter, mm & 8.78 \\
\hline Cladding inner diameter, $\mathrm{mm}$ & 8.94 \\
\hline Cladding outer diameter, $\mathrm{mm}$ & 10.2 \\
\hline Fuel rod pitch-to-diameter ratio & 1.098 \\
\hline Heated length, $\mathrm{m}$ & 4.27 \\
\hline Fission gas plenum length, $\mathrm{m}$ & 0.6 \\
\hline Coolant flow area, $\mathrm{m}^{2}$ /assembly & 0.0132 \\
\hline Hydraulic diameter, m & 0.00337 \\
\hline \multicolumn{2}{|l|}{ Moderator: } \\
\hline Number of water rods/assembly & 36 \\
\hline Water rod inner width, $\mathrm{mm}$ & 32.8 \\
\hline Water rod wall thickness, $\mathrm{mm}$ & 0.4 \\
\hline Flow area, $\mathrm{m}^{2}$ lassembly & 0.0387 \\
\hline Hydraulic diameter, $\mathrm{m}$ & 0.0328 \\
\hline Flow length, $\mathrm{m}$ & 6.36 \\
\hline \multicolumn{2}{|l|}{ Vessel: } \\
\hline Height, $m$ & 12.4 \\
\hline Inner diameter, $\mathrm{m}$ & 5.322 \\
\hline Outer diameter, $\mathrm{m}$ & 6.236 \\
\hline \multicolumn{2}{|l|}{ Core barrel: } \\
\hline Inner diameter, $\mathrm{m}$ & 4.30 \\
\hline Outer diameter, $\mathrm{m}$ & 4.50 \\
\hline Feedwater line inner diameter, $\mathrm{m}$ & 0.298 \\
\hline Steam line inner diameter, $\mathrm{m}$ & 0.442 \\
\hline \multicolumn{2}{|l|}{ Feedwater tanks: } \\
\hline Flow area, $\mathrm{m}^{2}$ & 10 \\
\hline Height, $\mathrm{m}$ & 4.0 \\
\hline Pressure balance line inner diameter, $m$ & 0.216 \\
\hline \multicolumn{2}{|l|}{ Isolation condenser: } \\
\hline Number of tubes & 300 \\
\hline Tube inner diameter, $\mathrm{mm}$ & 12 \\
\hline Tube thickness, $\mathrm{mm}$ & 4.8 \\
\hline Tube length, $\mathrm{m}$ & 10 \\
\hline Supply/return line inner diameter, $m$ & 0.284 \\
\hline \multicolumn{2}{|l|}{ Elevations, $\mathrm{m}$ : } \\
\hline Bottom of reactor vessel & 0.0 \\
\hline Bottom of core barrel & 2.6 \\
\hline Bottom of active fuel & 3.7 \\
\hline Top of active fuel & 7.9 \\
\hline Cold leg centerline & 8.2 \\
\hline Hot leg centerline & 8.7 \\
\hline Bottom of feedwater tanks & 8.7 \\
\hline Isolation condenser tubes & 18.7 \\
\hline \multicolumn{2}{|l|}{ Fluid volume, $\mathrm{m}^{3}$ : } \\
\hline Vessel & 192 \\
\hline Feedwater tanks & 80 \\
\hline Steam lines / hot legs & 182 \\
\hline Total & 459 \\
\hline
\end{tabular}


steady state represents thermal design conditions corresponding to $102 \%$ rated power, $95 \%$ rated flow, and increased $\left(2{ }^{\circ} \mathrm{C}\right)$ feedwater temperature. As reported by MacDonald et al. [2003], the calculated maximum cladding temperature exceeded the steady-state limit of $620{ }^{\circ} \mathrm{C}$ when the water rods were not insulated. Consequently, the water rods were insulated in order to meet the limit for the steady state at rated operating conditions. The thermal design steady state was performed without insulating the water rods to maximize the energy initially stored in the system.

Table 41. Calculated initial conditions for the SCWR designs with water moderator.

\begin{tabular}{|c|c|c|}
\hline \multirow[t]{2}{*}{ Parameter } & \multicolumn{2}{|c|}{ Value } \\
\hline & Rated conditions & $\begin{array}{c}\text { Thermal design } \\
\text { conditions }\end{array}$ \\
\hline Core power, MWt & 3575 & 3646.5 \\
\hline Steam line pressure, $\mathrm{MPa}$ & 25.0 & 25.0 \\
\hline Feedwater temperature, ${ }^{\circ} \mathrm{C}$ & 280 & 282 \\
\hline Feedwater flow, kg/s & 1843 & 1750.9 \\
\hline Steam line temperature, ${ }^{\circ} \mathrm{C}$ & 500 & 546 \\
\hline \multicolumn{3}{|l|}{ Flow rates, \% } \\
\hline Water rod & 91.0 & 89.6 \\
\hline Downcomer & 9.0 & 10.4 \\
\hline Core bypass & 5.4 & 4.8 \\
\hline Average mass flux in the core, $\mathrm{kg} / \mathrm{s}-\mathrm{m}^{2}$ & 913 & 874 \\
\hline Average fluid density in the core, $\mathrm{kg} / \mathrm{m}^{3}$ & $659^{1}$ & $467^{1}$ \\
\hline \multicolumn{3}{|l|}{ Maximum cladding temperature, ${ }^{\circ} \mathrm{C}$} \\
\hline High-powered channel & 594 & 772 \\
\hline Average-powered channel & 574 & 689 \\
\hline Low-powered channel & 559 & 611 \\
\hline \multicolumn{3}{|l|}{ Maximum fuel centerline temperature, ${ }^{\circ} \mathrm{C}$} \\
\hline High-powered channel & 1855 & 2169 \\
\hline Average-powered channel & 1191 & 1424 \\
\hline Low-powered channel & 856 & 994 \\
\hline Average linear heat generation rate, $\mathrm{kW} / \mathrm{m}$ & 19.2 & 19.6 \\
\hline \multicolumn{3}{|l|}{ Differential pressure, $\mathrm{MPa}$} \\
\hline Core & 0.225 & 0.305 \\
\hline Vessel & 0.628 & 0.721 \\
\hline Main coolant pump & 0.947 & 1.019 \\
\hline Feedwater tank level, m & 3.00 & 3.00 \\
\hline
\end{tabular}

1. Area-weighted average of the core coolant and moderator densities.

The boundary conditions supplied to the model were core power, feedwater flow and temperature, steam line pressure, and pump speed. The model was initialized so that $90 \%$ of the main feedwater flowed through the upper head to the water rods, $10 \%$ flowed downwards through the downcomer, and $5 \%$ of the total main feedwater flow bypassed the core by flowing through the core barrel-baffle region (Component 345 ) at rated conditions with un-insulated water rods. The various flow splits in the vessel were obtained by adjusting form loss coefficients. The adjusted form loss coefficients were then used to generate the steady states shown in Table 41. Because of differences caused by water rod insulation and between the rated and thermal design conditions, the flow splits varied slightly from the desired values and between steady states.

The energy stored in the system was much higher in the steady state with the thermal design conditions. This was due to the lack of insulation on the water rods and the differences in boundary conditions. The 
lack of insulation on the water rods resulted in a higher temperature at the inlet to the core compared to the case with insulation, in which the core inlet temperature was nearly equal to the feedwater temperature. The higher core inlet temperature caused higher cladding and fuel temperatures and a lower fluid density in the core. The temperatures were also higher with the thermal design conditions because of the combined effects of the increased power and feedwater temperature and decreased flow. These combined effects caused the steam line temperature to be $46{ }^{\circ} \mathrm{C}$ higher with the thermal design conditions.

The main coolant pump speed was adjusted to obtain the desired level in the feedwater tanks. The equilibrium tank levels were sensitive to minor changes in the pump speed and head. For example, a 1\% change in the head produced by the pump causes the equilibrium level to change by more than $1 \mathrm{~m}$. This implies that a control system will be needed to adjust the position of the valves downstream of the pump in order to establish the desired level in the tanks.

\subsubsection{Short-Term Loss of Flow}

The short-term response of the reactor to a complete loss-of-flow transient was evaluated to determine pump coastdown requirements. The pump speed was calculated parametrically as:

$$
\alpha=1 /(1+\beta \mathrm{t})
$$

where $\alpha$ is the pump speed divided by its initial value, $\beta$ is an input parameter, and t is the coastdown time in seconds. The parameter, $\beta$, was varied between 0.05 and 0.33 . The corresponding time required for the pump to reach $50 \%$ speed varied from $20 \mathrm{~s}$ to $3 \mathrm{~s}$.

Many calculations were performed to determine the effects of $\beta$ and reactivity feedback. As mentioned previously, $\beta$ was varied from 0.05 to 0.33 . Three different reactivity feedback cases were evaluated. The first case used the best-estimate reactivity feedback coefficients as described previously. The second case used $80 \%$ of the best-estimate feedback coefficients to account for the likely uncertainty in the feedback values. The last case assumed that there was no feedback, and was thus very conservative. The initial conditions for this transient are based on the rated conditions listed in Table 41. To provide an extra amount of conservatism to account for additional hot channel factors, the peaking factor of the hot rod was increased from 1.2 to 1.42 so that the maximum calculated temperature on the inside surface of the cladding equaled the steady-state operating temperature limit of $620^{\circ} \mathrm{C}$. The purpose of the analysis was to define main coolant pump coast-down characteristics that assure that the maximum cladding temperature will meet the transient limit of $840{ }^{\circ} \mathrm{C}$ provided that the steady-state limit of $620^{\circ} \mathrm{C}$ is met.

The transient was initiated by a complete, instantaneous loss of main feedwater flow and a simultaneous main coolant pump trip at $0 \mathrm{~s}$. This assumption might appear very conservative since it assumes two distinct failures as the initiating event. However, since only the short-term effects of the event are discussed here, the loss of main feedwater does not have a significant impact on the system response because the feedwater tanks provide sufficient inertia to delay the effects of the loss of main feedwater until late in the transient. A reactor scram signal was generated at $1.5 \mathrm{~s}$. The reactor scram signal initiated a turbine trip. The turbine trip caused the turbine stop valves to begin closing. The turbine stop valves were fully closed at $1.6 \mathrm{~s}$. The control rods began to drop into the core at $2.3 \mathrm{~s}$. 
Results from a typical calculation are presented below. The calculation simulated a pump coastdown computed from $\beta=0.20$, insulated water rods, and used $80 \%$ of the best-estimate feedback coefficients described previously. Figure 93 shows the calculated pressure in the upper plenum of the reactor. The pressure immediately decreased following the instantaneous loss of feedwater due to the continuing flow through the steam lines to the turbine. The response of the turbine control valves, which the control system would throttle in an attempt to maintain pressure, was neglected. Thus, the calculated depressurization is expected to be somewhat faster than would actually occur in the plant. The pressure increased following the turbine trip at $1.5 \mathrm{~s}$ until the pressure reached $26 \mathrm{MPa}$ at $2.9 \mathrm{~s}$ and the first bank of safety relief valves opened on each steam line. The pressure continued to rise until the second bank of safety relief valves opened at $3.3 \mathrm{~s}$. The steam relief provided by the two banks of safety relief valves exceeded that required due to power production in the core and the pressure gradually decreased until reaching the closing set point of the second bank of safety relief valves at $8.8 \mathrm{~s}$. The pressure cycled between the open and close set points of the second bank of safety relief valves for the remainder of the calculation.

The hydraulic response of the system is further illustrated in Figure 94, which compares normalized values of pump speed, mass flow at the cold leg nozzle, bottom of the average core

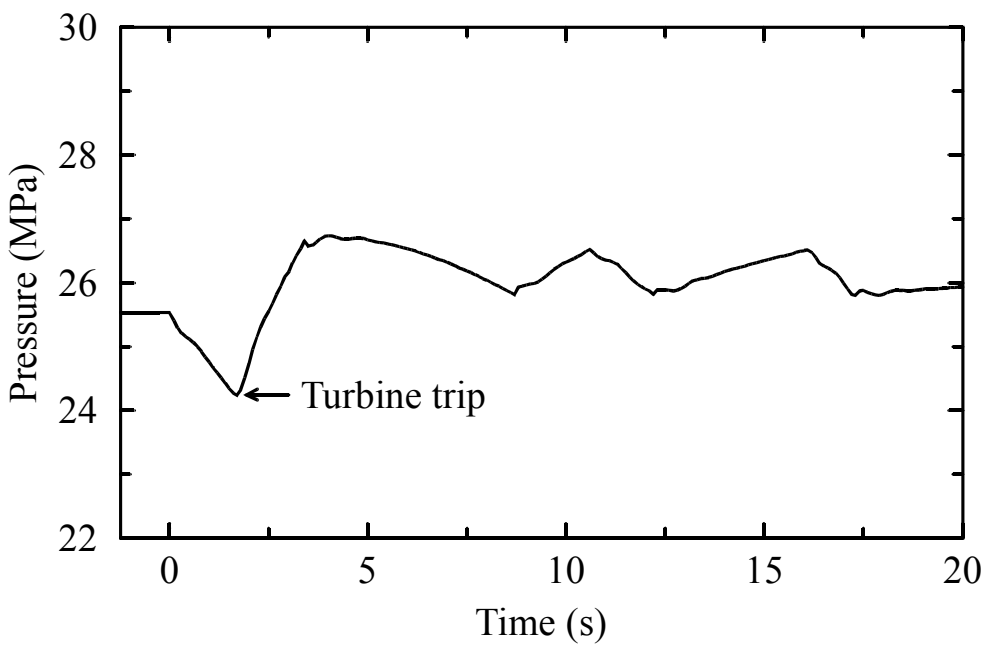

Figure 93. Reactor pressure following a total loss of flow (short term, $\beta=0.20$ ).

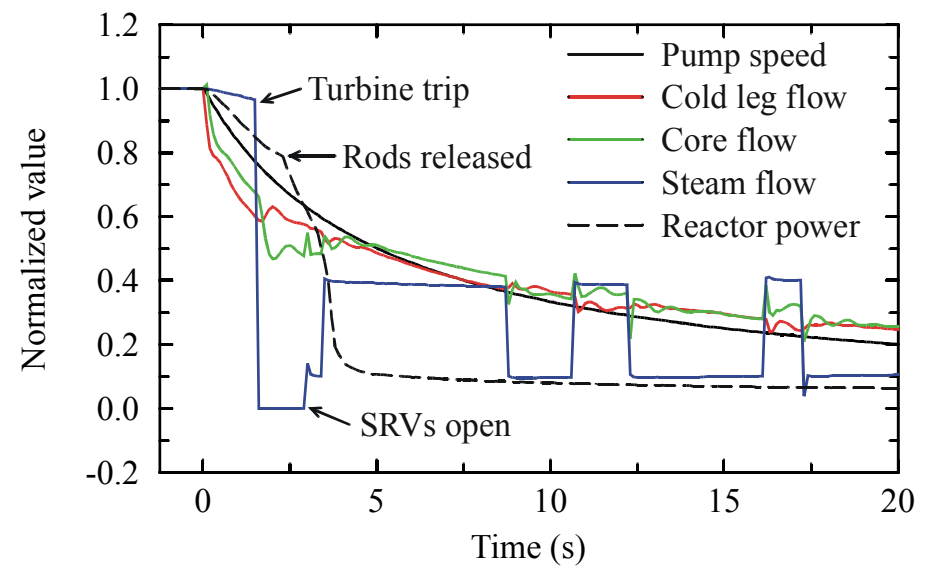

Figure 94. Normalized parameters following a total loss of flow (short term, $\beta=0.20$ ). channel, and the steam line, and reactor power. The pump reached half of its initial speed at $5.0 \mathrm{~s}$ based on Equation 6 and a value of 0.20 for $\beta$. The cold leg flow initially decreased more rapidly than the normalized pump speed, but tended to converge to the normalized speed following the turbine trip at $1.5 \mathrm{~s}$. The normalized core flow was generally greater than the cold leg flow during periods of high steam flow, such as prior to turbine trip and when two banks of safety relief valves were open. Conversely, the normalized core flow was less than the cold leg flow after the turbine tripped at $1.5 \mathrm{~s}$ and before the second bank of safety relief valves opened at $3.3 \mathrm{~s}$. The figure clearly shows that steam flow enhances the flow through the core.

Figure 94 also shows normalized reactor power. The power initially decreased due to reactivity feedback, and then more rapidly near $2.3 \mathrm{~s}$ when control rod insertion began. 
The thermal response of the SCWR during the transient is illustrated in Figure 95. The figure shows that the fluid temperature in the cold leg remained nearly constant during the transient. The hot leg fluid temperature initially increased because the reactor power decreased more slowly than the core flow during the early portion of the transient as shown in Figure 94. The hot leg temperature decreased after the normalized flow exceeded the normalized power near $3.4 \mathrm{~s}$.

Figure 95 also shows the maximum temperature on the inside surface of the fuel rod cladding. The cladding temperature initially increased due to the mismatch between the flow and power as described previously. The temperature increased more rapidly following the turbine trip at $1.5 \mathrm{~s}$. The peak cladding temperature was reached near about $0.6 \mathrm{~s}$ after the normalized flow exceeded the normalized power. The cladding temperature then decreased throughout the remainder of the calculation.

The calculated results are summarized in Table 42, which shows the effect of $\beta$ and reactivity feedback on the rise in temperature between the initial and peak values. Values shown in blue indicate that the transient temperature limit was met, while results shown in red italic indicate that it was not. The table shows that the effect of reactivity feedback on the

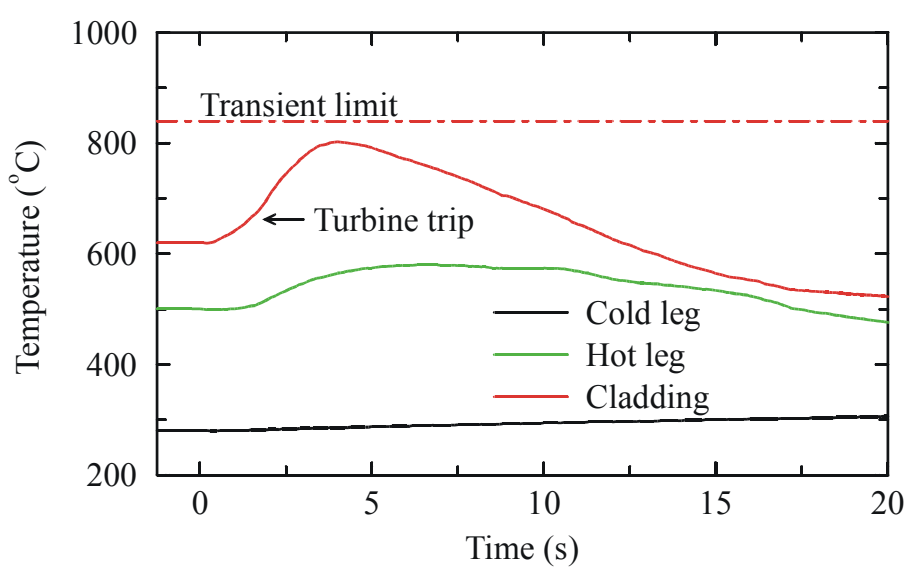

Figure 95. Thermal response following a total loss of flow (short term, $\beta=\mathbf{0 . 2 0})$.

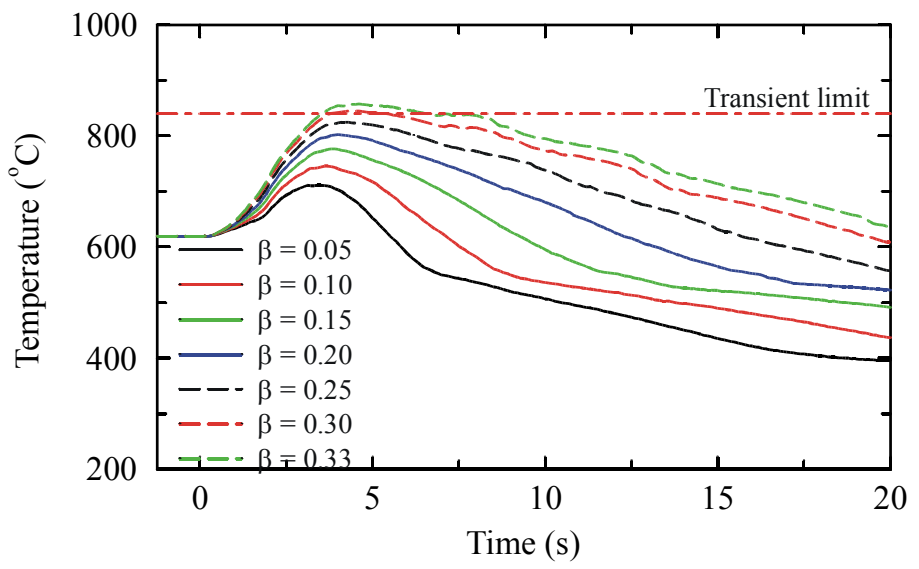

Figure 96. The effect of $\beta$ on maximum cladding temperature following a total loss of flow (short term). temperature was relatively small when the factor on the reactivity coefficients was reduced from $100 \%$ to $80 \%$, but was substantially larger when no reactivity feedback was simulated. The effect of $\beta$ on the maximum cladding temperature is shown graphically in Figure 96 for the case with the feedback coefficients set at $80 \%$ of the best-estimate value.

Table 42. Summary of calculated results.

\begin{tabular}{|c|c|c|c|}
\hline & \multicolumn{3}{|c|}{ Temperature rise, $^{\circ} \mathrm{C}$} \\
\hline$\beta$ & $\begin{array}{c}\text { Reactivity Feedback } \\
\mathbf{x} 1.0\end{array}$ & $\begin{array}{c}\text { Reactivity Feedback } \\
\mathbf{x} 0.8\end{array}$ & $\begin{array}{c}\text { Reactivity Feedback } \\
\mathbf{0} 0.0\end{array}$ \\
\hline 0.05 & 88 & 91 & 115 \\
\hline 0.10 & 121 & 126 & 157 \\
\hline 0.15 & 151 & 157 & 193 \\
\hline 0.20 & 177 & 183 & 223 \\
\hline 0.25 & 199 & 205 & 250 \\
\hline 0.30 & 219 & 226 & 274 \\
\hline 0.33 & 230 & 238 & 285 \\
\hline
\end{tabular}


Interpolation of the results presented in Table 42 indicates that the transient limit can be met if $\beta$ is less than 0.30 using best-estimate values for reactivity feedback. Interpolation of the results assuming no feedback yields that $\beta$ should be less than 0.20 . Assuming that a $20 \%$ reduction in the best-estimate feedback coefficients reasonably accounts for uncertainty in the coefficients, the transient limit can be met if $\beta$ is less than 0.29 . Thus, designing the inertia of the main coolant pumps to provide an effective $\beta$ of about 0.20 should provide a substantial amount of conservatism. A review of the safety analysis for three U. S. PWRs [Combustion Engineering 1982, Toledo Edison 1982, and Westinghouse 1975] indicated that the effective value of $\beta$ varies between 0.08 and 0.11 . Thus, the coast-down requirements for the main coolant pumps in the SCWR appear reasonable compared to typical values for operating PWRs. However, it is important to note that the main coolant pumps for operating PWRs use a technology different from that proposed for the SCWR, where canned motor pumps, similar to those adopted for all advanced Westinghouse passive plants (AP600/AP1000, IRIS), will be employed. These pumps are characterized by faster coast-downs than current main coolant pumps, but values of 0.2 to 0.3 are within the typical range.

The sensitivity of the calculated results to the pressure balance line size is illustrated in Figure 97. The initial calculations were performed with a pressure balance line inner diameter of $0.216 \mathrm{~m}$, corresponding to 10 inch schedule-160 pipe. Sensitivity calculations were performed with inner diameters of 0.173 and $0.257 \mathrm{~m}$, corresponding to 8-inch and 12-inch schedule-160 pipe, respectively. The smaller pressure balance line limited the flow into the feedwater tanks, which reduced the flow into the core and increased the peak cladding temperature by $50{ }^{\circ} \mathrm{C}$. Conversely, the peak cladding was reduced by $25{ }^{\circ} \mathrm{C}$ with the larger pressure balance line. These sensitivity studies show that the pressure balance line size in the current

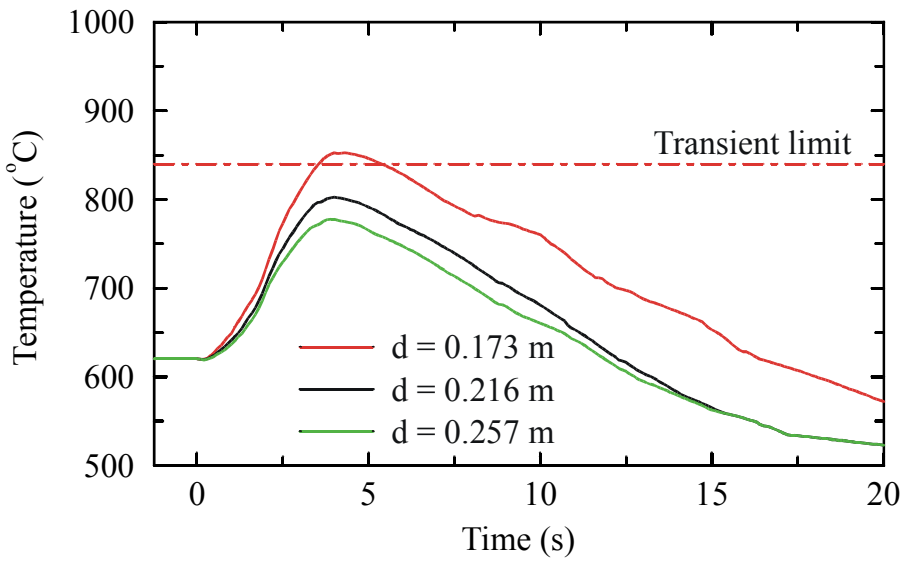

Figure 97. The effect of pressure balance line diameter on the maximum cladding temperature following a total loss of flow (short term) design is near optimal, but that a small additional benefit can be obtained by increasing the size further. Sensitivity studies have a fundamental importance at this stage of the design because they provide for an improved understanding of the system performance that allows the design to be optimized.

\subsubsection{Long-Term Loss of Main Feedwater}

A long-term LOMF transient was analyzed to size the isolation condenser. The isolation condenser was located $10 \mathrm{~m}$ above the hot leg to provide the driving head for natural circulation during operation. The tube bundle in the isolation condenser contained 10-m long tubes, each with an inner diameter of $0.012 \mathrm{~m}$. The tubes were angled $5{ }^{\circ} \mathrm{C}$ downwards from the inlet to the outlet of the heat exchanger. Supercritical water flowed on the inside of the tubes while the outside of the tubes was immersed in a water pool at atmospheric pressure. To simplify the analysis, the outside surface temperature of the tube was set $20{ }^{\circ} \mathrm{C}$ above the saturation temperature of the pool, near the temperature expected during nucleate boiling. A series of calculations was performed in which the number of tubes varied between 100 and 1000 . 
Conservative initial and boundary conditions were applied during the transient to maximize the amount of cooling required of the isolation condenser. The thermal design initial conditions, see Table 41, were applied for this transient. The reactor power and feedwater flow were set at $102 \%$ and $95 \%$ of the rated values, respectively. The feedwater temperature was increased by $2{ }^{\circ} \mathrm{C}$ from the normal value. Although the calculated maximum cladding temperature exceeded the steady-state limit of $620{ }^{\circ} \mathrm{C}$, the water rods were not insulated to maximize the stored energy in the reactor vessel. The decay heat was set at $120 \%$ of the best-estimate value. The best-estimate reactivity feedback coefficients were reduced by $20 \%$ to account for likely uncertainty in the feedback values.

The transient was initiated at $0 \mathrm{~s}$ by an instantaneous loss of main feedwater flow. The main coolant pumps continued to operate and supplied flow to the reactor vessel by drawing down the level in the feedwater tanks as shown in Figure 98. A reactor trip signal was generated at $16.4 \mathrm{~s}, 2 \mathrm{~s}$ after the level in the feedwater tanks decreased to $1.7 \mathrm{~m}$. The control rods were released $0.8 \mathrm{~s}$ later, beginning reactor shutdown. The main coolant pumps and turbine were tripped coincidently with the reactor. The main coolant pump coastdown parameter, $\beta$, was set at 0.2 . The turbine stop valves closed 0.1 $\mathrm{s}$ after the turbine trip. Prior to the turbine trip, the turbine control valves were assumed to modulate to control the steam line pressure at $25.0 \mathrm{MPa}$. If the turbine control valves had not modulated, the reactor pressure would have decreased relatively rapidly as shown previously in Figure 93 and an earlier reactor trip probably would have been generated on low reactor pressure. A sensitivity calculation in which the reactor was tripped on low pressure (at 22.5 $\mathrm{MPa}$ ) resulted in less severe thermal results than those shown here. After the turbine stop valves closed, the reactor pressure was controlled by the safety relief valves, which first opened at $17.1 \mathrm{~s}$. The loss of mass through the safety relief valves caused the level in the feedwater tanks to continue to decrease. The level reached $0.65 \mathrm{~m}$ at $99 \mathrm{~s}$. An isolation signal was generated $2 \mathrm{~s}$ later, which opened the valve in

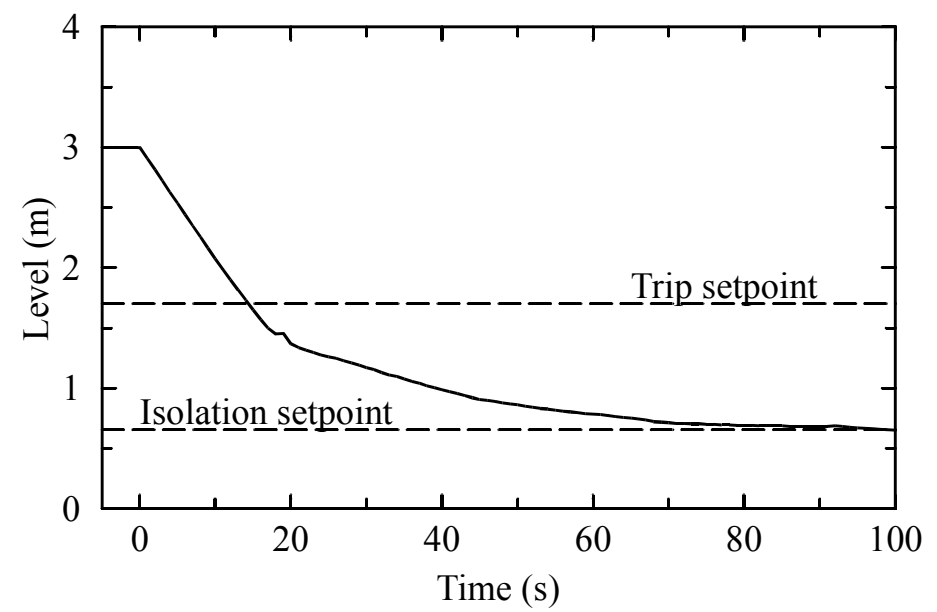

Figure 98. The effect of long-term LOMF on feedwater tank level.

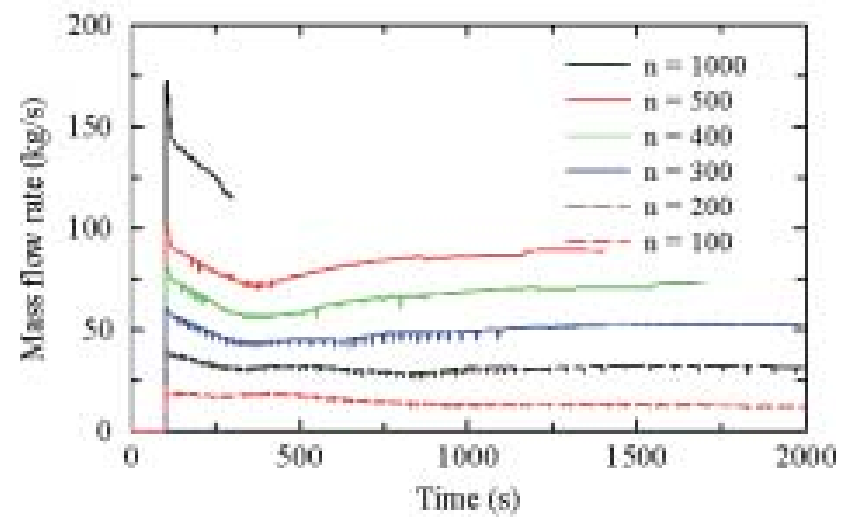

Figure 99. The effect of the number of tubes on the flow rate through the isolation condenser during a long-term LOMF. the discharge line of the isolation condenser and closed the main steam isolation valves. Opening the valve in the discharge line allowed flow through the isolation condenser due to natural circulation. Figure 99 shows the flow rate through the isolation condenser. The flow rate was nearly proportional to the number of tubes, especially for the cases with 500 or fewer tubes. For the case with 1000 tubes, the hydraulic resistance in the supply and discharge lines (Components 455 and 555 of Figure 92) was large enough in comparison to that of the tubes to reduce the flow rate per tube by about $20 \%$. 
Figure 100 shows the effect of the long-term LOMF on the maximum cladding temperature in the core. The cladding temperature decreased rapidly following the reactor trip at $16.4 \mathrm{~s}$. The number of tubes affected the results after the isolation signal at $101 \mathrm{~s}$. For the case with 300 tubes, the peak cladding temperature occurred at $330 \mathrm{~s}$ and was caused by the reduction in heat transfer to the water rods as the flow in the water rods reversed. When the number of tubes was 300 or more, the heat removed by the isolation condenser, see Figure 101, was sufficient to keep the peak cladding temperature less than $500{ }^{\circ} \mathrm{C}$. However, for the case with 100 tubes, the maximum cladding temperature was still increasing at $2000 \mathrm{~s}$ and probably would have exceeded the transient limit of $840{ }^{\circ} \mathrm{C}$ had the calculation been continued. Based on these results, 300 tubes provide adequate cooling of the core and long-term decay heat removal.

Figure 102 shows the reactor pressure during the event. Three banks of safety relief valves opened following the turbine trip, but the reactor pressure was generally maintained between the opening and closing set points of the first bank of safety relief valves. For the cases with 300 or more tubes, the heat removed by the isolation condenser eventually exceeded the core decay heat and, after a delay, the reactor pressure began to fall. The delay was associated with the relatively long time required for a fluid particle to flow through the reactor vessel. For example, the transit time, defined as the fluid volume of the vessel divided by the volumetric flow rate from the isolation condenser, for the case with 300 tubes exceeded $3000 \mathrm{~s}$.

The thermal response of the system is illustrated in Figure 103, which shows the calculated fluid temperatures entering and leaving the isolation condenser for the case with 300 tubes. The temperature at the outlet of the condenser decreased following the isolation signal, which opened the valves in the discharge line, and then remained nearly constant. The

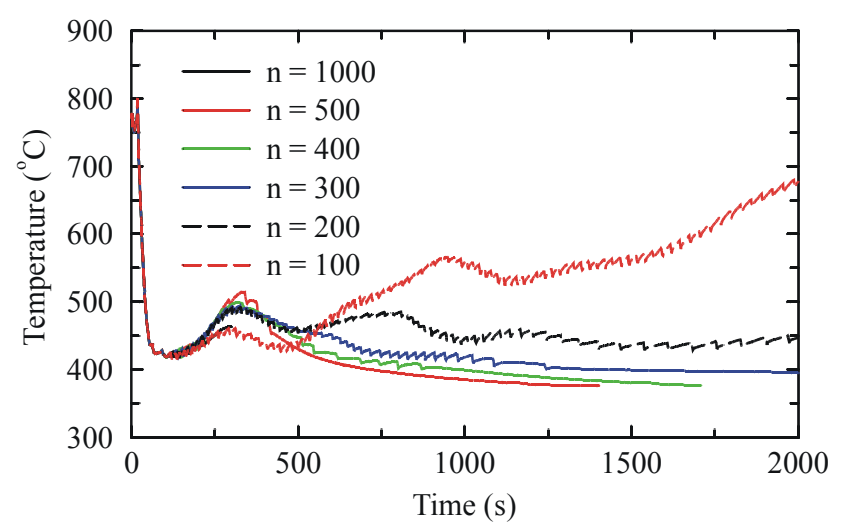

Figure 100. The effect of the number of tubes on the maximum cladding temperature during a long-term LOMF.

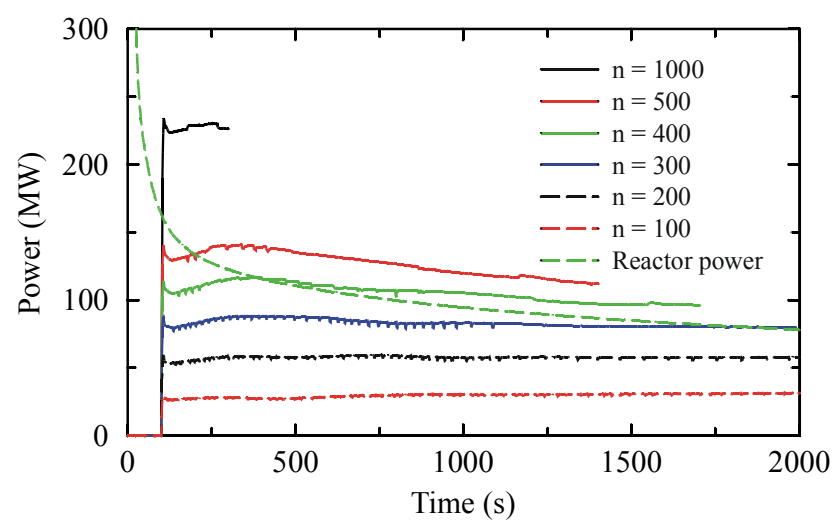

Figure 101. The effect of the number of tubes on the heat removed by the isolation condenser during a long-term LOMF.

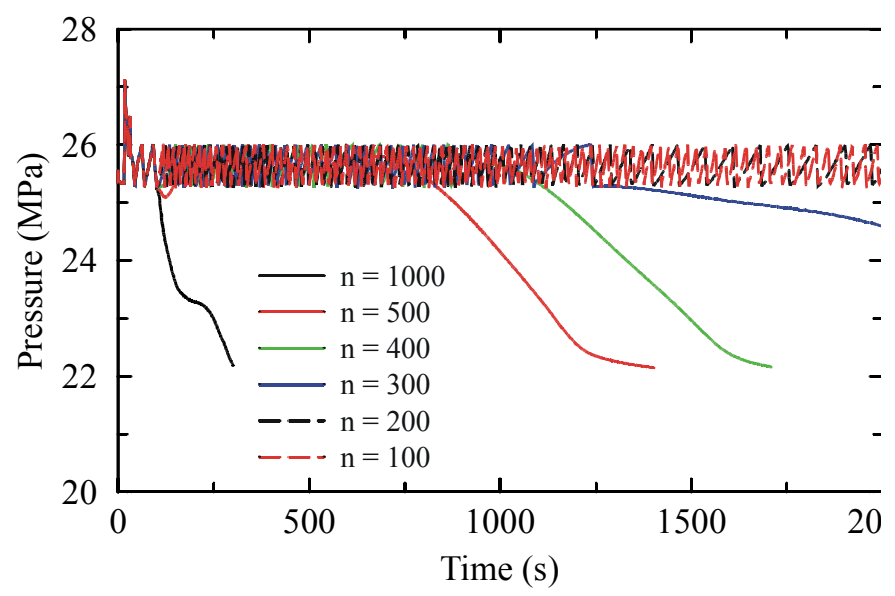

Figure 102. The effect of the number of tubes on reactor pressure during a long-term LOMF. 
temperature at the inlet to the condenser followed that of the hot leg following the isolation signal and was similar to the maximum cladding temperature shown previously. The maximum cladding temperature is also shown in the figure for comparison with the fluid temperatures.

One design constraint for the isolation condenser is to assure that critical heat flux (CHF) is not exceeded at the outside surface of the tubes during operation. If $\mathrm{CHF}$ is exceeded, the isolation condenser will not adequately remove decay heat. CHF is of particular concern for the SCWR

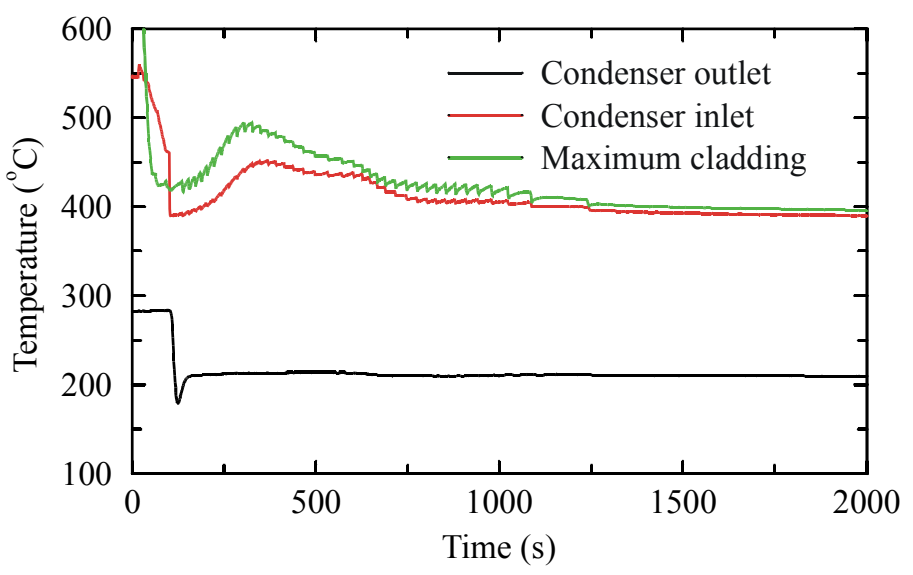

Figure 103. Thermal response of the system during a long-term LOMF (300 tubes). because the fluid temperature on the primary side of the heat exchanger is much higher, which leads to a higher heat flux, than in conventional LWRs. The maximum heat flux for the case with 300 tubes was about $60 \%$ of the CHF value predicted by RELAP5 for the case with the pool temperature set at the saturation temperature for atmospheric pressure $\left(100^{\circ} \mathrm{C}\right)$. Since CHF strongly increases with sub-cooling and some sub-cooling is expected in the pool, the calculated results indicate that the proposed design has adequate margin to CHF. However, the maximum calculated heat flux is sensitive to the thickness of the tubes, and the tubes are relatively thick for the analysis described here. (The tube thickness was set at $40 \%$ of the tube diameter, which was consistent with the thickness-to-diameter ratio for 0.5 -inch schedule 160 piping.) A sensitivity calculation was performed in which the tube thickness was reduced to $25 \%$ of the tube diameter. Although the total power removed by the isolation condenser increased by about $15 \%$, the maximum heat flux, which occurs at the inlet to the tube, increased to near the CHF value. A further reduction in the thickness of the tube would have caused the heat flux to exceed CHF. Thus, the sensitivity calculations indicate that the margin to $\mathrm{CHF}$ should be considered along with strength requirements in the ultimate design of the tubes. Because of uncertainty in the calculation of CHF for the tube bundle as well as that due to the application of the Bishop correlation for the supercritical water inside the nearly horizontal tubes, scaled experiments will be required before the SCWR could be licensed.

The calculations indicate that the measurement of level in the SCWR will not be as simple as in conventional LWRs. Figure 98 shows the results of a level calculation that was based on the differential pressure between the bottom and top of the feedwater tanks. The figure was based on an uncompensated level calculation in which the densities of the hot and cold fluids at the top and bottom of the tank, respectively, were assumed to be constants based their values at rated operating conditions. If the level calculation were based on fluid densities that were compensated for variations in the pressure and temperature in the hot and cold legs during the transient, the occurrence of the reactor trip set point would have been delayed by $7 \mathrm{~s}$ and the isolation signal would have occurred $40 \mathrm{~s}$ earlier. This indicates that level indications can vary significantly based on the method used to calculate them. Furthermore, the level indications will not be as accurate as can be obtained in LWRs because the density in the upper and lower part of the tanks can vary significantly from that in the hot and cold legs, respectively, because of the relatively large volume of the tanks, the delays associated with the time for the fluid to transit from the legs to the tank, and the large variation in densities that can exist within the "hot" and "cold" regions of the tanks during transients. In contrast, the densities of the liquid and gas in LWRs can be calculated relatively accurately from the pressure because both phases are generally near saturated conditions. 


\subsubsection{Loss-of-Coolant Accidents}

LOCAs initiated by large double-ended breaks in the cold leg, hot leg, and steam-line were simulated. In each case, the break was located in Loop 1 and the total break area corresponded to $200 \%$ of the area of the affected piping for each accident. The cold leg break was located between the reactor vessel and the discharge line from the isolation condenser. The hot leg break was located between the vessel and the supply line to the isolation condenser. The steam line break was located between the pressure balance line and the main steam isolation valve (see Junction 410 of Figure 92). The pressure downstream of the break was set at atmospheric pressure. The LOCA calculations were performed without emergency core coolant and automatic depressurization systems to provide an indication of the time available before these systems need to be aligned to mitigate the effects of the LOCA.

Conservative initial and boundary conditions were applied during the LOCAs. The thermal design initial conditions, see Table 41, were applied for this transient. The reactor power and feedwater flow were set at $102 \%$ and $95 \%$ of the rated values, respectively. The feedwater temperature was increased by $2{ }^{\circ} \mathrm{C}$ from the normal value. Although the calculated maximum cladding temperature exceeded the steadystate limit of $620^{\circ} \mathrm{C}$, the water rods were not insulated to maximize the stored energy in the reactor vessel. The decay heat was set at $120 \%$ of the best-estimate value. The best-estimate reactivity feedback coefficients were reduced by $20 \%$ to account for likely uncertainty in the feedback values.

Calculated sequences of events are given in Table 43. Each accident was initiated by a double-ended break at $0.0 \mathrm{~s}$. The reactor trip, turbine trip, and isolation signals were generated $2 \mathrm{~s}$ after the reactor pressure dropped below $23 \mathrm{MPa}$. The control rods began moving into the core $0.8 \mathrm{~s}$ after the reactor trip signal was generated. The reactor trip signal also initiated main coolant pump coastdown $(\beta=0.2)$. The turbine stop valves began closing at the turbine trip and were fully closed $0.1 \mathrm{~s}$ later. The isolation signal opened the valve in the discharge line of the isolation condenser, closed the main steam isolation valves, and terminated feedwater flow. The closure time for the main steam isolation valves and the main feedwater isolation valves was $7 \mathrm{~s}$.

Table 43. Sequences of events for the LOCAs.

\begin{tabular}{|l|c|c|c|}
\hline \multicolumn{1}{|c|}{ Event } & $\begin{array}{c}200 \% \text { cold leg } \\
\text { break }\end{array}$ & $\begin{array}{c}200 \% \text { hot leg } \\
\text { break }\end{array}$ & $\begin{array}{c}200 \% \text { steam line } \\
\text { break }\end{array}$ \\
\hline Break opened & 0.0 & 0.0 & 0.0 \\
\hline Reactor trip signal & 2.56 & 2.19 & 2.34 \\
\hline Turbine trip signal & 2.56 & 2.19 & 2.34 \\
\hline Isolation signal & 2.56 & 2.19 & 2.34 \\
\hline Main coolant pumps tripped & 2.56 & 2.19 & 2.34 \\
\hline Turbine stop valves closed & 2.66 & 2.29 & 2.44 \\
\hline Main steam isolation valves closed & 9.66 & 9.19 & 9.34 \\
\hline Main feedwater terminated & 9.66 & 9.19 & 9.34 \\
\hline Calculation terminated & 100.0 & 100.0 & 100.0 \\
\hline
\end{tabular}

The results of the LOCA calculations are summarized in Figures 104 and 105. These figures present integrals with respect to time of the total mass and energy flow rates from the reactor core cooling system to the containment. The curves represent the combined values from both sides of the break. The energy value is the integral of the product of the mass flow rate and the specific enthalpy. The mass and energy flow rates provide boundary conditions for the containment design. The figures show that the most mass exited from the system in the cold leg break and the most energy exited in the hot leg break. Based on these results, the hot leg break is expected to be the most limiting accident in terms of containment pressure. 


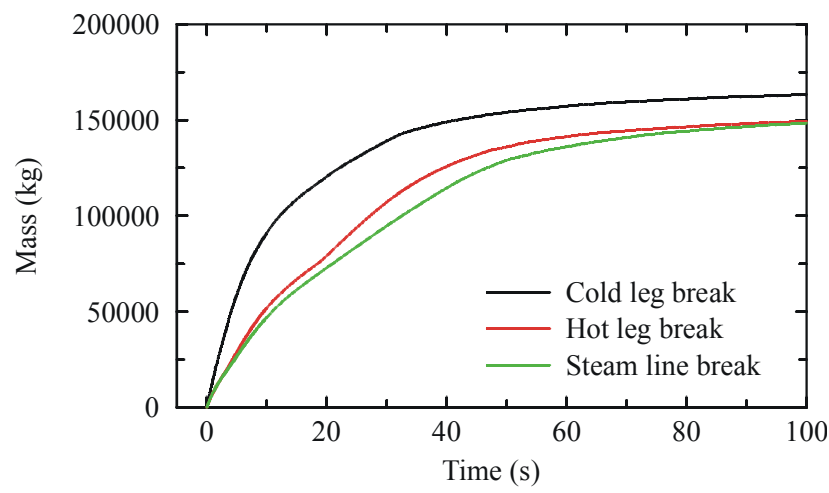

Figure 104. Integrated mass flow into the containment during a large-break LOCA.

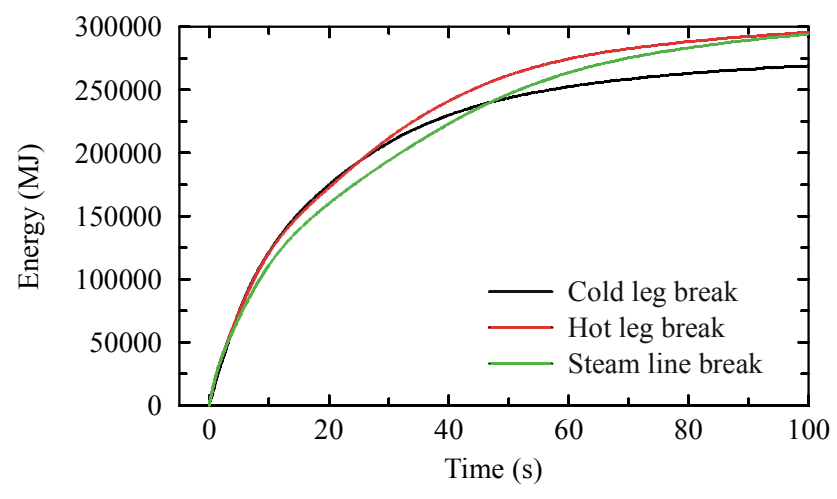

Figure 105. Integrated energy flow into the containment during a large-break LOCA.

Detailed results from these analyses are discussed in the following paragraphs.

Cold Leg Break. Figure 106 shows the pressure in the upper plenum during the LOCA initiated by a $200 \%$ cold leg break. The pressure initially decreased very rapidly, but then slowed somewhat at $2.56 \mathrm{~s}$ when the turbine trip closed the turbine stop valves. The rate of depressurization increased somewhat after $9.66 \mathrm{~s}$ when the closure of the main steam isolation valves isolated the reactor from the steam headers, which effectively reduced the volume of the system blowing down. The pressure continued to decrease for the remainder of the calculation, reaching 0.6 MPa when the calculation was terminated at $100 \mathrm{~s}$.

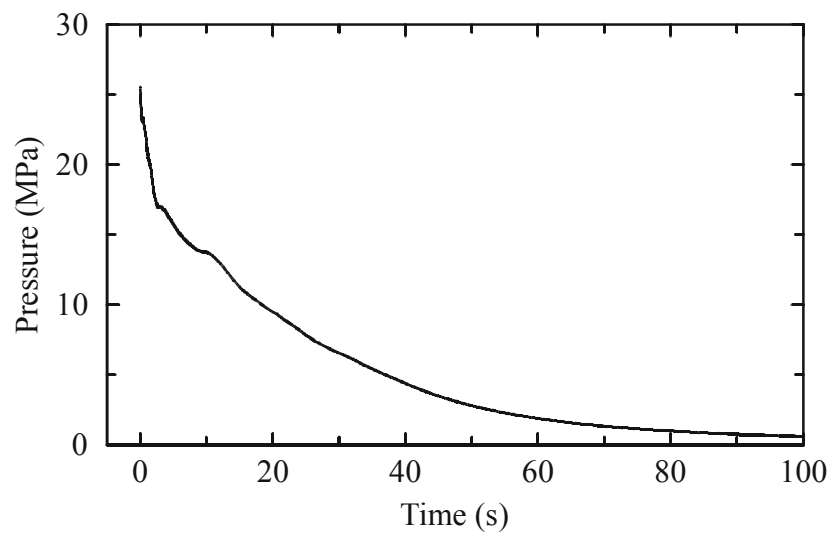

Figure 106. Upper plenum pressure during a LOCA initiated by a large cold leg break.

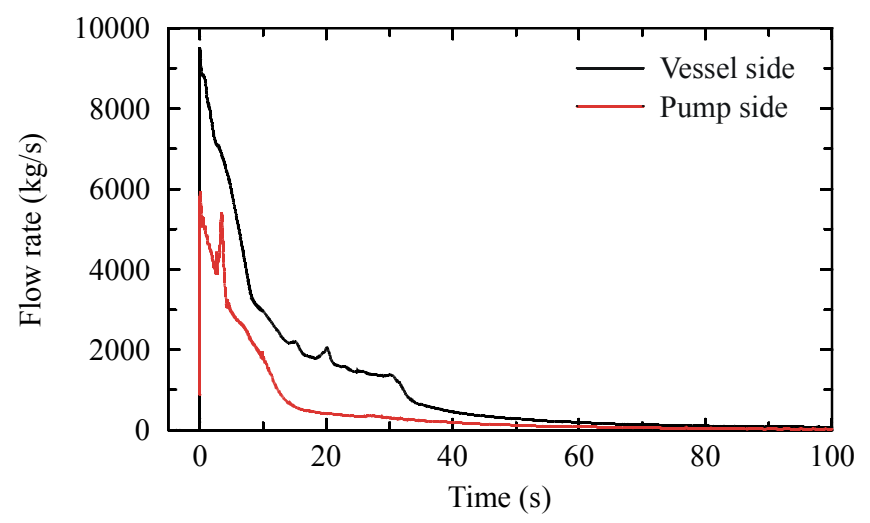

Figure 107. Break mass flow rates during a LOCA initiated by a large cold leg break.

The mass flow rates out the vessel and pump sides of the break are shown in Figure 107. The combined flow out of both breaks was more than eight times the steady-state feedwater flow given in Table 41. The flow rates were high enough that the main coolant pumps in the broken loop acted as brakes rather than pumps, resulting in a significantly higher mass flow from the vessel than from the pumps. Opening the isolation valve in the discharge line of the isolation condenser at $2.66 \mathrm{~s}$ caused the mass flow from the pump side of the break to increase. Otherwise, the mass flow rates out of both sides of the break generally decreased with time consistent with the decreasing pressure shown in Figure 106. 
The volumetric flow rates through both sides of the break are presented in Figure 108. The volumetric flow from the vessel side of the break was initially larger than from the pump side, consistent with the mass flow results presented in Figure 107. However, the volumetric flow from the pump side of the break exceeded that from the vessel side after $6.9 \mathrm{~s}$. The volumetric flow out the pump side of the break increased rapidly near $10 \mathrm{~s}$ due to the draining of the feedwater tank in the broken loop, which allowed higher energy and lower density fluid from the steam line to escape through the break. A similar increase in the volumetric flow was calculated near 30 $\mathrm{s}$ due to the draining of the feedwater tank in the unbroken loop, which resulted in lower density fluid at the break.

Figure 108 also shows that the flow through the turbine stop valve in the broken loop was comparable to that through the vessel side of the break before the turbine trip. Thus, the steam flow demanded by the turbine significantly affected the response of the system prior to the turbine trip.

The hydraulic response of the averagepowered fuel channel is illustrated in Figure 109 , which shows the normalized mass flow rate at the inlet to the core and the normalized reactor power. The normalized flow rate showed the rapid reversal that is typical of large cold leg breaks in current PWRs. The flow generally remained negative until $7.2 \mathrm{~s}$, when the flow reversed due to the draining of the feedwater tank in the broken loop as described previously. The flow reversal brought liquid from the lower plenum and water rods into the core. The normalized flow then generally exceeded the normalized power until $40 \mathrm{~s}$, after which the normalized power exceeded the normalized flow.

Figure 110 compares the maximum core cladding temperature for the proposed design with the results presented by MacDonald et al. [2003] for last year's design. The principal difference between designs is that the proposed design utilizes feedwater tanks and allows circulation between the hot and cold legs while the

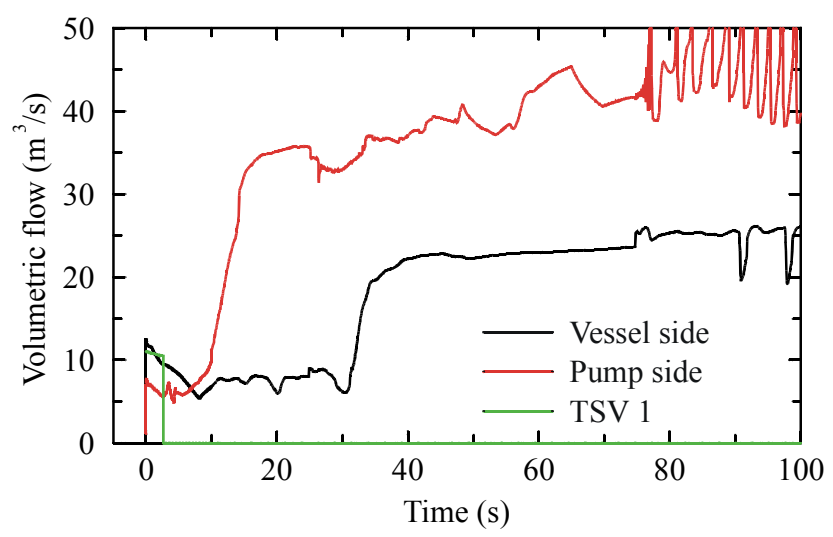

Figure 108. Break volumetric flow rates during a LOCA initiated by a large cold leg break.

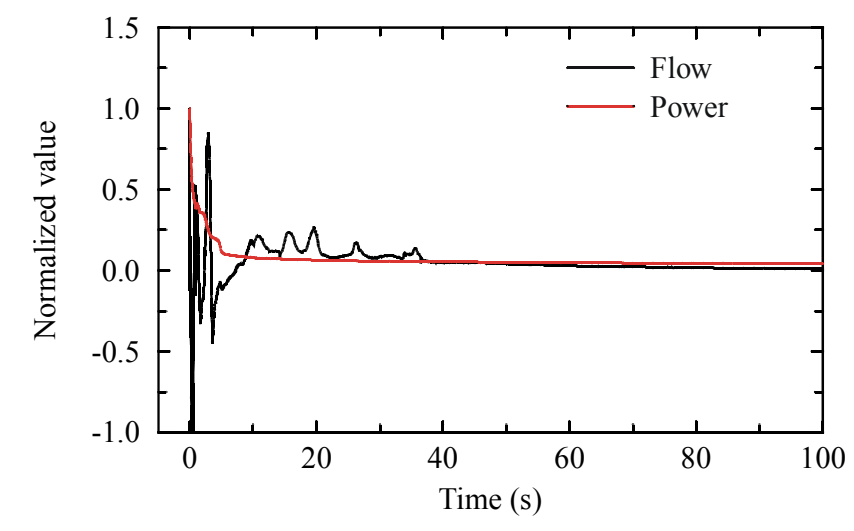

Figure 109. Normalized core flow rate and reactor power during a LOCA initiated by a large cold leg break.

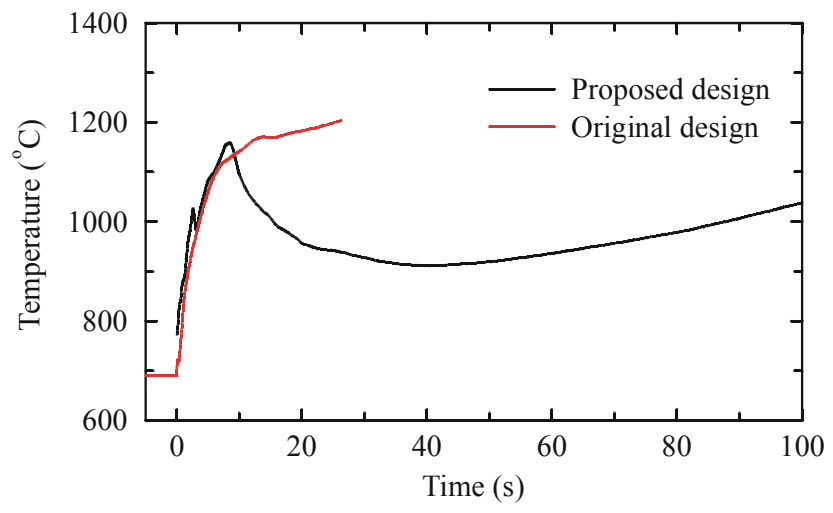

Figure 110. Maximum cladding temperatures during a LOCA initiated by a large cold leg break. 
original design was a once-through system with no tanks or circulation. The initial cladding temperature was considerably higher in this year's calculation because of the use of the thermal design, rather than the rated conditions shown in Table 41. The maximum cladding temperatures increased rapidly following the break with both designs. This temperature increase was caused by the flow reversal that resulted in the core being supplied by high-temperature steam from the upper plenum rather than low-temperature liquid from the lower plenum and the reduction in the normalized flow rate compared to the normalized power. The decrease in flow reduced the heat transfer from the surface of the fuel rods, which caused a redistribution of stored energy within the fuel rods. The fuel centerline and cladding temperatures approached an average value due to the decrease in heat flow across the fuel rods. This redistribution of the stored energy was primarily responsible for the initial rapid temperature rise of the cladding. The two designs responded similarly until about $8 \mathrm{~s}$, when the peak temperature occurred with the proposed design. The flow reversal with the proposed design then provided significant cooling and the temperature decreased until $40 \mathrm{~s}$. The fuel rods then experienced a nearly adiabatic heat up for the remainder of the calculation. In the original design, the core flow could not reverse and the nearly adiabatic heat up began much earlier. With the once-through design, the maximum cladding temperature continued to increase until reaching the $1205{ }^{\circ} \mathrm{C}$ limit for current reactors with Zircaloy cladding at $26 \mathrm{~s}$. Because of the core flow reversal in the proposed design, the cladding temperature would not reach the $1205{ }^{\circ} \mathrm{C}$ limit until more than $130 \mathrm{~s}$ after the start of the event. Thus, at least 100 more seconds are available for the emergency core coolant and automatic depressurization systems to turn the cladding temperature around with the proposed design compared to the original design.

The calculated blowdown peak cladding temperature for the proposed design was $1160{ }^{\circ} \mathrm{C}$. Although the peak value is less than the current $1205^{\circ} \mathrm{C}$ limit for Zircaloy-clad fuel, it is relatively close to the current limit and is of potential concern because additional conservatisms, such as due to sub-channel effects, may eventually be required in the analysis. However, this concern is ameliorated somewhat because the licensing limit for steel SCWR cladding is likely to be larger than the current limit for Zircaloy cladding and the fact that the initial cladding temperature shown in Figure 110 exceeds the steady-state limit of 620 ${ }^{\circ} \mathrm{C}$ by a considerable margin. Since the development of an acceptable bundle design requires that the initial cladding temperature be reduced to $620^{\circ} \mathrm{C}$ or less, the higher initial value used here provides considerable margin to offset possible conservatisms required later.

The distribution of liquid in the reactor vessel is illustrated in Figure 111, which shows collapsed liquid levels in the downcomer, average core channel, average water rod, and lower plenum. The liquid levels are computed as the liquid volume fraction times the control volume height summed over the control volumes in the component. The liquid volume fraction is not physically meaningful at supercritical conditions where there is no phase change. The initial values shown in the figure were calculated by setting the liquid volume fraction to unity if the fluid temperature is less than the critical temperature and to zero if it exceeds the critical temperature. The

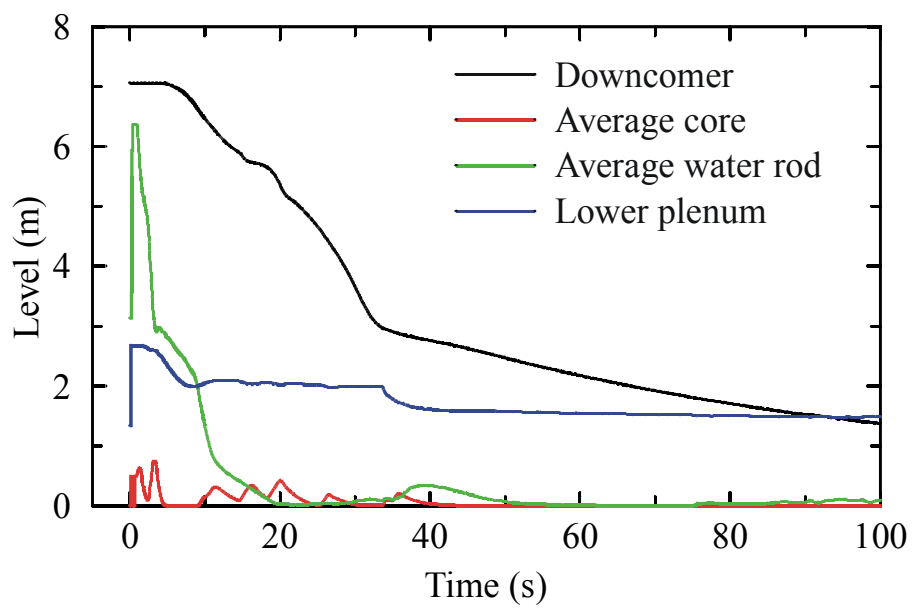

Figure 111. Collapsed liquid levels in the reactor vessel during a LOCA initiated by a large cold leg break. 
collapsed levels accurately reflect the liquid inventory after $0.9 \mathrm{~s}$, when the vessel pressure decreased below the critical value, but do not accurately reflect the fluid inventory for supercritical conditions.

Figure 111 shows that the water rods contained a significant amount of liquid before $20 \mathrm{~s}$, but were nearly empty after $50 \mathrm{~s}$. The downcomer and lower plenum contained significant amounts of liquid throughout the calculation. The collapsed liquid level in the core increased shortly after the core flow reversal at 7.2 s. Some liquid remained in the core until about $40 \mathrm{~s}$. The disappearance of liquid from the core coincided with a minimum in the maximum cladding temperature.

Collapsed liquid levels in the feedwater tanks are shown in Figure 112. The initial value shown exceeds the value given in Table 41 by about $7 \%$. The values given in the table were based on differential pressure whereas the levels shown in the figure were based on the liquid volume fraction. As described above, the liquid levels based on the volume fraction may not be very accurate for supercritical pressures. Tank 1, which was connected to the loop containing the break, drained relatively quickly. The liquid from the tank flowed directly out the break and was not available to enter the vessel. Tank 2 drained much more slowly and supplied liquid to the vessel, but most of it then flowed out through the break rather than towards the core.

Hot Leg Break. Figure 113 shows the pressure in the upper plenum during the LOCA initiated by a $200 \%$ hot leg break. The pressure initially decreased very rapidly, but then slowed somewhat at $2.19 \mathrm{~s}$ when the turbine trip closed the turbine stop valves. The rate of depressurization increased somewhat after $9.19 \mathrm{~s}$ when the closure of the main steam isolation valves isolated the reactor from the steam headers, which effectively reduced the volume of the system blowing down. The rate of depressurization slowed near $17 \mathrm{~s}$ due to the onset of flashing at the bottom of the downcomer and the lower plenum. The pressure then decreased relatively gradually for the remainder of the calculation, reaching $0.4 \mathrm{MPa}$ when the calculation was terminated at $100 \mathrm{~s}$.

The mass flow rates out the vessel and steam line sides of the break are shown in Figure 114. The peak value of the total break mass flow rate was only about half as large as for the cold leg break shown previously. However, because of the lower fluid density in the hot leg, the peak volumetric flow rate was 
much higher than that shown previously. Consequently, the initial depressurization of the system was faster than for the cold leg break. The mass flow rate from the steam line side of the break increased sharply at $2.19 \mathrm{~s}$, when the valve in the isolation condenser return line opened, which allowed liquid initially present inside the isolation condenser tubes to exit the break. The sharp increase in break mass flow rate on the vessel side of the break near $17 \mathrm{~s}$ was caused by flashing in the downcomer and lower plenum, which forced liquid through the core and towards the break. Note that the flow from the steam line side of the break was limited by choking in the pressure balance line, whose area was less than $25 \%$ of that of the hot leg.

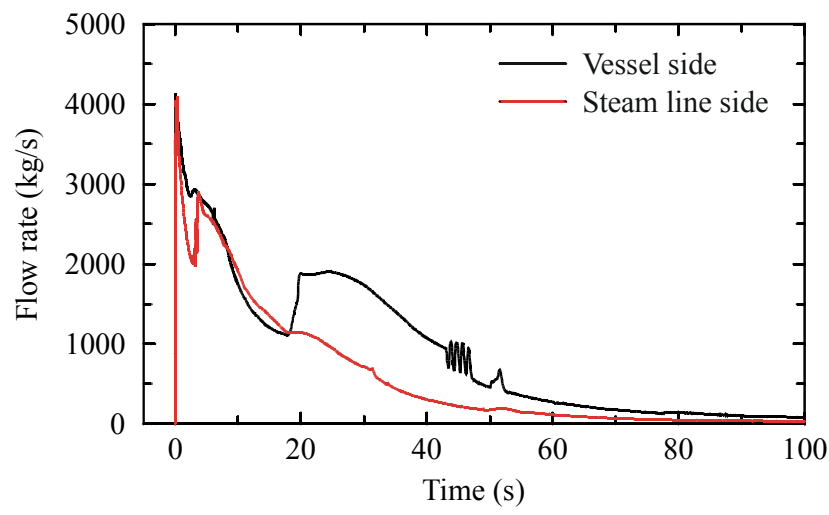

Figure 114. Break mass flow rates during a LOCA initiated by a large hot leg break.

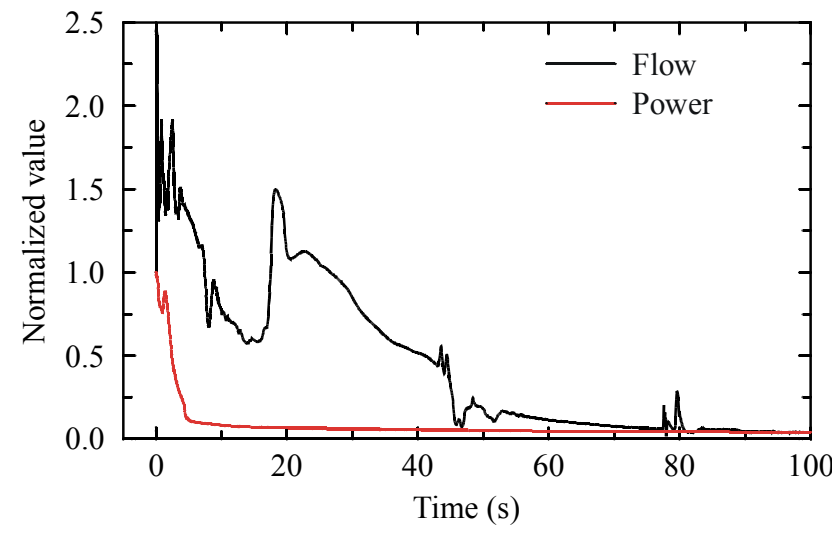

Figure 115. Normalized core flow rate and reactor power during a LOCA initiated by a large hot leg break.

Figure 115 compares the normalized flow at the inlet to the average-powered assembly with the normalized core power. The normalized flow rate exceeded the normalized power by a large margin before $45 \mathrm{~s}$. The high flow rate removed the energy initially stored in the fuel rod and reduced the cladding temperature to near that of the fluid as shown in Figure 116. After $45 \mathrm{~s}$, liquid was no longer entrained into the core, and the fuel rod began to experience a nearly adiabatic heat up. The adiabatic heat up began about $20 \mathrm{~s}$ earlier than reported by MacDonald et al. [2003] for the corresponding event with a once-through design. Thus, the results for the proposed design are somewhat worse than last year's design for a large hot leg break. However, the cold leg break is the more limiting accident and there is ample time for the emergency core coolant and automatic depressurization systems to turn the cladding temperature around before the cladding temperature limits are reached for the hot leg

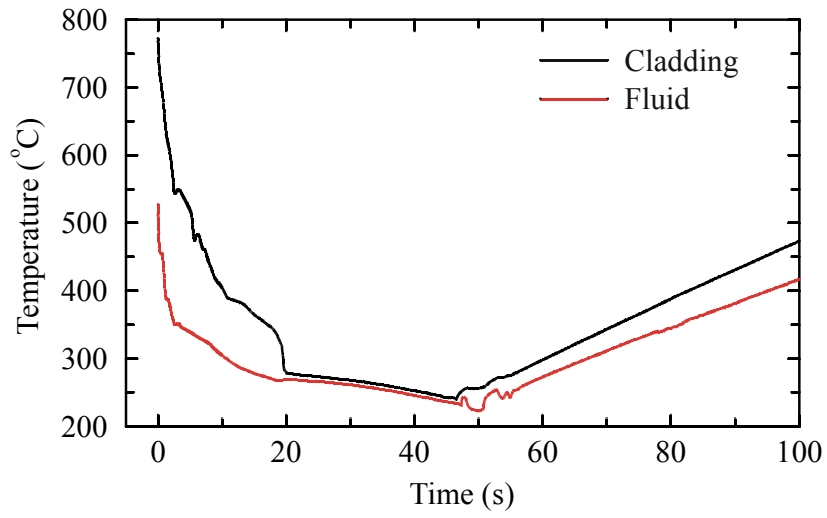

Figure 116. Maximum cladding temperature during a LOCA initiated by a large hot leg break. break. 
The distribution of liquid in the reactor vessel is illustrated by Figure 117, which shows collapsed liquid levels in the downcomer, average core channel, average water rod, and lower plenum. The collapsed liquid levels are not particularly meaningful at supercritical conditions, but are meaningful after $0.47 \mathrm{~s}$ when the pressure decreased below the critical value. Early in the blowdown, the flow divided in the water rods, with some flow going downwards towards the core and the remainder going upwards through the upper head and to the cold leg of the broken loop. Consequently, the liquid level in the water rods decreased rapidly, and the water rods were nearly empty at 12s. Flashing in the downcomer caused the flow at the top of the downcomer to change directions, bringing liquid from the downcomer back to the upper head and the water rods. The liquid level in the water rods then increased. The liquid level in the core increased sharply near $17 \mathrm{~s}$ due to flashing in the lower regions of the downcomer and the lower plenum. The liquid level in the core decreased sharply near $45 \mathrm{~s}$, when liquid was no longer carried upwards from the lower plenum into the core. The decrease in liquid level in the core caused the onset of the nearly adiabatic heat up discussed previously. The downcomer and lower plenum retained some liquid throughout the calculation, but the other components contained almost no liquid after $50 \mathrm{~s}$.

Collapsed liquid levels in the feedwater tanks are shown in Figure 118. The level

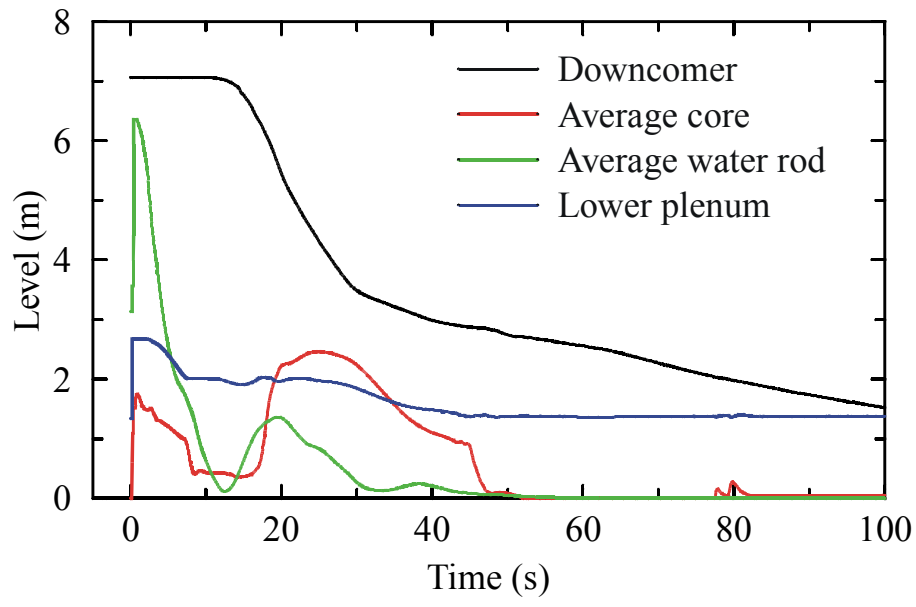

Figure 117. Collapsed liquid levels in the reactor vessel during a LOCA initiated by a large hot leg break.

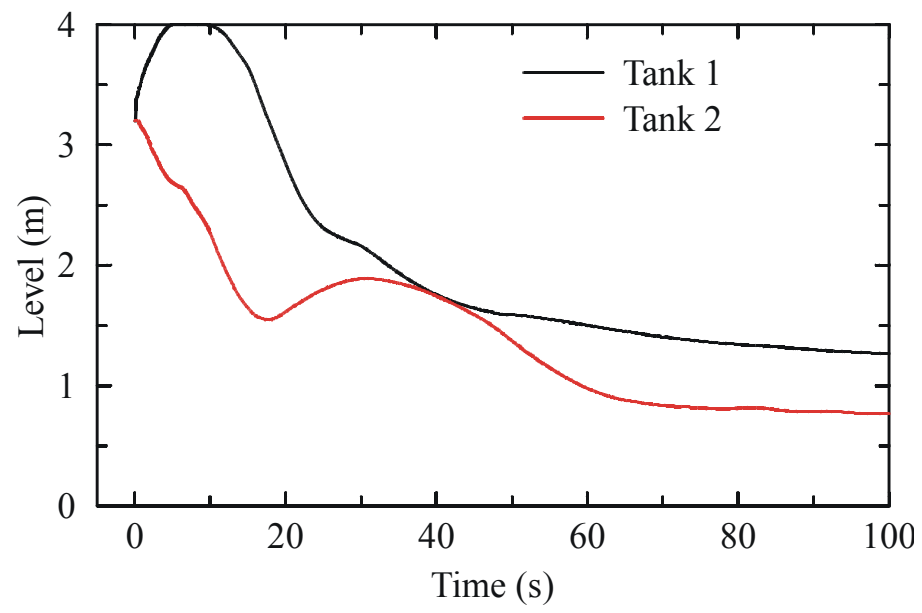

Figure 118. Collapsed liquid levels in the feedwater tanks during a LOCA initiated by a large hot leg break. in Tank 1, which was connected to the loop containing the break, initially increased as it received all of the feedwater flow. The tank filled with liquid, but the level decreased shortly after the feedwater flow was terminated at $9.19 \mathrm{~s}$. Flashing in the downcomer caused a flow reversal in the cold leg of Loop 2 near $17 \mathrm{~s}$, which caused a brief increase in the liquid level. Neither tank drained completely during the calculation.

Steam Line Break. Figure 119 shows the pressure in the upper plenum during the LOCA initiated by a $200 \%$ steam line break. The trends are similar to those described earlier for the hot leg break. However, the depressurization was less rapid because closure of the main steam isolation valves at $9.34 \mathrm{~s}$ isolated the reactor from the steam headers. As far as the reactor was concerned, the closure of the main steam isolation valves converted the double-ended break into a single-ended break. 


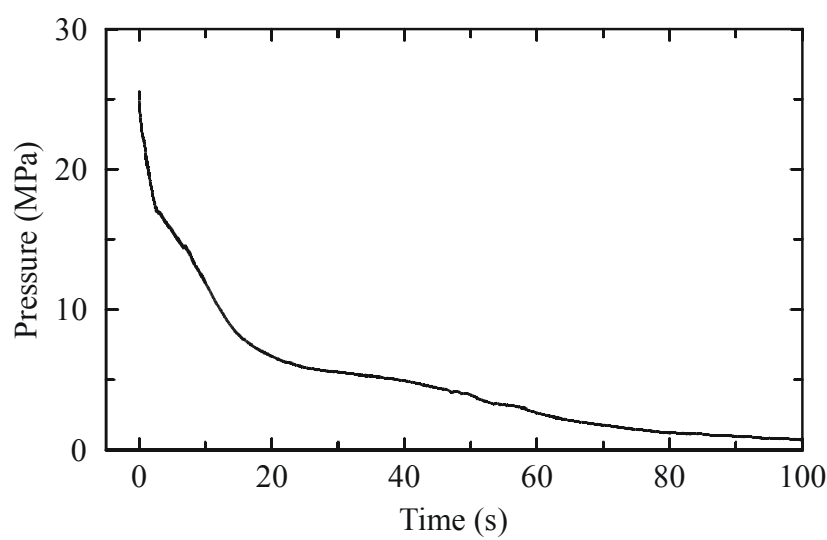

Figure 119. Upper plenum pressure during a LOCA initiated by a large steam line break.

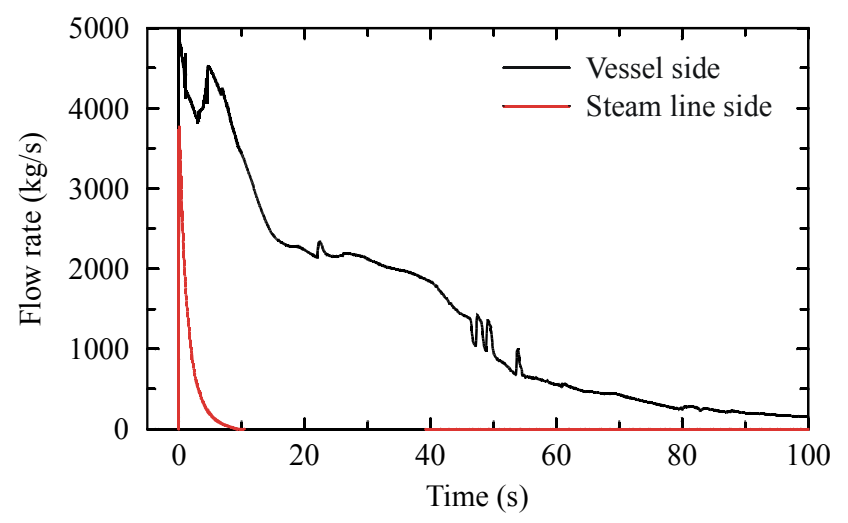

Figure 120. Break mass flow rates during a LOCA initiated by a large steam line break.

The mass flow rates out the vessel and steam line sides of the break are shown in Figure 120. The mass flow rate from the vessel side of the break increased sharply at $2.34 \mathrm{~s}$, when the valve in the isolation condenser return line opened, which allowed liquid initially present inside the isolation condenser tubes to exit the break. The flow out the other side of the break reached an early peak and then declined as the steam header depressurized. The mass flow rate was nearly zero after the closure of the main steam isolation valves at $9.34 \mathrm{~s}$.

The maximum fuel rod cladding temperature is shown in Figure 121. The results are similar to those shown earlier for the hot leg break except that the nearly adiabatic heat up began about $15 \mathrm{~s}$ later.

The response of the liquid within the reactor vessel and the feedwater tanks was similar to that shown previously for the hot leg break.

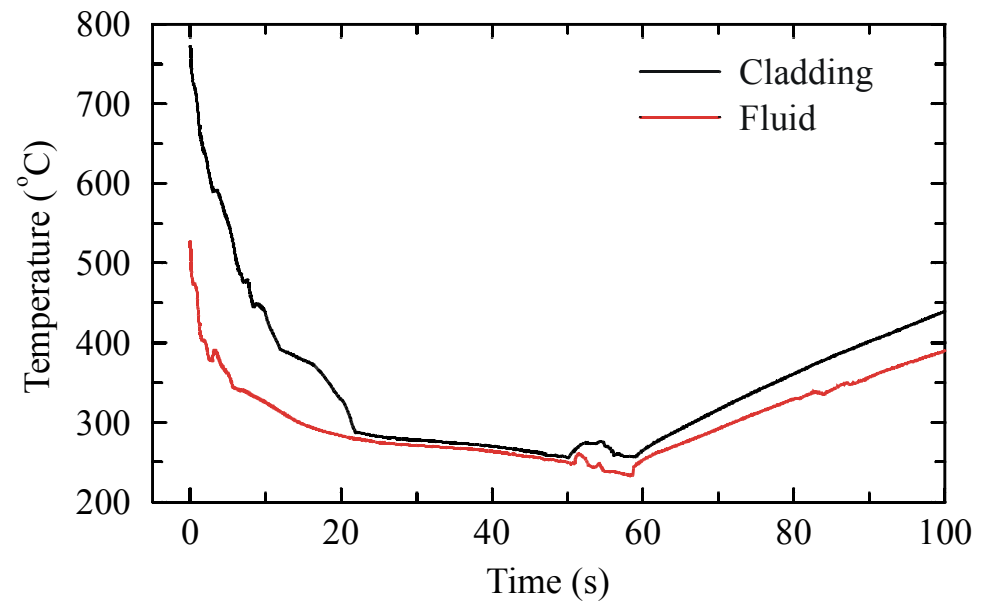

Figure 121. Maximum cladding temperature during a LOCA initiated by a large stea $\mathrm{m}$ line break.

\subsubsection{Conclusions}

An innovative safety concept for the SCWR was developed and evaluated. The proposed design features feedwater tanks that supply water to the reactor core and main coolant pumps that provide forced circulation during LOMF events. The feedwater tanks are connected to both cold and hot legs, allowing circulation during LOMF events. The combination of the liquid inventory in the feedwater tanks, the flow provided by the main coolant pumps during coastdown, and the circulation between the hot and cold legs allows the proposed design to passively meet cladding thermal limits following a LOMF transient. An isolation condenser provides long-term decay heat removal. 
The new safety design for the SCWR was evaluated using the RELAP5-3D computer code. A RELAP5$3 \mathrm{D}$ model of the proposed design was developed and initialized at rated operating and thermal design conditions. The model was used to simulate short-term and long-term loss-of-flow events and LOCAs initiated by large breaks in the cold leg, hot leg, and steam line. The RELAP5-3D calculations confirmed the potential of the new design for mitigating loss-of-flow events and LOCAs.

The evaluation showed that the required value of the coastdown parameter, $\beta$ (see Equation 6), depended on the amount of reactivity feedback assumed in the analysis. Assuming that $80 \%$ of the nominal reactivity feedback provides an acceptable amount of conservatism, adequate short-term protection for complete loss-of-flow transients was obtained when the main coolant pump coastdown was characterized by $\beta<0.29$. Using a very conservative assumption of no reactivity feedback, adequate short-term results were obtained for $\beta<0.20$.

Adequate long-term decay heat removal following loss of flow was obtained when the isolation condenser contained 300 or more tubes. With this number of tubes, the peak cladding temperatures following longterm LOMF flow events remained far below the transient limit and the power removed by the isolation condenser exceeded the decay power within 30 minutes of the start of the event.

The evaluation of LOCAs showed that the proposed design with circulation yielded significantly better results than obtained previously with a once-through design. The most limiting LOCA was initiated by a large cold leg break. For this LOCA, the maximum cladding temperatures with the once-through and proposed designs were similar until $8 \mathrm{~s}$. Because of a subsequent period of enhanced cooling, the cladding temperature would not reach the accident limit until at least $100 \mathrm{~s}$ later with the new design than with the original once-through design. The new design allows much more time for the emergency core coolant and automatic depressurization systems to turn the cladding temperature around, which should result in smaller, cheaper safety systems and/or an increased safety margin.

The benefits of the new safety system design are several including: avoiding potentially expensive upgrades to improve the reliability of the main feedwater system; no need to develop, test, and maintain a fast-acting, high-capacity auxiliary feedwater system; probabilistic arguments to justify the reclassification of a total LOMF as an accident rather than a transient are avoided; and smaller, cheaper LOCA safety systems become possible. The drawbacks of the proposed design include the cost of the new components, which is judged minor compared to the savings discussed above, and the additional cost associated with the larger containment required by the fluid initially contained within the feedwater tanks. In addition, the calculated results indicate that additional analytical and/or experimental work would be needed in the areas of CHF and heat transfer from the isolation condenser, measurement of liquid levels at supercritical conditions, and mixing of hot and cold fluids in the feedwater tanks during transients. 


\subsection{Structural Response of SCWR Reactor Pressure Vessel to Thermal Transients (INEEL - Prof. Robert Witt)}

Like other nuclear reactors, the SCWR must be designed to accommodate different types of transients. Previous investigations of thermal hydraulic response to a number of transients can be found in earlier reports. In the present work we present a process for converting the output of those thermal hydraulic analyses into input for a 3D transient thermal and structural analysis of the SCWR reactor pressure vessel. Specific results are obtained for an overcooling transient, in which the inlet flow temperature takes a step down due to the loss of a feedwater heater.

\subsubsection{Procedure Definition}

Simulation of thermal transients and the associated structural response requires a general- purpose finite element code, in this case ABAQUS. Although ABAQUS is a self-contained code (one can generate the solid model, mesh it, and solve the problem), ABAQUS' strength is in its non-linear solver. Other code packages (specifically, SDRC's I-DEAS package) are superior in their ability to generate the solid model and mesh it. Accordingly, the simplest procedure for using I-DEAS and ABAQUS can be represented as:

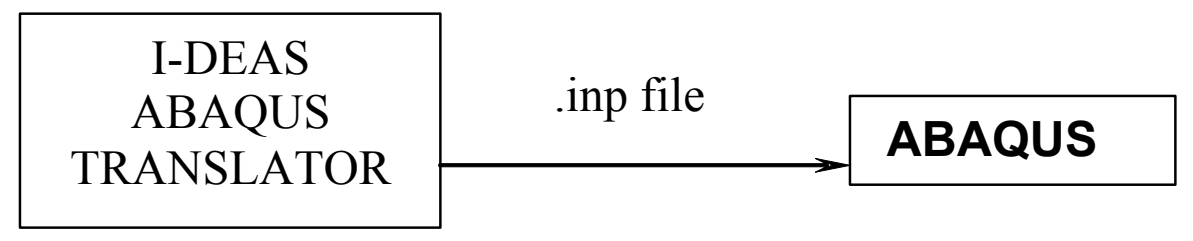

For simple problems (static, structural), it is literally as simple as preparing an I-DEAS model, clicking a single button from a pull-down menu to create an ABAQUS input file (.inp file) and then submitting this to ABAQUS for solution. The larger the departure from static, structural problems, however, the more intervention is required to modify the inp file to perform the analysis. For simulating SCWR transients, the above schematic is modified as follows:

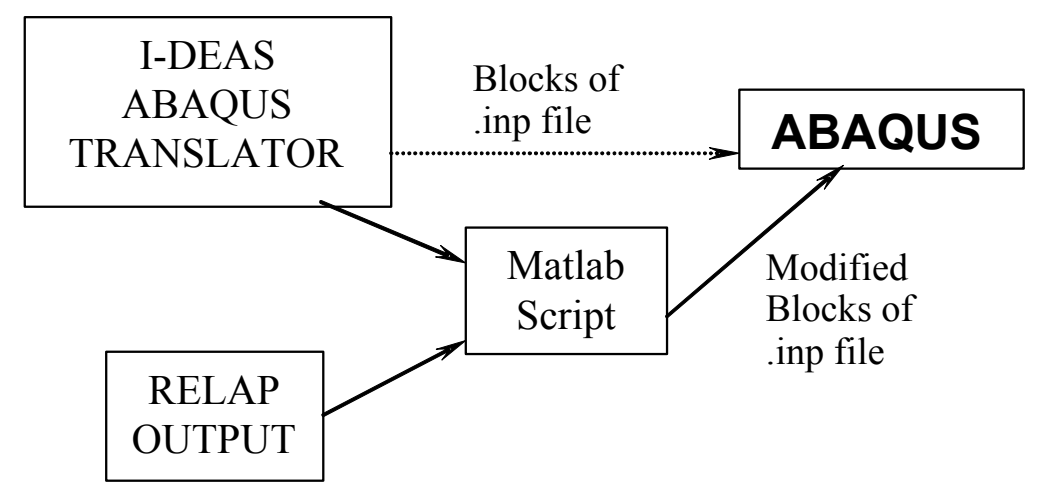

In this schematic, time-dependent boundary conditions for the transient thermal analysis are "informed" by RELAP results. We use the phrase "informed" because the RELAP results are coarser than those from a 3D continuum model. RELAP provides circumferentially averaged surface temperatures along a coarse distribution of axial nodes as a function of time. The Matlab script reads this RELAP information as well 
as the blocks of data from the initial I-DEAS .inp file (inner surface nodes and coordinates) and prepares smoothly-varying fields of inner surface temperature as a function of time. The results are then prepared in the appropriate form for an ABAQUS thermal transient .inp file and submitted for analysis. Once the transient thermal analysis is finished, the corresponding structural analysis is conducted by reading the time-dependent temperature fields from an ABAQUS thermal analysis output file.

\subsubsection{SCWR Transients}

Six SCWR transients were examined with RELAP:

1. Five percent cold leg break

2. One hundred percent cold leg break

3. One hundred percent hot leg break

4. Step change in main feedwater flow

5. Loss of feedwater

6. Step (down) change in main feedwater temperature (overcooling transient)

The first three produce significant changes in the axial surface temperature distribution, but they are also depressurization events. Whatever local stress is induced by such surface temperature changes is secondary to the reduction of stress accompanying depressurization. These transients might merit more investigation if they were followed for a longer period of time, when emergency core cooling is injected into the vessel at a much lower temperature than the nominal cold leg temperature of $280{ }^{\circ} \mathrm{C}\left(536{ }^{\circ} \mathrm{F}\right)$. The next two transients produce minor variations in system pressure, but there is virtually no change in surface temperature distributions with time. The last transient, the overcooling event, produces minor variations in system pressure and significant changes in surface temperature around the inlet nozzle where pressure-induced stress also peaks. We chose to focus on this transient because it promised to produce the most severe transient loading condition of the six transients considered.

The first task in preparing the RELAP output involved deciding on the time discretization appropriate for the ABAQUS simulation. RELAP's time steps are obviously driven by thermal hydraulic considerations, and are much shorter than what is required for the ABAQUS simulation. The overcooling transient contained 760 records (one quarter second intervals over the transient's 190 seconds). We settled on a 17-record discretization of the RELAP output for the ABAQUS simulation. Plots of circumferentially averaged surface temperatures and system pressure for this 17-record representation are shown in Figure 122.

One axial channel is missing in the temperature plot, and that is the channel "second from the bottom of the lower head." This temperature channel reflects the outlet temperature from the water rods and is substantially hotter than the other channels. While hot water emerging from the water rods is certainly physical, the mixing of this water with lower plenum water is handled crudely in RELAP. If implemented as given, it produces a large $\left(75^{\circ} \mathrm{C}\right)$ step change up (and then down) over a single lower axial region and distracts from the region of interest around the nozzle. This could be included in future simulations if a defensible way of mixing this hot exit water with lower plenum water could be formulated and implemented. For now it is omitted from the analysis. Figure 122a illustrates the evolution of circumferentially averaged temperatures at axial positions varying from the lower plenum to upper plenum. The influence of the main feedwater temperature drop is experienced first at the inlet nozzle and elevations above the nozzle, owing to the fact that $90 \%$ of the incoming flow is diverted to the upper plenum. Elevations below the nozzle experience the change after a time lag of 10 to 100 seconds, depending on the axial distance between the inlet nozzle and the elevation of interest. 


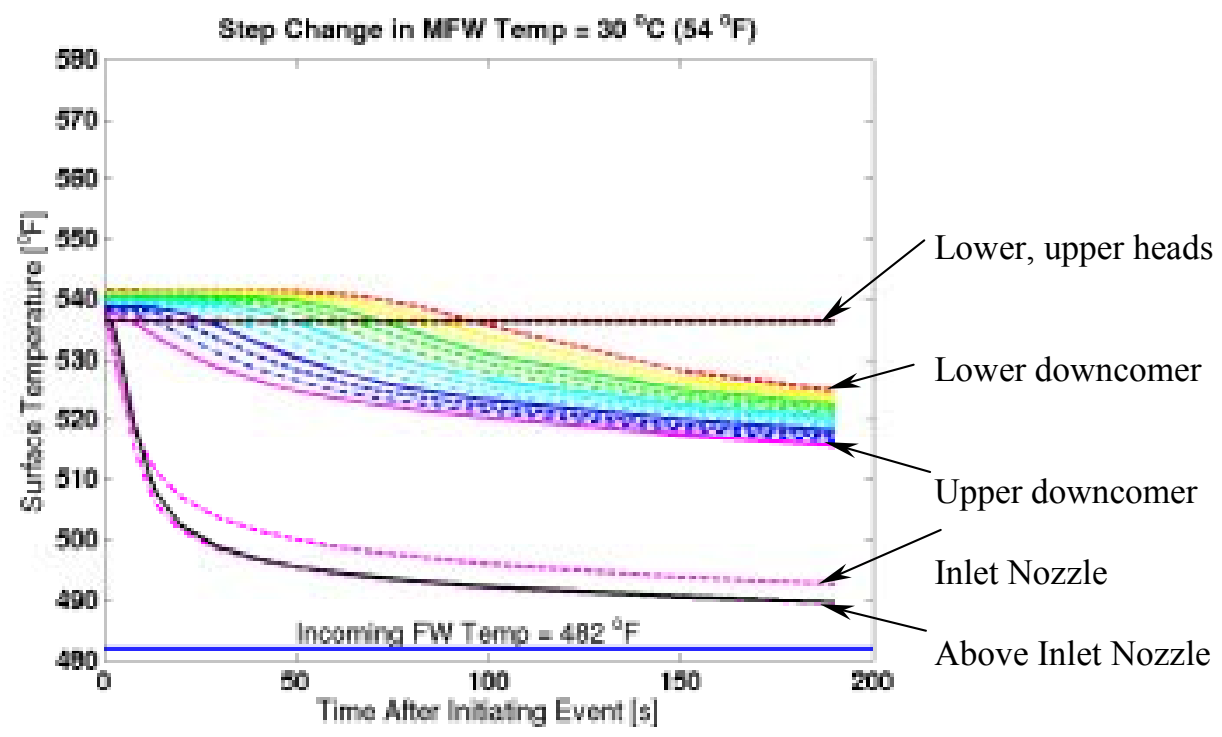

(a) Profiles of Circumferentially Averaged Surface Temperature versus Time

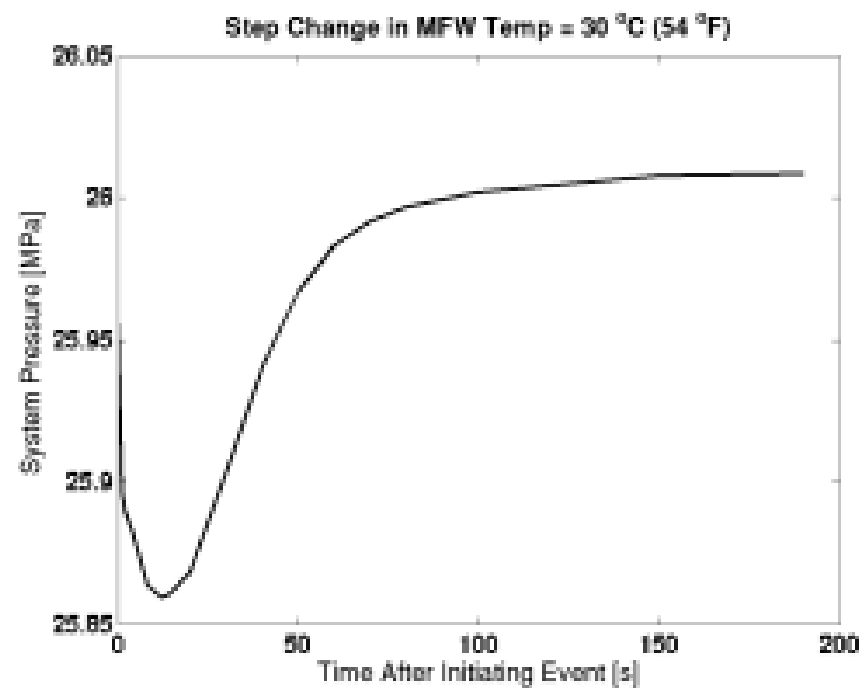

(b) Variation of System Pressure with Time

Figure 122. Edited (17-record) RELAP output used for thermal transient.

Given this temperature history, one approach to implementing surface boundary conditions would be to prescribe only axially varying temperatures, linearly interpolating the circumferentially averaged temperature histories at every axial location. Since the source of the change is a drop of $30{ }^{\circ} \mathrm{C}\left(54^{\circ} \mathrm{F}\right)$ at the inlet nozzle, however, we know that there is a circumferential variation in the surface temperature. The challenge is to find a way to implement such a variation in a way that is consistent with the other information provided. Our approach is to assume that the surface temperature can be described as: 


$$
T(z, \theta, t)=T_{i}(z)-\Delta T \exp \left[-(\gamma(z, t) \theta / \pi)^{2}\right]
$$

where $T(z, \theta, t)$ is the time-varying surface temperature, $T_{i}(z)$ is the initial circumferentially averaged temperature at an axial location (interpolated from RELAP output), $\Delta T$ is the magnitude of the main feedwater temperature change (given, equal to $54^{\circ} \mathrm{F}$ in this transient), $\gamma(z, t)$ is a dispersive coefficient to be determined, and $\theta$ is angular position of a node relative to a plane that bisects the inlet nozzle. The Gaussian form of this circumferential variation is admittedly arbitrary. We know that there are some physical problems (effluent or radioactive particle emission from a point source) having Gaussian dispersion solutions, but these are infinite or semi-infinite medium solutions. The intent is to choose a form that has some physical basis (consistent with the temperature drop at the inlet nozzle and symmetric about the nozzle, dispersion from convection and diffusion) and that also can be shown to be consistent with other information in the problem. Given this form, the circumferentially averaged surface temperature would be defined as:

$$
\bar{T}(z, t) \equiv \frac{1}{2 \pi} \int_{-\pi}^{+\pi} T(z, \theta, t) d \theta=T_{i}(z)-\frac{\Delta T}{2 \pi} \int_{-\pi}^{+\pi} \exp \left[-(\gamma(z, t) \theta / \pi)^{2}\right] d \theta
$$

Note that the left-hand side of this equation defines what is available from RELAP output and plotted in Figure 122a. The integral in the above expression can be evaluated and the result rearranged as a transcendental equation for the dispersive coefficient $\gamma$.

$$
\gamma=\beta \operatorname{erf}(\gamma) \quad \beta \equiv \frac{\sqrt{\pi}}{2} \frac{\Delta T}{T_{i}(z)-\bar{T}(z, t)}
$$

The parameter $\beta$ is a known quantity from RELAP output. Early in the transient, the temperature difference in the denominator of $\beta$ is sometimes very small, producing exceedingly large values of $\gamma$ and rendering a circumferential distribution that looks more like a $\delta$-function than Gaussian dispersion. For this reason, we revert to the circumferential average if the transcendental equation produces a dispersion coefficient $\gamma$ exceeding 100. Similarly, if the transient were to proceed for a much longer time, the temperature distribution would develop non-physical features at the outlet nozzle $(\theta= \pm \pi / 2)$. Specifically, we expect the outlet nozzle to be a symmetry plane, so that the circumferential gradient in $T(\mathrm{z}, \theta, \mathrm{t})$ is zero at $\theta= \pm \pi / 2$. The assumed form does not have this property, but early in the transient the Gaussian component of the temperature distribution is essentially zero at $\theta= \pm \pi / 2$ and the distribution appears to have the desired form.

The Matlab script evaluates the $\gamma(z, t)$ for each axial location and time in the RELAP output (an array of 20 axial channels $\times 17$ time records) and then linearly interpolates results between bounding axial channels for surface nodes at all axial and circumferential positions. This creates a smoothly-varying inner surface temperature field, $T(z, \theta, t)$.

\subsubsection{Limitations Of Finite Element Analysis In Step Change Problems}

Before presenting results from the ABAQUS simulations, it is worth considering a benchmark solution illustrating the limitations of finite element analysis in step change problems. Consider an infinite slab of material of thickness $L$, initially at uniform temperature $T_{o}$ and subjected to a step change down in surface temperature to $T_{s}$ at time $t=0$. In examining the structural consequences of this transient, the slab is further assumed to be unrestrained. (In the finite element analysis, just enough constraints are provided to prevent rigid body motion.) The temperature response is: 


$$
\frac{T(\xi, t)-T_{s}}{T_{o}-T_{s}}=\frac{4}{\pi} \sum_{n=1,3,5 \ldots}^{\infty} \exp \left[-n^{2} \pi^{2} a t / L^{2}\right] \frac{\sin (n \pi \xi)}{n} \quad \xi \equiv \frac{x}{L}, \quad a \equiv \frac{k}{\rho c_{p}}
$$

Because the slab is free to expand, the stress induced in the slab is due only to the material expanding or contracting against itself. The vertical stress at any time and position can be evaluated as:

$$
\sigma_{y}(\xi, t)=-\alpha_{T} E[T(\xi, t)-\bar{T}(t)] \quad \bar{T}(t) \equiv \int_{0}^{1} T(\xi, t) d \xi
$$

Here $\alpha_{T}$ is the thermal expansion coefficient, $E$ is the modulus and $\bar{T}(t)$ is the average temperature through the slab. Representative geometry and temperature response are shown in Figure 123. By definition, the gradient at the boundary is initially infinite and remains steep until enough time has passed for the step change to penetrate the material. The temperature solution shows that penetration is governed by the most slowly decaying harmonic with a time constant $\tau_{\mathrm{o}}=L^{2} / \pi^{2} a$. Surface gradients remain steep for times $t$ such that $t / \tau_{\mathrm{o}}<<1$.

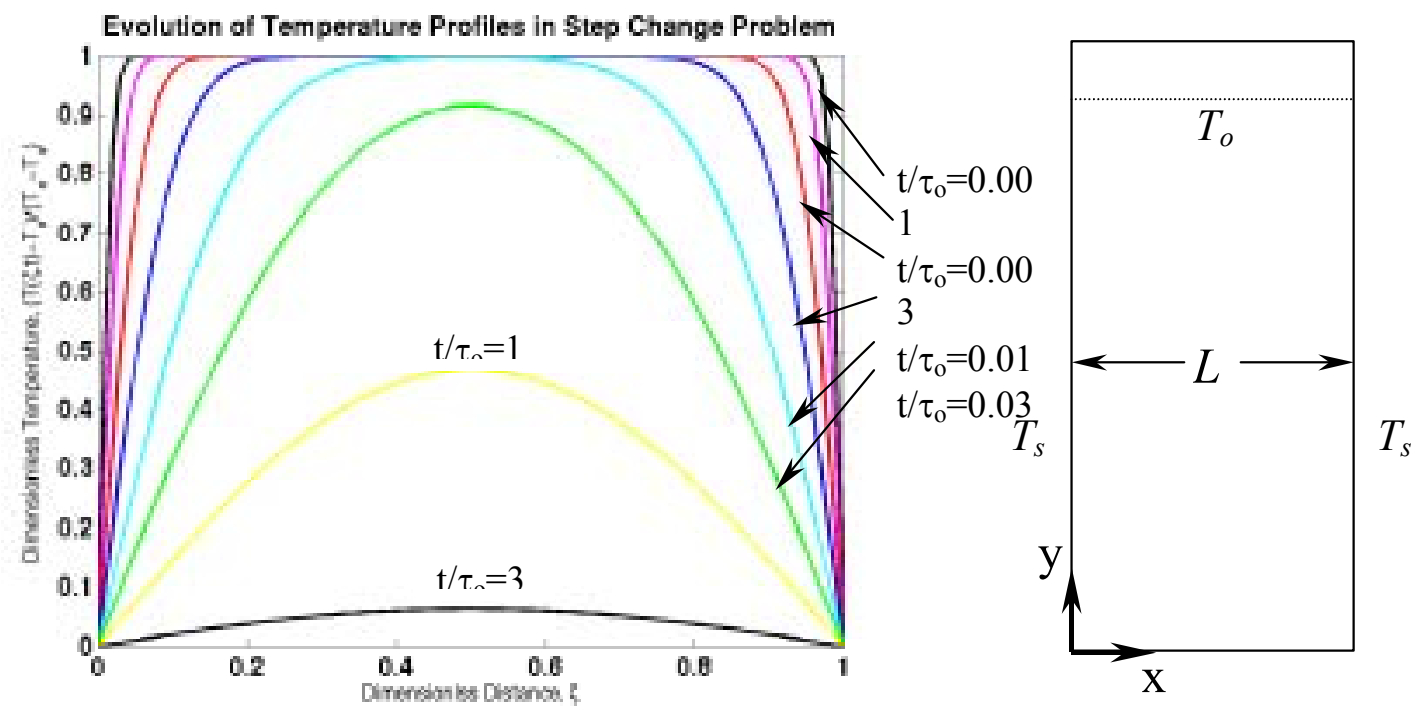

Figure 123: Analytical temperature solution for step change in infinite slab.

The significance of this with respect to finite element analysis is that interpolation functions within elements are low order polynomials. For the elements used in this benchmark problem and in the ABAQUS simulations, the highest order polynomials are quadratic. This provides good accuracy once there is significant penetration of the step change, but poor accuracy for $t / \tau_{0}<<1$.

Figure 124 illustrates the discrepancy between finite element analysis calculated stress and the analytical stress at the slab boundary $(x=0)$ as a function of dimensionless time, $t / \tau_{\mathrm{o}}$. The mesh used in this problem consisted of ten Q8

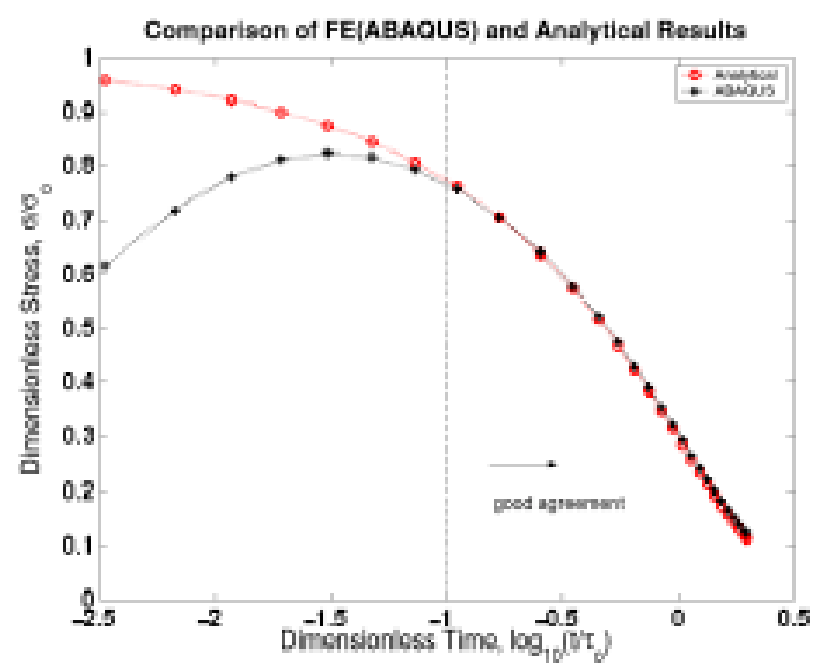

Figure 124. Comparison of analytical and finite element analysis results for step change in infinite slab. 
elements through thickness. The abscissa is plotted on a log scale to expand the time interval where agreement is expected to be poor. The ordinate is normalized to the maximum expected stress at $t=0$, $\sigma_{\mathrm{o}}=-\alpha_{\mathrm{T}} E\left(T_{s}-T_{o}\right)$. For this mesh, it can be seen that agreement between finite element analysis and the analytical result is good as long as $t / \tau_{\mathrm{o}} \geq 0.1$, or $\log _{10}\left(t / \tau_{\mathrm{o}}\right)>-1$.

Increasing the mesh density mitigates this deficiency by shortening the time interval of poor performance, but it can't be entirely eliminated. For 3D problems, increasing mesh density results in severe time and storage penalties. It is better to use a modest mesh density and simply be aware of and make corrections for initial surface stresses underestimated by the finite element analysis.

\subsubsection{ABAQUS Simulation Results}

For the SCWR reactor pressure vessel, the time constant $\tau_{\mathrm{o}}$ is long. Since the outer surface of the vessel is nearly insulated, the corresponding idealized problem thickness $L$ for the reactor pressure vessel is twice its physical thickness, or 49.5 inches. Steel thermal diffusivity is $a=0.018 \mathrm{in}^{2} / \mathrm{s}$. Then $\tau_{\mathrm{o}}=L^{2} / \pi^{2} a=1.38 \times 10^{4}$ seconds or nearly four hours. The RELAP simulation only lasts 190 seconds, so $\log _{10}\left(\mathrm{t} / \tau_{\mathrm{o}}\right)$ is -1.86 at the transient's end.

Figures 125 and 126 provide an indication of the mesh density of the 10-node tetrahedral elements used in the model. The highest order interpolation within one of these elements is comparable, but not identical to, the highest order interpolation in the planar Q8 element. There are $12 \sim 13$ elements through thickness, corresponding to about $2.5 \times$ the mesh density of the benchmark problem. The higher mesh density provides better accuracy at shorter $t / \tau_{0}$ than suggested by Figure 124 , but close scrutiny of the results is still warranted. As a rule of thumb, we can expect large errors in the results when the temperature contour plots indicate the temperature gradient is concentrated within a single layer of surface elements, while the results are expected to be reasonably accurate at the end of the transient where the temperature gradient spans several layers of elements through the vessel thickness.

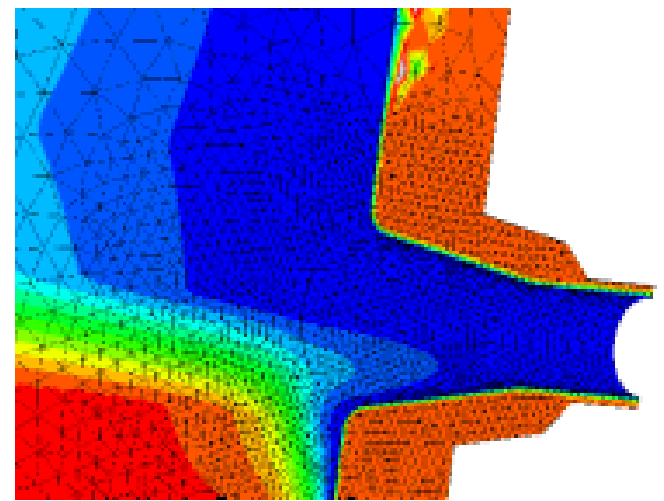

(a) at $t=10$ seconds into the transient

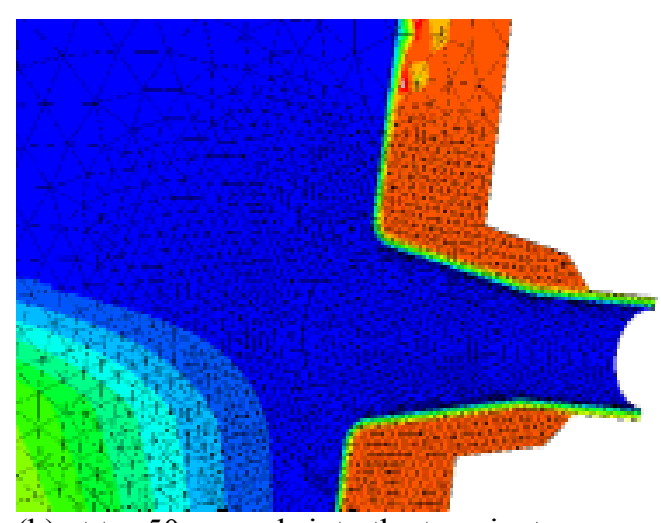

(b) at $\mathrm{t}=50$ seconds into the transient
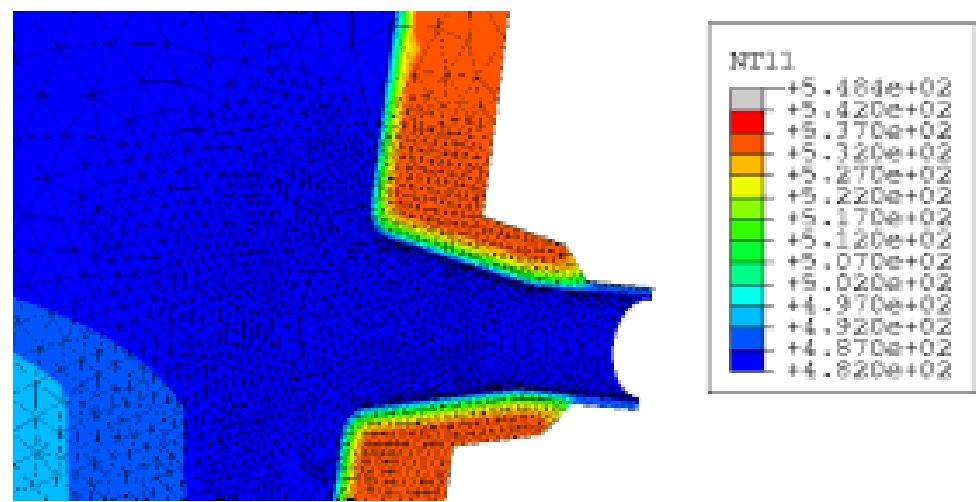

(c) at $\mathrm{t}=190$ seconds into the transient

Figure 125. Temperature distributions at different stages of the overcooling transient. 

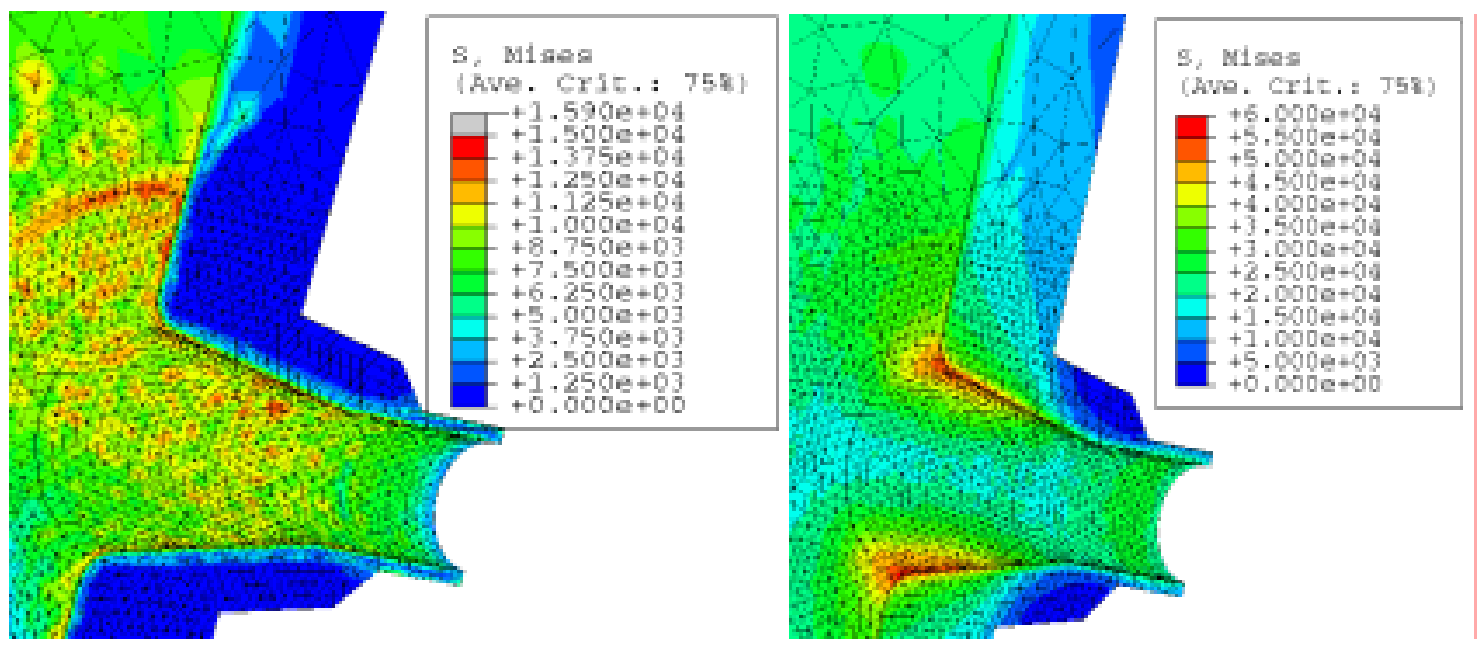

(a) Thermal Stress (left) and Total Stress (right) at 10 seconds into the transient
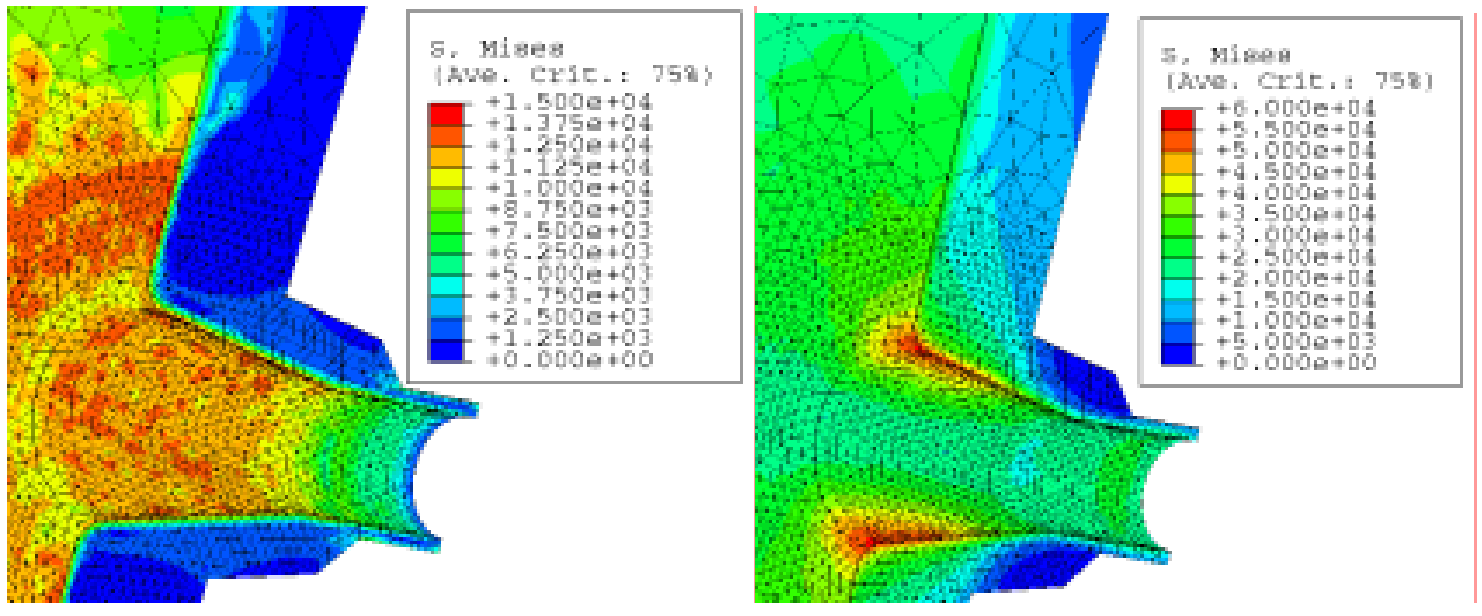

(b) Thermal Stress (left) and Total Stress (right) at 50 seconds into the transient
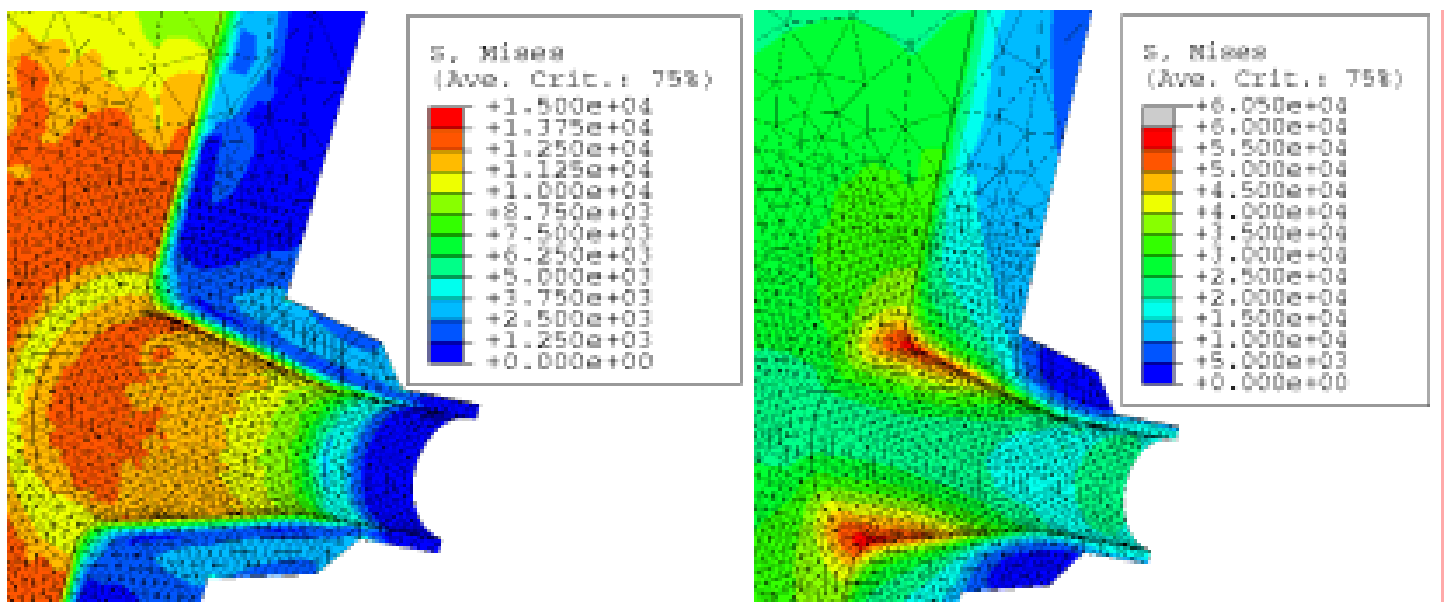

(c) Thermal Stress (left) and Total Stress (right) at 190 seconds into the transient

Figure 126. Stress distributions at different stages of the overcooling transient. 
Unlike 2D problems, increasing the mesh density to mitigate errors in the early part of the transient is precluded by storage requirements. We generated a quarter vessel model with only the inlet nozzle (and not the outlet nozzle) represented. The model contained about 44,000 elements and 66,000 nodes or about 200,000 degrees-of-freedom. We marched the solution through 16 load steps and a total of 52 time increments. Load steps at the beginning of the transient were as short as one second with time increments within the load step as short as 0.2 seconds, while load steps at the end of the transient were as long as 50 seconds with time increments of 10 seconds. The output files for a single simulation were as large as 3 GB and all files created in support of this one transient consumed about 7.5 GB. The disk space available on the UNIX fileservers ranges from $860 \mathrm{~GB}$ to $2,300 \mathrm{~GB}$ and this space must serve a large number of employees and programs. In light of these limits, it is not a trivial matter to increase the mesh density.

Figure 125 illustrates the evolution of the temperature distribution around the inlet nozzle and through the vessel thickness at three times: 10,50 and 190 seconds into the transient. The distribution at $\mathrm{t}=10$ seconds shows how the incoming cool flow is dispersed around the inlet nozzle. The surface temperature distribution just below the inlet nozzle is only beginning to experience the effect of the overcooling transient, while the region above the inlet nozzle experiences far more expansive cooling. Penetration of the transient is confined to the first layer of elements at the vessel surface, so we expect large errors in the computed thermal stresses at this time. The coarser the mesh at the vessel surface, the more pronounced this error becomes. Figure 125a shows that above the nozzle, there is a local region where the temperature distribution actually oscillates through-thickness. (Obviously, the physical response to this transient should provide a monotonic rise in temperature as we move into the vessel and as shown in Figure 123.) At this elevation, the temperature rise overshoots the initial vessel temperature (note the gray contour island), then falls back below the initial temperature (yellow/green contour islands) before damping out to the asymptotic bulk vessel temperature (orange contour).

Figure $125 \mathrm{~b}$, at $\mathrm{t}=50$ seconds, shows wider dispersal of cold water both above and below the inlet nozzle and slightly greater penetration of the temperature field into the vessel. The temperature gradient extends perhaps two elements through-thickness, so we again expect some error in computed thermal stresses, though not as severe as at $\mathrm{t}=10$ seconds. Note also that the non-physical, oscillatory contour region above the inlet nozzle has diminished in strength. At $t=190$ seconds, Figure $125 \mathrm{c}$, the non-physical oscillatory features have disappeared completely from the field of view and the temperature gradient extends through several elements. We suspect that by this time, the computed thermal stresses are reasonably accurate.

We'd obviously like a more quantitative measure for evaluating the accuracy of the computed thermal stresses than just an inspection of the extent of penetration relative to the mesh density. The expected values of the peak Von Mises stress for part of a solid body suddenly subjected to a temperature change (Young and Budynas, 2002) are: $\sigma_{\mathrm{o}}=-\alpha_{\mathrm{T}} E\left(T_{s}-T_{o}\right) /(1-v)$. For $\alpha_{\mathrm{T}}=6.5 \times 10^{-6}{ }^{\circ} \mathrm{F}^{-1}, E=30 \times 10^{6} \mathrm{psi}, T_{s}-$ $T_{o}=-54 \mathrm{~F}$ and $v=0.29$, the stress $\sigma_{\mathrm{o}}$ is $14.83 \mathrm{ksi}$. As shown in Figure 126a, at $t=10 \mathrm{~seconds}$, the plot of Von Mises thermal stress shows a mottled distribution on the inner surface. This is another measure of error early in the calculation. The noisy temperature distribution just under the inner surface produces noisy thermal expansion. Stresses are calculated from strains, which in turn are calculated from displacement gradients, and the act of differentiation amplifies the noise in the thermal expansion. Note that as the transient proceeds and this noise dies away (Figures 126b, 126c) the mottled feature disappears and the contours organize themselves into a less complicated pattern. Also note that, early in the transient, the ratio of penetration depth to local geometric feature (fillet radius, for instance) is small, and there is no difference between the stress pattern around the nozzle and anywhere else on the surface. (The mottled pattern in Figure 126a is more or less the same inside the nozzle, around the fillet and on the bulk vessel inner surface; there is no stress concentration effect from the geometric discontinuity of the nozzle.) As we reach the end of the transient, the ratio of penetration depth to fillet radius is about one, 
and the thermal Von Mises stress is different and lower around the fillet ( $\sim 10 \mathrm{ksi})$ than in the nozzle or bulk vessel ( $13-14 \mathrm{ksi})$.

The right column of Figure 126 shows the evolution of total (pressure plus thermal) Von Mises stress in the vessel and around the inlet nozzle. The peak stress is at the top and bottom of the inlet nozzle due to the stress concentration associated with the pressure loading. The variations in thermal stress barely manifest themselves in the plot of total stress since peak thermal stresses are only about $30 \%$ of peak mechanical stresses. At $t=10$ seconds, peak Von Mises stress is around $55 \mathrm{ksi}$, but at this time the thermal component of stress is significantly underestimated (equivalent to far left of the vertical line in Figure 124). At $t=190 \mathrm{seconds,} \mathrm{Figure} \mathrm{126c,} \mathrm{total} \mathrm{Von} \mathrm{Mises} \mathrm{stress} \mathrm{peaks} \mathrm{at} 60 \mathrm{ksi}$. We can think of this as $50 \mathrm{ksi}$ due to the pressure loading and $10 \mathrm{ksi}$ due to the thermal loading. At the end of the transient, however, the thermal stress around the nozzle fillet has dropped from its peak value due to the penetration of the step change into the vessel. Considering the entire transient, it would be prudent to assume the peak total Von Mises stress occurs at the beginning of the transient and is equal to $65 \mathrm{ksi}$, with a contribution of $50 \mathrm{ksi}$ from mechanical (pressure) loading and a contribution of $15 \mathrm{ksi}$ from thermal loading. This value of $65 \mathrm{ksi}$ can now be used to determine the acceptability of the peak stress with respect to low cycle fatigue limits of the ASME code. Alternatively, if this transient meets those requirements, we could use the ASME code to specify the largest step change in main feedwater temperature that meets code requirements.

\subsubsection{Significance of Stresses in Overcooling Transient}

The significance of these results can be evaluated from the perspective of low-cycle fatigue. The frequency of such transients is not imagined to exceed 100 over the life of the plant. The ASME code provides guidelines first for determining whether or not a particular cyclic transient is significant, and then for assessing the number of cycles to failure if the transient is deemed significant. Section N-415.1, Vessels Not Requiring Analysis for Cyclic Operation, provides such guidance. In part (c), detailed fatigue analysis is not required if "the temperature difference in ${ }^{\circ} \mathrm{F}$ between any two adjacent points of the vessel during normal operation and during startup and shutdown operation does not exceed $S_{a} /(2 E \alpha)$, where $S_{a}$ is the value [of the alternating stress] obtained from the applicable design fatigue curve for the specified number of startup-shutdown cycles...". For 100 cycles, the corresponding value for carbon steel is $S_{a} \cong 180 \mathrm{ksi}$, and the corresponding temperature difference is $460{ }^{\circ} \mathrm{F}$. By comparison, loss of one feedwater heater leads to an overcooling transient of $54^{\circ} \mathrm{F}$.

Alternatively, Section N-415.1 provides the definition of a temperature change it defines as "significant": "A temperature-difference fluctuation shall be considered to be significant if its total algebraic range exceeds the quantity $S_{a} /(2 E \alpha)$, where $S_{a}$ is the value [of the alternating stress] obtained from the applicable design fatigue curve for $10^{6}$ cycles." For carbon steel, this value of $S_{a}$ is about $12 \mathrm{ksi}$, so "significant" temperature fluctuations begin at $30^{\circ} \mathrm{F}$. The small amplitude temperature change $\left(54^{\circ} \mathrm{F}\right)$ for a small number of cycles (about 100) leads us to conclude there are no significant structural consequences for this overcooling transient.

\subsubsection{Summary}

A process for examining the structural consequences of SCWR thermal transients has been defined. We have to examine the computational results carefully because hydraulic transients are often much shorter than the reactor pressure vessel thermal diffusion time. For the case examined here involving a sudden 30 ${ }^{\circ} \mathrm{C}\left(54{ }^{\circ} \mathrm{F}\right)$ drop in main feed-water temperature, the peak Von Mises stress is about $30 \%$ higher (65 vs 50 $\mathrm{ksi}$ ) than that experienced under static conditions at nominal system pressure. Given the low number of 
anticipated cycles and the relatively small temperature change, the ASME Code indicates the transient is of no consequence with respect to low-cycle fatigue. 


\subsection{Design of Thermal Sleeve for SCWR (INEEL - Prof. Robert Witt)}

\subsubsection{Introduction}

The Supercritical Water Reactor (SCWR) is a novel reactor design enabling higher thermal efficiency through higher outlet water temperature (Oka 2000). At an operating pressure of $25 \mathrm{MPa}$ and inlet and outlet temperatures of $280{ }^{\circ} \mathrm{C}$ and $500{ }^{\circ} \mathrm{C}$, respectively, the supercritical water's mass density varies by an order of magnitude between inlet and outlet. In order to achieve sufficient moderation to function as a thermal reactor, $90 \%$ of the inlet flow in the reference design is diverted to the upper plenum, where it flows down a series of water rods and functions as a moderator, as shown in Figure127.

An outlet water temperature of $500{ }^{\circ} \mathrm{C}$ poses another challenge. Under the ASME Pressure Vessel and Piping Code, Section III, Subsection NB, LWR vessels may be fabricated from conventional steels (such as SA-508) provided the operating temperature is below $371{ }^{\circ} \mathrm{C}$ $\left(700{ }^{\circ} \mathrm{F}\right)$ (ASME, 2001). Thus it is necessary to isolate the reactor pressure vessel outlet nozzle and surrounding reactor pressure vessel from the $500{ }^{\circ} \mathrm{C}$ outlet water. We propose to do this using a thick thermal sleeve, surrounded by an even more generous radial gap cooled by incoming cold leg water. Thermal sleeves in existing LWRs are designed to mitigate the effects of thermal transients (Shah and MacDonald 1993). The sleeve and water gap may both be of modest thickness (fractions of an inch or a few $\mathrm{mm}$ ). In the SCWR, however, the thermal sleeve and its associated cooling flow must provide much greater thermal isolation under steady-state conditions.

\subsubsection{FLUENT Model}

For a proposed geometry, we require an analysis tool that provides us with the flow pattern of water around the thermal

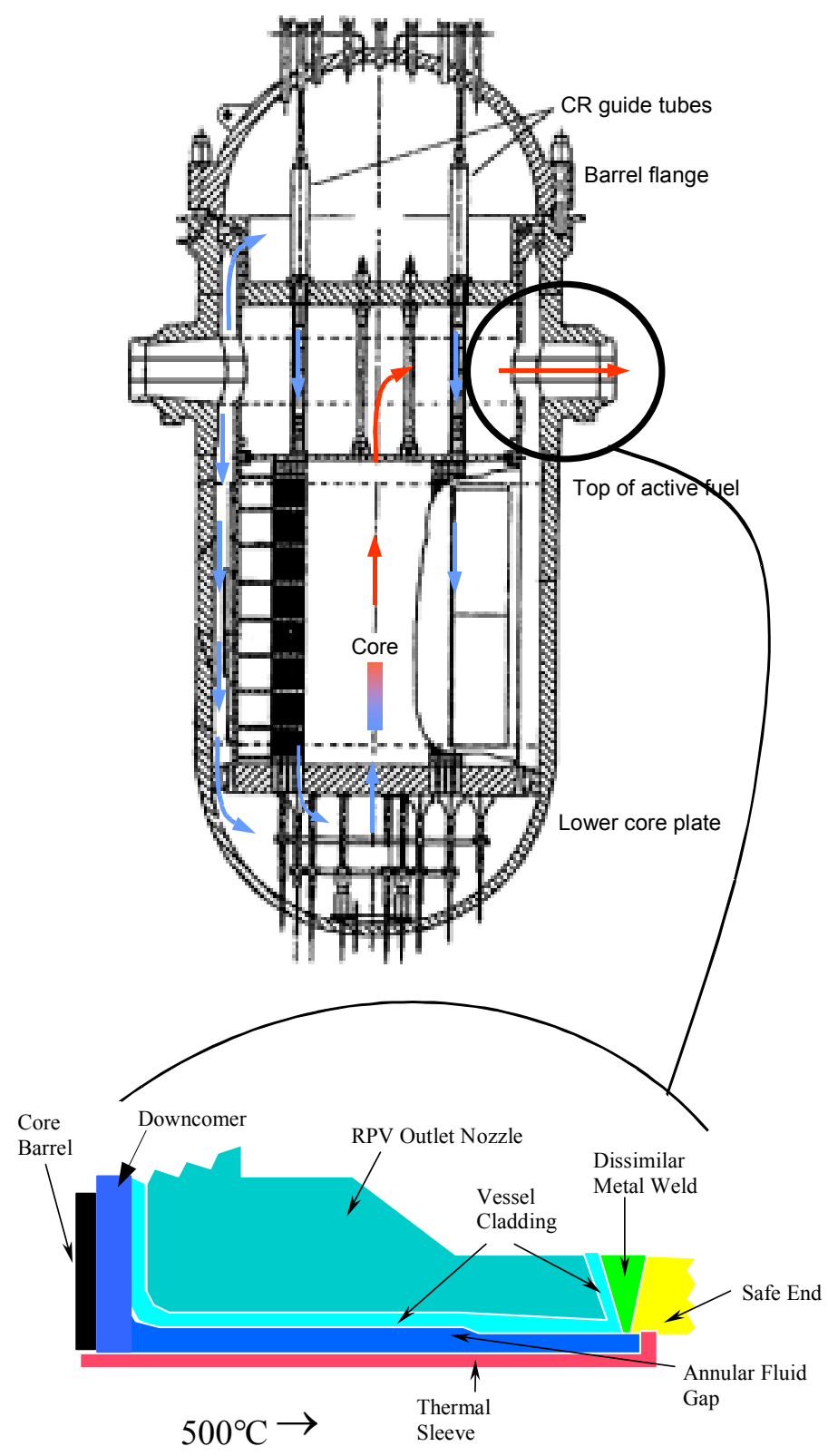

Figure 127. Schematic of SCWR reactor pressure vessel and outlet detail. sleeve and the resulting temperatures in the thermal sleeve, fluid gap and pressure vessel. The heat transfer portion of the problem is a fluid-structure interaction between the hot outlet water inside the 
thermal sleeve and the ultimate heat sink in the containment atmosphere around the reactor pressure vessel. The commercial code FLUENT provides this capability, in that solid regions are treated as fluids with zero-velocity flow fields. Previous investigations of thermal sleeve performance using FIDAP can be found in the literature (Kussmaul 1999), although here the investigation focused on conventional systems under transient conditions and the numerical models were two- rather than three-dimensional.

FLUENT is a general purpose, fluid modeling software package used by many industries. Like many commercial software packages, it has its own mesh generator (GAMBIT) but also permits meshes to be imported from other codes. In this study, meshes were generated using SDRC's I-DEAS software and then exported as "universal files" (.unv files). A complication of the problem under consideration is that it involves three separate domains: the thermal sleeve (a solid, assumed to be steel), the downcomer/annular fluid gap (supercritical water) and the reactor pressure vessel (solid, also assumed to be steel). In this study, no attempt was made to include all the elements shown at the bottom of Figure 127 as separate parts of the reactor pressure vessel. The cladding, dissimilar-metal weld, and safe end are not represented explicitly; instead, the reactor pressure vessel and all its components are represented as a single, monolithic material. The heat source is the $500{ }^{\circ} \mathrm{C}(773 \mathrm{~K})$ water inside the thermal sleeve and the ultimate heat sink is the containment atmosphere (assumed to be $300 \mathrm{~K}$ ) outside of the reactor pressure vessel. Separate meshes were generated for each of these domains, exported as .unv files, converted to FLUENT-compatible grid (.grd) files and then assembled into a single mesh (.msh) file using FLUENT utilities.

Meshes of individual domains as well as the assembled mesh are shown in Figures 128 and 129. Mesh density choices were driven by phenomena in the fluid region (Figure 128a). A standard $k$ - $\varepsilon$ turbulence model was used in the supercritical water region using FLUENT's default parameters and wall functions, but it was also important to choose a mesh density that reflected the assumptions inherent in the turbulence model and that promotes convergence in a reasonable number of iterations. This led to two important features of the fluid mesh: we preferred a mesh with hexahedral (hex) rather than tetrahedral (tet) elements, so that flow is aligned with the mesh near the boundary layer, and we wished to bias the mesh density toward the boundary layers to be consistent with the turbulence models. A detail of the mesh density in the annular fluid gap is shown in Figure 128d. Comparable biasing was employed in all sub-domains bounded by walls. A discussion of the sensitivity to mesh density and consistency with turbulence model follows in Section 5.4.4.

Because we wished to couple the thermal sleeve and reactor pressure vessel to the fluid, the solid meshes were also hex meshes and of a comparable density to those in the fluid region. FLUENT does not require the meshes to be conformal; that is, there does not have to be a one-to-one correspondence between nodes bounding the fluid and solid regions. It is possible to define coupled junctions between non-conformal meshes as long as the interfacing surfaces are reasonably simple and the mesh densities on either side of the interface are comparable. About ten separate interfacial pairs and coupled junctions were used to achieve communication between the fluid and solid regions on all overlapping surfaces.

The reference geometry shown in Figures 128 and 129 consisted of a $45^{\circ}$ circumferential segment of the system extending 50 inches $(\sim 125 \mathrm{~cm})$ above and below the hot leg outlet. The downcomer was six inches $(\sim 15 \mathrm{~cm})$ wide and the annular fluid gap was two inches $(\sim 5 \mathrm{~cm})$ thick. The thermal sleeve was one inch $(\sim 2.5 \mathrm{~cm})$ thick. The reference flow velocity of $0.86 \mathrm{~m} / \mathrm{s}$ was based on $90 \%$ of the incoming flow being diverted to the upper plenum to provide inventory for the water rods. Although the schematic at the top of Figure 127 illustrates an immediate diversion of cold leg water to the upper plenum, our results assume that inlet water at $280^{\circ} \mathrm{C}$ is first diverted circumferentially $90^{\circ}$ around the vessel, and that this inlet water then flows into the annular fluid gap before being directed into the water rods. 


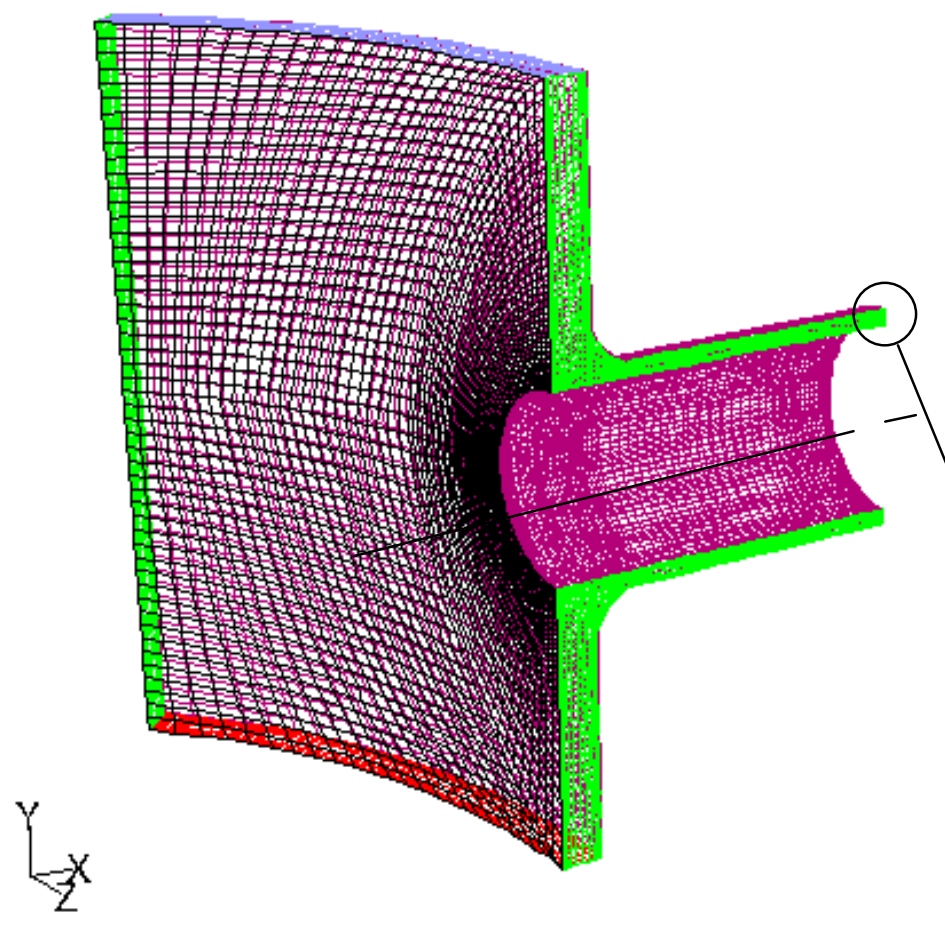

(a)

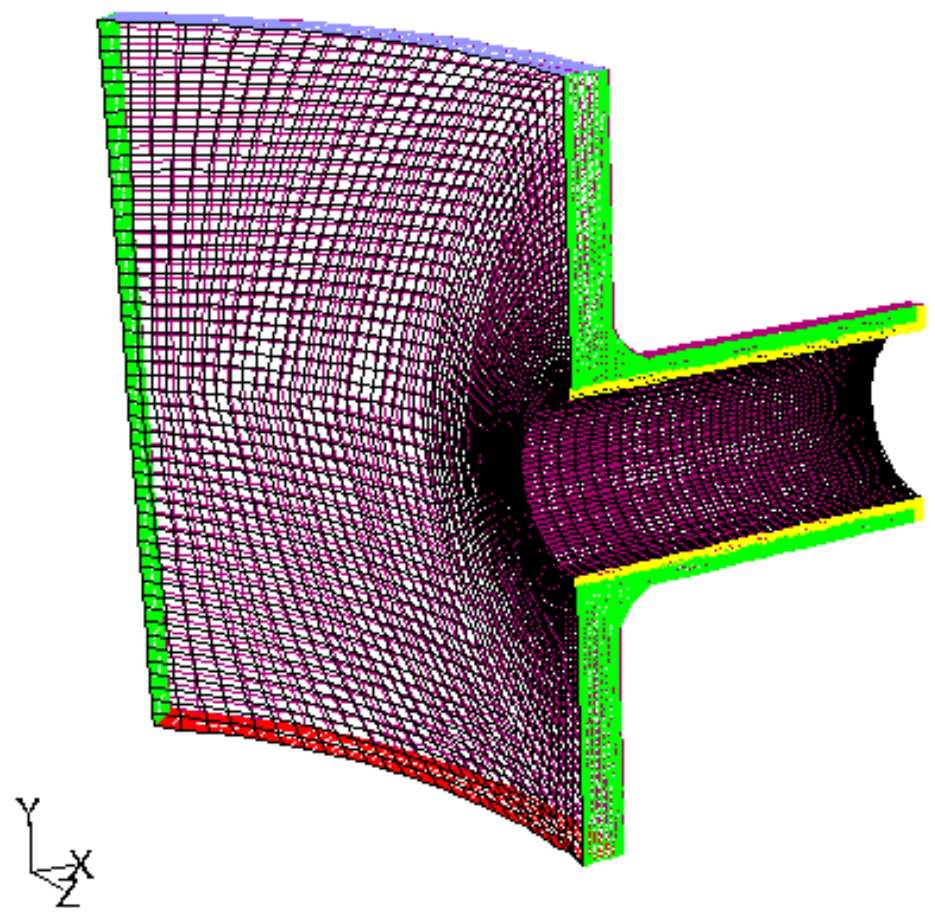

(c)

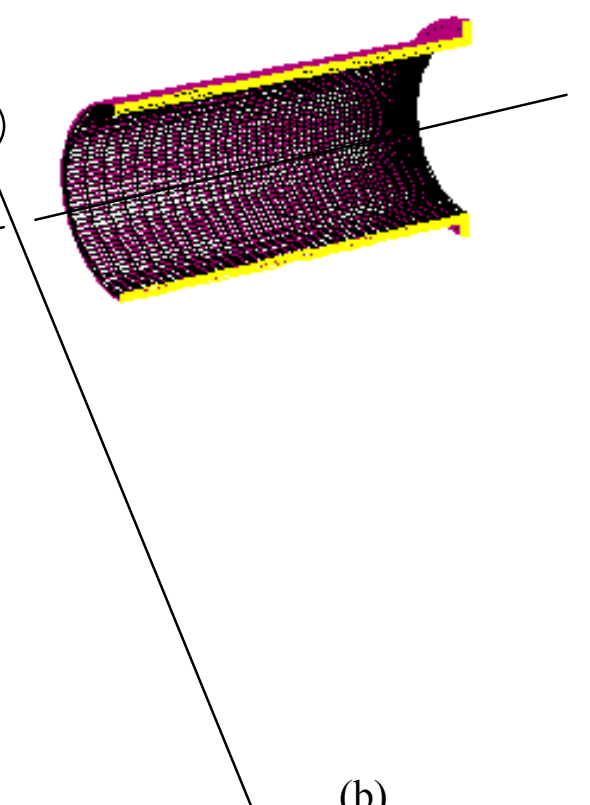

(b)

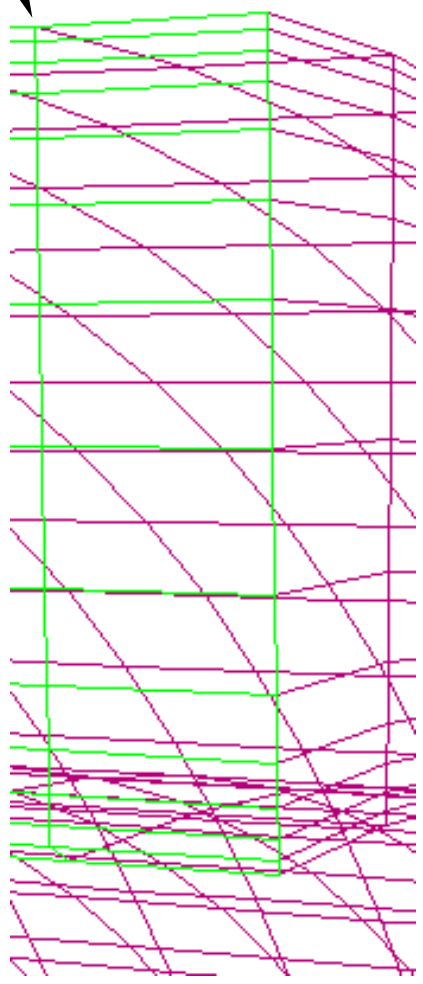

(d)

Figure 128: Meshed domains of the (a) downcomer/annular fluid gap; (b) thermal sleeve; (c) downcomer/fluid gap/thermal sleeve assembly; (d) mesh density detail at the end of the fluid gap. The relationship to the reactor pressure vessel and complete assembly is shown in Figure 129. 


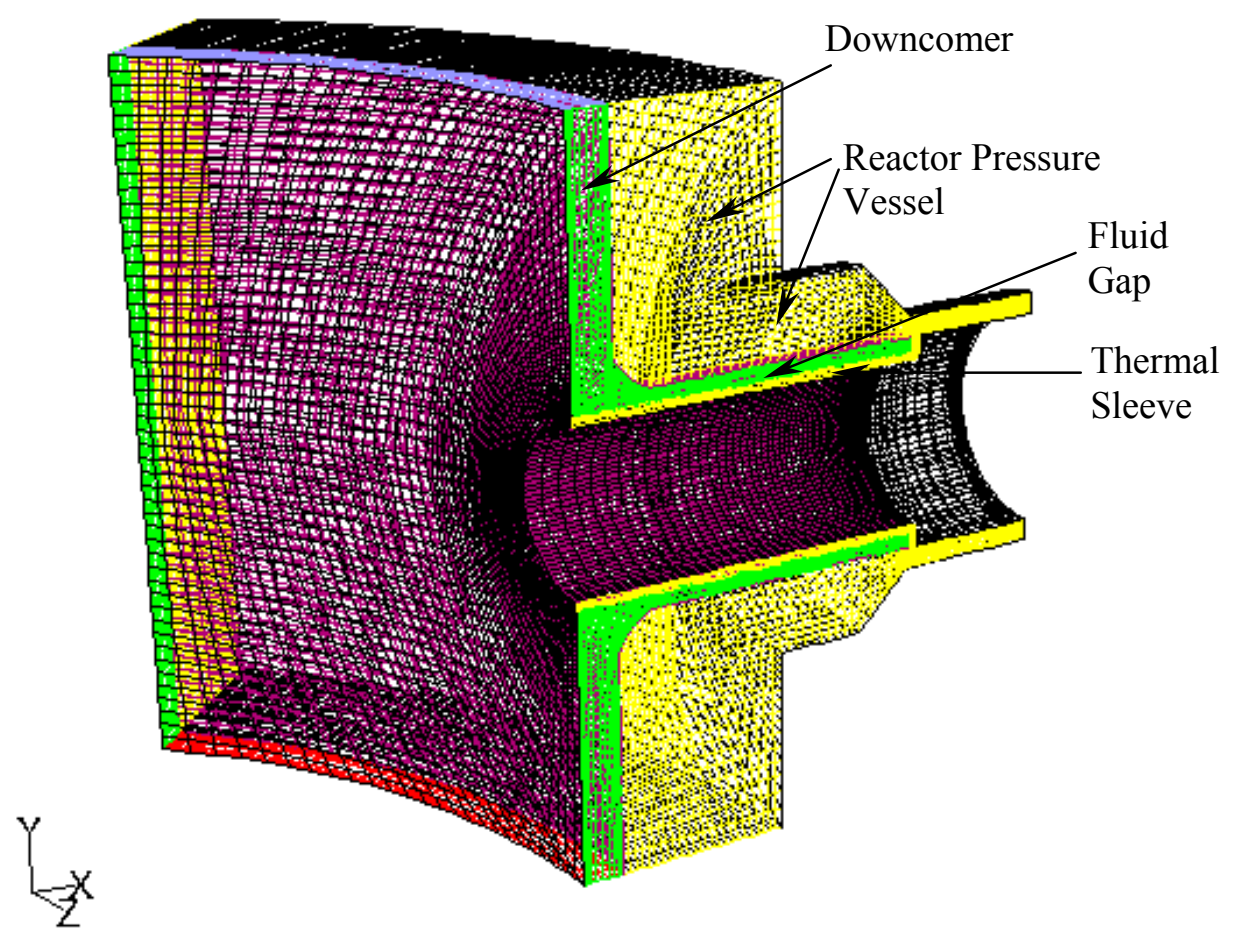

\section{Figure 129: Assembled mesh showing downcomer/annular fluid gap sandwiched between the thermal sleeve and reactor pressure vessel}

Issues to be investigated in the design of the thermal sleeve/fluid gap include the effect of different mass flow-rates, the effect of flow approaching the annular gap from different directions, and the size of the annular gap. The reference speed of $0.86 \mathrm{~m} / \mathrm{s}$ is based on a uniform circumferential dispersal of incoming cold leg water in the axial direction. If a greater flow-rate were to be required to achieve the desired isolation, then baffling would have to be required to ensure a larger local flow-rate in the vicinity of the hot leg. The reference geometry (Figure 127) of the whole pressure vessel includes inlet and outlet nozzles at the same elevation. This suggests a boundary condition involving cold water entering from the side of the model. Investigating the sensitivity of results to incoming flow from the top, bottom, and side of the model provided insight into the implications of positioning inlet nozzles above, below or at the same elevation as the outlet nozzles. Finally, for a fixed outlet nozzle diameter, a larger annular fluid gap provides a more restrictive area inside the thermal sleeve, which in turn affects the hydraulic resistance of the whole circuit. The implication of choosing a smaller gap needs to be assessed. In all cases, the goal is to prevent any portion of the pressure vessel from experiencing temperatures in excess of $371{ }^{\circ} \mathrm{C}(644 \mathrm{~K})$.

Boundary conditions vary depending on the inlet conditions (flow entering from top, bottom, or side of the model.) The surface colors displayed in Figures 128 and 129, explained below, are appropriate for flow entering from the top of the downcomer. Yellow and green surfaces denote symmetry planes. The light blue surface at the top of the downcomer in Figure 128a indicates a velocity inlet condition, while the red surface at the bottom indicates a pressure outlet condition. The purple surfaces are interfaces coupled to other parts of the model. Black surfaces indicate walls; these are either treated as insulated surfaces or coupled to the heat source or sink in the model. Flow from the bottom simply involves reversal of the inlet and outlet surfaces. Flow from the side changes the downcomer boundary conditions 
substantially, with the lower half of the far symmetry plane becoming an inlet, and the bottom surface becoming a wall.

Heat transfer from the hot leg water $(773 \mathrm{~K})$ to the inner surface of the thermal sleeve is evaluated using the Dittus-Boelter correlation, which is appropriate since the core outlet state is far above the critical temperature. The heat transfer coefficient is calculated to be $7440 \mathrm{~W} / \mathrm{m}^{2} \cdot \mathrm{K}$ for the reference geometry shown in Figures 128 and 129. The heat transfer coefficient between the cylindrical part of the pressure vessel and the containment atmosphere $(300 \mathrm{~K})$ is taken to be $1 \mathrm{~W} / \mathrm{m}^{2} \cdot \mathrm{K}$, while the heat transfer coefficient between the nozzles and the containment atmosphere is taken to be $5 \mathrm{~W} / \mathrm{m}^{2} \cdot \mathrm{K}$. The latter values are consistent with an insulated cylindrical vessel and the generally poor heat transfer within containment. The inner vertical surface of the downcomer adjacent to the core barrel is assumed insulated.

FLUENT enables a set of operating conditions to be established as part of the model. In this investigation, gravity was enabled in the $-Y$ direction (see coordinate system orientation in Figure 128a) at $9.81 \mathrm{~m} / \mathrm{s}^{2}$. Once enabled, buoyancy driven turbulence was also enabled in the viscous model. Material properties of the steel used to model the thermal sleeve and reactor pressure vessel were taken from FLUENT's internal library. The steel is assumed to have a constant thermal conductivity of $k_{s}=16.3$ $\mathrm{W} / \mathrm{m} \cdot \mathrm{K}$.
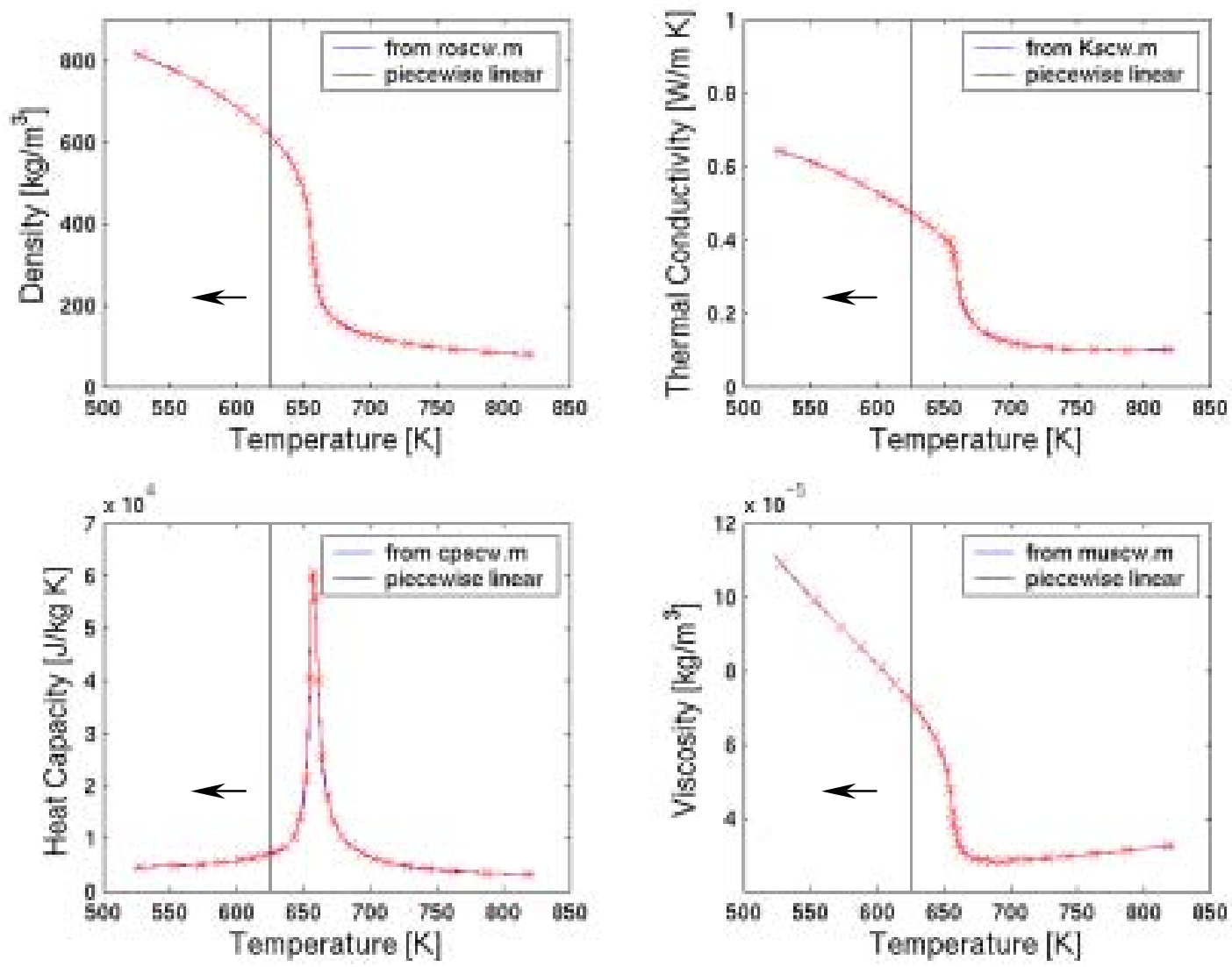

Figure 130: Piecewise Linear Representation of SCW Properties at 25 MPa 
A fluid material is created during model construction to model the properties of supercritical water. FLUENT has many options for modeling temperature-dependent properties, including a piecewise-linear option with up to 30 data points. This option was found to be most effective with data points clustered about the pseudo-critical temperature of $385^{\circ} \mathrm{C}(658 \mathrm{~K})$. Figure 130 illustrates plots of these properties as well as the piecewise-linear representation employed in the model. The solid blue lines are plots of the properties generated from Matlab scripts based on interpolation from ASME steam tables in $1 \mathrm{~K}$ temperature increments at $25 \mathrm{MPa}$. The fact that those blue lines are barely visible indicates the piecewise linear representation over the much coarser temperature set of 30 points is an excellent model of the properties. For this particular application of supercritical water, the fluid in the annular gap is mostly at a temperature far below the pseudo-critical temperature, where property variations with temperature are relatively modest. This has important implications for the choice of turbulence model as discussed in Section 5.4.4. It should also be mentioned that FLUENT requires the piecewise representation of properties in $\mathrm{K}$, so the simulations and all results presented in this work are in $\mathrm{K}$, not ${ }^{\circ} \mathrm{C}$ or ${ }^{\circ} \mathrm{F}$.

The flow field was initialized based on inlet conditions (specified velocity at $553 \mathrm{~K}$ ). FLUENT's coupled, implicit, single precision 3D solver was used to advance the solution. Convergence was deemed to have occurred if all seven scaled residuals (continuity, energy, $x$ - $y$-and $z$-velocity components, $k$ and $\varepsilon$ turbulence parameters) fell below the default value of $10^{-3}$. In addition, mass fluxes at the inlet and outlet could be compared to verify that inflow equaled outflow to within some acceptable error (less than $0.5 \%$ difference, and often less than that).

\subsubsection{FLUENT Results}

An array of cases and results is shown in Table 44 for the two-inch annular gap. Results vary with orientation of incoming flow and mass flow rate. The \% flow is incorporated by changing the velocity on the velocity-inlet surface; a case at $50 \%$ of total flow, for instance, corresponds to an inlet velocity of $0.5 \times 0.86 \mathrm{~m} / \mathrm{s}=0.43$ $\mathrm{m} / \mathrm{s}$. Results discussed below are organized into sections by flow orientation.

In most cases, a converged solution was obtained in $500 \sim 1500$ iterations and this is designated as

Table 44. Summary of Results/Peak Vessel Temperatures for Two-Inch Annular Gap

\begin{tabular}{|c|c|c|c|}
\hline & From Top & From Bottom & From Side \\
\hline $100 \%$ Flow & CVG & CVG & CC \\
& $305^{\circ} \mathrm{C}$ & $293^{\circ} \mathrm{C}$ & $290^{\circ} \mathrm{C}$ \\
\hline $50 \%$ Flow & DIV & CVG & CVG \\
& & $293^{\circ} \mathrm{C}$ & $293^{\circ} \mathrm{C}$ \\
\hline $25 \%$ Flow & DIV & $\mathrm{CVG}$ & $\mathrm{CVG}$ \\
& & $293^{\circ} \mathrm{C}$ & $293^{\circ} \mathrm{C}$ \\
\hline
\end{tabular}

CVG. However, some cases

diverged (DIV) and some

"conditionally converged" (CC). Conditional convergence is defined as having occurred if the scaled residuals fall to some small value (several may be below the $10^{-3}$ threshold) but do not all fall below the target value of $10^{-3}$. In these cases, one or more residuals also exhibit a clearly defined oscillatory structure with number of iterations, suggesting some periodic behavior preventing convergence. In these cases it can be shown that failure to completely converge is linked to some physical behavior. Indeed, it appears that the conditionally converged cases correspond to steady, oscillatory solutions rather than steady, constant solutions, though the frequency of such oscillations could only be determined with unsteady simulations. In the diverged cases, scaled residuals may initially fall but eventually "blow up" in a wildly unstable way. However, there are still insights to be gleaned from these cases in the direction 
the solution takes before it becomes unstable. For those cases that either converge or conditionally converge, the number provided in Table 44 is the peak reactor pressure vessel temperature adjacent to the supercritical water. In all converged solutions, the peak vessel temperature is at or below the desired value of $644 \mathrm{~K}\left(371^{\circ} \mathrm{C}\right)$.

\subsubsection{Forced Flow From The Top}

Although it is not the recommended solution, it is instructive first to look at those cases where flow enters from the top. These cases are representative of a more traditional PWR where inlet flow is directed to the lower plenum, rather than upward to water rods. Table 44 indicates that we obtain convergence for $100 \%$ of flow from the top, but diverge at $50 \%$ and $25 \%$ flow. Figure 131 illustrates the flow field inside the annular fluid gap for the $100 \%$ flow case.

Forced flow from the top penetrates about half the length of the annular gap, but penetration recedes as the flow navigates the circumference of the thermal sleeve. A second, countercurrent, buoyancy driven cell develops at the far end of the annulus. Peak flow speeds in the buoyancy driven cell are on the order of $40 \mathrm{~cm} / \mathrm{s}$, drawing energy from the bottom of the annulus. A stagnation region develops at the top, center of the annulus where forced flow penetrating from the outside meets buoyancy driven flow from within the annulus.

The fluid temperature distribution in the annulus is shown in Figure 132. Note that the scale here ranges from 533 $\mathrm{K}\left(260{ }^{\circ} \mathrm{C}\right)$ to $653 \mathrm{~K}\left(380{ }^{\circ} \mathrm{C}\right)$. Peak fluid temperature adjacent to the thermal sleeve occurs at the center of the buoyancy driven cell and is about $623 \mathrm{~K}$ $\left(350{ }^{\circ} \mathrm{C}\right)$. Figure 133a shows the temperature distribution in the reactor pressure vessel adjacent to the fluid gap and so provides the distribution of peak vessel temperatures to be compared to the limit of $644 \mathrm{~K}$.

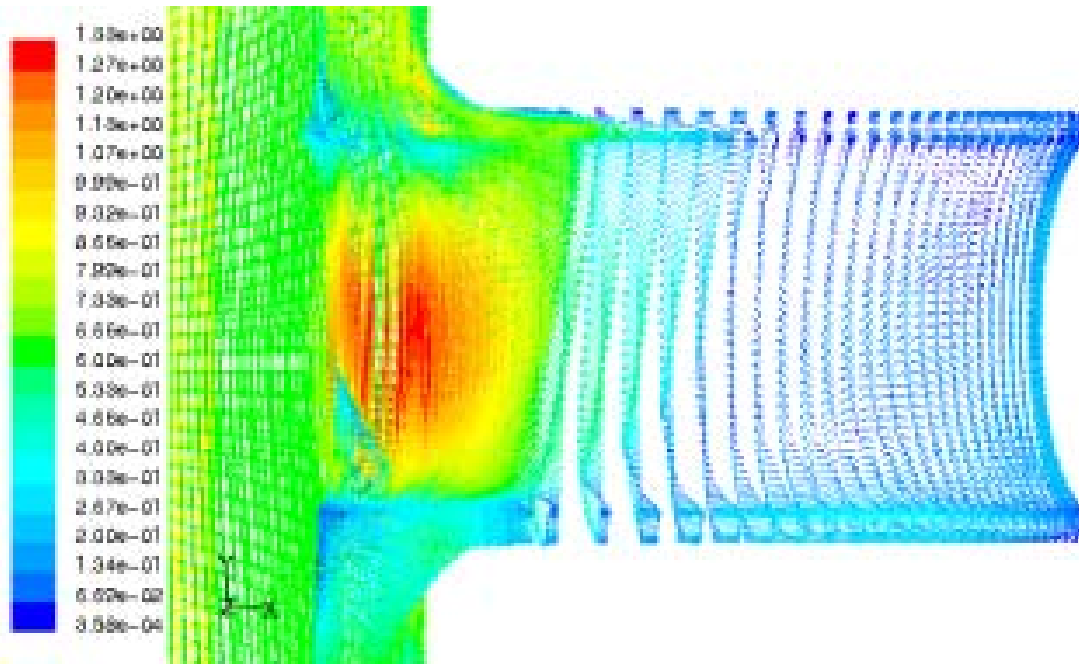

Figure 131. Detail of velocity field $[\mathrm{m} / \mathrm{s}]$ in the annular fluid gap: $100 \%$ flow from the top of the downcomer.

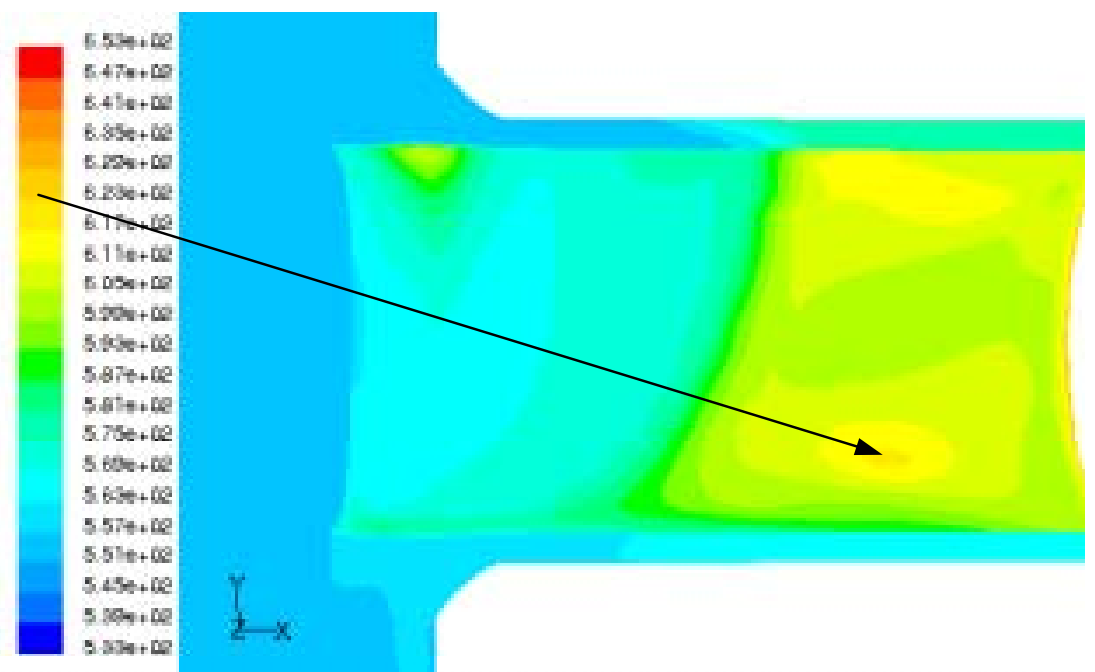

Figure 132. Fluid temperature $[\mathrm{K}]$ inside the annular fluid gap: $100 \%$ flow from the top of the downcomer. This is also the temperature distribution on the outside of the thermal sleeve. 
in Figure 133a has been adjusted to emphasize features of the vessel temperature distribution adjacent to the supercritical water. Temperatures in the hot leg approach $773 \mathrm{~K}$ and are better appreciated by the plot in Figure 133b.

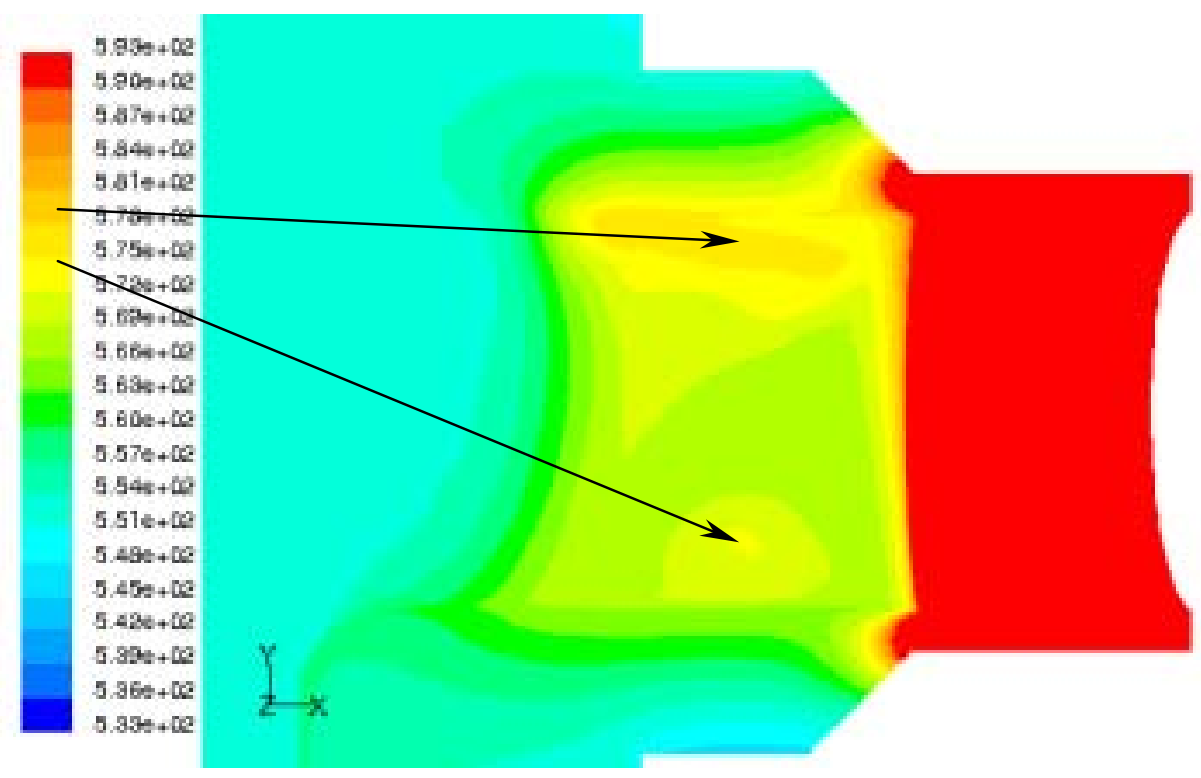

(a) Temperature Distribution on reactor pressure vessel inner surface/outer surface of annular fluid gap

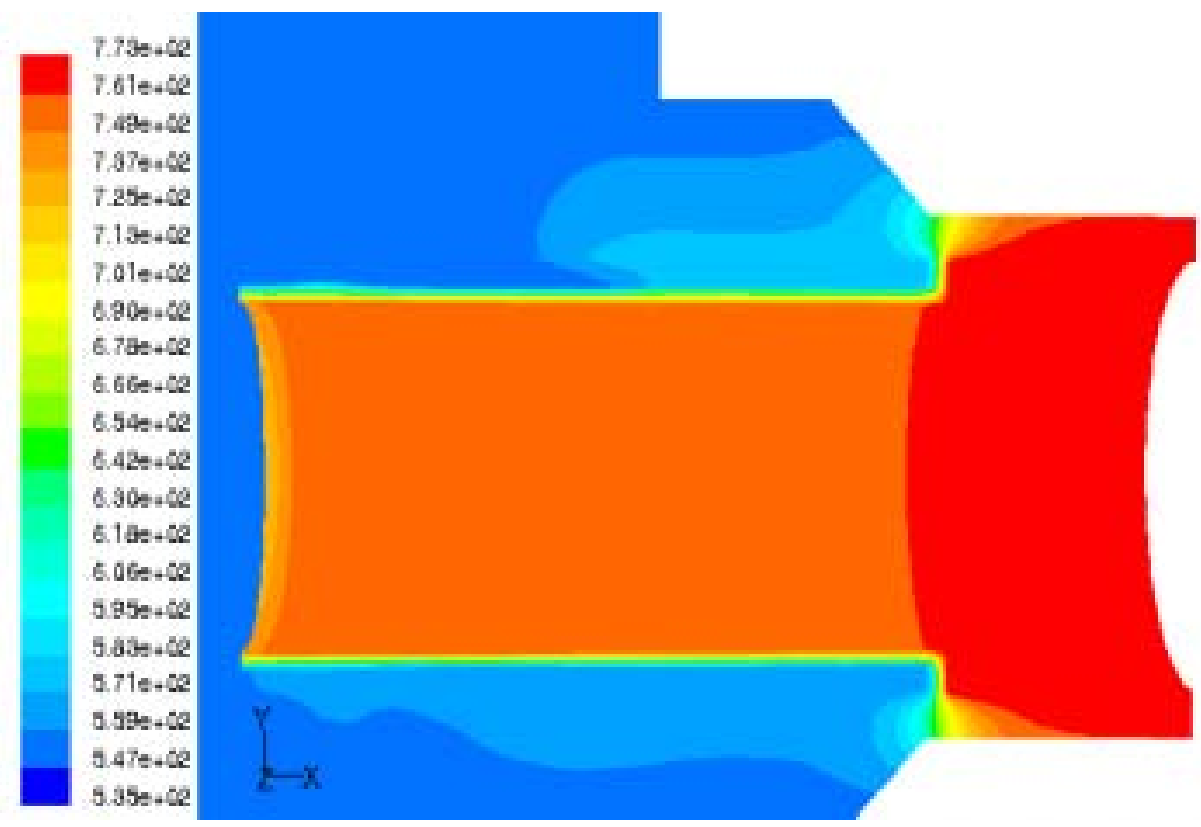

(b) Temperature field in assembled domain: thermal sleeve, annular fluid gap and reactor pressure vessel

Figure 133. Temperature fields $[\mathrm{K}]$ in components. In (a), the temperature scale is adjusted to emphasize features of the vessel temperature distribution adjacent to the supercritical fluid.

Because the heat transfer coefficient on the inside of the thermal sleeve is high $\left(7440 \mathrm{~W} / \mathrm{m}^{2} \cdot \mathrm{K}\right)$, temperatures on the thermal sleeve's inner surface are only a few degrees below the outlet temperature at 
$750 \sim 760 \mathrm{~K}\left(477 \sim 487^{\circ} \mathrm{C}\right)$ as shown in Figure 133b. The temperature distribution on the outside of the thermal sleeve varies considerably, as shown in Figure 132, but a representative outer surface temperature is $590 \mathrm{~K}\left(317^{\circ} \mathrm{C}\right)$, producing an average temperature drop across the sleeve of $165^{\circ} \mathrm{C}$. The average heat flux across the sleeve is:

$$
\mathrm{q} "=-\mathrm{k}(\mathrm{dT} / \mathrm{dr})=-16.3 \mathrm{~W} / \mathrm{m} \cdot \mathrm{K} \times(-165 \mathrm{~K} / 1 \mathrm{inch}) \times(1 \mathrm{inch} / 0.0254 \mathrm{~m})=1.06 \times 10^{5} \mathrm{~W} / \mathrm{m}^{2} .
$$

Total heat loss across all surfaces (the cylindrical section of the thermal sleeve dominates) can be obtained from FLUENT's Report Utility and is about $0.15 \mathrm{MW}$.

There are two local fluid hot spots adjacent to the reactor pressure vessel. The cooler hot spot is also centered about the buoyancy driven flow, opposite to the comparable hot spot on the thermal sleeve, and equal to $572 \sim 575 \mathrm{~K}\left(299 \sim 302{ }^{\circ} \mathrm{C}\right)$. The hotter hot spot is at the top of the annulus in the stagnation region and is $575 \sim 578 \mathrm{~K}\left(302 \sim 305{ }^{\circ} \mathrm{C}\right)$. The $305{ }^{\circ} \mathrm{C}$ is therefore recorded in Table 44 as the maximum pressure vessel temperature experienced as a result of this configuration and magnitude of flow.

Figure 133b illustrates that there are some portions of structure that experience temperatures well in excess of the desired temperature limit, but this is due to direct contact between hot outlet water and hot leg piping as well as heat conduction between the thermal sleeve flange and the safe end. In the latter instance, Figure 133b illustrates that this region of elevated temperature is highly localized and persists over a length scale equal to a few widths of the sleeve flange. In assembling the reactor pressure vessel to system piping, we simply note that the distance between dissimilar metal weld and safe end joining with the thermal sleeve flange (see Figure 127) must be the thickness of at least several flanges.

Before describing the evolution of diverging results at $50 \%$ and $25 \%$ of total flow, it is instructive to consider an intermediate case (not shown in Table 44) at $75 \%$ of total flow. This case qualifies as one of "conditional convergence," and the mechanism that contributes to this oscillatory convergence is described with the aid of frames in Figure 134. These frames show temperature fields in the annular fluid gap at sequential iterations within one complete cycle of fluctuating scaled residuals once the solution has settled into a predictable pattern after $\sim 2000$ iterations.

The source of the problem in this case is the forced flow's inability to navigate the entire circumference of the thermal sleeve without returning to the downcomer. A vortex is induced at the bottom junction of annulus and downcomer in the $+Y$ direction, and its circulation draws some flow away from the inner annulus. The vortex is clear in a plot of the velocity field and can be seen in the temperature contour islands at the bottom junction of annulus and downcomer in Figure 134.

The oscillatory nature of the field results from the tug of war between this vortex and buoyancy induced flow in the annulus. In Figure 134a, the vortex "wins" and produces a stagnation zone at the middle bottom of the annulus. This stagnation zone heats up in subsequent iterations, Figure 134b, until the buoyancy force becomes large enough to overcome the vortex strength. Fluid moves from the bottom to the top of the annulus and the local hot spot gravitates towards the outer end of the bottom annulus (Figure 134c and 134d). As fluid from the bottom annulus moves out of the way, forced flow from the top is temporarily able to penetrate further into the annulus and the vortex strength is temporarily suppressed. This is not sustainable, however, and as local buoyancy induced flow from bottom to top is diminished, the forced flow returns to its original pattern and the vortex is re-established (Figures 134d, 134e and 134f). Iteration 2170 (not shown) looks virtually identical to iteration 2012, and the pattern repeats itself. Note that, despite these changing local features, the peak temperature adjacent to the vessel at the top of the annulus remains virtually constant and is $587 \sim 593 \mathrm{~K}\left(314 \sim 320^{\circ} \mathrm{C}\right)$. 


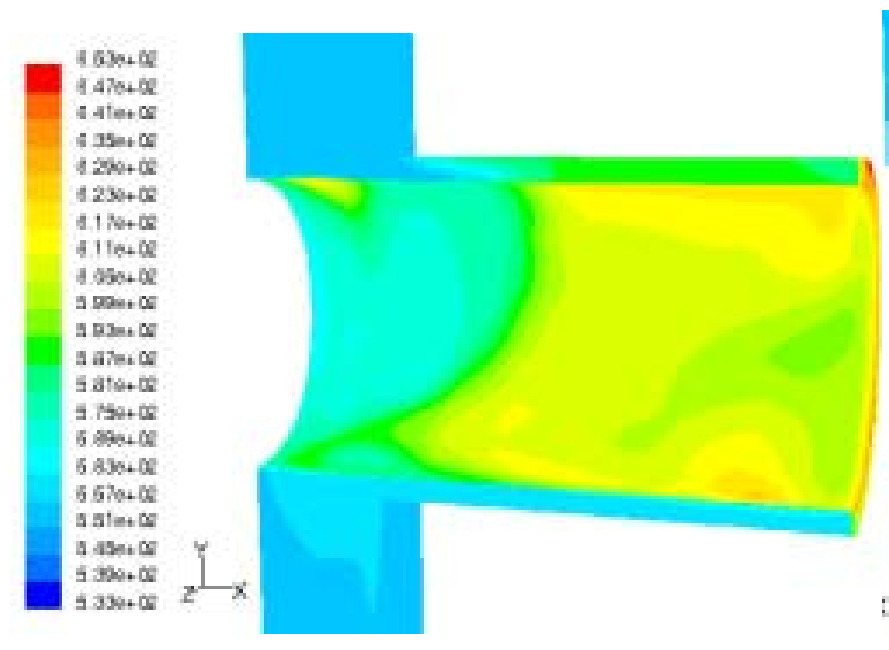

(a) Iteration 2012

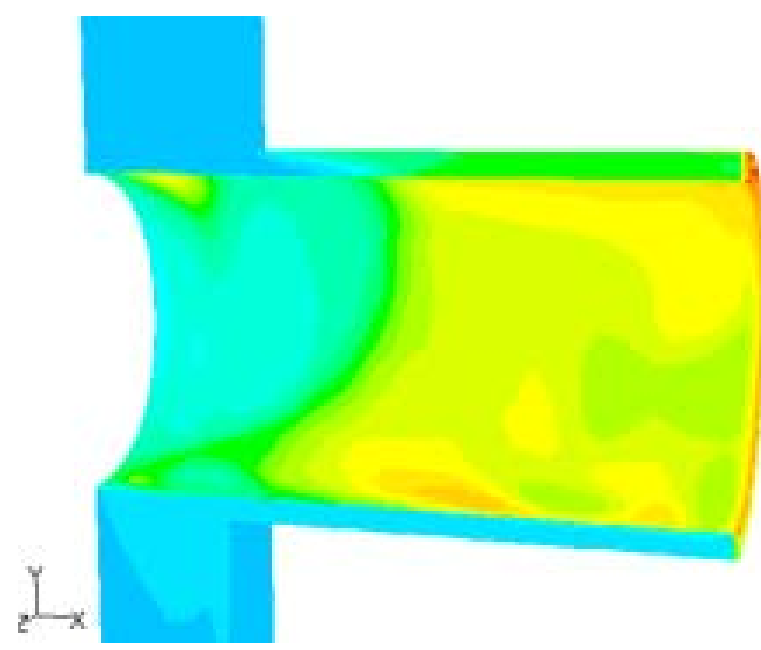

(c) Iteration 2050

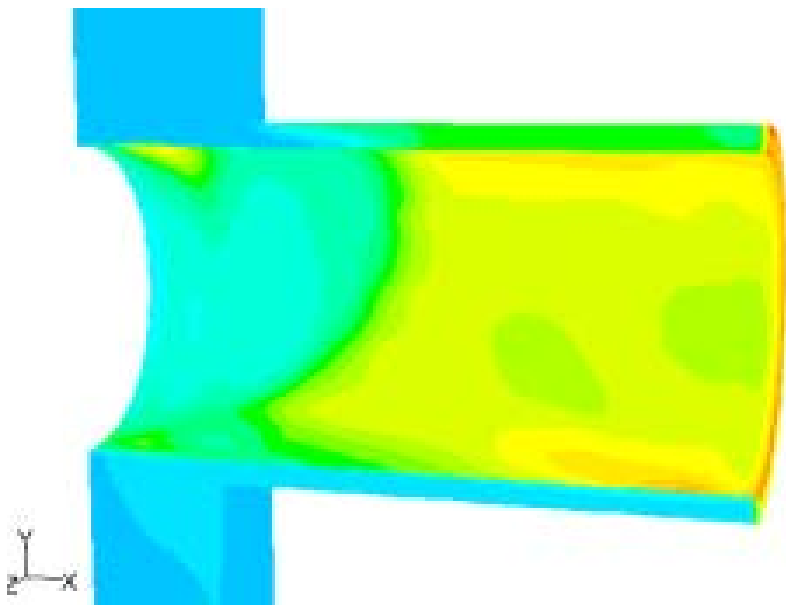

(e) Iteration 2121

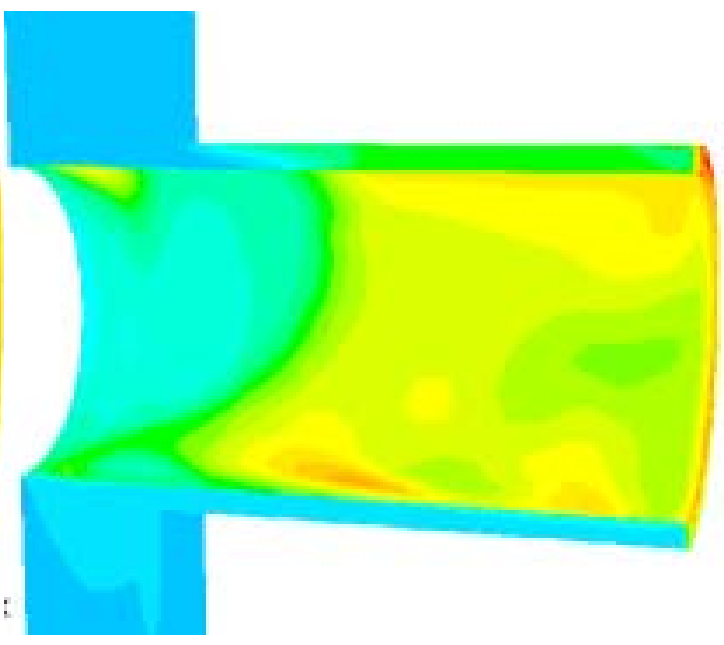

(b) Iteration 2028

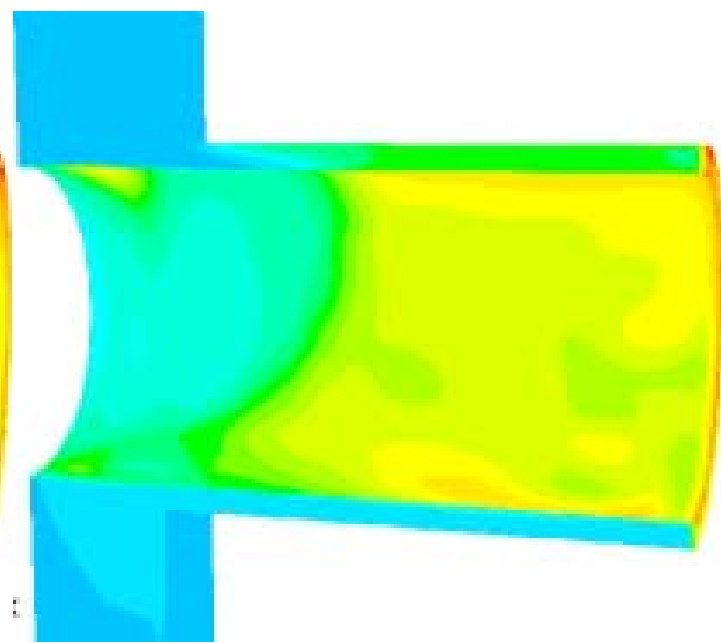

(d) Iteration 2083

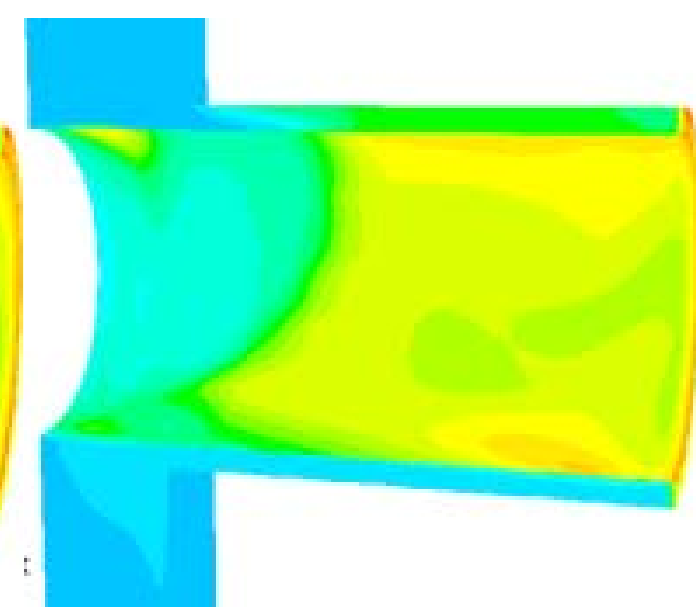

(f) Iteration 2139

Figure 134. Evolution of temperature field $[\mathrm{K}]$ in annular fluid gap for the conditionally converged case of $75 \%$ of total flow from the top. 
Seeing the behavior at $75 \%$ of full flow makes it easier to understand why the solution diverges at lower flow-rates. At $50 \%$ of full flow, for instance, the forced flow is only able to navigate a portion of the thermal sleeve circumference before returning to the downcomer. The buoyancy induced flow in the annulus begins drawing flow from the bottom regions of the downcomer, eventually producing flow reversal warnings at the pressure-outlet boundary at the bottom. Shortly after this occurs, the solution begins to diverge, producing unphysical results. The strength of forced convection in this case is unable to overcome the strength of natural convection. It may be more accurate to say that a solution to these problems (low flow from the top) may exist, but not with the relatively simple inlet and outlet boundary conditions envisioned in these models.

\subsubsection{Forced Flow From The Bottom}

Of course, one other conclusion to be drawn from these results is that aligning forced convection countercurrent to natural convection is not a particularly good idea. On the other hand, positioning outlet nozzles above inlet nozzles and creating internal flow paths that direct inlet water up and around the annular fluid gap reinforces natural convection and is also consistent with the eventual delivery of fluid to the water rod inlets. Not surprisingly, the results in Table 44 indicate that under these circumstances, the solution converges for all three cases and that peak fluid temperatures adjacent to the reactor vessel are low and insensitive to the forced convection flow-rate. Velocity and temperature fields in the annular fluid gap for 100\% flow from the bottom are shown in Figures 135 and 136.

Figure 135 shows that the flow pattern within the annulus consists of a single convection cell, in contrast to the two countercurrent cells in Figure 131. Because forced convection reinforces natural convection, no stagnation zone of any significance exists in the annulus and temperatures on both the inner and outer surfaces of the fluid region are lower than those in Figure 132.

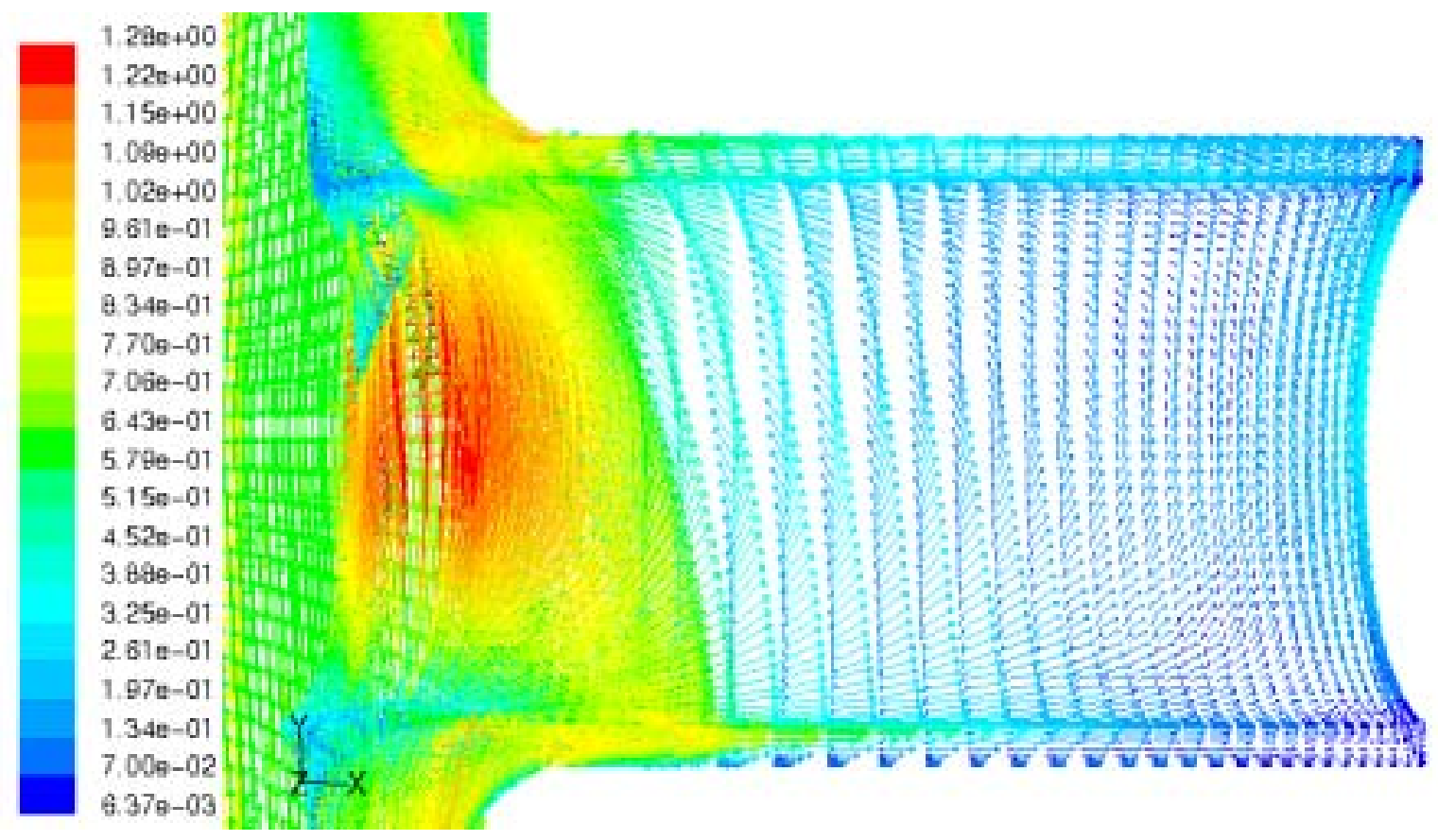

Figure 135. Detail of velocity field [m/s] in the annular fluid gap: $100 \%$ flow from the bottom of the downcomer. 


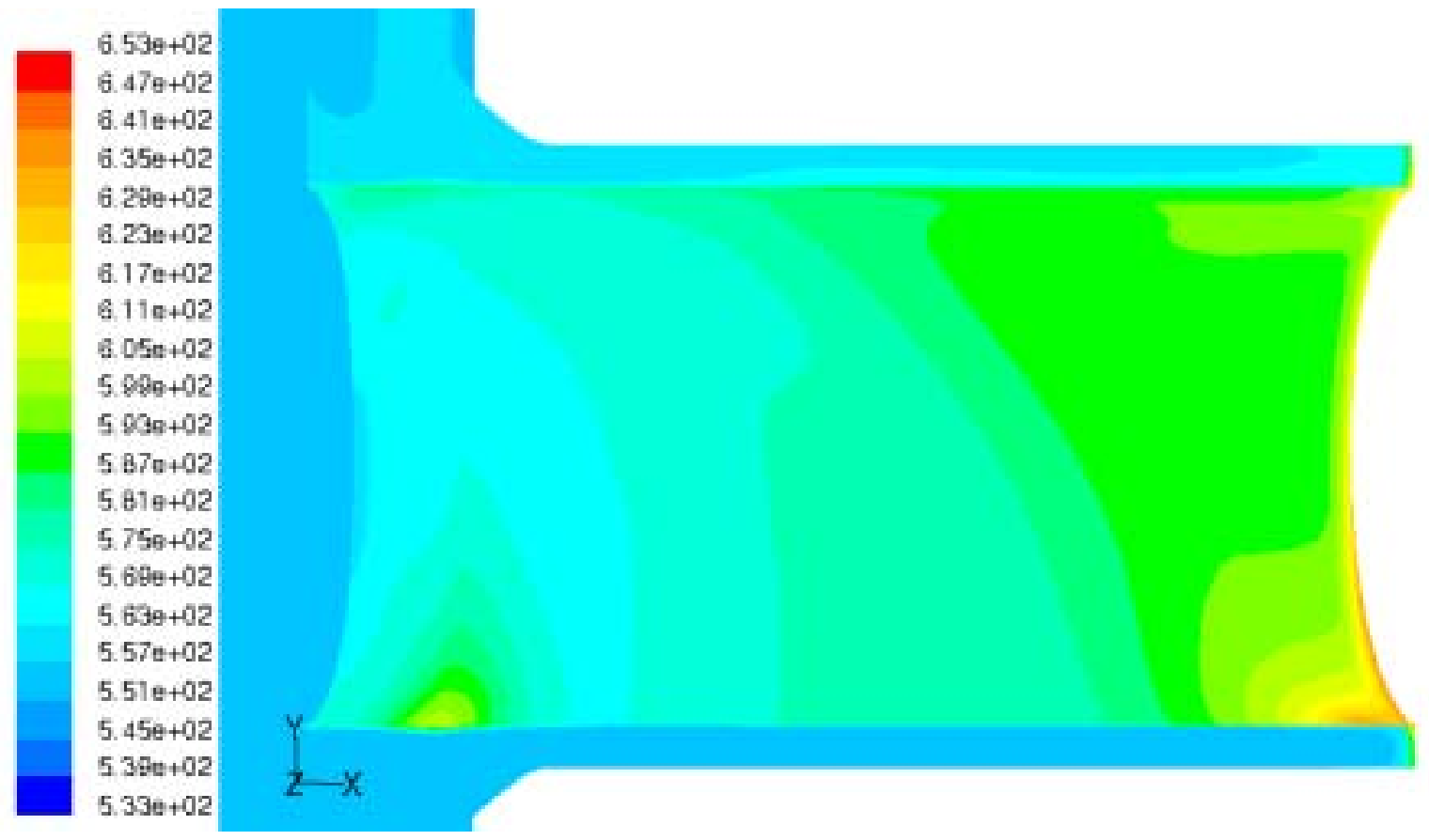

Figure 136. Fluid temperature [K] inside the annular gap: $100 \%$ flow from the bottom of the downcomer.

The one exception to this is the hot spot at the far bottom of the annulus, but this is highly localized. Peak fluid temperatures adjacent to the reactor pressure vessel occur at the top center of the annulus and are $563 \sim 566 \mathrm{~K}\left(290 \sim 293{ }^{\circ} \mathrm{C}\right)$.

The annular velocity field and peak vessel temperature for the cases at $50 \%$ and $25 \%$ of full flow from the bottom are nearly identical to those at $100 \%$ of full flow. The contour band corresponding to peak vessel temperature expands and shifts a bit compared to the $100 \%$ of full flow case, but peak temperatures do not exceed $293{ }^{\circ} \mathrm{C}$. This method of cooling the thermal sleeve appears to be the best choice because the resulting annular flow field is simple and peak vessel temperatures are insensitive to mass flow-rate.

\subsubsection{Forced Flow From The Side}

The only complication with flow approaching the thermal sleeve from the bottom is that it requires outlet nozzles to be positioned above inlet nozzles. The traditional choice, as shown in Figure 127, has the nozzles positioned at identical elevations, which implies flow approaching the thermal sleeve from the side. This also requires a change in boundary conditions. Figure 137 illustrates the velocity field in the whole domain as well as a detail of the annular region for the case of $100 \%$ flow from the side. (Note: the flow velocity for $100 \%$ flow from the side is not as well defined as the cases of $100 \%$ flow from the top or bottom, where the inlet velocity of $0.86 \mathrm{~m} / \mathrm{s}$ is calculated from uniform circumferential dispersal in the axial direction of the $90 \%$ of total flow that is directed to the upper plenum. However, the flow velocity at $100 \%$ of full flow from the side is still taken to be $0.86 \mathrm{~m} / \mathrm{s}$ in these cases and fractional flow cases refer to fractional values of $0.86 \mathrm{~m} / \mathrm{s}$.) 

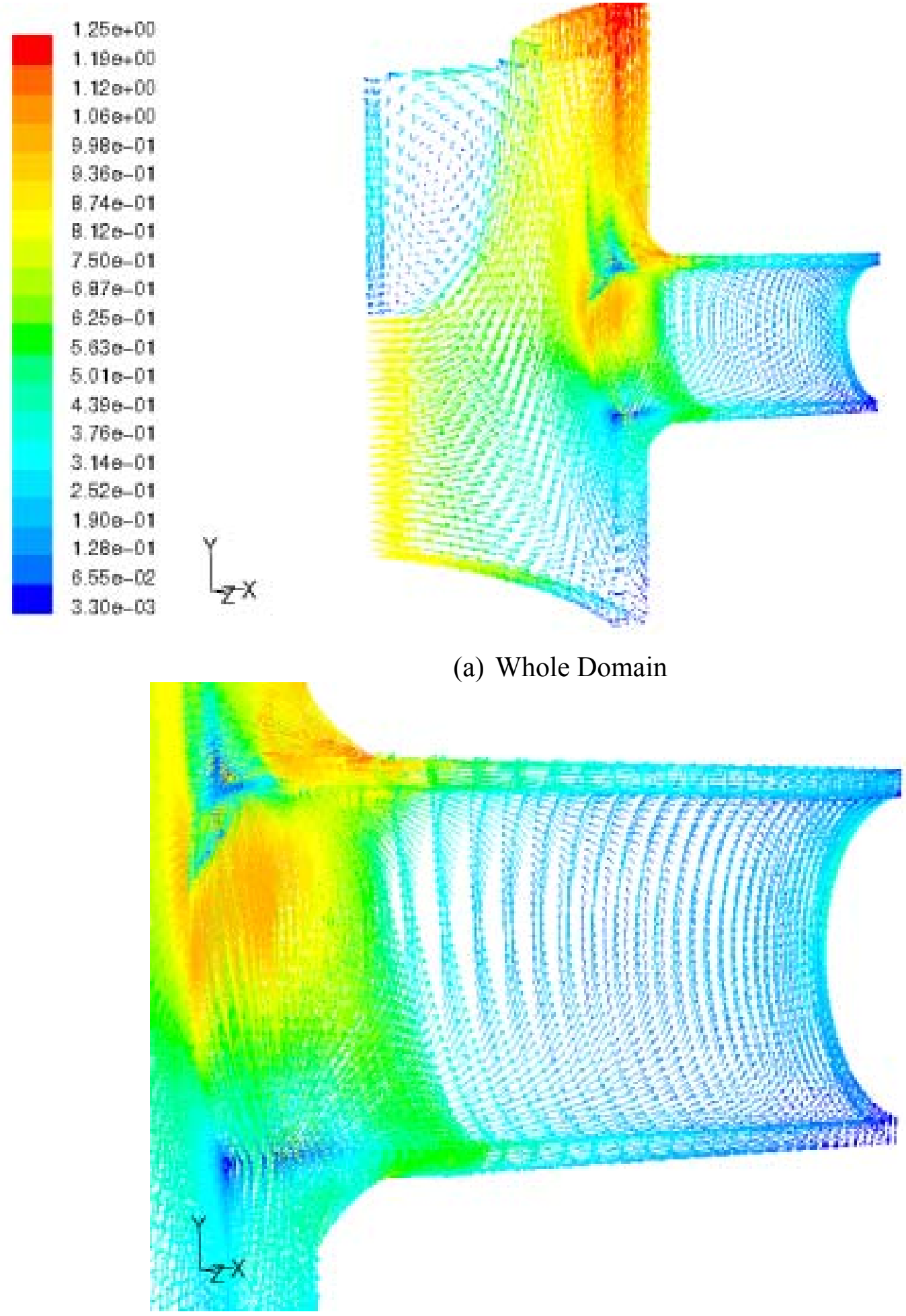

(b) Annular Region

Figure 137. Velocity field [m/s] in fluid: $100 \%$ flow from the side. 
Figure 137a shows a recirculation zone in the far, upper region of the problem domain. Initial attempts to solve this set of problems involved converting the entire far symmetry plane to a velocity inlet condition while keeping the top surface a pressure outlet condition. Under these circumstances, the inlet and outlet surfaces share a common edge, and these models did not perform well. By converting the upper half of the far symmetry plane and the far half of the top surface into wall boundary conditions, inlet and outlet are sufficiently removed and a solution evolves more easily.

The bottom surface of the downcomer is converted to a wall condition, so all flow in and around the thermal sleeve is eventually forced upward. The symmetry plane at the nozzle remains a symmetry plane, since flow is brought to the outlet nozzle from identical inlet nozzles on either side of it. In some respects, flow from the side resembles a very low flow case of flow from the bottom. Since a stagnation zone is created below the thermal sleeve from the two inlet nozzle streams meeting in the middle, a large portion of the flow enters the annular region from the bottom at low flow speeds. In fact, inspection of the detail in Figure 137b shows the same single, large convection cell in the annular region as is seen in Figure 135.

Despite this similarity, this case is seen in Table 44 to be classified as conditionally converged. Figure 138 illustrates the evolution of the temperature field in the annulus over one complete cycle of fluctuating residuals after the solution settles into a predictable pattern $\sim 2000$ iterations into the solution. Similar to the case in Figure 136, there is a hot spot at the bottom, far end of the annulus, but the hot spot in this case is slightly larger and is the source of the oscillatory feature. As this region heats up (Figures 138a, 138b and 138c), buoyancy eventually becomes strong enough to pull it off the bottom, and the region cools off (Figure 138d), only to begin the cycle again (Figures 138e and 138f).

Inspection of the velocity field within the annulus indicates that the flow at the upper top half of the annulus is slightly larger than is the case in Figure 135. It appears that the sweeping flow from the side creates slightly more suction, helping to draw flow from the top of the annulus. This in turn results in a slightly more pronounced diversion of the incoming flow from the bottom of the annulus to the top, increasing the isolation of the hot spot at the far end and creating the oscillatory feature of the solution. As forced convection from the side is lowered, this additional suction is diminished and the solution converges without the oscillatory behavior.

In all cases considered from the side, however, the peak vessel temperature is again low and insensitive to total mass flow-rate, just as it was in flow entering the thermal sleeve from the bottom. The peak temperature is slightly lower in the case of $100 \%$ flow from the side $\left(290{ }^{\circ} \mathrm{C}\right)$, owing to the higher flow speed in the top regions of the annulus, but otherwise there is no distinction between peak vessel temperatures in cases where flow enters from the side or the bottom. One might conclude that, with such infinitesimal differences, it is preferable to leave the inlet and outlet nozzles at identical elevations and bring the flow to the thermal sleeve from the side. However, it seems preferable to avoid the oscillatory heating of the far end of the thermal sleeve seen in 100\% flow from the side. All cases cooled from the bottom behave identically and produce steady, constant flow patterns and temperature fields. 


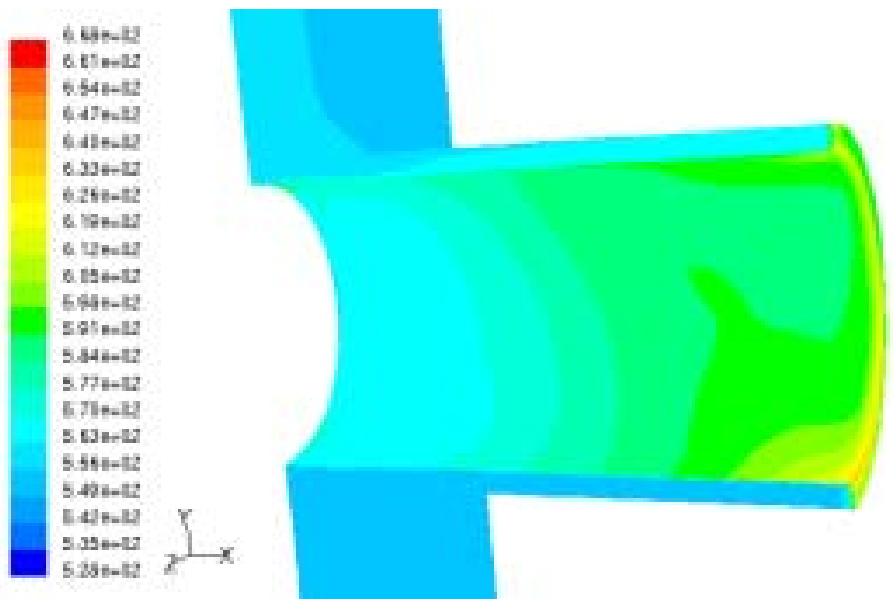

(a) Iteration 2017

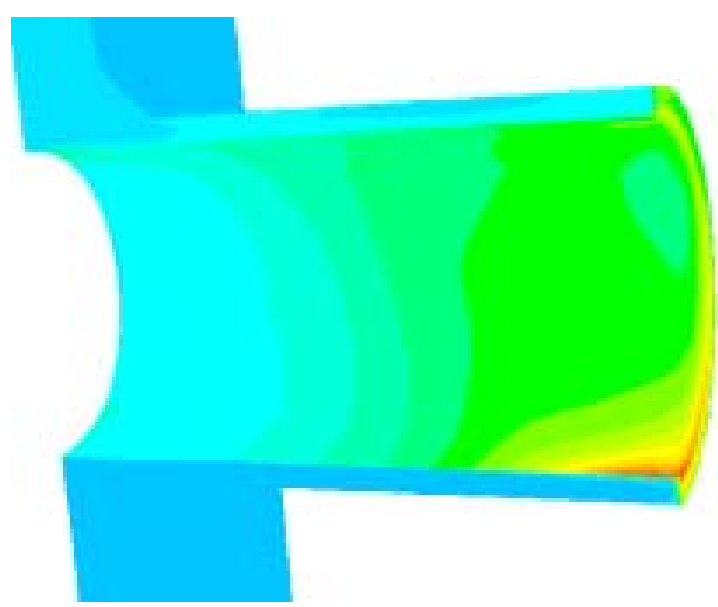

(c) Iteration 2044

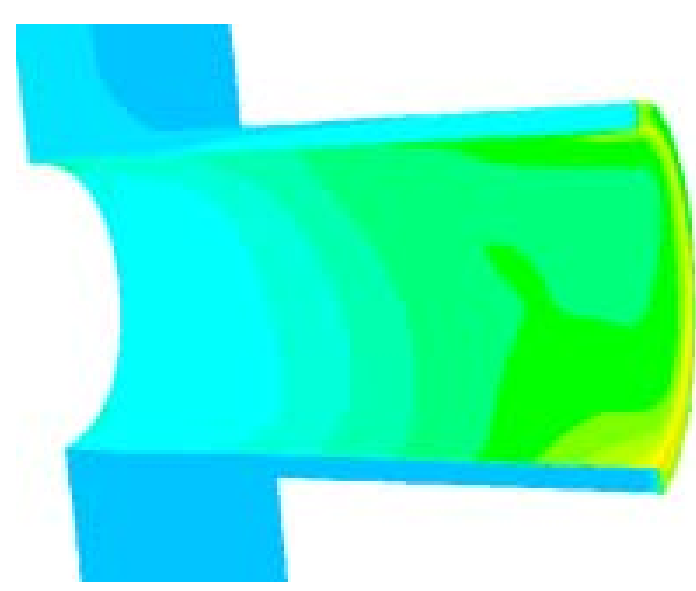

(e) Iteration 2071

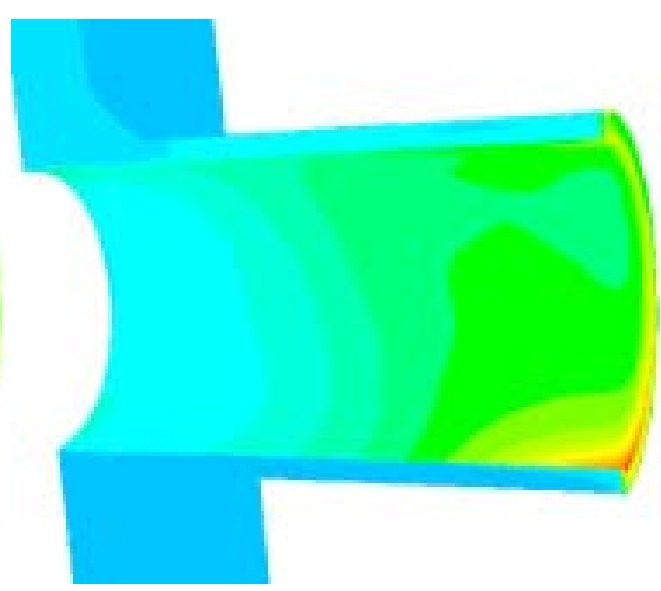

(b) Iteration 2028

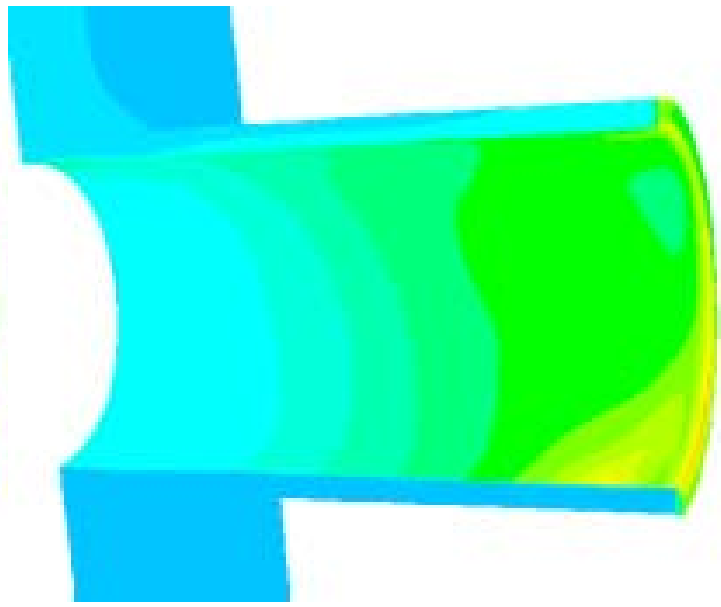

(d) Iteration 2057

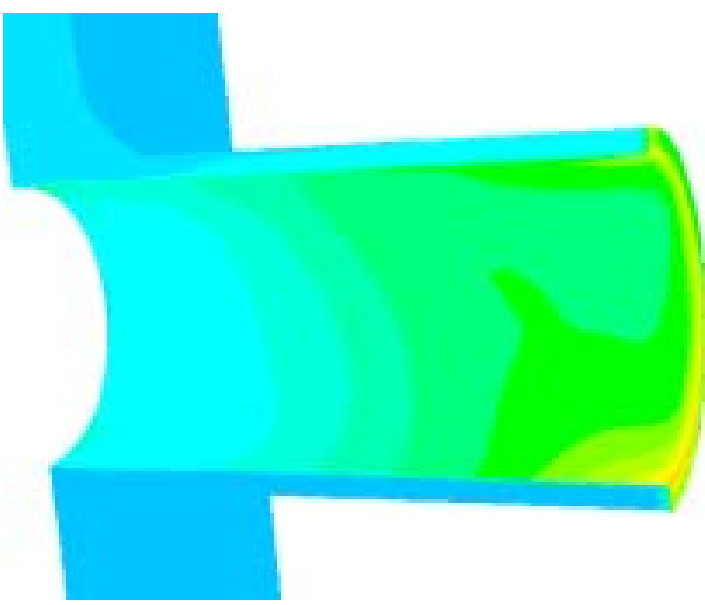

(f) Iteration 2085

Figure 138: Evolution of temperature field $[\mathrm{K}]$ in annular fluid gap for the conditionally converged case of $100 \%$ of total flow from the side. 


\subsubsection{Forced Flow From Top Or Bottom With Smaller Annular Gap}

Finally, we consider the possibility of reducing the annular gap from two inches to one inch. Table 45 indicates an array of results based on $100 \%$ and $200 \%$ of full flow from the top and bottom of the downcomer. Higher flow-rates are required to push flow deeper into the more restrictive channel.

The case of $100 \%$ flow from the top with the oneinch gap diverges. The thermal sleeve is hotter and fluid expansion requires higher forced convection from the top to avoid the problems described previously in conjunction with $50 \%$ of full flow into the two-inch gap. The temperature distribution in the annular region for the case of $200 \%$ flow from the top is shown in Figure 139. Peak temperature at the fluid/vessel interface jumps to $605 \mathrm{~K}\left(332{ }^{\circ} \mathrm{C}\right)$.

Table 45 also indicates that, for those cases involving forced flow from the bottom, results conditionally converge. Again, flow does not penetrate as deeply into the narrower annulus, and the results suggest local hot spots grow and detach from the bottom end of the annulus in a manner similar to that shown in Figure 138. The annular temperature distribution in the case of $100 \%$ flow from the bottom is shown in Figure 140 after it has settled into a predictable pattern $\sim 2000$ iterations into the solution. Peak temperatures at the fluid/vessel interface in this case increase to $572 \mathrm{~K}\left(299^{\circ} \mathrm{C}\right)$. In spite of the fact that this is within our temperature limits, it is again advisable to avoid the fluctuating hot spot at the bottom end of the annulus, and the larger (two-inch) annular gap is recommended.
Table 45: Summary of Results/Peak Vessel Temperatures for One-Inch Annular Gap

\begin{tabular}{|c|c|c|}
\hline & $\begin{array}{c}\text { From } \\
\text { Top }\end{array}$ & $\begin{array}{c}\text { From } \\
\text { Bottom }\end{array}$ \\
\hline $100 \%$ & DIV & CC \\
Flow & & $299^{\circ}$ \\
\hline $200 \%$ & CVG & CC \\
Flow & $332^{\circ} \mathrm{C}$ & $299^{\circ} \mathrm{C}$ \\
\hline
\end{tabular}

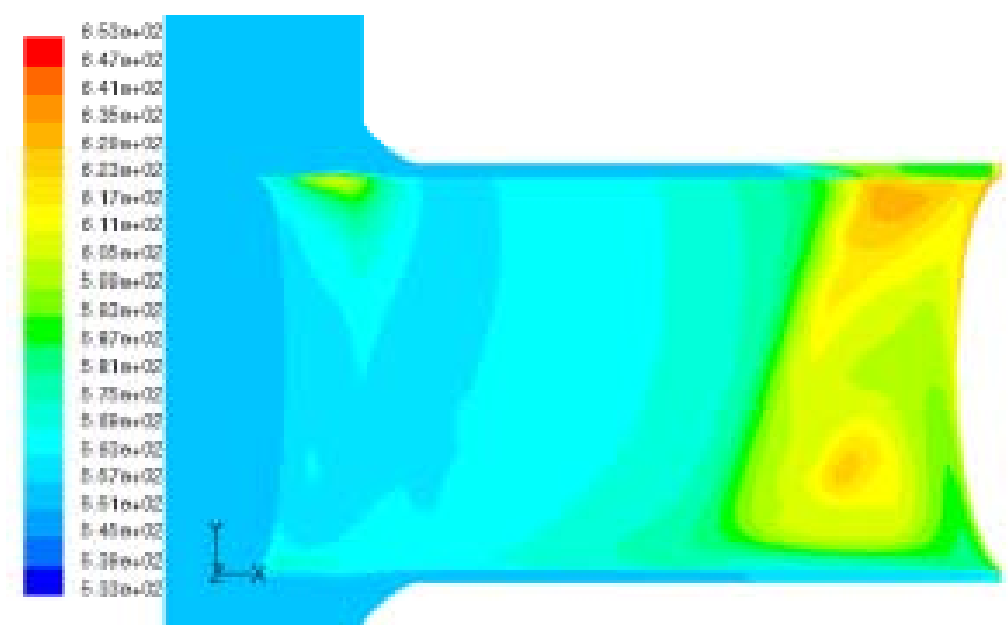

Figure 139. Fluid temperature $[\mathrm{K}]$ inside the annular fluid gap: $200 \%$ flow from the top of the downcomer (one inch annular gap).

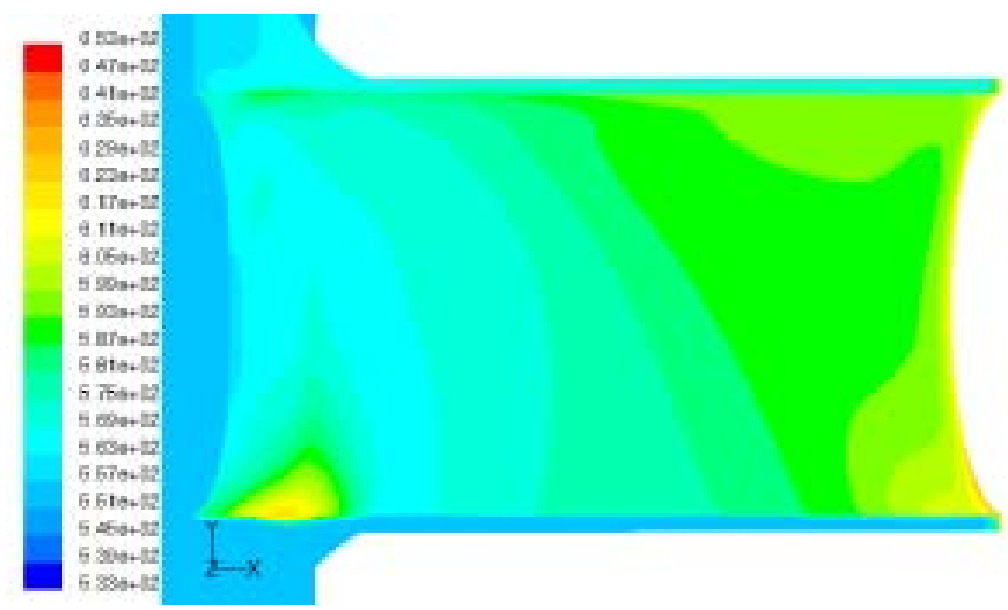

Figure 140. Fluid temperature $[\mathrm{K}]$ inside the annular fluid gap: $100 \%$ flow from the bottom of the downcomer (one inch annular gap). 


\subsubsection{Sensitivity of Results to Modeling Choices}

Among the many choices made in constructing these models, two were selected for further investigation. One was the mesh density and the other the turbulence model. Of related importance is the suitability of the mesh density for the selected turbulence model. Results based on the mesh density illustrated in Figures 128 and 129 (all results up to this point) are designated as "coarse" model results. Figure 128d shows only 14 elements through the annular gap. Nevertheless, in this $3 \mathrm{D}$ model, the mesh illustrated in Figure 129 contains 10,000 hex elements to model the thermal sleeve and about 75,000 hex elements each for the downcomer/annular gap and the reactor pressure vessel. A second set of results, designated "fine", was based on a model in which the annular through-thickness mesh was doubled to 28 elements, retaining the biasing shown in Figure 128d. The mesh density along the annular axis (X direction in Figure 128) was similarly increased. The original mesh density along the annular circumference was retained ( 50 uniformly spaced elements from top to bottom) and mesh density parameters for most other regions of the fluid domain were the same as in the coarse model. No change to mesh density was made or needed for the structural domains. Nevertheless, this fine-mesh model contains about 275,000 fluid hex cells.

The suitability of $k-\varepsilon$ turbulence models in supercritical water problems has been discussed in other papers, e.g., (Koshizuka 1995) and (Howell 1999). In these and other investigations, the focus is on idealized 2D problems (supercritical water in a heated cylindrical tube), where both the axial bulk fluid and the radial temperature distributions move through the pseudo-critical temperature. In these investigations, the fluid domain sees the full range of temperatures depicted in Figure 130 and related property variations, particularly in the radial direction, are severe. For this reason, investigators argue that the wall functions used in conjunction with standard $k-\varepsilon$ turbulence models are inappropriate, and they choose extreme mesh densities in the radial direction with the wall-adjacent cells well inside the viscous sublayer $\left(\mathrm{y}^{+} \equiv \mathrm{y} \sqrt{\rho \tau_{w} / \mu^{2}}<<1\right)$. In the study of deterioration phenomena (Koshizuka 1995), the investigators used 83 radial elements with a meshing bias that produces wall-adjacent $y^{+}$of $\sim 0.1$. To achieve a comparable mesh density in the 3D thermal sleeve problem, the mesh density in the annular gap would have to be increased by a factor of four beyond the "fine" mesh results presented shortly. Although it may be possible to run such simulations (anticipating a number of fluid cells in excess of $10^{6}$ ), we believe that this is unnecessary for the following reasons.

The thermal sleeve problem differs from these previous investigations in that the sleeve prevents any part of the fluid from reaching the pseudo-critical temperature (see again, for example, temperature contour plots in Figures 132 and 136). The exception to this is in local hot spots near the end of the annulus where the fluid is adjacent to the sleeve flange. The vast bulk of the supercritical water, however, experiences temperatures no higher than $625 \mathrm{~K}$ in the annulus, to the left of the vertical lines in the property variations of Figure 130. Under these conditions, property variation is significant but nowhere near as extreme as encountered in these earlier studies. We therefore argue that the standard wall functions are sufficient and seek models with wall-adjacent $\mathrm{y}^{+}$in the recommended range of $30 \sim 60$.

Figures 141 and 142 illustrate the temperature distributions in the annular fluid gap for fine-mesh simulations of the cases shown in Figures 132 and 136, respectively. Some differences are visible in the case of flow from the top; the center of the convection cell is not as well defined in the fine mesh case, and the fluid adjacent to the thermal sleeve is cooler but better mixed through the annular gap. The peak fluid temperature adjacent to the reactor pressure vessel increases by $6{ }^{\circ} \mathrm{C}$ to $311^{\circ} \mathrm{C}$. The fine-mesh case of flow from the bottom is virtually indistinguishable from the coarse-mesh case. 
Figure $\quad 143 \quad$ illustrates distributions of $\mathrm{y}^{+}$in the walladjacent cells in the annulus at the symmetry plane $(Z=0$ in Figure 127). The plots indicate that $\mathrm{y}^{+}$falls in an acceptable range $\left(30 \leq \mathrm{y}^{+} \leq 60\right)$ for both coarse mesh models and the fine mesh of the simulation of flow from the bottom. The fine mesh simulation of flow from the top contains some local $\mathrm{y}^{+}$values approaching or slightly within the viscous sublayer and so may not be entirely self-consistent. In any case peak vessel temperatures show little change when the fine mesh model is used and so the conclusions about the suitability of the proposed design are unchanged.

Finally, we generated coarse mesh models of the cases in Figures 132 and 136 using a $k$ - $\omega$ turbulence model. Temperature distributions in the thermal sleeve for these cases are shown in Figures 144 and 145. Again, there are some local differences, but the conclusions are unchanged.

Peak vessel temperatures in the cases of $100 \%$ flow from the top and bottom are $311{ }^{\circ} \mathrm{C}$ and 290 ${ }^{\circ} \mathrm{C}$, respectively, in the $k-\omega$, coarse mesh, turbulence model. These peak values differ by +6 and $-3{ }^{\circ} \mathrm{C}$ compared to the values in the $k$ - $\varepsilon$ model.

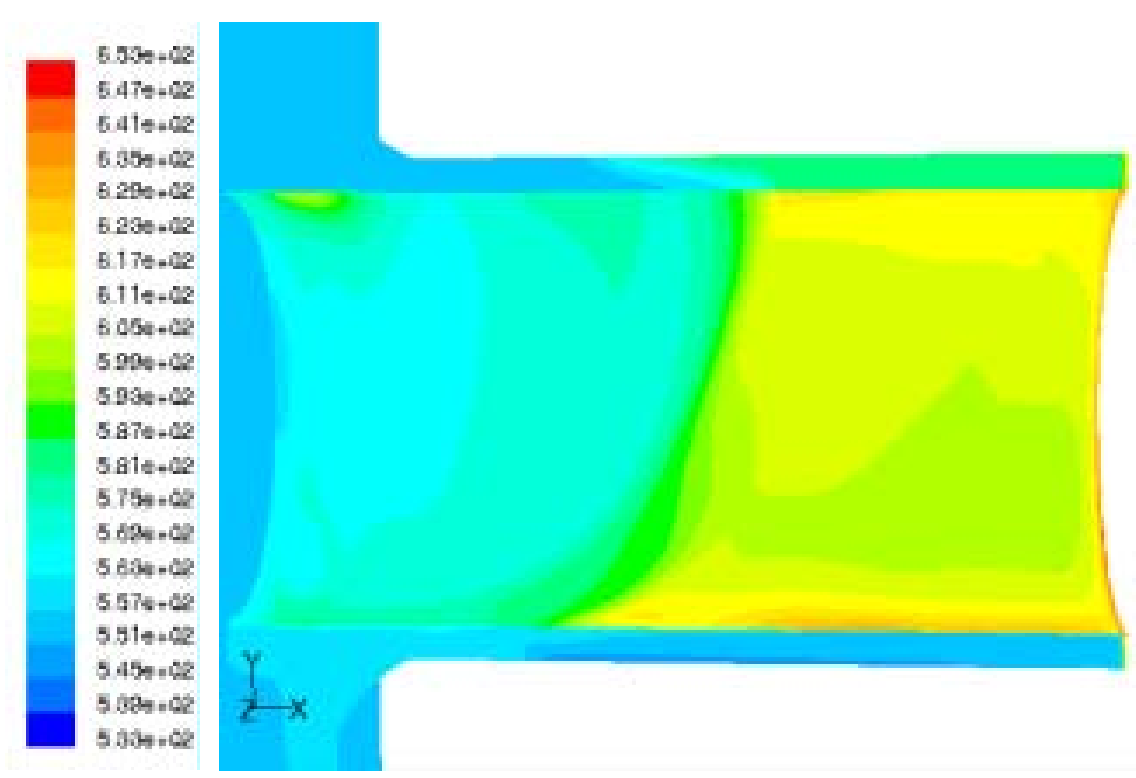

Figure 141. Temperature distribution $[\mathrm{K}]$ for case of Figure 126 (fine mesh).

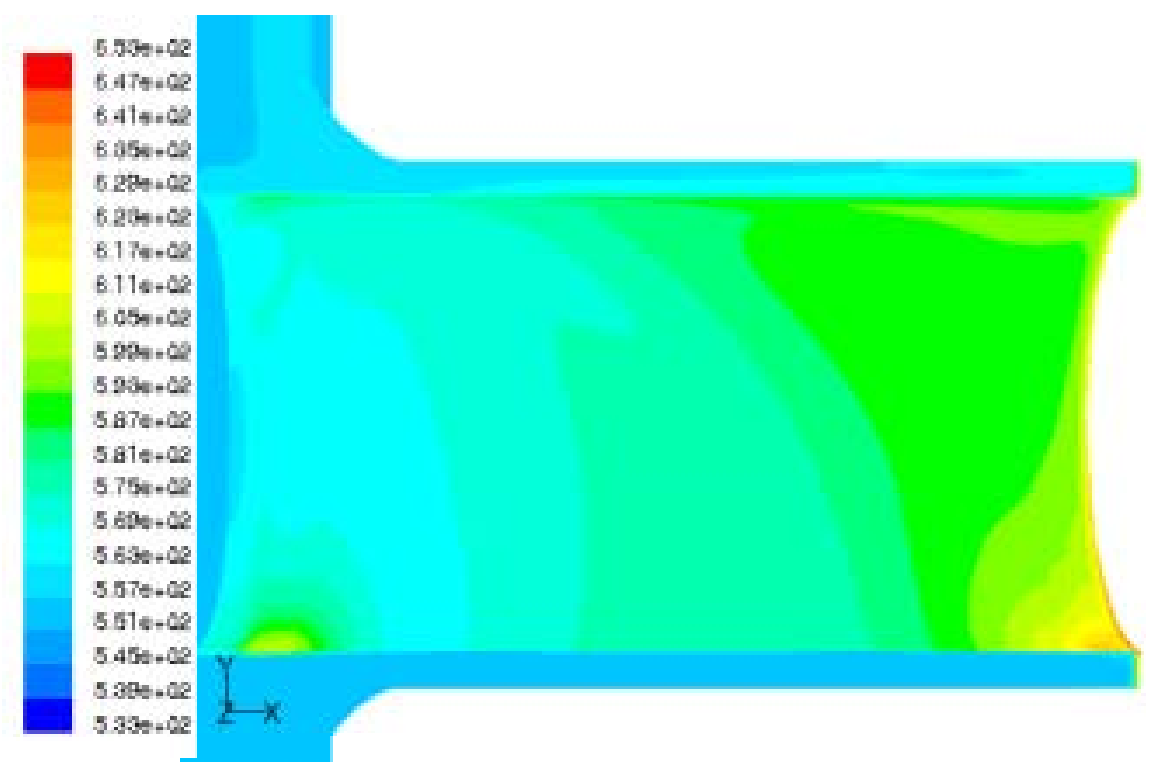

Figure 142. Temperature distribution [K] for case of Figure 135 (fine mesh). 

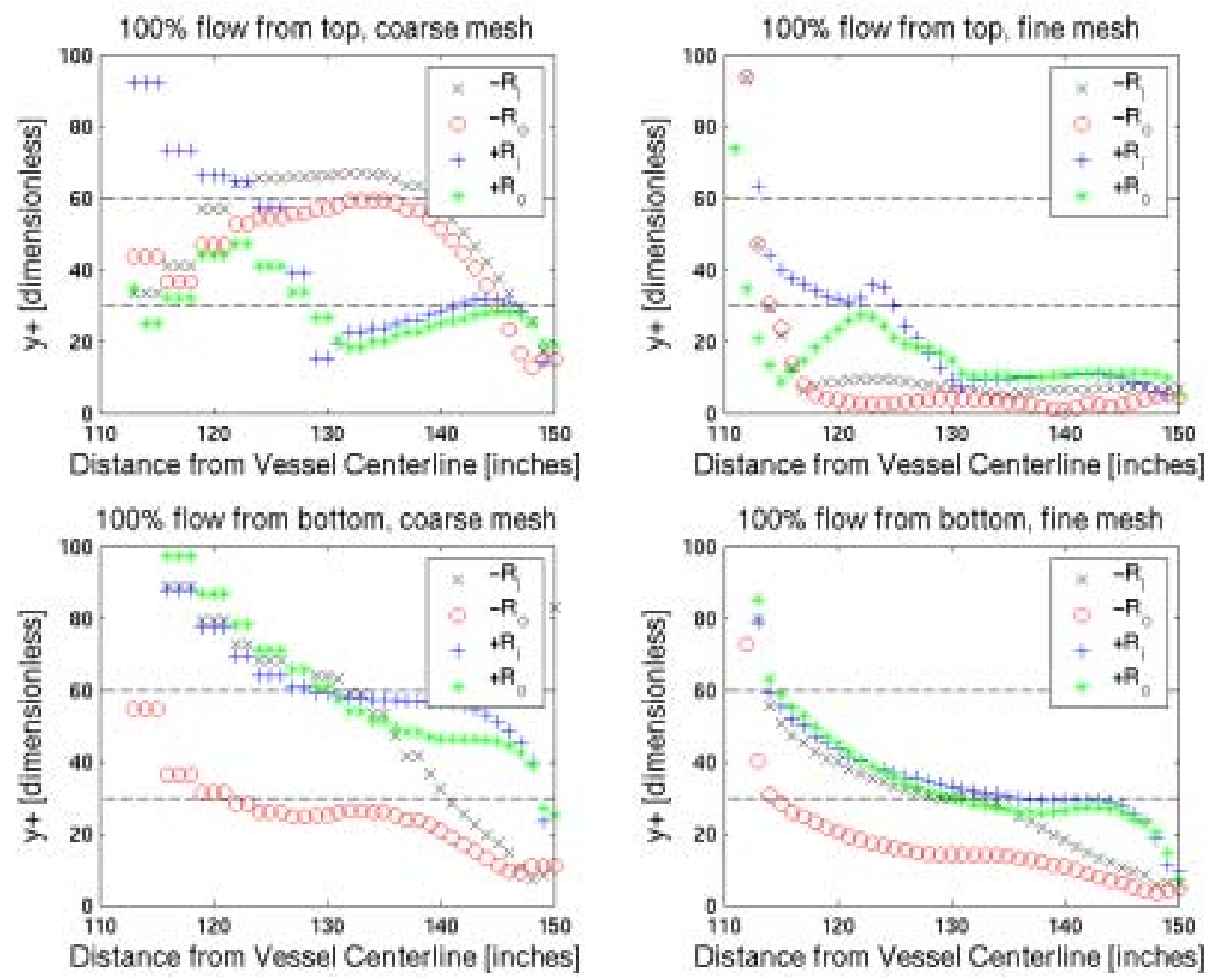

Figure 143. $y^{+}$distributions at symmetry plane $(Z=0)$ for cases in Figures 132 and 141 (top) and 136 and 142 (bottom).

\subsubsection{Summary}

A coupled fluid-solid model has been constructed for investigating the behavior of a thermal sleeve in a SCWR reactor pressure vessel using FLUENT. Isolation of the reactor pressure vessel from the hot fluid is most easily accomplished by means of a one-inch thick $(\sim 2.5 \mathrm{~cm})$ thermal sleeve surrounded by a generous, two-inch thick $(\sim 2.5 \mathrm{~cm})$ annular fluid gap. Outlet nozzles should be positioned above inlet nozzles, so that inlet flow is first directed circumferentially towards the outlet nozzle and then up, into and around the annular gap. Supercritical water density falls rapidly with increasing temperature and this enables establishment of strong natural convection cells in the annular gap. Forced convection from the bottom reinforces this natural convection, producing peak temperatures at the fluid/pressure vessel interface less than $15^{\circ} \mathrm{C}$ above the inlet cold leg water temperature of $280{ }^{\circ} \mathrm{C}$. Under these circumstances the reactor pressure vessel can be fabricated from conventional low-alloy steels such as SA-508. 
An annular gap of two inches $(\sim 5 \mathrm{~cm})$ is recommended to achieve the desired isolation and ensure a fully coupled flow field. Even though it may be possible to use a narrower gap, simulations suggest that oscillatory features may develop (hot spots growing, detaching and rising from the far bottom end of the annulus) and such unsteady features in the flow field are best avoided.

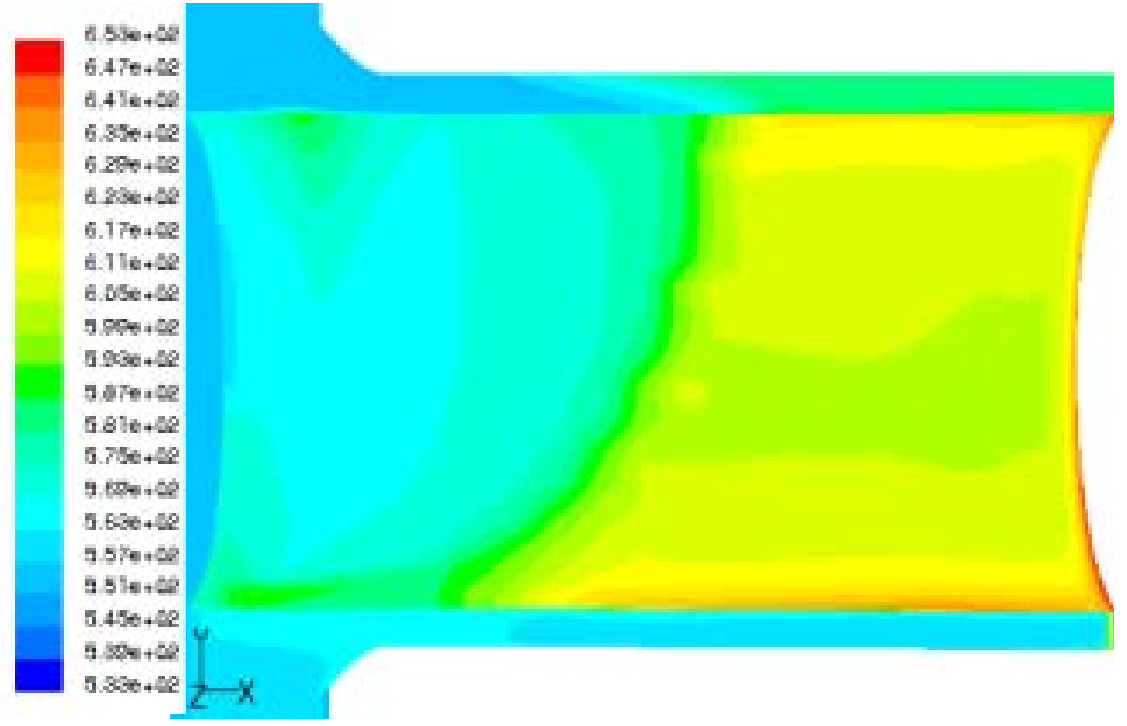

Figure 144. Temperature distribution $[\mathrm{K}]$ for case of Figure 132 using a k- $\omega$ turbulence model.

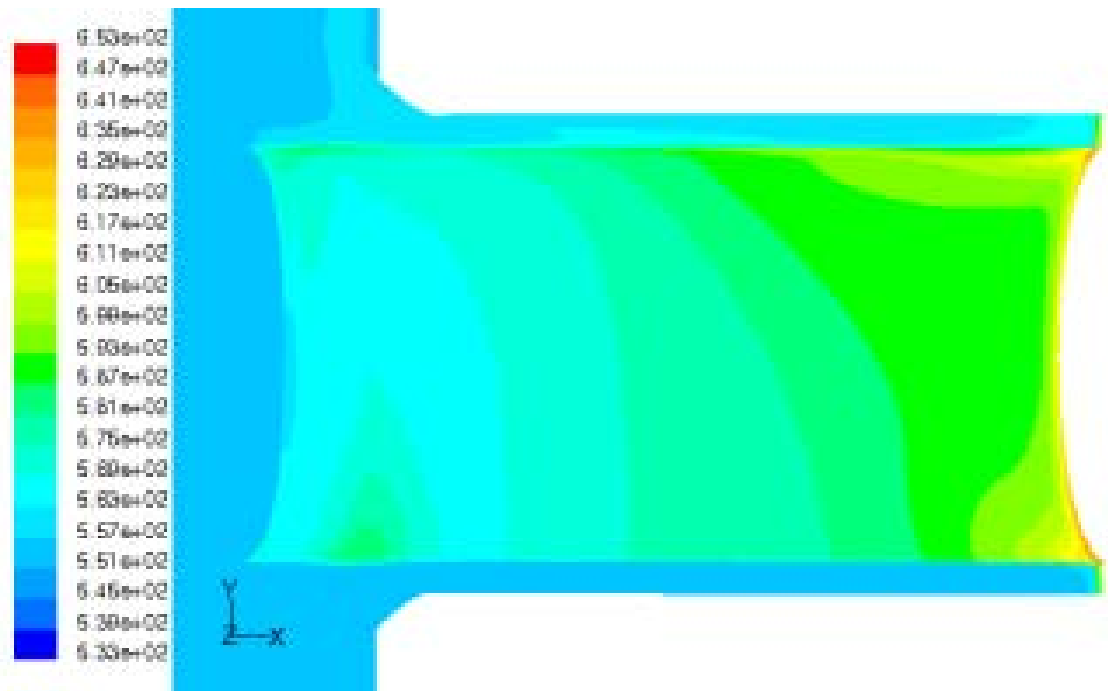

Figure 145. Temperature distribution [K] for case of Figure 136 using a k- $\omega$ turbulence model. 


\subsection{Fuel Assembly Conceptual Design (Westinghouse - Dr. Bin Liu, Lawrence Conway and Dr. Luca Oriani)}

\subsubsection{Description of the SCWR Preliminary Fuel Assembly Design}

Figure 146 shows the cut-away view of the reference design SCWR fuel assembly. The fuel assembly consists of:

- 36 water rods

- 300 fuel rods

- 1 instrumentation rod

- A water chamber

- A top and a bottom water rod tie plates, and

- Handle and Spring

The main difference in the design between the SCWR fuel assembly and the traditional PWR or BWR fuel assemblies is the flow direction of the coolant. The coolant water in PWRs and BWRs has a once-through path from the bottom of the assembly flowing upward to the top of the assembly. The SCWR reference design flow path is a U-type, with downward flow of subcooled water for neutron moderation and upward flow of this fluid for core cooling. A large fraction (up to $90 \%$ ) of the inlet water in the reference design enters the SCWR fuel assembly at the top of the assembly and flows downward to the bottom through the water rods. This water then mixes with the remaining fraction of the inlet flow from the downcomer in the water chamber below the fuel rods and turns 180 degrees to flow back upward to the top of the assembly, where all the fluid exits the fuel assembly. The downward flowing water must be kept separated from the upward flowing coolant since they have different temperatures and densities. This adds complexity to the SCWR fuel assembly design.

A water in-take distributor is used to connect each fuel

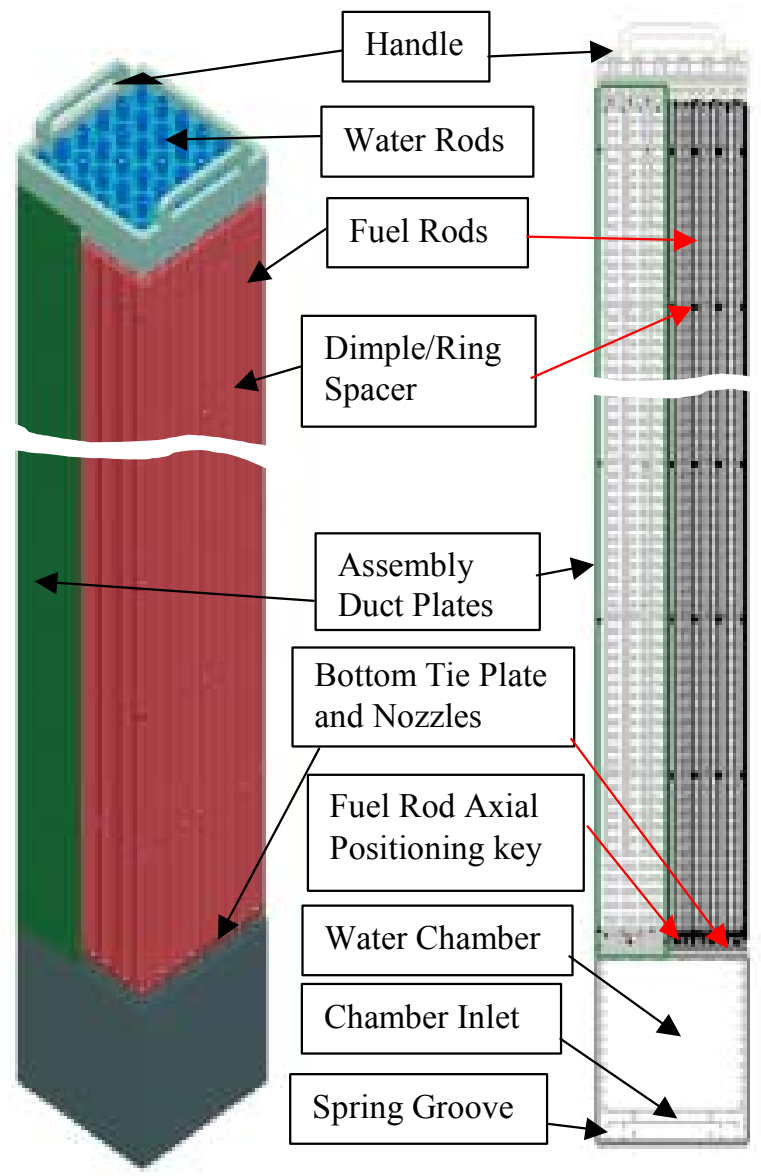

Figure 146. Cut-away View of the SCWR fuel assembly (part of the assembly duct plate is cutout).

assembly to a calandria tube, which transports the $280{ }^{\circ} \mathrm{C}$ inlet water from the reactor vessel upper head to the fuel assembly. The water rod inlet distributor consists of a cylinder that mates with a calandria tube that encompasses the 12 center-most water rods in the fuel assembly. The distributor has 12 vertical discharge pipes that connect to the 12 central water rods and 24 pipes that extend to the remaining 24 water rods in the fuel assembly. This distributor directs the inlet flow to each water rod and keeps it separated from the hot upward flowing fluid exiting the top of the assembly. The distributor can be part of the fuel assembly and would then be replaced during refueling when the fuel assembly is replaced with a fresh fuel assembly. Alternatively, the distributor could be fixed to its calandria tube and not be part of the fuel assembly so it does not need to be replaced during re-fueling. Having the distributor be a part of the fuel assembly would seem to be advantageous since alignment of the distributor inlet to its calandria tube would appear to be easier than aligning the 36 distributor outlet pipes to their associated water rods. 
Since the detailed design of this component is not completed, the fuel assembly illustrations have not included this distributor device.

Each water rod is a closed square channel and there are total 36 water rods in a fuel assembly. Figure 147 displays the top view of the fuel assembly with all 36 water rods shown. All 36 water rods are fastened to both the bottom and top tie plates with cylindrical end tubes and thus they act as tie-rods and hold the fuel assembly together as a whole structure. Figure 148 and 149 illustrate the water rods mounted with the top tie plate and the bottom tie plate. The water rods are shown with cylindrical end tubes that could be threaded and so that nuts or other fastening techniques could be used to fasten the top and bottom tieplates. The square cross-section of the water rods with the fuel rod packing and outer fuel assembly wrapping are sufficient to prevent rotation of the water rods.

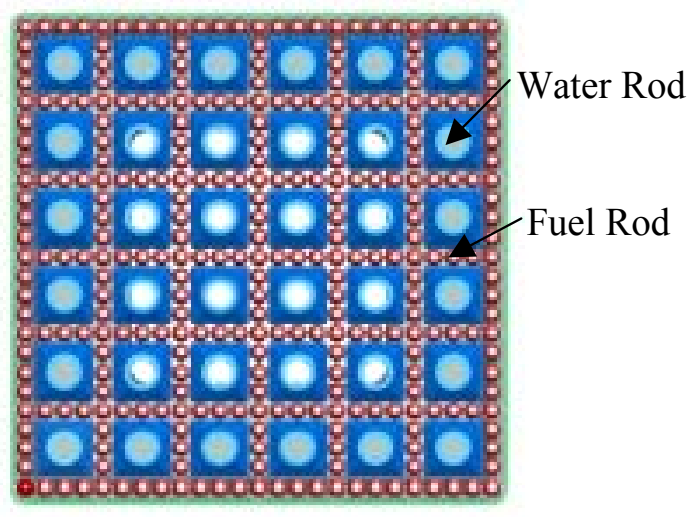

Figure 147. Top view of the SCWR fuel assembly (top handle and tie plate are not shown).

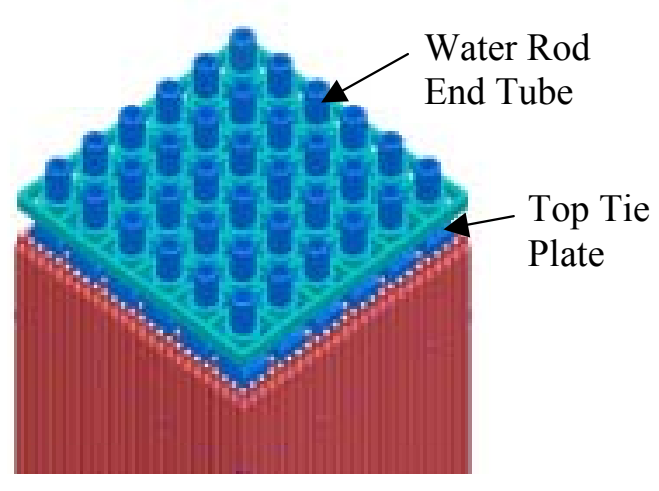

Figure 148. Top tie plate holds 36 water rods.

As discussed above, a large fraction of the inlet water goes through the water rods and down to the water chamber that is located in the bottom of the fuel assembly. Figure 150 shows the water chamber. The water will make a U-turn in the chamber to pass through the bottom nozzles in the bottom tie plate and flow upward in the fluid subchannels outside the water rods. The water from the reactor vessel downcomer will enter into the water chamber from the bottom inlet which is seated on the lower core support plate.

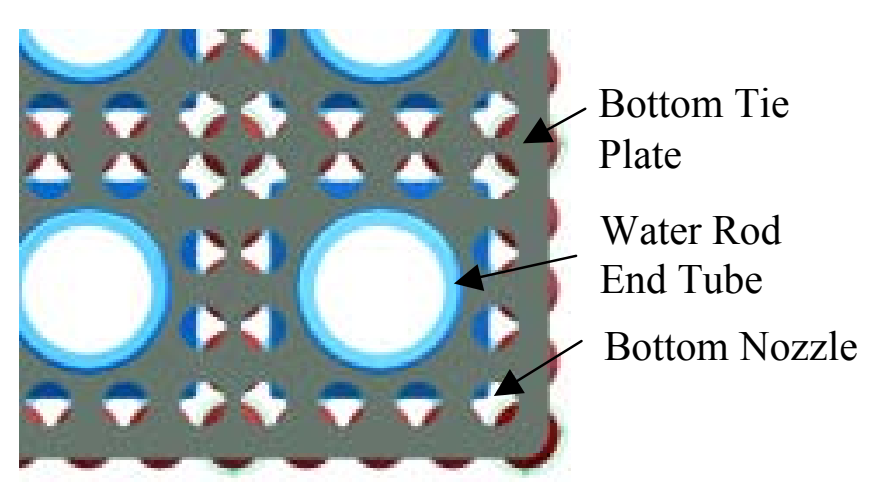

Figure 149. Bottom tie plate and nozzles (view from the bottom).

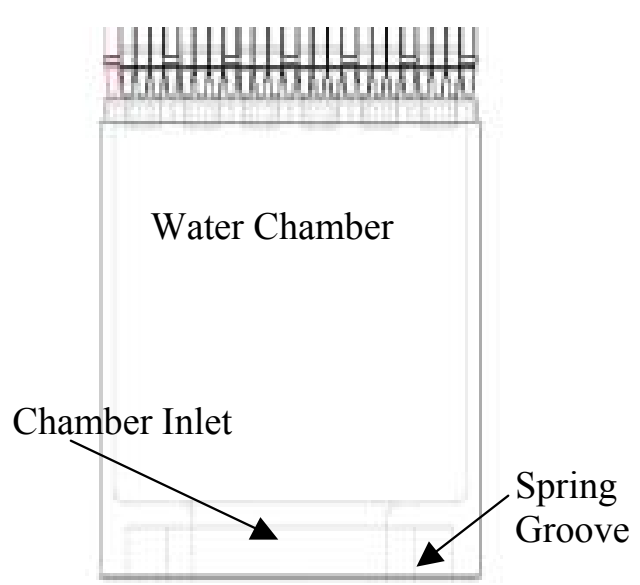

Figure 150. Water chamber and spring groove. Note that the fuel assembly spring is located in the bottom of the fuel assembly. 


\subsubsection{Spacer Design}

The traditional grid spacer used in LWRs is a standard industrial application and has more than onehundred thousand fuel assembly years of operating experience. This type of standard spacer was the preliminary candidate for the SCWR spacer. However, the clearance between fuel rod and water rod of the SCWR is only $0.5 \mathrm{~mm}$ and thus the introduction of a typical grid spacer would block a significant portion of the flow area of the channel. Alternately, a wire wrap around each fuel rod has been used as a spacer in the liquid metal fast reactors where the small rod pitch results in tight geometries. However the applicability of a wire wrap spacer to the SCWR fuel assembly concept is questionable. Its good performance in liquid metal applications is due to the fact that heat transfer is dominated by conduction, but in the SCWR reactor, convection will dominate the heat transfer process. Therefore, the use of a wire wrap spacer raises the potential for hot spots to occur in the SCWR.

The present design concept uses the water rods as the tie rods and the base for dimple type spacers for the fuel rods. The dimple is prism shaped and can be pressed outward from the inside of the water rods. Figure 151a and 151b show the dimples near the lower end and upper end of a water rod, respectively. The height of the dimple is $1.2 \mathrm{~mm}$ and the distance between the centers of a dimple pair is $5.1 \mathrm{~mm}$, which forms a 60-degree inclination between two radiuses from the fuel rod contact points to the fuel rod center. It will insure that the fuel rod will be securely held between the dimple pair. Figure 152 displays the water rods with installed fuel rods.

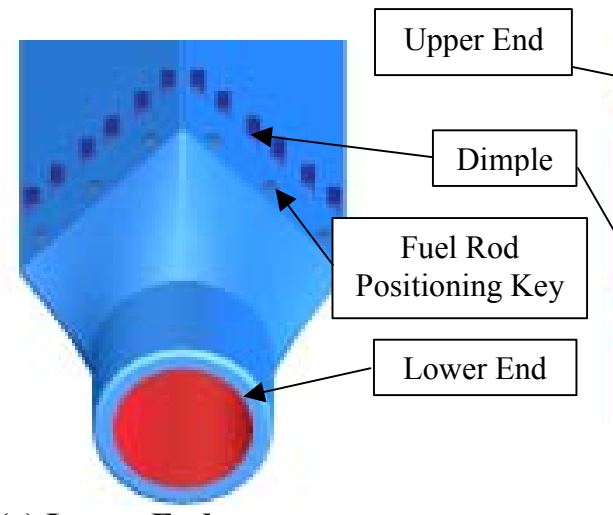

(a) Lower End

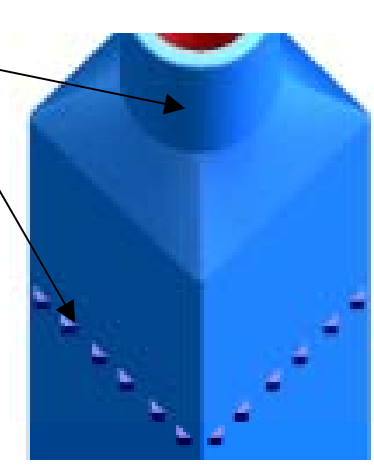

(b) Upper End

Figure 151. Spacer dimples on the water rods.

As shown in Figure 152, all the fuel rods between two adjacent water rods can be held in position by the water rod dimple spacers. The peripheral fuel rods can also be held in position in the same manner by having inward facing dimples pressed into the assembly duct plates. However, a dimple type spacer cannot be used for the fuel rods located between the corners of four adjacent water rods, and the central instrumentation pin. At these locations a simply ring-type spacer can be welded on the fuel rods. If hot spot behind the ring spacer is a concern, two or three reduced enrichment fuel pellets could be used at these

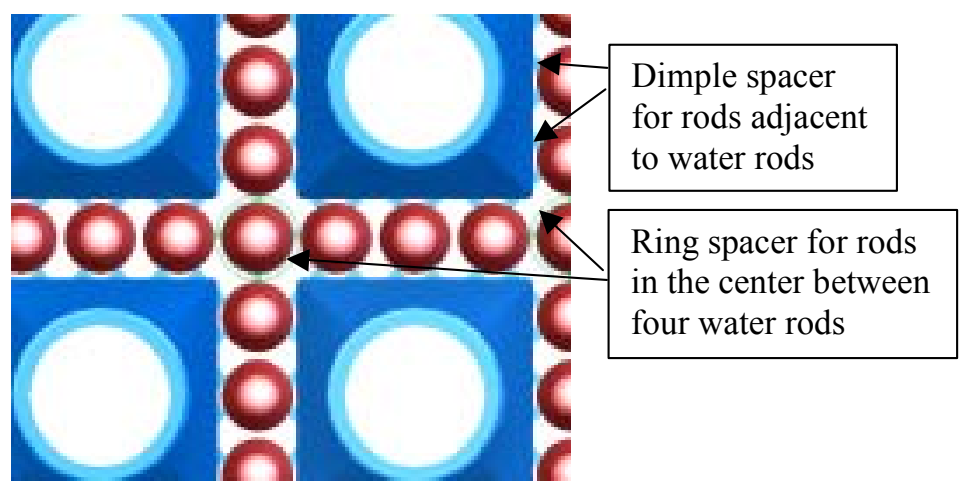

Figure 152. Fuel rod spacers. 
elevations instead of normal enrichment fuel pellets. The ring spacer is also shown in Figure 152.

The fuel rod is 4.63 meters in length with an active fuel length of 4.27 meters. The fuel rod will be divided into nine axial spans, with ten spacer positions covering the whole fuel rod length. The dimple type spacer and ring type spacer could be placed in the same elevation but it is not necessary to place them at the same elevation.

With this dimple-type spacing arrangement, the water rods need to be relatively stiff in order to support the fuel rods during the operation. Hence, strengthening ribs must be added inside, or inserted into the water rods. Note that for the most central 12 water rods, the ribs will combine with the control rod guide thimble. The shape and size of these ribs are not specified in this report but we do not foresee difficulties with design and fabricate of such ribs.

\subsubsection{Fuel Assembly Top Structure}

As mentioned in the previous sections, the top structure of the SCWR fuel assembly is one of the most challenging parts of the design. The cold inlet water flows from the reactor vessel upper head in a calandria tube and enters the water rod inlet flow distributor where the water is distributed into 36 water rods, evenly with minimal leakage. The hot fluid leaving the fuel assembly passes through the top tie plate and the upper core support plate into the core outlet plenum (with the vertical calandria tubes) and flows to the core outlet nozzle. The space is limited in the fuel assembly top region, where the water intake distributor is a key part. The water in-take distributor in the upper end has a flange to connect to the calandria tube on the underside of the upper core support plate, and in the lower end has 36 exit tubes to connect the 36 water rods of the fuel assembly. It looks like an elongated 36-leg spider. The control rod with 12 rod-lets is inside the central part (body) of the water distributor. The distributor needs to be big enough for control rod-lets but it also needs to be small enough to leave enough space for the hot fluid flow path. However, the water distributor does not need to be replaced during the refueling and it is so not the part of the fuel assembly. This report does not provide any drawings for the distributor.

The top tie plate, 36 water rod upper end tubes, and the upper handle of the fuel assembly are shown in Figure 153. The key parameter of the design of the tie plate is that it leaves enough open space for the hot fluid path while has enough strength to hold the whole fuel

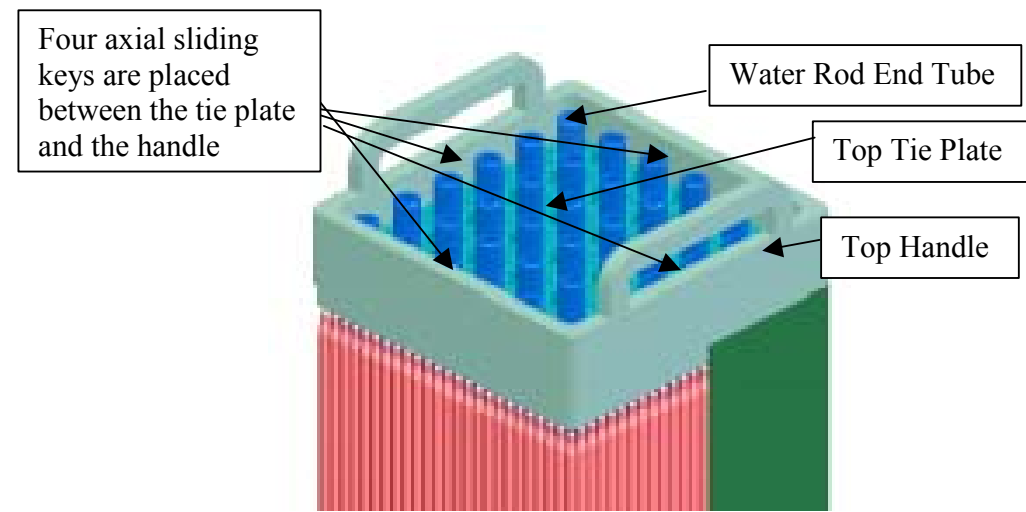

Figure 153. Top structure of the fuel assembly. assembly.

\subsubsection{No Resistance Thermal Expansion Design}

The temperature difference between the cold inlet water and the hot exit fluid of the SCWR is much higher than the traditional PWRs and BWRs. The $500{ }^{\circ} \mathrm{C}$ operating temperature in the SCWR will impact the fuel assembly components design. During the start up and cooling down of the reactor, all components will be subjected to very large temperature changes. If two attached components have different thermal expansion rates or different working temperatures, large stresses due to differential thermal growth will occur. These stresses can cause the component material to yield and stretch, distort 
or even fail. The best solution to this challenge is to allow the components to expand freely in guided directions. Guided expansion can be realized by use of positioning keys and the sliding keys.

The fuel assembly is 5.17 meter in length with the three longest components being the fuel rods, the water rods, and the assembly duct plate. They all are very long thin wall structures. The working temperatures of these three components are different. The fuel rods are subjected to extremely high temperatures, the duct plate works at temperatures ranging from $280{ }^{\circ} \mathrm{C}$ near the bottom to $500{ }^{\circ} \mathrm{C}$ or more at the top of the assembly, and the water rod is at the cold-water temperature of about $280{ }^{\circ} \mathrm{C}$. Therefore, the thermal expansion of these three components will all be different. If they can expand freely, they will generate little thermal stress and ensure the safe operation of the fuel assembly.

The fuel rods are designed to be 50-mm shorter than the distance between the two tie plates, which leaves enough space for the rods to freely expand in the axial direction. To prevent axial movement, the fuel rods are positioned by keys located near the lower ends of the rods. Figures 151,154, and 155 illustrate where the positioning keys are located. The keys are only at the lower elevation so the rest of the fuel rods can expand freely.

In order to allow relative free expansion of the water rods and duct plate, four sliding keys are used between the upper tie plate and the top handle. The sliding keys allow relative movement in the axial direction of the two components but still keep the relative positions in the lateral plane. Because the water rods are fastened to the top tie plate and the assembly duct plate is fastened to the top handle, relative axial movement caused by thermal expansion is allowed between the water rods and the duct.

The free expansion of the fuel rods does not cause a fuel assembly length change. However, the expansion of the water rods or assembly duct will change the total length of the fuel assembly. Therefore, similar to PWR fuel assembly, a set of springs are necessary to allow the free expansion of the

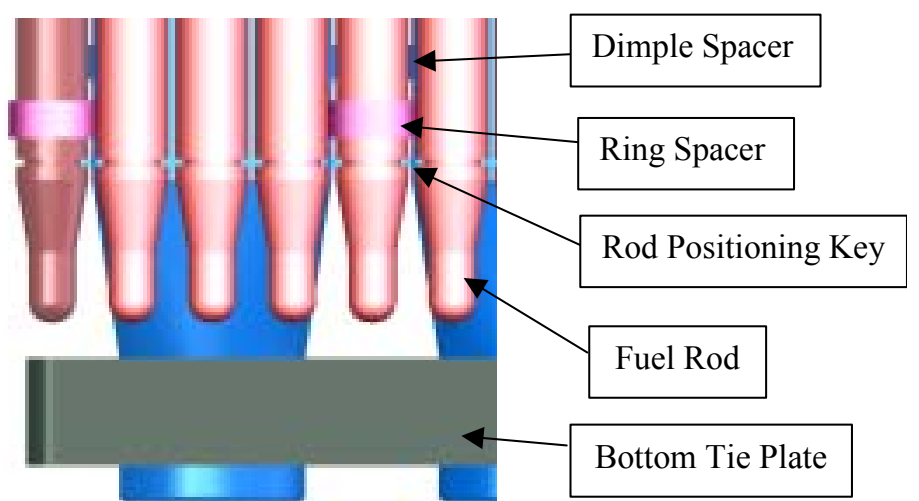

Figure 154. Rod axial positioning key.

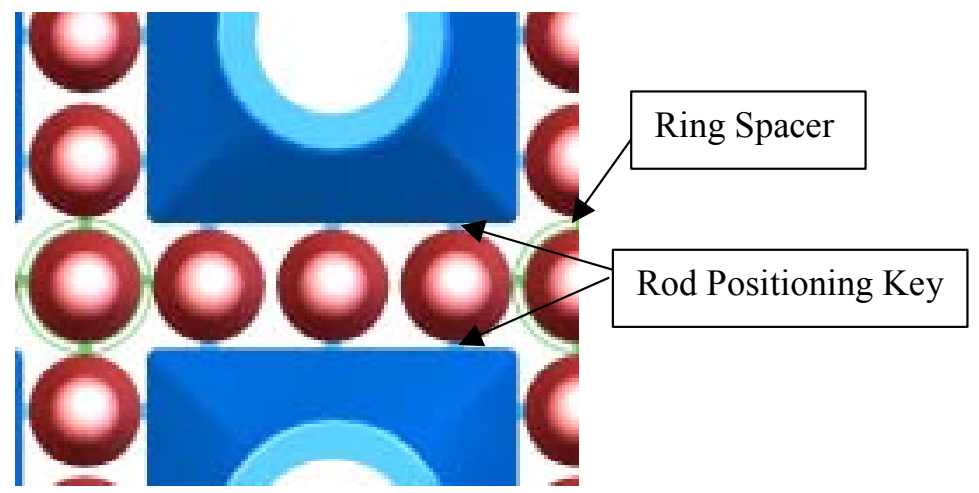

Figure 155. Top view of the rod positioning key (dimples are not shown). fuel assembly while holding the fuel assembly in its position. Unlike a PWR, the spring of the SCWR fuel assembly is located in the bottom of the fuel assembly because there is no space for the spring to be located in the top of fuel assembly. The spring is placed in the spring groove and works against the lower core support plate where the fuel assembly is seated.

\subsubsection{Assembling of the Fuel Assembly}

Unlike PWR and BWR fuel assemblies in which the fuel rods are vertically inserted into horizontal grid spacers, the SCWR fuel assembly can most easily be assembled horizontally, since the water rods provide 
the spacers for fuel rods, and the water rods cannot be installed and fastened without the fuel rods fully positioned.

One proposed method is to have the assembly flow duct in two, full length, "L" shaped pieces. One "L" shaped half of the duct is mounted with the bottom base and top handle as well as bottom and top tie plates, and the fuel and water rods are positioned layer by layer. The water rods would be fastened to the bottom tie plate during this layering operation, but not to the top tie plate. After installing all fuel rods and water rods, the top tie plate is positioned with the help of the sliding keys. The second "L" shaped half of the duct is then attached to the first " $L$ " duct to form the complete, ducted fuel assembly.

The fuel assembly data considered in this evaluation is listed in Table 46 below.

Table 46. Fuel assembly data.

$\begin{array}{ll}\text { Fuel Assembly } & \\ \text { Total length } & 5,170 \mathrm{~mm} \\ \text { Lower to upper tie plate length } & 4,680 \mathrm{~mm} \\ \text { Number of fuel rods } & 300 \\ \text { Number of water rods } & 36 \\ \text { Number of instrumentation pin } & 1 \\ \text { Number of spacer locations } & 10 \\ \text { Spacer } & \\ \text { Dimple spacer length in flow direction } & 5 \mathrm{~mm} \\ \text { Height of the dimple toward the rod } & 1.2 \mathrm{~mm} \\ \text { Width of water rod dimple base } & 2.8 \mathrm{~mm} \\ \text { OD of the ring spacer } & 12.2 \mathrm{~mm} \\ \text { ID of the ring spacer } & 10.2 \mathrm{~mm} \\ \text { Ring spacer length in flow direction } & 5 \mathrm{~mm} \\ \text { Fuel Rod } & \\ \text { Fuel rod length } & 4,630 \mathrm{~mm} \\ \text { Active fuel pellet length } & 4,270 \mathrm{~mm} \\ \text { Fuel rod OD } & 10.2 \mathrm{~mm} \\ \text { Fuel rod pitch } & 11.2 \mathrm{~mm} \\ \text { Water Rod } & \\ \text { Water rod length } & 4,750 \mathrm{~mm} \\ \text { Water rod side } & 33.6 \mathrm{~mm} \\ \text { Water rod pitch } & 44.8 \mathrm{~mm} \\ \text { Water rod duct wall thickness } & 0.4 \mathrm{~mm} \\ \text { Water rod upper end tube OD } & 22 \mathrm{~mm} \\ \text { Water rod upper end tube ID } & 18 \mathrm{~mm} \\ \text { Water rod lower end tube OD } & 25 \mathrm{~mm} \\ \text { Water rod lower end tube ID } & 21 \mathrm{~mm} \\ & \end{array}$

$\begin{array}{ll}\text { Water Chamber } & \\ \text { Water chamber side } & 267 \mathrm{~mm} \times 267 \mathrm{~mm} \\ \text { Water chamber height } & 300 \mathrm{~mm} \\ \text { Water chamber inlet } & 147 \mathrm{~mm} \times 147 \mathrm{~mm} \\ \text { Bottom Tie Plate } & 15 \mathrm{~mm} \\ \text { Plate thickness } & 276 \mathrm{~mm} \times 276 \mathrm{~mm} \\ \text { Plate side dimensions } & 432 \\ \text { Number of the nozzles } & 36 \\ \text { Number of the water rod holes } & 7 \mathrm{~mm} \\ \text { Nozzle diameter } & 25 \mathrm{~mm} \\ \text { Water rod hole diameter } & 15 \mathrm{~mm} \\ \text { Top Tie Plate } & 276 \mathrm{~mm} \times 276 \mathrm{~mm} \\ \text { Plate thickness } & 36 \\ \text { Plate side dimensions } & 22 \mathrm{~mm} \\ \text { Number of the water rod holes } \\ \text { Water rod hole diameter }\end{array}$




\section{References}

- American National Standard Institute N18.2, "Nuclear Safety Criteria for the Design of Stationary PWR Plants," 1973

- ASME B\&PVC, “ASME Boiler and Pressure Vessel Code," Sec III, Div. 1, Subsec. NB, Class 1 Components, 1974 ed., American Society of Mechanical Engineers (July 1974).

- ASME, Boiler and pressure vessel code, Section III, Subsection NB and Section II, Part D, Properties (2001)

- ASME Code Case 1592, "ASME Boiler and Pressure Vessel Code," Sec. III, American Society of Mechanical Engineers (1974).

- ASME Supplement, "Requirements for Construction of Nuclear Components at Elevated Temperatures," RDT Standard, RDT F9-4T (Suppl. To ASME Code Cases 1592,1593,1594,1595,1596), Reactor Development and Technology Division, U.S. Energy Research and Development Administration (1976)

- Babcock, R. S., D. E. Wessol, C. A. Wemple, and S. C. Mason, “The MOCUP Interface: A Coupled Monte Carlo/Depletion System", EG\&G Idaho, Inc., Idaho National Engineering Laboratory, presented at the 1994 Topical Meeting on Advances in Reactor Physics, Vol. III, Knoxville, TN, April 11-15, 1994.

- Beaumont, M.D., et al., "Properties of Fuel and Core Component Material," WCAP-9224 (Nonproprietary), July 1978.

- Bishop, A. A., R. O. Sandberg, and L. S. Tong, "Forced Convection Heat Transfer to Water near Critical Temperature and Supercritical Pressures", WCAP-2056-P, Part-III-B, February 1964

- Boyd, W. K. and Pray, H. A., "Corrosion of Stainless Steels in Supercritical Water," Corrosion, 13, pg. 375 (1957).

- Briggs, Seah, Practical Surface Analysis, "In Auger and X-ray Photoelectron Spectroscopy," Vol 1, Wiley, Chichester, p. 509, 1990.

- Buongiorno, J., W. Corwin, P. E. MacDonald, L. Mansur, R. Nanstad, R. Swindeman, A. Rowcliffe, G. Was, D. Wilson, and I. Wright, "SCWR Survey of Materials Experience and R\&D Needs to Assess Feasibility”, INEEL/EXT-03-00693, Rev. 1, 2003.

- Buongiorno, J., and P. E. MacDonald, "Study of Solid Moderators for the Thermal-Spectrum Supercritical Water-Cooled Reactor (Neutronics)", Proceedings of the $11^{\text {th }}$ International Conference on Nuclear Engineering (ICONE-11), Paper 36571, Tokyo, April 20-23, 2003a.

- Buongiorno, J., and P. E. MacDonald, "Study of Solid Moderators for the Thermal-Spectrum Supercritical Water-Cooled Reactor (Thermo-mechanics and Cost)", Proceedings of the $11^{\text {th }}$ International Conference on Nuclear Engineering (ICONE-11), Paper 36572, Tokyo, April 20-23, 2003 b.

- Burns \& Roe Enterprises Inc., Supercritical Water Reactor (SCWR), Study of Power Conversion Cycle, Control Strategy and Start-up Procedures, September 2003.

- Carelli, M. D., and C. W. Bach, (1979), "Predicted Steady State Thermal-Hydraulic Performance of the Fuel and Blanket Assemblies in the CRBRP Heterogeneous Core," Clinch River Breeder Reactor Plant Report, WARD-D-0210, Westinghouse Electric Corporation

- Carelli, M. D., and D. R. Spencer, (1976), "CRBRP Assemblies Hot Channel Factors Preliminary Analysis," Clinch River Breeder Reactor Plant Report, WARD-D-0050, Westinghouse Electric Corporation

- Carelli, M. D., P. W. Rosenthal, and W. R. Rymer, (1985), "Final Predicted Steady State ThermalHydraulic Performance of the CRBR Fuel and Blanket Assemblies," Clinch River Breeder Reactor Plant Report, WARD-D-0324, Westinghouse Electric Corporation 
- Chelemer, H., L. H. Boman, and D. R. Sharp, "Improved Thermal Design Procedure”, WCAP-8568, nonproprietary, July 1975

- Cheng, X., et al., "Thermal-Hydraulics of a Supercritical Pressure Light Water Reactor," IKET

- Cheng, X., and T. Schulenberg, "Heat Transfer at Supercritical Pressures - Literature Review and Application to an HPLWR", FZKA-6609, Forschungszentrum Karlsruhe, 2001

- Cheng, X., and T. Schulenberg, "Design Analysis of Core Assemblies for Supercritical Steam Conditions," Forschungszentrum Karlsruhe, 2002

- Combustion Engineering, 1982, "System 80 CESSAR FSAR," Chapter 15.3.

- Croff, A. G., "ORIGEN2 - A Revised and Updated Version of the Oak Ridge Isotope Generation and Depletion Code," ORNL-5621, Oak Ridge National Laboratory, July 1980.

- Da Cunha Belo, M., M. Walls, N.E. Hakiki, J. Corset,E. Picquenard, G. Sagon and D. Noel "Composition structure and proprieties of the oxides films formed on the stainless steel 316L in primary type PWR envirionment," Corrosion Science, Vol. 40, No. 2/3, pp. 447-463 (1998).

- Dobashi, K., Y. Oka, and S. Koshizuka, "Core and Plant Design of the Power Reactor Cooled and Moderated by Supercritical Light Water"

- Dobashi, K., Y. Oka, and S. Koshizuka, "Conceptual Design of a high temperature power reactor cooled and moderated by Supercritical Light Water", ICONE 6, May 10-15, 1998

- Dooley, B., B. Larkin, L. Webb, F. Pocock, and A. Bursik, "Oxygenated Treatment for Fossil Plants", IWC-92-16, proceeding of 53rd International Water Conference, Pittsburgh, Pennsylvania, Oct. 1992, p 154-161.

- Dooley, B., J. Mathews, R. Pate and J. Taylor, "Optimum Chemistry for All-Ferrous Feedwater Systems: Why use an Oxygen Scavenger?", Ultrapure Water, July/August 1995, 48-55.

- Dupin, P., M. G. Gosser, B. Walls, J. L. Rondot, S. Pastol, M. G. S. Faty, M. Fereira, and M. Da Cunha Belo "Influence du $\mathrm{pH}$ sur les proprietes chimiques et structurales des films d'oxyde formes sur l'acier 316L et les alliages 600 et 690 dans les milieux aqueux a haute temperature," Ann Chim Sci Mat 27, pp. 19-32 (2002).

- European Utility Requirements for LWR Nuclear Power Plants, Revision C, April 2001

- Fournier, L., D. Delafosse, C. Bosch, and Th. Magnin, "Stress Corrosion Cracking of Nickel Base Superalloys in Aerated Supercritical Water," NACE's International Annual Conference, Corrosion 2001, Houston, TX, Paper 01361, pp. 1-11, 2001.

- Friedland, A. J., (1980), "CRBRP Core Assemblies Hot Channel Factors Preliminary Analysis," CRBRP-ARD-0050, U.S. Department of Energy, Technical Information Center

- Friedland, A. J., and S. Ray, "Revised Thermal Design Procedure," WCAP-11397-A, nonproprietary, April 1989

- General Design Criterion 10, 10 CFR Part 50, Appendix A, "Reactor Design".

- General Design Criterion 10, 10 CFR Part 50, Appendix A,

- Graham, J, L. E. Strawbridge, and P. Bradbury, "Safety of the Clinch River Plant", Nuclear Engineering International, 19, 221, 854 (1974)

- Harvey, A.H., et al., "NIST/ASME Steam Properties", NIST Standard Reference Database 10 Version 2.11, 1996

- Haymard, T., Svishchev and R. Makhija "Stainless steel flow reactor for supercritical water oxidation: corrosion test" J of Supercritical Fluid 27, pp. 275-281 (2003).

- Howell, J. R. and Lee, S. H., Convective heat transfer in the entrance region of a vertical tube for water near the thermodynamic critical point, Int J Heat Mass Transfer 42 (1999) 1177-1187.

- Idel'Chik, J. E., Handbook of Hydraulic Resistance: Coefficients of Local Resistance and Friction, AEC-tr-6630, (1966).

- INEEL, 2003, “RELAP5-3D Code Manual,” INEEL-EXT-98-00834, Revision 2.2, October. 
- Jackson, J. D., 1979, "Mixed Forced and Free Convection - The Influence of Buoyancy on Turbulent Forced Flow in Vertical Pipes," The Euromech Meeting on Boundary Layers and Turbulence in Internal Flows, Session 5, University of Salford, England.

- Jackson, J. D., 2002, "Consideration of the Heat Transfer Properties of Supercritical Pressure Water in Connection with the Cooling of Advanced Nuclear Reactors," Proceedings of the $13^{\text {th }}$ Pacific Basin Nuclear Conference, Shenzhen, China, 21-25 October.

- Kasahara, S., J. Kuniya, K. Moriya, N. Saito and S. Shiga, "General Corrosion of Iron, Nickel, and Titanium Alloys as Candidate Materials for the Fuel Claddings of the Supercritical-Water Cooled Power Reactor," GENES4/ANP2003, Kyoto, Japan, Paper 1132, Sep. 15-19, 2003.

- Koshizuka, S., Takano, N. and Oka, Y., Numerical analysis of deterioration phenomena in heat transfer to supercritical water, Int J Heat Mass Transfer, 38 (1995) 3077-3084.

- Kussmaul, K., and Mayinger, W., Numerical and experimental analyses of the behaviour of a nozzle with thermal sleeve under stratified flow, Nucl Engr and Design, 190 (1999) 127-140.

- MacDonald, P. E., et al., 2002a, "Feasibility Study of Supercritical Light Water Cooled Fast Reactors for Actinide Burning and Electric Power Production, Nuclear Energy Research Initiative Project 2001-001, Progress Report for Year 1, Quarter 2 (January through March 2002)", INEEL/EXT-0200579 ,

- MacDonald, P. E., et al., 2002b, "Feasibility Study of Supercritical Light Water Cooled Fast Reactors for Actinide Burning and Electric Power Production," Nuclear Energy Research Initiative Project 2001-001, Progress Report for Work Through June 2002, $3^{\text {rd }}$ Quarterly Report," INEEL/EXT-0200925.

- MacDonald, P. E., et al., 2002c, "Feasibility Study of Supercritical Light Water Cooled Fast Reactors for Actinide Burning and Electric Power Production, Nuclear Energy Research Initiative Project 2001-001, Progress Report for Work Through September 2002, $4^{\text {th }}$ Quarterly Report", INEEL/EXT02-01330.

- MacDonald, P. E., et al., 2003, "Feasibility Study of Supercritical Light Water Cooled Reactors for Electric Power Production, Nuclear Energy Research Initiative Project 2001-001, Progress Report for Work Through September 2003, $2^{\text {nd }}$ Annual, $8^{\text {th }}$ Quarterly Report", INEEL/EXT-03-01277

- MCNP4B: Monte Carlo N-Particle Transport Code System," Contributed by Los Alamos National Laboratory, Los Alamos, New Mexico, April 1997 and distributed as package CCC-660 by Oak Ridge National Laboratory.

- MCNP4C Monte Carlo N-Particle Transport Code System", Contributed by Los Alamos National Laboratory, Los Alamos, New Mexico, February 29, 2000 and distributed as package CCC-700 by Oak Ridge National Laboratory.

- Montenor, M., N. Ferreira, M. Hakiki, and M. Da Cunha Belo "Chemical composition and electronic structure of the oxide film formed on $316 \mathrm{~L}$ stainless steel and nickel based alloys in high temperature aquous environments," Corrosion Science 42, pp. 1635-1650 (2000).

- Mukohara, T., S. Koshizuka, and Y. Oka, "Subchannel Analysis of Supercritical Water Cooled Reactors", Proceedings of SCR-2000, Nov 6-8, 2000, Tokyo, Japan

- NUREG-0800, "Standard Review Plan for the Review of Safety Analysis Reports for Nuclear Power Plan,” U.S. Nuclear Regulatory Commission, February 2002 update to April 1996 version.

- Oriani, L., L. E. Conway, P. A. Dolck, A. Johanson, N. O. Jonsson, and T. Ohlin, 2004, "Generation IV Supercritical Water Reactor - Progress Report First Quarter of FY 2004,” SE-04-001, January.

- Oka, Y., and Koshizuka, S., Design concept of once-through cycle supercritical-pressure light water cooled reactors, Proc SCR-2000 Symposium, November 6-9, 2000, Tokyo, The University of Tokyo, Japan (2000).

- Petrov, N. E. and V. N. Popov, "Heat Transfer and Hydraulic Resistance with Turbulent Flow in a Tube of Water at Supercritical Parameters of State," Thermal Engineering, 35, (10), 1988 
- Riemke, R. A., C. B. Davis, and R. R. Schultz, 2003, "RELAP5-3D Code for Supercritical-Pressure, Light-water-Cooled Reactors," Proceedings of the $11^{\text {th }}$ International Conference on Nuclear Engineering, Tokyo, Japan, April 20-23, ICONE11-36125.

- RTD Criteria, "Supplementary Criteria and Requirements for RDT Reactor Plant Protection Systems," RDT Standard, RDT C-16-1T, Reactor Development and Technology Division, U.S. Energy Research and Development Administration (1974)

- RTD Standard, "Guidelines and Procedures for Design of Nuclear Systems and Components at Elevated Temperatures," RDT Standard, RDT F9-5T, Reactor Development and Technology Division, U.S. Energy Research and Development Administration (1974)

- Shah, V. N., and MacDonald, P. E., Aging and Life Extension of Major Light Water Reactor Components, Elsevier, (1993)

- Tang, Y. S., R. D. Coffield, and R. A. Markley, “Thermal Analysis of Liquid Metal Fast Breeder Reactors", American Nuclear Society, 1978.

- Toledo Edison, 1982, "Davis-Besse Nuclear Power Station No. 1, Updated Safety Analysis Report," Volume 12.

- Tsuchiya, Y., F. Kano, N. Saito, A. Shioiri, S. Kasahara, K. Moriya, and H. Takahashi, "SCC and Irradiation Properties of Metals under Supercritical-Water Cooled Power Reactor Conditions," GENES4/ANP2003, Kyoto, Japan, Paper 1096, Sep. 15-19, 2003.

- Watanabe, Y., H. Abe, and Y. Daigo, "Environmentally Assisted Cracking of Sensitized Stainless Steel in Supercritical Water: Effects of Physical Property of Water," GENES4/ANP2003, Kyoto, Japan, Paper 1183, Sep. 15-19, 2003.

- Westinghouse, 1975, "Reference Safety Analysis Report RESAR 3S", Volume VII.

- Westinghouse, 2003, "SCWR - Design Review and Design of Safety systems and Containment Status, September 2003," SE 03-044, October.

- Wu, T. H., Z. Xu, and J. D. Jackson, 2002, "Mixed Convection Heat Transfer to Water Flowing Through a Vertical Passage of Annular Cross Section," Transactions of the Institution of Chemical Engineers, Chemical Engineering Research and Design, 80, Part A, pp. 239-245.

- Yamagata, K., et al., "Forced Convection Heat Transfer to supercritical water flowing in tubes", Int. Journal of Heat Mass Transfer, Vol. 15 (1972), pp2575-2593

- Young, W. C., and R. G. Budynas, Roark's Formulas for Stress and Strain, 7th Edition, McGrawHill, 2002.

- Zielinsky and Kurzylowski, "TEM study of the oxide scales formed on type 316 SS during annealing at 600C in a vacuum and air." Scripta Mat. 43, pp. 33-37, (2000). 


\subsection{INEEL}

\section{Budget and Actual Costs for Year 3}

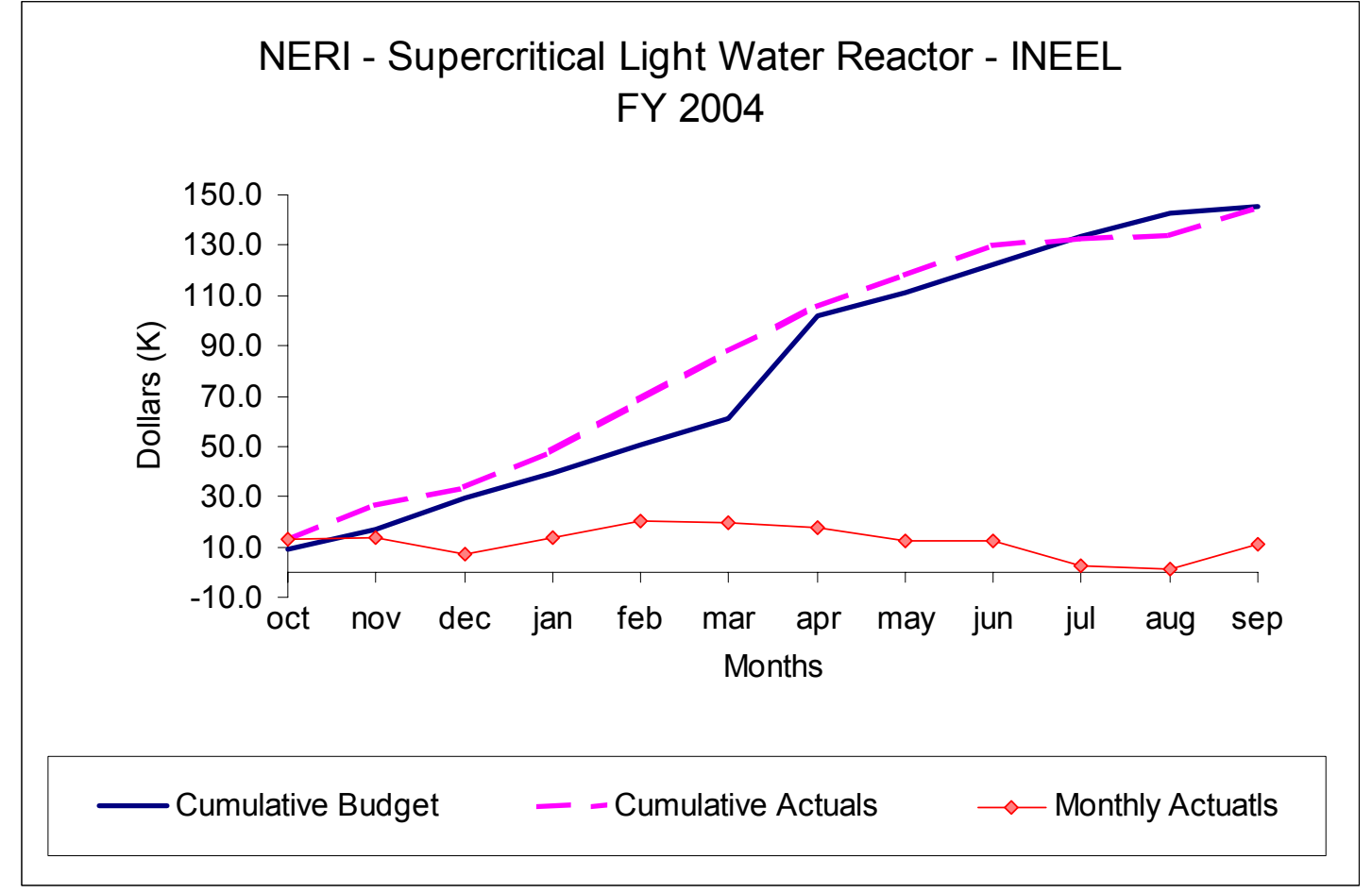

\subsection{University of Michigan}

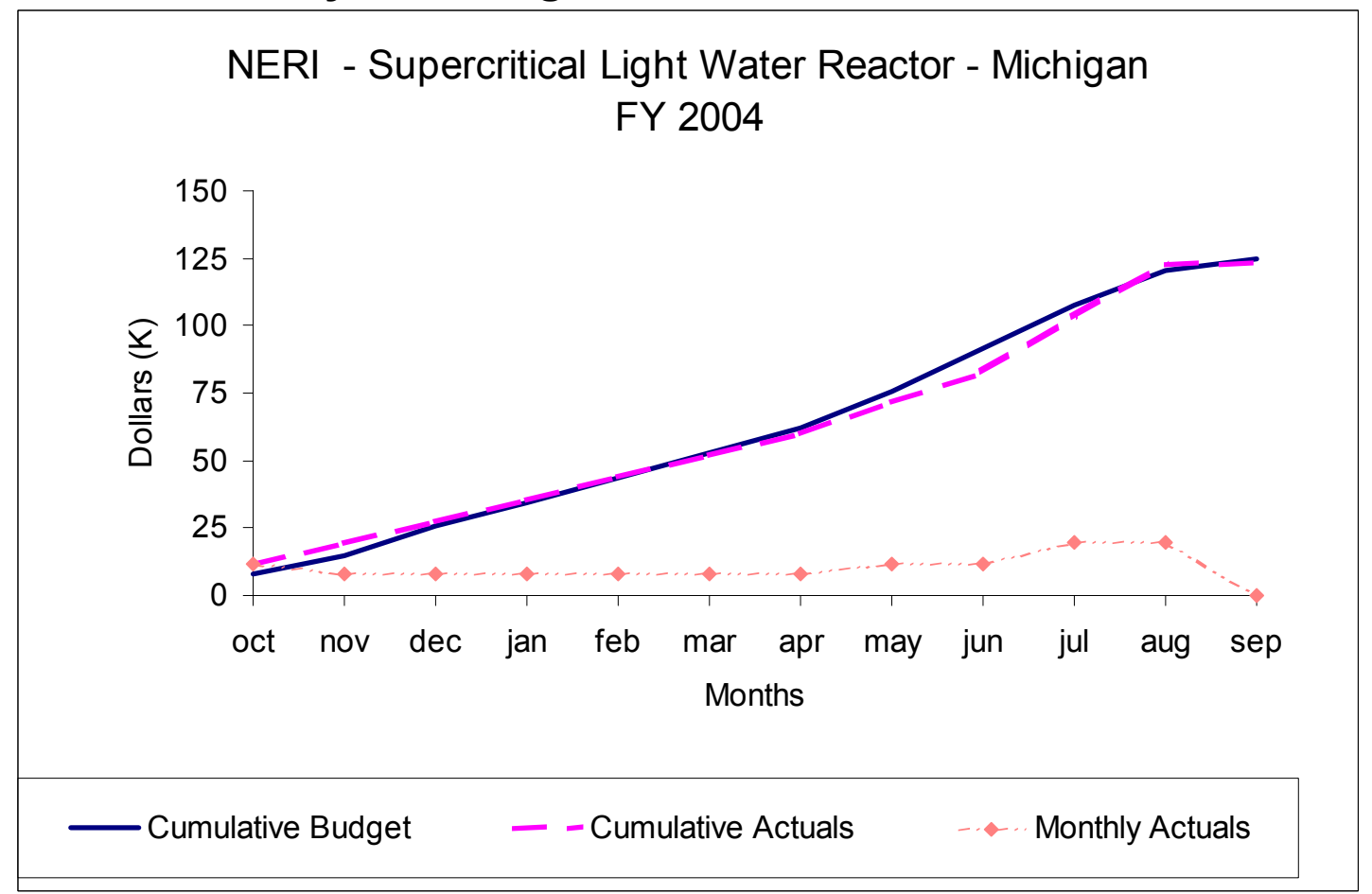




\subsection{Westinghouse Electric Co.}

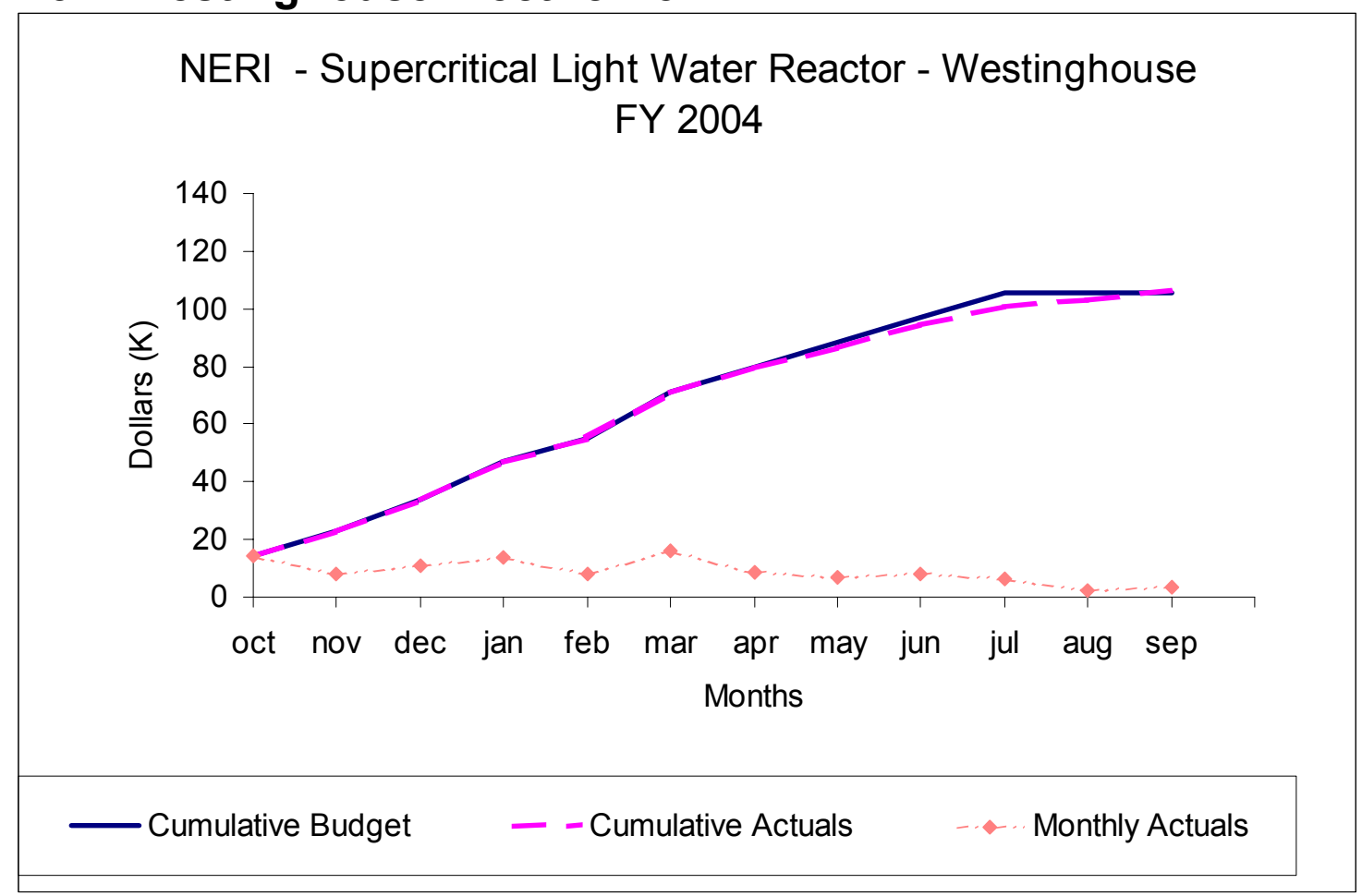




\section{Publications}

S. Teysseyre, J. McKinley, and G. S. Was, D. B. Mitton, H. Kim, J-K Kim and R. M. Latanision, "Corrosion and Stress Corrosion Cracking of Austenitic Alloys in Supercritical Water," Proc. 11 ${ }^{\text {th }}$ Int'l Conf. Environmental Degradation of Materials in Nuclear Power Systems - Water Reactors, American Nuclear Society, La Grange Park, IL, in press.

R. A. Riemke, C. B. Davis, and R. R. Schultz, "RELAP5-3D Code for Supercritical-Pressure, Lightwater-Cooled Reactors," Proceedings of the $11^{\text {th }}$ International Conference on Nuclear Engineering, Tokyo, Japan, April 20-23, ICONE11-36125, 2003.

J. Buongiorno and P. E. MacDonald, "Study of Solid Moderators for the Thermal-Spectrum Supercritical Water-Cooled Reactor (Neutronics)", Proceedings of the $11^{\text {th }}$ International Conference on Nuclear Engineering (ICONE-11), Paper 36571, Tokyo, April 20-23, 2003.

J. Buongiorno and P. E. MacDonald, "Study of Solid Moderators for the Thermal-Spectrum Supercritical Water-Cooled Reactor (Thermo-mechanics and Cost)", Proceedings of the $11^{\text {th }}$ International Conference on Nuclear Engineering (ICONE-11), Paper 36572, Tokyo, April 20-23, 2003.

C. B. Davis, J. Boungiorno, and P. E. MacDonald, "A Parametric Study of the Thermal-Hydraulic Response of Supercritical Light Water Reactors During Loss-of-Feedwater and Turbine-Trip Events," Paper 1009, Proceedings of GENES4/ANP2003, September 15-19, Kyoto, Japan, 2003.

J. McKinley, G. S. Was, D. B. Mitton, H. Kim, J-K Kim and R. M. Latanision, "Corrosion and Stress Corrosion Cracking of Austenitic Alloys in Supercritical Water," Proc. Int'l Conf. Global Environment and Advanced Nuclear Power Reactors, GENES4/ANP2003, Atomic Energy Society of Japan, Tokyo, September 2003.

G. S. Was, "Stress Corrosion Cracking of Austenitic Alloys in Supercritical Water," Workshop on Radiation Effects on Water Chemistry of Supercritical Water-Cooled Reactor, SCR-2003, University of Tokyo, September, 2003.

B. Fischer, M. Przywojski, J. Buongiorno, "Nitrogen-16 Generation, Transport and Associated Shielding Requirements in the Supercritical-Water-Cooled Reactor", submitted to Nuclear Technology, September 2003.

J. Buongiorno, “An Alternative SCWR Design Based on Vertical Power Channels and Hexagonal Fuel Assemblies”, Paper 87696, Proceedings of Global 2003, New Orleans, November 16-20, 2003.

J.W. Sterbentz, "Neutronic Evaluation of a 21x21 Supercritical Water Reactor Fuel Assembly Design with Water Rods and Silicon Carbide Clad/Duct Materials", INEEL/EXT-04-02096, Idaho National Engineering and Environment Laboratory, January 2004.

G. S. Was, S. Teysseyre, J.McKinley and Z. Jiao, "Corrosion of Austenitic Alloys in Supercritical Water," Corrosion 2005, Houston, TX, April 3-7, 2005, NACE International, Houston, TX. Paper \#05397.

G. S. Was, S. Teysseyre, J.McKinley and Z. Jiao , "Stress Corrosion Cracking of Austenitic Alloys in Supercritical Water," Corrosion 2005, Houston, TX, April 3-7, 2005, NACE International, Houston, TX. 
G. S. Was and T. R. Allen, "Time, Temperature and Dissolved Oxygen Dependence of Oxidation of Austenitic and Ferritic-Martensitic Alloys in Supercritical Water," Proc. ICAPP '05, Seoul, KOREA, May 15-19, 2005.

P. Ampornrat, C. Bum Bahn, G. S. Was, "Corrosion and Stress Corrosion Cracking of FerriticMartensitic Alloys in Supercritical Water," $12^{\text {th }}$ International Conference on Environmental Degradation of Materials in Nuclear Power Systems - Water Reactors, Salt Lake City, UT, August 8-13, 2005.

G. S. Was and S. Teysseyre, "Corrosion and Stress Corrosion Cracking of Alloys for the Supercritical Water Reactor - A Review and Recent Results" $12^{\text {th }}$ International Conference on Environmental Degradation of Materials in Nuclear Power Systems - Water Reactors, Salt Lake City, UT, August 8-13, 2005 


\section{Feasibility Study of Supercritical Light Water Cooled Reactors for Electric Power Production}

Nuclear Energy Research Initiative Project 2001001, Westinghouse Electric Co. Award Number: DE-FG07-02SF22533

\section{Final Report $12^{\text {th }}$ Quarterly Report}

Principal Investigators:

Philip MacDonald, Dr. Jacopo Buongiorno, Dr. James W. Sterbentz, Cliff Davis, and Prof. Robert Witt Telephone: 208-526-9634

Fax: 208-526-2930

Email: pem@inel.gov

Collaborating Organizations:

University of Michigan

Principal Investigator: Prof. Gary Was, J. McKinley, and S. Teysseyre

Westinghouse Electric Company Principal Investigators: Dr. Luca Oriani, Dr. Vefa Kucukboyaci, Lawrence Conway, N. Jonsson, and Dr. Bin Liu 